\title{
UC-NRLF
}

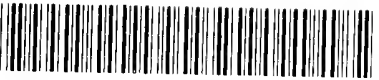

B $4 \quad 147$ 2b6

59

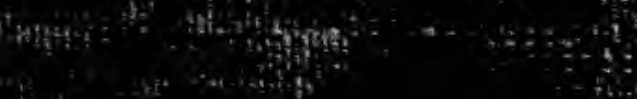

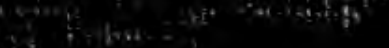

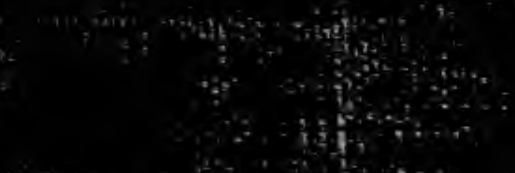



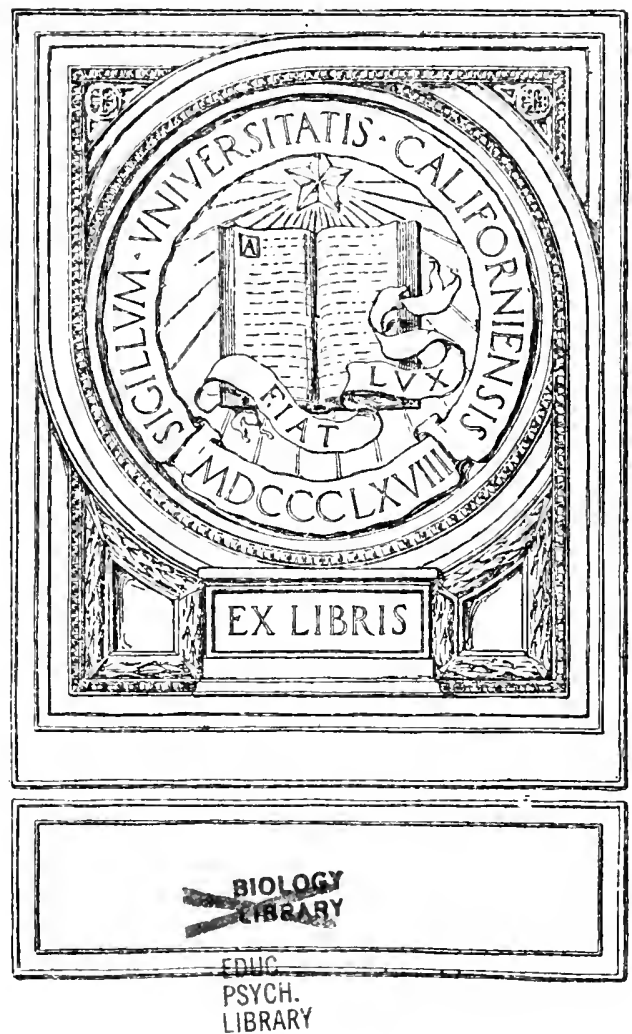


$$
\text { - }
$$




\section{CHARACTER AND TEMPERAMENT}

BY

JOSEPH JASTROW

PROFESSOR OF PSYCHOLOGY

UNIVERSITY OF WISCONSIN

NEW YORK AND LONDON

D. APPLETON AND COMPANY

1915 


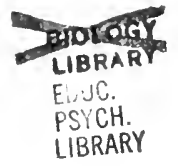

Copyright, 1915, BY

D. APPLETON AND COMPANY

Printed in the United States of America. 


\section{Tn The łnimergity of}

A PIONEER IN THE ACADEMIC
RECOGNITION OF PSYCHOLOGY 



\section{INTRODUCTION TO THE CONDUCT OF MIND SERIES}

It is the purpose of the series to provide readily intelligible surveys of selected aspects of the study of mind and of its applications. In this self-conscious age, inquiring minutely into the nature of the forces that direct the endeavors of men, psychology has come to its own. Recent advances have made possible definite and enlightening accounts of the mental processes; the psychological laboratory has refined, extended, and controlled the data; the evolutionary conception has coördinated conclusions derived from widely different sources. Particularly has the psychology of the social relations been given a central position in the practical world, where endowment, motive, and circumstance meet. The emotional as well as the intellectual, the aesthetic as well as the moral, the occupational as well as the relational impulses and expressions of men have been duly recognized as part of the psychological endowment-as integral aspects of human nature.

The desire to apply this knowledge reflects the stress of the practical temper; the need of adaptation of the mental equipment to the complex conditions of modern life is insistent. Mental economy enforees the importance of shaping eareer to capacity; the conservation of mental resourees enters vitally into the problems of national welfare. The varied liability of the mind to defect and decay, to distortion and vagary, to degeneration and reversion, sets in relief the critical importance of sanity, which is a eugenic endowment exereised in a wholesome environment. From these several sources there has resulted a sense of psychological value by which to gauge the worth of the educational and cultural provisions which society organizes for the maintenance of its cherished ends. Furthermore, the ready intercourse of mankind has conferred a cosmopolitan and an humanitarian outlook, mingling and comparing, while yet contrasting, national and local standards and ideals. The products of intellectual, as 
of other achievements, are seen to belong not to one race or to one era or to one order of eulture. The beginnings of mind in the animal world, the growth of mind in childhood and in the race, contribute notably to broaden the conception of its mature capacity and its potential future.

To set fortl and interpret the significant conclusions within this engaging realm forms the dominant motive of the present undertaking. The project, if too ambitionsly conceived, invites failure. The practicable procedure favors the selection of a modest aspect or phase of the psychological domain, and its presentation as a concrete contribution upon which the larger illumination of a comprehensive survey has been brought to bear. The importance of principle is to be emphasized throughout. In simple situations a shrewd empirical tact suffices; in complex ones sound practice is mare and more dependent upon sound theory. Knowledge of principles is needed to offset the limitations of experience and the narrowness of interests; the corrective of application is needed to make principles real and vital. The search for panaceas as for rules of thumb is futile; yet the desire for a royal road to learning has a strange attraction for the direct democratic temper. Psychology, like all science, exacts a patient analysis, which discountenances a too ready leap at conclusions and hasty application. Yet science does well to utilize the actual interests of men, to build upon them the knowledge that makes for power. To supply the foundation in principle for the guidance of practice is to be the consistent motive in the several volumes of the series. To make that guidance effective requires a judicious appeal to popular interest, and an adaptation of the material to the needs of the every-day reader with serious purpose.

To give the largest freedom in adapting the presentation to the varied requirements of the several topies and the individual bent of the contributors, it is proposed to permit the volumes to assume such length, form, and construction as eircumstances determine. The singleness of purpose and unity of design will appear in the support of each contribution to the general plan, and in their common appeal to the popular interests in the affairs of the world of mind, and in the regulation of mental conduct. 


\section{PREFACE}

The subject of this volume is the psychological sources of human quality; this might well be its title or subtitle. The composite term character and temperament has the currency of tradition; the possibility of interpreting it for present-day psychology is an inviting task. The course followed in this survey is substantially without precedent; though there is naturally a considerable community of content with volumes bearing a similar title, and with others that consider the analysis, the emotional basis, and the social expression of human nature.

The historical phases of this venerable topic are variously interesting. ${ }^{1}$ They reflect the persistent desire to penetrate into the mystery of human personality, to seize its secret and direct its fortunes. A related practical motive, more scientifically guided, has given rise to didactic methods of "character training"; a closely related interest is the vocational one. In all there is the common intent to understand and thus to sound impulse, gauge capacity, direct endeavor, regulate the desires and energies of men. For the whole of human conduct, as of civilization, follows the elew of the endowment, needs, satisfactions, potencies, aspirations of the human mind. As the individual and the social life develop toward the consciousness of purpose, the cultivation of endowment to secure cherished ends becomes the dominant interest, and in its selective expression reflects the emphasis of native quality.

To bring maturing powers to effective expression is an artthe art of living. Education is the comprehensive name for it; moral education-if we include the schooling of experience-its most universal phase and the most concrete. Art proceeds in a practical temper; the perspective of its concerns is distinetive. Such consideration is but slightly included in this survey, for the reason that it requires and deserves an independent treatment. More closely related is the art of "character-reading" not in its crude, ambitious and as commonly false and irrelevant attemptsbut in the sober, painstaking, systematic study of the laboratory, to

1 They are briefly considered in an article in the Popular Science Monthly, June, 1915. 
determine individual fitness and take the measure of a man. In this application likewise, in so far as the practitioner's point of view dominates, it falls beyond the present confines. The principles of diagnosis embody the common field of science and art; at every step "character training" and "character reading" depend upon analysis. However to be applied, the underlying facts, relations and principles of interpretation are the same. The limitation of this volume to analysis and interpretation is deliberate, and makes possible the unity of construction that determines its procedure. ${ }^{1}$

Beyond a modest insight, practice without theory is vain. The tendency to proceed directly to action is inherent, and for many types of occupation justified. The appeal of this presentation is to those whose responsibilities include the guidance of conduct and affairs for themselves and others through knowledge. Interpretation-like the curriculum of studies in which nominally the same subject reappears with different elaboration in the common school, high-school, 'college and university schedules-proceeds upon increasing grades of thoroughness, perspective, detail. The psychologist's view of human nature is broad and general. It is his function to correct as well as to direct the more specialized interests in phases of motive, endowment, or expression, that practical pursuits entail. It is also true that theory without the corrective touch of practice is bare. The issues of human quality are firmly established-yet with the elasticity and progressiveness of a living movement-in human institutions. The psychological analyst in undertaking a survey of the issues of "character and temperament" assumes a practical interest. The qualities of men, which form the data of his study, are made real in the intricacies of social relations, in economic development, in the genius of institutions and traditions, and the sway of belief.

The differences and contrasts, as intimately as the communities of buman kind, stand centrally in the interpretation: those of sex, of race, of family strain, of one individual and another. The inequalities of men are the interesting and the valuable expressions of endowment. But as they come to the surface they are not biological but sociological; the specialization of modern life imposes itself

1 To maintain the proportions of the several chapters, I have placed corroborative and explanatory matter in the notes. For the student these form an essential part of the presentation. 
upon human quality; it is a part of the larger reconstruction of original nature which civilization matures. The artificial environment acts after the manner of a natural one; it encourages and discourages selected qualities, yet projects the stresses and strains of original nature. The interpretation of such differences draws upon the composite resources of the psychologist's equipment. It involves excursions into the domain of the laboratory, into the abnormal, into the economy of the nervous system, into the network of the intimate and intricate personal life. The efforts of the social organism to provide a place for and to utilize these differences places them in the arena of human quality.

The ready assertion that human nature is ever the same expresses a partial truth, and that imperfectly. It must be replaced by a more discerning view that projects with some degree of illumination the areas of fixity and the wider realms of variable human traits: their hereditary conditioning, their relations to one another, their allegiances to the original and to the acquired nature of man. The fact of evolution for the individual and for the race demonstrates the plasticity, as the slowness and the uncertainty of the process of civilization testifies to the fixity of human traits. The enlightenment of "character and temperament" is to be sought in the mutual reënforcement of the several aspects of the presentation. The foundations thus surveyed are no less comprehensive than those of the science of psychology itself; nothing less will suffice to set in its true proportions the sources of human quality. Psychology proceeds more teclinically, after the manner of the plans and elevations for the architect's and builder's use; the differently motived sketches of the student of character and temperament present the "livable" construction, the uses, the service, the values, the life of the edifice. By virtue of this relation their appeal to the layman and to those who in one calling and another come in professional contact with the psychological traffic, is direct and pertinent. That the interpretation must frequently proceed upon the level of description reflects the inherent imperfections of our psychological insight, but imparts a realistic touch to the presentation. If it contributes to a truer appreciation of the indirect and difficult routes from theory to practice, and of the necessity of the ampler study of foundations, it will have served its purpose. 
The several chapters indicate the generous use of the results of fellow-workers. Attention may be directed to three works, in their several fields the most suggestive and helpful of recent writings. The one is Professor MacDougall's "Social Psychology," (1909), a title in favor among the sociologists, but in this instance fully justified by the treatment. It seems proper to explain that the central place of the emotions in relation to instincts there set forth, and the closely parallel and more detailed analysis here elaborated are in large measure independent. The outline of the present volume was sketched as early as 1908 before the contributions of Professor MacDougall were known to me. His prior conclusions were encountered in the preparation of a course of eight lectures on "Character and Temperament," which I delivered at Columbia University in 1910. In the same year I published a small volume on the "Qualities of Men," which sets forth in a more literary treatment the concluding considerations of the present volume. Professor MacDougall's statement still remains the most effective for sociologically-minded readers. With it may now be associated Mr. Graham Wallas's "The Great Society" (1914), which likewise recognizes in human traits the basis of the social strueture. Next is Professor E. L. Thorndike's "The Original Nature of Man," (1913), which is authoritative in its field and has sterling value for many purposes, practical and theoretical. It is devoted primarily to the quantitative aspects and approaches of the subject. As the present study is decidedly qualitative in temper, the two volumes apart from marked divergence of treatment and scope are in a measure complementary, despite the fact that I cannot share in equal measure the confidence of Professor Thorndike in the potency of the quantitative instrument, and that he presumably entertains a like scepticism of the value of the qualitative approach. The third volume in question appeared after the present manuseript had substantially assumed its final form: Mr. Shand's "The Foundations of Character." It is a thoughtful, comprehensive and richly suggestive treatise. It is conceived and exeeuted in a widely different manner and purpose than that which sustains the present survey. Its appearance is a notable indication of the interest which the subject commands in contemporary thought.

The University of Wisconsin :

Madison, June, 1915.

JOSEPH JASTROW. 


\section{CONTENTS}

\section{CHAPTER I}

The ScIentific Approach
A retrospective view and the idol of interest and of the practical mind-The scientifie approach as a general inquiry into sources-Heredity and environment-The quantitative and the qualitative study of human differences-Similarities of nature and of nurture-The range, order and distribution of human traits-Central and derivative traits-The individual as a composite-Variety and intensity of quality-The nature of traits-Their place in character-Traits as instinctive responses of the nervous system-Their biologieal import and survival value-Original traits and derived proficiencies-Emotional sources-Functional reference-The setting of traits-Their evolutionary status-Traits and the level of their expression-The environmental imposed upon the natural service-The esthetic endowment and its development-The intellectual functions-Their analysis-Applied proficiencies-The history of culture a record of the achievements of human traits-Their directive trends-Their orders of expression-The principle of transfer-The transformation of traits-Community of aequired traits-Illustrations of transfer and persistence-The system of application-Its social determination-Complexes-The appraisal of quality -Encouragement and discouragement.

\section{CHAPTER II}

\section{The Sensibilities}

The organic root and the special-sense root of sensibilityFeeling and the growth of emotion-The pain-pleasure aspect-Its assumption of an esthetic status-Feeling value and knowledge value-The rôle of the intellect-Sensibility as a primary regulation of response-Illustrations in the several senses-Feeling as enhancement-The acquisition of meaning-Presentative and representative-Resumé-Analysis and derived sensibilities-Their refinement and elaboration-The hygienic sensibility deseribed-Higher levels of its expression-The "food" sensibilities-From feeding to dining- 
The social complications-Language sensibility and the complexity of standards-Good taste and its sourees-Impressionism and reasoned distinction-Sensibility as temperamental-The supporting sense, the functional service, and the scope of development of sensibilities-The application to the arts-The interplay of sensibilities-Regulation of conduet by sensibility-'The individual the sum of his sensibilitiesThe molding power of sensibilities-Their support to eareers - Fine and coarse varieties-Sensibilities of a composite and derived order-The moral sensibilities.

\section{CHAPTER III}

The Emotions and Conduct . . . . . . . . . 104

The emotions as sourees of human quality-Organic conditioning and variety of expression. Irritability, anger, indignation, lament-Funetional service-Inlet, central diffusion, and outlet-Primary situations-Fear as primitive emotionEmotion as spur to meet urgent situations, as zest of experience, as motive to conduct-Emotions and sensibilitiesThe motor aspect-Emotional regulation-Sex and food situations-'The luxurious sensibilities and esthetic emotionThe intellectual expansion-The primary emotions-The analysis of fear-The expression of the emotions-The faeial and related miens-Expression as incipient response -The classification of the emotions-The attitudes, the situations, the direction, the stages of emotional expressionIllustrations from animal responses-The complexity of human emotion-Refinement of emotion and of its expressionThe facial language and its prineiples-Mien and gestureThe varied sources of facial expression-The specialized expressions-Differentiation and transfer-Natural and acquired expression-Manner and restraint-Emotion and its object-The rôle of instinct-The complication and interplay of the emotions-Attention, interest and curiosity-The flexibility of emotion-The evolution of emotion-Presentative and representative stages-From pain to grief-Inteliectualization-Special bearings of the principle of transferGregariousness and sociability-Transfer in expressionEmotional congenialty in transfer-The evidence of language -Emotion central in human quality-Its sources and their persistence.

\section{CHAPTER IV}

The Higher Stages of Psycinic Control . . . . . 174 Adequaey of man's original equipment-Its transformation 
through intellectualization and socialization-The social direction of the individual trait-Play and the evolution of the socializing process-Jealousy as a social response-The self-asserting and the self-withdrawing trends-The derivative issues as curtailed forms of original response-The development of sympathy-From gregariousness to psychic contagion, to sympathetic emotionalism, to altruistic sacrifice - Sensitiveness to social esteem-The social self-The intellectual routes of suggestion and imitation-The larger and the transferred social loyalties-Their source in the family and other social situations-The play of the courtship relation-The social dependence-Social coöperation-The complete issue in the dread of solitude-Higher phases of estrangement-The uncertain hold of the altruistic trends-The natural history of love-Romantic love and the intellectualized emotion-The issue in the sentimental life-Sentiments supply rationalized motives-They establish complexes and regulate conduct-The psychology of pride and of humilityTransferred prides and shames-The derivative fears and apprehensions-Traits as the balance of sentiments-Selfrespect-Shame and the evolution of justice and punishment -Ideals and systems of sentiments-The support of the intellect in the guidance of response-The problem-solving traits-Desire, energy, and determination. The quality of action.

\section{CHAPTER V}

\section{Temperament and Individual Differences}

Temperament as original nature-Variation and normality - Temperament a biological emphasis-The stages of growth - The expressions of temperament-The types of temperament-The traditional distinctions-Emotional and intellectnal dominance-Mood, temperament, and the organic economy-The temperamental ages of man-Temperament as susceptibility to ranges of emotion-The somatic determination-The sensitive-active type and its varieties-The bent or Anlage and the artistic careers-The stress of temperament - Variability, adaptability, and originality-What men are and what they d.o.-Temperamental qualities-The resulting complexes-The analysis of the "miser" complex-Temperamental proficiencies and community of traits-"Individual psychology" and the measure of a man-The auditory equipment as illustrative-Sense capacity and mental capacityThe rôle of vision and of movement-Sense endowment, skill and the higher expressions-The qualities of mental elaboration-The limitations of the programme-Endowment 
and achievement-General intelligenee-The laboratory tests and the tests of experience-The environmental stimulus-The factor of energy-Ardor and enthusiasm-Motive and incentive-Command of resources.

\section{CHAPTER VI}

\section{Abnormal Tendencies of Mind}

The abnormal as the assets and liabilities of specialized temperaments-Psychic fluctuations-Organic condition, mood, energy, and quality-Critical periods of unfoldmentMinor fluctuations and major disabilities-Stresses, strains, faults of maturing disproportions of development-The temperament of defect-The temperament of excess-Anger, choleric temperament, and mania-Sanguine temperament and intoxication-The extreme liabilities-General paralysis and the exalted personality-Excess of sensibility in the nervous temperament_-The loss of "nerve"-The neurasthenic temperament-Assets and liabilities-The intellectual aspects -Its motor entanglements-The introspective trends-The hysterical temperament-The overpersonalized responsiveness -Intensity and irregularity of action-Emotional conflict and impaired control-The varieties of hysterical typesContrast of masculine and feminine liabilities-By-paths of hysterical expression-The views of Freud-The expressions of sex interest-The invasion of the personality-The abnormal as the excessive dominance of primitive emotionsMorbid fears-The pathology of anger, of jealousy, of grief -The theory of shock-Intoxication and drug actionMegalomania-The insanity of power-Loss of proportion as the central abnormality-Degeneracy and perversion-The criminal tendencies-Deviation from the normal as a social handicap-Eccentricity and abnormality-The genius.

\section{CHAPTER VII}

\section{The Psychology of Group-traits}

The individual the point of convergence of hereditary streams-Sex the supreme differentiation-The bodily clewThe genetic clew-The communal clew-The pathological clew - The differential traits of sex-Bodily contrasts of structure and function-Pathological liabilities-The nervous liabilities-Masculine and feminine insanities-Masculine as venturesome, variable, energetic, catabolic-Feminine as conservative, stable, affective, anabolic-The correlations of sex traits-Derivative traits-Their expression and reën- 
forcement-The further derivative traits under environmental influence-Primary situations and the traits emphasized therein-The transfer of sex traits from the biological to the sociological realm-Secondary traits as consistent issues of primary ones-Slight contrasts and momentous issues-A survey of masculine psychology-Greater variability; vagrant energies; venturesomeness; objective interests; coöperationA survey of feminine psychology-Greater affectability; conservatism; mobility-Favored forms of responsiveness and minor traits-The contrasted liabilities-The differentiations of race-Organic aspects-Race a specialized adaptation to condition-Uncertain source and meaning-The flag of color -Racial differences and superiority-Community of racial endowment-The argument from achievement-A critical view-Achievement an uncertain evidence of endowment -Rate of emergence and capacity for progress as criteria--Practical consequences of slight differencesRacial Status and primitive traits; in variability; in precocity-Race, remote ancestry and immediate family-The heredity of traits-The family strain-Genius-The criminal trend as a group-trait-The environmental factor-National formative influences tending to uniformity-The stamp of vocation-The composite issue.

\section{CHAPTER VIII}

Character and the Environment .

Environment as the biological setting-The potency of the physical environment-Adjustment in primitive and in civilized conditions-The establishment of control of the environment-Habitat, food-supply, vocation, and the artificial life -Environment as natural, economic, sociological-The environment increasingly psychological--High-grade civilizations equalize environmental conditions-The transformation of animal traits-Survival of original traits in domestication-The original and the transformed nature of manPsychic control-The group-mind as primitive mentalityThe mass consciousness responds to the concrete, the dramatic, the effective-Suggestion, contagion, and the lack of initiative-The leaders supply initiative-Prestige-The primitive fixation of belief-The cultural products of the primitive mind-Tradition and institutions serve as an environment for the individual-Mores, conscience and the tendency to conform-Fashions, taboo, and the tyranny of conformity-Survivals, folk-ways, and the ingredient of rational sanction-The changing issues the focus of attention-Class and mass-Conservatism and liberalism-The collective spirit 
or Zeitgeist-The local genins-The assertion of individuality-The dominant regulative systems-The attachment of value-Ideals.

\section{CHAPTER IX}

The Qualities of Men

Analysis and appraisal-Civilization makes small differences count-The social environment makes the specialistAdjustment by special proficiency-The elevation of standards-Fine differences determine awards-Urgency sets the earlier scale of value-Finer satisfactions determine in highgrade levels-Slight differenees estrange-Prejudice-'The social strata-Exacting vocations require nice adjustment of quality-Enviromment reënforces selected traits-American enterprise-Advertising-The susceptibility to derivative influences-The status of women and the play of ideals-The military institution and the maintenance of human qualityThe transfer of quality-Progress implies the reconstruction of human quality-The upper-level qualities sensitive to social favor and disfavor. Circumstance, endowment and reward-Utopia as a refuge-The poietic mind-The kinetic mind-Variability and originality-The position of democracy-The pragmatic position-The service and dis-service of ideals-The political temper-Social appraisal and the systems of values-Selection and the recognition of talent"Mute, inglorious Miltons"-The disastrous effect of distorted values-The conflict of standards-Cherished qualities must be given an outlet in careers-Callings and the redemption of quality-Quickening of appreciation the step toward progress-Careers as invitations to qualities-Social esteem holds the balance of power-Standards of success-Responsibility of leadership-The transformation of human quality.

Notes to Chapters . . . . . . . . . . . . 507

IndEX • • • • • • • • • • • • • • • . 591 


\section{CHARACTER AND}

TEMPERAMENT 



\title{
CHARACTER AND TEMPERAMENT
}

\author{
CHAPTER I
}

THE SCIENTIFIC APPROACH

Mental traits and their varied distribution among all sorts and conditions of men have ever engaged the attention of the observant and the thoughtful. The systematic study of the nature of the mind and of the sources and relations of its qualities gives rise to psychology. The dominant interests that direct the survey of the mental realm determine its course. An old established interest is that in human diversities and in the understanding and control of human traits. To designate the bearing of the body of knowledge thus resulting the composite term "Character and Temperament" is serviceable. The term reflects the two pervasive molding forces : that of native endowment, and that of acquired capacity in adaptation to circumstance; the latter in relation to a composite world which is, in part, the issue, in part, the field of operation of human qualities. It carries along the traditional interest in the delineation as well as in the training of character, yet is compatible with the comprehensive restatement of the problem and its mode of pursuit under the resources of modern psychology.

The standard survey of psychology, serving as an introduction to the subject, presents an orderly sketch-map of the mental domain, and dwells upon the detailed features of the more important and familiar points of occupation. Its simplified topography is adequate for an un- 
derstanding of the surface features of the psychological landscape and for a moderate insight into the deeper, "geological" forces to which they are traceable. The present construction, hardly less comprehensive in scope, is in the nature of an oblique section-a view from a different angle. It builds upon the same foundations that underlie the standard surveys, from which it differs mainly in its perspective and purpose.

The subject has a venerable history [1]; and from it may be learned the futility of the several ambitious attempts to seize and control the determinants of character and temperament, to solve the riddle by a happy guess. They all involve the assumption that the problem is in the nature of an enigma with a recondite solution. The doctrine of the "temperaments" was one such guess, and a thoughtful one, placing the origin of distinctive human quality within the bodily nature; the astrological solution was the most remote, placing the determination of nature as of career in fatalist fashion, quite outside the controllable orbit; physiognomy, ancient or modern, was another hypothesis-an attempted decipherment of the hieroglyphics of the face and head; phrenology and palmistry were still others, and equally ambitious systems of interpretation. Their common goal, variously and arbitrarily sought, was the determination of character; their common attitude was an inclination toward some single and complete revealing clew; their common search was for a key to unlock the cabinet where psychological mysteries lie revealed - a pursuit akin to that of the philosopher's stone, the elixir of life, or the fountain of youth. Such quests reflect less the discoveries of plausible clews to knowledge than the urgency of a desire. They indicate the strong practical motive to know and control fate, and by such insistence misrepresent the nature of the realities of life. A more mature insight recognizes that it is the aim of science to propose significant problems as well as their solu- 
tions, to guide the thoughtful student to and through accessible and profitable approaches.

The turning-point of the inquiry was the recognition of the nervous system as the embodiment of human traits, whatever their variety and original nature; equally pivotal was the recognition that the nervous system, along with the rest of the organic inheritance, has been continuously subject to and molded by the evolutionary forces of nature. Before the supremacy of the nervous system and the masterkey of evolution were established, the study of character, as of all mental functions, was open alike to discerning and plausible speculation, and to imperfect and irrelevant, though confident, solutions, sponsored by propagandists lacking logical standards. While these false leads have been abandoned, the tendencies that gave rise to them persist, though in less disturbing fashion. They find expression in the overpractical and overdetailed questions which popular inquiry addresses to the psychologist. It was ever in part an impatience with the laborious processes of unraveling the intricacies of nature, together with a false view of their sources, that prompted the attempts to cut the Gordian knot. The desire to find a short circuit from theory to practice, though no longer inviting so crude a stultification as phrenology and palmistry demanded, still discountenances the patient analyses indispensable to a useful and consistent interpretation. A like tendency is apparent in the occasional rebellion against the slow and sure procedures of science-in medicine, in education, no less than in practical management-with a consequent recourse to fads, systems, "isms," and "ologies," that offer large promises of quick returns. This general tendency to demand prescriptions and to disparage principles may be called in Baconian fashion the idol of the practical mind; its corrective is an appreciation of the necessary intricacy and indirectness of the trail from theory to practice, of the indispensableness of broad topographic surveys. 
More defensible is the related idol of interest. Like much that is legitimate and profitable within limits, this attitude is apt to exceed such proportion. Obedient to its important psychological function, interest indicates, creates, and illuminates differences; in its absence or subdued presence, the appearance remains vague or merges into a confusion mistaken for a similarity. Chinamen look alike to us in the casual impression; which means that the type is as far as our interest carries. To a Chinaman another Chinaman offers the same measure of individuality as the procession of faces in our streets presents to our accustomed eyes and interested minds. Through the very steps by which science replaces impressionism, it transforms the range of interests, as well as the standards of their satisfaction. The ideal of the study of character is the determination of traits and their values in the scheme of nature, not in that of any one specialized range of human applications. Yet the conspicuousness of traits, physical or mental, that leads to their detection and emphasis, is itself a significant quality. Analysis must correct impressionism by completing as well as by supporting casual observation; for traits have roots as well as blossoms. The idol of interest applies peculiarly to the problem of character, in that a narrow personal appeal is apt to overshadow a broader intellectual inquiry. The fallacy becomes the specific one of overrating what is personally engaging, and is allied to the too detailed interest as well as to the irrelevant interest; it has a common counterpart in the tendency to generalize from a few striking instances. The observations falling within the individual experience inevitably count too heavily; the individual considers too lightly the limitations both of vision and of opportunity. The insistence upon the seeing that is believing, though a prudential virtue, may at times lead to a serious defect. Verification is to be sought as sedulously as credulity is to be avoided, but the overemphasis of personal experience, the 
false value attaching to experience as ours, is responsible for a larger range of logical defection.

The scientific interest is general where the personal is detailed. This statement requires illustration. It is less profitable to inquire why the particular flat stone which I throw with a given fillip skims along the surface of the water, makes so many "skips" of such and such lengths and then sinks, than to ask generally: Why do flat stones thrown nearly parallel to the surface of the water skip at all? But in this observation there is no personal interest to disturb the attitude; the latter question is as acceptable as the former. The detailed behavior clearly conforms to the general law; and its individual peculiarities, though not removed from like accounting, hardly require it. They may be referred to chance, in the sense of a variable detail accidental in the larger consideration that is confined to essential factors. Such a scientific attitude is not so readily assumed and the ability to assume it not so widespread, when applied to personally interesting traits. To one who happens to have red hair, the origin of his peculiarity seems a more real question than a general inquiry in regard to the distribution of red hair in the races of men or in his racial or family lineage; yet the latter is the scientific inquiry. "The child has its mother's nose but its father's temper," is a more direct and engaging observation, seems more pertinent, than an inquiry into parental influence upon the inheritance of physical and mental traits. The strong personal interest in traits of character both facilitates and obstructs an objective general interest in their source and significance. That the latter is the scientific view by no means argues that all interests should be limited to systematic inquiries and general trends. It urges only that the specific should be subordinated to the general and reached through it. The laws of motion and the principles of heredity are the stuff that science is made of. Inevitably will their application be shaped to urgent 
needs and to the perspective of natural and practical interests, and rightly so. Even the problems pursued will legitimately be direeted by the same considerations, but ever under the guidance of general principles disinterestedly established. To the practitioner the case is still a case of this or that type, despite his sympathetie interest in the peculiarities even in the personality of the patient; just as to the student of mechanies the "skipping" stone is but a case of such and such laws of projectiles.

The bearing of these considerations may be reduced to a brief if blunt illustration. If the solutions of the problems of eharacter and temperament were in the custody of a Sphinx disposed to speak, what inquiries would we address to her? Shall we ask that she explain why A has no sense of humor; or why $B$ is fond of ehildren; why $C$ is a miser, and D a Philistine? Shall we ask to be enlightened why one man is apt at languages and another not? Shall we inquire why one man shows himself cruel, another courageous, a third shy, a fourth impulsive, or a fifth spiteful? Why is E socially inclined, and his brother a rechuse? Why does history appeal to you, and psychology to me? Or why do I collect pewter, and you postagestamps? Why does an overdose of alcohol make one imbiber eonfiding and silly, and his neighbor solemn and sick? Why ean one man get along with six hours of sleep, and another require nine? IVas $\mathrm{F}$ a born poet, and $\mathrm{G}$ a born mathematician? Why are there no born steam-engineers or proofreaders, and what would have beeome of men of the same brain-organization had they been born before the days of steam or printing? Are criminals born or made? Have they definite tendencies, the one to theft and another to burglary? Shall we describe poverty or bad taste as a disease, a sin, or a misfortume? What determines whether one becomes a sociaiist or a suffragette?

These questions in a measure are real; they deal with the actual differenees of men as they come to the surface, in the 
terms of current interests and cireumstances. With proper allowance and a little ingenuity most of the queries may be referred to their proper domain, may be given a modest place in the composite of human qualities, and brought within the range of legitimate inquiry; others may be, (in due course, will be) restated to make a more general and significant appeal. But, as it stands, this motley questionnaire shows how easy it is to make nonsense of psychology by asking wrongly put or too detailed questions. Personal interest invites this fallacy. Its prevalence accounts for the persistence of superstition: why it is that men consult a palmist or a phrenologist or a medium to learn character-traits already familiar, to have the known past revealed, or to compare prediction with fulfillment with a charitable negligence for failures, rather than read a book upon Character and Temperament. It may be tedious and smack of the pedagogue to dwell upon these matters of logical attitude and procedure; but the old and persistent inclination to "read character" rather than understand its sources, shows their pertinence. It is a part of the social and educational mission of science as well as an aid to its advancement, to direct interest into profitable channels. The first steps determine the direction of progress; upon a proper approach, a fair and adequate conception of the problem and of the methods of its pursuit, depends the success of the venture [2].

Accordingly the study of character and temperament attempts an analysis of human quality, maintained as a general inquiry. It uses all available resources, by no means slighting the very impressionism at times to be deplored; it applies the broader to the narrower situation, while equally detecting in the specific the clew to the general. Throughout it proceeds upon definite principles; the constant purpose is to reach the data in their natural significance, and not to be misled by the specialized interests imposed by practical concerns. The science of character, 
though in a large measure an ideal, presents a concrete program.

The avoidance of the "idol of the practical mind," as also of the "idol of interest," particularly of the too detailed and the personally engaging interest, clears the way for the consideration of human traits as natural realities, as significant issues of natural processes. The secure foundation for this view requircs an interpretation of traits primarily as functions of the nervous system. Such functions are molded by evolutionary forces. The evolutionary process is embodied in the continuity of living organisms summarized as heredity; the structures and tendencies which it conserves and continues are adjusted to the enviromment in which they operate. Heredity and environment stand as the two mighty shapers of human quality. To the Greek mind, possessed of our knowledge, they would have suggested heroic or divine forces, cosmic in their proportions. The different spheres of their operation offer a persistent problem; their separation, though inevitably incomplete and uncertain, must be attempted. The distinction is that between the original nature of man and the progressive modifications to which such nature is subject. What are the original human traits and what the vicissitudes of transformation that constitute their life-history?

The force of heredity may be variously conceived. It represents the traits to which the race, the species, breeds true; it is the continuity of the germ plasm; it is the common denominator of the traits shared, and is measured by degrees of resemblance; it is the convergent expression of ancestral forces in varied connection and opposing measure; it is the directive set of potencies released by the impetus of the environment; it is the limit imposed upon the transformation of the environment and the goal of desire; it prescribes the values of the factors expressed in our several personal equations. However viewed, heredity forms the material for the molding forces of the environment and 
equally their limitation. At each stage it embodies the irrevocable past leading to the inevitable present, and projecting the presumable, if unpredictable, future. It involves an inherent developmental course, yet one not rigidly set; nature is a possibility as well as a reality. The hereditary process must be reconcilable with a material substratum; the inheritance is containable in the germ. The mental heredity is similarly conditioned, is part of the same fact. The uncertainty of the mode of its operation need not lower our confidence in the process; nor can we avoid some statement, however conjectural, as to the nature and scope of the inheritance. What do we inherit: general tendencies or specific traits? What order of traits do we possess by original nature? To what extent, in what manner, do they receive their determining set through the modifying play of the specialized environment? Which of the inherited traits are due primarily to race, which to remote or to immediate ancestry? What is a "unit" trait? These are the more general inquiries, the answers to which must fundamentally affect every view of the source and significance of the qualities of men. The temperamental represents the inherited phase of qualities; character relates to the issues of environmental stress, and to the available channels of expression under given ranges of incentive. The psychological analysis of traits considers them as the embodiment of the hereditary equipment and of its variation and direction under natural and artificial environments.

A definite approach leads through the gateway of statistical data. The illuminating principle sets forth that the degree of community of endowment may be tested by the degree of resemblance among the individuals affected by it. Conversely, degrees of resemblance of traits may be used as a test of community of origin; provided that such resemblance of traits is not due to environmental influences. The principle is thus broadly formulated by Thorndike: 
"Men are mentally like one another and unlike dogs or horses because men spring from a presumably common remote ancestry which was not the aneestry of dogs and horses. Men, dogs and horses are more alike than men, dogs, horses, worms and elams are, beeause presumably men, dogs and horses spring from a common ancestry which was not the ancestry of either worms or clams. Certain men, for example the American Indians, springing from a eommon ancestry whieh was not the ancestry of Europeans, may be expected to be mentally more alike one another than like Europeans, if their common ancestry differed mentally from that of Europeans." For the fundamental traits of our eommon elementary psychic endowment, this argument is deeisive. It emphasizes the massive community, the generic resemblances of human mentality under any and all conditions; it indicates the permanence in the aggregate of the basic qualities of men as of their more generic types and variations. This broader view is essential to correct the impression of the magnitude of the differences between men in their detailed variations, favored by the enlarged scale of the psychological ground-plan here to be followed. We shall presently be absorbed in traeing the significance-the very large significance for our interests-of the diversities of human endowments. It is well to consider how far this eontrast refleets the scale adopted for their contemplation: whether under another order of perspeetive they would be reduced to slighter, truer proportion. Interest and practical import magnify; but the result will not disturb our eonclusions if the source of the appearance is recognized. We continne to inquire with one motive or another why and how you and I are alike or different; but our inquiry will be profitable only in so far as we understand the general principles that govern the origin and distribution of traits, in so far as we determine the sources of likeness and unlikeness.

What is significant as well as commonplace is the general 
likeness of human nature. Humanity implies the participation in the common human inheritance. Such community has a place in human consciousness, and to this likewise there attaches a practical import. The "brotherlood" of man is limited by the felt resemblances, the kindred impulses, the sympathetic expressions of men; racial and other prejudices are indications of its limitations. Divergent environments and interests estrange, just as common traditions amalgamate despite racial diversity. Blood relationship is the true brotherhood, however variously it enters into the conscious assimilation, however subject to growth and decline under artificial stimulation, neglect, or opposition. The sense of relationship furthered by national pride (or hindered by racial prejudice) cannot be accepted as a true index of community. On the one hand, the tendency to magnify differences which our interests make conspicuous, and on the other, the superficial resemblances due to likeness of acquired culture, are apt to distort our comparisons. The mathematics of measured resemblance confers a true objective gauge of likeness, which, though not at all decisive for regulation of conduct and eareer, is authoritative in determining the range and scale of human diversities.

It must be admitted that such differences, however objectively determined, rarely bring with them an adequate allowance for the degree of community (or differences) for which a common (or a divergent) environment may be responsible. Men may be like one another by original nature; and men may also come to be like one another. As a rule we must be content to exclude any very marked equalization or differentiation through the environment, and thereupon interpret the differences as having a natural basis. When-as is the common case-the environmental play, though influential, is presumably equally operative upon the entire range of traits, or at least not notably favoring any one set, the actual distribution of the traits 
studied may be accepted as a true measure of resemblance or difference.

Basal resemblances lie deep; blood is thicker than water. The statistical argument remains, though its application is often difficult. Considered individually, it is obvious that of the traits which an individual presents, some are his by virtue of his ancestral inheritance, and others by virtue of a common environment; it is also pertinent to remember how naturally the common inheritance develops a common environment. The relative degree of a trait which an individual presents (by virtue of its distribution in his racial or ancestral strain in comparison with its distribution in other strains) becomes significant as a factor in his mental make-up. To be a member of a superior race, of a gifted stock, of an exceptional family, may well be the most important factor in one's nature as well as in one's career. Yet the statement is but partial; its complement follows upon later considerations.

It is of fundamental importance to know whether the differences of men or of groups are of one order of magnitude or another; whether, for example, races (and consequently all groups allied by a common ancestry) present quite distinct grades or types of mental traits; or whether the differences are slight, with large overlapping areas and a broad resemblance. The general trend of the conclusions favors the latter view. Such a result opposes the natural impression that these differences are large, which is due to the interest in their minute variations, which makes them important; brothers, even twins, are to our eyes different because we view them closely, and unrelated Chinamen alike because we do not. This consideration requires also the separation of the problem of the degree of the inherent differences from the values of the achievements for which in a measure these differences are responsible. In the discussion of the psychology of group-traits this principle is basal. It favors the conclusion that the intellectual ca- 
pacity of man has presumably changed but little within historic periods, and that other orders of forces must be responsible for the large diversities of achievement which the history of civilization records.

In all such considerations the quantitative argument is directive. It is so likewise in another order of problems; namely, whether the range of variation due to or correlated with one set of differences is greater or less than that presented by another. The orders are set by nature; they are in terms of sex, race, kinship, individuals, etc. Whether the differences of traits-in this respect or that-between men and women, between white, black and red races, or again between men of the same race, are the greater ones, is an important consideration in determining how far observed composite differences may be due to sex, to race, to kinship, to individual endowment. The conclusions seem to indicate that the widest variations are the individual ones; that white men of comparable ancestry and environment differ from one another in morals, in mathematical or musical capacity, or in whatever the trait measured, by more than the average difference in any one regard between the mass of men and the mass of women of comparable ancestry. The several "Tom Browns," "Dick Joneses," and "Harry Robinsons" differ more among themselves in any one direction, such as musical ability, despite their converging heredity and circumstance, than their average capacity in that respect differs from that of the group composed of their sisters, or of Toms, Dicks, and Harrys, or of Browns, Joneses, and Robinsons of other stocks or persuasions. The individual variation (in certain directions) overbalances the sex factor, and, it may be, the racial "group" factor as well. Just what this fact means and to what extent it applies or how it applies, is another matter. The present purpose is to indicate how quantitative considerations, especially under the technique of recent methods, affect conclusions of fundamental im- 
portance to our views of the nature and perspective of hrman differences.

Before proceeding to the problems in whieh qualitative methods and interests dominate-the problems central in this volume-we may pass in review certain aspects of traits in which both quantitative and qualitative relations enter; for there is no conflict of conclusion or purpose between the two methods of approach. They are different instruments of researeh, adapted to somewhat divergent interests and pursuits; they answer different ranges and types of questions. Their common reference is to the question: What do we inherit? For this includes the content as well as the extent of the inheritance. Both aspects are implied in the formula which the study of eharacter aims to reaeh and interpret. The selection of the terms necessarily involves a differentiation from other terms, and a quantitative implication of possible units or degrees of resemblance and differenee. Detailed eonsideration will in due eourse be given to the interrelation of traits, to their several spheres of influenee, and partieularly to their status as central or tangential to the psychic nature. The psychological studies of human diversities seem thus to divide aceording as the interest is centered upon the degree or upon the nature (and significance) of human differences. While each bears upon the other, and while partieularly the interpretation of the latter must ever eonsider the eonelusions of the former, they for the most part pursue their several ways. For the studies of degrees and distributions of resemblance, it is often fair to assume that, within limits, the selection of the traits whose variations furnish the basis for the conclusions, is, if not indifferent, at least fairly equalized. The essential relations will appear, despite uncertainties of significance or aecidental choice of terms and units. In the qualitative studies the interest eenters upon the type, the range, the bearing of the traits.

There is a common interest in the assumptions of the 
formula; for the view that the individual temperament (and character) is a concrete combination of such and such traits involves some assumption as to the nature of such standard component traits. The formula, however abstract, requires a definite conception of its terms [3]; for these must inevitably be concrete. Let us proceed to an example. The human iris contains a variable pigment; eye-color is thus a variable trait. Whether or not it is a unit-trait in the Mendelian sense may be left undetermined. It is clearly related to other traits, being part of the fact-indeed is accepted as an index-of pigmentation, correlated in some measure with the allied traits that give rise to blonde and brunette in hair and skin. For researches into degrees of resemblance and the mode of operation of hereditary processes, eye-color forms an acceptable test-its conclusions to be considered along with similar conclusions on the basis of other traits. Yet its selection is due to its conspicuousness; and that is not without significance. The shape (together with other properties) of the human blood-crystals is also a variable trait; and so, we may add, are height or finger-print patterns, or shape of skull, or other physical traits amenable to measurement or classification. These may equally serve for the determination of degrees of consanguinity or hereditary community. It is when we turn to the part that traits play in the functional life, that we are disposed to draw distinctions. If the sexes were so constituted that eye-color especially and pigmentation in general played the chief rôle in determining elective affinities-not too extravagant an assumption, since odes have been written to blue eyes, as well as to blonde hair, red lips and white cheeks-the significance of this trait would be altered, though the manner of its carriage in the hereditary process would remain the same; it is a type of trait not subject to cultivation but only to selection. If strength of arm or shrewdness of wit were the decisive factor, they could be both selected and cultivated to the neglect of other 
qualities. Since all sorts of factors actually enter in manysided competition in the selective process, the decisive traits are subject to a varied and ever fluctuating emphasis. The shape of the blood-crystals is removed from direct play in selection; although it is conceivable that this trait in some obscure manner conditions other traits which come to the surface and thus influence selection. Unquestionably are eye-color and shape of blood-crystals carried along in the germ through determinants of comparable.status. In all studies in which that factor is decisive, the two traits may enter on a par.

The problem becomes more uncertain and more complex in regard to mental traits. It is hardly plausible though not impossible that musical ability, like eye-color, is a factor absent or present through the absence or presence of a factor in the germ; a still more extreme assumption would be necessary to consider mathematical proficiency or a keen moral sense as thus conditioned. (The supposition need not be summarily dismissed; it is, however, far too conjectural to play a part in the present view of character-traits.) Since musical ability is directly conditioned by a delicate functional responsiveness of the minute structure of the internal ear, it stands closer in one aspect to a definite basis of plysiological inheritance; mathematical ability and a moral sense require a much more complex interpretation to bring them within the formula of the hereditary mechanism. Yet such marked deviations as feeble-mindedness (quite as conspicuously as eye-color or color-blindness) show a parallel application of the same laws of heredity as obtain in the case of definite physical characters. Once again is it clear that the traits basal to our study are subject to the same biological laws of hereditary transmission, and subject also to quantitative formulation in so far as the definiteness of the data permits. Yet the point of emphasis is equally that in many respects the data of the mental life cannot be brought under this conception with 
sufficient certainty and without violence to their natural status; and again, that the problems of central significance to our purpose are of other nature, and demand other methods of investigation.

The quantitative implication remains in the formula of composition of traits. Each one of us has more or less of musical ability, a mathematical aptitude of this or that order, a moral nature of a eertain degree of susceptibility and control. The considerations are rarely of absence or presence of traits, but of strength or weakness, of slight, moderate, or marked degree. It is the rule that among individuals, qualities alike in kind show very unlike distribution in degree. The distribution, when subject to natural forces (which implies no more than the composite influence of a very large number of factors, no one of which has in itself a very marked effect), follows the "probability" or "frequency" curve. This curve shows how the relative number of persons presenting degrees of excess or defect of any given trait decreases decidedly and in a law-abiding manner with each such degree. The number of persons (or better, the proportion relative to the whole group concerned) who are one centimeter taller (or shorter) than the average (or have an $x$-degree more or less of musical ability, of general intelligence, or of moral sense, or of what you will), will be relatively large in comparison with those who deviate from one to two such units from the average; and these again far more numerous than those deviating from two to three such units, and so on. The curve represents the relative frequency of deviation of any given amount of deviation. Stated more generally, it gives a pictorial survey on the pattern of an accurate outline, of the distribution of degree of one or another trait. It makes it plain that the largest number of men possess a near to average degree of any given trait [4]-indeed, that, roughly speaking, is why such degree is the average; further, that there will be a very considerable number of 
men of moderately more, as likewise also of moderately less, than average intelligenee, let us say; a markedly smaller number of distinctly more than average intelligence; that with each such successive increase in the degree of intelligence, the number attaining that degree will rapidly diminish until we reach the upper degrees of the few exceptionally brilliant men, and still more removed, the rare men of genius. The curve of distribution is significant in part and as a whole in comparison with other curves of similar origin. If the variations of the trait, within the group measured, are slight, the eurve will be tall and narrow; if very considerable, the curve will be extended and flattened. Relative homogeneity and heterogeneity of different groups may thus be pictured to the eye; and deviations from normal distribution, resulting from mingling of data differently centered or from other disturbing eause, may be graphically revealed.

Such are some of the useful quantitative conceptions that we carry over to the field of qualitative analysis. Even when they cannot be applied, their theoretical pertinence controls and eorrects our views. Nor need the fact that in many eases there are not available definite and equal units -like inches or centimeters for measuring height-to measure degree of deviation, interfere with the generic application. The bearing of the conception is clear; it yields a consistent view of the distribution of human traits; in particular, of the relative infrequeney of marked deviations, of the growing rate of elimination as we raise the standards which are to be met, up to the more exacting reaches, and finally to the extreme limits of the scale [5]. The individual application is direct, though it may not be adequate for all our purposes. It sets forth that one's place in musical, mathematical, moral or other type of proficieney is indicated by one's position in the curve with reference to inferiors and superiors-what proportion surpassing, by what proportion surpassed. Such quantitative aspects, 
standing in the background of our survey, influence the course of investigation and the interpretation of results. Their apparent retirement is due only to the oceupation of the foreground by the qualitative relations central to our analytical and expository purposes.

The question recurs: What is a trait? A positive determination would be equivalent to a decipherment of the alphabet in which natural deviation is expressed. Such a possession we cannot claim. As we use the term, it is an algebraic symbol on occasion converted into a quasi-arithmetical expression. At times an $x$ of unknown value, it may under certain assumptions be assigned a value of $a$ or $b$ of determinate range. A primary uncertainty arises from the question already asked: What do we inherit, general tendencies, or specific traits? The argument from animal psychology distinctly favors the view that animals inherit definite conduct-reactions to specific stimuli; it is this fact that underlies the conception of instinct. An instinct is such a specific trait, a definite responsive tendency of the nervous system. To prevent misunderstanding, let it be added that such a tendency need not, commonly is not, rigidly bound to a single inciter; it is more serviceable to render the organism responsive to types of stimuli. "Thus instead of a number of fears of special enemies, such as cats, hawks, skunks, etc., chicks have a general alarm at strange and impressive objects." (Thorndike.) Similarly, the early responsiveness of the human inheritance as it appears in the infant, is little more than a bundle of instinctive specialized reactions and tendencies thereto: to ery when uncomfortable, to suck when the lips are invited, to eling when the palm is touched, to struggle when held, to reject unpleasant stimuli, to blink when light strikes the eye, and so on. At this level a functional trait seems little more than the strength and direction of an instinct. But even in infant life such regulation soon becomes inadequate. The variability of the excitants modifies situations and re- 
sponsiveness alike; the responsive tendencies develop interrelations and conflicts of tendency; and yet more derivative variations ensue through the large range of environmental appeals in the psyclic life of an organisin of any degree of complexity.

The central bearing of this body of facts is that the elemental reactions in which the instinctive adjustment is commanding, furnish the clew to the nature of primary traits; this principle will find due recognition. A trait comes to mean a more generic reactive tendency, related closely or remotely to a specific natural situation, and retaining at all events a direct functional significance. The term acquires a variable meaning, and gets its value from the actual range of its application. Such is always the case in regard to products of evolutionary forces which in one direction hark back to elemental origins, in another reflect the environmental adjustment, and in yet another embody the issues of conflict, amalgamation, and complication with other tendencies of like status. At the level at which it is profitable to present the analysis of human qualities, traits appear as generic reactive tendencies or as partial modifying factors of such tendencies, yet reflect the setting of the specific reactions in which they had their source [6].

Traits are issues of original and definite responsive tendencies of the rervous system; they represent functional trends or aids, and get their meaning from the part which they play in natural situations and the complications both naturally and artificially arising from them. Traits as they come to be recognized and named owe their selection to their conspicuousness, which reflects the interest in observing them-the interest itself reflecting their practical import in human conduct. Practical efficiency and psychological insight develop together. The psycho-analytical bent is favored by the practical need of referring action, attitude, and motive to their source-introspectively for 
ourselves, objectively and inferentially for others. A world-wise experience with familiar situations however complex, brings about an adjustment to them on the basis of previous facilitation in meeting simpler situations of allied nature. The differences of men appear as affections and dispositions to response, in the main, to original primitive situations, but even more to the supporting, modifying, partial factors that both extend and complicate their scope and expression.

If we return to our motley questionnaire under the guidance of these principles, we observe how the traits assembled may be given a place and a meaning in the general scheme. A considerable number of the medley of qualities belong to the emotional group and indicate the relative strengths and kinds of feeling aroused under common situations in human intercourse; such are the qualities described as "cruel," "courageous," "shy," "impulsive," "spiteful." These traits are exercised dominantly in one's relations to others, in which relation the maintenance of selfesteem is a natural and primary impulse. They imply the object of consideration which completes the situation; in such a trait as "love of children," this is named. Another group specifies the manner in which dependence upon physical organization comes to the front-such as the necessary hours of sleep, or the manner of succumbing to intoxicants. A further group of traits refers to proficiencies as exercised in actual pursuits upon the basis of a native keenness of the intellectual powers-a grasp of relations; a gift for mathematics, psychology, history, or engineering is a variant and high-grade expression of such insight, which has developed far away from the original field of the parent trait. For the rest-the most miscellaneous group-we are dealing with still more remote, still more accidental or incidental applications of combinations and offsets of qualities derived from divergent phases of our nature. Thus a sense of humor is a complex issue of an in- 
tellectual keenness, a sense of proportion, and an emotional sensibility to incongluities between aim and result; to descrilhe it adequately wonld denmond an essay. And the like is true of such a sophisticated term as "Philistine," which required the social-philosophic criticism of the complex reeonstructive ninetcenth century to establish. For the sake of completeness a referenee must be made to the moral traits (miserliness, criminality), and the esthetic ones (bad taste), and to their eomplication with intellectual eonvietions (soeialistic trend, ete.). They, too, represent issues of eonflict between tendeneies in shaping attitude and action, as well as native powers of resistance. By such varied routes, long and short, direct and cireuitous, may qualities as superfieially noted be brought back to natural orders of traits, and to derivative issues and modifying factors of sueh traits. The traits are thus placed in an artificial system, yet carry an implieit reference to the natural situations of their origin. That we deseribe and detect them in the terms of the markedly modified situations and applications of our own lives is as natural as the persistent similarity of the traits through all varieties of situations.

The functional aspect of traits must be more closely considered. Funetions are not of one order only; yet the individual, the embodiment of the funetion, survives as a whole. Supreme in the natural order are reproduction and survival; the latter comprise the food-getting, mastery, and enterprise activities. The mental life no less than the physical is surrounded by eondition; in the control of condition it finds its object. With inereased complieation the drama of life beeomes endlessly variable, the acts and scenes recurrent yet not stereotyped. Traits acquire a place aecording to the rôles that they play, primary or supporting to the chief movements. They are earried in, and by the organism which must embody all the traits essential to the operations of life. The mental equipment is in this sense but a derivative eomplement to the physiological one. 
Functions commanding in the latter aspect will inevitably condition the former. Divergent natural functions will develop divergent mental traits. A given group of men and women as alike and equally human, likewise members of the same stock and generation, have a cumulatively and convergently common inheritance; by virtue thereof they present the largest community of traits. Still more narrowly, a man and his sister should be and are comprehensively alike; yet they differ as a man and his brother do not, and must so differ if the one is to be a normal man and the other a normal woman. Men and women will be alike by virtue of common heredity just so far as they are not different by virtue of differentiated natural function, despite that community of inheritance; and men will resemble other men by virtue of functional community despite their divergent ancestries. The factor that determines sex carries with it an endless series of remote issnes, affecting a large range of mental endowment; it is as such issues that the psychologist encounters them and traces them to their source. Thus the manner of differences of traits becomes clear in virtue of the import of the difference. The same applies to the degree of difference in common traits. Differences small in their quantitative statement may be efficiently large. Races like sexes may in certain respects differ little because slight differences are adequate to the differentiated functions or situations. Or again, variation may be slight because a larger variation would be incompatible with functional normality. Traits and the differences of traits in their manifestation among individuals or groups must so far as possible be brought back to a functional reference, to determine their true and natural significance. The enormous modifications resulting from the artificial significance which traits derive from the fostering or discouragement of the environment is a further and a vitally important consideration; the effect of civilization is to make small differences count. This influence af- 
fects mainly the upper-level, derivative qualities, but may extend fairly deep; its interpretation belongs elsewhere.

Traits are selected not only as conspicuous and interesting, but as central in survival value in one respect or another; nor does superiority helong unreservedly to one degree or order of quality. There may be several types of adjustment, compensating and conflicting vantages, so that the battle may be at one time to the fleet, at another to the strong, at another to the cunning. Traits are interpreted as they are estimated, according to the manner of their participation in conferring vantage and disadvantage in the recurrent situations. It is this service that directs attention to them, makes them conspicuous in the mental life, leads to their cultivation in practice, and in the analytical view determines their status. Once more let it be noted that the individual survives or prevails as a whole, with the sum total of his traits; with their advantages and disadvantages, virtues and vices, strengths and weaknesses. They are all comparably carried forward in the heredity, though variably molded by the social pressure; they stand in different relation to the survival values. Stature, strength, fleetness, endurance may all be of vantage and of different vantage; clearly of different service. Quickness or slowness of perception, susceptibility to fear or anger, resoluteness or despondency, prudence or shiftlessness, are yet more variably involved, and in so far as they are more derivative in scope are thereby open to environmental modification. The observed traits as they engage our interests are all fairly derivative; they have been carried forward, away from their primitive source and situation, by the maturing of the mental life and its artificialization. The ultimate consequence is this: that we can study and test functional capacities far more readily than true traits in the deeper sense. These it is difficult to refer to any precise range of service; they stand as issues of development under the combined influence of natural endowment and en- 
vironmental adaptation. It is even difficult to determine just what range of powers in relation to other powerswith these in turn to be referred to traits set in their natural service-a given facility involves. The psychologist measures acuteness of vision for distance, for illumination, for color, for form; of hearing for range of audibility or of pitch, for bare differences of tone and for accuracy of musical intervals; he measures quickness of response to signals, and both quickness and accuracy of distinction, span of memory, and rate of acquisition; he soon reaches tests where appraisal and judgment replace or modify measurement, and thus gauges liveliness of imagination, creative or problem-solving ingenuity, associative play of ideas, complex comparisons, judgments of "value," and the like. Even these (falling largely within the intellectual sphere of fairly definite distinctions) are more amenable to exact reduction and comparison than are qualities of large emotional play; the latter are more readily referred to a place close to natural function. Such tests may be said to offer a gauge of partial factors of derived products of the indefinitely complex psychic endowment. They measure them differentially, comparatively in so far as the factors are subject (under certain assumptions and with reservations) to a quantitative reduction; for the rest they yield a qualitative appraisal of the relative development of this or that phase of mentality and disposition, picture (the bases of) the preferred responses, the favored inclinations, constituting the measure of a man.

In such measure we are inclined to return to the primitive perspective in which the emotional appeal is the motive force of conduct, and qualities are intimate as they stand close to feeling and desire. In this perspective a man's character, as a reflex of his nature, is determined by what he desires, what he cares for, in what he finds satisfaction, what annoys, pains or grieves him, in his sympathies rather than in his opinions, in his sensibilities and 
tastes rather than in his knowledge and skill. The strength of motive, the appeal of situation, as the original forces, continue to mold conduct, however complex, and to determine attitude, however subtle. The natural direetness of relation between desire and the eonduet which is its satisfaction, has indeed been so overlaid by the fabric of reasonconsiderations at first plain and homespun, but ever more elaborate and fine spun, as they beeome conventionalized and systematized-as to eonceal the mental anatomy, which, like our bodily functions, through excessive reserve we are loath to recognize. The instruments of diagnosis must indeed be refined to meet the delieate and intrieate relations in whieh emotions suffused with prineiples and beliefs, seruples and inner eonflicts, standards and ideals, confusedly and indirectly find expression. Yet such is the problem of the psychologieal interpretation of character. The present equipment of the psyehologist is confessedly inadequate to the task. For interesting or important individuals the biographer attempts a selective impressionistic portrayal; or the novelist or dramatist attempts it yet more freely, according to the license of his art, presenting ideally eonstructed types and situations in the psychological novel or drama. The psychologist, however, need not and should not relinquish the prerogatives of his calling. The prineiples of analysis of the art are one, however different the training and eapaeities required for their divergent applieations. On the basis of his attainments, the professional psychologist-if his tastes and ambitions ineline him to such a task-may attempt to penetrate directly into the vital moments of endowment and their part in disposition and achievement on the basis of a general insight into the interplay of psychological forces at the high-level stages of their operation. He has, indeed, with a kindred purpose extended the psycho-analytieal method-whieh in its eurrent application brings to reeord trends that evade the search of eonscionsness or through inner conflict are re- 
pressed or distorted-to the interpretation of actions, achievements, failures, complications, of men grcat and small, individually or in groups and types. So considered and analyzed, one's work and one's career become a confession-assuming, if we may, that the psychological equipment is equal to this sacerdotal office. Yet however imperfect the interpretation, it illuminates the significance of careers as of the qualities that direct them, and brings a large range of accredited psychological principles to bear upon problems too exclusively considered from without. This domain represents the uppermost levels of analysis, for the most part beyond the prescribed limits of this essay, though subject to the bearings of its conclusions [7].

In resuming at closer range the consideration of traits as components of character, we have still to determine the construction of the projected composition before we can, as it were, put brush to canvas. Like other psychological terms, a trait is a working concept-a logical product-but also corresponds to a reality, since through it psychological analysis aims to project the actual structure and operations of the mind. At best the result is a rendering in which one set of values replaces or represents another. Accordingly the question: What is a trait in the sense of is this or is that a trait, or what types and orders of traits are there, or how are they defined? becomes subsidiary to, and indeed is answered by, the tracing of the natural history of traits, in the general manner here attempted. In this process justifiable assumptions enter; we may speak of traits as typical, of centers or foci of traits, which in turn involve a composite orbit or sphere of influence. To attempt a chemistry of the mind is indeed vain; but to reach some understanding in regard to the logical adjustment of the problem to the necessities of the pursuit and to our present knowledge is indispensable. Clearly it is against a logical economy to assume an indefinite number of traits of coördinate value. Such a conception would 
make each individual endowment a mosaic composed of substantially like minute fragments, significant only in the ensemble, would ignore the organic setting in which the traits develop and the relations between them of precedence, dependence and interaction. It would carry no clew to the motive of the composition. Such a clew is furnished by the genetic conception of traits as primary and subsidiary functional products of an evolutionary order. As a conscquence a trait, revealing its nature through its expression, will vary according to its original or derivative status, central or tangential place, as well as to its level of expression and mode of supporting the ensemble; it takes its definition and likewise its rating for practical ends from the evolutionary level at which it is considered. Thus regarded, a trait has a biological, a psychological, and a practical aspect.

The biological reference is direct and paramount at the lower levels of the great trunk-lines of traits, that maintain the organism in its environment. It places the trait according to the trend, the contribution of its survival value, its part in conferring vantage in one phase or another of the situation-meeting reactions. In situations above the simplest, a directive factor in the operation is of that distinctive type for which we have no other properly comprehensive term than psychological; it indicates that the process of adjustment-now in the nature of the solution of a problem-proceeds as the mental elaboration of an underlying biological trend. From the outset the environment reacts upon the trait and conditions its expression; for life as we know it and live it, the environment is largely artificial; traits are exercised upon objects and purposes having a place in that artificial system. An artificialized function replaces a natural one. The world of practical values develops a complex elaboration and transformation of traits, equivalent to new varieties thereof. The rich vo cabulary of psychological terms refers to the finer distinc- 
tions within the upper levels of expression. As compositely biological and psychological trends are directed more particularly to one set of objects or situations (ordinarily artificial upon a natural basis); or as they represent different interactions (combinations or conflicts) of responsive tendencies with a varying dominance of one trend or another, they receive distinctive names. Thus pride, conceit, vanity, haughtiness, dignity, confidence, and so on, are varying high-level expressions of the same selfassertive trait, which psychologically projects the influence of attitude upon conduct, and biologically becomes part of the combative equipment of aggression and defense. Jointly the terms reflect a complicated social world, offering a wide range of situations for the application of such traits and a varied series of achievements of practical import in that world, of which one may be proud, conceited, vain, etc. Such traits are differentiated because of their practical import. The term "practical," though it suggests but one aspect of the complication, is acceptable because it is neutral; it indicates that the high-level expression of traits is shaped predominantly by the system of values current in the environment in which the traits operate. The "real" and psychological differentiation refers to the mode and type of elaboration of traits thus exercised, to the qualities of mind thus resulting. As we view a trait predominantly as a biological, as a psychological, or as a practical product, its perspective alters; the trait describes a different orbit. The study of character and temperament considers the whole as a unified product, and traces the unitary course of unfoldment-the relations developed in the growing complications of the mental life. The largest considerations will be given to the high-level expression of traits because of their practical import, of their intimate appeal to our interests at that level, and of the fact that there alone appears in full richness of growth the mature products of character. The due consideration 
of the earlier stages has a notable service to perform. Just as our perspective of the historieal past is apt to be illusory - the earlier centuries condensed and bare and the nearer ones expanded and detailed, beeause of our larger interest and eloser appreciation of the times nearer to our own-so the psychological perspeetive of the natural history of our mental past needs the eorrective of a seientifie study of origins. The study of history makes the eenturies distinet and real; psyehology must be eontent with a more general and more problematical illumination of the story of the stages of mental expansion and conquest.

At this juneture illustration will best serve our purpose. Let us eonsider a trait to which we attach a high-level meaning-the esthetie trait. At first blush it seems strained to traee so highly developed a trait to a biological status; yet such is the prineiple of a "physiologieal estheties" [8]. The trait reaches back to the pain-pleasure aspeet of conduet-regulation, to the stage at which the pain or pleasure is no longer the ehief determinant of the reaction, but less gross, less direct, supplies the added zest or the minor deterrent. Esthetie, though at its lower level of expression, is the direct sensory joy in color and sound; it is a stimulus to activity, a contributory aid to selection of response through enhancement or modification of the organie tone. Whether we regard the song of the bird to its mate as an esthetie joy or as a compelling organie impulse-singing beeause it must-will depend upon the level of the trait at which we hold the term "esthetie" to beeome appropriate. Denying this quality to the bird, we indicate that in our definition the trait implies a more mature development; that it must affiliate with meaning, lose its too direct organie stimulus, and acquire a place in a preferential psychology. The song may be a preësthetic expressionsomething in line for promotion (in an organism eapable of such development) for the esthetie status. The infant begins with the physiologieal pleasure of strong eolor- 
a psychogenic stimulus-but soon attaches meaning to its preferences, and finds things exciting and joyous, and in due course pretty, because so complicatedly attractive. The physiological flavor has retired; the psychological import becomes the central, almost the complete content of the experience. When matured in practical endeavor, the esthetic sensitiveness leads to the fine arts. Objectively these are shaped by the conditions of the material, the mastery of a technique; but more intimately they reflect the nature of the traits which the art-products satisfy. The pleasure of sensory tone is variously complicated by natural associations and artificial meaning before it becomes a musical expression; the joy of music must be in the soul before it finds outlet through the voice or hands. It may appear in this illustration that the notion of usewhich the term "practical" suggests-is foreign to the nature of the esthetic; but it is the application and development under actual circumstance for material ends that is the essential part of its meaning, which is here, as elsewhere, relevant. The ministrations of the esthetic order are in this sense comparable to those that more directly serve the vital needs, in the regulation of conduct. Also let it be noted that such a vital situation as courtship is in part esthetically directed-predominantly so, it may be, at its higher stages; and in this affiliation lie the deeper roots of the esthetic life. The inner antagonism that has at times made morality suspicious of art is a (high-level) testimony to the reality of this deep-seated connection. It inclines to assume that because the roots of conduct directed by pleasure and by duty are distinct, every development of quality and career dependent upon the former must at all levels be antagonistic to the latter. Thus arises at least one aspect of the divergences of careers-the alternative of the cloister or the hearth-and of the misunderstandings of men.

The same line of analysis is applicable within high-level 
stages of the esthetic expression. If we visit an ethnological museum and survey the arts and crafts of the Alaskan Indian or of the Soutl Sea Islander, we realize that the study of the decorative and representative motives there assembled requires a very different attitude and consideration than we carry to the study of Greek sculpture or Renaissance painting in a representative museum of Classic art-the existence of the museums furnishing a convincing tribute to the continuity of the esthetic interest. Yet in the psychological perspective-which is vast, like the geological one-these variations are substantially of limited range, fall within one order. The essential nature of the esthetic trait, the needs which it satisfies, the avenues which it creates for its expression, and the arts that result therefrom are of a nature all compact. They are all high-level products; those of highest level, touching our interests and traditions most intimately, are, indeed, in the enlarged scale in which we present them, of a very different cultural order. For students of the most evolved forms or levels of esthetic expression, considering the traits that make possible modern music, modern love of nature, modern drama, the term "esthetic" would necessarily acquire a different range of reference and the subject a wholly different method of pursuit than attaches to the term and the trait as a factor in the general psychology of character and temperament. Yet it remains true that were it not for the place of the esthetic in man's original nature, these several phases of the fine arts would not have developed. Once they appear in association with the varied qualities of men subject to similar evolution, they mature under varied influence of the aggregate human endowment and are played upon by all the conditions of human life-by religion as well as by economic struggle, by social condition as well as by racial inheritance, by ideals and standards drawn from all phases of experience, until the esthetic becomes ore of the most comprehensive expres- 
sions of the human "psyche." The esthetic traits have a venerable history which affects our conception of their nature and function. Psychologically the essential complication enters early, close to the primitive stages of its development; the rest is but refinement. True, such refinement becomes important in its issues because these issues lie so close to our living interests and appreciations; because to attain them we laboriously seek a critical training. Essentially, primitive man is as truly an esthetic being as the schooled modern artist or connoisseur; the fields of application and the levels of expression to which the common trait attains, place them poles apart. In each case the esthetic trait as a component of character, as a partial factor in the equipment for appreciation and control of experience, exercises comparable function; it is at once allied by the common and separated by the varied worlds of thought, feeling, and social relations to which it is applied. Man from first to last is an esthetic creature.

This illustration projects the general course of our procedure. Having brought to bear upon the esthetic trait the entire range of considerations that constitute its lifehistory (in which its function in ministering to the psychological nature of man remains central), we may confer upon any one of a hundred contributory traits or separate attitudes or partial factors in the composite of a quality, the distinctive type and value needful for its comprehension in this aspect, by calling it esthetic. The trait at once acquires a reference to its mode of participation in the ensemble, and needs but the further specification of the manner of its participation and the level of its operation. The trait is thus placed, classified, defined. The same process applies to all the great trunk-lines of traits that have a parallel place in human nature. They, in turn, divide into major and minor branches and secondary radiations, all of which are equally entitled to be enrolled as traits-the vocabulary enlarging with the increased scale and conse- 
(quent refimement of the delineations and analyses. Such sub-traits or partial modifiers of traits emerge at all the higher levels of expression, grow out of the increased complication and specialization of the social life. In this essay the general psychological function, rather than the detailed expression, is directive.

Brief as must be their consideration, the great intellect'xal phases of human nature must be touched upon together with their momentous development constituting the history of the mind's rationality. The intellectual trend conforms to the general evolutionary course and takes its direction close to its source. Its function is to differentiate situations: to perceive, to compare, to relate, to interpret; it achieves the nicety of adjustment of response to situation. In complex applications the variety of demand upon the intellectual powers leads to such differentiations of qualities as intelligence, wisdom, insight, reason, of one type or another. So long as situations are relatively simple and clews obvious and gross, the adjustment is easily reached; yet a specific intellectual process of recognition and reference intervenes before the stimulus excites an appropriate response, calls into associative play some organized group of motor mechanisms. Conduct becomes more complexly selective by variable association with variable situations more minutely analyzed; it expands into a vast intricate network of relations in which experience and discernment are needful for guidance. / Yet in the intellectual as in the esthetic development, the maze-like complexity is but an enrichment and refinement of a pattern-type that has received its distinctive stamp at relatively early stages of its unfoldment. Man exercises the essential qualities of his rationality in the early steps of his life-history, racial and individual. Substantially the entire range of powers responsible for the abundant wealth of the intellectual life enters near the simple beginnings of intelligence and culture. Far as we may travel along the highways and by- 
ways of science, complex as may become the equipment for further progress, the essential endowment remains in type the same as that which directed the first tentative and uncertain steps. We have added endless knowledge, records of experience, profits and losses of trial, refinements of procedure, but no new inherent powers. Truly these powers find very different orders of expression and are applied to different and vastly more complex ranges of data; and for the intellectual progress of humanity these refinements are all important. So fundamental is this perceptive trait that we develop a close interest in its many and minute contributory and subsidiary processes, giving each partial function a name, examining its detailed mode of operation, testing its diversified efficiency. Thus emerges the psychology of the rational life-always commanding and at times too exclusively dominating the conception of human nature; it is familiarly the favorite definition or vaunt of man, that he is a rational animal. Memory, imagination, association, perception of relations, judgment, and the like-the essential endowments are not many-are distinguished and their varieties carefully scheduled, to gain an insight into their specific functions, if possible, a control and direction thereof to our set purposes. In all these respects men differ by dower of birth as well as by cultivation; in respect to them each has his measure. In all this the biological reference is not difficult to discern; for intelligence makes the struggle for existence a battle of wits rather than of valor and strength. Intelligence appears as resourcefulness in meeting situations, a perceptive keenness of observation in recognizing their nature, an associative reference that is accurate and ready, a skilled direction of response. Our psychological cunning picks the situation to pieces and distinguishes the several contributory processes converging upon the solution of the problem [9]. Practically it does more than this; for the issue of it all is that situations may be tried out in thought, 
may be prepared for before they happen, and reflected upon after they have oceurred. The scope of experience is vastly enlarged and the attitude toward response elaborately altered. The presentative life gives way to the representative; the grasp of the mind spans past, present, and future; experience is integrated, and limitations of time and space lose their confining restrictions. Mens agitat molem.

The intellectual traits, by reason of their varied scope and manifold applications, are likely to be described in terms of a special psychological aptitude, or, still more narrowly, of a practical proficiency. The latter presents an easier path to their examination. The processes of learning and knowing become systematized in and through their applications. It would be a useless circumlocution to speak of such and such mental traits as find application in mathematics or in language or in engineering; it is simpler to speak of a mathematical gift, a linguistic gift, a constructive gift of this or that order. Just how far or in what manner the qualities thus expressed overlap, or in what directions they diverge, it is not easy to determine. In the more general view such proficiencies whether exercised in meeting the simpler "play" situation of childhood, the problem-solving attempts of primitive peoples, or our own elaborate difficulties, are of a common nature. They depend upon and express an intellectual development of one level or another, involving the exercise in different combination and emphasis, of the fundamental powers developed primarily as a biological equipment to meet simple recurrent and urgent situations, and conveniently called intellectual.

The further analysis of the intellectual traits leads in one direction to their intimate psychology, and in another to their specialized applications in the arts and occupations. There is a limit to profitable specialization in either case. The former pursuit occupies the technical studies of psychology, particularly in its experimental phases; the psy- 
chological laboratory attests the recognition of its importance. Research lays bare the mechanism of perception, memory, imagination, association, inference, in themselves and in their support of the combined processes which they serve, and reveals individual differences in their command. On the practical side we cross-divide differently, noting the diversity of aptitudes down to minute variations. In one respect we observe a sense of detail, an aptitude for construction, the power of abstraction; in another we observe that one person is adept in the learning of languages and another quite without facility; that one has an aptitude for speaking and another for understanding; one for vocabulary and another for construction; one for French and another for German; that one has a mechanical, another an exploring, a third a ruminating type of mind. Needless to say that we cannot assume these variations to have independent existence as "faculties" in any sense. They represent a compromise between our practical interests and our psychological expertness. By virtue of the familiarity of the applications of such proficiencies, we use them as tests of capacity; their presence directs the course of psychological experiment, which by its practical conditions must always deal with the concrete. But the collateral requirement is that they shall be analyzed in terms of the processes which they embody. This is not an easy task; the element sought is a general process or type of mental procedure; the test applied measures a specific familiarity. In reaching conclusions there is no other resource to depend upon than a critical insight and the offset of one result by another. Similarly from the point of view of occupation, we may find it of practical importance to distinguish and to detect an aptitude for banking or clerking, for manufacturing or trading, for advertising or organizing, but do not suppose that these represent either divergent or independent proficiencies. In so far as these applied proficiencies determine the course of study, the analytical psychologist, 
while not wholly retiring, is ready to give way to the practicing psychologist-the vocational psychologist-as soon as he appears to elaim his own.

Yet another mode of combination of process and application finds its embodiment in the vocabulary of traits. Such terms as "common seuse," “originality," "shrewdness," "foresight," indicate the selection of a common factor in a reeurrent situation differing constantly in detail but true to its type, and a certain generalized proficiency in meeting such situations; this constitutes, or at least designates the trait, whether applied to one set of problems or oceupations or another. In such a term as "judgment" we have both usages: that of process and application. The psychologist applies it to a special process in reasoning; the quality is practically rated as poise, as a balance in weighing the pros and cons of impulse or policy. Naturally all these proficiencies and the traits which they embody may be expressed at different levels of complication, applied to the large or to the small concerms which a complex society requires for its maintenance. They are here introduced only to indieate how qualities ordinarily recognized are circumscribed by the eireumstances growing out of the natural history of the mind. The difficulty of defining a trait results inevitably from the eriss-cross of influences that affect its course, and from the consequent varieties of its embodiment and appreciation that different interests develop.

To trace the several levels from low to high at which the human traits thus founded and conditioned find expression in securing a partial control of natural forces and materials, in shaping the organization and the management of affairs, in developing an insight into relations of cause and effect, would require nothing less than an outline of the story of intellectual achievement and the eulture-history of mankind. Civilization represents the diversified issue of the play and sway of human qualities of low or high degree; it represents compositely the issues of the productive 
traits of human nature that combine with and modify profoundly the functions intellectual; for it is the latter that in developed stages assume the directive rôle. No less would an account of the step-by-step advances by which the naïve mentality of the child grows to the mature wisdom of the adult reflect the levels of operation of the intelligence; it would show how the standards of belief, of evidence, of explanation and interpretation that satisfy, change with mental growth; the scope of memory, the profit of experience, the curb of the imagination, the control of desire, proceed through the ages of man as the mind matures to its adult stature. Vast as may be the ultimate achievements-like a great literature-the elements of which it is built are-like an alphabet-relatively simple. In this sense the whole of life is an educative process and an educational product. Within its course it is often of moment to distinguish between the growth in strength and control of the intellectual processes-which we may call wisdom-and the larger acquaintance with the data to which they are applied-which we may call learning. With either notably in defect, there appears ignorance or folly-not the same, though akin. A firm grasp of simple situations secures adjustment; a groping, uncertain management of large enterprises invites failure. Situations demanding intellectual solutions vary considerably as the data to be assembled and coördinated are more concrete or more abstract. The former find reënforcement through sensory impression; the latter depend upon construction in terms of intangible ideas and elusive concepts. The former is associated more particularly with executive skill and the management of men or affairs; the latter with the exploring and pioneering ventures in ideas and principles. But as we leave these differentiations of intellectual quality, it is well again to recall that the individual combines and "compromises" the several orders of proficiency which an analytical interest distinguishes. Viewed psychologically, 
individuals-particularly notable ones-are marked in character as in achievement by the emphasis of their qualities, some becoming predominantly men of thought, others men of feeling, and others men of action. All, great and small, exercise and express the composite grouping of the complex but common elements of human nature.

By carrying the conception of levels of expression backward instead of forward, we reach the types of function which are regulated less and less by psychological considerations and more and more by physiological adjustments. Automatic action and reflex action are the current names for such orders of responsiveness, serving primarily the bodily rather than the mental economy. A large measure of illumination lies in the basis supplied by these processes for the understanding of the intellectual responses and of their supporting traits. Common to all are the factors of sensory distinction and motor coördination which condition the entire intellectual life. We are sense-bound, however we subordinate bare sensory discrimination to the highlevel elaboration in terms of which we conduct the mental operations; and we are helpless in bringing such products to expression except through some form of motor control. It is true that the former has lost its simpler direct value as a sensory clew, and has become merely a symbol to indicate the abstract situations which for the most part we encounter. Our situations are substantially intellectual ones, yet with an imbedded sensory nucleus or core; and the very nature of the situations, so largely of our own making, no less than the attitudes and sensibilities, the interpretations and insights, which we have developed for meeting them, reflect the original schooling in the more direct intercourse of sensory appreciation and motor control.

The relation is a parallel one and equally significant on the side of expression. The direct simple messages of sense, couched in natural terms, yield to the indirect elaborate ones of artificial language. Throughout situations are ex- 
ercises in reading meanings. The response, at first simple, direct, protective, immediately serviceable, becomes intrieate, delicate, skillful, versatile, yet continuously significant by virtue of the meaning that enters into and fashions the common motor expressions that serve responses of low or high degree. The backward extension from the intellectual level toward the physiological emphasizes the specific element in adjustment-as embodied in the conception of instinct-which continues in some form and enters into the content of the higher adaptations. In parallel manner it points back to the subconscious stages, urging that impulses are often truer than reasons, that the psychological is broader than the explicitly conscious, that mentality is inherent in orders of responsiveness that have not emerged into the reality of consideration and control. It there bridges the intellectual and the emotional life, converging toward the regulation of action by feeling. Within the intellectual field it gives rise to the conception of intuition or insight-a conception prone to be mystically and inconsequentially developed, but capable of proper inclusion in the developmental scheme; on its expressive side it is allied to the quality that is known as tact. The physiological regulation stands as the lower limit of the psychological, with the boundary broad and shifting. It is important not only because it persists in and through all upper levels, but equally because responses (conduct) early achieved and recurrently exercised in early mental situations tend to lapse back into a quasi-physiological regulation. These closely imitate the patterns of nature, though actually second nature. They constitute mental habits, the foundation for the upper intellectual life through the automatic security of the supporting processes. So generally do we recognize the importance of fixed mental habits-acquired on a natural basis-that they are inevitably included in the make-up of character. Indeed in a more intimate sense such deepseated habit-traits represent issues of endowment, whose ef- 
fects reach well up to the levels at which reflective consideration operates. Their influence is felt rather than traced; they enter into the eomplex of temperament, as an emphasis of natural trends, born and bred in natural situations.

We have been considering the psychie products at the different levels of expression; we turn to certain conditions presented by the process itself. It has been seen that the great trunk-lines of traits spring from the provisions for adjustment to fundamental, vital situations; and that derivative traits are likewise determined by their place in such a whole, viewed as a genetie series. The process by which a primitive status of a trait gives way to a more complex and elaborate one has not received an accredited name; it may be referred to as the "overlay" of quality. The general conditions of its operation may be presented directly as general conelusions.

First, the original trait persists in and through its transformation; its original bearings and mode of operation are never lost; the root vitalizes (and thus survives through) the process at whatever level.

Second, the primitive direction or trend of the trait is determined by considerations of its uses. Such use or function applies to its rôle in meeting a situation, to its place in a biologieal order of adjustment. This aspeet of the trait at whatever level may be spoken of as its directive trend.

Third, in consequence of the evolutionary stages the trait finds a larger and more versatile order of expression. It expands from the primitive situations to others allied to it, though in standard relations departing from it but sliglitly in type of service.

To illustrate these relations in detail would unduly anticipate the purpose of the suceeding chapters; their bearing may be briefly suggested. By virtue of the first principle the unity of the trait is preserved; which means that it is not the case that an old form of adjustment disappears 
and a new one takes its place, but that the old is continued in the new with additions and transformations; not that the infant, for example, is at first impelled toward vivid color's by their direct psychogenetic attraction and later replaces this by another order of preference, but that the former physiological factor continues in the esthetic reactions, though overlaid and overbalaneed by considerations of later acquisition. It continues up to the highest forms of color-combination, contrast, or conflict, because it remains as a part of the basis of selection. Our tastes may and do change; we may find distasteful what once we liked or accepted. Much of this is due to convention, to acquaintance with other standards (for taste like everything else takes its direction from the patterns and standards to which it is exposed), to freedom of expression, far more than to any real change of esthetic sensibility. The essential endowment is the original one that carries through to the highest forms of expression; the sciences make their appeal to specialized interests developed from a lowly and irregular euriosity. Similarly the learning that is teachable depends upon the native keenness of perception that is not; the latter persists through and conditions the former. It finds new and more complicated fields of application but never dispenses with the original quality. The spark carries by virtue of the original power of discharge; it becomes the flash of insight-or of inspiration, it may be, at the highest-no differently than it bridges the gap between conclusion and premises, between stimulus and response in simpler situations. Owing to such persistence, emotional antipathies retain something of the quality of physiological aversions, and sentiments grow about a core of physiological attraction. In social intercourse, however formal and elaborate, may be traced the persistence of aggressive and defensive reactions that hark back to primitive relations. The fact that the veneer may be thin and easily worn away exposes the persistence of the inherent grain that at all 
times shows through. The principle is important when practically applied to the emotional life in that it shows the value of transformation, of finding new and more appropriate outlets for old impulses, as against the policy of repression or extermination. The evidence from mental pathology illustrates not alone the tendency under lowered control to lapse back to the persistently primitive, but at times also the cost of blocking or thwarting the natural outlets of emotion.

The directive trend has been sufficiently considered in reaching a working conception of the nature of traits. It maintains the unity of the trait (not as the principle of persistence which directly continues it) but in terms of its function, its rôle, its Tendenz, its métier. It makes the common factor the type of service, both generically in the larger psychological adjustment-mechanism and yet more specifically in the manner of its contribution. A fair example is offered by the emotional factor in conduct, the attitude that begins with attack or retreat, aggression or defense, and shows this alternative trend in its most remote issues. The facial and bodily expression retains it in the contrast of smile and scowl, threat and caress, joy and grief. Within the group a common directive trend affiliates the several varieties and contributory traits from simple emotion to complex sentiments. Thus disgust, antipathy, shyness, fear, dread, even awe are affiliated as psychic dispositions to withdrawal and recoil [10]. The principle is not always clear in its application because the process follows the complication of product. Its bearing is central in classification, defining a trait primarily in terms of what it tends to accomplish or facilitate, while not neglecting the instrument that it uses for the purpose.

The third factor emphasizes the milieu, indicates that traits are bare of meaning until exercised; that in turn from such application the trait derives its richness of quality and acquires it specifically in the order of expression 
which it reaches. In fact many traits carry with them the natural implication of their setting; yet others leave it in doubt. Courage more naturally applies to physical valor, but may refer to moral courage, and is no longer quite the same trait in the latter reference; yet the evolutionary relations of the two are close. We may properly speak of pride as a quality and of a proud man as exhibiting it, without stopping to specify the manner or the object of his pride. Yet it is implied that the pride has a mode of exercise and an object. "Purse-proud" and "vain" suggest the expression more explicitly. The principle carries a genetic reference, allying while yet differentiating the pride of low from that of high degree; of child and adult, of prince and peasant, of savage and civilized man. That these have different objects of their pride is no more and no less characteristic than that the pride displayed is a variant order of psychic expression. What is true of pride is equally, though differently, true of shrewdness. The principle emphasizes the unity and continuity throughout the series of the common functional response and of the satisfaction which its exercise brings with it; it establishes the conception of a trait in accord with a functional psychology.

Turning to another aspect of these principles, we note their common reference to the process of transformation of traits in the evolutionary series, to the common circumstances attaching to the trait and its expression. As a further consequence, our several characters expressive of such traits present a considerable community amid diversity. Our personalities individually and collectively illustrate the persistence of the original trend and value-the nucleus-of the trait; the original mode of appeal and of operation remains and functions as a part of persistent and common nature. But in the mode of exercise of our traits, the directive trend-the application-reflects equally the largely parallel conditions to which they and we are subject. We become complex as individuals through the growing com- 
plexity of situations which we both meet and ereate, but become similarly complex withal; each of the several large components of our psychie nature continues to serve about the same range of functions, to develop comparable modes and degrees of elaboration. It becomes largely a matter of the perspective and of the detailed nature of our interests whether the communities or the divergenees are the more striking. There ean be no doubt that the influence of largest scope in thus maintaining our traits and their exercise in like orders of expression is the social and institutional environment. A membership in a given people or nation or community at a certain stage of its development beeomes the largest determinant of the manner of expression of one's traits. This fact is so important as a principle that it merits illustration at this juncture. It will serve to set in clearer relief how the environment acts upon the raw material of the common inheritance.

If a Kaffir infant were to be adopted by American fosterparents and given an American education, the entire set of objects and oecupations upon which he would exercise his endowment would be of a strikingly different content and range than would have been the case had he remained among his own people. We need not go so far as to eliminate wholly the influence of race by assuming that he would become indistinguishable from an Ameriean of accredited ancestry, nor assume that the American infant transferred to the Kaffir environment inevitably would remain at the average level of Kaffir culture. That the orders and levels of expression of their several traits would be enormously altered by an interchange of institutional and social environment is elear, and for illustration decisive. In corroboration we have only to observe how rapidly the amalgamation of peoples of divergent originthe Americanization of foreigners-proceeds; how quickly, though partially, they enter upon the national heritage; how comprehensively they express their traits through the 
American medium, in the American manner, and direct them to the objects of pursuit current and prized in American civilization. By a still more subtle and delicate process, the American child grows to be American in character, and the French child French, and the German child German, while yet their social status and opportunities are so largely the same. The perspective of value of the common elcments in their overlapping pursuits remains distinct and divergent in their mature characters. Admittedly the contrast is of a more refined order, but no less illustrates how the milieu leaves its impress upon the order of expression of traits. Similarly we do not suppose that had an individual of about our psychic nature and endowment been born in Italy in the fifteenth century, he would have been substantially different from the men of that time and community. His social environment then as now would determine his career and the divergent scope of expression of traits in themselves (assumed to be) comparable. These illustrations enforce the importance of the environmental factor in securing apparent and real community and divergence of traits, particularly in their mode and level of expression. Their pertinence for the moment relates to the part that they play in the transformation of traits, and consequently in the natural history of character.

In the process of the elaboration of traits, which forms the focus of consideration, several varieties of procedure enter. 'To one of these there attaches a special importance; it may be known as the principle of transfer of service or of application. The most direct application relates to the transfer from the physical to the mental, the literal to the figurative. The clew of expression is significant: we express by the signs of pain the emotions of grief, and by the signs of the welcome accorded to physically pleasant sensestimulations the varieties of joy, though we cultivate the psychic expressions to a far more elaborate and refined degree than is possible or necessary for the original type. 
Similarly moral punishment replaces physieal punishment, and social preferment and honors and dignity are as effective as material prizes, and more so. In the higher stages of such transfer the operation eontimues by extending as well as transferring the personal and social value of one order of responsiveness to others; the trait changes both in nature and value; the transfer is from what is in itself a derivative yet early situation to other more derivative and more complex fields of operation. [11] An apt illustration is found in the important trait that makes us sensitive to the esteem of others. We like to be well thought of, and through such expression on the part of others, we receive a weleome stimulation of our self-esteem; the varieties of self-esteem in their upper level extend the trait and its expressions. Self-esteem can be only socially maintained. A prominent and early, though probably not original, aspect of this trait is aroused by the relations of courtship and is still exereised (another example of persistence) with a peeuliar zest and flavor in that or its derivative situations. Men react to the compliments and flatteries of women, and women to the attentions of men, quite differently than to similar tributes from their own sex. The sensitiveness to esteem was, if not born, at least matured and intensified in a sex relation, but has been transferred to other relations, where it confers a general sensitiveness to the esteem of others, and becomes a social force of the first magnitude, naturally not in itself alone but in common with other forees that have undergone a similar transformation in their high-level expressions. The sensitiveness to esteem thus transferred enters into a variety of sentiments, affects the eode of behavior and etiquette, the conception of honor and fame, and all the varied insignia of worth and station by which society seeks to express its rating of men. The subtle intrusion or re-introduetion of the parent (or fosterparent) quality of the trait in undertakings apparently foreign to its nature is suggestive. The knight-errant 
sought adventure and displayed prowess as a tribute to his lady love; the bull-fighter elevates what might readily assume the appearance of butchery to an act of chivalry by dedicating the doomed animal to a chosen dame; and the flower of the land assemble to witness the exhibition of prowess. When an author dedicates his book or the sportsman names his yacht or his horse in honor of one esteemed, the token of regard has a different flavor when the recipient of the honor is of the opposite sex. The token of esteem, reflecting its transformed quality as a general "social" attention, returns to its earlier sphere, and assumes the composite quality of both sources. The transfers of traits in their applications may be mutual-an interaction and reciprocal influence; traits acquire their finer varieties through such blending and composite application-a process limited to high levels of expression. Such a complex sentiment as honor, which reflects the complexity of the acquired sensitiveness to shades and grades of insult, slight, and disregard, owes its subtlety and complexity to its derivation from a variety of sources. In complex individuals honor touching the relations of courtship is of one kind; touching one's debts or business dealings or promise or reputation, yet another. The duel may have originally been a contest in the form of a challenge for a lady's hand; so considering it, we can readily see how it may be transferred to all contentions, even to the journalistic thrusts of Parisian critics. The evolution of traits through transformation and transfer does not stop here; its further course will be considered later.

Inasmuch as the principle takes on a distinctive aspect with each particular application, it may be well to add another example. The trait called "curiosity" will serve. Its origin may plausibly be placed in the alertness to natural situations-a power of observation-vital in the pursuit of food, the contest much sharpened by the fact that the quarry presented a psychology of its own. Such 
proficiencies as wood-lore and hunting shrewdness approach the primitive type of the quality. When transfersed it becomes an interest and an occupation in problems for their own sake-an inquisitive bent and an inferential habit. A notable and widespread produet thereof appears in the game, the riddle, the puzzle-the occupation of the mind with something to solve; incidentally and negatively, it illustrates the displeasure of mental vacuity. The ingenuity in inventing situations and the diversity of outcome-as in the game of chess-become absorbing mental interests, in which another vital faetor, that of defeating an adversary, is not absent, though it may be represented by nothing more tangible than a score; for this factor, likewise, is a transfer from combat to friendly sport. Similarly the emotional trait developed in the same situation which we call "being a good sport," has a natural history by virtue of which it retains a place in the composite of character. The original quality, combining curiosity with ingenuity in natural situations, developed more specifically into an artificial contest of intellectual shrewdness. Even in primitive society the wise man was honored as well as the hero of exploit, and the solver of profound riddles as well as the performer of arduous labors, as elassic myth records-recording also that by either method have fair ladies been won. Applied in other ways, the specialized intellectual acuteness gave rise to seience. Men study, explore, experiment, record, in field and laboratory, because in the primitive situations of life, the qualities thus exercised-however extended, refined, transferred, in later pursuits-had a part to play. The product is never the issue of a single or simple root; the complexity of the product often appears as the mixed. motives in our present pursuits, reflecting eompositely the original types of situations. Thus curiosity and daring both enter into ventures, possibly allied with the spirit of romance, as the plots of popular novels illustrate. It is or was a favorite discussion whether polar expeditions were more in 
the nature of sporting or of scientific ventures, whether the mantle of science was thrown about them to confer a more accredited type of glory. The traits to which the venture appeals may well be complex; and the popular approbation will ever reflect the type that has an early and strong place in the evolution of human nature. The discovery of radium or the invention of quaternions may well require the rarer gifts, but does not evoke the like applause of men. Such applause goes out to achievements more allied to the situations in which the qualities concerned arose, to qualities in such situations more readily appreciated. The principle of transfer obtains, but the transferred exploit does not carry with it the intense and direct qualities attaching to the nearer-to-nature situations. It thus appears that traits become complex by complication of condition; such condition, however, is itself matured in the process of following the lead of the more developed, specialized and refined traits. The trait changes in regard to the range of the pursuits which bring it satisfaction, and concomitantly in the nature of the satisfaction itself.

A further and all-inclusive transformation that affects the life-history of traits and conditions their high-level evolution is their absorption and formulation-explicit or implicit-into a system. The most readily described of such systems is that of the several intricate orders of sentiment which the social organization evolves for its own protection, but is capable of evolving only because they have a hold upon, and a place in individual character. The sentiment of honor is a subtle, complicated and variable restraining influence to adapt the individual impulses to social ends, and equally to maintain the individual efficiently and fairly in the protecting social organization. In such service the sentiment of honor does not stand alone but combines with other sentiments-such as those of justice, tolerance, reasonableness, truthfulness, chivalry, loyalty to clan or country - which have similarly crystallized 
into a system of attitude, belief, principle, and faith-all vitalized and maintained by the enotional warmth carried over from the carlier stages of their common development. Such systems are significant in that they concentrate and harmonize the several contributory motives of action and attitude-esthetic, intellectual, moral, spiritual-and carry them jointly to their highest consummation. Their nature changes as they express more dominantly the one or the other factor in their composition and support, their source and natural history; and these are the varieties that give distinction to the social products of different civilizations. The sentiment of honor changes from class to class, from age to age, from country to country, because of the varied emphasis of one factor or another in its social expression and more or less conscious formulation. Custom, practice, convention, tradition, are the more objective deposits and records of such systems of sentiment; and institutions and measures are the means adopted by society for their safeguarding. Clusters of systems within systems cumulate and interact, and together constitute the social-psychological environment.

That this play of influences is primarily a psychological one will be abundantly illustrated in later considerations. There is, however, one special aspect of this aggregate transformation that brings forward its inner foundation and warrants a specific term. The term adopted, though of general application, has a special relation to certain abnormal developments of mind. In such a system of delusions as that of "persecution," the victim absorbs all experience through the medium of his dominant motive and conviction. He is convinced that every act and incident, every attitude and approach, is significant as the expression of a widespread social hostility aimed at his discomfiture and undoing. He cunningly orders his regimen and his behavior to thwart these imaginary and insidious plottings; and his thought and his brooding rarely depart from the 
contemplation of his unfortunate state. Objective interests and occupations are unable to maintain themselves against the absorbing demand and insistent presence of the dangers that surround him. That, objectively considered, the situation is fictitious, the conspiracy imaginary, and the precautions needless and absurd, has slight bearing upon the reality of the fact that the "system" exists vividly and vitally for his mind. $\mathrm{He}$ is laboring under the delusion of a "complex" of persecution and suspicion. The subjective view of the "system" is a "complex" in this sense. If we extend the term to include the normal exercise of the body of sentiments, motives, appreciations, reasons, which guide and pervade attitude and conduct, we reach a very useful formulation of the ultimate expression of traits of character modified by situations. The ease of Hamlet, the case of $\mathscr{E}$ dipus, becomes a "complex," and a more or less typical one in the composition of character and the vicissitudes of experience. The intermediate ground is also well occupied; and in it fanaticism, asceticism, overweening and vainglorious self-assertion (megalomania) as well as Quixotic enthusiasm find their varied representation. The least as well as the greatest of us expresses his personality, his allegiance to the dominance of traits central in human evolution, in a "complex" which summarizes the perspective of impulses and of values in his socialized, systematized responsiveness.

A consequence of this complexity of development is the difficulty of unraveling the thread once the web has been spun. The difficulty may be somewhat too simply indicated as that of determining the trait or the traits from the manner of their expression, at times of distinguishing the one from the other. But the actual problem is far from simple. There is the general underlying fact that comparable systems of regulation are differently composed; that different formulæ of combination arise from substantially similar ingredient traits. And yet despite these inherent perplexi- 
ties the standard situations and the standard endowments bring about standard relations of character, standard ranges of temperamental endowment. The difficulty that must be more specifically faced is of a somewhat different nature; it is the consideration that capacity must be inferred from achievement, and quality of endowment from its quality; motive from action, and trait from expression. There is the further fact that what reaches expression is not any trait in its purity, but the resultant of interactions of mutually supporting, modifying, or antagonizing traits. Expression thus becomes the indispensable and yet the perplexing index of quality-the seal as well as the key of the record of original and acquired nature. The formula of completed conduct contains several constants and variables; with the failure of one or another term the whole issue lapses or is altered. It may be that a combination of traits is necessary to action; in the lack of either the other fails. Failure may be due to incapacity or to lack of desire, reasons, or impulses; hence the common misunderstandings of unsympathetic natures. Furthermore, like traits are directed to unlike objects, and like stimuli arouse to responsiveness unlike traits. If we inquire whether primitive peoples have a sense of shame, or of honesty, or of self-restraint comparable to our own qualities, we are likely to go astray in our conclusions unless we discover the situations in their lives in which such traits are likely to be expressed-unless we enter as best we can into the complex of their psychology, the spirit of their attitudes, and interpret action and motive, achievement and capacity, traits and their expression in their mutual relation. Even with far slighter divergences of training and outlook than obtain between savage and civilized man, the interpretation is beset with uncertainty; and the practical approaches of men are fraught with danger of constant misapprehension. These inherent difficulties of the pursuit will go far to excuse the vagueness and uncertainty of the presentations. 
Their presence affects all further considerations; they are here pertinent in that the source of the difficulty of interpretation is itself an issue of the relations that must be analyzed and considered in a scientific approach to the problem.

It has become apparent that two dominant attitudes obtain toward the traits of human nature: that of understanding their source and relations, and that of appraising their value in the practical life. At some stage in the development of the argument, the point of view must shift from analysis to value. There is constant danger of the intrusion of the latter upon the former; yet it is fair to observe that the appraisal of human quality is not foreign to the discovery of sources and relations. It is evident that use and application themselves condition the manner of complication. In the main the two interests diverge, while yet they correct one another. What is focal in the one consideration is remote from the other, and vice versa; their perspectives are different. The present essay is devoted to the problems of analysis. It would be appropriate to follow it by a similar consideration of the values of traits as demanded and exercised in the situations of present-day life.

The appraisal of quality becomes in practice the attempt to direct it to desired ends and purposes. Such ends are embodied in the organization of society, and lead directly to standards and ideals that control conduct and the training of character; these in turn are matured and developed as systems of principles and influences, acting practically as social forces. The two most prominent of such systematized ideals are those introduced by morality, enforcing the distinction of right and wrong, and by the allied purpose of education enforcing the desirable and the sanctioned in the mode of life, and the differentiations of truth and error. Traits are thus encouraged or suppressed, fostered or eliminated by attaching to them profit and honor 
(or their opposites) as values. The methou is that of nature herselt; for nature selects and stamps in or weeds out by attachment of value. The distinction is mainly bettreen values in terms of the natural and of the artificial environment. To a large extent the latter is an unfoldment while Iet a transformation of the former. In the process the modifiability of traits, later the plasticity of character, is a factor of peculiar moment upon which the environmental influences play, without which qualities would be too definitely stereotyped and adaptation retarded. In the course of civilization ideals change, and with them the direction and stress of training. The sanctioned ranges of conduct reflecting the divergences of ideals and standards which determine them. are under different systems of cirilization surprisingly different. Even in the intellectual domain it is found that arguments which carry conviction under one system of thought and belief are quite ineffective under another - the two closely related historically. The reconstruction of values which results from the process and progress of culture indicates that value in the higher reaches is both an uncertain and a relative term. Remembering this and remembering also that the practical trend of traits forms part of their nature. We observe that we both analyze and appraise according to the parts that traits play in ministering to purpose: it is only as artificial ends replace natural function. that we are forced to assume the educational attitude and make our goal the training of character. It is the aim of the diagnostic study of character and temperament to restore the proper perspective by interpreting the entire range of the psychical equipment. and thus giving to the word "practical" a broader meaning and a larger wisdom. The longest way round may be the shortest path to the goal, both in the natural and in the artificial life [12]. Indirection and complication are inherent, when once the immediate stress of urgent need is overcome. A superficial practicality must be offset by a far-sighted wisdom or give 
way to the intermediate outlook of prudence; the value of human traits justifies the most painstaking inquiry into their sources.

The practical aspect of character dominated by the attachment of value confers an illumination upon every stage of the pursuit. It shows that human nature is ever set in circumstance, and makes the study of circumstance the speeial object of investigation. The most comprehensive consideration is that which summarizes to what extent man has developed the environment that shapes his ends. The insistence that human nature is ever the same, is but an emphasis that the original traits persist despite the modifying influences of circumstances; therein we recognize the community of traits. Yet human nature forms the sole material for the medium of control of traits, which we call education, and which constitutes the practical problem for each generation. The profit of experience, the pursuit of ideals, the formation of standards are all examples of the changes of human nature. The variability and the versatility of human nature are all that we have to work upon, all that we have to work with. It is this plasticity and its limitations that set the problem and offer the resources upon which the reformer must rely. That in this pursuit a knowledge of first principles may serve as a compass for whatever goal may be set by one venture or another is the fundamental conviction that guides the course, the approach to which has been traversed. 


\section{CIIAPTER II}

\section{TIIE SENSIBILITIES}

A SURvey of the qualities conditioned by sensibility [1] offers a favorable introduction to the study of the sources of our common psychology. Sensibility depends directly upon nervous organization; it represents the primitive form of reaction of living organisms. The process within the nervous structure may be pictured as a wave of irritation flowing through organized protoplasm and disturbing its equilibrium, which, through the removal of the irritation or by motor readjustment, is again restored; or, it may be, a favorable excitement emerging above the even flow of the physiological or psychological stream of which life consists. The process presents two varieties: the one is responsive to stimuli from within the body and regulates the bodily economy; the other responds to forces playing upon the organism from without and regulates worldly intercourse. The inwardly directed response develops characteristically to the status of feeling spreading to emotion. The outwardly directed response reflects the environment; the adjustment to the physical forces of nature conditions the avenues and expressions of the mental life. From the beginning sensation reports the bodily needs and their satisfaction; the developed senses serve as alert sentinels of the mind; in both aspects they guide the living and moving in which we have our being. Primarily the sensory routes determine the highways of the mind's journeyings. In common with other organisms man develops a responsiveness to such of the forms of energy that play in the world about him as it profits him to notice. He is assailed through eye and ear and skin and nose by a medley of impressions, 
which, as they yield to analysis, are interpreted as signs of situations bearing upon his welfare. Certain situations, because of the satisfactions which they bring to and through his nervous system, he seeks; and others by reason of their opposite effect, he avoids. He seeks and avoids because he feels and distinguishes. Action is guided by sensibility; feeling underlies conduct.

The contrast of function between the inwardly and the outwardly directed sense-feelings points to the organic and the special-sense roots of the sensibilities. These mature to different service, yield a divergent yet allied range of quality. The composite function of each developed sense carries the qualities of both sources. Organic sense-feelings may be specific, like hunger or thirst, with specific modes of satisfaction; or they may be more or less generic, vague, massive, like fatigue, nervous tension, nausea, malaise. These, as disturbing, yield to gradual relief; other varieties, more constant and positive in type, contribute to and merge with the tone of responsiveness, with the quality of feeling [2] as a stimulus to motor expression. The impeding, thwarting orders of "feeling" are more marked and extensive than the furthering varieties; the negative toning is more pervasive and explicit than the positive. Pains are naturally assertive; but the normal state is a moderate, adjusted well-being or euphoria. Such normal experiences, conveying the milder organic pleasures of positive tone or the fairly neutral sense of adjustment, support the constructive service of the sensibilities. Positive and negative organic feelings contribute jointly to the general affective (emotional) course; but whether organic and body-informing, or sensory and world-informing, the feelings regulate reactions : we respond only to what we feel or perceive.

The special senses are specialized toward distinction, yet carry the original affective factor along, or are carried by it. The affective element varies widely in kind and degree; 
it persists even in the senses of sight and hearing, which have traveled farthest from the organic type. The principle of overstimulation accomnts for a limited but significant range of sensory distress; it indicates why blinding lights and deafening sounds are painful; why also, though less intensely, such maladaptations as flickering flames and "beating" tones are nupleasant. Both violate the natural and favorable mode of functioning. The displeasure of harsh discords and garish color-combinations presumably involves kindred infractions of slighter and subtler play; their mode of operation reaches over to the derivative sphere of esthetics. The stimuli acting upon taste and smell convey no less distinctive information, yet function predominantly as direct "feelings"; as such they yield a not inconsiderable variety of attractive or repugnant impressions. Yet the pain-pleasure quality in odors, flavors, tastes, is not a simple or pure response to functional excitation, but shows esthetic complication, though of a primitive, organic order. The remaining field of touch and movement-the pains and pleasures of the skin and tissues and of the muscular (including glandular) functions-is rich in organic quality; is, indeed, the reference-map of the ills that flesh is heir to. The categories of pains particularly are described in tactile and motor terms : burning, pressing, pinching, pricking, itching, straining, stretching. The vast areas of tissue exposed to outer contact and to inner stimulation offer an equal area of potential pain. The principle of overstimulation applies; in terms of temperature, things too hot or too cold hurt-that is, pain and harm. The principle of maladapted stimulation may account for the disagreeableness of the "feel" of sandpaper or of chalk. The positive phase of the esthetics of touch and movement is recognized in the demand that knobs, handles, and feelable surfaces shall be smooth, or that the luxury of silk and velvet shall have a tactile as well as a visual token [3]. 
The more prominent citation of the pains than of the pleasures of organic sensibility and of the allied ingredients in the special senses, is due to their readier illustration of the principles of service. Displeasures, gross or fine, pronounced or slight, arise from interferences with natural function, constitute minor vital drains or losses; the state of neutral equilibrium or bare indifference implies their avoidance. Such a zero is largely an abstraction; adjustment is a positive rather than a negative condition, and involves a more or less advantageous set or balance of function. The lesser, derivative, furthering varieties of stimuli bring their contributions constantly though unobtrusively; they form the minor vital profits. Both support the argument for a physiological esthetics, yet present the esthetic reaction and its far-reaching issues as a complex superstructure in which the foundations are commonly concealed or disguised.

For human quality these relations are fundamental. They indicate that the psychic life of each of us is expressed by the sum of his sensibilities, by the aggregate of the reactions that confer pleasure or pain, by the system of vitalized responsiveness through which adjustment is sought and found. To curtail the range of sensibilities is to restrict and impair psychic vitality. The deprivation of a sense, carrying with it the sensibilities based upon it, is more than a loss of convenience as a guide to situations; it is an exclusion from a share of the world of the affective life. For the moment questions of value are premature; whether the valued quality lies in the sense or in what we build upon it is important only in that it emphasizes that a given de. velopment of sensibility is not conferred without effort by the mere presence of the sense that conditions it. Many who have eyes to see are almost immune to the esthetics of color and form [4] ; but obviously, the blind, however temperamentally endowed, are cut off from this heritage irretrievably. 
The maturing of the range of sensibilities as the issues of sense is the central theme; its pursuit proceeds upon the natural history of the senses. A matured special sense, acting through the specific feelings which it arouses, may be regarded as a device of nature for making the organism definitely and profitably responsive to pertinent happenings in the environment-to noises and colors and forms and odors and movements. The feelings aroused in the more primitive phases of such responsiveness lead to pleasures that attract and pains that deter, and in more developed phases to the esthetic satisfactions and aversions. But the leading factor of the response is directed outwardly to the situation in quest of recognition by way of distinction -the what and where and how of the intellect-the knowledge that is power. The primary condition of sensibility for distinction lies in the nervous organization. Cases of gross defect are convincing but not illuminating; the blind see not and the deaf hear not; and their mental development is not only handicapped but is deprived of its full consummation. More suggestive is the fact that some persons with seemingly normal vision prove on examination to be color-blind; and that others properly responsive to sounds are obtuse in the distinctions of the musical scale; they are moderately tone-deaf. This inlerent deficiency depends upon some minute abnormality of the sense-apparatus. We cannot specify it, but are convinced of its existence through its psychological revelation; such imperfection of knowledge is typical of the relation of mental qualities to "nervous" condition. If we substitute for defect the minor variations within the normal range, we reach the familiar individual differences of sensibility which apply, though not in the same terms, to esthetic and to intellectual distinction and enter into the personal equations of our natures. Persons gifted with a delicate musical ear are sensitive to fine distinctions, to tones out of tune, to discords and subtle deviations in shades and grades of 
harmony, that wholly escape those of modest musical capacity. The condition implies an innate difference of nervous organization, indefinitcly minute and defying precise detection, but real, and for quality decisive. The potential musician requires more than average tone-sensibility. Likewise there are those (not color-blind, for this is a specific type of defect) whose color sensibility is subnormal, who perceive the coarser color-distinctions adequately, but for whom delicate blend and play of contrast and gradation of values are non-existent. It is important for the sequel to recognize such nature-set barriers of the nervous organization. The artist in color or tones, yet more literally than the poet, is born and not made; for all alike, training has a distinct service to perform. Many an insensitiveness to distinctions-to intellectual ones especially-yields to an improved attention to their alphabet, to an increased interest in their message. Promotion from one class to another, and elevation as well as direction of sensibility are vastly facilitated by education. Yet fundamentally the status of individual sensibility is conditioned within fairly rigid limits by organic structure and function. We find rather than make our sensibilities; but we cultivate them to our great benefit, and particularly so as we leave the proficiencies most closely bound to sense, and approach those subject to the complications of other ranges of endowment.

We have not yet adequately disposed of the reactions within the organism in terms of which impressions are registered. These are the psychological first-things in consciousness; their direct function lies in their feeling-value as pain or pleasure. The grosser, more organic pains involve direct injury, interference with function, lowering of vitality; the pleasures accompany relief of needs, satisfaction of impulses, exercise and furtherance of functions. But attraction and repulsion are neither absolute nor of one order; grades and shades of invitation or recoil develop. Enhancements of sense-pleasure and complications of sense- 
pain appear in manifold variety, of moderate degree; they modify and accompany sense distinction, and affect the careers of the sensibilities. In principle both orders of effect-fecling-ralue and knowledge-valueare attached to every variety of sense-impression, but this aetually in very different degree. In some sensory qualities (taste, smell, even, in part, color) the feelingvalue predominates, and the knowledge-value remains slight or undeveloped; in others (forms, the sounds of words) the reverse relation holds, and the feeling-value is submerged, transformed, or detaehed. The intermediate status is common, with the two orders presenting separate contributions blended in a common impression.

The sense of smell affords an instructive illustration: it shows strong, positive, quasi-organie reactions of attraction and repugnance. The significant quality of an odor is its agreeableness or disagreeableness. In terms of function it ineites to and directs action without recourse to the by-paths of knowledge. From the blossom's lure to the insect, to the mating instinets of high and low degree and the subtler attraetions and aversions of sex and race in human kind, it ministers mainly to an organic service through specialized sensibility [5]. Considered in the regulation of appetite, the nose protects and guides, accepts and rejects by verdicts of agreeableness and disagreeableness, variable yet not capricious, subject to habit and condition and idiosyncrasy, yet normally holding to its types and serviceable to primary needs. Throughout it is eapable of cultivation, is prone to assume a modest esthetie bearing, and thus refined, to yield a delicate index of preferenee, while in its course it advances also in the realm of distinction. Its feeling-tone remains strong; its affiliation remains closer to the emotional than to the intelleetual qualities. Its status is near to sense. To express this quality we specialize the neutral "sensory" to the more explieit "sensuous," or with closer reference to the organic pleasures, "sensual" - a 
term attaining its most salient application in the sensory gratifications of sex [6]. In this field individual differences are directive; natures disposed to strong sensory reactions will inevitably shape their lives differently, develop a different perspective of qualities from those of natures weakly endowed in this direction. The sensory reactions thus conditioned determine inclinations, which mature as phases of character. As a group-trait, favored by a common nurture as well as nature, they may present the contrast of the richer, more joyous responsiveness of sunny climes and luxuriant environment, with the colder reserve, the harsher condition of less hospitable lands, as well as of the different traditions and standards thus fostered. Considered individually a strong sensory responsiveness in the primary realm of the "food" situation may incline to the coarser satisfactions of appetite-after the manner of the glutton, the gourmand-or, if otherwise supported, to the refined appreciation and special sensitiveness to flavors and savors, characteristic of the epicure-the gourmet. Psychologically the artist in tastes and aromas is exercising a function comparable to that of the artist in color or tones. The esthetic rating of the art, and, by implication, its ethical status may be markedly different in the two cases; the psychological evolution is similar. The reason why the pleasures of eye and ear are held above those of the palate concerns the different ranges of quality which they serve; this in turn, harks back to the zest and service of the primitive sensory stimulation. Similarly the disposition toward the satisfactions of the life of sex profoundly affects the tone and order of living directly and indirectly, and demands large regulation through counteracting qualities of character.

The principle of the inverse relation between the feelingvalue and the knowledge-value of sensory service is important. The closer the connection with the primitive organic needs, the more restricted remains the eventual in- 
tellectual range. It is because what we sec and hear-in contrast to what we taste and smell-affeets the slighter profits and losses of bodily feeling less directly and less decidedly, that sight and hearing become available for the ligher, less use-full service. The predominantly or obtrusively useful senses are too limited in range, too closely bound in indispensable function, to yield the freer and more versatile type of responsiveness requisite to the higher calling. They must in a measure be released from the one service to qualify for the other. Despite easy gradations between them, needs and luxuries are opposed. For this developed, complicated, overlaid order of sensory quality, we require a specific word, and find it by an appropriate return to the Greek esthetic. The esthetic responses are distinctive and momentous for the development of the sensibilities toward the psychology of endowment.

Proceeding to selected details drawn on a larger scale, we recall that the constant issue of responsiveness is conduct; we feel and perceive differently that we may act differently, or be disposed differently toward action. If feeling and action are joined in a quasi-organic bond wliereby the instinctive feeling passes over effectively to impulsive action, the end is accomplished. But even at the lower stages distinction supplements feeling in a fusion of impressions; recognition accompanies, quickens, and defines responsiveness on the way to becoming the condition thereof. What we see or feel or taste mingles with the how of the impression; we recognize as we shrink or approach, are attracted or repelled. The discrimination itself becomes a subtle and complex ingredient in the esthetically guided response. At the higher levels of sensibility, the reverse relation obtains; recognition dominates, absorbs, and re-directs the affective factor; the estletic element is merged, but not lost, in a critical recognition.

The subdued, retired quality of the feeling-tone of a sense-impression becomes a condition of its advance in in- 
tellectual status; it clears the way for the variety and delayed considerations of knowledge. The esthetic thus rises to stages of service extending vastly beyond the mere sensory. Yet, in part, colors and tones retain their original feeling-values; some noises are physiologically intolerable; the "red rag to a bull" finds its analogy in the exciting or depressing effects of color on the human sensibilities. While the senses continue to awaken painful and pleasurable feeling, and thereby give headway to action, their comprehensive service consists in arousing recognitions, to which associatively affective values are attached directly or indirectly in endless variety. Eventually the recoil from or attraction toward particular sensory experiences is far more a derived than an original aversion or preference. The complexity of sensory quality arises as the surplus and extension and overlay of sensibility, particularly through its infusion with meaning. The end is ever the same-the regulation of conduct; but the means of impression, the channels of employment are various. The most profitable route follows the interests set by the intellect, making shorter or longer excursions among the highways and byways of knowledge. Typically, the form-perceptions of the retina-the visual situations-acquire meaning through experience and association with the reactions proper to their appreciation and control. The meaning may be dominantly esthetic or dominantly intellectual. The former appeals to artistically sensitive natures; and they more eagerly turn to such experience because of the deeper satisfaction, the stronger interest, the more varied responsiveness which their nature offers for that phase of sensibility. That fundamentally the sensibility is conditioned by the structure of the eye or the ear or other sense-organ will not be overlooked; nor will the more significant factor of the degree of sensibility available. The common contrast is that of those normally, those subnormally, and those supernormally sensitive to tones, to colors, to sensory nuances, to any of the 
refinements and issues of trained sensibility. In ministering to the higher psychic development, the leading senses are sight and hearing; as between the two, the auditory (musical and related) function involves the stronger sensory dependence; it leans more directly upon natural endowment, and develops more largely, more primarily, by the support of the inherent affective response; it makes less explicit and less extensive excursions into the intellectual domain.

In one aspect the contrast may be regarded as that of the presentative and the representative service-the carrying of a message more directly by what the sensation is or incites, or more distinctively by what it means. In their advanced stages sensations (reversing the original relation) become but secondarily stimuli and are predominantly signs or clews-signals not for bodily but for mental response. Consequently the representative scope of a sense goes far to determine its status in our mature "psychology." Sight is the intellectual sense par excellence by virtue of its availability as an avenue of perception. We compose pictorially, associate, combine, compare, contrast, analogize and elaborate in terms of observed resemblance; we reason in diagrams, find sermons in the appearance of things, books in the operations of nature, and good and bad in everything visible. The preferred material of memory and association in direct presentation is the image composed of form and color. On this basis we acquire a comprehensive photographic sense and a system of eye-minded experience. While the visual impression may be crudely developed and repeatedly retouched, possibly vague and blurred, and above all, desultory and defective, it is yet in type graphically presentative-a sketch to recall the original. More momentously for intellectual assimilation, vision becomes the preferred instrument of representative thought, not literally reproductive in temper, but at once constructive and analytic, working with images selected 
from situations and transferred to other situations by analogy of mental relation, by simile and metaphor.

The contribution of sight is commanding, but by no means exclusive in this service. Moreover, it is explicit; and this explicitness confers the largest availability of the visual material for the abstract construction that we call thinking. Sound and touch, smell and taste, and notably the sense-experience of movement-alike in skill of member and expression of muscle and exercise of vigor and agility-all enrich the presentative aspects of the mental life, and diversify and extend the mind's representative excursions. Yet in the larger contrasts they occupy positions of lesser scope-though in part of comparable statusthan those attaching to the elaborations of the visual field. Consistently this difference finds explanation and compensation in the more direct presentative hold of sound and gesture and touch, by virtue of which their service lies closer to the affective nature and makes a stronger appeal to the feelings. For sound: the plaintive voice, the cry of distress, the sigh, the groan, the laugh, the shout, the song of joy, the pran of triumph, the dirge, the wail ; for movement: the dance, the quickening march, the stirring gallop, the tragic stride, the broken step of sorrow; for touch: the grasp of the hand, the pat on the shoulder, the soothing stroke, the fondling caress, the kiss, the embrace-all are infused with affective quality, express complex emotional relations, yet would be meager of content and bare, if not enriched, as is ever the case in mature imaginations, by representative items and associative values of visual origin. Through such affiliation of sound and gesture and contact with the scene, the mimic accessories of the dramatic art arouse a picture or a story even in detachment from the spoken word or appropriate setting [7], which, if present, they supplement and support.

If we return to the sources of sensibility and view them from a different angle, we may divide them according to 
their service to the more urgent phases of response-the things that one must see and hear and feel and smell in order to do the things that one must do to live adequatelyor to the slighter profits and more leisurely benefits of the refinements of life. Thus barely stated the division seems artificial, for the one order of appreciation merges into and with the other; but it is this very distinction that enters into and determines the psychic products of greater complexity. The sensibilities enlisted in urgent regulation are the same as those available for esthetic appreciation; we sense danger and beauty with the same organ. As an evolutionary process the organ is shaped by the urgent service, and it is its unemployed energies that are drafted to the esthetic ministrations. Thus eonsidered the sensibilities of the esthetic type form a seeondary, even an adventitious, order; they may be said to be an offshoot from the central trunk at a higher level, a by-product developed to noble and extensive service. The relation appears in the fact that this secondary service has a lesser, though not a negligible, play in animal psychology, where urgeney occupies a larger place, and "luxury" a more limited seope. It is in this conneetion a suggestive and a plausible speculation that the esthetie sensibilities owe their being to the sex relation. The enhancements of display and attraction in courtship would thus form the original, as they continue to be the persistent and elaborate playground of esthetics. The incidents of sexual selection would beeome the media of sensitizing the psyche to the preferential responses which find their highest expression in the esthetie life. The song of birds, the exhibition of phmage, the graces and eharms of movement are thus all of one significance. That by-products of other ranges of activity - of the play and constructive tendeneies notably-contribute to and enlarge the scope of the esthetic is evident; and the root from which they spring may be an independent one. However established, the pressure of each of the origins or the centers of growth 
of esthetic sensibility reacts upon the others. The composite humanized esthetic sensibilities embody them all and mature through the persistent vitality of their several roots. The esthetic life takes its complexion jointly from the sensitizing developed in sex attraction, in food preferences, in bodily care, in constructive craft, in the social relations. The conclusion has large bearings upon the nature and careers of the emotions thus furthered, and in the consideration of that high-level product will again be encountered.

By way of résumé, it appears that genetically the earlier forms of the responsiveness of sense are more closely allied to the organic in type, to the stages at which sensation serves bodily welfare and yields simple feelings of agreeableness or the reverse. When this phase of the responsiveness is less urgent and more diversified, it makes for the indirect attractions and aversions of the esthetic life. The scope of the esthetic is broad, and comprises many varieties of feeling-values. Nearly co-extensive with the organic and sensefeeling (which matures as the esthetic development) is the function of sense as distinction or recognition. The two factors are in a measure opposed; the stronger feeling-tone may solve the situation without awakening the delayed consideration of reflective distinction; the latter in turn is drawn upon and left open to, or requires, intellectual consideration. The sense must be released from the immediate, obtrusive, useful service to qualify for the more indirect, versatile [8] elaboration. Characteristic is the different status in these respects of the several senses-sight, hearing, touch, movement, taste and smell-as contributors to the life of the mind, both in the nature and range of their contributions and in the manner of bringing them. At each stage of human development varieties of sensibility sprout and blossom; and one's personal equation is represented by the individual values which the several orders of responsiveness assume in this composite. These form a sig- 
nificant, possibly the central group of the qualities eharacteristic of our individual and of our eommon natures.

The interest of analysis is eentered in the sources and varieties of sensibilities; the practical interest centers in their refinements and elaborations. The latter enter with the pragmatic consideration of the conduct and attitudes which the sensibilities regulate in part or in whole. For when we turn to the field of the sensibilities as actually operative in their full-fledged maturity and varied embodiment, we realize how far we have left behind the simpler regulation of direct sensory stimuli and readily adjusted response. Yet the elew to the later complexity is found in the earlier relation; the situation never departs wholly from the natural model. The fitness of sensibility to serve adjustment persists; preeise and ready orientation in the environment is the normal issue, however true it be that life begins as a "big, buzzing confusion," or would so appear were its manifold appeals attended to. The avoidance of misery and the pursuit of happiness of however modest proportions proceed upon simple feelings of pain and pleasure; their inducing occasions or signs are recognized, and on this basis the mental life is established. The instrument of adjustment has instinctive yet plastic tendencies; so that the process is guided, but not rigidly, by bent, and is matured by that response of impulse to occasion which we eall experienee. The range of the sensibilities is conditioned by the normal scope of the senses and of the familiar stimuli that confront them. With this native alphabet and the tendency to put it to use, the sensory language is acquired and a vast literature of experience made available. The book of nature-the human version of it-and the revised, transformed reconstructions which generations of men have created is entered into and possessed. The wonder and the mystery of it are as patent in the primer as in the encyelopedia. The world of things emerges; and the routes among them become familiar as the 
mind makes its home therein. Such is the normal life of sensibility enjoyed by normal man. By feeling, tasting, smelling, hearing, seeing, he gains control of conduct and directs knowledge to purpose, mindful of profit and loss, of bareness and richness of living. Sensory alertness conditions it all, no differently for the fool and the genius, and the many grades between. Things are different as we have sensibilities to distinguish them; the sensibilities of each make the world of each; and the similarities of our sensibilities make the common world of our understanding and intercourse. All this is not omitted but rather assumed in the course here pursued. The great trunk-lines of endowments are not slighted on the map; they underlie the finer contours here traced over them and by them. For the most part the sensibilities serve lowly and familiar purposes; they make us at home in the world of daily life. We carry them with us in all our journeyings, however intricate or remote.

None the less our present psychological along with our practical interests lie in the refinement and elaboration which the sensibilities acquire at the upper levels. The process is one of transformation; the composite reaction is shaped in direction and quality by its intellectual phases, including both its presentative and representative scope. It points backward to sense as its source and clew; it reaches forward to intellectual procedures in which sense is subordinated to meaning and becomes woven in the network of mental elaboration. The response may remain dominantly an esthetic expression and present the relations distinctively; for the term esthetic refers to a situation in which the feelings serve the intellect rather than the reverse, but ever in varying degrees and relation. In esthetic matters one must feel rather than reasom one's way, though feel intelligently, and for the more technical phases of esthetics, analytically and consciously. The term, when applied to a complex preference, carries two further im- 
plications: it indicates that the sensibility no longer operates in terms of direct sensory stimulus, though sueh sense-stimulus is earried along in the developed status and may at any moment assert itself; and it indicates that the order of sensibility rests more and more upon the products of (artificial) refinement. Such refinement is a complex and combined issue of sensory stimulus, esthetic impression, and intellectual distinction; it summarizes the conception that we carry over, with an appreciation of its psychological lineage, to all derived aspeets of human qualities. The sensibilities become the exemplars of our most complex orders of appreeiation. We may accordingly employ the term sensibility in its secondary sense for the direction in a unified order of selvice of types of responsivenessthrough any and all avenues of sense-conducive to the more refined regulation of conduct.

We proceed by selecting a few types of sensibility for detailed consideration. The hygienic sensibilities (the name apposite to the higher stage of their development) are rich in suggestiveness. They cover an extensive range of application, yet from low to high present a unity of type, traditionally recognized in the acknowledged kinship of physiologieal cleanliness to spiritual godliness. The personal quality concerned, when marked, may be called fastidiousness. Its direct service is to keep one clean or to avoid contamination [9]. But cleanliness is at once a matter of degree, of convention, of habit, of attitude, of association, of reason; yet also-here its affiliations with primary sensibility-it rests upon sensory and organic reactions of attraction and recoil, and finds various natural outlets for its expression. These include the serutiny of food, which extends beyond the protection against noxious food or a bare gastronomie verdict of decided umpleasantness, to inelude also its purity, or presumable freedom from "dirt." The nose is the original and persistent hygienic and gastronomic guardian. Putrid meat or decaying vegetable 
matter offends the sense of smell sufficiently to drive away appetite. The sense of disgust, through which aversion is aroused, assumes the mimicry of food-rejection; and this attitude becomes the type-form of strong avoidance through sensibility. Intense disgust, though aroused by situations unrelated to a "food" situation, turns the stomach. But the appeal need not penetrate to the sense of smell. Sight, the great anticipating sense, heralds and summons the "hygienic" sensibilities quite as readily. The food looks nasty, as though it might be unclean; and that is sufficient $[10]$. Nicked and coarse china, untidy linen, spotted knives and forks, depress the appetite, serving as visual clews of situations offensive to an increasingly fastidious sensibility. Intellectual elements are prompt to make their appearance, and complicate the channels of impression. A fly in the cream or hovering over it may arouse effective disgust. Knowledge alone does not produce so vivid a reaction; the fly in the cream or the worm in the chestnut looks disgusting. When we learn by unemotional investigation that flies carry disease, we welcome this rational reenforcement of our affective aversion; yet we recall that other aversions may be quite as pronounced and lack such scientific sanction.

The "food" situation is met by the sensibilities that arouse sensory recoil directly and intimately; but human and other contacts summon them quite as distinctively. Visible or suspected dirt produces an uneasiness ready to grow into disgust. The great unwashed arouse a repugnance that hardly needs the convincing verdict of olfactory stimulation, so completely does the eye anticipate the impression. The telltale disclosures of face and hands or the more critical test of troublesome ears and finger-nails proclaim the measure of the underlying sensibilities; all of which are readily transferred to the personal habitat and belongings, and particularly to the more intimate investiture of the body. Filth, squalor, foulness, pollution, 
provoke disgust and offend a common sensibility. They form the grosser transgressions, menacing or disregarding the safeguards of health which the major hygienic sensibilities protect. It is the slighter infringements and neglects that illustrate the familiar level at which their behests are practiced. The whiteness of linen proclaiming an unsullied raiment stands but one or more removes from the cleanliness of the body which it protects or adorns. A frayed collar and an unbrushed coat, like nicked china and rusty cutlery, or a slovenly bed, or an unswept floor, or a frowsy toilet, suggest defections from proper standards. As such they betray a lack of underlying sensibilities. Appearance becomes the clew to the minor and more delicate violations; sight replaces rather than awaits the confirmatory veraict of what in coarser form may offend the original censor-smell. Such is ever the process of refinement - the development of a useful toward an esthetic sensibility, enlisting any and all the senses helpful to the purpose. Much of it is the product of education, which both enlarges the field of application and refines it. It acts not alone positively by cultivating an eternal vigilance against minor defection, but constructively develops a sense of satisfaction in all the outward show of tidiness, care, purity, spotlessness, even luxury. It broadens its scope by including the secondary extensions radiating from its original service; thus, while still most exacting in the acceptance and rejection of food and its accessories, it embraces all the visible signs of the cherished quality as conveyed by the brightness, smoothness of glass or porcelain, all the varied elaborations of the food situation and of its setting. It similarly extends its domain congenially to all situations of personal contact and the more derivative and remote accessories of habitation, clothing, public and private environment. The extension and elaboration is a psychological one; the sensibilities matured in one relation extend to others by virtue of an inner congeniality and a cultivation 
due to a common quality [11]. Refinement in reaction to "contacts" becomes a significant quality.

Cleanliness of food and person-including the vital protection of the lungs' supply of inviting or at least breathable air-constitutes the natural sphere of operation of the hygienic sensibilities, which the civilized endowment but extends and refines. Cleanliness begins as wholesomeness; but it is difficult to say where it ends; and that becausetrue to the nature of complex sensibilities-it affiliates with and draws upon others of its kind, to their mutual transformation. It affiliates with the habits of neatness and orderliness, evolved from more developed situations, which like cleanliness indicate care-the index of sensibility. The well-groomed condition, the spick-and-span, ship-shape appearance of one's surroundings, satisfies an order of sensibility in which cleanliness is implied but by no means stands alone in responsibility. Pride, display, the sense of value, the esthetic appeal, the social esteem, imitativeness, conformity to standards-all enter and complicate the situation. Negatively, litter, mussiness, squalor, suggest an unkemptness hospitable to dirt, but offend the allied, more derivative sensibilities as much or more than the "hygienic" ones. Order, designated as Heaven's first law, is quite commonly man's last; whence he has been cynically defined as the messy animal. In the end the sensibilities involved, and the complex phases of character which they reflect and mold, travel so far away from their point of departure as to make the term "hygienic" quite unsuitable; it is far too use-full, too limited in its implication to suggest the rich connotation which civilization confers upon it.

The gospel of soap is lowly to begin with, but reaches the highest places. At the top where we supercivilized folk practice it, it is a highly rationalized product; it carries the atmosphere of disinfectants and antiseptics and the familiarity with causes and effects that a former generation 
landly know. Through intellectual chammels, open to the med, we have discovered that eertain procedures avoid (wil: and we follow preserpptions, not our likes and dislikes, thomph we may come to arpuire a liking for that which wo know to be wholesome. At the mper levels the aceptable is no longer in matter of seusibility alone, but largely of knowledge; ret knowledge may both support and correct sensibilities and prejuclices alike. Promisenons expectoration is in itself discrusting to sensitive natures; a sense of mublic hygiene both quickens and justifies its offensiveness and appeals to reason in putting down the evil. Public drinkiner-cups and communal towels are likely to be abolisher by an educational campaign; in the future, sensibility made fastidious in this direction may adequately protect against such indiscriminate communism. On the other hand, one may be taught so to overcome or control his sensibilities in the service of the intellect as to hold to a task which without such support would be distasteful. Iabituation does much, and use dulls sensibilities favorahly and unfavorably. The nurse and surgeon subordinate sensibilities of one order to intellectual interests of another. The melical student in his early experience with dissectingroom or clinic-the latter appealing to the sympathetic sensibilities as well or mainly-is keenly aware of the conflict. 'The occasional or amateur cook loses appetite through intimate contact with the unsavory preliminaries to a savory meal. Many a person enjoys the sight and flavor of a juicy grilled steak who has an aversion to the carcass in the butcher-shop-the latter again a mixed hygienic and sympathetic aversion.

The rationalistic support of the hygienic as of other sensibilities operates by conferring a derived sense of satisfaction in a conformity to accredited practice; but in so doing it furthers a direct sensory satisfaction as well. Snch satisfartion continnes and proclaims the original olfactory dominance. The clean, the sweet, the pure exhale an 
aroma of wholesomeness, of direct vital pleasure, which is accepted and enjoyed as an index or clew of the cherished quality. The (olfactory) terms of admission to the group are enlarged to include the antiseptic order of preparations. The more primitive scents of nature's offerings are retained, but are combined in the esthetics of odor with the developed satisfaction of hygienic ministrations. The intricate accessories of the toilet, represented in Oriental luxury and Roman baths no less than in the modern boudoir, ministered to by the perfumes and lotions that form an inviting cormer of the druggist's shop-all testify to the permanence as to the elaboration of the hygienic sensibilities and others of near kin, of which the olfactory sense remains the direct and original guardian.

From olfactory guidance to social sanction is a long psychological step; yet both are exercised upon the hygienic order of regulation, and properly so [12]. In each station there is a common desire to be about as clean as one's neighbors and associates. In the social rating, the "hygienic" test, along with many another, is applied. The cleanliness of the Dutch household becomes an outward show of social station and prosperity quite as plainly as are material possessions; it may be compatible witl far less exacting standards of personal hygiene and herein show the effects of social convention. Because thus subject to the influence of public opinion, social approval, communal measures, and the restraints of ethics, etiquette, tradition, religion-all of them responsive to similar ranges of social influence-the particular acceptance and avoidances that we meet or practice are not readily referred to their natural or their nurtural sources, nor is it clear to what phases of natural impulses or acquired habits they dominantly apply [13]. It becomes difficult to say whether such approval or disapproval, prescription or proseription-and the like holds of the appeal which leads to their observance -is maintained as an hygienic precaution, an esthetic ex- 
pression, a moral regulation, a racial, class, or national custom, or a religions rite. In such a merged or cumulative sanction or prohibition the social influence often stands forth as the most conseious and compelling force; and this for the reason that such conseiousness attaches to the strongly emotional or sentimental roots of impulse rather than to the rational ones. In the last analysis an actual sense of acquired disgust may become quite as strong as a primitive or original one, while yet acting wholly through indirect mental channels. Indeed, when the social taboo is accepted-as it is commonly in primitive and not uncommonly in advanced societies-with the fervor of an unquestioned injunction, it constitutes the chief motive force of social regulation, utilizing the sensibilities while yet extending them far beyond their primary range.

It is in the degree and kind of responsiveness to this as to other orders of sensibility that a significant source of personal quality is found [14]. The standards followed, and the loyalty in following them, measure one's place in the scale of sensibility; the test becomes the perspective assigned in the personal equation of life's values to this or that group. In the main, the sensibilities have a natural and enduring sympathy for their kind; and high-grade sensibilities of one order have a tendency to affiliate with and to support high-grade sensibilities of allied orders. The contrast between one level and another remains consistent and distinctive. Yet it must be admitted that the several factors-or rather the force of their appeal-that combine to make effective a social sanction or a personal scruple, are quite various and more and more so in complex civilizations teeming with old ancestral and overlaid modern enforcements and motives. It becomes intelligible that what one man avoids as unclean, another shuns as unesthetic, a third shrinks from as bad form, a fourth eschews as religiously forbidden. Such divergences indicate that men differ, and civilizations yet more so, as to the general level 
at which their sensibilities are active as well as to the different kinds and degrees of sensibilities which they maintain. Yet the correlation of sensibilities is strong and finds expression in composite terms crystallizing their common essence and expressing their common ideal, as in the conception of a "gentleman." The kind of behavior and appearance, the standards of considerations, of sentiment and expression, of morals and hygiene, of ideals and impulses, of traits to be counted upon and infringements not to be feared, that belong to one thus characterized, radiate to all contours of human nature. But above all the gentleman represents an order of sensibility-a man gentle in manner and in all things possessing the traits that affiliate with gentility [15].

To trace the development of any variety of sensibility gives the perspective of the factors disclosed by analysis a definite set. The example portrayed is apt and, apart from its limitations, typical. It presents the relations of what is fundamental to what is derivative in manner and scope of sensibility, of the interplay of primary and secondary factors, and the simple, direct and complex indirect forms of expression which they attain early and late in the transformations of culture. However briefly, a few other types of sensibility must be considered for the sake of other and distinctive contributions which they offer to the natural history of the genus.

We may profitably turn to a form of sensibility operative mainly in the esthetic realm, in regulation of the satisfaction of organic needs: the evolution of the natural function of eating into the social-esthetic "function" of dining-the gastronomic sensibilities. Primarily we must eat and drink; the enjoyment of food is ever legitimate. To live we must be fed; yet feeding must be overlaid, disguised, sublimated, and subordinated by complex appeals to sensibilities before it comes within sighting distance of "dining." Its evolution begins in the sensory realm that 
directs the primary gratification concerned. We whet appetite by savory eooking, by seasoning and flavors, by zest of the choice and the rare, yet also by the bounty of the feast. We order the courses of the repast-the sequence following the empirical clews of taste and digestion aliketo grive each its optimum effect. With the proper preliminaries of appetizer, we lead through soup and fish to the heavier untritious joints, tempered with sauces and relishes; then invite with the more piquant flavors and spices of rame; counteract with salads; tempt the satiated appetite further. with the lure of dessert and sweets; throughout promote digestion and secure a mutual contrast and offset of (puality with appropriate wines; and conclude with the peculiar aromatic stimulant of coffee. Even that we still imbibe; the eigar in the psychological sequence completes the series, and flavor is all and even the suggestion of nutriment is gone. All this belongs to the field of gastronomy-by no means a despised esthetic art. The distinctive point is that attention to and enjoyment of eating for flacor distracts from the grosser satisfaction of cating for nourishment, however ready we are to admit for daily application that natural appetite is the best sauce. It is an appeal from the coarser to the finer satisfactions of sense. In this field as in others, despite the differences of taste and custom, there is suffieient agreement to indicate where the coarser and where the finer satisfactions lie, to justify preferences, and to establish orders of refinement and standards of judgment. Yet gastronomy utilizes all the collateral sensory appeals which it can enlist in its service. The eye serves as its herald and attendant. The appearance of the viands, their form, color and garnishing -all leading away from, yet inviting to the test of the pudding-the service, the whiteness of linen, brightness of silver, delicacy of china, luster of glass; the festal illumination; the flowers, central in the arrangement of the table becanse ornamental only; all these add to the impression of 
the dinner as to the mood of the diners, and derive their effect from an appeal to varied sensibilities which the decorative arts of other realms employ. Yet these arts are but subsidiary to the central moment of the "function"- the diners themselves, who to proper sensibilities of a very different order of appraisal, must be so worthy that the worthiness of the repast retires to a very incidental place. The occasion engages other modes of esthetic appeal; the formal dress permitting the maximum privilege of ornament to the ormamental, and for the other sex prescribing a conventional, dignified propriety as a foil. Ultimately the social and intellectual stimulus, the good feeling, the play of word and wit, the feast of soul, the spirit of the occasion, must justify the setting [16]; and, one might add, the traditions and standing of house and host, the dignity of the occasion, the honor of being included, even invidiously as against the lesser fortune of those excluded. How endlessly far has an invitation to dine traveled from an opportunity to feed! Yet any marked defection or poverty of food would mar either occasion. With the ethical rating or overrating of either the dinner or the accompaniments and the cost which it entails in terms of sacrifice of other interests, we have at the moment no concern. It is the psychological factor's operative in the transformation and the orders of sensibility to which they appeal, that form the present center of interest.

Sensibilities may be far more artificial, may be developed for orders of response more remote from the ordinary type of situation, and yet be indispensable to the regulation [17] of complex socialized expressions, equally derivative and artificial. Such expressions are particularly subject to esthetic influences and social rating. The instance to be selected-the language sensibility-in that it reflects the composite influences of usage is peculiarly instructive. Direct sensory guidance is practically superseded in speech; imitation of set usage determines (upon a slight natural ten- 
dency) how one shall speak. In mature speech social selection provides the aceeptable models among which sensibility, both sensory and intellectual, is exercised. Brogue and dialect or local accent assume a social aspect-as the standards of cosmopolitanism are sought and the taint of provincialism avoided. Early breeding may fix the Cockney or the Yankee beyond the possibility of later conscious assimilation of accredited models. Within limits the niceties of pronunciation, the cultivation of voice and expression and the choice of phrase, give to one's speech a leading and fit social rating. Once beyond the infant prattle, the learning of language hardly presents stages of transformation because the sensibilities concerned start at so high, so artificial a level. Organic use and primitive service are but faintly reflected. The grunts, groans, sighs, laughs, chuckles and other human noises, are disciplined to standards of behavior. We readily set apart the uncouth and the refined varieties of their expression; or if beyond control, we beg pardon for coughs or sneezes as intrusions into the regulated order of polite society. The distinctive field of operation is the intellectual one; the offense to the ear of unacceptable pronunciation is akin to the offense to the eye of wrong spelling; both yield to the offense to the mind of unacceptable phrases or constructions. Let us assume a creditable logical and grammatical correctness; for these but serve as a foundation for the finer preferences of word and phrase wherein the "esthetic" sensibilities, disciplined under intellectual tutelage, rule. Language throws an almost blinding illumination upon sensibility, fixes class and mass. Slang is usually objectionable not when or because it is illogical or ungrammatical, but because, in slight or pronounced measure, it conveys the proof or suspicion of insensibility or vulgarity-the tolerance of lower standards, the indifference to better ones. It is a pardonable exaggeration to say that usage is acceptable-or if one prefers, right or wrong-not intrinsically by 
structure or meaning, but because the right persons or the wrong persons use it. The freedom of speech among equals, and the deference of tone and address to those esteemed by reason of station or authority or merit, are likewise guided by social sensibilities of a most complex kind. The older social order emphasized and exalted such etiquettes; and only one to the manner born, whether served or serving, could feel quite at home and trust to his sensibilities to guide conduct on all occasions. The sensibility for correctness and propriety of usage depends upon an intellectual grasp. Yet it is acquired as well upon the basis of a semiesthetic discrimination of the right or wrong models to follow-a procedure of good form like that which regulates table manners. As ethics shades into etiquette, so correctness of diction shades into propriety; and in doubtful issues-suggestive of the indecision as to the use of this or that fork for salad or entrée-we observe and copy those whom we trust. Favorably or unfavorably, the language sensibilities lead each speaker to gravitate to the language level of his kind. It would be invidious and misleading to mention any one of the shibboleths [18] which are certain to be established to separate the linguistically saved from the lost. The net issue is this: that a correct and proper use of the English language is within reach of the intellectual capacity of a score where but one attains it; the others fail through defective sensibility, just as they may fail in manner or dress through an acceptance, willing or unwilling, of a less exacting standard. A social-esthetic defect is responsible for the issue. So characteristically does speech brand the individual that in the conversational portraiture of novels, the placing of just the right shades of deviation into the mouths of the several characters is a peculiarly subtle art, requiring observation guided by sensibilities. In real life it remains proper to judge men by their speech, finding as a rule that which is said is of a piece with the manner of saying it. Expression, here as elsewhere, re- 
flects the quality of the thoughts as of the thinker. Content embodied in form yields the criterion of style, which is manner, quality, character.

Sensibilities have a wider play than that indicated in these selections of their types and operation. Though supported originally by the organic affect and by that element in the play of the special senses, in their maturity they determine the acceptability of sensory stimulation, however elaborated. Such acceptability or its opposite (largely through the associations conferred in the service of distinction) develops to a selective preference-a guide to attitude and conduct-which in the main is what we mean by taste. As the factors of selection become complex they involve esthetic, emotional, intellectual, moral considerations. The several senses and the situations which they serve present marliedly different tendencies to assume such complications and equally distinctive trends in the issues thus resulting. Of fundamental import is the function thus regulated; whether it stands close to organic welfare, or, released from such utility, serves as an indirect channel of adjustment to an artificially expanded environment. All such varieties of conduct-that is, all acceptances and rejections, selections and preferences, dispositions and inclinations, regulated in part or in whole by the sensibilities -retain this original sensory element, though it may be slight and transformed. It is marked and persistent in the "dirt" sensibilities offensive to nose and skin and eye. The composite clew shows how one sense anticipates the impression of the other senses and indirectly but effectively arouses the repugnance which need not be carried to its completion in the original terms [19]. Much the same is true of the "food" sensibilities-one of the most organically intimate of our contacts [20], and the one responsible for the extension of the word "taste" to all allied "sensibility" preferences. Taste, originally pertinent to preferences of food, is a term applied to embodiments of color, form, and 
design, to tones, to textures, to nicety of discrimination in any realm; at first directly responsive to sense-stimulation, later it is overlaid more and more by derivative impressions, and ultimately is shaped by standards and judgments more or less consciously entertained and conventionally sanctioned. Good taste extends throughout the whole of the wide span of human preferences, wherein we reveal the quality of our endowments and attainments.

The most important alliance of the sensibilities is with meaning through the mediacy of recognition or distinetion. The sensory (including the organic) faetor recedes-though it ever persists and vitalizes the issue-and the associational values enter and are prone to dominate. This gives rise to the characteristic esthetic situation, and to the quality of "impressionism" in esthetic preferences. To cite a familiar range of distinctions: our noses inform us of the flavors of tea, coffee, tobacco, wine, fruits; our eyes inform us of the differences between forged and cast iron, between machine-made and hand-made lace, between wood and "oomposition," between stone and scagliola, between mahogany and stained birch, between linen and cotton, between velvet and plush; our fingers, as well as our eyes and noses, distinguish between an apricot and a peach, or an orange and a grape-fruit; trained fingers tell apart the texture of silk and satin, or of "bond" and "linen" paper, of forged and cast iron; the genuineness of coins may be tested by the feel, and by the ring of the metal ; the ear distinguishes between a fingered performance upon the piano and the rendition upon a mechanical "player," or its reproduction by a phonograph, between a natural and a "stage" cough or laugh or sneeze, and it detects the slightest foreign aceent or trace of sectional pronunciation, even specifying its provenance. Much of this recognition. proceeds on the basis of an impressionism which is an issue of sensibility, dominantly of an esthetic order. The mechanical "player" fails in the varied vital touch of a hu- 
manized expression; the phonograph distorts the tone qualities. 'The stained birch gives the impression of being less rieh, less pure or less pleasing than the mahogany, before the eye consciously absorbs the telltale of the grain. The expert summoned to pronounce upon the genuineness of a painting rated as an "old master" instantly gets the impression (by its lack of appeal or weakness of effect) of a copy or of a "school" picee badly retouched, which impressionistic judgment he then reënforces by examination of brush-marks, texture, pigment, canvas, and the like. The impressionistic factor in our recognitions is extensive and underlies the appreciation of manner, style, or quality. In the appraisal of tea, tobacco, wine and other commodities where objective tests are difficult, the critical sensibilities of the connoisseur remain the chief criterion. Such expertness-which is at bottom an impressionistic one, refined by attention-becomes a practical asset in the specialized trades. Indeed the prevalence of fraud and imitations and of inferior quality masked as superior-summarized in the satirical admonition that "things are seldom what they seem"'-provides a constant challenge to our sensibilities. The deceived fail to distinguish, are not forewarned by sensibilities, not forcarmed by knowledge. It is interesting to add that when suspicion is aroused in commercial transactions, it may be by the appearance or other "qualities" of the article itself, or it may be by the very different quality of the manner or circumstances of the transaction. As in other situations, we prefer to substitute a psychological quality of an intellectual, or, it may be, of a moral order -which we call expert knowledge for the one and reputation for the other-to safeguard the uncertain verdicts of sensibility alone.

We thus return to the central intellectual factor-the expertness of distinction, the tap-root of the tree of knowledge. Subjectively it directs the readjustment of native impulse; objectively it secures the control of natural forces. 
It is represented directly by the sensory power of precise discrimination and indirectly by the logical quality of insight into relations, and is at once a support of sensibility and a check upon it. Keenness of perception, however supported or to what end directed, remains the prerequisite to intelligence. Although our direct concern is with sensibility and not with rationality, we must accord the latter its proper place in the composite psychology, because at every stage, insight no less than sensibility supports and controls appreciation and perception. Indeed, one of the most comprehensive contrasts of mature character is reflected in the relative development of the one or the other of these affiliated yet divergent trends. Within the field surveyed, in which, although sensibility is primary, insight enters almost at the outset and remains throughout all stages, it presents the contrast of intelligence tempered by sensibility with sensibility tempered by intelligence. Feeling guides or drives reason, or is urged by it. In anticipation of its remoter issues, it may be said that the contrast, when widened, becomes that of the matter-of-fact, calculating, practical, hard-headed man of affairs and his antipode, the sentimental, impulsive, sensitive, sympathetic, imaginative enthusiast. Psychologically its import lies in the inherent inverse development of the "feeling" factor and the "distinction" factor in the joint impressionism; it lies also in the contrasts of the temperamental trends which lead to the emphasis of the one or the other in the determination of attitude and conduct [21]. Yet the presumption is strong that a decisive factor in such trend is the underlying disposition-a disposition primarily of the direction of sensibility-through which the one order of responsive service carries a more vivid, more confident impression than the other. By virtue of this quality the esthetic nature gravitates to a different psychological type from that represented by the scientific mind in one aspect and by the practical mind in another. The latter distinc- 
tion lies within the field of intelligence, and relates to the kecuness of discermment for concrete realities and the landling of situations presentatively, or of the mastery of alstract principles and logical deductions. The praclilioner and the thcorist are both rationalists, each moderately conversant with the other's domain, yet diverging in bent and capacity sufficiently to mark the separation, the specialization of their habits and careers. Observation and cxperiment require keen and intelligent sensory distinction; ret also must they be directed by a perception of relations framed in a system of interpretation. When the former dominates the practitioner emerges; when the latter, the theorist. In both pursuits the esthetic appreciations find occupation-more than is commonly recognized -although in a transformed and subordinated service.

Dwelling for a moment on the contrasted service of the intellectual and estlietic factors in the development of sensibilities, we may note that in matters of taste, the question may not be which esthetic judgment carries the keener perception or reflects the higler standard, but whether the intellectual or esthetic factors in the composite judgment shall prevail. Judgments, like sensibilities, emerge from mixed motives; which may be the source of reënforcement or of conflict. The esthetic temperament follows sensibilities where the scientific follows logic; to the former is justified the principle that "manner maketh the man"; and manners spring more directly from sensibilities than from consciously entertained reasons. Hence the art of social intercourse; and hence also the futility attaching to manuals of etiquette that aim to inculcate rules in the absence of the sensibility necessary for their application. The fact that the arts are less teachable than the sciences, and manner less so than matter, indicates the larger dependence of the former on qualities eloser to endowment and absorbed and encouraged by a favorable appreciative milieu, and of the latter upon a more direct acquisition by 
an objective effort sustained by zest of analysis and insight. To all this we shall return in a eloser survey of the practical phases of human quality. So far as their sources are concerned, the arts and the sciences appear in the genetic view as remote and complex developments of contrasted phases of responsiveness; and in this resultant, as in the history of the race, poetry precedes science. The esthetic is earlier, more comprehensive and pervasive than the scientific trend; and is so by virtue of the priority of sensibility in the psychological unfoldment; hence the justification of the emphasis of the sensibilities in a study of the sources of human quality [22].

The more formal relations of the several orders of sensibility may be set forth in terms of (a) the supporting sense (or senses); (b) the function served or the direction of its exercises; (c) the development which it undergoes -that is with reference to its status in primitive sensory and organic preferences and to its transformed ranges of application: all of which are mutually conditioned. Thus in human psychology smell would be rated as strongly sensory, with an intimate, organic, body-protecting service; as maturing a meager intellectual power, of limited derelopment. The functions most intimately served by it are those growing out of the "food" and "care-of-body", situations. By contrast, sight retains slight stimulationvalue (marked only in color); develops a vast world of esthetic and intellectual meaning; is related to no one specific function, but serves the general adjustment of all forms of reaction (movement, skill, observation, experiment, the technique of the arts and crafts), particularly of the intellectual reactions, to the natural and artificial conditions of life. Clearly both the senses and the reaction which they direct, must have a place in the original nature of man. The smell-guided instinctive reactions need no further specification. Visual exploration and visually guided manipulation (both linked to an equally instinctive tendency 
toward assertive muscular and mental control exercised in making changes happen to things felt and seen) are also a part of original nature; they underlie the acquired experimental interests, as observation of infant activity convineingly shows. The removal of the criterion of sensory judgment from the nose-mouth to the eye-hand center of control marks an interesting stage of development. However far from this original stage men may travel upon the support of their sensibilities in the cultivation of the arts and scicnces, they continue to reflect the sensory dependence; the inventions of man, like the telescope and the microscope, and all the many devices by which forms of energy are registered, are so many extensions of his sensory apparatus-most of them additions to his visual equipment.

It would accordingly have a meaning to speak of the "visual" sensibilities or of the "auditory" sensibilities or of the "kinesthetic" (movement) sensibilities. But the meaning is more adequate when the function served is considered. So long as that function is close to natural need, the functional aspect dominates; the "food" sensibilities, the "hygienic" sensibilities indicate the type. When we turn to scnsibilities ministering to the derivative esthetic nature or to the developed intellectual nature, the sense still conditions; but the "function" requires a considerable restatement. The esthetic as well as the discriminative sensibilities of the eye lead to the decorative and representative arts and to expertness in scientific observation; in the process they call upon the dexterity of the hand, whose evolution is directed by a useful, prehensile service of the greatest aid to bodily mastery and to control by intelligence. The ear is the gateway to music and to the allied arts of language; but music is a by-product of the voice, originally apprenticed to directly useful service, seconded in due course by artificial instrumental aids. The esthetics of bodily movement leads to the dance and to the manifold 
graces of social expression [23], and enters also into the "form" of athleties and sport. The skill of hand is of all the most distinctive of kinesthetic accomplishments; the works of man are originally, and remain characteristically, handicrafts; his civilization is the work of his hand. The hand is most intimately the associate of the eye, and shares in its intellectual preferment; visual sensibility combines with manual deftness. Obviously all accomplishment implies a trained organ of execution as well as a critical sensory appreciation. Eye and hand, ear and voice, form intimate and indispensable partnerships. The "function", becomes the field of application of the joint media of psychic expression; the conditioning factor in shaping the product is sensibility. Such, reduced to its psychological terms, is the groundwork of human achievement and of the differences of individuals in endowment. Though it may appear somewhat strained to reduce to such bare psychological terms the vocational proficiencies or the spheres of the muses and graces, the analysis, setting the theme to the evolutionary movement, remains suggestive.

It will be evident that we have gradually shifted our ground from the consideration of the origin and nature of sensibility considered close to their sources, to the service of the sensibilities in their mature development. Once again a summary may be helpful both retrospectively and prospectively. It is true of the sensibilities as exercised (1) that the issue is typically composite, several orders of sensibility sharing in the process of preference, distinction, expression, regulation; (2) that such compositeness brings about a reënforcement of impression, but also the possibility of rivalry and conflict, and this not alone as a coöperative enterprise with varied demands, but as a rivalry among the several orders of sensibility that may claim a voice in regulation; for (3) we carry with us constantly all the several orders of sensibility which have a fit place in human psychology, prepared to exercise them upon any "function" 
that invites their play; (4) that the exercise of sensibility is typically complex, an elaborate transformation through levels of refinement, of original sensory responsiveness redirected by infusion and overlay of acquired psychic processes; (5) that the original range and service of each type of sensibility conditions its mode of participation in the composite issue and its possibilities of development; (6) that the element of value enters early and directs the development and the education of sensibilities, bringing it about that practically they are rated and defined in terms of their aequired applications. These principles readily emerge from the observation of the play of the sensibilities in the practical life; their bearing upon the foundations of character and temperament invites further comment.

The central factor in any practical rating of a given order of sensibility is the "function" served; closely associated in the rating is the level at which it arises or to which it attains; yet the medium through which it is maintained is neither accidental nor incidental to its status and course; the result reflects each of these aspects. Even though we consider the sensibilities as exercised, the "biological" situation which gave them birth is not negligible; for the native quality of the original disposition directs and persists in the most developed psychologieal transformations. The arts severally and jointly flourish because of the original surplus of gratification in sensory experience. And no less in the sciences: sanitation, however scientifically pursued, cannot dispense with the directive impulse of sensory comfort and discomfort, which at each stage of its progress makes its ministrations desired or acceptable. Men's surroundings will continue to be as artistic and as hygienic and as rational as their sensibilities [24] direct, and no more so.

The gradation from natural service to applied direction of sensibilities is responsible for much of the complication so eonstantly met in this exposition; the sensibilities seem- 
ingly and actually change with the manner of life, yet reveal their ancestral allegiance. On the basis of a limited protective reaction-which it shares with the "food" situation-the hygienic sensibility develops to a fine art of cleanliness and affiliates with both orderliness and purity; it expands from person to clothing, to belongings, to surroundings-all of it man-made and socially standardized. By reason of the supplementary influences that thus come forward, many of our sensibilities, though provided for in nature, have so large an element of acquired. redirection that they follow the laws of acquisition more loyally than those of endowment. Such are the derived orders of sensibility that still properly bear the name but not the full implications of the primary order [25]: the "language", sensibilities, the "social" sensibilities, and certain types of "artistic" sensibility. By reason of their divergent course and origin, the several orders of sensibility present varied and complex affiliations and congenialities as well as incompatibilities. If we kept too constantly in mind the hygienic conditions under which our prized Indian baskets or Oriental rugs are woven, our esthetic enjoyment might suffer through our hygienic distrust. In a similar strain Bohemianism resents the prim orderliness which interferes with the free expression of impulse and banishes the picturesque; or again the musician may be insensitive to the decorative arts, and the painter to the niceties of music, or both crude in the appreciations of literature. Yet these individual or class deficiencies or rivalries will not obscure the underlying kinship of quality. A composite art like that of the "opera" combines the scene with the action, with the melody, with the sentiment; the song is as much an aria as a poem. The medium conditions the product, yet forms no barrier to the expression in different arts and in different phases of life of a comparable sensibility. There is no real violation of principle, only a rivalry and dominance and limitation of expression. Obviously the 
issue involves more than the sensibilities alone; mueh depends upon the emotional development fostered by the sensibilities, and much upon the parallel advaneement of the intellectual interests. The sensibilities reach far into the eventual possibilities of the common compass of human nature, and share in its complexities of development.

Fundamentally the sensibilities of whatever stage of development, in whatever direction applied, make situations attractive or lepugnant, determine what and how we select, reject, seek, avoid, prefer. They serve their part in regulating conduct, in modifying attitudes and inclinations, in shaping careers. Their permanent deposits are the qualities of character thus matured and favored. In this generic aspect sensibilities are but one variety of endowment, one evolutionary issue, one device of adjustment among several. The like purpose of adaptation may be served by other psycho-physiological equipments, utilizing the sensibilities or supplementing or transeending them. Such, we may antieipate, is the status of the emotions, of the sentiments, of reason, and of ideals, all merged and eulminating in systems of regulation. It is beeause regulation through sensibility oceupies this intimate place near the souree of quality that it becomes a type-form of such regulation, and secures a preferred value in the run of qualities, in the make-up of character. We remain individually the sum of our sensibilities; these eondition our appreeiations and guide our acquisitions. As the sphere in which our appreciations are exereised and our acquisitions guided beeomes artifieial and complex, the distinetion between the natural bent of sensibilities and the sanetioned mode or range of their expression inereases in scope and significanee. The complieation likewise refleets the increased tendency for the sensibilities to act not in detaehment or self-suffieient independenee, but to form allianees with other regulative media, even to be absorbed and overlaid as well as reenforced by them. Of these the most direet is the emotional 
expansion-the radiation and expansion of the motive of attraction or recoil to a larger, more persistent, more versatile sphere. This may be succinctly expressed by saying that the sensibilities become emotionalized. It is precisely the possibility of becoming thus naturalized in a larger domain that constitutes a distinctive quality of sensibility, differentiating those orders of sensibility that possess it largely from those that possess it meagerly or lack it wholly. Therein lies the peculiar fertility of the esthetic order of sensibility, particularly in that division thereof leading to the fine arts: in that the preferences which are directed upon a sensory-esthetic basis affiliate so richly with the emotional nature and also, though not equally, with the issues of intellectual insight. It is because the "food" sensibilities and their like are by nature debarred from such expansion that their lowlier place in the psychological perspective is ordained. Thus for sensibility the status or level of potential expression becomes definitely formulated as the susceptibility to emotional elaboration; or, more simply expressed, a sensibility takes its rank and value from its capacity for emotional alliance and growth. The higher careers of the sensibilities are opened after their enlistment in an emotional service is accomplished. To interpret the significance of the transformed domain into which the sensibilities are adopted and absorbed requires a parallel survey of the emotional nature-the task of the following chapter.

The practical phase of the sensibilities has not been neglected in this exposition; it has, however, been made secondary to analysis and principle. A survey of the subject from the practical aspect affords an inviting retrospective vista and a convenient basis of review; for in practice as well as in principle, the place of the sensibilities in human psychology is fundamental. Sensibilities go far to mold the eventual nature that on the basis of original endowment matures through cultivation. The rôle of the 
sensibilities appears most clearly in the leading parts which they play in the carecrs depending primarily upon them. The musician embodies one order, the painter, another. With equally pertinent differences the architect, the actor, the novelist, the eraftsman, represent careers based upon cultivation of sensibilities combined with other proficiencies. All are artists; each in his sphere is more delicately sensitive to a certain esthetic range of differences, is more nicely appreciative of their values than is the man of average endowment. Upon this native superiority is developed a technical proficiency. Such proficiency while guided by appreeiation is professionally expressed in skill of execution; the artist is a performer, one who produees. The quality of the production reflects sensibility as well as skill. Either quality may be present out of relation to the other; technical skill may far exceed sensibility, or may be conspicuously inadequate to bring it to expression. As a rule both mature together though with variable preponderance. Virtuosity is a name for technical mastery; it is frequently applied to the musical performer who, if deficient in the other respect, is commonly said to lack soul or expression or intelligence-a composite defect of sensibility. A review of the professional careers and differences within these careers based upon sensibility would furnish a rich illustration of the complications to which the esthetic field is subject, but would contribute little new in principle. It would consider differentially the prominence in one painter of sensibility to color and in another to form, in one to the decorative, in another to the dramatic factors in composition; it would differentiate the sensibility of form-perception upon which the portrait painter and that upon which the sculptor proeceds; it would differentiate the epic poet from the lyric, the comedian from the tragedian, in part, the romanticist from the realist in any art. Through all it would differentiate the several orders of standards and ideals reflecting the sphere of culture and the genius of the 
social forces under which the sensibilities have been molded, by which they are directed; schools and allegiances would be contrasted, and the varieties of esthetic sensibility disclosed. In the analysis the varied dependence upon the collateral function of discrimination-of which the intellectual quality is the type-would likewise be recognized, making one artist thoughtful and another sentimental. These conspicuous differences, which reappear in later considera. tions, are cited here as illustrative of the careers in which sensibility is fundamental and remains fundamentally of the esthetic variety.

Such is the issue when the sensibilities play the leading rôle in endowment or career. The subordinate functions which the sensibilities exercise in endowments, proficiencies, and careers elsewhere centered, constitute their second great order of service. The support of the sensibilities appears most directly in the companion quality to esthetic sensibility; sensory and intellectual discrimination. Keen observation, a sensory alertness, a finely adjusted instrument of appraisal, is its condition. The psychological instrument registers impressions as a balance registers weights. The fact that the grocer's scale is coarse means essentially that it will not respond differently to two weights of very slight difference, will not detect differences of a hundredth of an ounce. Furthermore for practical use it will and need read only approximately, say to quarter-ounces or half-ounces; for in the operations in which the grocer's scale is the suitable instrument, precise readings are unnecessary. The chemist's balance responds to the minutest differences of weight; it is an instrument of precision. It is sensitive to the thousandth of an ounce; the range of its use is a refined one in which minute differences count. The psychologically sensitive visual instrument discriminates complexly as well as finely. Tints and shades substantially alike for the house-painter are wide apart for the portrait-painter; and more significantly than the bare 
units of differences are the varied ranges of value and esthetic significance which are decisive in the one and nearly negligible in the other. A portrait executed with a house-painter's palette and a house-painter's sensibility and skill would be a travesty of art indeed. Coarse and fine sensibility, while in a limited and legitimate interpretation a matter of scale, are separated in reality by a complexity of mechanism-a reference to divergent systems of value, for which the grocer's scale and the chemist's balance offer altogether too meager and inadequate an analogy. By way of corollary, let it be added that a similarly contrasted sensibility is involved in different types of movement. In coarse occupations, like scrubbing a floor, the movements may vary in inches from the intention and yet be efficient; in writing or in plain sewing they may vary slightly yet appreciably; in the surgeon's craft or the jeweler's they may vary hardly by a hair's breadth or miss their purpose. Movements of precision require sensibilities of precision to feel when the execution departs the slightest "shade" from intent or desire. Only the singer who hears the falsity of the note sung will and can correct it; only the craftsman or the sportsman who feels the defect of the stroke can improve it [26]. Expertness is ever dependent upon refinement of sensibility.

The comparison of the units of the underlying scale, though inadequate, is profitable. It pictures the operation of sensibility concretely; it suggests the measurable or appraisable factor for which discrimination-quasi-intellectual discrimination-is the psychological counterpart. This likewise may play the chief rôle or a subordinate part; when it leads, it finds support in esthetic sensibility; when it is subordinate, it supports the latter. Scientific expertness is a trained instrument of precision for the detection of differences, not of bare or minute, but of significant ones - pertinent to an artificially regulated welfare yet ever in the original terms of the sensory alphabet. The signifi- 
cance is logical; it arises from the insight afforded by a rational system of interpretation; it is at once a difference of fact and a difference of meaning. The careers in which sensory-intellectual discrimination is fundamental reflect the acquired proficiencies of this order. The chemist, the physicist, the astronomer, the engineer, the geologist, the biologist, the psychologist, the economist, the philologist, all exemplify it; the diversities of their mode of applying it are in the larger outlook but secondary [27]. And in each specialty, though differently, the esthetic type of. sensibility supports discrimination and insight. The man of science is an artist in some measure; and many an artist is in a comparable sense somewhat of a scientist. There are phases in the activity of each supported by the supplementary trait; there are qualities in the character of each that reflect the strength of the compensatory factor in the personality.

The rôle of the sensibilities is capable of further illustration. The sensibilities become a supporting factor of other mental processes - a theme more pertinent to later considerations. Sensibilities support reason; they combine to form tact and judgment; they stimulate the imagination; they direct association; they determine the stream of perception. Matured preferences are complex; the sensibilities form a typical factor in the composite. Lying close to the foundations, the influence of the sensibilities is often concealed by the elaborate and conspicuous superstructure to which decisions are credited. It is the common situation that reason-here used as a type of the consciously recognized forces in conduct or attitude-reënforces or justifies preferences and decisions rather than inspires them. The motive force is apt to be imbedded deeply in sensibilities favored by esthetic leanings and the appeal of fundamental interests.

Sensibilities, it has been variously illustrated, are acquired, often redirected, on a natural basis, at times quite 
transformed. The derivative use of the term applies it to a complicated product, which operates in analogy to the original procedure, though of different range and import. The moral sensibilities aptly illustrate such a derivative issue; and their instrument of aeecptance and avoidance is reeognized as the conscience. Conscientiousness in moral eonduct is analogous to artistic sensibility in esthetic preference, to sound diserimination in practical judgment, to reason in aeecptance of eonclusion or in the regulation of belief. The judicial attitude, the eritieal distinction, actually proeeeds upon a very different range of eonsiderations than those which sensibility directs; yet the "sensibility" type or model is not wholly departed from, and in some cases clearly persists. Moral action, we all know, is a matter of inelination as well as of sensibility; doing right and knowing right may be estranged, despite their ready intereourse. But intent alone may be futile or worse; and causes like persons must at times be saved from, as well as by, their friends. The eultivation of moral sensibilities proceeds upon a refinement of discrimination for which the sensibilities in the primary field furnish the parent type. Quite similarly in the intellectual domain: the issue of constant association with exacting standards develops attitudes and habits of outlook with reference to what should be aceepted, entertained, held plausible, or rejected, as fact or truth. It is established with referenee to inferenees, statements, and conduet. In all these relations the absorption of experience is of a complex order; it develops a keen scent for truth, for the signifieance of relations. Sueh kcen-mindedness is but the intelleetual counterpart of sensibility, of keen-scentedness. It is exereised in various directions, eommon or rare, exalted or lowly. It is the reportorial "nose for news" that scents the material for a story in the ineidents of life, often in disregard to eonsiderations which other types of sensibility would respect. It is the deteetive's sense for a clew, the following a trail of suspieion, 
no differently than the pursuit of a rebellious or an elusive fact and its final apprehension in a principle, its eventual application in an invention. The sense for the picturesque, for the dramatic, the shrewdness of the adventurer or of the trader, mature specialized sensibilities in the practical domain under the impulse of natural inelination and artificial stimulation. The model upon which sensibility acts remains directive.

In retrospect we observe the manifold proficiencies and careers in which sensibilities play the leading rôle; we observe yet more familiarly the proficiencies and aptitudes which thcy support; in such support an esthetic impression is commonly supplemented by a sensory or an intellectual discrimination, and in such service we find the most direct measure of our individual differences; we observe more generally how the sensibilities lead to and affiliate with other expressions of our nature; we observe the resulting derived varieties of sensibility, conforming to the parent patterns, yet diverging in trend and direction of service. By such observation we realize the span of human psychology in terms of one of its fundamental aspects. The substratum of the nervous system, and the superstructure of the mental equipment alike appear as instruments regulated by and regulating the sensibilities. 


\section{CHAPTER III}

\section{TIIE EMIOTIONS AND CONDUCT}

TIE sensibilities, though fundamental and far-reaching, require and find their complement in other psychic regulations and particularly in the emotions. Under the stress of situations of a larger psychic appeal and a more diffused spread, the sensibilities are inadequate; they accept or reject but do not propose or dispose. The central interest is in the emotions as sources of human quality; but this pursuit requires an understanding of their place in the psychic order-of their natural conditioning, of their primary scope, of their mature potencies. The affective life yields reluctantly to analysis. Its movement is deep; by nature it is felt rather than known; yet its report to consciousness in self-analysis, and the discerning interpretation of conduct in terms of motive and desire, form a body of knowledge adequate to direct inquiry profitably. A considerable range of personal traits may be confidently referred to qualities of emotional susceptibility. Emotions, as organically conditioned, must be approached as elements in the physiological economy; they are of manifold types, of varying explicitness, of varied status; hence the inquiries: Which are the primary emotions? What are the distinctive varieties of emotion? What is their place and mode of operation in human nature, in the composite psychology of man? Emotions develop, interact, compose with other psychic trends, are played upon by environmental forces; hence the further inquiries: What are the types of emotional complication? What are the careers of the emotions in mental evolution? 
We begin with the pain-pleasure root of feeling in its organic setting; but we do not dwell there long. The domain in which the smart or sting of simple bodily pain or the sip or thrill of simple bodily pleasure directs conduct is itself too simple to meet involved situations or to hold the mature interest, however absorbing to infant satisfaction. It may be insistent and on its punitive side is certain to enforce a hearing. Pains disturb the equilibrium alike of the physiological adjustment and of the mental poise; their slighter varieties, or our individual subjection to their tyranny, help to make or mar the success of our enterprises and the serenity of our dispositions. At all levels of existence pains continue to be avoided and pleasures sought; the susceptibility to both remains and colors the tone of all experience. But the qualities of pain and pleasure and the ranges of experience to which they are attached multiply (not in their original reactions presumably) as the range of experience becomes diversified and complicated. The pain-and-pleasure type of reaction acquires a richer emotional quality, not unrelated to the sensory and organic satisfactions but far transcending them.

The general influence of organic condition appears in the fluctuations of elation and depression, eagerness and lassitude, as they quicken or retard the play of emotion, favor the appeal of this or that range of the emotional register. Such organic incidents as hunger, sleepiness, digestive distress, and the vaguer and slighter fluctuations of physiological welfare, affect the susceptibility to the conduct-regulating stimuli; if of disturbing character, they may engender an emotional instability. Hunger, like anger, may quicken the struggle for existence; fatigue, like satiety, may dull its edge. The association of fasting with prayer is similarly though more subtly significant. Underlying the specific susceptibility to the emotional appeal of the moment is the general organic liability. In 
concrete illustration: If I am tired, have slept badly, crave my hreakfast, or am "out of sorts," any of the common slighter sources of irritation has a fair chanee to get by my self-control and release a puff of anger. Similarly a rankling thought of my own earelessness or poor judgment or plain hard luck may put me in a "bad humor." There are also certain occurrences that have somehow acquired a ready access to my irritability. I find eertain incidents, tasks, or ways irritating, possibly ont of all proportion to their intrinsic offense. A lond voice, presumption in address, necdless questions, the German language, mislaying my eye-glasses, paeking a trunk, losing at eards, the prospeet of being late for a train, waiting for a street-car, onions in my food, stubbing my toe-lheterogeneous as they are thus assembled-may each stir my petulance, and aronse a similar reaction-a seowl, sharp words, a lapse in manners. Let one of these legitimate inciters of wrath combine with a sullen mood, and the outbreak is aggravated; let it reaeh me when I am particularly at ease in mind and body, and it scarcely raises a flutter: "Fate cannot harm me; I have dined.' By the same token a piece of rare good news may go far to dispel a dejected mood of organic origin, as the visitor's sprightliness serves to ehecr the sick or the despondent. It is natural that my friends should judge a phase of my character by such emotional manifestation and regard me as testy, peevish, churlish-aceording to the frequent and constitutional habit of such outbreak; and I may be saved only by my scx from being put down as a shrew, vixen, termagant, or virago. The more charitable or more knowing may refer it to uncertain health; the rest to a common inheritance from Adamitic days, or to individual moral perversity or to bad training. Furthermore and under other oceasions than those cited, reflective consideration may enter to sustain the emotion, alike for self-interest and for my interest in others. The highly cultivated sense of insult or in- 
justice is also a provocative of so primary a response as anger, the inciter of my pugnacious instincts. As under its sway I scek redress, the anger grows by meditation and promptly or slowly matures attitudes and actions. If I observe a big boy bullying a smaller one, an official abusing his authority, a corporation imposing on the public, a prejudice or neglect from which innocent persons needlessly suffer, my reflections feed the smoldering fires of my righteous indignation. I feel aggressive and in striking mood, and may show it by word and manner as plainly as by deed. The like conditioning applies even in the intellectual sphere. In my general views of, and attitude toward, people, affairs, prospects, institutions, movements -all of which should be reasoned and reasonable positions -my prevailing disposition colors my outlook, and makes me much or little of a pessimist or an optimist. Such are the complexities of temperament and of the motive sources of conduct. Chronic dyspepsia, a falling on evil days or ways, ill-temper born of pampered or undisciplined habits, are all likely to be cited as causes of despondency or bitterness, from the lamentations of Jeremiah to the diatribes of Carlyle.

The course of emotional complication has been thus carried abruptly to its mature and familiar issues in order to use the interest in the upper stages in behalf of a more patient analysis of the earlier ones. For the primary questions are these: Why does human nature present this common trait of irritability? What is its original source and service? How does it acquire its present orbit or sphere of influence? What, similarly, is the source of the other appeals which turn its edge? How does it come about that so many different types of occasion induce a similar reaction? What, in a closer view, are the orders of transformation in the finer quality of such response or in the psychic play that induces it? In the first instance, we may assume, the emotion spreads an agitation specific enough 
to meet the outer disturbance that precipitated the situation. Such emotion must on occasion be ready and quick, instinctive and impulsive. In such direct service the anger is as essential as the sharpness of tooth or strength of claw that gives it play; the fear as serviceable as the fleetness of limb which it summons. In the response at whatever stage, the inducing stimulus or occasion of the emotion, its inlet first engages the attention; there follows the play of the cmotion itself, of which little is known positively and for which the inner feelings, the physiological changes, and the superficial miens and attitudes serve as clews. Lastly, there is the manner or type of conduct, the resulting reaction to the situation, which serves as the outlet of the emotion and as its consummation. If I am afraid of snakes, the sight of a snake (or in later stages through their imagined presence, the very mention of snakes) serves to set in operation my fears or aversions; snakes become a "fear" situation-possibly a "disgust" situation as well. If I shudder or tremble or grow pallid at their sight or even recollection, then these feelings and their revealing bodily expressions may jointly stand for the inner phase of the emotion. If I run away in good or bad form, the recoil and retreat supply the outlet and constitute my reactive behavior. If I like dogs, their presence releases some phase of my tender feelings, and induces a contrasted affect, which my facial expressions and bodily attitude disclose, and which lead me to approach and fondle. Furthermore and pertinent to later issues: in approaching a big dog of rather savage appearance, I am divided in my feelings and uncertain in my reactions. I recall that the dog has a psychology of his own, and I eautiously await the bodily expressions and reactions which serve as the outlet of his emotions. If he growls and snaps, I may be honestly afraid-and my heartbeat may advise me of the fact-and yet hesitate in reaction between pacification and aggression by voice or gesture, or 
even counterthreat with stick or boot. Evidently the emotions go but part way in the regulation of even simple conduct-as in the higher life, feelings are often an uncertain guide-and require the support of the intellect and the control of the will. But this moral anticipates later developments.

The initial consideration relates to the status of emotions as primary and secondary, as simple and composite, original and derivative, bare and overlaid. At all stages the distinction is decisive between (1) the attracting, inviting, engaging, emotional attitudes, and (2) the passively retreating, shrinking, withdrawing ones-or, in another phase of the same contrast, the actively repelling, aggressive ones: composure, sympathy, love, joy, as against disquietude, hate, fear, anger. The natural situations calling forth these affective tones and the behavior which they evoke, must all be considered together; for they share a common life-history. The recurrent satisfaction of the constant pressure of natural needs and the protection from hurt and harm or from the thwarting of impulse, point the emotions as well as the sensibilities to their primitive uses, and keep the nervous system keyed to effective pitch [1].

It is not essential to fix the stage-clearly an early one -at which the feeling-tone of organic response matures into an emotion. In the field of urgent activity, emotion implies the more complex satisfaction of more complex and variable needs, requires that the needs satisfied shall not be too constant, possibly intermittent, but typically occasional; not the interludes but the tense moments of the drama. Emotion applies the spur to the mental gait; it is an obstruction-meeting device reserved not for the run but for the jump in the hurdle-race of life. The subdued affective accompaniments of sensibility dispose of the minor fluctuations from the even tenor of-routine; they achieve the adjustments of comfort and composure, doubtless agi- 
tating a faint emotional undereurrent. The emotional situations tend toward the acute, the complex, the unusual; they must be distinetive, interesting, worth while, to disturb the balance of play of the organic equilibrium, to arouse latent impulses to expression. Urgeney alone is not of itself suffieient; breathing is vital, but arouses slight emotional accompaniment; its adjustment is too automatic. If we had to struggle for air as for food, the result might be quite different. If adjustment is required, as in a elose or sultry atmosphere, it contributes to the emotional tone, the euphoria. The first lung-full of salt air or the tang of the pine forest, or of the balm of rare Jume days, makes breathing a realizable joy. Vitiated air oppresses and ehokes; a sudden spasm of choking induces alarm, and a sudden fear finds expression in a gasp for breath. A distinctive range of emotional expression is respiratory in source. Yet in this illustration we have touched upon a double not a single souree of emotional quality; the spasmodie fear is summoned beeause of the danger of ehoking; the need of elearing the throat will waken a nervous sleeper to a moment of distressing agitation; the terrors of nightmare may in some eases be of like origin. By contrast the added quality of stimulating ozone is a surplus of experience. Both are departures from routine adjustment. Similarly, hunger and thirst in their primitive nakedness do not attain to an emotional quality; yet as commonplace urgencies, they have an affective aceompaniment. Metaphorical hunger-that is, desire-for less vital and rarer satisfactions may aequire an emotional setting; such as the longing in winter for the resurreetion of spring or the relaxations of summer. These arouse an emotional affiliation of whieh their availability for poetry is not an unfair test. We do not eall the appetite for a beefsteak nor the feeling of satisfaction in eating it an emotion [2]; nor do we write odes to beefsteaks or immortalize them in painting. But the more delieate satisfactions of flavor of 
fruits, wines, or rarer indulgences-remote from the grati. fication of appetite as bent upon nutrition-may thus qualify. Like the stimulus of the salt air or the balm of the pine woods, they are added zests, the surplusage or luxury of life when of the enhancing variety; the goads, the crises, the thrills, if exciting or menacing in trend. Thus we seem to lay bare the dual source of the emotional life: the one, the imperious emotional demand to make urgent impulses effective; the other the enhancement of ordinary even-toned responses by the infusion of an added zest-a minor by-play of interest.

Along with the occasional character of emotion-for we cannot maintain excitement long at even pitch-and the complication-inviting quality, there is needed a specific trend of feeling to give it inwardly a distinctive variety of disturbance and outwardly a definite bent or set of relief or satisfaction. All this makes for interest and for a place in consciousness; it likewise converges upon action and justifies the close association, the coalescence of the emotions and conduct. The emotion like the motive is something that moves to action; the psychology imbedded in the etymology is sound. Action must be both specific and intent. Mere contraction of muscle may result in a twitch, a spasm, or a fit-pulling these or those strings of our motor apparatus-but is no more conduct than a chance pouncing of all fingers upon the keys of a piano makes a chord. From the interests of conduct, simple automatic action takes care of itself without demands upon feeling or with only a faint, even-toned psychic pulsation; sporadic actions-the hill-climbing moments of dis-ease or the coasting moments of super-ease-introduce interesting, consciousness-engaging excitements among the level stretches. They sustain conduct by the inner excitement which they radiate; they guide it by the specific responses to which they incline and in the consummation of which they find relief and profit. 
The emotions considered specifically are distinct by virtue of the distinctive inclinations which they at once embody and further and direct. Emotions and sensibilities are subject to the common principle that action depends upon (differentiated) responsiveness; to act appropriately one must feel appropriately, be distinctly affected or disposed. The sensibilities achieve the adjustment by immediate stimulation in terms of an ingredient of pleasure that attracts, or of pain or disaffection that repels. The element of gratification or offense is the specific focus of the reaction and lies directly in the organization of the sense or senses which convey it. The horse may be led to the water but cannot be made to drink. Food acceptances or rejections as well as preferences are thus regulated. The sensibilities provided for the normal range of reactions in simple organisms may be adequate to guide conduct, and make an emotional life superfluous. Where this condition is realized-whether in amœba, snail, or crab-is uncertain. Types of sensibility-preferences favorable to an emotional growth are found in certain recurrent situations connected with organic excitement. The sex instincts are of this order; the attraction is fundamentally in terms of sense; but susceptibility, organically conditioned, determines the inner agitation, such as the organic stress of the rutting season, the uneasiness that by the call of impulse leads to a quest for its satisfaction, or is passionately aroused by its direct or indirect clew. In the more refined and individualized responses of sexual selection, the rôle of the emotions is vastly expanded. The hunting instincts of predatory animals supply an expansive recurrent excitement which is needed to maintain the chase efficiently and energize its central and collateral activities. Such instincts are capable of instant and violent provocation [3] by the presence-detected by sense-of the appropriate object. The relations, though simply stated, readily acquire a large complexity. Hunger arouses an affective disturb- 
ance for which sensibility supplies the selective appetite; the struggle for food vitalizes large areas of conduct saturated with emotional incentives. The sensory factor comes to be the spark that lights the eharge; it conveys the impetus to a prepared and organized energy of larger scope; the course of the fuse is set in the nervous structure. Conduct extending beyond the momentary situation, more urgent or more pervasive excitements requiring responses of variable type and energy, demand the diffuse internal agitation and the specific outward trend that constitutes the emotional wave. Yet once more the dispositional mood should be recalled. The invitations of situation propose; the inner fluctuations dispose. The influence penetrates to the finest inclinations of acceptance and rejection, affects subtly and selectively the reception and the course of emotional play. Organic disposition contributes to the tone of hospitality-a selective and discriminating, even a capricious hospitality-toward the several appeals which the day's occupation presents. Like the prepared attitude in the intellectual realm, known as apperception-which smooths the way for apprehension-the organically conditioned sympathy, the Stimmung, determines which of the manifold emotional attitudes will more congenially prevail, will be more readily responsive. The psychology of prejudice and predilection in its nicer applications has its sources here. Our sympathies and antagonisms are complicatedly conditioned; they obey a natural as well as a disciplined summons. A trait of character lies in the susceptibility to the appeal of such orders of stimuli and the regularity of their responses. Mood as predisposition must ever be reckoned with. There is a tide, however irregular, in emotional affairs; the ebb and flow of the psychic stream is unceasing.

The motor trend of the emotion dominates conduct. The situations in which emotions play their part are "conduct" situations; the affective attitude conditions as it ac- 
companies the total psychic reaction, which it scrves. Instinet and impulse refer to the organized tendencies of the nervous system, which by emotional diffusion diseharge accustomed mechanisms or response. The nervous system presents specialized areas of sensibility to receive stimuli, which in due course or originally are qualified to arouse emotional agitation; the movement from first to last pursues an organic route not rigialy charted, but following a well-marked natural course. The complexity of emotionally guided response reflects the complexity of situation; if the latter were simple, the former would be equally so. If the psychic state alternated between quiescence and exeitement, and exeitement alternated between attaek and withdrawal; if in an hypothetically simplified turtle all situations induced either a stereotyped snap or a fatalistic retirement within the shell, the psychology of the emotional endowment would be reduced to the simplest terms. The instinets, the nervously organized routes within the human organism are various; their multiplicity demands an intricate elastic adjustment. Instinct, blind in one sense, is keen of diserimination in another. Though driven, it steers; for impulse is manifold, and conduct, to serve its end, must be organized. The emotional route, though organically charted, as it runs its course, engages collateral trends without losing its central direction. The induced currents compose the complexity of mature emotions and appear in the early stages as well; the headway is derived from the primary source. The complex flow redirects the stream, yet is conditioned by the course of the nature-worn bed. Looking backward to the source and motive trend of the emotion, the psychologist applies one perspective; looking about him upon the rich issues of the emotional life, he applies another. The adjustment of the one to the other presents a problem of regulation as well as of analysis.

Sensibilities and emotions alike regulate conduct, dis- 
pose to response selectively. Sensibility supplies the invitation; its acceptance is so involved as to require the ampler influence of the emotional irradiation to carry the stimulus successfully to its satisfying response. Sensibilities and emotions combine, yet retain their contrasted status. Disgust is a sensibility reaction of avoidance; fear is an emotional reaction of avoidance. Disgust is not fear, though the two may be directed to a common object, and either induce the other. Snakes may be found both disgusting and fearful [4] ; the unpleasant affective tone pervades both attitudes. Appearance may attract by an appeal to an accepting sensibility; it extends and continues its attraction by arousing desire, or under suitable incentive, tender feeling. This expanding and complicationinviting quality finds two points of attachment; the one a spreading of the roots, the other an extension of the branches of psychic growth. The one attaches itself to strong primitive situations; the other to the derivative, secondary play of impulse. If recoil is to culminate in flight, it draws upon the sustaining excitement of fear; if a momentary interest is to mature into watchful ministration, it draws upon the sustaining excitement of love, at the least, of devoted concern; if the interest is to find its issue in attack, it draws upon the sustaining excitement of anger. These emotional expansions are derived from the field of primary, ardent emotion, attaching to urgent situations or to their minor contributory incidents, and derive their vitality as well as their quality from this source. Ultimately, the parts which these instincts play are so vast, the stages of responsiveness are so varied, that the emotional enhancement, corresponding to an organic tension, is indispensable for the variable and complex performances that intervene between the stimulus and satisfaction. The life of sex is typical in this relation. The spur of emotion goads desire, and also extends the agitation to by-paths of invitation. Emotions involve an inner spread 
organically, and objectively an adjustment to complex situations and to their subsidiary issues. Thus considerel, the emotional life is an cnhancement and complication and radiation of instinctive feelings connected at their source with urgent natural situations; it gives these tendencies a psychological setting, a career.

But this stream of activity is not the sole fountain-head of emotion; emotional enhancement is attached not alone to the regulation of the vital and urgent needs. In the second and contrasted variety of emotional complication sensibility remains directive but with a distinctive and different range. The emotional complication of protective pains and vital gratifications takes a different set from that of surplus pleasures. The urgency of situation, far from being essential is in this development wholly incompatible with it. Such by-products of sensory experience are congenially emotionalized. The very release from too direct a bearing upon survival liberates other ranges of psychic quality. The more luxurious sensibilities find a congenial support and expansion in the emotional career: the esthetic life demands a rich emotional basis. Like the arts, there are also the emotions of peace as well as of war. It is the emotionalized expansions of the esthetic sensibilitics that continue the course of evolution to the highest types of human satisfaction. In the end the susceptibility to emotional expansion becomes the distinctive trait, the distinctively human trait, of the sensibilities. To which of the sensibilities this emotionalizing susceptibility more particularly obtains appears from the place of sensibility in original regulation, and in the considerations of the preceding chapter.

Pertinent at this juncture is the important consideration that the existence of the esthetic sensibilities, as of the situations which they direct, contributes to the life of the emotions a vast enrichment and complication. The emotional life of man would present a very different, a very meager 
and bare and even crude aspect, were it developed wholly from the urgent primary types of situation: from fighting and fleeing, from food foray and sex rivalry, from aggressive hunting and defensive flocking, and the maintenance of offspring against competitors. The limitation of the emotional life of even the most sympathetic animals may find its source in their incapacity for the esthetic range of emotionality. Yet the intrinsic strength and leading quality of the more indigenous emotional order maintains its place in all later developments; the vantages and the liabilities of such primitive emotionality continue to shape the problems of moral regulation in the highest eivilizations. Human pugnacity, though not in its original ferocity, will endure; but it depends largely upon the correct psychological interpretation and control of the original combativeness, whether the conclusion is reached that war is inevitable, or that these impulses can be safely and profitably directed to other outlets. The essential consideration of the moment is that man, having developed to high estate both orders of emotion, enjoys more than the sum of the two. The presence of each infuses the other with an added quality of potency. The susceptibility to the esthetic order of emotion profoundly modifies the hold and the manner of expression of the emotions that reflect primitive urgencies. The plays of men, the constructions of men, the surroundings of men, the intercourses of men, the pleasures of men, the standards of living in all respects, are markedly different by reason of the esthetic infusion, even though these expressions continue to embody and reflect the modes of solution of primary needs. That in this development the emotional regulation plays a primary part is the theme of the present chapter.

The complexity of the sense-impression in developed situations invites an intellectual expansion that supplies the emotion with an object, establishes it in an organized system of response, and saturates it with associative enrich- 
ment and values derived from all shades and grades of experience. When the direct sensory pleasure of a play of color develops to an esthetic harmony, it becomes the type of the complex luxurious issuc-like the enjoyment of a sumset-in which associated factors and educated interests enter and dominate. Such an emotional product can be grafted only upon a parent stem which itself stands in more indirect, more remote relation to organic adjustment. It is the esthetic aspect of the emotional life that engages the slighter by-products of luxurious sensibility, and, with the aid of the intellectual enrichment, composes them into the subtler, richer satisfactions. The two orders of emotional expansion merge and combine and carry the qualities distinctive of each to and in the higher reaches of the emotional development of man. The ultimate thrill and the matured complexity and intricacy of emotion reflect the composite source. Of this relation the life of sex offers a convincing example, exemplifying also the common organic bond of urgent and of luxurious emotion. The heights and depths of romantic attachment combine with the urgent decrees of nature-set desire; the still more remote realm of a spiritualized emotionalism is an efflorescence of the same parent stem. Man becomes an esthetic and a religious being, by virtue alike of his passionate nature and of the refined sympathies and exalted virtues which his insight and his sympathetic emotionalism discover in common experience. Life, though never remote from a struggle and a competition, may yet partake of the movement of a symphony. The emotional vitality pervades both aspects.

We return to the question of emotional primacy and the specific trend of the emotion. To direct the analysis concretely, we may use the method of illustration, beginning with an unquestioned instance of a primary emotion, fear. Fear appears early in human development, is widely present in animal life, has intimate physiological reactions, an 
ineorporated facial and bodily expression, affects the entire psychic disposition, arouses an instinctive response of retreat, presents characteristic abnormal variations particularly of excess. Thus ancliored in the organic life, its rôle extends by its modification through experience and control, its affiliation with other similarly directed emotions, its alliance with composite emotional states, its social complications. These traits, readily observed, confirm the diagnosis of fear as at once a primary and a comprehensive order of emotion. Fear is an important typeform of emotion with distinctive species and varieties.

Fear has branded its claim upon the nervous organization; it gives evidence of a deep and ancient sovereignty. Its somatic reactions are strong and direct: in fear, breathing is impeded, the heartbeat pronounced and irregular, the throat.dry, the skin pallid, the perspiration cold. In extreme cases (more familiar in journalistic accounts than in physiological texts) the hair stands on end or turns gray; the knees knock together; complete syncope occurs. The minor expressions, passing over to the controllable factors-the trembling, motor hesitation, broken voice, fixed stare, drawn face, open mouth, shrinking attitude, mental bewilderment, panic, remain significant; for even the least of these may point to the original status of a complex emotion that has wandered away from its primary orbit. Much of this, when the situation is or may be urgent, we cannot control; and if taken unawares-as by the sudden slamming of a door-the start or twitch is all over before our slower intelligence recognizes what has occurred and restores tranquillity. The abnormal expressions-the instincts gone wrong-are significant. The panic of fear, crowding out reason-as does likewise anger or any passionate emotional indulgence-is peculiarly subversive, both in its individual restriction of action and in its collective contagion; witness theater fires or stampedes of crowds with their tragic, needless loss of life. Such lia- 
bility or anomaly is not limited to human psychology; the horse in his mad dash for escape from unreal dangers exhibits it all too readily for human comfort. While exemplifying the extreme or misplaced expression (misplaced by reason of the altered environment), the horse indicates the original purpose of the instinct the more convineingly. Running away is the natural response, is what the fear is for. This consideration brings us once again to the view of emotion as the spur to action, and to the natural bonds of emotions and instincts.

The survey of fear as a type of primary urgent emotion invites the statement of collateral problems in its terms. First is the distinctive nature of the emotion-the joint clew to the problems of primaey, of definition, of classification. What, then, is fear? Superficially a mode of feeling. But how is its mode distinguished from other modes? Does the induced response define it? Then fear is the flight-inducing agitation [5]. But fear need not induce flight; it may go part way only and induce withdrawal, or only defensive caution as in response to a threat. It may induce concealment-quite as primitive a reaction as flight. Combining these tentative approaches, we make fear the emotional accompaniment of the "protective withdrawal" type of response to a situation of attack or threat; and then secondarily apply it to a like tendency and similar emotional play in situations subsidiary to those of threat and attack and derived from them. Yet in so generalizing the emotion we lose something of its specific directness as prompted by a specific instinct. For it has become elear that the position here developed is in accord with that of James and others, and first explicitly formulated by MeDougall : that at their source the primary emotions are determined by the principal instincts. The emotions are distinct as the instincts are distinct. An enumeration and classification of the one supplies the clew to the other; for the liberation of the response sets the trend 
of the emotion. In this view fear is the flight emotion, and in the equine psychology it is unreservedly such; for human psychology the more generic statement is truer. To repeat: fear is the feeling attitude conducive to the protective retreating type of response [6] ; similarly anger is the aggressive attitude expressed at its full in pugnacity; which, in turn, is equally contrasted with the friendly approach of tender fellow-feeling, or intermediately with the neutral inquiring approach of curiosity awaiting the signal that may turn it to fear, sympathy, or anger-to rumning, fondling, or fighting. Such is the clew to the principle of definition and classification. In applying it there will be substantial agreement in regard to the great primitive trunk-lines of instinct-emotions, and a moderate though not particularly notable divergence as to the exact points and manner of division.

To arouse the emotion a sensory channel is indispensable. For fear it may be smell; it may be contact; it may be sight; it may be sound. It depends upon how the organism is sensitized. The like is true of anger, the great counterpart of fear. Smell-induced fears are common in animal psychology: the deer is alarmed by the human odor and is approached by the cautious hunter from the leeward; the fittings of the trap are suspected by the fox because of the taint of human manipulation. Kittens with eyelids still sealed will spit and hiss when a hand that has fondled a dog carries the canine scent to them. For animal rage the smell of blood is as exciting as its color. Touch has its play in instinctive emotion; the contact of fur causes violent alarm in some infants, and shrinking dislike in others. Appearance and sound are the preferred avenues of fear-inducing stimuli. Enraged animals look terrifying; threat is written in every feature. But the hiss, the growl, the trumpeting, the roar add to the terror. Possibly by reason of its carrying power, possibly by reason of its gregarious service, the sound has 
gained a speeial inlet to fear [7], and not of fear alone but of other emotional attitudes, such as sympathy. A sudden sound is to human kind as well as to many animals a startling cxperience; and all unusual sounds excite suspicion; the hunter moves in stealthy silence so as not to alarm the quarry. While there is thus observable a natural preferment among the inlets of fear (as of other emotions), there is a considerable, almost an indefinite expansion of its terms. Which sounds and which appearances are to be feared, and which ones welcomed, must be learned, though upon the basis of natural but not always reliable clews; the unlearning of irrelevant, though in type natural, fears proceeds by the same process of education. But native trend or early set of experience may be too strong; and roaches, snakes, toads, mice, as well as thunder may continue to arouse violent and uncontrollable fear. The innocent insects, reptiles, or rodents that excite alarm may also arouse disgust; but the case of thunder stands as a pure terror of an "auditory" source [8]. An eclipse of the sun is an object of fear among many primitive peoples; and they follow the auditory clew by making loud and hideous noises to frighten the eclipse monster away. Among educated persons the eclipse is an object of curiosity alone, not unmixed, it may be, with an uncanny feeling, in the presence of the unusual, which is of remote kin to fear. Such fixing of fears by experience has a distinetive bearing upon the psychology of attitude, which makes its consideration more pertinent in a later connection.

The rôle of the situation as a whole is to be considered. The vital end to be accomplished by fear is protection; if this can be otherwise accomplished, the fear is needless. Fear is required when a general alarm, ready to inspire whatever response may be useful, is demanded; it is apt to engage the total organism with all its equipment of flight, concealment, defense; anger does the same. Thus 
in the food-quest, herbivorous animals are protected from injurious plants by an instinctive (odor) avoidance. The poisonous plant does not strike back, as does the snake equipped with a comparable protection; sensibility is adequate for the protection and an emotional irradiation unnecessary. The food-quest of carnivorous animals engages the active pugnacious instincts, as well as the shrewdly offensive and defensive ones; it engenders an ardent emotional tension. Similarly for the care-of-young situation: organisms that deposit eggs in large numbers and leave them unconcernedly to the sun to hatch, or to their fate, with a large margin for the destruction of the many-and the survival of the few-develop no emotional attitude to the situation. But those, like the birds, that have few young in a brood-which by their helplessness require constant attention-mature a complex range of specialized care-of-young instincts with an equally complex range of emotional agitation. Shrewdness as well as sacrifice enters, and the mother bird, when disturbed, draws attention to herself and away from her nest of fledglings. Similarly, the mode of fighting and defending sets the elew for the emotional life; for primary emotions are consistently derived from the primary instincts which they further, and the latter are shaped with reference to the situations which they must meet for the ends of survival and preferment. From all this conditioning man is not exempt; his emotional nature is derived from the nativeset habits of his primitive life.

The expression of the emotions offers a series of problems. How do we come to express our fears and our angers, so variously excited, in such similar ways? Similarity of organization is responsible for the issue; the generic similarity of the primary situations from which the expressions are derived, also plays a part. The consideration of the repertory of expression proposes such questions as: Why do we glare and set the teeth and raise the 
voice when angry, why smile and chuckle when pleased, why l'rown when worried, why sigh when sad? These natural outlets, sharing in a like mechanism with the visceral changes, constitute the inward phase of the emotional complex-the most unehanging faetor. Similarity of expression, both immer and outer, becomes a significant clew of similarity of affeet; the congenialities, compatibilities and incompatibilities of expression disclose the relations of organized emotions. The eonstaney of the visceral reactions has the same basis as their remoteness from voluntary influence. The facial and related expressions are also deep enough to make their control difficult though possible. The most urgent types of emotion are bound up with the most involuntary expressions. Anger and fear, even guilt and shame, are not easily eoncealed; for, like murder, they will out. The restraint of laughter and tears under strong provocation sets a task to the will, and serves as a proper index of maturity; but by the natural affiliations of the suppressed expressions the effort has a somewhat different range. Beeause of their remoteness from control, because of their genuineness, the visceral and related changes accompanying emotion form an invaluable record. They tap the emotion from within. If adequately revealed, such "readings" would differentiate the affect of fear and of anger, of submission and elation, of tenderness and indifference. How far this clew may eventually be followed it would be rash to predict; practically it remains partial and limited, and throws us back upon the outward visible expressions (interpreted by the light of our own fallible introspective experience) for the interpretation of the subtler and slighter emotional play, and the regulation thereby of social attitudes and responses. The situations of stronger urgency excite the stronger expressions; the hot jealousy and pugnaeious anger of sex rivalry, the desperation of a panic, reflecting the eruelty of primitive struggle for existence, offer examples. In these the outer expressions 
are strong enough to bring to the surface the internal excitements, the reddening or the pallor, the motor contortions, the panting, the general physiological upset. The full-fledged expression is significant as a magnified rendering applicable to the reading of the lesser miens in related expressions. It is such intense anger that makes it clear that anger is the "striking" emotion: witness the expert and uncontrolled rage of children, which may make use of "biting" and all the attacking armor of fist, teeth and nails. It is such complete expression that indicates that all expressions of rage or irritation are miniature and incomplete approaches to the original consummation. There is often an unwelcome evidence of the primary hold of the instinct in the involuntary tendency to strike when accidentally jostled or when one's toes are stepped upon, and even irrationally to kick an unoffending footstool over which one has tripped in the dark. The slamming of a door in leaving a room in anger serves as an outlet of "impotent rage" and, like the tendency when angry to smash something, may relate destructiveness to anger, attack and its sequel. Such response may be released the more readily because of the absence of fear of counterattack which restrains in meeting a "real" foe. But the point is mainly that the occasional revelation in sophisticated and well-bred persons of a tendency, possibly related to the original trend by which conquest was completed by extermination and the slaughter of war by pillage and conflagration, discloses the intimate bond of the emotion and the primary impulse for the sake of which it came into being. It is further interesting to observe the response when several original tendencies may be jointly operative. The fact that fear is also the concealment tendency may account for the tendency to throw the bed-clothes over one's head when alarmed by thunder, or even by the suspicious sound of a possible intruder-a conduct as wise and as natural as that of the proverbial ostrich. It has been sug- 
gested that the physiological counterpart of the dual response is traceable jointly in the paralysis which is at times the effect of fear and belongs to the "concealment" complex, and in the quickencd heartbeat which belongs to the "flight" complex. The latter, as the more common, may indicate that the typical anthropoid fear reaction was flight; and that possibly in extreme cases concealment was the more favorable alternative: when too much frightened to run we, like our ancestors, are rooted to the spot. In milder variety fear induces consternation as well as hesitation; it induces also a search for social security.

As a result of such evolutionary excursions, we obtain a richer sense of the history imbedded in the play of emotion, of its occasions and expressions, and of our common and our individual susceptibilities to its sway. We may resume the more orderly course of exposition by restating the results of analysis in simple form. We recognize (1) the stimulus or outward invitation to the release of the emotion which the environment supplies and to which the sensory equipment is open; (2) the internal changes of feeling thus aroused, including (in addition to the preconditioning disposition) the adequate range of distinctive attitudes of attraction, repulsion, attack, defense, curiosity, sympathy, elation, submission, and their variants and derivative affects; and (3) the combined expression of, and reaction to, these processes. Such psychological terms as instinct, impulse, the Latin nisus, the German Trieb, the double sense of passion, indicate shiftings of emphasis toward one or another of these phases, while yet extending over all. The one aspect emphasizes that which sets the instinct in its specific course, makes the cat the bette noir which the dog fights and the mouse fears, makes the young of the species the object of tender concern, determines less rigidly what sights, sounds, contacts, odors, will alarm or attract. Incidentally the same consideration cmphasizes the psycho-physiological predisposition: 
such as the emotional tension in animals during the rutting or the breeding season, and in human kind the slight inducement needed to arouse fear when by nature, mood, or circumstance, one is timid. The other aspect emphasizes consistently the terminus ad quem. As we think of the Trieb as the driving force or as the action to which we are driven; of the nisus as the inner inclination or the outer trend of the instinct; of the passion of what we inwardly suffer or what we ardently and outwardly express; we place in the foreground one or another aspect of the emotion-complex. As we consider the more developed phases of our own emotional life, we regard as distinctive the inner trend, the tendency for the emotional irradiation to become psychically prominent and explicit, gathering about its nucleus of natural affect an enlarging as well as a differentiating mass of "ideas" and associative enrichments. The fear that arises when actually confronted by a danger or an ordeal leads to dread of its anticipation; and the telling of ghost stories, no less than organic enfeeblement, induces the mood of timidity. If we dwell upon the completing aspect of the emotion, we subordinate all other phases to the central clew of conduct. We look upon emotional agitation and upon consideration alike as suspended or partial responses, stages of delay, as indirect shapings of conduct, of promptings and impulses. Furthermore we look to the reaction as decisive for classification and evolution alike, value highly all that is expressive and motor [9], and in practice appraise and educate pragmatically in terms of ends accomplished-the enduring values-while yet recognizing how much of the science of psychology and the art of education is involved in the variability of the means. Sensory recoil, emotional distrust, conscience, imposed scruples and social restraint are all efficient regulators of conduct, and find a common value through the common affective disposition which they arouse. Situations in which what men 
do is less significant than why they do it, become increasingly frequent with the growing complexity of mental life. The reverse order of importance is more pertinent to primitive cultures and situations, and by the same token, to analysis. Leaning upon this evidence, we should look for the distinctive instincts of man, as of animals, in what they cause organisms to $d o$, naming this or that emotion as primary in that it leads to a primary mode of reaction, yet considerate of the mode of inner agitation which colors the response.

To understand the nature of primitive instincts and emotions we must observe and interpret them in primitive situations [10]. These are provided in the first instance by the struggle for existence under the conditions of nature -the ultimate battleground of human quality. It is not a constant warfare, but a preparedness for it; a confrontation with warlike situations which must be met before peace is restored. The fundamental issue is that of advance or retreat, the attitude of aggression or of defense. In terms of attitude, the distinctive groups or types of emotions are on the aggressive side, anger, self-assertion, and, with allowance for more remote issues, curiosity and tender emotion; on the defensive side, fear, repulsion, subjection.

Among the primitive situations, the "food" situation, the "combat" situation, the "sex" situation, the "care-ofyoung" situation are conspicuous and definite; but intermingling with these more specific appeals to response are the generic ones suggested, though not adequately described, by such terms as the "play," "activity," "occupation," "enterprise," "function," "welfare," "interest," "experiment," or "plot" situation. For the concerns of combat, sex, care of young, and even food, are severally and jointly occasional, at all events, not constant; and the frequent intervals of their pressure must be filled by movement, exercise of function, adjustment, men- 
tal and physical occupation, recreation, and most characteristically by "play"-itself disposed to assume the mimicry of the realities of life. In any systematic view this commanding situation must be recognized, difficult as it is to give it a distinctive name applicable at once to its versatile expression and varied intensity of engagement. If one could establish the word "play" in this far more generic sense, extending it from its juvenile, which remains its fundamental, setting to include the adult "interval," "experimental," "enterprise" activities, vocational and avocational alike-as recent theories incline to extend it-it would be the preferred term, peculiarly appropriate for the higher organisms with their increasing periods of varied premature and mature occupation, through which all other functions and the emotionally tinged impulses involved, find their maturity and service. Reduced to their lowest terms, which still show large overlapping spheres of influence, the comprehensive and absorbing situations become "play," "food," and "family." In terms of the instinctive habits primitive man may be defined as a playing, feeding, family-bred-and-breeding animal.

The instinctive reactions to each of these several situations enlist distinctive emotions in their service; furthermore, the situations have common factors, or aspects, as in turn the supporting emotions present intimate physiological affiliations. Thus men (or animals) compete for food, for supremacy, for mates; and it is for this reason that James regards the agitation centering about emulation or rivalry as a primary emotion-the emotion taking its name from the situation which arouses it. If the food depends upon the chase, the traits expressed in prowess, endurance, and skill as well as the emotional accompaniment of pursuit, triumphs, failure, are of no very different order from those engaged in combat and war. If the food supply is fairly secure, the combative instincts turn to other outlets. Nature's demands are slight-self-preservation 
in as favorable condition as possible, and reproduction of the species. But it is more in poetry than in life that "man wants but little here below." The craving for exereise of function, expressed in "food," "play," and "family" reactions develops a varied and rich life of activity. The soeial situation particularly-as established within the family and the tribal-group-is so inherent and pervasive as to form part of the primitive nucleus of the emotion-instincts. Apart from "play," the general divergence of "food" and "family" activities as ends of existence not inaptly marks the great divide of the individual or selfish impulses and the social ones, the two potent molders of human quality. From another aspect it is suggestive that the aggressive, antagonistic, destructive, emulative impulses are more naturally and emphatically aroused by the personal, food-getting variety of situation; the defensive, sympathetic, preservative, coöperative emotions by the "play" and "family" type of situation. Finally on the motor side, action and restraint form the two decisive responses of the muscular system-release of energy and inhibition, and by direct and not distant descent, the two great moral attitudes of self-assertive expression in wrath, defense, conquest, or whatever other employment, and of self-subjecting humility, prudence, compassion, obedience, or allied deference. As by analysis we lay bare the roots of human quality, we touch upon the vital points of its germination, the issues of which, through a consistent unity of organization, persist in its most complex fruition.

Summarizing we find (1) two distinctive attitudes toward the several appeals to response offered by the environment; the aggressive and the defensive. In the statement of the alternative lies the origin of choice, the germ of the will. "C'est à prendre ou à laisser"_- "take it or leave it" - is the spirit of the issue from the fish's hesitation toward the bait mysteriously entering his watery horizon to the introspective perplexity of the melancholy Dane: 
"To be or not to be." (2) The situations admit of flexibility in enumeration, making many or few, throwing the emphasis here or there, according to the grouping. The three groups of "play," "food," and "family," in the enlarged sense indicated, seem adequate. An aggressive or defensive attitude may and on occasion must be assumed in the activities centering about play, food and family, if life is to go on and to go on favorably.

Furthermore, for human purposes, shared in some degree by all social, even by merely gregarious animals-a distinction momentous in its issue, however obscure in its origin-is the direction, the purpose, the objective pointing of the emotion-instinct, as directed to and by self alone and to and by others-the individual and the social direction. Certain of the instincts arise and persist largely, even wholly, in their social phase or expression; others are notably modified and developed by becoming socialized. There is a fourth distinction to be introduced, which has been postponed to avoid too involved an exposition, and to differentiate the situations as presented. (4) There are two stages of operation in these primary activities: the preliminary and the active or consummatory. The quality of the emotion and the trend of the instinct are alike shaped by the prominence of their rôles in the one or the other act of the drama [11].

The distinction of preliminary and active is significant for the course of evolution. If all reactions were immediate, the stimulus irresistibly inducing the keen eagerness and quick response-the bait instantly snapped, the blow struck, the attack made-they would remain simple, mechanical. In fact they are variably and indefinitely mediate and indirect, and consequently complicated by delayed hesitation and consideration. The preliminary (inner) stages begin to stand apart from the (outer) active instinct-expression, and develop a more intricate emotional regulation. The issue may be very different 
because of the intervention of conflicting impulses which induce and favor consideration. The relation of the preliminary to the active stage of the emotional complex is suggested for animal as well as for human character by the common experience that "the bark is worse than the bite." Barking precedes biting to signal to companions and to warn the enemy-interpreted socially-or to energize the biting propensities-interpreted individually. It is equally, perhaps chiefly, significant as the stage of cautious inquiry - a preliminary defensive eheck which in the end makes the biting needless or harmful. By building upon this psychology, we use watch-dogs against intruders and for our own protection. Canine sniffing presents a parallel stage for food or sex or friend-or-foe approach; and jointly, the aggregate of such preliminary stages of reaction builds up a generalized attitude of curiosity (and caution) applied to many situations, particularly to ambiguous ones-a stage of tentative examination and holding back, the filling of the reservoir of energy if a strong aggressive (or defensive) response is the ultimate issue; the draining it off in harmless ways if the alarm is needless, the disturbance mild. It thus becomes intelligible why all strange situations should excite fear, curiosity, or anger, as the case may be, the familiar ever finding ready adjustment.

The contacts of human and animal psychology will furnish an illustration. If in a cross-eountry stroll I enter a pasture, the young bull becomes "ugly" at the approaeh of a stranger, though tractable enough in the owner's care; the cows approach in idle, vacant curiosity, or chew the cud in stolid indifference; the crows overhead promptly emit their shrill gregarious cry of alarm; other birds keep at a safe though not unfriendly distance; a rabbit or a gopher observes me curiously yet remains near enough to his burrow to make an instant dash for safety; the sheep, if accustomed to trespassers, are indifferent, yet quiver 
on the "tenter-hook" watchfulness for the reaction of the leader and then scamper as a flock; the dog approaches menacingly but in answer to my friendly call and assurance-or through some subtle instinct finding me not a vagrant or a lawless intruder-checks his growl, reverses his emotional brakes, and frolics to my petting. Such animal reactions, selecting among the alternative emotional attitudes of fear, curiosity, friendliness, and anger, exhibit a preparedness for action-a series of preliminary responses that may or may not develop to their distinctive and useful consummation. The fact that such responses show a considerable adjustment and control indicates the formative power of experience, the enrichment of the response by association, the finer differentiation of situation, the nicer adaptation of conduct. Much of it, however, like the difference of attitude to friend and stranger, retains a vestige of that vague organic and possibly emotionalized order that is termed instinctive. The response moreover is determined not by any one emotion but jointly by the several appeals of contracted emotion and by their combination and interplay [12]. The complexity is apparent to human consciousness because of the report which the course of emotion returns to the mind. For animal behavior it is not easy to determine or to imagine how much of the internal agitation which we associate with the release of an emotional wave accompanies the reactions. We judge mainly by analogy of outer expression, and thus judging, are prone to "humanize" the psychological state expressed; yet some simpler type of emotional experience is presumably present in the higher animals. We may safely infer that it lacks the reflective and imaginative accompaniments that convert fear into apprehension, or make the human mind shudder in recalling past danger. What is accomplished through ideo-motor channels in conscious humanity must find a regulation in animal life in more direct, organically determined relations. 
The analysis of the primary emotional range has been conducted upon the central position of fear and anger as the eontrasted and dominant currents of the emotional stream; and the illustrative material has been developed upon the same emphasis. This course has been chosen because of the resulting definiteness of presentation; it is also justified by the actual dominanee of fear and anger in urgent emotional situations and by their characteristic place in the composite nature at all stages of development. They are positive and all-absorbing emotions when pronounced, and give the set to eonduct and attitude and temperament when mild; they suggest the persistence of the older attitudes of aggression and defense as the constant price of the struggle for existence: the eternal watchfulness that now may be directed to concerns of derivative value, to the mature interests of the mental and the moral life. The emphasis thus adopted has carried the argument dominantly in terms of the food situation, and less centrally, of the sex situation so elosely involved in a eommon pursuit. This series of contrasts of primary emotional trends must now be amended; for the duality, as has been suggested, is not adequate to the faets nor to the integrity of their interpretation. A triad of situations and a triad of central emotional trends yields a more convineing, a more fluent, and a more adequate interpretation of the emotional life. The food situation sets the initial course and oceasion of aggressive anger and defensive fear; the sex situation and the family relation continue these attitudes and enlarge them to varied service and enriched inner experienee by the added by-plays of emotional response which these situations entail and invite. The third type of situation-the play situation-is essential to the completion of the emotional interaction, and is responsible for much of the complieation of the courtship qualities of response, and for the like subsidiary attitudes aroused in connection with the food situation. It is important to 
supplement the exposition, indeed, to revise it-in the light of the contributions of "play" to primary emotional psychology.

It is in this attempt that the inadequacy of the term is conspicuous. Between the excitements of fear and anger is the large interval of adjusted composure and the exercise of function, not unrelieved from the stress of sex or food but yet centrally directed under their retirement to ways and means of other type. The presence of so complicated a neuro-muscular system adequate to food and sex functions involves a larger adequacy for the varied incidental functions of which life, and particularly a complex life slowly maturing its bases of control, consists. The presence of functions demand their exercise; with the claims of food and sex adjusted, there follows either fatigue, rest, sleep, stagnation, or restless seeking of stimulation, release of pent-up impulses, free expenditure of energy in animal spirits, idle curiosity, occupation of some sort. Life is not full, is indeed bare without this completing interstitial activity which rounds its contours and expands its opportunities. The vacancy of the cow seems to reflect the imposed burden of chewing the cud so constantly as to leave little or no incentive for play; the unemployed interval is too slight and is absorbed in placid rest. Even the active cat, fed and established in its home, goes to sleep, when once it has lost the added incentive of its kittenish play or the cares of family. The dog though stretched on the hearth in dozing content eagerly awaits the call of his master to supply the incentive of a walk to relieve his ennui. The susceptibility to the call of play is a fundamental quality of the higher emotional nature and has far-reaching consequences for the emotional life of $\operatorname{man}$.

The specific emotional quality that is thus furthered may be set forth under the general terms of joy and grief-the emotional counterparts of pain and pleasure. The fur- 
therance of function is accompanicd by pleasure so far as it is a sensory satisfaction, and by the spreading emotion of joy as a larger gratification. In the general conception of the series of emotional waves, it is the slighter fluctuations of joy and sorrow, the milder ups and downs of the psychic barometer, that set the course of the movement; and the point of present consideration is that the source of these, though by no means exclusively thus excited, is in large measure to be found in the incidental situations of general welfare, enterprise, occupation, play, exercise. The zest of pleasure is the added incentive of the continuance in whatever activity or experience it is aroused. The sting of pain as the pang of grief is the recoil from the undesirable. In sense-gratification-which is the simple type of pleasure-each morsel carries the lure of flavor so long as the appetite holds; a favorite dish, a choice delicacy points the pleasure to a maximum. A good dinner is enjoyed as food, however much other factors contribute to its " joy." Pleasure is attached to furtherance of function, and to the satisfactions of food and sex as well as and even more directly than to others. But it extends equally to all satisfactions of impulse and desire however conditioned, and extends with a peculiar pertinence to those activities complete in themselves, containing in recurrent sequence stimulation and satisfaction-the emotional zest to supply the continued incentive. Art even more than play, or as the esthetic form of play, embodies the principle. A thing of beauty is a joy forever in that contemplation brings a thrill of satisfaction, and the joy thereof continues the contemplation. The self-sufficient stimuli of play, or the like contemplations of art, are not without direction of impulse -as fear animates flight and anger vitalizes attack-but direct the impulse to their own continuance as an end until appetite fails, satiety or fatigue sets in, interest or novelty wears off, rival impulses displace. To continue beyond that point may turn pleasure to indifference or even to 
loathing. When one is surfeited there is no zest of appreciation or action, no longer a furtherance but a hindrance of desire; pleasure then attaches to rest and inactivity and recuperation, to quiet and freedom from stimulation or incentive to action. Hence the shifting adjustments of pain and pleasure; hence also the pleasure of free unimpeded activity when the going is easy, and the sense of effort allied to pain when obstacles intrude and thwart. To be vigorous and young assures in certain elementary directions the zest of free activity and imparts a ready joy to all incidents of living; to be weak or old, wearied or blasé, depressed or careworn, lessens the joy of action and contemplation, or turns the joy to other consolations.

As joy is the emotional accompaniment and incentive of furtherance of function, grief or sorrow, like pain, is the expression of any frustration, most typically of frustrations accepted, possibly under compulsion. The acceptance may be helpless or protesting, or even rebellious and thus arouse anger, or be submissive in resignation, or appealing in the cry of sympathy or distress. In its social aspect it is a call for aid-the cry of weakness, an appeal to others, a prayer. It is all this even in the infant's cry, while yet the plaintive wail may yield to the solace of fondling, the satisfaction of feeding, the charm of a new toy. It is as characteristic when it turns to anger and rage as when it sobs in distress or fear; for it is the protest, weak or strong, against the frustration of impulse, the checking of unsatisfied desire, the loss of the stimulus or the opportunity that continues its own satisfaction. The toy that is taken away or broken, the play that must be stopped, the merrymaking that must be forsaken, the holiday that must be postponed-all occasion sorrow; the loss of money is a transferred and more potential deprivation and hampering of impulse; true and deep grief reflects the loss of the zest of living in the compelling contemplation of what was but can no longer be enjoyed. In this 
survey the ordinary rum of joy and sorrow attaches so characteristically to the minor sitisfactions of furtherance and fiustrations of parts and aspects of situations of enterprise, play, or exercise, that it seems justified to connect these emotional attitudes not exelusively but centrally-at least in theil emotional fertility-with the situations thus created. Freed from occasion for either fear or angerand likewise from the stress of food or sex-play develops the pleasure of function, of living, moring and being, of looking and listening, of prospect and song; and it combines with these experiences the resultant complexities of play in the pursuit of fool and sex. Motor self-expression is pleasurable; and by trawing upon the self-expressions of other varieties-of combat, rivalry, triumph, fortune, pride, vanity, applause-such cxpressions carry the flavor of joy to psychic furtherances. Sorrow leaves the field of pain and expresses the emotions of defeat, despair, mental distress, submission, disappointment, guilt, misfortune, failure, and all manner of psychic frustrations. The wider emotional aspects of joy and grief span the full measure of the emotional nature. The reverberations of the organic welfare and the special gratifications of sense as of exereise of function continue in the more complicated, more ettusive joys and sorrows, and give tone to mood and disposition, outlook and reaction. The emphasis of the moment is that a large share of such attitudes is connected with the activities of play and exercise: that the enrichment of the emotiona? life connected with this range of activities is responsible for many of the distinctive traits of character: that the qualities thus introduced in turn combine with and play upon the emotional products of other situations. Play joys and play sorrows set the pace for the emotional life, modify the self-assertions of food and sex pursuit, enrich the aggressive and defensive, the self-assertive and self-abasing trends, and expand ritally the general emotional susceptibility. Joys and sorrows go 
out to food furtherances and sex furtherances, to food frustrations and sex frustrations, and in these relations shape the emotional repertory; yet a distinetive rôle is added in the versatile activities of play essential to the evolution as to the comprehension of the emotional nature of man.

Since our central purpose is not to inventory the types of emotional attitudes nor yet to survey the varieties of emotional experience, it will be adequate to leave the analytical pursuit at this stage. Central in the conditioning of character and temperament is the play of emotion in securing appreciation and control: how the psychic nature by virtue of which we severally become the individuals that we are, is conditioned by its participation in manner and measure, in scope and depth and in the diversities of its allegiances, in the several fundamental persistent trends of response, of which our complex responsiveness in the elaborate phases of our characters are but the mature issues. In the further pursuit of this purpose, it will be helpful to consider the expression of the emotions for the sake of the side-light which they throw upon the evolutionary relations. Such evolutionary history is incorporated in that marvelous palimpsest-whose decipherment awaited the genius of a Darwin-the face; not the face alone, but facial expression as the center of interest, supported by the attitudes of the more mobile parts of the body. Properly interpreted the face becomes a venerable human document, the most ancient of records, compared to which the picture-writings on rocks and outlines scratched on bone by the cave-dwellers are recent. The face reveals the most primitive emotion-engaging interests of men, and still serves its social purpose as an indispensable instrument adaptable to the highest ends of human intercourse.

The psychic movement, it has been duly set forth, is a 
wave running into, through, and out from the nervous system; a sensory inlet, a central diffusion, a motor outlet, form its components. The facial (and bodily) expression is a derivative accompaniment of the motor outlet, reflecting the emotional tone and import of the central diffusion. By natural organization the anger under which I strike, the fear under which I run, and similarly if less directly, the tender feeling under which I approach to fondle, and still less directly, the curiosity under which I examine, all give rise to distinctive attitudes and miens which are "associated serviceable habits" - in Darwin's phrase-of the striking, running, fondling, examining responses, or of preliminary approaches to them. For anger the expression of setting the teeth or clenching the fist are associated serviceable habits of biting and striking, are indeed a specialized part of these responses, induced by the same tension which, if continued, discharges the bite or the blow. At one remove the expression stands as a faint incipient approach, a minor associated habit; the menacing scowl associates congenially with the set teeth. At yet another remove the faintest play of the slight muscles that in stronger contraction compose the scowl, gives the eye the firm set of stern severity and shapes the elosed lips of displeasure. The expression is faint, incipient, delicate, remote; so remote as to lose its meaning if detached. Yet because our primeval ancestors worried their enemies, we set the teeth in anger, and glare sullenly with closed lips when unsympathetic in mood. As the arts are built upon the esthetic by-products of sensory appreciation, the art of expression arises from the by-products-even the byproducts of the by-products-of serviceable response.

The facial expression of man is versatile because his emotional life is rich and varied, and the fullness of emotion has its source in the manifold instincts which serve his complex adjustments. Expression accompanies activity as part of its motor vent; it is only because such ac- 
tivity is characteristically emotionally inspired that we accept the expression as dominantly the clew to the emotion and its "sign-manual." In interpreting the rôles of the facial repertory, we are referred back to the instinctive activities. The "food" activities (in terms of affect, the "food" satisfactions) and the use of the teeth in the seizure and biting of combat as well as in the chewing of food -both accompanied by excitations of smell-fix the mouth (and nose) as the expressional center for a great primary range of satisfactions ; the expression persists, while the satisfactions change. Out of the by-play of the muscles concerned in such occupation, a considerable part of the facial mimicry arises. Disgust is the mimicry of food rejection; and the open mouth is (in part) the incipient stage of the pleasant act of food acceptance. The smile may have part of its origin here, and for the rest is shaped (through Darwin's principle of antithesis, it may be) by its contrast with the open mouth, baring the teeth. We smile to show that at least we are not going to bite, just as in more artificial analogy, we extend the open hand of welcome to show that we are not going to use the member as a fist. The welcoming smile of the face is thus a remote yet legitimate descendant of the welcome of food; the "sweetness" of human disposition by not too remote a metaphor means "attractive enough to eat." That the mouth is the early center of expression the infant convineingly proves by the comprehensive experimental use of this receptive organ to test the sense-values of all objects that the hands can convey to the lips. Gradually the eye center of expression comes to its own; through its indirectness of affiliation, it refines the expressional miens. The open eye and raised eyelid of surprise (differentiated from the fixed stare of fear) expresses the expanding interest of curiosity. It is evident that expression as a product of "luxury," itself playful, reflects the large share of the "play" activities in human development. Eager curiosity 
expands to general attention, and the attention attitudes are of all the subtlest facial expressions; these are largely eentered in and around the eye which plays the leading part in supporting the intelleetual interests of the mind. Ont of the motor by-produets of sensory proeesses are fashioned the most delicate expressions of interest and sympathy, of amusement and expeetation, of pity and coneern, of understanding and perplexity, of approval and displeasure. The plasticity of the features animates the face and gives the cast of "expression" which in human intercourse we have learned expertly to associate with intelligence and sympathy [13]. We are so aeeustomed to read the finer grades and shades of emotion, intention, and character in these highest grade refinements of expression, that we find it diffieult to realize them as motor muances accompanying the sensory activities of ordinary range, upon which the intellectual life is founded, in turn modified, by the play of mild emotion by which all activity is sustained. A negative example may be the more convincing. The ears play no part in human expression because man has lost the motor aeeompaniment of the "listening", proeess ; its possibilities are evident in the ears of the horse, constantly moving, and responsive to every emotional excitement. "Prieking up the ears" is for man a metaphorical expression; similarly, the "sitting up and taking notice" is an associated bodily habit which man shares in restrained manner. Its completer counterpart is observed in the alert raising of the head of browsing animals alarmed by a suspicious sound.

The range of activities determines the repertory of expression. The fact that we not alone hear but make sounds gives to the quality of the voice an emotionally expressive value of high degree. Vocal expression like manual gesture or bodily attitude requires a consideration of general emotional states. An aggressive emotion like anger radiates to every part of the body [14]; the com- 
bative attitude, and no less the threat thereof, sets the body tensely to facilitate the blow. In the pouncing eat and the pointing dog the action and the expression are one, or nearly so. It is necessary to recall that along with the specifie incentive which disposes now to this and now to that activity, there is an organic predisposition which carries over to attitude and response, and by such participation becomes represented in expression. By virtue of their organic hold, such conditions - typically in the form of elation, depression and allied fluctuation of nervous tonefind diffuse expression in general bodily attitudes. The body writhes in severe physical pain; in fatigue the posture is slouchy; in grief, which is mental pain, the body is characteristically bowed. Depression may be read from head to foot. It is part of the skill of the sculptor to reproduce the bodily pose that carries and supports the bearing of the head and the set of the features. Laughter may be explosive in violence, the body thrown back, the sides shaking, the voice uncontrollably roaring, all possible vents utilized. In equally real but gentler emotion one may dance and sing for joy. Dancing as a fine art refines and composes while it also conventionalizes bodily attitudes to an expressional drama; the pantomime concentrates upon the facial repertory, but is equally dependent upon the larger range of bodily expression. The face as the specialized center of expression uses finer strokes, and to our specialized interest in its revelations discloses the pictorial meaning more subtly, more effectively. The drooping mouth, the downcast eye, the careworn brow, are the finer phrasing of the bowed head, the enervated body. If the affect is stronger, it may show its tendency to find relief in expression in the wringing of the hands, the moan, the tears, the wail, the restless contortions. The tragic mood gives way to its opposite through the sense of inconsequence, when an accidental blow of the hammer upon the finger-nail induces a rapid violent shaking of the in- 
jured member, a hopping about or stamping of the foot, to say nothing of repressed profanity; the open mouth, taut muscles of the face, engage other safety valves for the escape of motor impulses to ease the regaining of composure. The bodily tone, concentrated in the mobile play of the face, carries the report of "feeling well" and "looking well' in the popular and the professional diagnosis. What all this means is that there are certain charted drainage routes of motor impulses open to the fluctuations of organic tone, which reveal themselves as expressions and merge with and complicate the more specific repertory. The animal spirits of youth, or the hilarity of good humor offer apt illustrations. This is in essence Darwin's third principle of explanation of the sources of expression [15].

The grosser bodily expressions stand forth more conspicuously when the face has not monopolized the leading rôle. The dog's body is the more expressive because his facial muscles-retaining their primitive functions-are less so. The slinking body and tail dropped between the legs are as eloquent of canine submission, as are the guilty face and averted eye for human humiliation. By the same argument, the infant expression, by the very fact of its lesser differentiation, is more pronounced, nearer to nature, more authentic because less controlled. Infant rage or pain-the two not yet differentiated-offers a complete picture of passion in the intense reddening of the face, the tightly closed eyes, the clenched hands, the long restrained breath eventually bursting into the shrill cry; all seem as instinctive as impotent, yet they indicate the strong organic route of agitation that in due course and by the same decree of nature specializes expression to distinctive situations [16]. The month-by-month and year-by-year maturing is reflected in the expansion and refinement of the expressional repertory, and early gives a forecast of its adult dramatic possibilities.

Intermediately between bodily attitude and facial expres- 
sion is the development of manual gesture. The human hand by a like partial release from original service (most originally and completely from walking and climbing, then more partially from mauling, scratching, grappling, striking) qualifies for a supporting rôle in expression. The hand may threaten or appeal, warn or insist, command or beg, bless or curse. The more derivative status of such expression is shown in its larger subjection to control, as in the part of imitation in the acquisition of its language. Some races and societies encourage and others discourage manual expression. Its service in conveying the sympathy of contact appears in the pat on the back, the fondling stroke, the hand-shake-all affected by the play of custom. Convention and refinement enter together; the slighter and derivative dramatic gestures of the eloquent hand enter into the complex manner as into the refinements and conventions of the dramatic art. But by preferment of parts, the face at the same time carries the message more subtly and more incisively. The subtleties of expression develop the questionings, the suspicions, the disdains, the sarcasms, the sneers, the considerations, the flatteries, the sympathies, the understandings; and the face conveys them to those of the same schooling. They remain complex derivatives in increasing remoteness of origin from the motor accompaniments of the cruder and more direct responses, in which their coarser antecedents played a more primitive part. Manner, as an index of sensibility and breeding, has its warrant in these relations. The story of expression parallels and reveals the evolutionary course and significance of emotion in regulation of behavior. Without this convincing and objective corroboration, our exposition would lack confidence as well as completeness; with it we acquire a version in a translated and accessible language - and yet a vernacular-of a development obscurely imbedded in the primeval growths of bodily and mental evolution. The language of the face proves, as it exhibits, 
the phrasing of the emotional life and the validity of the psychological analyses and interpretations. The story of the emotional life and its vicissitudes is written doubly, onee in its own vernacular and again in the facial rendering.

Resuming the account of the emotional development in its approaches to the ligher ranges of the inental life, we may present concomitantly the growth of emotion and expression; their species and varieties, their complication and elaboration. In elear-cut situations the response, and with it the associated expression, is equally definite; but witl situations variable, uncertain, and far from simple, the expressions, linked with the dispositions which they accompany, like the overtones of a fundamental, reflect the play of conflict or of combination of trends. In animal life the expression is the ehief if not the sole index of the emotion; but the inference is unmistakable. Two "strange" dogs meet with sullen challenge, ominous growls, fierce looks; they circle eautiously with alternate approach and retreat; each eventually goes his way with honors even and impulse appeased. In such maneuvers pugnaeity is contending with flight, the strength of each apparent, though the resultant in this parallelogram of emotional forces is inaction. In human diplomacy valor and discretion contend more delicately. Darwin tells of a conflict in monkeys between fear and curiosity: he placed in their cage a bag containing some harmless snakes; they peeped in the bag, scurried off with frightened look, and returned in fascination to look and run again [17]. The "play" situation depends upon a parallel eheck and interaction of impulse. Playing dogs growl and bite, but do not set their teeth; children romp and tumble and throw one another, but without malice or hurt; play of this order may easily go too far and become earnest. The game is a combat with restraint, a contest under rules; but it is a good game-which means a contest en- 
gaging the same order of emotional interests as vitalize the original activity upon which it is patterned-only when one plays hard, with heart and head. Sport must have the element of risk and venture, or it is tame; the effort must find resistance, antagonism of some sort, fictitious or real, to be emotionally worth while. The foeman must be worthy of our steel, and the play must be fair to retain its flavor. Conflict and combination of emotions merge and find mixed expressions; for while the one emotion gains the day, the other modifies its triumph. Both leave a record in the expression, though this is too static or statuesque to embody more than a suggestive moment of the moving picture of emotionally guided conduct. Such combinations show a further variety according as each of the combining factors enhances the other, or as the issue reflects the tempered product of the whole. The joy of destruction may be a primary expression of combative aggressiveness, but it is completed by the self-assertion of victory, concentrated in the visible humiliation or suffering of the victim. Anger, gloating, and the pride of success, are cumulative in the expression of triumph. Cruelty is the yielding to its sway; vindictiveness is the same with a special motive. Scorn is a composite of combat and rejection; and the expression of hate varies as the components of anger, tempered by fear and modified by loathing, shift the emphasis of emotion and play of features. Jealousy arouses a warring conflict of emotion, typically when stirred by sex rivalry. The tender feeling may turn to resentment by transfer of the anger toward the rival to the object of devotion who shows him favor. In ironic laughter the anger goes out to the foe; the laughter is a derision of his pretensions.

There is thus brought forward the largest factor in emotional complication: the adjustment of coöperating and of conflicting impulse, the control of their interplay discriminatingly and prudently in the interests of purpose. 
This theme will presently be resumed, and in its completer perspective developed in the following chapter. There are now to be assembled and interpreted the collateral trends and processes that participate in the issue. Refinement proceeds by differentiation and specialization; the emotional life becomes rich by distinetion as well as by complication; and distinction is itself diverse and of varied implication in terms of the support which it requires of other phases of the psychic endowment. It is well to observe that in such development expression becomes more than a vent of impulse or a by-product of responsive trend; it assumes a socially serviceable part; the expression becomes more than a registry in that it is a notice. Attitudes of social import must be published and read-the reading as one runs. Hound and hare, eat and mouse have their antagonisms fixed by decree of nature; man to man may be friend or foe, as the expression decides. The dog barks because it is his nature to; but part of that nature is the gregarious habit in which barking, while no less serving for the outlet of emotional tension, serves to keep the pack together. Once thus established in its setting and associated with excitement, barking becomes a natural expression of excitement, dominantly a joyous one reflecting the chase, but ready to become the preliminary to biting, as that action, too, represents the possible outcome of the excitement. The growling bark of menace is differentiated from the gregarious belling; the baying strikes another tone and tempo; the howl of pain of a retreating dog still another; the incessant whine of the deserted pup is equally distinctive, and each is associated with specific bodily attitudes and emotional states. The differentiation has in part a gregarious source or reënforcement, as the challenge or the appeal of the voice is answered in like terms. Two principles thus appear even at the level of eanine expression: the one is the expansion and transfer of the expression from its original to a more generic situation of similar 
emotional quality; and the other is the play of social serv. ice in the process. The transfer of the expression is significant of the change of status which the emotion undergoes. It appears in canine psychology in that the "chase" bark of joyous excitement greets the returning master; the dog's capacity for human companionship is founded in his gregarious nature and in the individual habit which the gregarious pursuit established, of which the gregariousness consists. For human psychology the socially available expressions, reflecting socially serviceable emotions in the regulation of socially serviceable activities, are of peculiar moment. The bark of the dog, the caw of the crow, as auditory signals, the raised tail of the dog, the white spot appearing under the stubby tail of the deer, as visual signals, are primarily "gregarious" signals. The human expressions are far more than this; hence the need and the value of the term "social." They react upon the individual expression, modify it, and jointly with it carry the message to others as complexly as they relieve the impulses of self. Though we need not go so far in making human expression a social response as to assume that a Robinson Crusoe, deprived of the social motive, would lose his facial expressionability-even neglecting the inevitable absorption of the art in his formative days-we know that by its social service is expression matured. The blind smile, and the deaf laugh--proving the strength of impulse set in its natural course; but they fail to develop the rich facial and vocal repertory of the seeing and the hearing-proving the large range of acquisition through imitation. That the emotional development of blind and deaf is handicapped through deprivation of the social interplay thus furthered by the give and take expressionally assisted, can hardly be questioned. The cry of distress brings assistance, and the look of distress brings sympathy; human intercourse requires that we read as well as show intent and disposition. The socialization of emotion forms an integral phase of its 
career; its medium is in large part the socialized play of expression as a basis of human intercourse.

Differentiation involves intellectual distinction. The infant smiles and chuckles and waves its arms at the sight of food, when fondled or tossed or tickled, when splashing in the water, and presently at the sight of nurse or mother, or when amused or interested; the infant without marked discrimination scowls and frets and cries when hurt, when uncomfortable, when tired or hungry, when afraid or shy; and its emotional susceptibility (which presumably is no more fincly differentiated than its expressions) is elastic enough to be appeased by a sweet sip or a toy to banish fear or pain, much as maturer souls use other potations or diversions to drive dull care away. Recurrent exposure to similar situations, though it dulls the emotion, as custom stales, endows the response with the value of distinction and recognition, and gives to the expression a distinctive, familiar quality, the token of understanding. Yet the generic similarity of the expression makes it at times a dubious index of the extent to which distinction has gone. Until the command of language enters and decides, it is uncertain whether the eager smile and the brisk waving of arms greeting the return of the father after a brief absence-or the prancing of the dog greeting the master after a long one-indicates the pleasurable welcome of a sympathetic human being, or the recognition of the parent or master. We infer the recognition from the exuberance and the spontaneity and the specialized quality of the expression; we recognize that the tendency to express joy when sympathetically approached is by nature present in the infant and in the dog, but that the degree to which the emotion is aroused, the scope of the emotion itself, is determined by the values of experience. In the shaping of these values distinction plays its major rôle.

There is a fair agreement among comparative psychol- 
ogists that what nature provides is an instinctive yet plastic equipment, laden with useful tendencies to certain responses together with certain dispositions under emotional stress to release them; and that, once thus aroused, under slight repetition of experience, the instinct takes the set or bent of its direction and embraces the experienced object within the sphere of the reaction. Thus chicks have the "instinct" to follow; and if raised by hand, as Lloyd Morgan recounts, will follow the human foster-parent, and when thus accustomed pay no attention to the maternal advances of the hen. The instinet, having found its object (or range of objects) natural or unnatural, clings to it; here lies the organic basis of conservatism, and here the paramount significance of early experiences of attachments and repugnances alike. Chicks have no instinct to follow the hen; in nature as in the poultry-yard the hen is the natural object of the "following" instinct, as the hen by like nature is inclined to mother the brood. There is plasticity on both sides, and hens will mother ducklings, and dogs give suck to young lion-cubs. How far the instinct can be bent from its natural inclination is uncertain; the story of Romulus and Remus will presumably remain a myth. In the establishment of a habit the instinct expends its force; and the habit includes the fixation of the object. Thus instincts not originally specific readily become so, and give the appearance of being specific from the outset. Yet in the course of nature the adaptation of a certain range of objects to provoke certain ranges of reaction is marked, and in some cases specifically conditioned to insure urgent ends. Other instincts are by like nature plastic. The pecking instinct in chicks is their great experimental endowment; and their acceptances and rejections are partly ready-made, but largely acquired upon a very brief experience. Once stepping in water, they are tempted to drink, and learn it in a single lesson. When presented at an innocent age with such formidable 
objects as a caterpillar and a worm, chicks learn promptly -and in terms of sensations accurately reflected in the mimicry of expression-to shun the caterpillar and bolt the worm; yet for a time mock worms of bits of brown worsted aroused the same pecking and even swallowing reactions as did genuine worms; cigarette ashes and fragments of white of egg were confused; but knowledge soon came, and the wisdom of acceptance and rejection lingers. New associations are formed; old ones abandoned. Birds on remote uninhabited islands show no fear of man, but if disturbed soon learn to keep aloof; and the report and then the appearance of a gun or gun-like stick induces flight, and man as an object of fear is established. Taming or training toward or away from fear are all subject to association. To a young child a dog is an interesting object, arousing at once the fondling and fearing impulses; if snapped at, the fear impulses dominate, and dogs become objects to be feared. A parallel process obtains in extending food acceptances and rejections, where a primitive reference to sense at first decides. Despite the natural orders of preferences adapted to normal physiological needs, there is a large field for uncertain reactions and the caprices of appetite, in which a fortunate or unfortunate early experience with this or that food candidate may be decisive. Nonetheless, tastes are acquired and tastes change, and the spice of variety is sought, while childish tastes are often stubborn and capricious. Withal the instincts are dominantly conservative; new foods and dishes become objects of attention-interest, but also objects of suspicion. We fall back upon the security of the familiar, and cannot restrain our surprise or our disgust that foreign peoples should eat such queer things.

The definiteness of relation between the impulse and the object or range of objects which arouse and satisfy it is necessarily determined by the place of the impulse, by what it is to effect in the order of nature, a principle ap- 
plicable more specifically to the sensibilities, but with proper allowance to the emotions as well. If an organism had but one enemy to shun, but one rival to fight, but one source of food to seek, but one possible mate to court, but one monotonous environment to which to find adjustment, its fearing, fighting, feeding, courting, prowling impulses might be so rigidly fixed that but one situation would arouse each, and that at once recognized instinctively. For the mating impulse such limitation approaches the actual state of affairs; yet sexual susceptibility is promiscuous, though sexual selection operates. Such selection enters among the higher organisms, and in human kind reaches a baffling complexity, in the regulation of which eugenics and romance find equally ardent defenders, while the aloofness of race testifies to an organic recoil. Considered near their source-as we have just considered the food impulses-such impulses may be as specific as that of the young of mammalia seeking and sucking the maternal breast, yet in due course turning to other food under the more general impulse of curiosity. Yet appetite represents both a need and a selection; under severe stress men and animals will eat what they would otherwise refuse. Man's feeding is so omnivorous that his fare is far more largely a matter of education than of nature; yet the bond of appetite and suitable nutrition remains and is set by organization. In the emotionally regulated responses of courtship, for the man it is only the maiden, for the maiden only the man, who can arouse the distinctive emotional attraction that brings them together. Under stress of restricted opportunity the finer claims of selection give way. But with proper consideration of the full richness of the human sex-emotion, it is as true as significant that even for the susceptible youth, the qualifying maidens capable of arousing the culmination of falling in love at first or later sight, are limited in number. The play of forces determining the issue is-as is so generally true 
of the regulation and assertion of human instincts-artificial upon a natural basis, in terms of social, conventional, prudential, considerations. The point of present interest is that once the impulse has found the object, the object attaches to itself the full vitality of the impulse, and becomes its "be all" and "end all." Thus, as James observes, through the spur of appetite we establish our dietaries, through the spur of sociability we find our friends, and through the spur of sex our mates; and with them once foumd and established, we cannot understand that the established objects of these settled instinets can be other than they are, however tolerantly we observe the varied predilections and aversions of others.

The importance of this flexibility of relation will appear in the sequel. In tracing its psychological foundation, we may approach one step nearer to the conditioning process. The explicitness of the relation between the stimulus and the response, appears in the familiar fact that the cat is the ereature that the mouse fears and the dog fights; and for this end, each to the other, though with opposed reactions, is by nature an object of compelling interest. Apart from the mechanism by which the object gains access to the emotion, there is the broader condition of attentiveness as a prerequisite for the genesis of the emotional wave; and in the attraction of the object to the attention lies the germ of the intellectual life. Underlying the specific impulse is the general attention-attitude; nature provides and experience vastly extends the perspective of attentioninterest; the senses are its instruments and the pleasures its lures. Objects are questions before they become stimuli; they are inlets to attention-interest before or as they become inlets to fear, or love, or anger. They are disposed to arouse a response and thereupon an ardent and explicit one. Objects of indifference lie beyond the attentive pale [18]. In tentative exploration alertness of taking notice passes over to a concretely emotionalized atten- 
tion and then to an adjusted response. The result is (though with limitations incompletely explained), that a general timidity keeps the organism at a safe distance from all but the most familiar and adjusted objects, and a goneral curiosity attracts to a large range of possible desirable or engaging objects. Curiosity is the most positive and thus the more efficient; timidity is mainly the protective and cautious and conservative instinct. Curiosity becomes the great enlarger and extender and enhancer of experience; the mental, and with it the emotional, life will be the more complex as experience is wide. The susceptibility to the general shrinking conservative timidity, or to the like general venturesome curiosity constitutes a highly significant trait of character. Underlying both tendencies is the still more general one of attentiveness, interest, capacity to observe, alertness of mind, which stands as the natural incentive to the intellectual life. The ranges of such interests, their points of attachment and motive source, go far to shape the varieties of human quality and careers.

The service which distinction-the exemplar of the functions intellectual-performs for the development of emotion is parallel to but not the same as its service in the field of the sensibilities. For the latter it supplements and replaces impressionism by analysis ; for emotion it supplies the object, in the sense that it directs the finer adjustment by which stimuli presented as candidates are accepted, and assigned to service. As already set forth, it is the plasticity of bond between the emotionally inspired response and what shall arouse it, that summons the diagnostic service of "distinction." Where that bond is more rigid by dint of nature, the intellectual rôle retires, though it does not completely withdraw. Thus considered the child is the object, the stimulus to, and the recipient of, the mother's love; and the strength of the emotional susceptibility of this order-which, with the usual range of 
variations, all persons share-is indicated by the readiness and the warmth with which tender feelings are aroused by the presence of a child. Despite Solomonic judgments, which may be offset by the stories of changelings, there is no individual recognition by the maternal emotion of the particular object that in due course will arouse that emotion to an intensity, which no other substitute, however favored, will command. The mothering emotions are by nature strong; they are strongly aroused by the engaging helplessness of the very young child; the feeling extends to others' children so far as the appeal is not opposed by contrary emotional claims; it extends to pups and kittens; it extends to all the properties and associations of infancy - to everything that is tiny and "cute." By the principle of transfer, woman, thus sensitized, infuses all her ministrations with the flavor of the original emotion: her ministrations to men, her philanthropic and social endeavors. In shaping the course of the emotion, distinction enters to determine when that and not another phase of womanly nature shall be released. The state of being a mother, by like decree of nature, heightens these susceptibilities to their full intensity; they are organically keyed to a pitch which they cannot otherwise attain. But it is only the associational wealth conferred by the experiences of mothering the child that attaches the ardent emotion to the particular child as to no other.

It is in the careers of emotional impulses that are less specific that the play of distinction is larger and more characteristic of its central place in emotional development. For sensibilities and emotions alike distinction organizes the situations; it differentiates those that are to be shunned or sought, to be examined and reacted to thus or so. Nor should it be overlooked that in higher stages, the direction is subject to an element of control; we make friends easily when we give our sociable impulses free rein; we release our fears when distinction determines 
that the occasion warrants, and restrain them when the verdict is opposed; not that such yieldings are simply or wholly voluntary-any more than is falling in love-but that to the organic prompting is added, and more and more so in the higher acquired responses, the release of consent. Distinction and control, the intellect and the will, coöperate congenially in such service. Distinction assorts and fixes the objects upon which the varied range of impulses shall be exercised; and by such exercise the associational bond is strengthened, and the emotional complication proceeds as part of the general psychological development. The burnt child dreads the fire because the pain is vivid enough to fix the attention not vaguely upon things in general or upon future pain, but specifically upon the fire; which fear by instruction is directed to the stove, to the lamp, to matches, to insure the protection which only distinction can confer. But all this identifying, this comparing and contrasting, this detection of clews to situations, all this reading of meanings, in the actual confrontation with experience under the general stimulus of the attention-interest conferred by a catholic spirit of curiosity, quite inadequately describes the service of distinction in enlarging and directing the sphere of influence and operation of the emotional nature. It is the reinstatement of the emotional warmth of cumulative experiences representatively that inspires action, and enriches the meaning and the ardor of our responses. Distinction not merely supports the power to meet the situation when it is upon us, but anticipates it in imagination. When and only when thus exercised does emotion attain the full human stature. The sight of the child to its mother reinstates with a cumulative rush of reminiscence, a concentrated cluster of hopes, the endless longings, satisfactions, cares, reliefs, hopes, fears, attentions, which the child means and means emotionally. The enlarged and transferred power of emotion has its liabilities as well as its assets. The intellectual guidance or 
stimulation of the emotion may be extended unwisely or too well; the dread of anticipation may be worse than the pain of the ordeal; the sensitization of the fear impulse by the imagination may induce a general hampering or harassing timidity or an irrelevant, useless, or disordered one-as the prevalence of superstition and delusion abundantly illustrates. Fearing, thus intellectually encouraged, may ereate a terror of belief, arousing an excitement which only real dangers command by "natural right"; it replaces enemies by bogies. By compensation the imaginative mind anticipates and thus enjoys in twofold measure the joy of anticipation and of consummation; and in the fullness of its powers finds enduring pleasures in the world of ideals.

We have, however, been proceeding too rapidly. Retracing our steps we find a safe point of departure in the emotional life of animals. There may be simple orders of creatures, that pass their lives in unreflecting alternation of alarm, and security, a more or less vivid and constant alertness for danger (or opportunity), all furthered and operated by inner promptings and outer occasions, with no commentary of imagination, no deposit of memory complications, no extension of the mind to past or future-a wholly presentative, living-in-the-present existence. But for human psychology, at all events above the infantile stage, such an "out of sight, out of mind" mentality is far too rudimentary. It is true that the present remains absorbing, and that the representative types of mental operations like the prudence to which they lead, require special and prolonged training to give them worthy efficiency, whether in provisions for rainy days or in profit by past experience, or more generally, in the complex absorption, interpretation and control of experience as it comes. But for human standards the objects out of sight that remain in the mind enrich emotional experience and condition foresight. Emotion, to be sustained, requires an object; 
the explicitness of the object and its availability for mental procedure absorb and convey the explicitness of the emotion, at that stage released from too literal and narrow bondage to situation, and ready to develop with large strides to its complete psychic stature. The object, the moment of intellectual distinction and recognition, forms the psychological nucleus-the point of growth and attraction-of the experience. It does so largely for human nature by virtue of the representative qualities which it presents, the imaginative functions which it engages, yet engages in an emotional motivated course [19].

Illustration may still be serviceable. When a dog chases a squirrel up a tree, the squirrel is for the time a busily scampering creature, but no sooner reaches a place of safety than it "scolds" at the dog volubly, the violence of its expressions decreasing as the excitement wears away. The spasmodic "scolding" is apt to persist with puffs of renewed and then lowered intensity so long as the dog remains in sight, yet may occur although the dog is at once out of sight. The behavior is clearly an outlet of the exeitement of fear, an emotional surplusage bridging the regaining of composure; but it may be little or nothing more than that. The human observer, in sympathy with the flutter of excitement of the harassed creature, is apt to conceive the agitation as accompanied by the rehearsal of such representative incidents and items as accompany any narrow escape from danger on his own part. He would be haunted by the scene; he would be emotionally upset for days; and if the danger had occurred on the water, it might lead to a permanent dread of boating; the recollection would recur in waking thought and in dreams. A like critical experience directed to the future would be even more absorbing; anxiety would fill the approaching horizon with pictured terrors, ordeals, consequences. The squirrel a moment later resumes his busy scouring for food or mates as though dogs were unknown. Similarly 
his instinctive method of laying up stores for the future gives no hint of mental anxiety, or of restraint in the present in the interests of prudence. He buries nuts because he must, and domesticated goes through the motions on a carpeted floor and crowds nuts into a wholly impervious covering where they remain completely visible. In this mock burial-service, has lie any picture of the woods, and the leaf-and-mold strewn carpet, and the prospect of the wintry covering of snow? A needless assumption! The presentative and representative life are lived at different levels; the chasm that separates them or the bridge that unites them, we may be quite unable to discover. It suffices to recognize how largely, engrossedly, and inevitably, we live in both worlds; how they overlap and react upon one another, yet how the privilege of the representative life radically changes the tenor of all our presentative experience.

We thus lay bare the underlying process of emotional transformation: the intellectualization of emotional experiences-the quality that lifts it spontaneously and mightily to a loftier plane of operation. This alliance of emotion with intellect is a mutual interaction. Recognition gains in vividness and motive efficiency; emotion attaches itself tenaciously to the object, and in the object finds a renewed life. Such, at all events, are the careers of emotions not too closely tied to their physiological moorings. The capacity for expansion, the power to enter into the higher phases of the psychic responsiveness, to play a part in the shaping of human character, represents the privilege of the fully matured emotion-a privilege acquired intimately and largely by its intellectual affiliation and transformation. The susceptibility to sex-emotion is fixed in the organism; the comprehensive manner in which its highly evolved operations sensitize the entire emotional life is the issue of the influences whose course we have followed. The disposition to fall in love is both organic and generic; 
the implications of the process are specific and complicatedly psychological. Vague longings, perplexing disquietudes, and irregular bursts of impulse seemingly unrelated to the central motive may be stimulated by undercurrents and side currents of the adolescent transformation. Once an object of the emotion is found, it becomes the object, and magnetically attracts all the poetizing, romancing, idealizing tendencies that the intellectual, emotional and social maturing have for years been cumulatively preparing for the great passion. Indeed, so strongly is the object recognized as the primal cause, creator and unique author of the situation, that the emotional susceptibility is overlooked. Disillusionment is not pertinent. Presentative experience quickens the emotion; the touch, the glance, the kiss, the caress, the exchange of esteem and consideration strengthen the bond; but proverbially absence makes the heart grow fonder, and the representative moment, the longing, comes to its own again as the major factor of the state. Falling in love is a normal susceptibility; but what it means is determined by the sum total of the emotional, intellectual and social nature modified by the like forces of the molding environment. It may be of high, it may be of low degree-an incident or a transformation. And similarly for all the intellectualized emotions. Pain hurts but ceases when relief comes; grief broods and grows by reflection. Fear does not remain an indiscriminate timidity, but finds an outlet in wolves, snakes, fire, burglars, bandits, tramps; and we think and dream of these, and through such thoughts increase the emotions of terror when traveling on deserted roads or passing the night alone in a strange house. For the inlets to emotion the decisive factor in the complex as ordinarily established is the representative value of the object as the gathering point of the emotion. It is pictorial, persistent, recallable, extendable, associational; while emotional excitement wanes, subsides, and finds ri- 
vals in succeeding presentative experiences. Grief dies in consolation and resignation; joy mellows to content. For the emotionally regulated conduct, the decisive factor is the play of considerations which affect the quality of the emotion, as it arouses the several susceptibilities, which together constitute the endowment of temperament and the force of character.

The principle of "transfer," repeatedly encountered in the course of emotional development and peculiarly significant for the interpretation of expression, requires special consideration by virtue of its diversified applications. The principle is fundamentally unitary. It indicates that an impulse or its quality, bred and fostered in one relation and a more primary one, is carried over with altered play to another and more derivative sphere-a transfer of service or function. But the principle acquires a different bearing as the nature of the transferred service engages varied psychological processes and products. The principle is related to the more general one that we use a sensory endowment or other psychic equipment for more than its original service. Having the sense of hearing as a warning and a social bond, we build upon hearing language and music. More generally, an attitude, an inclination, a disposition, a form of responsiveness, originating dominantly in one situation, nurtured in one phase of human nature, is transferred to others. Because of the necessary and useful place of distinction in the practical guidance of conduct, there comes to be an eagerness for the perception of relations for their own sake, a joy of discovery, a keen pursuit of acquired purposes. Subjectively, because of the interest fostered by the attention fundamental to the incorporation of experience, there is developed a general avidity in the welcoming of new experience, an intellectual curiosity, a zest of enterprise, a spirit of inquiry and venture. In the elaborated situations we lean upon the invitation of the earlier ones, use the primary momentum for 
our transferred employments. Because natural situations set problems simple or complex, the mind thus stimulated matures a problem-solving interest, which, transferred to other fields and larger ones, makes the scientific habit. In the incidental allurement attaching to the surplus of sensory stimulation lies the potency of the esthetic nature and ultimately the achievements of the arts. By virtue of the original emotional appeal of the voice, man comes to have music in his soul. The interest, the pleasure, and the utilization of experience extend beyond the moment; the imagination thus fostered functions for its own sake; poetry, myth, and the creative drama result.

To continue in another direction: because the relations within the family as well as the pursuits of courtship sensitize the individual to the esteem of others, that sensitiveness is available as a social force. It influences ambition, the code of honor, the social rewards and punishments, public opinion. But in this, as in many another illustration, the principle is already involved in the complications of other tendencies, so that the transferred quality is of a different order and is but partially and uncertainly an example of transfer. It is no longer a transfer so much as the modeling of attitude and response upon a design, a psychological pattern of similar motive. A sensory shrinking becomes an embarrassed shyness; a direct aversion of a sensory order leads to a complex fear in which the original shrinking is at once incorporated, transferred and remodeled; and the presentative fear thus complicated in turn develops to a representative dread of ever broadening scope. Neglecting these finer distinctions, we may summarize that gregariousness as a feeling of adjustment leads to sociability as a trait of character; passion anchored in sex-attraction makes for ardor of pursuit and of devotion; self-assertion reared in primitive circumstances matures in courage, in pride, and, it may be, in affectation or idiosyncrasy; self-seeking aggrandize- 
ment develops love of property and the hoarding instincts; the sympathy and dependence nurtured in the family relation, prepares the individual to be generally sympathetic, ultimately altruistically so. Nor is the transferred service of a simple origin; it reflects its composite source. The fondness for sensory stimulation leads to fondness for stimulation in general-a sensationalism, superficial or profound, supported dominantly by the emotional or by the intelleetual nature. Play in one development leads to experimental exploring and to sport in another; both combine with other primary trends in the resulting transformation. Aversion may be so tempered as to lead to anger, and anger so directed as to become moral indignation. The ugly, the base, the false are in some aspects transferred reactions from the repugnant, the nasty. Morality - a product of "transfer," and a highgrade systematic embodiment of restraints-derives its vitality widely from fear of consequences, from fastidious aversion, from desire to retain the esteem of others. Indeed the resistance of temptation requires all the safeguards afforded by our composite nature. The moral life is the clean life, the honest life, the considerate life, the sympathetic life, the sensitive life, the life regulated by standards and ideals; its sources are as diverse as its expressions.

The principle of transfer as embodied in expression affords a conerete and a pictorial rendering of its values. The expression, typical of the evolution of which it is an integral part, preserves the original attitude, but with an added and specialized nuance, giving it a more distinctive meaning adequate to the transferred employment. The transfer, however, must be congenial ; for in the emotional congeniality lies its being and justification. The signs of grief are not merely similar to the signs of pain with the similarity of a common vitally depressive tone; a smile of sensory gratification and one of amusement are not merely 
set in a common medium of vitally exhilarating tone; but the grief expression is the pain expression, the amusement expression is the expression of a more primary gratification, draughted to another service and an ampler one; and they are thus enlisted, thus qualified, because of the congeniality of pain and grief, of physical pleasure and mental joy. The psychic orders of responses of the higher range find the expressional channels set, the available muscles preëmpted by the expressions of direct import, and can but turn them to their own uses. Tears served pain before they served grief. Though grief is pain or of close kin, it is other than pain in that it is open to the larger complication, the alliance with other and related emotions, the suffusion by intellectual memories, the vast enlargement of representative elaboration. Parting is such sweet sorrow because it is retrospective and prospective at once. The expression follows, but in its limitations cannot be expected to do more than suggest to a sympathetic and delicately sensitive recipient the sway of emotional complication thus coming forward in the sensitive face. The portrayal of emotion discloses the limitations of even the elaborate literary arts, despite the insight of the poet and the mastery of explicit utterance; it may be more sincerely reflected in the emotional medium of music; it sets a problem to the trained powers and natural sympathies of the actor. The reference to spoken language invites the application of the principle of transfer to the psychological processes of which words and phrases are the products. The mental operations are of one genius; they may be traced in language as in other human products of like order. Language is an artificial expression upon a natural basis. As now exercised, the natural basis has retired to a slight place, and artificiality dominates. Yet such psychological artificiality means that the product follows the psychological lines of development of an acquired order but modeled upon a natural pattern. In the verbal em- 
bodiment of the mental processes the principle of transfer is recognized as metaphor; carried out more explicitly as an avowed comparison, it becomes a simile; when in terms of relations and resemblances of a more indirect order, it becomes an analogy. Generalized it appears in the tendency to use words and phrases figuratively, not literally. Employing the familiar terms, we may say that grief is metaphorical pain, and amusement metaphorical gratification. A garish combination of colors hurts, but less literally than a bruised finger. The expression of the physical pain more delicately rendered is the metaphorical expression of the esthetic pain; the same expression more refined, and blended with other equally derivative miens, reflects the pain of hurt feelings. There is an intermediate product of the same tendencies similarly exercised, not so close to the natural patterns as the mimiery of the faee, and not so remote as the artifices of phrase-the language of gesture. Gesture is richly metaphorical; and its metaphors span the entire range from natural associative motor outlets to conventionalized, figurative allusions. Facial gesture partieipates in the composite issue. For, closely considered, the allalogy of facial miens, of gesture, and of words is something more than an analogy; it is the evidence of a like mental and emotional functioning, a common psychologieal habit of thinking in symbols and relations, and particularly in terms of similar or allied emotional qualities or effects. I cough literally to remove a physiological obstruction; I clear my throat nervously to get rid of a psychological embarrassment. When I seratch my head when puzzled, I use the reaction to a physical irritation to express a mental one. The metaphor of speech and of facial gesture agree: I say that so-and-so's behavior makes me "sick" or "tired"; and as I say it, my face assumes the motor contractions of incipient stages of the nausea which I feel morally but express physically. A figure of speech may reflect an organic analogy. 
Such metaphorical expressions are plainly of the same order as the metaphors of gesture-the strutting like a peacock when making a fine drive at golf, a witty speech, or a lucky hit on 'change. The situations which use the expressions fixed and made significant in a more natural setting, are themselves but one or more removes away from the primary occasions of similar emotions. The analogy may be strongly intellectualized; but typically it proceeds upon a common emotional affect. Many of the developed expressions are imperfectly, if at all, provided for in the natural situations; these artificial gestures, though devised, are framed upon natural patterns. The metaphorical habit has taken its set, and continues to enlarge its resources by playing upon the complex and derived as upon the simpler orders of situation. The expression itself may thus show transfer. When annoyed at my own forgetfulness or stupidity, I punch myself, and say that I feel like kicking myself; in so doing, I not only transfer a physical act of resentment to a moral situation, but I treat myself as I might a remiss inferior. In the eruder days of frontierdom, under the provocation of insult, the hand reached as naturally for the hip-pocket, as in boyish encounters it forms a menacing fist. Why shrugging the shoulders indicates a state of enigmatic doubt, is not easy to determine; but it is an acquired gesture, equivalent to the slang: "You may search me." Metaphor may be formed upon crude and coarse or upon delicate and refined models; and as employed in words and gesture alike, it forms a test of manners, for it is a manner of psychological expression. Characteristically, the figurative expressions tend toward the refined, transferred expressions because they so largely are used in the transfer of physical to mental and moral situations; the guffaw and side-splitting laugh is aroused by horseplay; the smile is the fit appreciation of wit, the play of ideas. The contortions of disgust are appropriate to the strongly repulsive physical situation; the delicate play 
of disdain to the moral offenses. So natural has it become to treat mental situations after the pattern of physical ones, figurative after the manner of literal ones, that without this habit expression would fall short of its full value for individual revelation and for social ends. The writer at a loss for a phrase looks to the ceiling, or half-closes his eyes with his finger placed reflectively upon his forehead, as though the object of search had a physical habitat or would yield to an inner directed vision. In social intercourse the expressions of surprise, sympathy, interest, amusement, approval, dissent, similarly accompany imagined or related incidents, and give vitality and animation to the context of words. The expressional commentary is indispensable and particularly so in supplying the emotional key to conversation and intercourse.

Without stopping to point out the varieties of the embodiment of such metaphor in words and phrases, we may observe that they are often descriptive of actual miens and gestures. When I say that I wink at slighter offenses, find myself on the wrong scent, turn a cold shoulder to such a proposal, or turm up my nose at it, or hang my head, not daring to show my face, fight shy of debt, harden my heart or set my teeth to refuse an appeal, receive another proposal with open arms, or snap my fingers at it, or let it slip through my fingers, or find that I have inadvertently put my foot into it, I am using expressions referring to more or less usual and obvious (in part gestural) situations-some natural and others more artificial-analogous to the transformed mental or moral situations to which I appropriately apply them. Such appropriateness lies in the fact that the feelings which I now experience under the figurative situation, are best indicated by citing the expressions that have a more literal bearing and a familiarity of association with literal situations; the similarity is one of application, sympathy, or mood. By larger appeal to the imagination, and by a larger recourse to the artificial 
situations for my figure of speech-created and provided by the intricacies of my civilized and complicated life and onriched by conventional and literary traditions-I enlarge the field of metaphor and with it the range of emotional analogy. I say that I can turn so-and-so around my finger; that all this is merely a flourish of trumpets, or a device to see which way the wind blows; that I feel the ground slipping from under my feet; that I propose to bury the hatchet; am prepared to eat humble pie; to eatch at a straw; to throw off the mask; to get off my high horse; to make my opponent swallow his words; to turn over a new leaf; no longer to blow hot and cold; to stick to my guns. The very danger of mixing metaphors points to the variety of ways in which an analogy of emotion or situation carries over from the literal to the figurative, the real to the imaginary, the pictorial to the abstract, the presentative to the representative.

The central place of emotion in the sources of human quality is the theme of this chapter. The approach to it through the gateway of analysis leads to a survey of the volutionary forces in their natural and then in their more artificial setting. With this basis established, it becomes possible to summarize traits of temperament and character as the composite susceptibility to the different ranges and types of emotion thus surveyed. Emotional normality means a normal sway of the common fundamental emotional appeals; it implies also a normal susceptibility to the expansion of such motives in the secondary derivative play of emotion in the psychic maturing. But along with this common factor in normal endowment, each individual conformity involves a variable play both of the fundamental appeals and of the secondary modifications. The emotional sensibility is variously distributed, and particularly so among the second-growth products conspicuous in the familiar contours of character. Levels of complication thus mature; the ability to attain them, the mode 
of their partial attainment, constitute the emotional measure of the man. In such development the force of primary emotions-by their nature adjusted to meet the urgent primitive demands-seems to retire, and in proportion actually retires, as the secondary transferred varieties of emotional traits assert their claims and their acquired right to prevail. The altered environment favors and demands an altered perspective of emotional regulation. The indirection and enrichment of the emotional life is due largely to the intervention of the intellect and to the reconstruction of the social structure, which furnish the medium of its expression. This development and its consummation in the actual psychological perspective under which we contemplate the vicissitudes of human nature require an independent presentation.

The division between the simpler, earlier, more primitive emotional regulations of conduct and the higher phases of psychic regulation-the subject of the following chapter-is one of convenience only. A unitary evolutionary process combines the two presentations in a common theme. The present chapter supplies the principles of procedure, the analytic argument, the illustrations of the processes involved. It may be well to utilize this point of arrest for a summary of the conclusions by making the individual application, though such summary in a measure anticipates the further stages of analysis. In its larger foundation my emotional susceptibility is set by (1) my momentary, periodic and chronic organic state; (2) by the particular strength of the instinctive response concerned; (3) by the intrinsic nature and acquired appeal of the stimulus or incentive; (4) by the modifications and reconstructions of these conditioning factors through acquired setting and training; while (5) the manner of expressing the susceptibility is also and similarly significant. These conditioning factors have a markedly different play according to the status of the emotion-inducing situation; 
to its closeness or remoteness from the natural, and in that regression from an imperative, situation.

These conditions are to be considered first in the primary emotional responses, in the near-to-nature situations. The organic state underlies the emotional susceptibility broadly and generally as well as finely and specifically. The sexual emotions reach their climax of intensity when the organic invitation is at the full; falling in love is a predisposition as wcll as a disposition of youth. Moreover it is in the springtime that a young man's fancy thus turns. The ages of man are differentiated organically, to begin with, by the varied strength of appeal of instinctive emotions maturing to varied needs. Night thoughts are characterized by the emotional tinge-an organic disposition to the periodic ehanges of nature. Hunger predisposes to sullenness and irritability, makes it difficult for the contrary emotions to be aroused. It is hardly prudent to ask favors of a man before breakfast; and a good dinner is a strategical preparation to induce an indulgent mood-not of itself adequate, but yet a promising diplomatic step. Applied to animal behavior, it is proverbially unwise to interfere with a feeding dog. It was in part in the defense of his share of the quarry that the dog's pugnacious instincts were kept at keen edge; it is under the like situation that they are predisposed to pugnacity, even to the snapping at his master or friends, whose attentions under ordinary situations would arouse his acquired submissive or friendly impulses. The ancestral impulse remains even though the bone comes from the butcher shop and is placed on the dog's "own" plate. Similarly at the zoological gardens, though a regular feeding-time has replaced the food-quest of the great predatory beasts, a restless roar and eager excitement daily attend the keeper's meat-cart, and the daily ration is pounced upon with an intensity that may well be an organic reverberation, as to our imaginative eyes it is a rehearsal of an exciting 
jungle-scene. We know from animal psychology how marked is the altered emotional stress in the mother when attending to or defending her helpless young; the motherstate with its vast organic radiations develops a comprehensive emotional complex. Transferred to the human kind, the infusion of the developed psychic considerations and the transformation of the instinct by emotional enrichment make the mother relation a different "situation" indeed, but not for that reason released from its organic source and original assets and liabilities. Not all emotional reactions are so deeply set in condition or associated with so specific a range of activities. For the most part human emotion takes its set from the plastic ranges of the supporting emotions, from their more playful and generically serviceable rôles in advancing the interests of investigation, intercourse, the enlargement of interests and experience-in brief, from the open highways of accessory, subsidiary, derived, and acquired service of activity that forms the mental life of man. Though these fruits of the psychic tree are more cultivated and their flavors more appealing to our schooled appetites, they were gained by grafting upon the natural growth the selected products of our preferences; their vitality is derived from a common source. Above all are the expansion of intelligence and the refined system of preferences introduced by the maturing of the esthetic nature-both in a sense the issues of the leisurely, luxurious activities, from urgency released-responsible for the complexity of human psychology and the perplexities of the art of living and the finer differentiations of human character. Yet even at the level at which these influences operate is the release of emotion affected by the conditioning fluctuations of organic welfare. Vigorous aggressive health confers an eager selfassertion, a tone of venture and optimism, available for whatever action makes the stronger appeal, for good or evil as the native bent decides; the depression of ailment 
rakes for weak endeavor, submission, yet may also open ne restraints imposed by sympathy that have slight hance to be heard when all is well and the zest of life revails.

The Devil was sick-the Devil a saint would be; The Devil was well-the devil a saint was he.

et in this respect also a normal susceptibility is stablished in which the fluctuations recede under ordiary circumstances to a state of adjusted composure. The egularity of such condition determines moodiness, as the andard tone of the equilibrium disposes to elation or deression, inclines by temperament and the superimposed t of eharacter to irritability or serenity, to indulgence r severity, to sociability or seclusion, to sobriety or ivolity, to content or discontent. The individual suseptibility is the composite of them all; in it lie the jurces of character and temperament. 


\section{CHAPTER IV}

THE HIGHER STAGES OF PSYCHIC CONTROL

IN the ascent to a height the perspective of view changes there is a shifting of the approaching foreground in the higher levels, and of the receding background in the lowe ones; there is a redistribution of points and areas of fixa tion, resulting in an altered emphasis, a transformatior of relations and values. Yet the natural features are con tinuous, and at the higher level are determined by the un derlying structure. In like manner the conditioning sources of human qualities assert their potency in anc through the complications of their matured products Mental evolution may be profitably conceived as an ele vation and complication of the processes-a shifting o: perspective-in the several components, by which the in dividual regulates his responses and acquires a contro. of, even as he achieves an adjustment to, his environment At first largely under the sway of the physical situation his means of adjustment and control are found in the pro tective and useful instincts and impulses of his physio logical organism. The infusion of the psychical is never absent and grows rapidly until it dominates. Intellect emotion, will-explicit understanding as well as strong im. pulse and regulated desire-secure the ends of life; the by-product of the earlier stages becomes the central pur. pose of the later ones. The higher stages of the psychic control which characterize the life of organized humanity above the most primary condition involve no radical de partures from the bent of original nature, do not dispense with the instruments of adjustment that constitute the measure of a man in however early an estate. They con. 
tinue these, enlarge them, reconstruct their application, refine their employment. It is the higher stages of psychic control that stand close to our practical interests and furnish the interpretation to the life of mind as we live it.

The original psychic equipment of man has presumably changed but little. Primeval man felt, saw and heard, feared and trembled, rejoiced and laughed, grieved and wept, loved and hated, remembered and imagined, com. pared and distinguished, reasoned, desired, planned, and acted quite as humanly, with the same complement of essential endowment, as his remote, cultivated, sophisticated, and schooled descendant. The bases and occasions for the employment of this range of qualities were shaped and fixed in the many generations of primitive human, even prehuman existence. Unmistakably the scope and the manner and the quality and the proficiency of these operations have decidedly and decisively altered; above all the intellectual horizon has vastly expanded and been redisposed; but the original predispositions remain consistently operative and now as of old dominate human nature. In the present mature outlook there is a foreshortening of remote beginnings where the great roots of vital trends lie, and a disproportionate enlargement of the nearer prospect where acquaintance, interest, and the vitality of experience sharpen details and enhance values. The race and the individual live in the shifting present-the moment of the outlook-and perceive the components of the psychological topography from that engaging position retrospectively and prospectively. The complement and correction of the resulting perspective are the functions of science, which, in such measure as it succeeds, yields an appreciative understanding of the past, a sympathetic interpretation of the present, a serviceable guide to the future.

Attention is to be focused upon two momentous transmuting processes acting upon instinctive dispositions, as 
yet considered in their initial bearings only. The one is the increasing infusion of action with the intellectual quality of distinction, leading to the dominance of reason in a large realm of human activities; the other is the complication of motives, measures and expressions, by virtue of their setting in an inherent social disposition-the complication shaped and favored by the expansion of the social enviromment. There are no accredited terms to designate these processes; they will be referred to as socialization and intellectualization. Socialization refers to the aggregate and mutual influences upon instincts, emotions, ideas, desires, and actions, of the play of like processes in another, and in naturally and conventionally organized groups of "others"-mates, companions, family, clan, tribe, nation, class, society. It refers also to the contribution of these relations to the reconstruction of the human environment and its reflex effect upon the expansion of human qualities. It would be misleading to imply that the distinctive psychological functions first came into being and were then socialized; the consideration of the involved processes in their natural setting discloses the sideby-side origin and coördinate growth of the individual and the social nature. Species and races compete and survive not as individuals alone but as groups; their grouptraits are the social traits of the constituent individuals. But self-preservation is rooted so firmly in the survival motive of natural function, is so insistent and pervasive in its demands, that it shapes and establishes the play of instinct and impulse. It rules by primacy of natural right where the elemental demands of psychic regulation are strong and deep. It occupies and organizes the psychic domain, so that the deferred and gradually maturing instincts and the issues of their growth must make terms with, and find adjustment to, the claims of the established settlement [1]. The terms individual and social represent an emphasis in direction of function primarily, in which 
the precedence of the former for the molding of the latter is unquestioned. The type of responsiveness from which these terms derive their meaning is for human kind not a detached or non-social one; yet the self-seeking trend dominates moderately or immoderately, even though it employs the social medium for its expression. The "social" responsiveness is at its source a one-sided dependency inherent in the "family" relation, of which the nursing infant presents a typical picture. Such dependency makes for social ties. The incubated chick, pecking its way out of the shell, might be forced to lead a hermit life, devoid of occasion for such social impulses as its inheritance favors; but the young of mankind is both fated and privileged to a prolonged dependent infancy-to a slow acquisition of powers following upon a ripening of impulses, and giving wide scope to the plasticity of individual promptings, and a large field for the reflexive socializing influences. The responses of play-the typical activity of the young-provide the great playground of interaction, rivalry, incentive, and coöperation; for the "play" order of responsiveness is clearly one in which what one feels and does responds to the feeling and doing of another. Neglecting the instinctive blindness of the impulse, we may conceive that the kitten's strategic pursuit of a string or of its own tail, the dog's seizure and punishment of an old shoe, poses the object as a reacting one, the player ignoring that the impulse of escape is supplied by the pursuer. Play spontaneously creates the "other" relation; its "give and take" reflects a social responsiveness. Analogous to this play of kitten or pup, but of a higher order, is the play of the child [2]. When playing alone, the child plays with the imagination as much as with the toys; the child personifies and projects the contrareactions to which the responses in propria persona constitute the play. Yet self-expression is dominant, though it requires a complementary presence for its fullness of development. The 
more mature child, like the adult, sets himself tasks and problems, and finds a spur in surmounting difficulties, a thrill in their successful overeoming-all of it a reaction to and mastery of conditions paralleling the eneounter with individuals of his own kind. Yet no play or work with things can replace the richness of psychological interaction which playing and working with other human beings provide. The projections of one's own intentions upon others, the discovery of like motives in others, the adjustment of the two, constitute the play as well as the maturing of the psychological endowment. An aneient evidence of the strength of the habit of self-projection, stimulated by the like feelings produced in the presence of forees as of persons of superior power, is the interpretation of the forces of nature as personalized beings acting with human motives, which appears so generally in early "psychology" and represents its inevitable anthropomorphic tendency. It finds varied expression in primitive cults in the personification of wind and storm, of sun and moon, of grove and stream, of sea and mountain, of cliff and cave, of eclipse and earthquake, no less than in the humanized representations of the virtues, vices, graces, ideals of men. It appears in the ascription of human qualities to animals, from Esop to Brer Rabbit. The environment, animate and inanimate, which man confronts, is looked upon as moved by the same desires and intentions as shape his own attitudes and conduct in the social and competitive relations with his kind. The traits developed and grown strong in primary situations, matured in primitive human intercourse, continue to direct later and more complex types of response. They are considerably modified by the stress of adjustment to a changing environment, and are thus transferred in later stages to express acquired interests and meet artificial situations. Outgrowing the old incentives, yet under their prompting, man finds and makes new ones conforming in large 
measure to the older patterns of behavior and interest. The early interpretation of external nature, called animistic, follows the clew of man's conscious experience, and projects its findings to other realms; quite as naturally the traits developed in a primitive social setting are transferred to situations of large complexity, presenting analogous stimuli, and met, however tentatively and imperfectly, by like responsive trends.

By reason of its commanding place in the formation of character, the socializing process must be subjected to a psychological analysis of its stages and development. In an early and distinctive stage, the socialization represents the complement of individual function through a social expansion, much as reaction in general requires an environment that provides incentives and occasions as well as media of response. The fact that each individual grows up with others interweaves the individual development with the products of social interaction. The growth of each acts upon, as it is acted upon by, the growth of others. Children gravitate to play with other children of like level of development; while yet other ranges of social response are appealed to in play with younger children and with their elders. Such reactions are not imposed upon the young, though a strong element of suggestion and even sompulsion exists; in the main they proceed upon the principle that by original nature the presence of the kin and kind is a natural inlet disposing maturing instincts to response. Yet the response is never passively to the bare presence of another, but is aroused by the engaging interest of varied vital movements. The infant smiles to my smile or call or antic receptively, in so far as I tap the natural incentives to its satisfactions; but soon it responds expressively with a measure of recognition and expectation. As intelligence develops and command of endowment ensues, the child becomes responsive in a world of responsive beings who provide the situations inviting to 
its incentives and to the satisfaction of its needs. The human individual lives and matures in the medium of a socialized responsiveness. The social setting operative in the formative period fixes and favors the social disposition, gives a set to the expression of impulse; the fact that such impulse embodies the inherent gregariousness of the species reënforces the social trend. The foundations for social development are laid deep in human nature; the large capacity for the expansion of the social-psychological responsiveness reveals the sturdiness of the social roots.

The implications of "sociality" are drawn so largely from the contemplation of its mature, high-level, artificial products-and from certain limited friendly aspects of these-as to obscure the broader psychological conception indispensable to analysis. The reasons for this usage are adequate: the term takes its meaning from the practical range of exercises of the quality; the commanding interests lie in that realm; and sociality is a growth that sprouts luxuriously at its upper branches. As we are now prepared to follow the higher stages of psychic regulation, we shall for the most part adopt the practical perspective, without ignoring the early stages of sociality. Such consideration returus to the primary ranges of emotioninstincts and their original situations. The food-quest is a selfish struggle, a concern for number one, and remains so, whatever the means by which it is carried on, until discipline or altruism tempers its quality. That the raising of the young has a gregarious setting and presents a dependency upon material ministrations, surrounds the early appearing instincts with a favorable social atmosphere, but does not divert them from their central trends. With several in a brood or litter, the social phase of competition and conjoint response presumably shapes early development more decisively than when the relation is with the mother alone. It is, however, the higher phases of psychic 
regulation that concern us; and these assume a fairly matured and independent basis of conduct. In human psychology such a stage is still an early one; for the social trends of impulses sets them to social satisfactions. In the human setting the forces with which they contend, the influences which they meet, are themselves of a psychological order. Persons and their behavior constitute the preferred inlets to the attention-interest from which all but the simplest emotional reactions emerge. The instincts thus pointed to a social-psychological stimulus respond upon the basis of a gregarious susceptibility. When the social aspect of the response dominates, it implies well developed psychic capacity.

If we accept jealousy as a type of such "social" emotion, then the possibility of jealousy implies something more than the intensifying of the bare impulse to contend and compete. Jealousy grows out of rivalry, and rivalry is enforced by the subsidiary attitudes growing out of the competitive struggle for existence and out of the finer contest for fuller existence. Jealousy is a social product of the relations of the competitors. The reactions to which it leads are closely similar to those prompted by selfcentered desire alone. The added quality lies in the psychic diffusion of the emotion, the quality of the diffusion determined by the social nature of the re-agent. It can be inferred only from the incidents and manner of the response. Though we interpret jealousy as liberally as possible, we cannot expect evidences of its action among animals until the response attains an individual expression and a fair emotional range, of which the capacity for domestication may be an index, while a natural gregariousness may also be a favoring disposition. It is possible that the natural rivalry of dogs hunting in a pack, or of seals contending for mastery of the females in the rookery, is itself adequate to develop a relation upon which jealousy is readily grafted; yet the contest may proceed upon 
the "individual" impulse alone. The quality seems to emerge more assertively under association with man. In the bidding for favor of the master-in the transferred situation-an older dog regains the sprightliness of his youth; the dormant incentive revives under an increased and ancestral stimulus, and develops a modified attitude toward the rival. When trained seals behave in a jealous manner when punished by exclusion from their "parts," the thwarted hope of food and petting may still be the assertive factor, though the indication of other factors is strong; and if seemingly reliable accounts may be credited, the elephant carries jealousy to the point of vengeance.

The assignment of the place of "leader" among dogs drawing the sledges in Arctic expeditions stimulates responsive attitudes of the jealousy type; the dogs seemingly insist upon their acquired places, and contend for mastery almost as fiercely as the older bulls among seals for the dominion of the harem. The gregarious setting of the lives of these animals may be an important factor in all such developments. In the behavior of children the emotion of jealousy and the growing occasions of its provocation are prominent, while the "pre-jealousy" indications of direct self-seeking retain their primitive strength. Children want things for the satisfaction of their own desires; but they want them much more when others want them or have them, and sometimes only then. Quite apart from the influence of suggestion, the "social" jealousy sets the spurs to desire. To grant a privilege to one child quickens in others a desire for the same favor; emulation becomes a social instrument of individual discipline. It is readily so utilized because its native appeal is strong. "Thou shalt not covet" is included among the primary injunctions of the moral code because coveting is the issue of deeply natural traits, and forms a stubborn obstacle which the individual trend of an instinct places in the way of a social-sympathetic ideal. The behavior of both ani- 
mal and child conforms to the rather neutral psychological description that what one feels and does is affected by the feeling and doing of another. The childish jealousy is clearly open to a far larger range of psychic influence than the animal variety. The more the privileged child gloats and displays its triumph, the keener the envy of the rest; the tendency to gloat and to display is itself part of the complication and of the social complication. It ministers to self-assertion-an individual trait; but the selfassertion is feeble and incomplete in its satisfaction until reënforced by the "social" evidence of the envy of others. The individual reward of competitive assertion is possession and enjoyment, and this may set the limit of attainment of animal response; the social reward is triumph and by further social expansion, the visible discomfiture or deference of the dispossessed. The prominence of the induced satisfactions in the complex indicates the elevation of the whole. The rank assertion of the secondary satisfaction above such justification as the primary motive may attain, becomes the anti-social vice of cruelty, its fuller consummation appearing in revenge. It is indeed a growth of higher level, the primary motive being all-sufficient for primary regulation. The eat playing with a mouse is by decree of its limited mentality a tyro in cruelty [3] compared to the expert capacity for torture to which human depravity may attain. Jealousy-and, with reservations, its derivative trends just noted-is strong in children because it is sirong in the race; and cruelty may be similarly favored. This means that the social-psychological nature of man makes human competitors jealous and vengeful. The sympathy which is counted upon to offset its hold is a slighter and later growth. In the neutral psychological sense, jealousy is as distinctly social as sympathy; for in its scientific use, "social" designates the play of a certain range of influences upon the expression of a trait, and disclaims appraisal of its positive or nega- 
tive value in the system of purposes cherished by society, without denying the trait a place in such system. The childish jealousy is ready because of the child's ready dis. position to a social response by virtue of a gregarious trend. The social aspect of jealousy is distinctive in that the emotion arises only through the (social) presence of another; its stimulus is the other. The emotion stirred by the "jealousy" situation rises in complexity with the complications of desire and the intellectual and emotional capacities. It finds its expressions in the rivalries of sport, in the competitions for preferment, and keenest of all because then animated by the richness of vitally social and fully matured instincts of the race, in the rivalry for mates. It is aggressive in tone, affiliating with anger and attack, but affiliates as congenially with the indirect intellectual weapons of intrigue, strategy, and the wound and hurt of malice and slander. Thus anchored in an urgent instinctive need, and capable of a vast social expansion, jealousy remains one of the strongest motives of human action, and offers a problem in the higher phases of regulation through all levels of social organization [4].

The conception which leads to the view of jealousy as a typical social efflorescence of the self-assertive trends, combining their primary values and giving them a wider career, requires a parallel socialized expression of the opposite trends-the self-withdrawing tendency, leading to fear and flight or similar response in the primary situations. Such a "retreating" smotion aroused only by the presence of the suitable "other," is shyness. This shrinking from human presence and contact is a familiar trait of infancy and childhood; it is close to fear, as is jealousy to anger, and seemingly closer because of the more obvious similarity of response. In children, as well as in animals, it is rather capriciously exercised. The protective instinct leading the child to shun strange contacts is of a piece with the gregarious nature that leads it to welcome familiar 
ones. We may suppose that the young of primitive humanity were exposed, if momentarily deserted, to the attacks of an approaching enemy in human or animal form. In such a situation the tendency to emit a cry of alarm and to run for protection to the mother would be a useful one. The shrinking child would be protected, while an indifference or friendliness to strange contacts would be perilous. Yet the temperamental shyness may be part of a weak self-assertiveness, which in other and later situations may be detrimental. Obviously the status of a quality, as well as the interaction and rivalry of qualities, is affected by their social complications; the individual survives and competes with the sum total of instinctive traits which nature transmits and matures. The career of each trait is influenced by the integrated career of all. In all but very young children the "shyness" is more than a bare organic shrinking; it is already set in a budding emotional complex; in its wayward and conflicting expression, it behaves after the manner of an ancestral habit somewhat at a loss to discern its proper occasion. Shyness is a persistent and enduring trait; its complications expand with the several distinctive relations and situations which the social nature of man imposes. Most distinctive is its adolescent type, which is in essence a new and differently occasioned variety. The shyness of adolescence is an aggravated and a richer form, readily grafted upon the general temperamental shyness, but like the jealousy that arises in the same situation, with an added range of motive and expression. Thus heightened and specialized in the sex relation, the shyness in the expression of social intercourse seems almost a transferred product of the former. It assumes yet another distinctive form in the alarm and embarrassment of a public appearance; its dimensions in that relation entitle it to the name of fright; yet the reasoned fear of breakdown which the imagination summons to justify the terror is often pale by con- 
trast with the organically motived emotional upset. In the more simple forms of shyness simpler principles are operative. The conflict of motive is apparent; in the objective relation it is a conflict between fear and fascination, between a prudential withdrawal or a curiosity-satisfying exploration. Natural curiosity and a prudential reserve have equally an instinctive basis; which order of stimulus will more strongly stimulate and thus prevail, experience in the end decides. It is, however, not a free decision, but one freighted with the shifting values of the opposing traits and the strength of certain specifie types of sensory disturbance as inlets to release their specialized emotional responses. The hesitant approach is the characteristic observable response of shyness, and equally so the inner embarrassment-the uncertainty of command of resources, the wavering decision as to which phases of the responsive nature are to be released, or, in later stages, the uncertainty of control, though desire is plain. The shrinking or hesitation in the presence of unfamiliar objects is a simpler shrinking than the shyness in the presence of "social" strangers; the latter is a socialized emotion, while the other is not; both may become intellectualized though with a different order of complication-as in the differentiation of fear and awe. The deeper hold of the socialized variety of shyness appears in the tendencies to abnormal expression which it assumes in predisposed individuals; the "phobias" are apt to take the form of social apprehensions. In brief, the social quality of the "shy" response typifies the central part which the social nucleus oceupies in the self-assertive and self-abasing trends of personality - the conjugate foci of character.

The consideration of the more highly intellectualized, more complexly socialized phases of the composite attitude of shyness, is corroboratory. The element of conflict persists; the response is a hesitant approach: the approach aggressive, the hesitation retreating. The youth is eager 
to make an impression, yet afraid of the possibilities; the maiden is willing to be impressed or to charm, yet is complexly timid by natural coyness, by modesty, by convention. The speaker is anxious for the opportunity of the appearance, and appreciates the honor of the occasion, but the trial of it still more keenly. On the one side are arrayed the forces making for self-assertion-conquest, display, charm, prowess; on the other the retreating tendencies, moving toward self-abasement or withdrawal-timidity, modesty, humility, homage, submission. Most of these attitudes may be viewed as curtailed emotional states, approaches and incidents of the completer response: such as the triumph of success and its attendant self-enhancement, or the complete subjection and humiliation of selfabasement. Thorndike's analysis is suggestive and corroboratory. He considers display as a curtailed form of the behavior of mastery, shorn of its completing stages of domineering threat and control. The displayer, becoming the cynosure of all eyes concerned, attains the satisfaction of triumph as well from this social source as from the abject submission that would form the completer behavior of the mastered one when on mastery bent; and the partially mastered or subdued subject becomes merely shy. The situation is social throughout, but ,changes its social flavor in the presence of a group or a crowd in whom respectful admiration replaces submission. Similarly shyness is the "submissive behavior minus the gross bodily cringing, and the inner acceptance of subserviency." The modification of the original tendency occurs in both parties to the social relation, and occurs through inhibition under the influence of contra-dispositions appropriate to the situation. The male confronting a resisting male will be disposed to persist in mastery to the stage of enforcing submission, even cruel subjugation. The male confronting a coy female turns to display for the technique of mastery. To cite directly: "Thus where a powerful and hostile crowd 
would provoke submission in toto, a mere crowd or a fairly friendly crowd provokes shyness, and the speaker simply cannot look at them quite squarely or speak naturally. Similarly, while a sufficiently domineering mistress may provoke submission in toto, the ordinary nice girl makes her admirers simply shy." The shyness in these several situations is clearly of a variable psychic order, and is so by the quality of the social situation in which the response has its setting. The responses in their design may indeed follow the "Ur-form" of the primitive combat situation, as Thorndike presents them; but sex-shyness, stage-fright, and social embarrassment introduce new qualities or, at the least, new flavors of qualities, significant in the sphere of regulation. Moral courage replaces physical courage, and moral temerity physical fear; and the complex occasions of their display induce or engage subdued undercurrents of reflective hesitation, subconscious involution, selfconscious entanglements.

It becomes clear from these illustrations that the central bearing of the socialized emotions is upon self-feeling, the ups and downs, the veers and shifts of the personal meteorology; and that these induced changes are possible only in their full measure to a highly socialized individual, responsive in a complex social atmosphere. In conformity with their higher development, the pain-pleasures give way to the "personality" satisfactions and dissatisfactions, and these reach ever more and more complex and reflective varieties in the social-psychological setting which becomes the field of operation of human quality. The objects of jealousy and shyness and the other socialized trends are beings in the social relation [5]. It is by virtue of this circumstance that expression acquires a peculiar social value; through expression each reads the other's meaning even as his own is read, and thereby is intention met and answered, purpose anticipated and aided or thwarted. In so supremely social a being as man the individualistic in- 
stincts are socialized in the sense of being set and matured in a medium requisite to their satisfaction; yet they remain self-directive in trend. The display impulse is thus social; children love to show off, and their elders play to the gallery. Exhibition and admiration as enhancements of self-assertion form a tremendous social motive, a great incentive to effort; they account for the glitter and pomp of worldly vanity, the rustle and sheen of silk or the clanking of silvery harness, as directly as for the frank "see me do this" of a five-year-old. The vanity that finds an individual satisfaction in the mirror-in more than one sense, a dress rehearsal-would be vain indeed without the social reflex of the presumable effect of the attraction upon admirers. All this belongs to the natural tendency in a highly socialized individual to respond to the approval and disapproval of others; it is reënforced and directed by discipline of parent and teacher and world at large. Modified and chastened socially, it is still self-interest that directs the pursuit of the esteem of others and the avoidance of their ill-will. The environment is itself a socially effective one; the social medium absorbs and redirectsfrom early infancy to the formation of mature character - the individualistic trends of instinct and emotion, as it sets the direction of thought and conduct.

We turn to a factor of primary import in the socialization of responsiveness. As is typical of the derivative social impulses, it is not specific in its trends, but generically plays upon a considerable range of primary impulses; it has however specific or preferred inlets which are determined by the social nature and more primarily by the emotional nature of man. We approach the broad emotion of sympathy. It is founded in the community of human nature. By original nature we share common satisfactions, are pleased and pained by a fundamentally like range of stimuli, are attracted and repelled by like approaches, are made afraid and angry by like incidents, tend to like ex- 
pressions, are moved by like motives and desires. Upon this common psychology and common organic eonditioning-to which we may now add, a common socialityexperience imposes its differentiating stress. There is, however, to be recognized a speeial reënforcement of this community in the gregarious impulses. Community of nature reënforced by gregariousness supplies the basis upon which the high-level products of sympathy may be built; yet in one aspect they are more generic, more fundamental, more primary than sympathy. Infants ery-as dogs bark and growl-when they hear the cries of their kind, or when disturbed by a common alarm, and presumably are swayed by like emotional excitement. The contagion of fear spreads by the sensing of the audible, visible, tangible signs of fear-shrieks, pallor, trembling, motor agitation. Gayety and depression (through their expressional counterparts in a merry or a sad face), composure or excitement, curiosity or indifference, are all in some sense contagious. In such sympathetic contagion the inherent gregariousness is but the starting-point of the emotional response, which develops quiekly and richly to its consummation through the complication of other factors. The panieky scurrying of sheep when alarmed means not alone that by community of nature what frightens one sheep frightens another, but that the fright of one itself induces the wave-like spread of the agitation through the signs thereof which the rest pereeive. Even among the ants when a catastrophe occurs, the rapid excited movement of the antennæ of one ant against the antennæ of another quickly circulates the alarm through the nest. That about the same result is repeated in the human herd when assembled in unstable crowds inviting disaster, is all too true; but it is obvious that the gregariousness thus appealed to is a far more eomplex though equally a social product. A similar spread of emotion occurs even in realms where reason is supposed to rule- 
in "runs" on banks, and in the vagaries of fads and fashions. The contagiousness of mind is a graft of complex nurture upon the parent trait of "gregariousness."

Returning to the evolution of sympathy, we note that by implication of the facts cited, the audible or visible sign of the emotion aequires the rôle of a special inlet to the dissemination of that emotion, or to some appropriately related emotion-the appropriateness socially determined. By virtue of this principle expression attains a high value as a social force. It accounts for the peculiar power of sudden, loud, unexpected, or unfamiliar sounds to alarm; once the alarm is started, the terror spreads by all the various signs of terror. In that sense the expression of each emotion forms a special inlet to that emotion. The sight of anger in another encourages or invites or precipitates the assumption of anger in me; but when the anger first shown is directed against me, my responsive anger is protective and not contagious; if directed against a common enemy, the action producing the anger in another as well as its signs in another may have the same effect upon me as upon others; or I may be more readily disposed to a resentful anger contagiously (or more probably sympathetically) by the sight of another angry. The latter response may proceed dominantly upon my gregariousness or dominantly upon my sympathy or my native pugnacity; I may by nature find it difficult to keep out of a fight. Briefly, gregariousness absorbed in sympathy and acted upon by other impulses becomes an ingredient in a composite of rather different range. It is true that when alarmed, we shout, and that the shout alarms others, at first largely by mere organic contagion, later by added reflection upon the danger itself. The first panic of alarm-as in the case of a fire in a theater-is a presentative contagion, a herd-like response. If the audience can be kept from shouting and scurrying, can be held quiet and calm, the danger of panic is likely to be averted, and a more rational yet fear-inspired 
response may prevail. It still remains true that the expression of an emotion as observed in others inducesserves as a special inlet to-the summoning of emotion in oneself; but the application of the principle is limited [6]. The response may be seemingly contagious but really protective or socially sympathetic. It is true that the infant. smiles to my smile, but equally that it cries in fear at my scowl; another's anger may induce my fear, and the smile of derision may induce my anger. The psychological analysis of an emotional response is not so simple as the "practical" recognition of its bearings.

Sympathy in the special sense is the tendency to feel a like or an appropriate emotion in the presence of tense emotion. The sight of pain may actually go so far as to induce the feeling of like pain; but that borders upon the abnormal. The sight of pain produces pity, which is the sympathetic response to pain; any of the suggestions of pain, particularly the strongly presentative ones, like the sight of blood, will produce emotional upset, and sympathetically a fellow-feeling, and, it may be, altruistically the tendency to minister and relieve. By way of the imagination the description of painful scenes induces the like effect, but is ever enforced by presentative details, as the gruesome illustrations of a sensational press too commonly set forth. An apt example of "pure" sympathy, that rises above contagion or a presentative clew and is equally free from an altruistic quality, and yet involves the assumption of others' sensations as our own, is the experience in observing acrobats on the trapeze, tight-rope walkers, or performers of other thrilling feats of conspicuous peril. The flesh creeps, the heart thumps, the breath is held, the hands become clammy, the eyes half-averted yet fascinated; and there is a sigh of relief when all is safely over. Yet the performers as persons have no relation to our personal sympathies. Moreover there is no suffering here, no visible or audible appeal to sympathy, such as would keep the 
pectator who enjoys the performance because of or depite the thrill quite uncomfortable at the bull-ring, and which would sicken him literally or metaphorically in the resence of accidents or of their realistic portrayal. The "thrilling" fear in observing others in positions of peril (actual peril to us if we were on the trapeze or on the tightope) parallels the sensations which we experience on the op of a sheer cliff, or even on the outer platform of a tall vuilding, well secured by a railing. The danger of the sitation is a mental one, quite as much so when it is real as vhen the presence of the railing makes it imaginary. The ympathetic thrill reflects both socialization and intellecualization. That a similar sympathetic effect may be proluced by sensory stimulation alone-such as that of the lissecting-room experiences-has been made clear in the reatment of the sensibilities; for the sensibilities are so eadily emotionalized that they carry a sympathetic apveal as efficiently by the suggestiveness of the object as loes the expression by portrayal of the affect. The quality if sympathy-the simpatico which is the favorite complinent of the sympathetic Italian to the foreigner-is the ongenial responsiveness in the presence of emotion and its igns. It is the sympathetic man who cannot endure the ight or ery of pain, or exposure to situations that induce hem; hence the compelling power of tears, and hence also n occasion the crocodile variety. Hence the interference f too sympathetic an emotional response with the calmless needed for proper ministration; the surgeon must ose or control his emotional susceptibilities to permit his rofessional insight and skill to prevail. More generally, ympathy forms the running commentary and support of uman intercourse; in this service, it requires further conideration.

Sympathy is social and as such is both a giving and a retting; a sensitiveness to the fate of others and to the steem of others are in themselves very different, but alike 
social products. Sympathy thus broadened becomes the great medium of socialization. It makes us responsive to a situation whether centered about self or about another; sympathy-so far as it goes-making it ours. Without sympathy the social life would be merely the gregarious life, a sharing of experience and a helpful one, but limited and bare in comparison with a socialized existence. Sympathy does not cease to retain a self-reference (and by a curious involution one may direct sympathy to oneself, self-pity being a very common attitude observable in children among the early products of their socialization), but is not self-centered; and by that grace it contains in germ the altruistic factor which expands into the richest growths of the emotional nature. Sympathy employs various channels: organic and sensory by expression, through the interpretation of experience representatively, by the intellectualized imagination in its largest reaches. The susceptibility to emotional affect without the strong original clew of bearing upon personal welfare is its central feature, though in the larger view a derivative product. In the course of its growth it develops various relations, some reciprocal in part or whole, others dominantly one-sided in attitude, but in some measure amenable to the blessing of giving and receiving. The merely gregarious herd receives a collective benefit from the individual tendency to respond for all; and certain herds post sentinels to give the signals of danger and safety. The individual receives the protective benefit of the collective response; the shying of the horse and the mad dash may be the tendency to seek the shelter of the herd-the obedience to a signal for a collective stampede. The taxes imposed and the benefits received by a primitive natural organization suggest the patterns of our artificial socialized relations in forms of government and regulation of private and public interests.

It has been set forth that high-level emotions proceed upon an intellectual elaboration; the intellectual aspect of 
sympathy is already involved in certain of the illustrations given, but appears more explicitly as the emotional element retires. The name given to this stage of the process is suggestion. It plays a part in the contagious spread of emotion, but is more marked (because its course is slightly more indirect) in the contagion of yawning than of laughter; even sea-sickness is contagious, in the sense that the succumbing of one's companions weakens the powers of resistance. Suggestion in its completer formulation involves imitation; and imitation carried to its explicit issue involves an attention to the copy and a more or less deliberate or at the least a consenting intent to repeat it; its route is ideo-motor [7]. Imitation expresses a deliberate intent, even an effort, and when mature proceeds upon an intellectual analysis and a trained guidance of muscles to fashion a reproduction which the senses recognize as true to the model; such exercise satisfies the constructive impulses - the expression of self in things made and done. The imitativeness of children proceeds upon this intellectual basis, and the imitativeness of society no less. This ultimate issue of a natural gregarious, sympathetic sociality, when transferred to the mental realm, becomes one of the greatest socializing forces, responsible for the achievements as well as the limitations of men as social units.

We are at present concerned with analysis applied to the mental routes of social response. The suggestion route and the imitation route cross one another's trails. Suggestion proceeds upon a complacent and not an assertive will; it whispers and insinuates its behests to avoid the possible resistance of an aroused individualistic desire. Projected to a plane of conduct in which this description is pertinent, "social" and "individual" begin to show their opposition, which opposition is part of the social-moral problem of all ages. The tendency to follow a lead and the tendency to set a lead are both social issues; and both bear upon the social development of an individual trait. 
Suggestion calls upon the "following" tendency, and (when occasion warrants) proceeds gently and indirectly in its approach, in order not to awaken the slumbering "Ieading" tendency. The latter becomes the "leading" tendency when socially completed; it is first and always the individual tendency to self-direction. Projected to the competition of rivalry, it takes the form of insistence, domineering, contentiousness, obstinacy-all qualities exercised in the impulse of mastery; projected to a larger group, it becomes true leadership with its vast social reënforcement of submission and approval on the part of the following. Though rather formidable when thus described, these qualities are as characteristically exercised in the nursery, or on the playground, as in the political arena, the social whirl, the marts of trade, or campaigns in the field or on paper. A factor presently to be included in the complex social responsiveness, must be anticipated at this juncture. Leadership and deference may both retire to an equality of fellow-feeling; the pleasure of acting as one of a group, as "belonging" to the group, is a part of one's socialization, and promotes the acceptance of the socially accredited pattern as readily as does subserviency. The "belonging", is both a possession and a being-possessed. The appeal is at once to the assertive and to the submissive self-feelings. Fellow-feeling is congenial to an emotionally infused responsiveness; and by that token does the emotional basis remain the large, primary, reliable basis of communal socialization. It is ever important that collective action shall be based upon like feeling, common enthusiasms, loyalties, sympathies; for only thus can the greatest common factors of human nature be reached.

Principles and ideals as well as doctrines and dogmas, though formulated as creeds or slogans, must be enthusiastically embraced before they become massively effective. The individual, assertive, "leading," tendency is congenial to intellectual explicitness, to consideration, exploration, 
and the reflective type of initiative; the more individual one's attitude, the less amenable is it to suggestion. The field of suggestion accordingly lies closer to the realm of emotional than of intellectual regulation, though its intercourse is with both. Suggestion and imitation imply the tendency in the presence of a model to copy it; when the tendency is animated rather decidedly by a social conformability or a social complacency or a mere gregarious "following" trend, the modus operandi of the copying is referred to suggestion as its vitalizing principle; if the directive tendency approaches the status of an adoption rather than an acceptance, an intent rather than a consent, an appreciation in some measure of the steps of the process rather than a blind succumbing to their sway, the copying is imitative. The boundary between the two spreads broadly and uncertainly, yet remains a boundary [8]. In concrete illustrations the coopperation of the two tendencies is prominent; as in the actual stream of experience we often really follow when we seem to lead, or flatter ourselves that we act from convictions won by individual effort, when we follow prejudices imposed by convention upon an emotionally receptive and intellectually dependent deference.

Disposition, typical of the emotional phase of the complex, favors the play of contagion and suggestion. I am the more ready to laugh in a gay company, if I enter it in a gay mood; I am the more disposed to yawn when others yawn, if I am a bit tired; I am more apt to feel hungry as I observe others eat, when I am somewhat hungry myself. But when at a restaurant I order what I see others eat, suggestion is completed by imitation. Children are by the same range of qualities suggestible and imitative, yet ever distinctively along the grooves of common trend and nature. They imitate other children and the patterns engaging to their impulses far more congenially than the example of forbidding elders; otherwise education in morals and manners would not be the problem that it is. The indi- 
vidual responsiveness to social influences is predominantly by way of suggestion and imitation on the basis of an appeal to a common endowment, the selection among the presented patterns depending upon the relative strength of appeal to natural impulse, as well as upon other considerations not at present germane. It is because the emotional appeal in simple cases is to such large eommon factors of disposition and impulse that the resulting community, contagion, spread-or whatever term best expresses the socialized product-is inevitable, and hardly presents the problem of selection; what appeals to one appeals to many others; the common social sympathetic action is rooted deeply in the normal sources of human nature. In such instances nature and nurture converge and make the problems of the distinction of their contributions perplexing, because the patterns suggested or designedly supplied and imitated by our nurture are in such large part built upon or addressed to the redireetion of the impulses of our nature. This, indeed, is what is meant by the ready popular verdiet that human nature is ever the same; that commonly reeurring situations make a like appeal to like qualities, and do so not alone by virtue of the acquired social impulses and the disposition to conform which they engender, but by the reassertion of original trends. Socialization thus finds its tap-root in sympathetic emotionalism. It operates by communal reënforeement; it redireets natural individual emotion-impulses by and through the "other" situation.

In the present perspective through which we look upon the field of operation of our own psychology, the social phases of traits seem as intimate and primary in the components of human nature as the individual phases. Jealousy, shyness, and sympathy are summoned as readily as fear, anger, self-assertion; there are as common occasions for the one group as for the other. We are familiar with love and hate, and see little purpose in reducing them to 
tender-feeling and pugnacity, with which we have as distant acquaintance in a "pure" state as we have with "pure" sensations. Intellectnally we know objects and not qualities; and yet an elementary psychological analysis proves that but for the persistent recognition of qualities, objects would not emerge from the chaos of impressions. The service of the intellect for the elevation of the emotional life is part of its catholic mission-to many students of human problems, the most important part of the mission. As the socialization of the human endowment is applied more and more to fields where community of natural bent is less decisive, and community of acquired experience and views more so, the commanding share of the intellect grows by rapid advances. In this vast domain suggestion and imitation are added to and replace organic community or gregarious contagion, to support the work of sympathy, and jointly warrant the definition of man as a social ani$\mathrm{mal}$; they furnish the clew analytically, and the instrument practically, to his social domestication. But such service is possible only by the inclusion and marked perfection of the intellectual guidance. Imitation becomes the central highway of socialization and the road to its issues in the compositely emotional and intellectual solidarity of feeling and coöperative conduct, which proclaim the measure of the individual transformation of character. With this stage of socialization accomplished, the sympathetic direction may transform self-regard to the inclusion of the altruistic end and motive, the perfection of the sympathetic trends, the eulmination of the socializing of the human endowment. Yet at every level the original strain, the emotional foundation, shows through; it appears in the "social character" of man as the motive of sensitiveness to esteem, as susceptibility to imitation and suggestion, and as a general sympathetic responsiveness to the social motives. This social sensibility dominates the entire emotional growth; as it progresses, intellectual considerations 
sct the course, but the vitality of the emotional impulses furnishes the motive power.

The place of sympathy in the higher phases of psychic regulation has led to the consideration of the socializing processes as a whole. We must now return to include a survey of a factor in sympathy, of uncertain origin. All that is clear is that the relations of mother and young, and the ministrations imposed by the care-of-young situation, make necessary an other-directed impulse, which in the human psychological setting involve attitudes of devotion, properly termed altruistic; such ministrations give pleasure, yicld altruistic satisfactions. While sympathy is an extension of the self-feelings to others, altruism is the preference of the other and finds its consummation in sacrifice, small or large or complete. It is altogether probable that the roots of altruism, though slender, spring from other natural relations than those of mother and young; but the evidence is not clear. It is plausible to suppose that the trend thus introduced in the maternal relation would modify the sympathetic nature in general; that while it would act dominantly as a sex differentiation to insure maternal care, it would collaterally include a paternal solicitude to complete the protection of the family interests. Altruism seems weakly set in human nature and may have no inherent part except in the sacrifice imposed by decree of nature upon the older in favor of the younger generation, if the race is to survive; the social self-assertion of race extends to the coming generations. Yet the very complexity of the "family" relations matures attitudes of love and loyalty congenial to sacrifice. None the less the altruistic maturing is in its present sway an artificial product; it requires the combined disciplines of education, morality, religion, and other systematized and inculcated loyalties to maintain its place in the higher psychic regulation. The instruments of maintenance are the approvals of social esteem and the sensitizing of the moral conscience. Altru- 
ism is so uncertain a motive, even in the field of operation which it has itself created, that we are prone to detect the motive of self-satisfaction in philanthropic display, and to suspect the taint of money gained by predatory disregard of sympathetic considerations. To the modern mind the suggestion is certain to occur that the technique of courtship as at present exercised engages like tendencies to devotion and sacrifice of an altruistic flavor. Modern courtship is enshrined in an atmosphere of romance, gallantry, chivalry and sacrificial attentions; in appearance it provides a favored medium for the expansion of altruistic conduct. If we are tempted to give this trait a place in original nature as a real and strong root of altruism, we are at once met by the contrary evidence of history. Early courtship was dominated by the appeals to mastery and possession; capture rather than persuasion or ingratiation was its primitive method, and there is reason to believe that the success of bold advance and elopement, if not seizure, in the most formally conducted courtships reflects the hold of primitive techniques. Submission rather than the power to enforce devotion was the cherished quality of the primitively feminine. Doubtless attraction always played a part, and the coyness of response shows the conflict of mixed motives; but the conclusion stands that the altruistic flavor in courtship is to be regarded as a product of high-level evolution, and cannot be appealed to as a natural or even a very early source of other-directed sympathy. Yet it would be misleading to dismiss the trait with so final a statement. It is obvious that with the desire for the esteem of the opposite sex once established upon whatever source or basis, it plays a large part in spreading the sensitiveness to esteem as a general social instrument. The relations of courtship of more than the primitive form utilize, absorb, and develop the altruistic flavor of devotion and sacrifice. If the attention of the male is but selfseeking disguised, the disguised status itself involves the 
play of other ranges of motive; the effective disguise upholds the consciousness of the lover in a romantic network of admiration and the quest of approval. Once slightly transformed so as to come within the reach of the altruistic impulse, the love passion reënforces that impulse and expands it. There is a large truth in the generalization that only because the slight altruistic roots are stimulated by the emotional warmth of the love passion, is the further growth of the altruistic nature made possible. Without this transforming medium the altruism of the average man would be far more uncertain, the possibility of the use by society of the desire for approval far more limited than it is. It remains true for the practical spans of social evolution that the sensitizing to sex-esteem serves as a powerful stimulant to social esteem. From the exhibition of prowess as a means of captivating the fair sex to the gallant chivalry of romanticism there runs a common trend. It has a further chance of growth in commection with the paternal sliare in the solicitude for the offspring, and in that relation also may derive strength from a borrowed source. The appeal of wife and child facilitates other appeals; the composite altruistic susceptibility attains, as it requires, the support of all the natural relations that can further its establishment and growth.

Collateral evidence supports the conclusion that the relation of mother and child is the natural point of germination of altruistic sympathy [9]; though with it we may at once associate the entire range of family relationships that come from and with the sharing of the same protective nest. The "group" relation is thus established, and may well be the model for the wider group relations that human sociality has at all times developed. The stronger hold of family ties upon women, the intensity of the maternal concern, may account for the readier emergence in the feminine nature of the altruistic flavor of sympathy, and the stronger hold upon men of objective coöperation, making 


\section{HIGHER STAGES OF PSYCHIC CONTROL 203}

room for mutual benefit and leadership. Yet feminine sympathy is doubtless related to the dominance of the emotional regulation in the feminine perspective, as well as to the readier play of the "suggestion" type of influence in feminine psyehology. However this may be, it is clear that the sensitizing of the self to the sympathetic participation in the life of others forms one of the great media of socialization; and that this sensitization is in part altruistic and by that token is more than the competition for the social esteem as a mode of enhancement of self-esteem. It is the policy of social institutions to encourage the altruistic factor by the esteem whieh they confer upon (certain forms of) sacrifiee; the larger loyalties thus flourish, and the smaller allegiances derive an added enforcement. The ultimate issue is that in present society social favor becomes a dominant object of competition. Jealousy is directed to the eoveting of social rewards and preferments; shyness is induced by any of the artificial forms of social contact; the competitive energies with all the emotional panoply accumulated in food-forays, offensive and defensive tactics of war, capture or persuasion of mates, assertions of mastery and superiority in minor encounters, personal and tribal, are redirected with an expanded scope to the contest for social goods. In this redirection the social sanction acts negatively as well as positively; it imposes an intricate system of checks and restraints upon discouraged forms of self-seeking, and thereby favors the altruistic trends by the strong disapproval of the chief obstacles to their emergence. Custom and convention are the media through which these influences are exercised; there results the socialized conscience, supporting the sympathetic emotionalism and building the superstructure of character.

The socialization of impulses proceeds by "first nature" directly self-concerned; next, and by a like process, it acts upon later types of emotional responsiveness through the development of "second-nature" impulses intrinsically so- 
cial in origin, in trend and in their genius; the two jointly set the personality for which these impulses are the media of expression, toward the culminating issue of a social self. On the positive side the activities and relations of the day and of the hour are socially directed or socially tinged or infused by and with the interaction of like processes in others, both specifically with these others and generically upon the basis of a social consciousness. The avoidance of such relations is the mark of a recluse; which trait, if pronounced beyond the limits of social shyness and touched by a misanthropic aversion, readily assumes an abnormal form. Unsympathetic and anti-social tendencies are allied to criminality-much of it also an abnormal expression. The opposite tendency is also prone to marked expression and proves the strong hold of the earlier stages of socialization. To be so slavishly dependent upon others as to find meager satisfaction in self-directed energies suggests the absence of inner resources. Reading, study, occupation, music, sport, avocations, hobbies, are all utilized as forms of self-complete pursuits, in which the satisfactions, like virtues, are their own reward. In a sense they replace the "others" as points of contact with our own personalities. The manner of our lives determines the direction and intensities of our social cravings. A crowd seems necessary to the social-psychological setting of the city bred; country life develops a psychology of its own. Yet the need of privacy for self-development is variously recognized, and the prominence of its claims forms a significant distinction between the ideals of different peoples. An ethnological student, living for a long period among the North American Indians, found nothing more wearing than the total absence of privacy in the enforced communal life. Yet despite these marked differences in expression of the social consciousness, of the social dependence and of the social approval, which customs and modes of life present, the general trait remains and expresses itself in a desire 
for and a satisfaction in the "diffuse notice and approval" of others. A greeting, a nod, a bare acknowledgment of our presence suffices. In its abscnce the self-esteem suffers; disregard, slight, disdain, scorn, insult are stronger expressions of the common affront to the social self, which guards our honor and our reputations as vitally as our persons; yet even these imply notice. In James' authoritative description: "A man's social self is the recognition which he gets from his mates. We are not only gregarious animals, liking to be in sight of our fellows, but we have an innate propensity to get ourselves noticed, and noticed favorably, by our kind. No more fiendish punishment could be devised, were such a thing physically possible, than that one should be turned loose in society and remain absolutely unnoticed by all the members thereof. If no one turned round when we entered, answered when we spoke, or minded what we did, but if every person we met 'cut us dead,' and acted as if we were non-existent things, a kind of rage and impotent despair would ere long well up in us, from which the cruelest bodily tortures would be a relief; for these would make us feel that, however bad might be our plight, we had not sunk to such a depth as to be unworthy of attention at all."

It is accordingly not in the bare acknowledgment of one's presence but in the degree and manner and refinement of such acknowledgment that the art of human intercourse consists. The sensitiveness to its forms and expressions becomes a significant trait of the social character; it is this more explicitly than any other trait that is referred to as "sensitiveness." The sensitive person is responsive in an exaggerated measure to every slight suggestion of advance, compliment, disregard, offense-often imagining its presence where it is not intended. It is this surface play of self-regard, received and offered, that forms the ripples on the stream of psychic impressionism socially directed. Systems of regulation in codes of manners and morals are 
developed about this central nucleus; ideals shape their formulation. Distinctions enter: the approbation of some groups is sought and preferred; that of others disdained; schools and parties, cliques and affiliations are establisked; sanctions are elevated to rules and philosophies of life. The consolations of religion, the supports of conscience, the faith in an ultimate justice, the finer satisfactions of disinterestedness direct the quality of self-esteem sought and found. Such are the issues of the social consciousness, without which the individual could not take his place in a social system, without which the system could not prevail. Yet the inherent range of self-directed motives must ever be acknowledged, and their dominion given a place in the social competition, however helpful the dream of a Utopia where the altruistic act is sufficient unto itself.

There is a further aspect of the socialized consciousness which finds its origin in the practical basis of coöperation. There are endless situations which a man cannot meet or solve alone, but can master with the aid of others. The social quality which results from such collective enterprise is a sympathetic zest in acting as one of a group; it is a "team-play" feeling that yet gives abundant room for individual assertion, and indeed assures to such assertion the approval of the witnessing as well as sharing companions. The bearing of this spirit upon communism of living eventually absorbed in the play of economic forces, in the fostering of friendship, alliance, patriotism and the larger loyalties, will be considered where it more properly belongs-among the group-traits of men. Our present concern is with the psychological setting of the motive that leads to "lending a hand," and with the resultant effect upon social responsiveness. The expression of the collective action in defense or offense, against invasion by foe, fire, flood, in the management of a hunt, a ship, an expedition, a campaign, an engineering construction, a drama or game, a ceremony or cult, are conditioned by practical 
organization; but the very tendency of organized human actions to take such collective expressions of human interests and desires, builds upon the socialized impulses and leads to the trained coöperations of men. So deeply saturated in the social setting and reënforcement are our activities and their satisfactions, that to many persons a large range of the luxurious experiences is possible only in the social setting. To such persons the enjoyment of a concert may depend intimately upon the sympathy of companions with whom comments and approbations are interchanged; the enjoyment is influenced by the appreciative mood of the audience; the vigor of applause of any group of enthusiasts is repeated by the collective outburst, that grows by spontaneous contagion and eulminates in an ovation. The most natural expression of admiration is to summon the admiration of another: "Oh! look at this! Isn't it beautiful?" Solitary enjoyment is limited and bare, because the richest fruits of psychic cultivation must yield the social flavor. In travel, in the theater, in an art gallery, among the beauties of nature, at church (wherever the finer feelings which are themselves the product of a disinterested pleasure are concerned), while the impression is an individual one, it craves the social reënforcement. It may be supplied in imagination by rehearsing the impression as if to an absent mate or companion, so great is the sense of lack in solitary surplus of experience. The socialpsychological values thus resulting from shared enjoyment are utilized to lift the selfish pleasures to the same disinterested plane. The table becomes the symbol of sympathetic hospitality and the occasion of social intercourse; and eating in solitary state becomes a bore, lacking at once the social distraction and the social enhancement. To be sociable means not alone a craving for companionship, but a dependence upon the customary socialization of experience in all realms where the self-centered interests are not exclusive. Of these in turn, if too pronounced and selfish 
in tone, one is more or less ashamed-by virtue of his social consciousness-or in more innocent instances, decently secretive. The point to be emphasized is the socializing of the emotional attitudes, not primarily by way of their demand for the approbation of others or the rewards of society, but by way of their dependence upon the sharing of others for their own inner satisfaction: hence the pangs of loneliness - of a fictitious or figurative loneliness, it may be, when amongst people but a stranger in their midst, lacking the ties that establish the approaches of self to self; or a yet more select loneliness in that the companionship offered is not satisfactory to one's standards, predilections, and ideals; or yet of the literal loneliness of constant solitude, that affects the entire disposition. The loneliness of a stranger in a big city and the loneliness of village life in the winter are very different but equally "social" expressions of a complex dependence. It is the sense of detachment from the social environment that makes working or even sleeping alone in a house a trying situation to many socialized individuals; the trait then aroused more directly reflects the primitive gregarious hold, turning the emotion toward fear. Yet it is the more complex phases of the trait that operate in the higher reaches of the social sensitiveness. The landscape may seem a barren waste until there is discovered the touch of the human hand, the sign of human habitation, even though it be no more than the smoke of a chimney in the distance. It is the sense of solitude that makes the poetry of the desert, the impressiveness of the obscuring star-lit night, the awesome expanse of the wilderness too mighty for human powers to compass. In these finer esthetic realms of emotion the social consciousness refinedly asserts its sway. In the beginning socially dependent, maturing in a social medium of responsiveness, seeking social rewards, sensitive to social restraints, expanding experience through a socialized sympa-. thy, finding enhancement in socially shared pleasures, al- 
truistically responsive to the satisfactions which others enjoy through his efforts, bound to social interests by ties imposed and associations assumed, the human individual finds his psychological expressions so thoroughly incorporated in the socialization of his traits that he cannot readily conceive of his nature in any other terms, cannot construct a hypothetical psychology stripped of social complications, cannot picture a world of action for his qualities that does not represent a constant appeal to his social self [10].

The altruistic turn of the social-sympathetic emotions introduces in psychic regulation a factor as distinctive as momentous. Despite its uncertain origin, its precarious hold, and its essential limitation to high-level expressions, the altruistic quality is as strongly to be reckoned with as any derivative phase of acquired nature. Altruistic consideration is maintained by the eternal watchfulness that is the price of moral safety; and the manners so carefully and wisely fostered in lighter considerations are readily forsaken under stress or strain of personal advantage. The scratching of the Russian that discloses the Tartar may be repeated with the same result upon almost any average example of civilized humanity. Despite the glorious records of heroism, philanthropy, and devotion, it takes but the urgency of a panic, a crowding of the means of subsistence, a rush for immediate advantage, a fierce clash of individual interests, to send the human struggle back to a sauve qui peut scramble. The proverbial "Devil take the hindmost" spirit indicates too pointedly the attitude of the foremost. Although altruism is valued intrinsically for its effect upon character and is thus a moral quality ultimately, the import of this comment is not moral but psychological. The preceding survey serves to indicate the variable play of altruistic emotional trend in its sources and earlier manifestations, and the transformations which it affects among the composite impulses of individual and social human nature of like derivative status. It is pertinent to recall that al- 
truism has a chance to assert itself through the medium of a disturbed sympathy. The sympathetic man may undergo large sacrifices to make others happy, because others' miscry makes him miserable sympathetically; or consideration may lead prudentially to the morality of the golden rule with its inevitable altruistic trend; or the mutual reënforcement of coöperation, the congeniality of friendships, the glow of a social solidarity in loyalty to causes and institutions, may attract toward self-effacement and "other-seeking", efforts. It is equally pertinent to recall that the altruistic flavor, if not pure, at all cvents in a creditable approximation, directs human motives and energies, enhances and molds the emotional thrill, offsets the individual set of impulse as effectively as imposed restraint, enlarges the outlets of affections and interests. Joy becomes doubled as it is shared; grief more bearable by the same enrichment. Emotion directed to others returns upon itself and gives an added and a keener zest to individual effort. The consolations of poetry, the vicarious experiences of the drama, would be barren were it not for the altruizing trait, which makes the human being humane, makes it impossible for the sympathetic man to attain a full sentimental expression without the reflex support of kindred souls. Practically it supports the institutional expressions of sympathy and social solidarity; psychologieally it creates a new order of susceptibility.

It is in the spirit of these considerations that we turn to the emotion of love-a term of ready familiarity in every language, but far from definite in its psychological bearings. The contrast of love is with hate; they are distinctly of the upper-level, "sentimental" order and require a considerable psychological maturity for their unfoldment. While withdrawal is significant of shyness or fear or disgust, the alternatives of approach are in the first instance as contrasted as are fear and flight with anger and pugnacity. To approach in friendliness or in hostility, with 
the open palm of amity or the closed fist of enmity, with the frank smile or the clenched teeth, with word or mien of blessing or curse, must be "instinctively" distinguishable as vital and urgent situations of opposite import. The "sentimental" stage of antagonism or aversion is hate; the hater feeds the embers of his wrath, and broods revenge. The "sentimental" stage of affection and friendly approach or welcome acceptance is love; the lover glows with the warmth of his fondness and dreams of bliss. But the very fact that human love is "sentimental," makes it difficult for man to strip it of its "sentimental" accretions and stand face to face with its pre-sentimental stages. The psychological analysis requires a neutral term for the basis of friendly approach; in recent discussions "tenderfeeling" answers that purpose. The desire for such attention appears in the solace of fondling, caressing ministrations, though these may afford equal or greater satisfaction to the giver than to the recipient. They mean far more to the mother than to the child; pet dogs and cats have learned to cherish them at human hands. The instinctive tendency whereby only the maternal (or kindred) touch is soothing and every strange contact is instinctively responded to as a hostile one, gives way to the acquired association. The cubs of even the most feral carnivora may be freely fondled-that is, their instincts accept contact as protective-but in due time are swayed by the mature feral instincts which resent contacts. Domestication, like a simplified civilization, aims to let the ape and tiger die, and to enlarge, eventually to enlarge rationally, the range of welcome approaches. That in a primitive perspective the attitudes called forth by food-acceptances as well as by organic antipathies and sympathies contribute to the reactive habit is inferable from the mode of operation of loves and hates. The hateful is also the repugnant; language, reflecting the feelings, merges affection and sensory predilection. "Loving" is loosely used as a stronger sense of 
"liking." Such enthusiastic exaggerations as a passionate fondness for peaches, or a doting on chocolate creams, or $^{2}$ an adoration of roses, are pardonable by reason of the underlying congeniality of the sentiment. Conversely the "sweet" disposition is the lovable one. The esthetic element enters and is swayed by the affect; love makes the beloved object beautiful and the hated one ugly, whatever more critical judgments may decide. To maternal eyes there are no ugly babies. Love is blind to faults, and the prejudices of hate are equally blinding to virtues. The emotions of love and hate are indispensable and inevitable products of the setting of our approaches and contacts in the socialized and intellectualized medium; they become complicatedly friendly and hostile, reservedly and versatilely welcome and unwelcome. The same contrast inheres in the projection of emotional states into the future, where the welcome inspires the sentiment of hope, and the unwelcome is included in the enlarged compass of fear. The situations contributing to the development of the emotion of love are threefold: the care-of-young situation, social friendliness, and sex appeal; by transfer the tender feeling, welcoming joy, and impulse to devotion, bred in these relations, are applied to one's work, one's pleasures, one's larger interests. Maternal devotion, cordiality of friendship, and attractions of youth and maiden are as distinctive in their source as in their manifestations; they are blended in a common emotion-in due course a common sentiment-and find a like support in a passionate nature capable of deep and ardent feeling; yet they mature with a different range and quality. The friendships of men and women camnot be as those of men to men, or of women to women; the drift of friendship to love marks the change of the emotional-sentimental current. The emotion as felt is commonly suggestive dominantly of one source and in minor measure of the others; the relation of father to a daughter of congenial temperament may combine parental, 
companionable, and gallant devotion. The loves of men, as well as their allegiances to causes and ardencies of pursuit, are distinctive because man is (really or potentially) a fond parent, a true friend; an eager lover. The loves of women are distinctive because of the distinctive ties in the complementary relations. Thus emotions, however designated, take their psychological meaning from the concrete conditioning of their exercise.

The dominance in the mature civilized psyche of latterday generations, of the romantic relations of courtship, enshrining the passion in a sentimental tradition, liberating its power to transform thought, feeling and energies, has conspired to give the lover-beloved relation a precedence in the love complex. The condition of "being in love" has but one reference, and in that reference develops a unique psychology. If it were fair to disregard the history of courtship and the customs of nations and times and the divergences of classes, as well as wayward amorous expressions and uncertain "elective affinities," and accept as the standard relation the highly romantic elaboration of the "sex" appeal under modern, occidental refinement, "courtship" love-the complement of sex to sex in enduring attraction and devotion-could be unreservedly set in a position of exalted supremacy. How far the imperial sway of sex rule is established by divine right of nature, how far the enthronement is the work of man, the psychologist must consider, though he hesitates to decide. To those of our minds, moods, and traditions it seems natural and inevitably ordained that no other avowal of love, however sincere, disinterested, deep, spontaneous, and enduring, can carry the emotional thrill, can so transform the psychic nature and occupation, so enhance experience by the depth of the emotional background against which it is projected, so vivify ideals and animate resolve, as this one. Its keynote thus construed is devotion, in which the other becomes dearer than the self; yet its gratification is saturated with self- 
indulgence; and in all its moods and phases it proclaims its loyalty to nature, reveals that the wealth of its treasures have been gained by refinement of sentiment and transformation of idcals in the intellectual and the social alembic from the primitive crude ore of human nature. The attempt to develop it in isolation from its organic basis, to present in ideal a sacred and a contrasted profane love, to detach from the sympathetic devotion of man and woman the added charm of sex allurement, led to the conception of Platonic love-a psychological abstraction.

That the lover theme has become the leit-motif in the movements of the modernized psychic composition may be admitted, whatever the decision as to its place in original or primitive nature. In surveying the upper levels of psychic regulation, we seem to find the issues of the common theme; we think of acts of devotion and loyalty to deeply cherished human interests as finding their vitality in the passionate strength that belongs to the plighted troth. We find it interesting if aimless to speculate how far the loyalties to social and philanthropic causes would have developed and present civilization, have assumed its creditable altruistic appearance, without the absorbing, compelling, transforming sweep of the love-passion to teach men the potencies of desire and devotion. The psychologist may more confidently recognize that the susceptibility to the love passion reverberates to the most remote psychic recesses, and vibrates characteristically for masculine and for feminine nature; and recognize the collateral presence of the maternal, parental, filial ties, the allegiances of kith and kin, of friend and clan and race, of associates in mental and moral sympathy, that make the overtones of the harmony. The meaning is clear when we speak of the artist as wedded to his art, of the consecrated nun as the bride of the Church, of the amateur (lover) who roams the woods for the love of nature, or searches the depositaries of human products for the choice embodiment 
of what men wrought with love for their work. Even the thrill of discovery and the scientific ardor, though exercised in the realm of thought, and the undertaking of exploits of venture, though motivated by other phases of nature, take their support from the ardor of the love susceptibility. They are at times turned to as compensations for the lacks of the authentic passion; and eareers are abandoned or modified by reason of its rival claims; wives have been known to become jealous of their husbands' professional absorption, intuitively aware that the acquired interest has usurped when it should but borrow from the resources of a prior claim. The common conclusion remains that the strengths of pursuit derive their vitality in some measure from the potencies of the love-passion set in a natural urgency but developed to a far-reaching consummation by virtue of the same psychic enrichment that permits its transfer to the socially and intellectually determined enthusiasms of life.

To draw a distinction between the elaboration of an emotion and the establishment of a sentiment is possible; but the distinction would be gained at the expense of continuity of development, would become a somewhat arbitrary emphasis of contrasts above affiliations. In the consideration of the emotion of love-which might with equal right be called a sentiment-anticipation was inevitable. Accordingly it seems better at this stage to pass at once to the consideration of the intellectual factor by virtue of which the sentimental stage of the psychic elaboration is gained. Intellectualization refers to the influence upon the responses stimulated by the affective disposition, of the presence and radiation of meaning-of objective reference. Situations are responded to not only by the disposition which they arouse but by what they are and mean in a system of recognition and consideration; knowledge organizes feelings and actions. As conduct becomes complex through the complexity of relations between the sev- 
eral factors of the situation and the several alternatives of response, and again the several ranges of inclinations and aptitudes to be drawn upon in preparing it, the route to action comes to be mainly through ideas-ideo-motor rather than emoto-motor. The rôle of the intellect in furthering distinction, recognition, comparison, in the analysis and appraisal of the situation and its further play in suggestion and imitation in shaping response, has already been set forth. By its operation the representative situations become as real as those in sensory terms; mental situations not only replace physical ones, but create a new order of situations in the "ideal" life. The more concrete embodiment of this range of forces lies in the action of the imagination, the representative experience. The route of suggestion, when it follows this course, vastly enlarges its scope and makes mental suggestion a far more important factor in psychic regulation than suggestion on the sensory plane, makes beliefs of even larger influence than experiences, imposes speculation upon observation and interpretation upon facts. The result is not alone that one may become thirsty or aware of one's thirst through the sound of running water, or at the sight of someone drinking-as the odor of appetizing food makes the mouth water-or in reading about life on the desert, but that the situations thus responded to are far more commonly and more significantly those of the last order than those of the other orders. Nor is the essential relation so bare as this: it is not alone that attitudes shape mental situations and determine policy and the spirit of responsiveness, but that the instrument of psychic control thus intellectually shaped sweeps over the whole range of experience with momentous reconstructive effect. The mental element leads in the approach to situations, and makes for apprehension and comprehension. Intellectualization refers to the prominence of the recognitional, the objectively referring, the associational, the explicit factor in appreciating the situation-by im- 
plication a mental one-and the further play of such factors in reshaping the affective attitude and in maturing the response. Considered generally such participation determines the actual status of the emotion and the conduct: whether feeling guides with the aid of distinction and its associated processes, or whether consideration leads, modified and supported by emotional promptings; at still higher levels, whether we reason our way to conduct and compromise or restrain our feelings, or whether we follow our impulses, impressions, and predilections, finding such support in reason as we may. It is the contrast of acting more by feeling how or more by knowing what and why.

As it affects distinction, the quality was portrayed in considering the natural impressionism of the sensibilities; in distinction, analysis proceeds to determine whether feeling is dominant, incited by a recognitional moment, or recognition is dominant, sustained by an emotional appeal. The comprehensive reason why intelligence is so vital to regulation lies in the first instance in its support of the emotional interest, in its direction of impulse into the channels of purpose and design, toward the integration of experience. The desire is vitalized by emotion, as is also the satisfaction of accomplishment; but the means of attainment are intellectual and constitute the specific plot of the action. Impressionism stands for the fact that a slight ingredient of recognition, at least of explicit recognition, is sufficient and is effective through the emotional affect which it inspires, though in higher stages readily and commonly reënforced by an organized group of distinctions. As already instanced, animal and infant responses frequently leave uncertain the degree of intellectual meaning which the response entails: whether father or master is greeted by infant or dog specifically with the joy of recognition, or is generically received as a friendly, sympathetic, welcome but unassociated presence. Language alone is a sufficiently explicit and developed intellectual product to furnish an 
adequate expressional statement. The dumb creation and the infant (literally : not-speaking) have only an emotional language at their command, and presumably respond only to the emotional appeal however couched. The tone of endearment and reproof in the language of father or master is understood long before and more intimately than are the words in which the attitude is conveyed. Emotional language is earlier, as the emotional life runs deeper than the intellectual.

There is no need to dwell more minutely upon the initial stages of intelleetualization; we soon reaeh the very extensive realm in which the appeal embodied in the elew between stimulation and its response is composite, yet tends toward an intellectual type. The resulting impressionism extends to various phases of human nature; at more complieated stages it becomes the contrast of the esthetie responsiveness of different orders of quality of pleasure or pain: in what manner and degree subeonseious, implieit, subjeetive, or eonscions, explieit, and analytie of situation. It appears in the form of insight, intuitive feeling of values, as against reasoning-eritieal knowledge of signs and connections; it beeomes the sense of direetion as against the points of the compass, the rule of thumb as against the rule of head. The theme set forth in terms of the simpler orders of sensibility may be transferred with variations to the higher levels, where emotion and reason and their composite assoeiations operate. Sensory distinetions, general impressions centering about the pleasurable moment, and a schooled experience combine. Feeling recedes as the intellectual eriteria advanee; as the sensory elew to distinction retires, judgment-considerate of relations, reasons, and motives-replaees a more subconseious emotionalized impressionism, yet never wholly supplants it. Feeling one's way to a solution gives way to and is absorbed in reasoning one's way to it. Yet the situation must be complex to bring forth the intricate play of the contributing 
factors; and none is more so than the complexity of human intercourse with its strongly socialized relations. The reading of others' motives, the anticipation of others' actions, proceed upon the distinction of situation, in which sympathetic feeling is uppermost. Consideration is prompted by individual sensibility, is its sympathetic extension; and morality, no less than sociality, waits upon an impressionistic insight. Upon the same insight rests the capacity to distinguish between the false and the genuine in this as in simpler relations. The appraisal of social advances and attitudes at their true value in order to avoid presumption as well as deception, to maintain selfrespect and yet present a due friendliness, to meet expectations and yet neither give nor take offense where none is intended : all this is a fine art-the art of tact-based upon an intellectual sympathy, conversant with the acquired conventions of its exercise.

Our purpose will be advanced by the consideration in the first instance not of the general play of intellectualization in the higher psychic regulation, but by consideration of the distinctive products which intellectualization contributes to human evolution. Such products must by law of nature build upon the regulative provisions operative at lower levels of development, and by the added integration give them a reconstructed service. The dominantly emotional response infused and guided by the appreciation of meaning remains central in psychic regulation. Applied to the several distinctive appeals of which the emotional life consists, the intellectualization of these traits gives to each a distinctive career. The issue is a sentiment-a term both popularly and scientifically referring precisely to the intellectualized, presumably socialized, often conventionalized, feeling trend or Trieb that determines attitude and action. Sentiments develop only upon emotions as operative in a properly qualified and matured self. The sentiment retains the motive power of the emotion, with the spe- 
eific carrying power and center of radiation of the idea. Sentiments form the leading, derivative, upper-level products of instinctive human qualities. They are subject to extensive evolution, and reflect as does no other phase of our psychology, the historical vicissitudes of the human psyche and the conditions of human progress. Their prominent position in the psychological welfare involves an intimate bearing upon conduct-always the test of efficiency of character. The emotions are "feeling" incentives to the favorable release of natural impulses; the sentiments supply rationalized motives to complex, considerate, artificial conduct. Gusts of emotion find outlets in direct expression; waves of sentiment more or less indirectly affect attitudes, modes of thought, and through these elaborated channels, shape conduct. Mere emotionalism unallied to impulse is apt to be vain; and overindulgence in sentiment, by its remoteness from resolve, runs the risk of enfeebling and devitalizing conduct. Yet at the high-level development where sentiment guides, the relations are so inherently complex, that a certain remoteness of interaction between feeling and doing is legitimate, indeed, requisite to the expansive and refined function. Furthermore, a distinctive trait of human quality appears in the relative absorption in, and affectability by, sentimental considerations, with the motivation subtle and indirect, the character contemplative and receptive; and again in the contrasted disposition which passes lightly through brief moments of vivid and intense feeling to the joy of impulsive satisfaction in doing. Quite as significant as the emotional is the intellectual factor in the process and product; it serves not alone as the fixation and rallying point of maturing attitudes, of systems of psychic and moral regulation, of trends of desire, resolve, and endeavor, but equally supplies the concreteness and explicitness of representation through which, in manifold variety and growth, the sentiment is maintained, fashioned, revived, and redirected-pointing it to a practical moral as 
well as adorning it as an engaging tale. For thinking, which is reflection, readjustment of experience, redirection of impulse through consideration, is the life of the mind; and conditioned by practical aims, tested by results, it finds its issue in set habits and attitudes, which are the concrete deposits of traits of character.

The simpler-and as applied to more cultivated individuals, the truer-statement results from a substitution of the intellectual for the emotional perspective. The higher psychic control is a process of thought; it is thinking under the spur and guidance of feeling. Thinking requires an object, also a road upon which to travel, and a conveyance to carry the utilities and the impedimenta of the journey. The journey may be sentimental or utilitarian, real or imaginary; the tempo, the spirit, the nature of the journey is largely determined by the interests and capacities of the traveler; yet most journeys have a common or ordinary purpose, a standard range of incidents, pleasures, and trials, and a commonplace route. Moods come and go, and purposes constantly change; their persistence while they last is due to the taking thought-the direction of sentiment and emotion in and by the stream of consideration. Such is brooding if the sentimental tone be depressing in grief, resentment, revenge, hatred, despair; such is bliss, if the sentimental course be cheering in love, hope, triumph, admiration, gratitude, relief; such is mixed contemplation, if the sentimental tone be one of intellectual inspiration in insight, discovery, surprise, curiosity, resolution of doubts and worries. Equally characteristic are the alternations and conflicts and interplays of sentiment that make the complexities of the thoughtful life-its thorns close to its roses-and the perplexities of right knowing and doing.

In one great realm through the sway of sentiment, in another through the dominance of reason, the intellect enters into and possesses the higher regulation of the psychic life. To appreciate its scope and perspective, we may pass in re- 
view the chief types of sentiments and their service. The bare mention of the leading sentimental attitudes-love, hate, admiration, surprise, pride, honor, shame, modesty, sorrow, joy, scorn, reverence, rage, despair, pity, gratitude, respect, repugnance-indicates two points of community. The first is the bearing of these sentimental movements upon the ups and downs of the inner, emotional, personal welfare; they represent the meteorological vicissitudes of a sensitive self responsive to the shifts and veers-the thermometrical, barometrical, and other intricate changes in the "personal" atmosphere-in the social-psychological climate in which we live and move and have our being. The second is the converging power of the sentiment in the fusion and amalgamation of many varieties of emotional disposition. With the object fixed in a sentiment of love, I converge upon the loved one affection, sympathy, jealousy, hope, anxiety, admiration, favorable prejudices, pitying reproach if offended, tender sorrow if disappointed, ready forgiveness without resentment, a double measure of gratitude if served, enhanced joy if approved; I converge upon the hated one, revenge, a joy in his woes and an indifference to his joys or cares, contempt, an unfavorable prejudice, ruthless anger if offended, an unforgiving resentment, a scorn of his kindness or compliment. Each of the larger sentiments gathers about its central core of affect a considerable cluster of related and subtly interacting and counteracting contributory influences, converging upon the complex veerings and shiftings of self-esteem and selfabasement. Yet it is equally true that toward the same object I may feel a like complexity of sentiment. I may love, fear, respect, and pity, the same person. Opposing and combining sentiments determine my composite attitude toward my friends, my social and my professional obligations. Brothers and sisters quarrel readily and remain friends by ties of blood; the ties imposed and those freely made entail different sentimental relations. Relatives, if 
they happen to present a different social standard and a wholly divergent set of interests, are trying to natures that thrive only upon an intellectual congeniality. While these situations form sentimental problems, they enter the field of reflection, and practically require compromise and restraint. Yet the sentimental life, however strongly it reflects at every stage its direction by reason, is determined by the fundamental range of the emotions; and the emotions have a backward reference to the urgent or luxurious situations which they meet, and to the responses which they infuse with the added zest of interest, meaning, refinement. Certain ranges of sentiment are strongly intellectual in bearing and composition; others, less disinterested, are in the main emotional expansions and complications. Their boundaries overlap; definition gives way to the rendering of types; moral and esthetic considerations, with their intrusions of value, are insistent; custom and the environment divert them to contrasted issues; the abnormal varieties present extremes of development; the balance of sentimental allegiances offers the individual problem of regulation. Individuals, groups, classes, nations, and civilizations diverge and find mutual understandings difficult because of their divergent allegiance to one and another sovereignty in the domain of sentiment.

Pride is a sentiment direct in its reference and expression; it is the sentimental elaboration of conquest, supremacy, the getting the better of persons or difficulties; it is the emotion of success, attainment, exultation, stripped of its coarser implications. The proud man draws himself to his full height, holds his head high, disdains, exults, may even strut like a peacock. This aggressive by-play remains attached to the self-assertive sentiments, such as vanity, conceit, dignity, authority, majesty. The expression needs the context to interpret it. We refer vanity to the peacock because we humanize the peacock's instincts by irrelevantly imposing upon them the sentimental values of 
the human expression. The pride may take the form of vanity in elothes, serving-like the parade of the peacock - the instincts of display. It may be of very different range and ally itself with dignity in the badge of office, the precedence of rank, or take its tone from distinction in the gaining of a prize, an honorary degree, a title of privilege, membership in a limited body; or from achievement in authorship, construction, invention, management, finance. It is indeed a most elastic sentiment, and characteristically extends to all one's belongings and connections, most intimately to such personal connections as reflect credit upon one-the distinction of one's family, the success of one's relatives, the qualities and achievements of one's children. All these are the extension of the individual self by virtue of the social self and of the intellectualized system of relations surrounding them. One may be proud of one's birth, one's family, one's ancestry, of one's physique, one's wealth, one's good taste, one's home-grown vegetables, one's yacht or automobile or horses and the records which these have established; of one's skill with cue or golf-stick or trout-rod; of one's choice English or cosmopolitan accent; of being a busy man or a man of leisure or a man of the world; of rising from the ranks or of one's early advantages; of being in the height of fashion or of being superior to fads and fashions. We judge a man by the manner and objects of his pride, and to such of these as he takes pride in, he gives attention. They aid and abet his self-esteem; they are to him objects of value by virtue of their status in a social systcm of values; they represent the inlets to his pride, as the care and attention he places upon them serve as the outlets of the sentiment. Yet emotional disposition, however subject to training by society, school, and Mrs. Grundy, or by systems of morals and ideals, still shows through. It still has a meaning to speak of a man as proud or of a woman as vain; or to call one humble, modest or subservient, and another overbearing, conceited, or defiant. 
Such character-traits and the modes of exhibiting them represent the strength of self-regarding impulses. The masterfully assertive man and the meekly submissive man regulate their conduct by different perspectives; they must be dealt with by different methods.

The satisfaction of pride becomes a motive. It is such motive that determines the goal of desire, the direction of effort, the restraints of conduct; it is this motive that social forces use to establish a hold upon the individual. Yet character is judged not alone by the strength of one appeal or another, but by the classes of objects and achievements in which the individual chooses or is impelled to feel and exhibit his pride-his selection among the patterns offered by the mental, moral, and material aims and interests of his social environment. Once more is it well to recall that pride and the group of sentiments of which it is the type-form would not have developed, had there not been an emotion of elation instinctively connected with the primitive self-assertive tendencies (in combat, play, rivalry) that gave it a natural rôle; and in addition had not the general social and intellectual development expanded these relations and transferred and differentiated the motiveimpulse to appropriate stimulations in the larger system of interests which the larger life creates. For their efficient operation in the higher phases of regulation, the sentiments imply a centralized self, a self capable of assimilating the sentiments and understanding as well as feeling their appeal. A self-consciousness, a more or less reflective assimilation, accompanies understanding; the sentiments thrive in the medium of such consideration. They are incorporated-again more or less deliberately-in institutions, customs, beliefs, ideals, and are stimulated by these social forces. Such artificial stimulations exist because the needs and satisfactions of the sentiments create them; their fundamental source is in the qualities of men. The socialized and intellectualized man requires a sense of pride for his 
devclopment to a proper place in the conduct-regulating system. The pride represents at once the hold of the system upon the individual and the individual's participation in, his susceptibility to, the forces of the social organization. The sentimental life grows with and marks the growth of the self: the sentimental life of children is not that of adults; of primitive peoples not that of the highly civilized; of peasant not that of patrician; of the laborer not that of the scholar. The differentiations of men, while founded in native temperament and set by the circumstances of their lives, proceed ultimately by the support of their sentimental divergences, assisted by the like divergence of intellectual capacity and of the simpler regulative systems already passed in review. Of such regulation the stimulations of self-esteem, as embodied in the type-form of pride, offer the standard illustration.

The survey of pride may be supplemented by a like consideration of the opposed self-restraining, self-withdrawing, or self-detracting sentiment. It presents itself as a closely organized cluster of sentiments, best indicated by humility, modesty, shame, and the attitudes of admiration, reverence and submission toward others. The common basis of the group is a feeling of the lowered, retreating submission of the self; it has the common negative trait of being nonassertive or non-aggressive, but for the rest is promptly divergent in its quality. The sense of modesty carries the tenor of the trait most directly. As applied to the exposure of the body, modesty assumes as its complement the sense of shame. The age of innocence and the story of the fall of man enforce the lesson of its moral bearings upon the distinction of good and evil; its intellectual bearing is symbolized in the fruit of the tree of knowledge. But the central bearing of modesty is modesty of spirit, a modest view of one's worth and attainments and exploits; it takes the form of a genuine humility, checking a too pronounced or too inconsiderate self-assertion. Socially it becomes the 
deference to others, the acknowledgment, the ready admiration of excellence in others. Applied to one's shortcomings, it becomes a factor in moral regulation and imparts the sense of shame in the consciousness of remissness or offense. Such response may approach in expression the earlier phases of timidity; we shrink and hide in shame as in fear, yet are expert enough in analysis to distinguish the shrinking of humility and that of guilt, or other type of self-abasement.

Modesty of person presents the most varied and curious conventions of race and custom; and this circumstance points to its true status. As actually applied, the sentiment is substantially an artificial product; hence its fluctuations. The growth of the sentiment in children is an index to their maturing character; shame is in large part an inculcated feeling. The complicating relations of the life of sex have more to do with the extreme development of the sentiment than has any other factor. They spread a secretive character over the entire relations of sex, and sensitize to the remotest suggestion of impropriety in mention or thought of sexual incidents; the extreme form of the sentiment leads to prudery. But the net issue of the sentiment as exercised is this: under an exacting social standard, a man may be distressingly if absurdly embarrassed by the absence of his necktie; a different play of the social sanction under sway of sentiment may give propriety to a bathing-suit. Things are modest by their place in thought; honi soit qui mal y pense; and the spirit gives and takes or holds immune from offense. Such considerations make it plausible that modesty of person is a reverse transfer of a high-level sentiment to a (lower) natural situation, originally regulated without such intrusions. This derivation may be otherwise stated. Having developed a moral sense of modesty and shame, man projects it upon the exposure of the body and the suggestions of nakedness. The true range of the sentiment is mental and moral, even de- 
cidedly artificial; it is possible only to organized individuals. In direct reference, one is ashamed of offenses, of opportunities neglected, of remissness of obligation, of lack of consideration, of slight or gross selfish indulgence. In type the things of which one may be ashamed are as various as those of which one may be proud; and so divergent are standards that one man may be ashamed of that of which another may be proud-witness the social shame or pride of humble origin. One may be ashamed of untidiness, shabbiness, poor work, humble surroundings, of a meager bank account, of one's associates, of being out of fashion, of losing one's position, of an outburst of temper, of negligence, of offense to any of the standards of good behavior [11], or of any type of failure in any cherished direction.

These illustrations of the operation of the sentimental regulation affecting in contrasted manner the rise and fall of self-esteem will suffice to bring forward the general manner in which such regulation transcends and supersedes the earlier types. 'The evolution of fear as the parent type of the shrinking emotion is equally apposite. Let the higher range of forces play upon fear, and it becomes dread, apprehension, hesitation, embarrassment, precaution, consideration, worry-all set in an elaborate system and forming nicely differentiated series of expressions of a common concern. The reasons for this equipment are capable of simple statement. If all that we had to care for were our bodies -as is nearly true of many animal forms-the only dangers would be those of physical injury, the only responses those tending to avoid and protect against bodily harm; the range of fear excitements would be the flutter accompanying the simple measures of protection-flight, concealment, shamming dead, running to cover, or other organized habit. As a fact we fear for all we care for ; and our fears, like our cares, grow with our possessions and our responsibilities. Our interests and protections extend to all the objects of our desires, however established. For diverse 
and obvious reasons we all care more or less for power - prefer to rule than to be ruled-and for property by attachment to what we have, for our reputation as a vital social asset, for our friends, our families, our city, our nation. Any loss of or injury to these is a hurt to us; such injuries we "fear" in the transferred sense. It is not that they actually make us hide or run; though we feel like deserting, and say that we tremble at the thought of what is before us.

By similarity of attitude the language of fear is available for the slightest occasion: we fear that we cannot linger, when urged to extend a visit; we fear that it may rain before we reach home; we fear that it is getting late. Any hesitation, shrinking, avoidance from an undesirable consequence, however contingent or trivial, becomes a transferred fear-an ever so minute, indirect, derivative, metaphorical imminence of loss or disquietude [11]. Fears become the offsets of our desires, the possibility of failure lurking near to the venture for success. The conflicts of motive again become pertinent: the honor of an invitation to speak at a public dinner as something to be proud of is offset by the nervous apprehension of the approaching trial, which spoils the enjoyment of the repast. However controllable and remote from the primitive occasions of fear, the affect continues and presents the same physiological complex-the drawn face, uncertainty of response, motor instability. Prominent in psychic control is the rational meeting of undesirable consequences by prudence, foresight, forethought, all weapons of forearming. We thus regulate our withdrawals, take our precautions, are ever careful, mindful, on our protective guard. This is equally true of the checks which we place on our words, on our actions, on our investments, even on our thoughts. We scent danger everywhere; but the dangers have vastly changed in the reconstructed life-infections, poisons, electric shocks, pickpockets, missteps, collisions, unreliable 
banks, adulterated foods, misleading advertisements, intrigue, stock-jobbing, false friends-while the older and standard risks lave vastly altered their character by their increased complication. The armament needed to meet these situations is wholly different from that which we have inherited to meet the natural dangers; nature cannot be prophetic, and instincts are protective only from natural dangers. To act toward the artificial transferred dangers as one might toward the natural threats to the body-to run away from microbes, or hide when a bank fails-would be foolish in the extreme; yet in limited measure the unsuitable responses of animals may be cited as cases of such survival. But the central bearing remains that of the selfreference, not to the limited natural primitive self, but to the expanded socialized and intellectualized self. The extension of the personality extends fears and desires and the scope of each and all of the sentimental elaborations of primitive impulses; the objects of interest extend to actual or possible possessions, however immaterial, contingent or remote, and to all the derivative circumstances that compose or influence their values; the attitudes toward them become complicated by the manifold varieties and refinements of sentimental relations. It is essentially the same process, by whatever name it is described, that is responsible for the evolution that converts primitive exultation to pride, primitive shrinking to shame, modesty, humility, in one direction, and to apprehension, embarrassment and worry in another. If we add to this conclusion the further corollary that from such extension and at the different levels of its complication (and furthermore from the interplay of the several motive trends, thus differentiated) there arise offshoots and by-plays of relations and attitudes of a derivative status, referring to parts and abridgments of the complex, and to refined specialized relations arising within the complex, we have a fair sketch-map, an intelligent plan of the phases of higher psychic control. In interpreting the 
map we use the conception of value, and may most simply indicate the resulting change by the statement that the psychological expansion and the enrironmental complication introduce and create new ranges of value in the regulative process. Desire implies the attachment of value; fear of loss is of possible diminution of value. It is obvious that we still cling to the original perspective and value our lives most highly, saving our skins when all else must go. But ordinarily the acquired perspective of value dominates; and the scale presents the characteristic variations that attach to civilizations, social stations and individual characters. Whether expressed as values or as psychological complications, the changed status of regulation remains the central point of attention in analysis and in the practical perspective. The understanding of the nature of the process in its reference to the sources of human nature is as vital to the practitioner in any of the relations of human concern as it is to the psychological analyst [13].

With the mode of establishment of sentiments thus illustrated, it remains briefly to note the interplay of sentiments with and upon another and the modified, derivative, partial sentimental attitudes thus resulting. Sentiments of kindred order combine by congeniality: tender feeling and pity attend love; hate breeds loathing. Sentiments are offset by opposing trends: scorn issues from anger with the check of fear and the support of superiority; it may combine disgust, lose the semblance of dread, and become contempt; it may soften its features toward disdain, leaving mainly the superiority. Self-assertion ever moves cautiously or considerately between the threat of insistence or compulsion and the fear of withdrawal and compromise; between the desire to impose and prevail and the fear of wounding. Sentiments are complicated by by-products and subsidiary attitudes; revenge is an issue of hatred fed by anger and of a desire to repair wounded self-feeling by exultation over the fallen foe-a turning of the tables, in 
which the previous discomfiture but intensifies the present triumph; resentment is the reflective preparation for the vengeance; jealousy is itself a by-product of combat moved by anger, while destructiveness is a motor by-product of pugnacity, even to the slamming of a door as a parting shot in terminating a disastrous argumentative encounter. Sentiments develop by a scheme as variable as the psychical capacity, and differentiate nuances of attitude as intricately as the circumstances of their setting.

Self-respect becomes a happy mean between conceit and overmodesty; condescension rearranges or assumes elements of both. Envy is admiration of another and detraction of one's own lesser fortune; grudge expresses the envy without the kindlier element. Reproach is anger expressed toward one who is the object of affection; criticism is sharp-tongued or good-natured; chaffing, bantering or teasing shows appreciation, is both loving and irritating; flirting is both serious and playful; humor appeals to sense and to the divergence from it; irony and satire assume the semblance of praise with the indirect sting of censure or belittlement. Gratitude is a tender emotion toward the source of benefaction and a certain submissiveness (negative self-feeling) of its beneficiary. To offer and accept a favor graciously is a fine art of social intercourse on both sides, so delicate is the shifting of values of the self-regarding sentiment in sensitive personalities. Lady Bountiful may easily become odious by an exacting condescension; and a shameless acceptance equally with an overweening refusal may destroy the beneficence if not the benevolence of the act. The hero-worship of a great man is the more engaging when modestly received; though false modesty will also turn its edge. Adoration of unworthy popularity or of ill-proportioned type like toadyism, becomes nauseating to sensitive souls; and the worship of money grates upon lofty sentiments.

It would be as impossible as unnecessary to follow the 
source of development or even to indicate the status of each of the components that together form the register or repertory of sentiments and sentimental attitudes; all highgrade emotions are more or less sentimentalized. The forces to which the emotional trends are exposed through the social and intellectual environment turn them to a sentimental stage. If capable of such affiliation, they attain it; the sentimentalization may be more or less explicit, may be more or less encouraged by the environment, or fail of such encouragement by mere absence of place and partthe environment developing it feebly - up to the discouragement exercised by an opposed sentimental strain. Sentiments themselves vary in the manner and degree of dependence upon the environmental forces; the most complex sentiments or the most elaborate development of simple ones regularly embody the strong play of environmental influences, and are for that reason more satisfactorily considered from the environmental point of view. The operative force is known as convention; the contrast of the component tendencies in such sentimental issues becomes that of their relatively natural or markedly conventional status. Yet so familiar are these sentimentalized products in human relations that they participate as naturally in the acceptances and rejections as those based upon such direct organic equipment as the sensibilities; by virtue of this naturalization of the sentiments we speak of a "sense" of justice, and await and encourage its appearance in children along with their early introduction to the social and intellectual regulations of conduct. "Fair play" and a "square deal" are as familiar concepts in the nursery as in economic discussions.

The stages of expression of punishment will serve to continue the argument. Punishment is modeled upon the natural sequence of pain upon infringements of natural adjustment. Contact with a flame hurts because tissue is injured; the process is substantially as "natural" as that 
by which the pricking of a thorn hurts or the bitterness of gall repels. Playing with matches is not hurtful but hazardous, is, indeed, interesting and pleasurable. If it is punished by a rap on the knuckles, the disciplinarian has stepped in as a deus ex machina and interposed a wholly artificial consequence, that follows only when the transgression is observed or reported. But once thus acting, the threat replaces the fear of consequences as efficiently as the actual hurt of the burn, which also becomes a fear of similar pain. The attachment of value as reward and punishment is the universal method employed by the environmental play. Punishment thus considered begins as corporal chastisement; it inflicts physical pain, which is unpleasant by natural constitution; the avoidance of such literally unpleasant consequences, it is assumed, will deter from repetition of the offense occasioning it. Yet also the rod by further association incites fear; fear of pain has a natural place in psychic control and increases the smart. The threat of the whip may be as effective as the sting; the power of fear asserts itself early and persistently. So accustomed are we to view punishment as a moral instrument in end and means, that we shrink from a return to its primitive form. Even when resorted to, parental punishment is impressive by stern severity of discipline and restraint of blow. The transformation of attitude is accomplished when a moral punishment is substituted for a physical one, when the appeal of the punishment is to an organized system of sentiments--sentiments shared and exercised by both parties to the situation.

A typical psychological appeal is to shame, especially to shame socially manifested. In school the rod may be replaced by the foolscap or by detention after school-hours, which in turn may be less "felt" than the taunts of inconsiderate companions. The stocks of more primitive days were intended to be moderately painful and equally to subject the victim to public gaze and jeer; and the scarlet letter 
became the symbol of the tragedy of proclaimed shame publicly expiated. With the changed status of punishment the appeal changes: disgrace hurts more than pain only when the social sensitiveness is present to make it hurt. Deprivation must really deprive of something that is cherished. "What is banished but set free from daily contact with the things I loathe," was presumably but a Ciceronian taunt or consolation. Children recite that,

Sticks and stones

May break your bones;

But names will nerer hurt you,

and disprove the sentiment by their sensitiveness to names and their indulgence in malicious verbal teasing. As a fact the appeal of reward and punishment alike is to something that one cares for; the something may be both material like confiscation or payment of damage, and far more usually sentimental and spiritual-loss of rank, honor, esteem. The disgrace of punishment becomes its sting. And if we adopt the altruistic sentiment, punishment is intended not merely to deprive but to reform and redeem; punishment itself must stop before the spirit is broken and the appeal to self-respect destroyed. It has taken society a long time to learn the lesson. Whether we seek effective moral punishments of children or a properly regulated system of punishment of hardened offenders, we must find a real deprivation or affliction, a curbing of unrestraint, and also protection of self-respect-an appeal to saving virtues. Everywhere we seek for available motives, something that people care for, some factor that in a complex appeal may save the situation. The mean between the selfregarding and the self-detracting sentiments may be difficult to find, but practically it must be found.

Deprivations grow with the extension of varied desires and the constancy of their satisfactions. The same outward punishment is glaringly unequal in severity when 
imposed upon different persons. The opposition between making the punishment fit the crime and making it fit the eriminal is the difference between the recognition of convention and institutional interests and the recognition of the psychology of sentimental regulation. The mixed system prevails-in the family, in school, in society, in formal institutions. The withdrawal of the usual marks of social regard serves as punishment; displeasure, neglect, unfriendly looks, act as deprivation of keenly cherished social favors; and these replace the physical deprivations of "no dessert," or "'being sent to bed without supper." The same play of motives determines the formal punishments of the State to deter from offenses against its laws. The psychology of punishment must make terms with the common fundamental psychology of emotions and sentiments. While the whipping post is still retained in isolated punitive systems, and physical deprivation prevails, disgrace and dishonor always accompany them and commonly outweigh them. Indeed discipline and restraint are of themselves unable to carry the sentiment of punishment; and martyrdom for a cause may make the prison an honorable servitude in the eyes of sympathizers. Likewise, where moral motives fail to make an appeal, punishment fails to punish; materially, life within the jail to a chronic vagrant may come to be more secure and quite as welcome as that in the uncertain world without. The psychology of punishment must consider both the social environment and the psychology of those subjected to the process. In the lighter disciplines and encounters the manner of punishment reënforces the same moral. "Adding insult to injury" becomes a real aggravation because the insult hurts more than the injury; it injures one's reputation, and suits for libel are recognized as equally legitimate as suits for assault. The discomfiture of reproach rankles; honor and all that for which the organized sentiment stands becomes the object worth fighting for and open to the keenest hurt 
or wound. Everywhere the moral replaces the physical, and ever in more refined and more remote derivation. Here, as in all such developments, refinement tells. Debate and controversy may be carried on with the same zest and even heat, but with very different weapons. A political campaign may be clean or dirty, acrimonious or fairminded, courteous or rude. Vilification, slander, innuendo, irony, magnanimity, free field and no favor: each chooses his weapons according to his sensibility and his standards. But the efficiency of the weapons, the very existence and availability thereof, spring from the common source of "sentimental" psychology.

One further aspect of the sentimental product may be noted. The transforming power of sentiment, when reënforced by principles and ideals, may in its remoteness from nature turn against it. The difficult problem of the altruistic trend recurs. If altruism as a sentiment is carried too far, may it not destroy the integrity of the self-regarding impulses? The conflict is significant psychologically: to turn the other cheek to the smiter suggests a reversal of natural inclination seemingly too radical to be grafted upon the parent impulse, and suggests no less an exaggerated self-detraction, itself liable to confusion with timidity or overhumility. Yet ideals, as will duly appear, have in many respects turned human qualities radically from their natural orbit; and asceticism, stoicism, and the cloistering and scourging as well as the denudation of the emotional life have in turn been practiced as meeting the highest ends of human destiny. Thus sentiment, issuing from consideration applied to natural emotional incentives, in the end analyzes and reconstructs, organizes and eriticizes in terms of artificially established values the issues of its own growth. It decides that the ends thus rationally remodeled require provisions and encouragements, and devises means to establish them; it decrees that the ape and tiger in humanity shall die, and determines what qualities shall re- 
place them. The enforcement of the decree and its formulation consummate the process of rationality, and enthrone morality as a psychic regulation. For this end sentiments must be systematized; and the systems of sentiments, variously embodied in the institutions of culture, constitute the actual molding forces of social progress and social stability.

With the attainment of sentiment the sources of human quality are in a sense complete, however endless the possibilities of evolution of the sentimental life, however rich its social and intellectual issues, however elaborate systems of conduct, moral codes, and philosophies. Despite its manysided limitations, it remains a deeply significant truth that we "can bring no more to living than the powers that we bring to life." Living is more than life-the life natural. It is overlaid and complicated by acquisitions, enveloped in convention, directed by ideals. Even abnormal qualities and products are brought about by the stress which living places upon the powers by which we live. While the traits of human character do not directly yield the forces of human history, or the organization of human society, or even the realized varieties of social intercourse and conflict, they illuminate these issues, even as they take illumination from them. Social influences and events deal with human totalities set in condition. It is logical to reach their consideration through a study of the sources from which the issues spring. Yet psychology, like life, must in the end deal with individuals and environments. The special complication of an applied human psychology lies in the circumstance that the intricate plexus of qualities evolved in that transformation of human nature which we call eivilization, itself contributes the effective factors of its own progressive environment.

This survey of the sources of human quality directive in psychic regulation, is inadequate by reason of the too slight consideration of two momentous factors. Their brief supplementary consideration can hardly restore the true 
perspective of their place in the mature psychology of man or in the step-by-step unfoldment of his powers. If, however, it be recalled that the legitimate empliasis of the present pursuit is upon the relations of types of quality-notably in and near their origin - to the varieties of character, the perspective employed will be justified, and a due correction readily introduced. The first factor is the logical regulation by insight and reason [14]; the second, the energetic factor of determination and will. The sense in which man is predominantly a rational animal is not likely to be overlooked; and the practical lesson that qualities can reach expression only through will is likewise not apt to be neglected by the moralizing propensities that make man not only a reflective but also a pragmatic being. Psychology has quite too exclusively dealt with the former quality of reason; and the stress of practice and the urgencies of conduct are equally prone unduly to emphasize the latter quality of will. It may be possible to give each its due, while remaining loyal to the general design set by the scope of the present undertaking.

It remains central in the genetic view that the significant contributions of the intellect are its infusion and transformation of other psychological dispositions-the intellectualization of the instinctive impulses and the tendencies emerging and maturing from them-rather than its independent achievements, potent as the latter are at the outset and increasingly so in the psychic growth. To say that rationality is the scaffold, conforming to the same outlines, without which the building could not be erected, conveys the partial truth of analogy; the figure would be more apt if we imagine the scaffold-like a skeleton-absorbed and preserved in the structure which it supports in use as in construction. The elew to the life of reason lies in its service to an emotionally derived conduct; its marvelous power to remodel the products of original impulse gives it an architectural supremacy in the modern world, but dimly fore- 
shadowed in its primitive estate. Yet so potent a factor, whatever its ultimate scope, has a vital primary psychology of its own; it finds in the natural environment a large field for exercise and encouragement, and thus parallels as it conditions the growth of other phases of regulation.

In the accepted analysis of the reasoning tendencies, the fundamental intellectual requisite is the approaching step of attention-the emotional phase of which is represented by interest. It is the impulse that, conditioned by natural dispositions and equipment, brings the situation within ken, and then holds it there for distinction and recognition -all preparatory to action. The emotion-instinct thus comprehensively effective we call curiosity; it invites and receives experience, recognizing and relating under the pleasure of familiarity, or assimilating under the spur of novelty, or avoiding under the warning of caution. On the active side it leads to the experimental impulses, which enter prominently in the "play" complex. The reaction to and redisposition of the situation, resulting in new stimulations and satisfactions, engage constructive and inventive impulses. Experience thus becomes knitted together by association; while anticipation in the one direction and memory in the other make way for adjustment beyond the present. The representative trends of thought and imagination that give the intellect its direction are developed for their own sake: the exercise of "thinking", is itself a satisfaction, while yet it extends the zest of action, and comes more and more to color the satisfactions of the composite psychic life. Through its exercise invention brings rewards in achievement; if thorough and developed, it confers insight into the relations of cause and effect. At that stage it favors the keen and abstract perception of relations-a culminating fusion of insight, ingenuity, and comprehension, upon which the ministration to human needs sets a premium. The parentage of invention is not quite so simple as is commonly assumed. Neces- 
sity may act as a spur, but hardly confers the discernment that determines true relations: the analysis of the nature of things, the breaking-up of experience into intelligible parts, and the confirmation of the analysis by the test of further experience. The desire to avoid effort, often rated as a predominantly masculine quality, may equally supply a spur to invention, and develop resourcefulness. The environment, to which adjustment must be attained on penalty of extinction or loss of vantage, by this selective process sets the direction of emphasis, which a favorable variation in a favorable endowment provides. In tracing the original "natural" condition setting this trend, it has been suggested that when the animal ancestor of man gave up his arboreal habit, his feeble olfactory sense threw the burden of his survival not alone upon the keen use of his eyes but of his wits. With no formidable natural weapons of defense, he found them or made them, using strategy or invention. By keen observation or shrewd guesses, as well as by traps and plans, he asserted his dominion. Reducing his fears by recognizing their groundlessness, he increased his confidence and extended his control over nature. Turned to intellectualism by stress of nature, he accepted and developed the necessity into his choicest possession.

Whatever the origin of this quality by which we distinguish, compare, contrast, analogize, infer, it soon comes to its own, in shaping reactions directly by the knowledge that is power [15]. Its distinctive elevation to a higher efficiency may be said to attach to the power to consider the relation apart from the terms thereof, to handle the situation as a type, or abstractly: to count not stones or trees or shells, but to count in numbers, eventually to reason in numbers-to conduct the campaign in imagination or on paper before taking to the field. The stages of the process are capable of succinct statement. From direct response to experience through sensibilities, there emerge by attentive selection the perceptions of objects and their 
behavior, then of the relations revealed by analysis under specialized attention, and from these by abstraction, the development of concepts, at first simple and then more and more complex ones. The concepts may be feebly explicit, even vague and but partially intellectualized, and yet effective. Such is apt to be the ease in the relations and conceptions developing upon an emotional basis. The sense of honor or of justice may be an effective motive as a sentiment, though the sentiment is not consciously reflected upon. In this deposit, as already reviewed, lie the richest values of the intellectualizing process as it affects the personal life-the control of self. Similarly in the recognition of causes and effects and in the development of such knowledge into a system of principles, lie the highest achievements of the intellect in its own realm-the realm of objective control of nature. In this realm there obtains the important distinction of theory and practice, the greater adeptness in comprehension of abstract relations and the relations of situations to principles, representatively; or the greater reliance upon the expert manipulation of actual concrete situations presentatively. In both aspects rational insight dominates and elaborates the scope of satisfactions along with the means of meeting them.

Situations set problems, and the problem-solving tendencies invite the ingenuity that is taking thought-the skill of mind that complements the skill of hand, and gives to intellectual conquest the same and yet added zest that primitively attached to physical supremacy. The battle of wits supersedes the encounter of blows. The correctness of solutions is pragmatically tested; errors of apprehension, of judgment, of inference, may prove costly, while proficiency and forethought may prove to be self-rewarding virtues. The special premium attaching to the resulting intellectual superiority, the practical shrewdness reflecting an intimate knowledge of human forces and the understanding of the sequences of nature through observation 
and experiment, gives the cherished quality a mique rating, and more than any other factor, provides the steppingstones for the advances of humanity in the increasing generations. All sorts and conditions of situations that are certain to arise in the everyday current of commonplace affairs continue to demand varied types of reasoning. Yet the special development of the intellect is reserved for the few original problem-solvers and problem-seers of the race. The same imitativeness that leads to convention leads to the acceptance of the solutions of others and confines the rôle of reason largely to application. Education formalizes the processes and covers the conventional range of reasoning presumably adapted to the routine demands of life. The enormous emphasis given to the maintenance of this quality by devoting to it in each individual life years of devised exercises and learning-which form the heritage of the life of reason, of the cherished traditions and achievements of the past-indicates how great and constant is the effort by which it is retained, how limitedly in a large view of human quality it is distributed, how artificial is its status in the psychological perspective. In a far more intimate manner intelligence continues to get its training in the realistic encounter with the situations of practical import, in the guidance of intercourse competitive and coöperative. Nature's school can never be superseded. Through substitution and alteration, the play of the environment has vastly modified the range of qualities demanded, but has not detached them from their original setting. The characteristic of the upper levels of the life of reason is that it operates so largely in an environment which more and more is made by the very processes which through their issues direct its further course. In self-analysis as in the history of science, rationality appears as a self-sufficient process; consistency becomes a virtue, if a rare one; by it alone can a place in the system be retained [16]. In the psychic regulation the ancient schooling of its lowly estate becomes 
again conspicuous; in the educational process as in the actual world, both aspects coöperate though with variable emphasis.

Of energy still less need be said. Considered first in its primitive expression, vigor and endurance seem the most necessary qualities for survival under rigorous conditions. Civilization reduces the physical harshness of the environment and weakens the powers of resistance by the sheltering protection which renders their exercise less urgent. In primitive surroundings the "tenderfoot" appears in unfavorable contrast with the native or the frontiersman. The civilized life is more delicately poised, its equilibrium more easily disturbed. Its gains are paid for by losses; luxury breeds vices as well as makes way for newer virtues. Yet all situations give occasion for the exercise of will; and the vigor of reaction, ever supported upon an organic basis, remains a dominant individual trait. The occasions for its application vary considerably, as also the manner of its exercise. Courage of a moral order replaces courage of a physical order, but it can never be too violently detached from its original tone and occasion. The manly virtues of self-defense cannot be wholly eliminated from the composite of human nature without loss; an outlet for them or for their derivative varieties must be provided. Athletic contests form one such outlet, competitive industries and the "game" of politics or business another; great coöperative engineering enterprises still another. Fundamentally vigor is a primary requisite to achievement: "Be ye strong'" is the command of nature no less than of morality.

It is however more germane to the present pursuit to dwell upon the common physiological factors underlying energy. For this end, we may in a measure disregard its varieties of expression, and may focus attention upon the types called upon in the more complex situations. In all relaticns energy represents the available reservoir, the supply of headway for action; it varies with and reflects 
the tone, the temperamental quality, of responsiveness. It fixes the budget of the bodily economy; it presents the further fluctuations of maximum momentary effort and of persistence, and of the distribution and reliability of command of the motor endowment that serves the purposes of the body and the indwelling mind. We speak of "voluntary" action and of "voluntary" muscles to indicate by contrast the realm of subvoluntary, automatic, and reflex actions that find their mainsprings in organic constitution and make slight demands upon conscious coöperation. In this relation-for the most part of coöperation but in no small measure of conflict-is found the source of training and the exercise of restraint. It is the vehemence of organic desire under the direct push and pull of instinctive impulse that must be restrained and subjected to training under the guidance of reason as well as of social enforcement. This struggle of passion with imposed restraintalways in the end self-imposed, however much leaning upon the aid of society and its institutions, or fearing its penal. ties - typifies the moral training and advancement of man. It is the yielding in any undue measure to the call of the primitive man that social etiquette and ethics frown upon, insisting upon fitness of occasion and subdued appropriateness of expression. Here likewise are found the deepest problems of moral education, the diversion of. primitive energetic impulses into wholesome channels, letting the ape and the tiger die, while yet preserving the energies bound up with primitive passions for larger, fuller, richer, idealized purposes. The "will" aspect of the problem is persistent. In its negative side it presents the quality which temperamentally is called phlegmatic, and refers to a disinclination to the release of energy-which is work-and quite as notably, a shirking of the sustained mental concentration requisite for bringing to a head the powers of thought. In some sense we are ever struggling against fatigue, while yet craving occupation and exercise; and this 
adjustment presents the practical problem of regimen and the special problem of the sustained source of energy known as determination and resolution. However vain mere strenuosity undirected by intelligence and unredeemed by moral rectitude, it yet presents the indispensable requisite for achievement; and coupled with it on the emotional side is the enthusiasm that keeps aglow the fires of devotion to persons, interests, causes, and movements. The quality is differently valued in different situations, and the mode of its adjustment makes varied demands upon human occupations. It allies itself with such emotional qualities as courage and the self-assertions of prowess and daring, as well as with the intellectual loyalties of cherished purpose. Its relation to the organism and to healthy physiological function is unquestioned. Strength of body is intimately, if uncertainly, related to strength of mind; muscular Christianity is not an incompatible ideal. The availability upon demand, the security and regularity of resource, is likewise a determinative factor. High-pressure, intermittent activities call for differently constituted releases of energy than low-pressure constant ones. These manifold variations occur as individual temperamental variations, and appear in the practical arena where qualities compete for supremacy. The quality of will that remains dominant in connection with the support of emotionally and intellectually guided conduct, is a combined resolution and restraintthe dual components of the moral life. The conflict of wills contributes an inherent complication, which is characteristically a social one. "The will to prevail" represents the enduring aspect of self-assertion; to prevail above others gives the added quality of competition implied in the evolutionary struggle. Success and triumph are reflexive and support and encourage such qualities as confidence, which in turn effects the expression of the will. While capable of simpler statement, the career of the will in the composite of qualities is as vital and versatile as 
that of sensibilities, emotions, or reason. It seemingly retires in the higher levels of thought and conduct, but in reality but changes the mode of its assertion. It has a peculiar place in the social organism where it becomes effective in coöperation and the socialized forms of expression, finding a unique embodiment in the collective will that represents the higher authority appealed to in the arm of the law or the force of public opinion. It is as the joint products of sustained regulated endeavor, schooled insight, and loyal enthusiasm that we regard the contributions to civilization, which stand as the achievements of human qualities at their best, evolved as the instruments of the higher psychic control. In the study of such cultural products we shall resume their consideration [17]. 


\section{CHAPTER V}

\section{TEMPERAMENT AND INDIYIDUAL DIFFERENCES}

TEMPERAMENT, though an elusive concept, is a useful one, and may be directed to a profitable meaning. It refers to a composite inherent bent of nature. When contrasted with character it represents the basis upon which the latter proceeds by support of training, circumstance and purpose, yet consistently along the trend of native disposition. Temperament is nature specialized upon the basis of a temper of qualities of a common inheritance [1], expressed in and through the functioning of the nerrous system. It is the ultimate condition of indiridual quality, the native rein of the psychological ore. The decree of temperament reminds us that, as a leopard cannot change its spots, no more can we by taking thought add a cubit to our stature, physical or mental. Yet ideals picture the lion and the lamb lying down together; and the direction of endeavor determines whether the metal of human quality shall be fashioned as spears or as pruning-knives, as swords or as plowshares. As nature underlies nurture, and heredity limits the influence of the environment, so temperament underlies and sets limitations to character.

What is temperament and what are the temperaments are not the same questions. A completer knowledge might merge the two, the one solution serving for both. As chemistry was assured of the existence of elements before their determination was at all complete, so psychology may emphasize the temperamental basis while allowing for the uncertainty of its applications. In both sciences the problem of elements of composition requires a true principle of 
differentiation-the confirmation more uncertain in the chemistry of mind than in that of matter. It is obvious that men differ comprehensively; these differences require interpretation and formulation at the psychologist's hands. The problem of "temperament" forms a vital part of the problem of the original nature of man. It proposes the question of the common human inheritances, the potencies and impulses, the eapacities and trends, upon which the environment direets its formative play; it regards such endowment, though individually presented, as a concrete formulation-a particular statement-of a general human inheritance. The problem of "the temperaments" is the problem of temperamental variation; it proposes the question of the reduction of individual differences to typeforms; for it recognizes that while men differ, they do not differ by chaotic or scattering divergence but by more or less systematic variations from standard norms. Psychology attempts to place such variant types in a consistent system of interpretation of the sources of human quality, and in so doing recognizes community above divergence. The inclusive problem concerns the play of the native psychic trends in the shaping of individuality and career.

The fact of variation forms a starting point. Nature admits of and provides for variability; such variation represents the favorable range of divergence compatible with life and with normality of endowment, itself an elastic standard. More narrowly it represents the limits of fair efficiency, of survival adequacy. For human estate these boundaries are eomplex by the eomplexity of original nature, and become yet more elaborately complicated by the cumulative as well as selective influences of nurture; the boundaries of the psychic territory are further complieated by artificial divisions and sovereignties. Simplify nature and nurture to the utmost, and the differentiations of temperament disappear. Organisms so simple that all the individuals, to maintain an existence in a rigidly fixed 
environment, must possess the same combination of efficiency-traits and, to a like extent, must inherit uniform temperaments and develop equivalent characters. The formulæ of their life-history would be expressible in a few combinations of simple qualities. Individual variation represents the limits within which organisms may be different and yet of comparable fitness-each viable, each sharing a common endowment sufficiently to be normal, each presenting in its make-up varying efficiencies of adjustment, compensating advantages and disadvantages. The temperaments, whatever their specific formulæ, are so many solutions of endowment compatible more or less favorably with normal humanity. The temperamental is at once the generic expression of inheritance and its specific value in the individual.

This interpretation of the sources of temperament fixes its scope, but leaves its differentiation uncertain. The guidance of biological principles continues. Negatively the substantial non-inheritance of acquired characteristics clears the problem notably; it eliminates the irrelevant. Positively the inheritance that determines the individuality is a convergence of determinations. The individual belongs to one sex, also to one race, also to one stock; there are no merely human individuals-only individual men and individual women, members of this race and stock, or of that. It is equally a biological consequence that men and women are matured children; the child is the father of the man. To be psychologically masculine or psychologically feminine is itself a mode of expression of an underlying humanity; the psychological community of child and adult is as comprehensive as convincing. Race, stock, family, remote and immediate ancestry, determine the individual biologically. Temperament is in essence a biological emphasis, but also a psychological "complex," that constantly repeats itself, in that the conformities to type far outweigh the deviations. By such determinations each 
personality holds true to its type, while yet it is the individual point of convergence of ancestral forces.

Holding this conception in reserve, we proceed to the practical consideration that temperament is known in and through its issues; that the solution of the problem that confronts us depends upon a correct interpretation and correlation of these issues. The more liberal as well as practical conception of temperament includes the temperamental factors as concretely exemplified. It considers the primitive qualities that change but slightly, and the emphases of life's demands, whose constant change gives these qualities a variable set. The sex-factor in temperament is not absolute; it plays its part and runs its course, though its formative rôle irrevocably conditions the entire psychic expression. In infancy the sex-traits are bare of eritical distinction; in adolescence, they come to their own; in the prime of life they reach their zenith; in senility they are softened. Yet the sex-factor inheres in all individuality. The age factor in the expression of psychic responsiveness is never negligible; to be temperamentally young or old carries a large significance. The formulation of temperamental expression implies a reading of the foundation through the superstructure, much as the landscape which the geologist contemplates is to him but the surface indication of a deeper structural formation. Temperament is imbedded in composite character, is expressed in traits heavily overlaid and transformed. The equipment of the psychologist for his interpretation of source from issue is less secure than that of the geologist; yet it is his task to apply to a comparable problem such insight and resources as he commands. The conspicuous features which he finds in his survey he aims to reduce to significant types, which shall indicate-in remote analogy to the geological formations-the natural history of the appearance. The sage and the fool, the saint and the sinner, the strong and the weak, the reserved and the passionate, the deliberate and 
the impulsive, the venturesome and the conventional, the original and the commonplace, the resolute and the vacillating, are all human, and all carry to expression underlying bents of nature present in some measure in each individual composite. They are issues of temperamental forces. For the most part these trends appear in moderate degree; accordingly the ordinary application of "temperament" refers to the middle ranges of variation in primary function and expression. Individuals may be assigned, more or less distinctively-in their extreme variations contrastedly-to types, by virtue of their temperamental allegiances, though these are but moderately strong. The original deviation widens as it extends, and leads to pronounced contrasts. The temperamental variations embody a phase of individual differences. In so far as these deep-lying sources are not directly accessible, the actual data of temperamental varieties become the issues at the surface: hence the indirect and composite procedure to be followed.

The stress of temperament is felt at many points; the conception of the "temperamental" gains in richness by consideration of its many-sided aspects. The development from childhood to maturity sets in relief the encounter of temperament with the demands of growth, and its imperious sway; its expressions in the young are strong and relatively uncomplicated. Sex is far more generally than is commonly acknowledged the temperamental clew to conduct-as commanding as subtle in its sway. The exaggerated and warped expressions of temperament in unusual individuals, and their approach to abnormal relations, complete the interpretation [2]. It is fortunate that we can in a measure recall and sympathize with the traits of childhood, can experience the complex incentives that radiate from sex, can understand or observe the eccentric expansion of impulses that we for the most part hold in balance. Without these personal corroborations we should have far 
less real appreciation of the Trieb, the driving force of temperament, than is our privilege. These three aspects of temperamental expression stand as psychological methods, each enlarging and corroborating the interpretation. The ordinary play of expression as it appears in the average adult, adjusted disposition is too subdued to suggest the salient issues of temperament; it requires the pronounced contrasts of masculine and feminine, of child and adult, of normal and abnormal, as well as the minor contrasts of types of character, to set forth its potencies. The question of value, though not in the first instance directive, is involved; it is ever implied in the distinction of normal and abnormal. We readily accept the accredited traits of character as virtues, and find it detracting to gauge human qualities by standards derived from the contemplation of the abnormal. But significance lies apart from rating; and vices may be as instructive as virtues. The two form a series: within the range of the normal there is a graded worth for service, great or small, and proportion frequently determines value; below and above are defect and excess.

With these indications of the bearings of temperament, we may proceed more systematically on the basis of the conclusions of the preceding chapters. Temperament comes to expression in the sensibilities, in the primary emotions, in the qualities of response to primitive situations; for these constitute the essential avenues of psychic expression. Temperament adds nothing to them because it is part of them; it represents an aspect of the whole. Temperament continues to determine the strength of appeal of situations and the finer qualities of response in the derivative complications of the life of mind. The bearing of temperament is far more directly and more decisively upon the primary than upon the secondary range of traits; its intimate bearing is upon the organic conditions of response, upon qualities of regulation constantly operative in the 
near-to-nature situations. This range includes not alone the protective urgencies of impulse and the vital conditions of their maturing, but also the types of qualities-such as the esthetic-that spring from the early by-products of natural functioning. Temperament as a modifier of normality attaches to the normal range of sensibility, the normal susceptibility to primary emotional stress, the normal range of instincts, the normal powers of distinction, the normal energies, the normal expressional trends, the normal capacity for growth and adaptation. Since all these psychic factors are present in the composite endowment which human heredity implies, temperament finds its métier-can find it only-in the color-scheme of the composition. The primary colors and even the standard combinations are the same; the palette of temperament is formed by the strengths, blends, shades and grades of the elementary components. The palette varies for the genre of the canvas that is undertaken, but holds to its favorite tones. Or, to replace the esthetic metaphor by an abstract one, temperament is as the depth factor to the length and breadth of human qualities which the analytic survey of endowment projects; it provides the point of view of an added dimension. It supplies form to content, composition to elements. When all the essential constituents of human nature have been considered-the common fears, angers, loves, hates, distinctions, sympathies, susceptibilities, zests, energies, and the rest-there is still possible a further and a consistent differentiation-an inclusive correlation of the components in a significant synthesis.

Furthermore, the general argument of this essay finds the fundamental expression of temperament in the relations of the trends of responsiveness to their releasing stimuli-the dual foci of the psychic orbit. The one series of psychic qualities is attached to the preparations and media of the response; the other to the quality of the action. Feeling, in its type-forms of sensibility and emotion, to- 
gether with distinction and consideration, as the typeforms of the intellectual processes, supply the groundwork for the varieties of temperament; the manner and intensity of the response is similarly distinctive, apart from its purpose and the other elements of its general conditioning. The clews of "the temperaments," so far as they are real, may be traced in the range of incentives that induce action and in the vigor and quality of the ensuing response. The fact of temperament appears in that individual " $A$ " and individual " $B$ " under similar situations and despite their parallel education respond differently by the different play of motive and by the different set of their motor impulses. The analysis of temperament aims to illuminate this difference; it seeks a consistent conception to explain the difference of nervous organization that leads to such contrasts of response; it thus proposes the problem of the source of individual differences. The sources of temperament and the contrasts of the temperaments must be expressible in analysis, as they are themselves expressed in reality, in elementary psychological terms-as ever-present factors of the most general psychological conditioning.

Under the guidance of these principles, we return to the sensibilities and the emotions to reach the terms of the desired formulæ. We return to them in their service as supports of conduct, as native variations in disposition of the nervous responsiveness. The type-forms of temperament inhere in the type-forms of such relations, in the emphases and perspective of common underlying trends. Proceeding in the first instance upon the distinction of emphasis, and indicating by capital letters the preponderant factor, we may distinguish (a) the sensitive-ACrIVE type, embodying an inclination to dwell lightly upon feeling and consideration, and under slight incentive to pass promptly to vigorous action: a practical, ready, executive type-the sanguine temperament in the older terminology; (b) the sensitiveactive type, in contrasted emphasis, embodying an inclina- 
tion to linger in the receptive, discriminating, pondering stages of preparation, coupled with a hesitant, feeble, or involved expression: a theoretical, deliberate, reflective or worried type-the melancholic temperament of the ancients; (c) the SENSITIVE-ACTIVE type, embodying an inclination to an energetic, presumably a limited, responsiveness, on the basis of a vigorous susceptibility to such factors of consideration and emotionalized motive as enter the mental sphere: a quick, energetic, impulsive, circumscribed typethe choleric temperament of the classic scheme; (d) the sensitive-active type, embodying an inclination toward a feeble susceptibility of impression and a weak expression: a placid, easy-going, heavy type-the phlegmatic temperament of the familiar system.

This outline is serviceable as a psychological clew-a revised version of the traditional temperaments. Let it be entirely clear that the value of such a classification lies in its suggestion of a plausible source of the temperamental factor [3] ; it affords a descriptive aid to the characteristic color-schemes of temperamental composition. We must not permit the seheme to dominate the interpretation or obscure the findings; we carry it along as a suggestive aid in analysis. But even such informal descriptive treatment requires an additional distinction: namely, the relative dependence and emphasis in the preliminaries of decision and the stress of motive upon emotional promptings or upon intellectual insight. This distinction makes way for an alternate sub-type within each division, but particularly in those types in which the receptive factor, the sensitive appreciation, dominates. This preponderant allegiance to the emotional and to the intellectual appeals of support in psychic regulation develops to far-reaching contrasts of character in the maturer, more specialized personalities. It is of consequence in the human development from the outset, because in human nature the offset of impulse by reason inheres in the early expressions of individuality. 
For the mature range of motive and conduct, what men do, desire, and attempt, carries its full significance only when completed by an account of why they do it, and how it is done. Conduct is action plus motive, impulse, incentive, intent, disposition, and takes its impress from the whole. The traditional diagnosis of temperament selected as its clew the prevalent emotional tone of responsiveness; disposition was made the standard measure of the psychic nature; and we may accept the emphasis as equivalent to the revised conception just set forth.

The basis of distinction is the natural vigor of physiological function, of which the psychological tone is an intimate index. Give this the complexion of strong, active impulse, with slight restraint of emotion or thought, and there results the native joy of doing, the zest of free, uninvolved impulse, the buoyant optimism of wholesome function. Reverse the perspective, encumber the path to action with uncertainties, entanglements of conflicting emotions, hesitations of purpose-and the mood of the pursuit is serious, perturbed, prone to depression. To refer the issues to the sanguine and the melancholic temperaments but fixes the (fictitious) name to the (real) composite. When the impulse to action is feeble by inertia of the responsive mechanism as well as by insensibility to stimulation, the tone of conduct is described as phlegmatic; when simple, fitful impulsiveness demands prompt expression, and is readily aroused to violent opposition by obstacles in the path of desire, the emotional tone is choleric. Or again: when the vital stream that finds its supply and headway in sensitiveness and its outlet in conduct, is both slender and sluggish, the surface appearance is phlegmatic; when the trickling feeders of the stream flow intricately and uncertainly, it is melancholic; when the stream is narrowed so that a slender supply makes a brief gush, or meeting obstructions rises to a sudden spurt, it is choleric; when open, unobstructed channels readily provide a bubbling flow, it is 
sanguine. Metaphor and analogy are suitable to convey the sense of reality that attaches to these contrasts. There is indeed a personal equation here, which expresses the manner of release of impulse, as determined by the sources of sensibility and the paths of expression, with their characteristic obstacles and by-paths of invitation. Such contrasts and delineations refer to the most general phases of expression; they do not disregard the varying appeal of different ranges of emotion and situation, but assume a standard play of these in their near-to-nature setting; in this reference their most constant appeal is to the ups and downs of self-assertion and self-abasement as the greatest common factors of the personal equation [4].

- Obviously the ordinary range of activity may not or need not call into play any marked temperamental bent; for such activities proceed upon the common endowment of all temperaments far more commonly and effectively than upon the divergent emphases which the variations of the temperaments represent. Tenser emotional situations, more exacting intellectual ones, strains of desires and conflicts of will and the mastery of circumstance bring to the fore the temperamental set, the specific inclination. Yet in slighter and subtler fashion the leaning-which is a constant one-affects the growth of all the powers in the reaction to experience of low or high degree, of serious or light import. Temperament conditions the formative reactions, shapes the absorption of experience, inclines to selection and rejection in the realm of preference, favors trends of interest and occupation. None of these, it may be, it effects strongly; for its usual color scheme inclines to neutral tones. Yet its presence as a factor of primary import is as real when its values are expressed in small units as in large ones. The dramatic interests center upon the stronger types and contrasts; such portrayal with its heightened color scheme serves to set in relief the keynote of the composition. The psychologist in pursuit of the 
temperaments emphasizes the salient divergences; in pursuit of temperament, the convergences. Ordinarily and characteristically, temperament is a subdued rather than a pronounced emphasis-a blending lacking salient flavors rather than containing them. For the usual application the motif of temperament should be set in the minor key, in the common scale of values, rather than in the unusual though engaging ones in which the movements are more sharply contrasted.

The temperamental distinction may be applied in like spirit to the shifts of emphasis embodied in the psychological ages of man. Vivacious childhood presents the complexion of the choleric; limited but urgent disposition demands instant and vigorous satisfaction and expression: witness the eager desire of the child, as well as its passionate rage when thwarted. At the other extreme is calm old age, phlegmatic, enfeebled in responsiveness, unassailed and unsupported by vivid incentives or needs. The expanding reactions to experience enlarge ambition, stimulate confidence and ambition, stir the rich red blood of youthful sanguinity. As youth passes, there matures the restraint of thoughtful consideration, that inclines the choleric child, and the sanguine, energetic youth to more settled, more sober ways, not, as its extreme form implies, despondent, but seriously considerate and with frequent moments of troubled doubt-and all in no simple or set manner. The turning point of adolescence characteristically introduces introspective hesitations, along with compelling stimulations; it remains an issue of temperament which of the voices of nature will prevail: whether contemplative intellectualism, receptive estheticism, or practical executive interests dominate. The prime of life brings responsible assurance, the command of resources disciplined emotionally and intellectually. Nature and nurture introduce manifold and unpredictable variations and improvisations upon the pervasive theme. When thus main- 
tained upon a suggestive, descriptive level, the classic distinctions yield their best flavor, their truest profit. An impressionistic diagnosis, though building upon spurious foundations, builded better than it knew. Seizing upon conspicuous contrasts, its empirical insight was truer than its vaunted explanations; for the observational findings were the only realities of the elaborate construction. Modern psychology can afford to extend its shelter to this ancient heritage, and need fear no abuse of its hospitality. The older view of the temperaments may stand for readily observable types of quality, to be properly valued in revised psychological terms as modestly significant, apart from, and indeed despite their extravagant and misleading associations.

The adaptation of temperamental response to the stages of psychic maturing is itself part of the organic conditioning. The child, as expressing a mental age, represents a temperamental allegiance as well as a limitation of experience and unfoldment. Though ever a child, the childish personality shows individuality in and through its infantile or puerile expressions; and the native bent thus shown persists throughout life, though it alters its play by the successive dominance of other organic stresses and other ranges of appeal. The process of unfoldment and parallel widening of interest and capacity and control is a gradual one, but is subject to mental as to physical leaps and bounds. The changes of adolescence are of this order, and equally so in the psychic and the physical scale; for both are common expressions of an organic change equivalent to a renaissance if not a revolution. It is sometimes precipitated by an overwhelming inner experience or by a radical change of the environmental conditions. Adolescence may be interpreted as the displacement of the youthful by the mature temperament; it is a change of psychic perspective. The stress of temperament comes forward with the assertion of shifting demands in the economy of natural de- 
velopment; for these demands must be adequately met if normal life is to be the issue, and the provisions for meeting them must be a part of the inheritance. This condition remains; while yet in the manner of meeting these, as of meeting the general run of situations, organic and environmental, there is discernible a directive quality of like temperamental order. The shifting emphases of life's demands are compatible with a stronger dependency upon a specific disposition throughout life [5].

Viewing the same complex of psychic allegiances from another aspect, we may summarize the conclusions by saying that the psychology of childhood is set in a high-pitched emotional key, but in that key presents the same underlying type-forms that are recognizable in the mature differentiations. Children in their own domain reveal the emphases of the elementary psychic components. In a sense they manifest them more strongly because so large a share of their responsiveness proceeds upon the primary range of psychic motive and expression. Less subject to the leveling effects of convention and saved by their limitations from too subtle or refined complexities of decisions, they live the more natural life, and by the same token the more primitively temperamental life.

In thus following the several aspects of the problem of temperament, radiating from a central conception of its functional nature, an important consideration has been slightingly regarded: the ranges of psychic expression, the varying play of one order or another of primary appeal in the general responsiveness. Applied to the classic temperaments, the view would describe a choleric person as one temperamentally susceptible to the sway and play of anger; and the nervous (melancholic) person as one susceptible to the sway and play of fear. Anger and fear, as the exemplars of the two great trends of aggression and withdrawal, by natural dominance are conspicuous in the temperamental trends. Because they are the primary motive instincts, 
the susceptibility to them is a primary component of temperament. Similarly the angerless (phlegmatic) disposition and the fearless (sanguine) disposition represent, with like pertinence, the contrasted types. Obviously these suseeptibilities are matters of emphasis only; the one disposition is decidedly prone to anger, the other decidedly prone to fear; the one markedly free from anger, the other markedly free from fear; yet all are subject to the entire range of normal susceptibilities and on common occasion show fear and anger, hopeful courage and hesitant timidity. Moreover and obviously, the temperamental trend is not limited to this duality of emotional allegiance. The remaining primary emotional trends have a like representation in the temperamental set; sympathy, self-assertion of other varieties (such as jealousy), variant submissive trends, enter into the temperamental susceptibility, form the natural highways of its expression and equally fashion its quality. Yet it remains suggestive that the casual psychology responsible for the delineations of the temperaments, found its clew in the two directive emotional attitudes. As a fact it is not the simple susceptibility to fear and anger or the relative freedom from their tyranny that differentiates mature temperaments, but the endless derivative consequences, the compatibility of other allied traits with the underlying trends of which this susceptibility is but a partial expression. It is a question of what other suseeptibilities merge eongenially with a proneness to the appeal of anger or of fear, and together constitute the temperamental set. The reflective consideration accompanying or inducing a hesitant timidity, or at the least making way for it or inviting it, may have a larger formative influence upon the shaping of the temperamental expression than the timidity itself; the absenee of the appeal of such consideration, the impulsiveness or rashness of action that dispenses with it, may be more significant than the confidence of attitude. Yet such admission does not 
diminish the intrinsic rule of primary emotion. The designations of temperaments are but ear-marks, convenient symbols of complexes, which require a more exact and systematic analysis to indicate their true scope and real nature. The susceptibility to different ranges of the emotional motives remains a permanent clew to the temperaments, however the allegiances of temperament come to expression; whatever their source, this factor remains. It represents a composite susceptibility to congenial groups of emotions, a composite insusceptibility to other groupsall relatively and in no simple relations. The question thus approaches that of the compatibilities of trends and traits, to be considered presently.

It is desirable before entering upon the consideration of the finer issues of temperament to have in mind more explicitly the physiological determinants; for these are ever present as potential factors or as actual ones. A difference of condition may release different ranges of suseeptibility; and the very subjection to condition is itself a clew to the temperamental dependency. There is mood as well as temperament to consider, although both reflect a like source. Beginning with familiar experiences, we are all aware, whatever our native strength of resistence or our readiness to succumb to organic stress, that illness obstructs activity, hampers expression, throws the attention inward upon an exaggerated sensibility, makes for hesitation, introspection, irritability and depression. The effect is conspicuous in cases of digestive troubles and affections of the lower viscera, and in the disturbed metabolism of internal secretions. This type of physiological irregularity, by some deep-seated connection, obscure though intimate, and properly called sympathetic in terms of its influence upon and by way of the nervous system, brings the pangs of physiological distress and the pained emotional tone. A chronic liability to such disturbance may induce and establish a permanent temperamental set of persistent peev- 
strness. inralidism. or distëerion. Carried to abnormal cxurcsion it mat reach the stage of true melancholia.

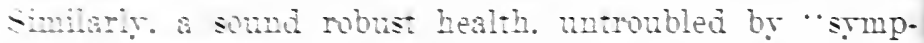
nom." using the phrsiological dapair treely for execu-

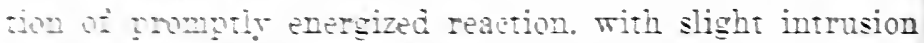
of exicr emotional or intellectual hesitations. is of itself a tain asurance of rebblowed actirits: it is the token of tre s.m. wi. wesome jor of ine artire temperament. The stones. Fiblity and command of resonres is simi-

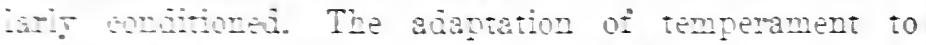
ouniry of a rierement prores to be a far more delicate

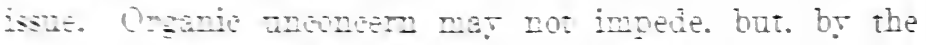

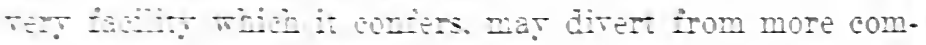

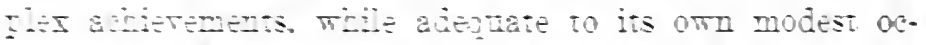
arans. It susti. the constimtional tactor in the

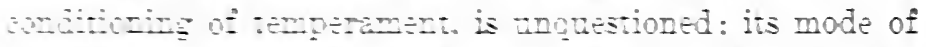

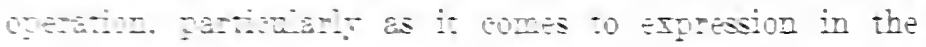

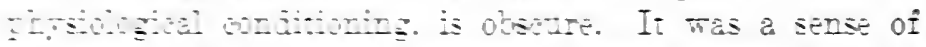
IE: $=$ :

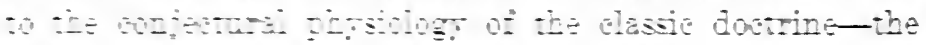

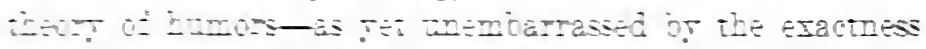

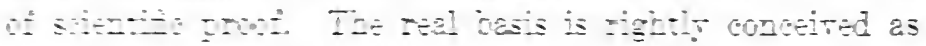
s-

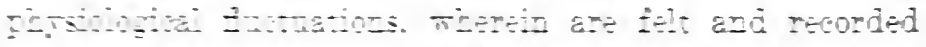

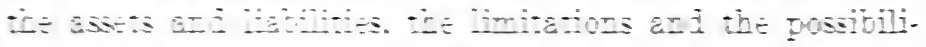
Zis o ET:

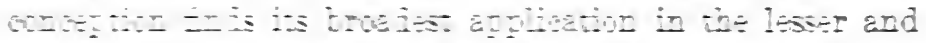

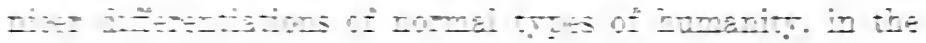

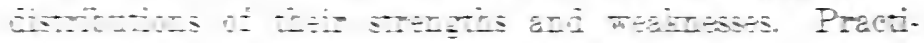
$\mathrm{cen}^{-}$ s

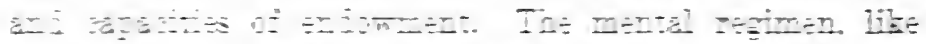
İ三

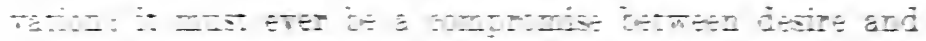

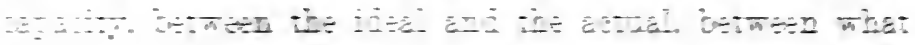


we have to "do with" and what we hare to "do." Tem. perament accompanies each and all in rocation and arocation alike, in waking and in sleep: it sets the pace for endearor, and complicates as well as directs progress.

The temperamental type [6] is but generically not specifically set by the emphasis of the sensory and motor processes in the formula. The secondary dependence upon the; emotional as contrasted with the intellectual phases of sinsibility leads to derirative rarieties. Because this con-l ditioned the sexistritactive trpe mas equally be termed the melancholie, the introspectire, the esthetis, the nerr. ous. With the emphasis upon the intellectual phases there results the "melancholr Dane"-introspectire, brooding, thoughtful, absorbed. insusceptible to dirersion. Inder the emotional emphasis it becomes the esthetic. the fastidious sensitiveness, the storm-and-stress unrest: or in other rariation, the shs, hesitant, imaginative. self-centered. irregular excitability and enthusiasm of the nerrous. possibly the sentimental indiridual-poet. musician. artist. en. thusiast, neurasthenic, or hrsteric. of whaterer profession or condition the fortunes of life ma! impose. The two trpes present intermediate allegiances: the interplar of values may be further presented as the special emphasis upon the capitals of the sersitrie-the receptive factor-or upon the small letters of the active phase-the expressire factor. The extreme impressionability. the acute susentibility to every nicety of emotion. to subtle harmons or delicate play of color or tone or word. or whaterer mar be the medium of expression, inclining to deep and eren mrstical absorption in the receptive attitude and contemplative occupation. and the resulting harassing and disturbing subjection to incongruities and annorances as impeding action-all this makes for overeritical hesitation. a ferling of rerelation that cannot be revealed, a message strongly crowding but inarticulate, conduct inrolred and shorn of decision. An intricate maze of troubled feeling no less cer- 
tainly than a "pale cast of thought" sicklies o'er the "'native hue of resolution," and makes high impulses and lofty impressionability nervously lose "the name of action." In the complementary variant the temperamental cxpression is less markedly a sensitive, contemplative absorption than a weakness of adequate and energetic response; the defect-for such it readily becomes-is more a matter of will than of sensibility. Once again proportion decides and divides favorable adaptation from maladaptation. Proportion enters into the finer delineations of character, produces the endless variations within the common type-form which are duly recognized by the casual as by the scientific student of human nature [7].

We have encountered at several points in the preceding considerations the specific Trieb or set of the temperamental stress. Its bearing demands attention; it enters into the conception of "the temperamental." The threefold allegiance that has served psychological analysis so faithfully in its historical career may once more be drawn upon. The temperamental bent may be traced in the emotional, in the intellectual, and in the volitional aspect of psychic regulation. The process is unitary; the span from feeling to doing is supported by the central pier of knowing. The temperamental expressions of feeling and doing are direct; the support of knowing modifies the stresses of the structure throughout. Such modification is directly traceable in the intellectual regulations dominated by a strong emotional tone, whether of primary urgency or of derivative status. Thus, on the one hand, the temperamental man appears in the man afraid and the man angry, in the man moved by sympathy and spurred by jealousy, in the man of joys and the man of sorrows, in the responses to situations that arouse pride, conceit, confidence, magnanimity, amiability, or shame, humility, despair, suspicion, hostility; and, on the other hand, the temperamental man appears in the man of taste, predilections, intellectual satisfactions, 
general susceptibility to the refining transformations under which the primary urgencies of the original order merge into and with the esthetic regulations of the derivative order. The latter are more specialized and more intellectualized; their cultivation upon a temperamental basis has important bearings upon training and career. Musical susceptibility is the fitting example of such temperamental bent, and the poetic and artistic talents no less so. One is musical temperamentally: which means not alone by dower of inheritance, in a sense comparable to that in which one is gay or despondent, impulsive or deliberate by like decree, but specifically by the combination of a certain range of emotional susceptibility with a supporting sensory-intellectual endowment (Anlage) [8]. The "being musical" implies a certain aptitude and a certain disposition-the two converging upon the musical susceptibility. The susceptibility implies that one is decidedly or deeply affected by the appeal of music and is appreciative of its medium; that one can feel the sensory values of the tones, their correctness and relations, can "tell" tunes and can respond to their meaning. The artist is both "sensitive" to colors and forms, and "sensitive" to the pieturesque in life as in art-to the esthetic values of this medium. The poet, in more general manner, is "sensitive" to the soundvalues of words and rhythms, but dominantly so to the intellectual meanings, the beauty of thought, and all the subtle charms of emotionalized experience brought to expression in words. And we are all of us more or less musical, artistic, poetic; the temperamental Anlage that gives each and all a modest power to respond to these appeals, is the same temperamental factor that, when present in far more pronounced measure, makes the musician, the artist, and the poet.

The temperamental set in the esthetic careers and in the esthetic phases of the dispositional aptitudes is by its nature specific; the musical, artistic, poetic disposition is a 
speeialized form of sensibility. Persons thus endowed incline to the type-forms in which the sensitive factor dominates, however eombined with either skilled aptitude or the persistencies and energies of will. The relations between the general emotional and the specifieally esthetic temperamental trends are sufficiently elastic to give to artists a fair variety of character-traits, such as occur in any other walk of life; and yet the esthetic bent is a real eommunity of temperamental allegiance. The intelleetual eapaeities diverge from this formula in that the speeialization is still more minute; they represent the elevation of a supporting insight to an independent value. While no less dependent upon native aptitude, they lean heavily upon the eultivation of powers by learning, while yet the zest for learning and the thrill of achieved insight into relations derive their vitality from temperamental dispositions. And similarly for the quality of energy, and the eareers executive: their growth proeeeds upon the vigor, enduranee, persistence, and other "will" qualities inherent in all responsiveness, and is equally temperamentally eonditioned. Their more detailed consideration follows. As illustrations of the speeific temperamental trends, both in their dependence upon the support of other ranges of Anlage as well as examples of the different types of appeal which are needed to bring forward the temperamental set, their present treatment will suffice.

The difficulty of formulation of the temperamental factor in human responsiveness does not imply that the reality thus reduced to statement is obscure or reeondite. The stress of temperament is intimately familiar; it appears in mood and disposition, in what we feel like doing and enjoy doing for the moment and more permanently. It is encountered practieally in the modification of trends under domestieation and eivilization; it sets the limit to the proeess, and advises the selection of individuals presenting the desired traits rather than the attempt to graft them upon 
unsuitable or refractory natures. Temperament is the defense of eugenics, as character is the justification of education. The spirited disposition of the full-blooded steed in prime condition, compared to the placidity of even the prize cow, furnishes a contrast of temperament; it explains why the horse is chosen for a part in the sporting instincts of men. The refractoriness of one child makes its upbringing a trial; while another trots complacently in the conventional harness. Temperament, though it gives the delicate touches to the psychic portraiture, is in itself quite commonplace; its reduction to psychological formulæ is unsatisfactory because, when so expressed, it seems to lose the richness of nature and the intimate meaning which it carries in experience. To conserve or restore that value, psychology must apply its principles of interpretation to the composite data of humanity.

The actual findings are the differences of men in terms of their reactions to the standard influences of the environment. Popular verdicts furnish such comments as that this musician or that painter, this poet or that actress, this or that character in life or romance is blessed or handicapped by a liberal measure of "temperament." The opinion suggests a far-reaching division of men: it places in one group those dominated by a positiveness, a strength, a distinctiveness of endowment, whatever its type or quality, which throws the emphasis upon the Trieb, the driving force of nature, and leaves a lesser play for the molding influence of nurture. From the point of view of imposed training this endowment makes a difficult, resistive, headstrong type; from that of worldly management, such individuals are less tractable, organizable, conformable to social and other molds; from their own point of view, they are opposing the leveling and deadening effects of convention and are shaping career to endowment, and not cramping endowment to the imposed conventions of career; they are following the lead of their natural bents and talents. The 
contrasted group is composed of individuals who are fairly characterized as slightly temperamental, who are consentingly molded in large measure by convention and standardized training. The distinction, thus expressed in terms of a highly specialized issue, reflects a primary contrast.

The distinction may be said to pertain to the biological character of adaptability, which in its issues in complex social enviromments, is no more and no less an unmixed virtue than many another factor born of nature's ways and man's superimposed purposes. The distinction suggests the opposition of nature and nurture; the nature-molded are temperamental, the nurture-molded adaptable. The strong temperamental bent yields less easily to environment, overcomes or resists untoward circumstance; while keenly responsive to favoring fortune, is at once sensitive to the world's contacts and impelled to effort by inner impulse. As a rule it favors and matures with a specialized, directive set of interest and desire. The contrasted, nore neutral, as opposed to the more positive temperainents, yicld readily to circumstance, take their impress 1rom without, while bringing to their work or play a fair range of impulse and capacity; they lean in expression upon the support of convention, and follow prepared models of conduct. Their temperamental trends appear moderately in the selection of the psychological patterns of hought and practical models of conduct, and in the emphasis of emotional and other predilections in their pursuit. In the extreme the one becomes strong with the weaknesses of special bent, the other weak with the strength of balance. Originality lies with the strongly temperamental, and a complacent, conservative, unimaginative trend with those slightly temperamental. However, these distinctions penetrate only to the threshold of the problem.

Such terms as variability on the one hand, and plasticity and originality on the other, have a distinct though overlapping reference. The first refers to the fiuctua- 
tions of qualities as exhibited by different individuals of the same species; it refers primarily to the range of distribution of a quality among a group. Plasticity refers to the individual quality of adaptability to the environment. The protracted period of the teachability of the young of human kind provides for a large plasticity of psychological traits. Originality is the individual tendency to depart from the group type-which at higher levels may be the conventional type-largely upon the basis of inherent disposition or capacity. Originality in the individual represents a concrete issue of biological variation; it stands in a measure opposed to the adaptability to circumstance characteristic of the more pliable, less rigorous and less vigorous set of nature. The one expresses the divergence from the type; the other the plasticity of the type-traits.

The contrast as well as the affiliation of character and temperament is in a sense equivalent to the difference of interest in what men $d o$ and in what men are; it implies that the range of responsiveness in the fundamental relations of life is more significant than that in the derivative occupations and proficiencies. Hence the pertinence of the curiosity to penetrate in biographies of noted men, back of achievement to the personal qualities in which it is set: to inquire what manner of man as a personality was the individual whose sayings, doings, exploits, views, activities, or influence engage our interests; what were his family relations, his associations with his intimates, his tastes, his amusements, his habits, his foibles, his hobbies, his daily routine, his susceptibilities, his love-affairs, his worries, his ambitions, his motives, his attitude toward the experiences of life? We cannot escape the conviction that different types of eareer engage the temperamental qualities with different degrees of intimacy: that some lean strongly upon the personal reactions to experience, and that others are built upon highly derivative and specialized 
proficiencies remote from personalized responsiveness. The latter may be adopted into the system of interests and by such adoption attain something of the original emotional zest of pursuit; they become the loyal devotions of persistent endeavor exereised in and attached to eareers. The eonviction reeurs that the poetic medium reveals the poet's temperament with a direct and intimate significanee that does not apply to the work of the engineer. Yet it is equally true that no man is wholly poet or wholly engineer: the underlying man in the poet and in the engineer participates in the quality of the poetry and of the engineering, as well as conditions the maturing of powers that turus the one to poetry and the other to engineering. That the poet is born and not made is about as true as that the engineer is made and not born; for either is less true than the prineiple of eorrelation, which reads: that what men are inclined to be by nature is reflected in and conditions what they suceed in making of themselves by applying capaeity to opportmity under the spur of native impulse. The importance of the temperamental factor in eareer, as in all conventional profieieneies, varies between such phases of disposition and conduct as temperament eonditions, directs and dominates, and such as it supports - to which it gives edge and finish, quality and spirit. In each the temperamental factor becomes inereasingly complex and indirect; it operates no longer as a primary emphasis in the earlier sense but as a series of temperamental qualities. Under this term may be ineluded in a liberal construetion the entire range of qualities, however coming to the surface in personal eharaeter as in eareer, that hark baek to the primary psychieal trends of original nature.

The qualities of men are those of their temperaments and their eharaeters. Temperamental qualities are so variously transformed by their development under imposed environments as to form merged complexes of traits. In 
such a complex certain trends-and these the temperamental ones of deeper hold-are directive. The stress of experience conditions the manner of yielding to their sway, of utilizing the aptitudes which they support, of adjusting their promptings to the control of circumstance. Thus the temperamental traits become the molding forces of character, the media of psychic regulation, the determiners of careers. Such trends-in that they arise so directly from one or another of the tempers or blends of primary disposition-repeat themselves in manifold ways and are further convergent by the similarity of conventionalized environments; they furnish common representatives in the gallery of humanity, and invite description as "types" of character. Such bias of temperamental leaning brings it about that as the situations of life make their appeal to the developing personality, they encounter an initial resistance if of one order, and a ready assimilation if of another. Such inclination gives a positive set or stamp to a cluster of interests which it vitalizes because in them the specific appetite finds food and satisfaction, and negatively by the absence of such appetite handicaps and restrains the individual from full and adequate participation in other phases of acquisition and intercourse. The dominant bent selects positively and negatively, by what it transmits and by what it obstructs from the spectrum of human qualities, revealing, as do the lines of the visible spectrum, the reactions of the elementary psychical components through their natural medium. It is the case of an instrument that by construction can play but a limited range of tunes; but the tune that is actually played is determined by the special environment in which the instrument comes to expression. Temperamental quality suggests the limitations of a repertory - at the extreme the limitation to a single rôle.

The setting of the temperamental traits may be said to follow the plan of nature; with a leading differentiation, 
the purpose of which is plain, is associated a considerable series of derivative and supporting trends. As is true of sex, so also of temperament: the central fact spreads to a radiating cluster of related facts. The derivative traits make the surface appearance; they are responsible for the psychological landseape of human quality. The clustering of congenial and supporting trends implies the important fact of correlation of qualities, the compatibility of traits. It may profitably be approached through the medium of illustration. Let us assume that some one trait-in this instance the hoarding trait of the miser-acquires a commanding, even a usurping hold upon the individual. By common observation and report so-and-so is a miser. What is a miser, psychologically interpreted? The trait is the expression of a temperamental trend present in original nature; it grows to such proportion that all experience is absorbed through its perspective, all impulses subordinated to the master passion. The trait is the first and foremost consideration in the individual's reaction to the stimuli of his environment; it is his constant reply to the appeals of life through the powers by which he lives. In all this he stands not for himself alone but for his type. The miser is the result of the play upon such temperamental type, of the social system through which the values of response are fixed. To say that the miser is such by virtue of a large "bump" or ingredient of acquisitiveness in his make-up is true with the meaningless truth of a verbal exchange of terms. The signifieant facts are broader as well as deeper. They reeite that in the psychic endowment there is a natural place for self-assertion and the will to prevail, leading to the defense of self against loss; that the social orcanization provides an outlet for that trend in the accumulation of goods socially desired; that, because of the accessibility or special appeal of this type of expression thus socially encouraged to the particular and limited form which the self-assertive trend assumes in the indi- 
vidual, his response to the original impulse thus diverted makes hoarding his absorbing pursuit. A different environment, a different social tradition, might have turned the impulse to other channels; yet the prevalence of the "miser" type through the ages indicates the open path of invitation. The miserliness may be the bare hypertrophy of thrift; and thrift may be the restless obedience to a limited range of interests. The qualities entering into the "miser" complex are variable. There is the merely negative factor of a defective imagination to find use for money, the narrow confusion of means for end, or the lack of cultivation to develop needs with increased resources; there is the neutral factor of imitation and inertia-the hoarding by habit and hardened set of interest; there are the positive inducements of the satisfactions of security against want, the control through financial power, the reputation of success in a socially esteemed pursuit, which replace the more primitive sensory gloating over the money-bags. The trait, as all such traits, must yield a personal satisfaction of some sort, and quite inevitably one that depends upon the social reënforcement. There must be a psychological satisfaction; and in this instance money, as well as the process of getting it, is the satisfier. By contrast, spending comes to be painful as a check upon the master impulse, as an unwilling concession to the inexorable decrees of existence. The satisfaction of saving overcomes the enjoyment of possession or indulgence [9].

Truly the miser is such by temperamental bent; but the bent is not an inclination toward penuriousness, such as he might have inherited from his father or may pass on to his son. If an individual of the same disposition were born among a primitive people living a communal life, innocent of the institution of property or wealth, the trend would perforce have found another outlet, have taken another set. It requires the coöperation of the environment to transform disposition into a trait, to make hoarding the par- 
ticular temperamental expression of self-assertion. It is accordingly the associatcd components of miserliness that furnish the psychological clew. The synonym of the miser is the churl, the niggard, the harpy, the hard, grudging, mean, mercenary skinflint. Typically he is a recluse. Does he shun society because society makes claims that interfere with hoarding, or because social ties have nothing to offer, make no appeal? Is he a miser because he is a recluse, and in his withdrawal finds hoarding congenial to his solitary pursuit? Or is he a recluse because he is a miser and can save by withdrawing? Or is he both because of a certain type of shut-in personality, a temperamental limitation of qualities which, as exercised in the cnvironment, is likely to produce the set of qualities that form the "miser" complex? The psychological solution favors the last conclusion, though in no simple manner. The unsociability may be otherwise motivated; for common symptoms may have unlike sources. The hermit may deliberately decide that the social struggle is not worth while; he may be a solitary scholar and in his own way may even have costly tastes with a generous disregard for commereial values. The "withdrawal" complex merely overlaps the "miser" complex at one point; but it is a significant point. It becomes clearly so in its abnormal manifestations. The abnormally shut-in personality may be misanthropic, may be shy to the point of sullen churliness; he is so by virtue of an innate warped disposition which all the machinery of social training is incapable of straightening. The acquisitive trait may run riot, may lose its more defensible expressions, and in insanity may labor under delusions of distorted values, and gather rubbish. For a considerable range of cases the most scientific is also the most charitable view of the miser: to regard him as unbalanced, the victim of impulses inadequately controlled. In this view the fact that commendable thrift travels for a distance along the same road which extended-and with 
no reference to the other essential highways of human intercourse-leads to abnormality, is but incidental. The parsimony of the miser is but a symptom; his social withdrawal, his churlishness, his hard unsympathetic nature, his pleasure in mean advantage, are vital. The same original defect which expresses itself in these traits-which carry a ready significance in the system of primary qualities-is responsible also for the further symptom of niggardliness, which happens to be the conspicuous one in the observed play of human qualities. The limitations of the "miser" complex are as significant as its assertions. The miser is cut off from large areas of psychic development which proceed upon the expansive qualities; for these have a parallel place in original nature with the assertive ones which in one limited aspect have gained control of his being. There are many other ways, and richly distinctive ones, of expressing self-assertion in the social setting. The expansiveness of generosity, the extravagance of display, the venture of the gambler, the joy of domineering, the sense of importance, the thrill of philanthropy, and a dozen other qualities-all of which minister in very different manner to self-esteem-are out of the miser's reach and orbit, by reason of the contracted personality under which he labors. Some of these compensations he may more or less deliberately forego; and an occasional if inconsistent manifestation-such as a fitful display-because of its association with successful money-making, gives color to the supposition. But for the most part he is cut off from the expansive forms of self-expression by the handicap of his temperament. The miser is anti-social, incompletely socialized, warped in his social reactions; such limitation, if extreme, gives rise to the set rut of habit, the endless circle of emotion, the persistence of fixed ideas, for which "monomania" is the accepted term. The pursuit of one idea, the dominance of one passion with a consequent loss of perspective, the rigidity of the mental movement, the 
narrow brooding of the emotional tone-all proclaim the absence of the varied and shifting appeal of complex interests in which normality consists. Miserliness is a minor form or phase of a temperamental "monomania."

It would be pertinent to continue the illustrations by extcnding them to other fields in which a temperamental quality achieves directive expression. The inner set and the outer setting combine: the miser lives to himself and hoards; lis world is commercial, as he is commercially minded. The musician lives in a world of delicate emotional susceptibility, and experiences its longings and its thrills; along with his fellow-artists he is esthetically minded. Around this central fact it is possible to develop the psychology of the musician [10] - an analysis of the musical complex. Such a study would begin with the trend of the personalized emotions that in the large run are congenially related to the special Anlage which makes the musician; it would continue by seeking to determine other ranges of common endownent, common handicaps, common congruities and incongruities that affiliate with the musical temperament. The fundamental principle that esthetic sensibility is an offshoot of a general emotional susceptibility, and lives and thrives upon it, while supported by a specialized capacity for expression, is abundantly illustrated in the biographies of musicians as in the ordinary observation of the musically disposed. The latter is the more pertinent corroboration in that it recognizes the more common musical susceptibility of marked degree, and is not limited to the professional career; equally important is the reminder that the musician is much else than a musician. The musical bent serving as an avocation is as intimately conditioned by temperamental disposition as is the musical talent serving as the basis of a vocation. Musicians as a class are fashioned by the converging force of common disposition and common avenues of expression under common social settings; thus 
the group-traits of men arise, and bespeak an independent treatment.

The problem of sources ends at this point; and in a measure we have already encroached upon the domain of application and the molding force of the environment. It was necessary to widen the survey in order to set forth the procedure by which psychology interprets the temperamental traits. The same procedure brings forward the problem of compatibility of traits. The temperamental set that favors one order of Anlage or expression also favors others. The favoring, as the expression, is for the most part of moderate degree-not so pronounced as to dominate, but marked enough to incline; the inclination is toward one direction and away from others. Such essential and valued compatibility gives consistency and unity to character, and makes the personality a composition and not a medley. The principle that development in one direction is incompatible with development in another is an aspect of the law of specialization; it is so in that temperament is a special emphasis. Coldly calculating intellectuality is opposed to warm sympathetic emotionalism; the scientific to the poetic temperament; the practical to the theoretical proficiencies; absorption in one range of interests may indicate unfitness for or lack of appeal of others. On the other hand, despite diversities of expression, artists-whether musicians, painters, sculptors, designers, poets, dramatists-have much in common; which means that the temperamental quality leading to their professional expression favors the possession by each group of other allied qualities, making their companionship congenial, their interests allied, their tastes related; and equally making it more or less likely that they present in but slight measure certain other ranges of quality that grow out of a radically different temperamental basis.

The problem of compatibility, when reduced to precise formulation, becomes the problem of correlation. Its so- 
lution would afford a basis for an applied psychology. It would inclicate how strongly the possession of one capacity is an index of possession of others, and of which others; it would prescribe what qualities, in what measures, should be possessed by candidates for this career or that. The difficulties of establishing any such body of knowledge are illuminated by the study of temperament. For it is clear that the individual endowment is composite, and at once versatile and limited. It is equally clear that the expression of traits-the sole source of knowledge-must be interpreted in terms of the accredited media of adjustment to the demands of a systematized artificial life. Most of all does learning handicap the inference; the tree of knowledge is symbolic of the evolution of human psychology. Acquired conformity replaces original quality; artificial devices and strategic skill replace original bodily mastery. Most of the situations to be met occur in prepared standardized form, and the conditions of meeting them involve a sheltering from the stress of primary demands. The learning of the rules and a knowledge of the nature of the game, more than the player's parts, may determine the score. Convention remodels the situations so thoroughly, encourages and discourages by such altered standards; circumstances and opportunities are distributed so out of relation to inherent gifts, that qualities do not come to simple expression; and the measure of a man is a thing of baffling complexity. Achievement becomes an uncertain clew to endowment, and experiment must replace observation as well as supplement it. None the less normal personalities develop under the most complex of conditions; and civilization proceeds in its transforming career, however halting the progress of the psychologist in his attempt to follow or interpret the process. By practical exigencies, we are each compelled to meet the conditions of existence with the defects of our qualities and the qualities of our defects. Within the field of the normal there is room for 
the side-by-side play of the most complex qualities massed in a reasonable compatibility, and shaping a life large enough for the satisfaction of the multiple needs of a consistent liberal personality.

It is at this juncture that we turn from the consideration of temperament, and by way of the problem of the compatibility and correlation of traits, to the general problem of individual differences. In modern psychology the temperamental differences of men are viewed as one phase - though a peculiarly important, comprehensive and even dominant one-of the range of psycho-physiological variations. All these differences proceed primarily upon the differentia of native endowment, upon the specialized variations of our several heredities; but as they come to expression, they are richly overlaid by the uses and disciplines imposed by the demands of the artificial life, by the altered perspective of values determined by adopted standards and cherished ideals. The terms "individual psychology," "the psychology of individual differences," "differential psychology," have been adopted to designate the specifie study, and particularly by experimental and allied methods, of the entire range of psychic differences among men; the study proposes to take the measure of a man. An important group of its problems relates to the correlation of traits; a consideration that is ever in the background is the possible reference of traits in proper measure to heredity and to education, to nature and to nurture; a constant purpose is the application of the findings in shaping eareer to endowment. A brief outline of the programme by which such study hopes to accomplish these objects will directly and profitably continue the argument of the present chapter.

In taking the psychic measure of a man, we begin with his sensory endowment; for the service of the senses sets a condition to the growth of mind. The standard test of 
sensory endowment is the power to make small, slight and delicate distinctions. The data of the sense of hearing may be cited as typical. The simplest auditory sense-quality is acuteness-the delicacy of the auditory function. To hear sounds of fccble intensity, as well as to distinguish the loudness of slightly differing or changing sounds, may prove a convenience and an advantage; it is but the first step in the mental endowment, however seriously any hardness of hearing or dullness of distinction may prove a handicap. Acuteness is secondary to discrimination; and the value of the lattcr depends upon the direction in which it is cxcreised. Without rapid and ready distinction of sounds, speech would be impossible; yet speech is an artificial acquisition, built upon the natural capacity to distinguish and interpret sounds significant to welfare. When applied to pitch-distinction, it plays a distinctive rôle, and when specialized for the accuracy of the relations of interval which underlie music, it becomes basal for further musical development. All three sensibilities-for intensity, for pitch, and for interval-combine and merge in musical diseriminations, and find their complement in the peculiar and intricate distinction of tonal quality, less measurable but equally fundamental. For musical sensibility the sensory endowment is indispensable; and yet it does not determine the emotional and esthetic susceptibility, does not fix the place of music in the life of the mind, with more than an approximate and partial relation. As thus conditioned by the innate musical "ear," the musician is temperamentally musical. Equally fundamental is the fact that hearing, as is true of all other senses, goes beyond awareness to distinction, and beyond direct distinction to indirect meaning. The poet requires an ear for rhythm, the linguist for niceties of pronunciation, yet merely as a requisite for the larger service to which it is applied. The delicacy of auditory discrimination conditions the arts of language and the vocal tcchnique. In all these respects 
men differ; and by measurement and comparison, individual psychology has increased the knowledge of the range and distributions of such differences. The acquired specialized distinctions are the more significant in their practical application by virtue of the principle that value for mind increases as interpretation moves away from bare sensory distinction. Auditory acuteness of whatever type becomes secondary to auditory comprehension. The significant equation is that of the total value of the auditory support in and for mental assimilation and elaboration. What really matters, speaking by and large, is the degree and manner in which I am ear-minded; the correlation, fixed or variable, marked or slight, of ear-mindedness with the above enumerated auditory powers of distinetion, forms the comprehensive determination. Ear-mindedness calls for more than sensory tests. It demands a measure of the value of the "ear" for apperceptive, assimilative work and attitude, and of its part in the sensory support of the mental movement. My ear-mindedness is shown in the more vivid appeal, the greater ease and carrying power, of an address when heard than of the same content when read; it appears in my vivid auditory imagery of voices and noises, in my marked emotional sympathy with cries and groans and laughter, in my suppressed rehearsal of the spoken words even as I write, as well as in my ready distractability by sounds that have meaning. It appears particularly in the imaginative control of absent auditory impressions, and in the shaping of my "style" by the prevalent critical pose which I assume to its effect, as a listener. Yet it may well be the case that I am intellectually ear-minded in a marked degree, while yet commonplace in correctness of musical appreciation, in which latter respect my musical taste may be much better than my "ear." Here arise a cluster of problems in correlation: how far do these various types of proficiency run in groups, how intimately is this or that proficiency, so far as it can be measured, re- 
lated to another? All this is part of the programme of individual psychology; its conchusions when developed will confor an authoritative insight into the correlations and distributions of type-traits, and into their relative status as issues of temperament or of training.

In gauging the significance of sensory differences, the principle is important that sensory acuteness is subsidiary and ancillary to perceptual capacity; good observation goes farther than good eyesight, however indispensable a fair degree of the latter is to the development of the former. Good cyesight does not assure good visual observation. The direction in which the perceptual capacity shall be applicd and developed is determined by the situations to which meaning is attached. Noises, tones, and words engage our powers of distinction because conditions make it important that we distinguish them. The interpretation of observed sensory differences among men is affected by this consideration. Sailors may not see better than landsmen, but know better how to use their eyes, and what appearances to expect under conditions at sea; the woodsman may not liave superior senses to those of the citybred nor use them more expertly, but knows better how to catch the sensory clews upon which wood-lore depends; the woodsman or the rustic is at a disadvantage in the complex sensory appeals of a crowded city street. Differences of direction of attention and training obscure differences of capacity. The absorption of the sensory powers in the service of mental distinction guides the life of the senses.

The determinations of the chief components in the service of the ear may be compared and contrasted with the service of the eye. In vision particularly, prompt and accurate distinction follows the clew of meaning; and meaning, in turn, takes its direction from training and interest: Yet primary sensibility remains and in some specialized callings becomes a conditioning factor, dominantly so in 
the field of color. The artist leans heavily on sense-distinctions; feeble sensibility to tints and shades and hues of color will handicap the landscape-artist but also the housepainter and the "ribbon-clerk." The color sensibility of the former is not that of the others raised only in degree, but a complex development and elaboration of it-the issue of a more intricate equation. The visual sense of form is doubtless the largest, most elaborate, sensory distinction in the psychological equipment. It is minute to the last degree of refinement, serving the botanist and the entomologist in his distinctions of species and varieties; serving in every domain for recognition of complex arrangements of "characters"; in natural and artificial products, serving the anatomist in identification, the chemist in analysis, and the surgeon in delicate operations; serving the nice discriminations of artists and craftsmen guided by impression; serving the shrewd clews of the detective in his intellectual interpretations; and serving no less the delicate psychological reading of social attitudes and expressions, intentional and undesigned. And yet despite the obvious handicap which sense-deprivation places upon the blind, their capacity for mental development suffers in the main by difficulty of support rather than in the ultimate quality of achievement. Their insight, though lacking the visual penetration and survey, is yet attained by cultivation of the rationalized procedures which sight more notably but not exclusively furthers. The blind travel upon the same road to learning, reach and pass the same stages as the rest of us, but travel in a slower, less serviceable conveyance.

The relative dependence upon ear or eye as well as upon the other sense-data, in mental elaboration yields types of mind-temperamentally determined-yet presents a considerable individual variation within the dominant group. Though ear-minded in mental assimilation, I may not be gifted musically; and may find myself possessed of a strong color-sense and form-sense; I may be more susceptible to 
violations of good taste and good art in the arts that are directed by the eye than in those directed by the ear. The same applies to accomplishment: I may not come within hailing distance of eomposing a tune, but can with studied aids put together a design. My eritical powers may serve me better, make more refined distinctions, in matters of color and form than in those of pronunciation or wordvalues, or of melody and harmony. Nor does my senseendowment end here. In addition there is in each a measure of dependence upon movement and the sensory experience of action; it appears in the intimacy of bond between observation and imitation. I may be a good auditory apperceiver (listener), and yet not a good mimic; though if the latter, I must have a fair standing in the former respect. For the bond of ear and voice and the yet more potent bond of eye and hand embody the relation of instrument to its direction; its medium is the kinesthetic sense, and its quality is skill. Individual differences in this respect seem vast because so directly expressed in achievement; the expert seems far removed from the layman, the skilled artisan from the tyro. Handiness or clumsiness appears in every movement of the muscles obedient to the directive will and the critical senses. The performance reflects the quality of the performer. There are comparable elements in singing or speaking, in carving or painting, in playing one musical instrument or another, in games of skill, in juggling, in the endless specialties of handicraft. The kinesthetic measure of a man reflects intimately his lative powers of coördination; in some sense every fully cultivated man is an artist; the human touch ever enters as a measure of the human product. The poise of the body as the instrument of the mind seems to be set by the adjustment of trained muscle to refined conception. Skill, grace, expertness, and all the technical proficiency of process and product compose the kinesthetic excellence. The contents of museums, no less than the exhibitions upon 
the stage-whether acrobatic, vocal, mechanical sleight-ofhand, or clever play of mind-testify to its enduring hold and value. Analysis is drawn upon to reach the elements of individual differences: strength, swiftness, accuracy, endurance, control, complexity of coördination, enter into performance and submit to properly designed tests. The correlation of these foundations of handiness and clumsiness, of mental as well as muscular coördinations, are practically significant. Brightness, quickness, cleverness contrast with dullness, slowness, stupidity. The intellectual factor dominates; heads are more important than hands; skilled labor commands its price. Most comprehensively, because achievement is measured in terms of performance, is the direction of muscle a vital measure of human efficiency; and because performance is guided by sensory distinction is sensibility the ultimate standard [11].

All this pertains to sense alone, the opening chapter of differential psychology. Prompted by the individual interest, I at once proceed to ask: How far is my status in this or that group of proficiencies and sensibilities related to my status in another? Which orders of trait or degrees of their presence go together? Which are the more, which the less temperamental traits? But the methods of approach to these questions are again through designed tests of specific factors in the general mental procedure. I ask particularly: What type of imagination do I exercise, not merely with reference to the sense-terms, the medium of my preferred imagery, but to the range of resemblances and suggestiveness in which my thought moves-its source, variety, quality. The issue involves my preferred types of association, both for apperception and for memory. Memory is the most reducible of the components. There is recognized tenacity and span; the depth and breadth of the intake and retentiveness. But memory is selective, like attention and apperception; not all is fish for my net; and the character of the net and of the fishing ground to which 
inclination and purpose take me, determines the kind of fish that may be lured and held there. Quickness everywhere comes to the front. There is a tempo in my mental doings, slow or alert, not umrelated to heaviness and dullness on the one side and brightness, lightness and eleverness on the other. Quick to see and quick to understand; quiek in parry and thrust; quiek in repartee and resource -these too are qualities, dimensions in the composition of traits in the individual.

Yet that elusive distinction that is ealled quality and is the essence of difference and individuality lemains paramount. All thinking requires the association and ordering of the materials of thought; and in the weave of the mental fabric, the warp and woof of thought, lies the secret of the product. It is not merely the graded and measured elements of the weave, not the patterns followed in the making of it, not the raw material, but above these something that has a standing in mental valuation-the originality, the texture and design of the whole, conditioned no doubt by the very factors that analysis discloses, and yet escaping its formula through complexity and delicacy of relation. The associational steps may be made to yield certain significant differentia of types, such as the dominance of logical as against the emotional procedures; within the former the dominance of ratiocinative and abstract, as against concrete and presentative steps: whether the thought moves mainly in concrete pictures and vivid externals, or in internal congruities of mood, affect, and abstract relations. Even in so simple a test as the attempt to describe an object, the natural bent appears. Some individuals truly deseribe the optical impression, others analyze the mental impression; if the object admits of it, some imaginatively weave a setting and a theme about it, others literally eatalogue the details, give a detached report of the scene. Attention yields a significant gauge, for it shows itself under test as persistent, resisting distrac- 
tion, or as light and distractable-adapted to the longer or the shorter shifts of effort. Judgment and the power of combining and of problem-solving have been reduced to "test" cases; suggestibility has been measured; even such qualities as the definiteness, the reliability, the confidence, the consistency, the impressionability of judgment-lingering upon distinction awaiting assurance, or rushing upon response-have been reduced to experimental terms. In conduct the type of reaction; the drift of attention as affecting expression; its spread and illumination; the natural precision and decision of responsiveness; the emotional involution; the variation of all these at the hours of the day; the mode of absorbing the recuperative processes of sleep, and the dependence upon them-these have yielded to quantitative data, not simple in their interpretation. Although all this approaches and passes the threshold of psychological efficiency, it does not reach the hearth of the domain, does not reveal the true inwardness of why and when and how my work now proceeds profitably, freely, and again painfully and muddily, or if fluently, of feeble quality. And no more does it reveal except in a crudely approximate manner, why my work bears the quality that inheres in it, finds its natural outlet in my preferred occupations, and its limitations no less. That eventually the correlation of measured proficiencies with specialized fitness may be accessible for a cautious prognosis is the hope of a vocational psychology. Diagnosis is the preliminary step and has bravely met and solved a considerable group of significant problems. Its findings, like the selections above noted of the programme of individual psychology, are tangible and suggestive. The project is well framed; particularly is the outlook hopeful for the establishment of "intellectual" types, on the basis of correlations of the proficiencies susceptible to training.

The limitations of the programme of individual psychology have next to be considered. The most notable is the in- 
adequate reduction of the intellectual quality of insight. That men differ and differ notably-in degree, composition, quality-in respect to intellectual capacity and proficiency is in itself manifest; such differences are conspicuously recnforced by the manifold play of intellect in the civilized environment. The world of civilization, the artificial life, is largely a world of mind; the adjustment to its demands is a test of intellectual power. As a consequence of our up-bringing and our familiarity in school and out with the products of invention and the records of the past, we apply a more fincly graded and more diversified scale to the appraisal of intellectual proficiencies. When slight differences count, a fine scale is needed and devised. The trend of the original endowment is at once overlaid, elaborated, and refined, and all to such a degree that the appropriate scale of values is substantially a reconstructed, artificial onc. But the units of the scale are uncertain; practically they are expressed in terms of the achievements employed in the intellectual machinery of modern life; in principle they should be reduced (or made reducible) to terms of psychological aptitudes and their elaborations. The compromise of theory and practice is apparent in the tests of life and in the attempted solutions of the psychological laboratory, designed, in large part, for application to vocational purposes and the determination of deviations from normality. Examinations for fitness abound in all callings and professions; and examinations to test progress attained are the constant instrument of educational procedure. They may serve their rough and ready purpose of differentiation; but do they test capacity or attainment? In taking the measure of a candidate for a degree or for a position, grades are undecisive, and an appraisal of the quality of intelligence enters; nor is its recognition a mere concession to popular impression. From the psychological approach analysis reduces the prime factor in intellectual insight to the perception of relations; inference, reasoning, 
logicality, describe the specific connecting process through which the data yield conclusions-the induction, deduction, and hypothesis of the logician. Observation recognizes a typical variation of the logical quality according as it takes a practical or an abstract turn. Theory and practice, principles and their applications, the handling of an argument and of an instrument of precision, or the organization of men, the planning of a campaign on paper and its execution, head work and hand work-all present allied contrasts of the bent of insight as well as of execution. The intellectual world seems to divide naturally into students and practitioners, as well as into the directors and the directed; the adjustment of the two constitutes the problem of infusing action with knowledge and of bringing knowledge to efficient expression. The distinction relates also to the facility in dealing with presentative or with representative material; to the leaning upon the support of the actual impression, or of its imaginatively constructed presence, of the sensory experience and its control, or of the mental experience and its interpretation.

It is clear that the more primary field of exercise of the rational quality, and the larger experience of the race as of the individual, is that of dealing with things and men; the more specialized facility is the dealing with ideas. The conception that directs the study of such differences among men is that of "general intelligence"; and the inherent difficulty is this: that while we aim to test this underlying quality, we can actually bring to a test only a specific proficiency, such as that demanded of successful candidates for particular callings. The reconciliation of the two factors has not been successfully accomplished; psychologists have adopted divergent solutions. An extreme position denies the existence of "general intelligence" altogether; it relies upon the indubitable fact that each brain contains only specialized connections between definite sensory appreciations (or their symbolic intellectual representations) 
and equally definite motor executions (or their rationalized tendencies). It points to the evidence that the facilitation of one such connection by a considerable amount of practice has but slight effect in conferring a readier facilitation of allied responses. The increasing curve of quickness and accuracy that marks my improvement in recognizing and checking all the " $A$ "' $s$ among a thousand letters is remarkably like the curve that shows the proficiency in identifying the " $B$ "' $s$, although the second process has the benefit of the accumulated practice obtained in acquiring the facility in the first. Practice is but slightly transferred. The learning of one manipulation helps me but slightly, as thus tested, in learning another and similar one; the having-learned-to-write with my right hand gives me but a feeble start in learning to write with my left hand. But critically considered, this evidence indicates the limitations of the learning process rather than the absence of gencral intelligence. The opposed consideration is the important one that the endowment and the strength of its native bent by which I readily learn to draw helps me also to learn to model; that my handiness in one craft supports the handiness in another in the sense that the degree of excellence which I may readily or eventually attain in one or the other reflects a common facility. The data of correlation prove this, and support the principle. Learning one particular manipulation, like learning one particular language, may help me in learning another only in so far as the two contain overlapping acquisitions; but I learn both by a common aptitude. There is a core of meaning in the comparison that I am more apt or more awkward than the average person in learning crafts or in learning languages. However, the purpose of this reference is not to present the arguments for "general intelligence," but to indicate a true source of human differentiation, and its bearings.

The several intellectual processes, serving as bases of tests, are steps and supports of problem-solving. The prob- 
lem-solving quality of the human mind is a vitally important factor of its efficiency; by the stress of artificial demands it has been elevated to a commanding position, and by the highly specialized nature of these demands it has been developed to a refinement that is itself a measure of the racial civilization. The measure of its possession divides men broadly into bright and dull; it divides them in the higher reaches of thought and the finer logical adjustments, into the alert, original, resourceful, progressive minds, and the plodding, imitative, unimaginative, conventional ones-into the ordinary and the extraordinary, into thase dwelling in the approaches to the intellectual highlands whose peaks bear the name of the summits of genius, and the dwellers in the lowlands, where life, though lacking notable outlooks, is well regulated and secure. The quality of originality is primarily an intellectual one; it stands as the counterpart, if not the correlate, of the strong temperamental trend in emotional responsiveness; if the Trieb of the endowment makes men feel things strongly, the vigor of the intellect makes them see things clearly. Superior sensibility to emotional play leads to exceptionality of the one order ; insight into relations, to exceptionality of another; talent is a common name for both superiorities and commonly implies a specialized trend. A talented person may have many talents and be notable by such versatility; yet his several talents are themselves specialized. The mistake must be avoided of comparing the lesser aptitudes of men possessing one marked talent with the proficiencies of those specially gifted in the lesser aptitude. A philologist's or a psychologist's mathematical ability may be very modest compared with that of a mathematician, but, as the group trait, is distinctly above that of the average man. The principle is still more pertinent when applied to less specialized aptitudes. The scholar of whatever speciality is more conversant with intellectual matters in general than is the average man; presumably 
he stands above the average in general power of adjustment to complex situations of varied type, notwithstanding the popular prepossession (founded upon extreme examples) to the contrary. The conditions and correlations of great abilities are instructive, but no less so the like relations of ordinary range. Studies of the heredity of genius prove the thesis that high orders of capacity depend in large measure upon native bent; moreover the specialized inheritance is the typical one-not merely that high orders of talents, but specifically that musical gifts, intellectual capacities, practical abilities, run in families. The intellectual aptitude is thus referred to a temperamental basis, while yet the dependence of its expression upon the derived and artificial order of living is abundantly recognized.

Life at all levels of human organization offers constant problems of an intellectual type; accomplishment and achievement, however directed, are the tests of life, which -speaking broadly-conform in their type and genius to the natural situations that through the ages have developed the power of adjustment and the control of experience. Compared with such "natural" trials of wits, the tests of the laboratory scem artificial and bare. They seem to lack motive as well as reality, to test detached processes dissected from the living problem. None the less they supply the only serviceable instrument of special analysis, and in due course promise to yield a consistent and authoritative interpretation of the individual differences of mind. Despite the uncertainty of analysis and application (together with the inevitable fact that it is only the specialized embodiment that is capable of being tested), the intellectual measure of a man will become more and more definitely and reliably established. The common elements are amenable to analysis: quickness and fineness of discrimination, the perception of relations, memory in scope and security, imagination and association in richness and quality, judg- 
ment, inference, abstract reasoning, symbolic thought. The difficulty, to repeat, is the comprehensive one that such community of endowment-expressed in process and product-as we are entitled to assume, yields incommensurable data. The determination that individual $\mathrm{A}$ differs from individual $B$ in powers of imagination more than in judgment, in sensory discrimination less than in wealth of association, or excels him in the one but not in the other respect, is uncertain not alone by lack of fit and comparable units of measurement of these qualities, but by the fact that when these powers are tested by one set of materials congenial to A's interests and acquisitions and not to B's, the "capacities" of the two may prove very different and A superior to $B$, while a different selection may reverse the evidence. The difficulty of deciding that $\mathrm{A}$ is a better engineer than B is a philologist is but an extreme instance of the disparity of terms.

In further illustration, tests of ingenuity may readily be arranged; but they will always be of special ingenuities. Mechanical puzzles, logical catches, mathematical devices, verbal combinations, imaginative riddles, may be used with equal validity. They will test not quite the same powers, but, in a general analysis, very similar ones. Yet it would be as false to draw too rigid conclusions from any one set of data, as it would be to gauge the general intelligence or mental ingenuity of all men by their ability to play whist or chess. The qualities that make a good chess-player or a good whist-player may in themselves be as significant as those that make a good philologist or a good engineer; the results of the one study may be as valuable as those of the other. We turn our powers to such different ends as to lose the common standards of comparison which "individual" psychology aims to restore. When I find through ordinary exposure to their appeal that I am "good," "average," or "poor" at riddles, cards, games, etc., it does not mean that the proficiency actually attained in these 
recreations represents the limits of capacity if their attainment were made an important object in life, but (disregarding opportunity) only that the actual appeal of these pursuits to the native quality is strong, moderate, or slight. One may lose not only one's taste or liking for chess-owing to the rivalry of later interests-but even the capacity to excel. For such powers, like those involved in learning a language, have their special relations to periods of development. Childhood and early youth is the favored time to learn a language, because the learning process falls within the plastic powers then at their readiest service. Memorizing, direct sensory associations, mechanical facilitations develop early; the logical processes, the power of representative and abstract thought, the philosophic outlook, the judicial generalization, are late in maturing and await expericnce as well as expert logical control.

The original difficulty continues, and is more and more complicated by the complication of the environment which tends to emphasize and differentiate opportunity, and to reflect social encouragement. Persons in one station of life have slight occasion or opportunity to develop a facility in handling ideas, while in another station, they will be encouraged or required to develop such facility, slight, moderate or marked as it may be, to its utmost capacity. A may be learned and studious, but not particularly bright, $B$ bright but ignorant; or A may go forward as a child by the push of native precocity, and $B$ progress by diligent forcing. In brief, the difficulty in the differentiation of men in terms of their composite intellectual qualities-as revealed and yet concealed in their expressions-forms the central difficulty of an applied psychology. It explains why in the absence of any such body of knowledge, at once authoritative and adequate, we are thrown back upon the tests of the accredited callings and the everyday demands of the vocational and the avocational life, of the powers of adjustment to them, the suc- 
cess in utilizing conventions and expressing individuality through them [12]. All this we recognize as a highly artificial test, a specialized composite one, with the factors merged beyond ready analysis. The transfer of the terms of individual differences from differences of capacity (which we seek) to differences of achievement (which we find) in a sense abandons the quest, and in so far expresses the limitations of the present status of individual psychology. It in no manner weakens confidence in the reality of the underlying differences as expressive of psychological capacities, nor in their practical operation. There is no doubt that men differ in the entire range of intellectual aptitudes. Talents are real; the inequalities of men furnish the basis of specialization and the efficient organization of the manifold work of the world. To test and express the foundations of these differences and to supply available formulæ for their application to actual needs sets the programme of a vocational psychology. Such considerations recognize that opportunity, encouragement, education as well as native gift, are responsible for the notable differences of men in problem-solving proficiencies as exercised. The demand of the environment as well as the quality of mind is expressed in the achievement. Beliefs, ideas, cultures, systems of thought, philosophies, separate men widely; but such divergences are largely accounted for in terms of nurtural influences, as the molding force of the environment. The regulation of life by such intellectual products is itself so high-grade and artificial a process, that the differentiations which it imposes are dominantly of a derivative order. None the less we are convinced by a conclusive though irregular mass of evidence that mental acumen and all the several ingredients of general intelligence, are variously distributed. With this conclusion we readily assimilate a similar view of the varieties of energy and the volitional support of action.

We thus return to the consideration of mental energy as 
a differentiating factor of the human endowment. It combines readily with the intellectual pursuits. Where distinction recognizes the goal and ingenuity points the way and consideration safeguards the advance, energy sustains the movement. Each supports the other; and the differentiation lies in the issue of which is master and which is man. Originality and initiative are complementary phases of individuality. Yet to have an idea, and to have the persistence to energize it readily and efficiently, diverge; for such inequality of impulse underlies the distinction of the theoretical and the praetieal turn of mind. Ardor of pursuit, refleeting native strength of appeal, is temperamental and in that relation specialized; it attaches to the strength of endowment; our best energies go to our favorite occupations. Energy and ardor, strenuosity or persistence, is turned by native bent to the expression in which such bent finds satisfaction; it grows by what it feeds upon. Furthermore, the social setting supplies the road to travel on as well as the friction to be overeome in locomotion. There is a rivalry of expression among the several impulses imposed by endowment, in which temperamental ardor may deeide; and there is a further contest between such impulses from within and the molding forees from without. The assertiveness of native bent must rise above the neutral tone as above the average eapacity in one respect or another; and, again, individuality emerges and measures its strength in the resistive reaetion to eireumstance. Compositely the individuality-combining energy and capacity - utilizes while yet it surmounts the standard patterns of endeavor. It becomes elear in this view why originality is the common though indefinite expression of the temperamental trend; why conventional conformity marks the commonplace.

Yet energy may be applied in the rank and file, or in leadership, or as a free lance. Energy applied under a strong motive and an independent one is intellectually more 
significant and dramatically more interesting. But energy may and must go into dull hard work as well. Drudgery is more or less inevitable. The natural situations still serve as remote patterns. The will to prevail leads to the will to succeed, and intellectual success depends largely upon the grasp of conceptions, the loyalty to ideals and persistence in their pursuit. Possibly the largest difference among men, speaking pragmatically, is this of energy and its emotional counterpart, courage; the orbit of achievement is determined by energy as well as by capacity. Where eapacity is nearly equalized and competitions proceed without handicap, the touch of the will, the added vigor of energy, persistence, steadiness, commonly determines the winner. That strenuosity as well as its emotionalized support in courage or confidence may go with feeble eapacity is quite familiar, but does not disturb the true value of "will" quality; the lack of balance between them, and their wayward expressions are strikingly illustrated in the abnormal phases of temperament. Morality recognizes the "will" factor by strengthening right knowing by right doing; it makes its strongest appeal to the will. Flabbiness of purpose, a lapse toward indifference, failure of interest, mere inertia, combine with or may be an index of feebleness of energy, or lack of persistence, to mar what their vigorous presence might creditably or nobly make. Right action is the temperamental meeting point of the will and the emotions; it sets the problem of the regulation of desire. It involves more than energy in that it implies intensity of motive; it is expressed in the qualities of enthusiasm, ambition, concentration, devotion, will; in a measure it reflects at once the ardor and the direction of purpose. For constancy of command of resources, the inspiration of imaginative readiness, the warmth of rital interest, still require the consummation of sustained effort to ripen into achievement. Ardor of pursuit is temperamental, is strongly nurtured in the interplay of natural 
impulse and the rivalry of imposed pursuits; when matured and disciplined and directed toward acquired professional activities it makes for large achievement. Even in its abnormal expression, in devotion to fads and fancies and extravagant views and positions, it retains a significant clew to temperament and may redeem an otherwise ordinary range of endowment. It is compatible with narrowness of outlook and insensibility to the wider appeals addressed to the complex phases of one's psychology. It supports the singleness of purpose that may be heroic or narrowing, even blinding. For loftiness of aim stands higher in the appraisal of human endeavor than mere tenacity without reference to the values of the activity in which it is enlisted. Scale as well as composition enter into the proportions of achievement as of endowment.

The determination of individual differences in terms of energy (or of courage) is affected by similar and yet more marked difficulties than those that attach to the consideration of intelligence. We cannot readily supply motives to induce the "will" quality or to arouse its presence. The tests of life are alone adequate; and observation and analysis in the ordinary range of responsiveness supply, as in the distinctions of temperamental variation, the available data. Yet we are not without resources in the experimental field. Fatigue is the constant expression of the limitations of the will; and the failure of attention is its most significant organic as well as psychic index. In a sense the problem of the will is to supply effective stimuli when the natural ones pale, to continue interest by support of purpose or duty or the stress of necessity, when the task becomes tedious or rival invitations tempt. Fatigue is constantly to be reckoned with, and mental fatigue particularly. Thought itself as a specialized and sustained process is an unnatural procedure, while feeling and action are direct and natural. The thoughtful life is the artificial life: hence the difficulty of sustaining endeavor at a high 
pitch, and the inevitable fatigue of attention; hence the necessity of reducing processes to a mechanical facilitation in which they may be pursued with a lax attention; hence the shortness of hours of work under strain; hence the constant desire for varied entertainment: the short story, the condensed paragraph, the brief address, the quick action and rapid dialogue of the drama, the change of occupation in school periods, the shifts of routine. Concentration and rapid dialogue of the drama, the change of oceuacquisitions, and are uncertainly exercised at the best. Ability without power of attention and application is vain; concentration implies both; it implies that natural distractability has been overcome. Maturity implies a control of longer shifts of attention supported by acquired interests. The study of mental fatigue and of the control of attention, even in artificial tasks, reveals significant qualities of mind; they have proved to be among the most helpful of differentiations in "individual psychology." They are so because they are intimately related to the capacity to aequire and control rather than to the bare evidence of facilitated acquisitions.

Capacity and energy furnish the composite criteria of both having resources and commanding them. This relation at once suggests the temperamental basis of appreciation and control. For in the equation that unites them is expressed the condition under which capacity comes to achievement. There is a strong impression that a pronounced temperament, when brought to its keenest expression in genius, is irregular, bound up with uncertain mood, is a fitful spark, an occasional glow, rather than a constant flame; and with it is contrasted the modest but dependable irradiation of a steady talent. To this difference-along with the closely related factor of energy and endurance-is often referred the largest discrepancy between endowment and achievement: the promise feebly fulfilled, the acknowledged ability and good parts that leave a disappointingly slender 


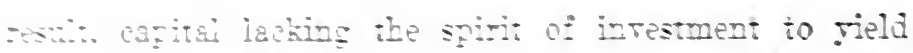

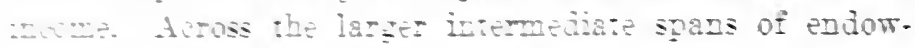

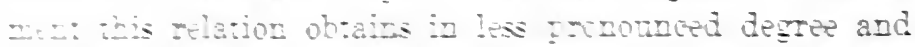

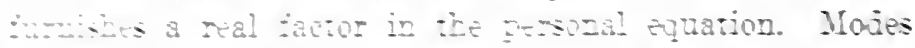

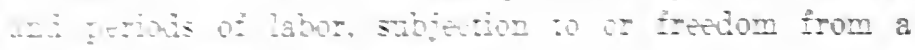

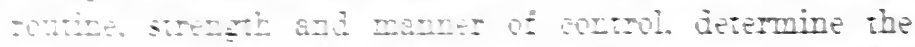

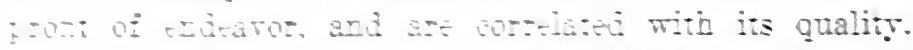

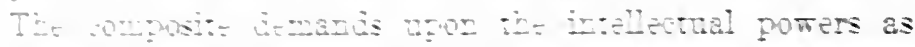

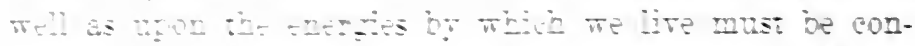

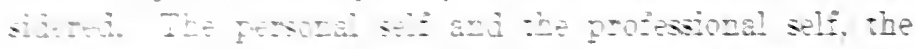

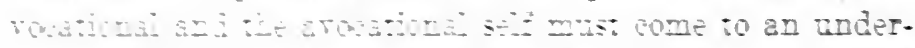

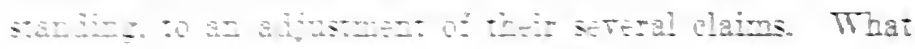

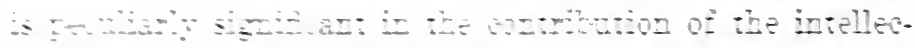

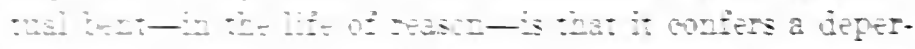

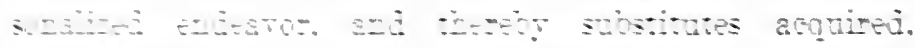

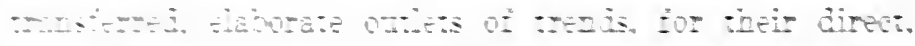

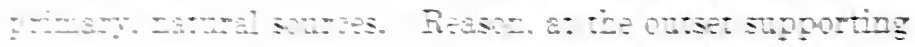

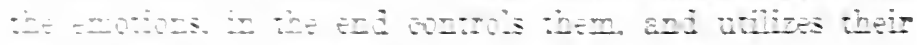

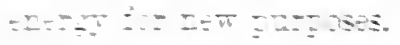

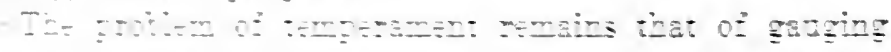

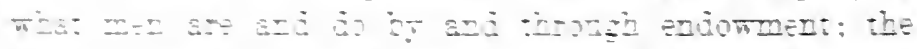
s.w

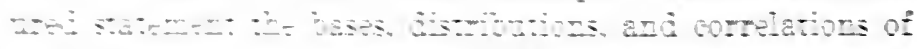
Zne

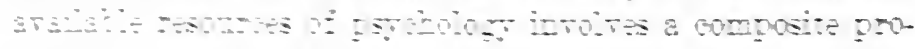

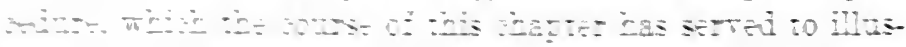

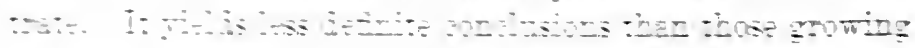

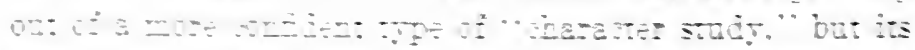

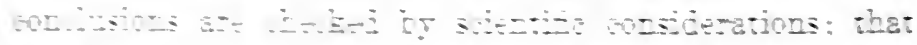

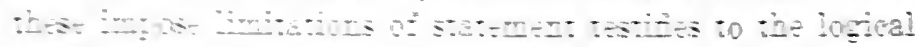

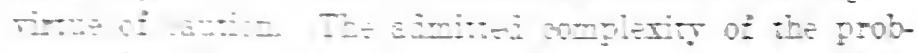

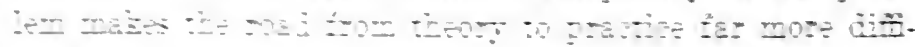
sil: a

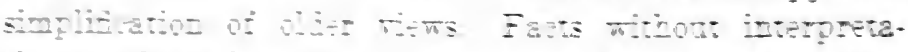

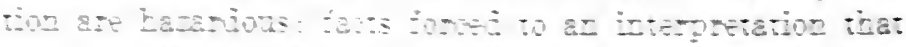

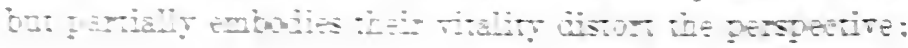


a compromise procedure that goes as far as possible to eXpress the claims of theory and practice alike seems the profitable one. Such at all events is the guiding principle of this attempt to reinstate an old term in a new meaning, and to supply the principles of interpretation upon which cautious application may in due course proceed. Temperament remains a significant expression of the sources of human quality, possibly its central expression, and as such must enter into every equation, howerer expressed, which proposes to set forth the signifeant indiridual differences of men [13]. 


\section{CHAPTER VI}

\section{ABNORMAL TENDENCIES OF MIND}

Miental abnormalities may be viewed as the assets and liabilities of variant or specialized temperaments, or as the irregular expressions of normal endowments under exceptional strain. The degree of normality, of sanity in one sense of the word, is tested by the violence of the shock that can be withstood without wrecking the psychic foundations; but the "shock" itself and its consequences, whatever the inducing cause, are determined by native susceptibility. Abnormal tendencies of mind are dispositions toward extreme or irregular functioning, marked enough to appear in the ordinary run of situations or at the more eritical periods of development or stress. The mode of inadequacy or irregularity is as significant as the setting in which it appears; the two phases direct the study of abnormal tendencies [1].

Temperamental abnormalities imply an organic conditioning; they bring to expression functional peculiarities of the nervous system. The limited knowledge of their operation is important; the more extensive knowledge of their issues constitutes the body of data of direct significance for the study of character. Minor transient variations of mental attitude connected with organic disturbance fall within the ordinary experience of the normalminded. The oscillations of nervous tone and the slighter fluctuations of the metabolism condition mood; recurrent suseeptibility to them determines moodiness-an uncertainty and irregularity of (sensory and) emotional susceptibility and of command of mental resources. Disturb- 
ances of a more violent nature may turn the disposition or carry the responsiveness so far from its ordinary channels as to verge upon the abnormal. Bodily ailment, by cnfeebling or deranging the nervous basis of adjustment, induces mental complications-anxiety, despondency, irritability, and their kindred disabilities and distresses. Pain in itself is psychically discomposing: headache incapacitates; excessive heat prostrates; and a peculiarly comprehensive alteration of interest and attitude attends that desperate wretchedness bearing no more formidable name than seasickness. The conventional inquiries: How do you feel? and How do you do? are suggestive; the "feeling well" or "not feeling well" is the report to consciousness-doubtless somatic in source-of the state of the psychic barometer. Although the welfare of "feeling", and "doing" is a matter of psychic disposition, the inquiry is commonly answered in terms of bodily health. The psychic expressions of the "feeling well," the euphoria, though in part directly physiological-such as the ease of breathing, energy, alertness, appetite, keen sensory zest-are "felt" in the developed psychological medium of the emotions, the depression, the lassitude, the vague distress, the apprehension, the irritability, the uncertainty of self-control, the sense of effort to keep up appearances, the wandering of attention, the lapse of interest, the general "out of sorts." The fundamental place of the emotions in psychic regulation is in no aspect more definitely indicated than in their primacy as indices and media of the euphoria of mind and body [2].

What is conspicuously true of the direct impress of physiological upon psychological condition is more subtly true of indirect influences. Above all are opinions, reflecting the rational nature, supposed to be steadfast and moderately immune from such "somatic" motive. Yet there is no "pure" thought; "the driest light of the intellect is colored in infinite ways." The tone of opinion as of at- 
titudes is emotionally, even organically tinged. It is upon this principle that "things" are allowed to lie in the mind over night, to profit by the light both of the evening and of the morning reflection. Corresponding to the minor oscillations of organic welfare are the psychological shifts of mood and capacity. Observing our own fluctuations, we await the favoring mood and find the "going" easy or sluggish; or obscrving another, we conclude that so-and-so is not quite himself today, implying that a below-par condition has impaired the usual poise of his reactions. As the mental attitude affects the quality and prominence of the bodily symptoms, it illustrates the mind's influence upon the body; the reverse influence of the bodily conditions upon mental state is equally familiar. Whatever may be the pertinence of the expressions, their reference is clear and indicates different aspects of a unitary procedure. When we are urged to smile, or not to look so down-in-the-mouth, the appeal is made to the bodily attitude to affect the mood; when we are invited to cheer up by thinking of pleasant things, the procedure is reversed, and our bodily distress is lightened by dismissing our mental woes or worries. When we resort to stimulants, to the "cup that cheers," or seek to restore poise by prodding the impeded functions by means of drugs and exercise to frcer elimination of the body's clogging toxins, we aim to affect the mental tone through direct physiological stimuli. The unity of the process affords an inlet through either approach. Bodily welfare is so insistent that its demands upon the nervous system oust all lesser concerns, which are in fact the more leisurely occupations of an adjusted condition. Just as under stress of situation, the finer feelings are apt to reveal their superficial hold and bare the natural man underneath, so disease bares the vital necessities of organic satisfaction and makes all else secondary. The lesser fluctuations of condition have a like motive source. One is not in the mood to enjoy a concert, or a 
picture gallery, or a comedy, when in physical distress, when fatigued, or hungry, or uncomfortable; and in the utter apathy of digestive trouble, even the strongest interests and desires pale.

The more permanent inroads of disease and invalidism modify the set of responsiveness, the tone of disposition, in which are read the marks of character. Deviation from physiological health affects the same order of change as temperamental conditioning; it is in a sense part of the same liability. The natural changes of life enforce the same principle. Mental aging is the alteration of interest and mood and responsiveness conditioned by subtle organic invasion. The alteration of character at the period of late adolescence is rapid and marked, because it accompanies nature's profoundest somatic redisposition. The psychological conversion that then occurs is not an act of will, but when real and deep involves and is prompted by organic maturing. The shedding of the milk-teeth to make room for their permanent successors (including the belated wisdom-teeth) offers an organic parallel to the laborious and deep-seated transformation of the adolescent. Nature makes a more serviceable set of teeth by two ventures than by one; the character is likewise twice formed but upon the same foundation. Throughout, conduct and the disposition that shapes it are organically, and by the same token, temperamentally conditioned. The "adolescence" is a pronounced temperamental product; yet in each adolescent the native liability persists through the reconstructive process by which temperamental trends are redisposed, and the traits of character given their more permanent set. The true man, the true woman, emerges in and above the stresses of growing adjustment. The hazards are greatest at periods of organic change. The abnormal tendencies then dominant appear in large measure as adolescent liabilities. If we were in the habit of insuring ourselves against mental losses or misadventures, including the minor 
distresses, maladjustments, extravagances and unprofitable investments of our minds, the risk and the rate would rise decidedly for the adolescent period. Yet because such developmental adjustment is an integral phase in the original nature of man, the successful issues of normal maturing constitute the vital assets of a full-grown personality. It would be an inadequate and a sad life that is deprived of a true childhood, and no less so would be the life that fails in due measure of its maturing privileges. The venture is inherent in the issue. A similarly significant period of increased liability is that of the change of life, when the primary purposes of nature have reached and passed their function. The genetic unfoldment runs its course, and stamps the ages of man. Maturity of function extends to all phases of capacity to meet adequately all demands of situation. Maturity is centered about the activities of sex; the critical periods for the life of the sexual functions become the recognizable foci of the psychological orbit. They become so not exclusively by virtue of the directive strengtl of impulses radiating from the sexual functions, but collaterally by virtue of their standard position in the genetic series. The most normal endowment is subject to large fluctuations of mood and capacity, which, in addition to their momentary occasions, are related to the stages of growth and the conditions of the environment. It is the maintenance of these fluctuations within fairly prescribed limits that constitutes normality; the liabilities of temperament remain, however diseiplined, however controlled. The abnormal tendencies are harbored in the relations fundamental to human life, indispensable to the expressions of endowment. How they reach expression is the subject of the present inquiry. The more general consideration of the conditioning of psychological expression by physiological fluctuation furnishes the keynote for the movement of the "abnormal" theme.

The conception of abnormal tendencies of mind as vio- 
lent or pervasive stresses and strains upon the nervous system, expanding normal variations of mood and attitude and expression into abnormal ones, affords but a partial view. It is supplemented by the conception of the abnormal as the revelation of inherent weaknesses of structure. The mental fabric is prone to give way at the seams and thus disclose the natural lines of composition, the inherent frailties of temperament, including the mode of meeting the genetic changes. By reason of weakness of one type or another, the maturing of functions and the decline of functions, as well as the standard streams of responsiveness, may not follow a normal course but diverge from it. Certain abnormal mental tendencies reflect distinctly the processes of faulty maturing. Similarly the disintegration at the close of life, the manner of one's wearing out, may proceed normally, or in its deviations reveal inherent weaknesses of temperament. Premature arrest or excessive enfeeblement of functions appears as the mental counterpart of degenerative changes in the delicate tissues of the brain. Yet another aspect of the common relation may be added to complete the basis of interpretation. It is that of the undue proportion, the excessive growth of one trend in relation to others. Disproportion is presumably the most common liability, since it is itself involved in the specialization which the temperamental emphasis and the increasing demands of the mode of living require of the nervous system. The hypertrophy of function and the consequent maladjustment, the warped responsiveness to the ordinary appeals of life, constitute familiar aspects of abnormal tendencies. The resulting interpretation combines the values of these several modes of approach. The abnormal issue follows in virtue of the native liability, in virtue of the inducing strain of occasion or circumstance, and in virtue of the extreme hold which one phase of responsiveness has acquired. The lack of poise, the unbalanced tendency, the disqualification, is a com- 
posite product; its composition follows the scheme of normal temperamental liability.

The illumination of normal and abnormal is a mutual one. The abnormal is made more intelligible as the normal in exaggeration; normal deviations suggest the abnormal in miniature. Foibles and failings and all manner of entanglements and disqualifications, present in minor degree in normal persons, have their significance reenforced in the light of the exaggerated appearances of the abnomnal; without this clew they would escape obscrvation or lose their meaning when displayed in their miniature counterparts. The abnormal forms a psychologieal mieroscope-the specimens, the experimental variations provided by nature. Yet abnormalities are the issues of the same general orders of psychic components as determine normal composition. The underlying faults, the deeper fraetures, must be considered as well as the superficial fissures to which they give rise. The latter are the readily observable issues at the surface; they are the concrete data of study; but their interpretation depends upon the principles of genetic and of abnormal psychology. Not vagaries of mind, but types of mental deviations-with reference to their origins and to their normal correlates-are significant.

The orders of human quality fundamental to normal character - the sensibilities, the emotions, the sentiments, the direction and eontrol of energies, the adjustment to situation, the intellectual elaboration-equally underlie abnormal tendencies. Abnormal action is not the result of a different set of laws; nor has it any different source for its impulses or different avenues for its expressions; alienation implies an altered or peculiar perspective of combination, a different interaction of the same components. The abnormal mind follows the same trend of elaboration from sensibility to emotion to sentiments-all intellectually and socially developed-but in varied handicap and distortion. 
The abnormal characters in the concrete appear in both the idiot and the genius, in the criminal and the degenerate, in the hysterical and the neurasthenic, the melancholic and the maniacal, the faddist and the "crank," the tyrant and the miser, and a host of other exemplars from the gallery of human frailty, perversity, or eccentricity. They are one and all the victims of their nervous inheritance. The presentation of types of deviation proceeds upon the principles operative in normal distribution and development, of which the abnormal tendencies represent extreme departures. Accordingly, the survey proceeds to determine such tendencies, not by way of the more pronounced insanities-though finding instruction therein-but by way of the lesser disqualifications that bear upon the vicissitudes of character.

The psychological complexes, summarizing leading trends in the mental composition, have been presented under the distinctive temperaments interpreted as types of impressionability in relation to conduct. Considered in terms of defect and excess and of irregularity of relation, they reach their abnormal expressions. Of these defect is the least engaging. Let the phlegmatio inaction reach an extreme; let the apathy of sensibility and emotion and the inertia of expression so reduce the mental life that it burns with a dim, flickering flame, and the condition is one of feeble-mindedness in various degrees. The extreme reduction of the indispensable substrata of human mentality -impressionability through sensibility and emotion, and an associated motor responsiveness-almost dehumanizes, The subnormal in degree becomes the abnormal in type. The dullness of sensibility, the obtuseness of feeling and imagination, the impaired control, become the most critical traits [3]; the resulting condition is as significant in its intellectual lack as in its emotional sterility. It is the temperament of the crudely defective.

It is, however, notable that the stronger impulses of 
gratification and self-assertion commonly grow with the bodily growth, and come forward with a far weaker assertion of the offsetting traits that guide and restrain conduet. Through such impulsiveness and unrestraint, the high-grade defectives become at once the inefficient and the socially troublesome or dangerous elasses. So distinetive is the type that a special term-the moron-has been adopted for the high-grade feeble-minded individual, who in ordinary relations may not be recognized as abnormal, but who is so limited in capacity, so wayward in expression, socially as well as temperamentally so unfit, that the exposure to the stresses and temptations of modern life is his inevitable undoing. The disqualifieation is hereditarily imposed ; it offers a praetieal problem, for which a psychological interpretation is indispensable [4]. There is, indeed, no phase of mental deviation quite free from the factor of limitation, which constitutes the eentral determination of defective temperaments. The normal limitations of endowment pass impereeptibly into abnormal ones; weaknesses beeome defieiencies. The brevity of their eonsideration implies no disregard of their practical import. Edueational measures find in them persistent problems, and industrial and soeial organization no less so. For the eentral purpose of the present argument they are rather barren of enlightenment.

Excess as the "supernormal" presents no simple formula. Consiclered as an emphasis upon the primary factors of reaction, it develops upon the basis of the eholerie temperament, which eonsists in an exeitable sensibility combined with eager responsiveness, the latter dominating. Such violent quality is distinetive of passion and of maniacal outbreak. If anger is a brief madness, the developed madness is a protraeted anger-an extreme expression of the eholerie temperament in its abnormal issue. The violenee grows out of a limitation of the field of endeavor and interests. Through it mania is affiliated with monomania, which is the exclusion from the mental and emotional hori- 
zon of all but the limited concerns which monopolize attention or disturb emotional poise. During the fit of anger for the moment, as during agitated mental obsession for a longer period, the perspective of values is lost. Expressions are exaggerated, extreme actions carried through in haste, if not repented at leisure; words and deeds show the loss of control as well as the violence of feeling that ousts reason in the hot pursuit of a narrowed purpose. Energy is as little considered as judgment; "working like mad" is not a vain expression.

The abnormal implies more than a temperamental extreme; deviation involves disturbance of proportion in the check and the offset of one impulse, one relation, one trait by another. Mechanical analogies are helpful but inadequate. High-pressure energies take their quality from the organization of the impulses which prompt them, but which they likewise serve. The abnormality lies not barely in their presence but in the service in which they are enlisted. The imperious will, brooking no opposition, may have as opposite issues as a persistent pursuit of a worthy and difficult project, and a reckless unrestrained passion of indulgence or destruction. The imperious pursuit, lacking the control of reason, lacking also its outlook and the offset of sympathies, degenerates to the abnormal; truly the madness does not lack method, but is, however, not thus dominated, but hemmed in by narrow, limited, blinding impulsion. The choleric heedless outburst, always narrow-gauged, is its milder variety. As a frailty of temperament it escapes the dominion in which normally it should find restraint; in its abnormal expressions, the dominion is too far abolished to be restored. The psychological mechanism of the choleric outburst, as of one-ideaed enthusiasm, finds its formula more explicitly enunciated-with all the terms writ large-in the compelling obsessions of mania; the liability of maniacal dethronement finds its initial clew in the disqualification of the ardent "choleric" disposition or 
attack-the "brain storm" that sweeps over a predisposed mind to its momentary undoing [5].

More commonly than excess are disproportion and entanylement in the adjustment of the factors of responsiveness, the clews to the most interesting abnormalities-those most closely allied to divergent temperaments. The too slight dwelling upon consideration with a large attraction for action forms a typical variety of folly, which is the characteristic failing of the oversanguine temperament. 'This temperament is ever imperfectly sobered by experience; it indulges the spirit of venture, prone to extravagance; it is responsible for the confident optimism of the fortunate and the reckless, of the healthy and the young. "In the bright lexicon of youth there is no such word as fail." The sensibilities and emotions are keen only in their direct support of action, are felt mainly as promptings to activity, and are reënforced through the pleasure of activity and the excitement thereof. Health and vigor open the motor pathways to the abandon that allies itself with the optimistic mood; there is little sense of impediment, of obstacles and hesitations, but in their place confidence, energy, daring, ambition, a sense of importance.

The abnormal expression of the temperamental trend is reached when the inner prompting fails of any adequate support of resources, material or mental. A state of intoxication, literal or figurative, answers to the formula. Alcohol cheers, expands, releases restraints, drives away fatigue, dull care, and sober consideration, as well as the hesitations that make for sobriety. This easement makes way for vaunting, elation, a sense of power, self-assertion, extravagance, grandiose projects-all inviting to ardent expression. Whether the resulting action is foolish, indiscreet, and extravagant, or brutal, violent and criminal, is in turn an issue of disposition. Exuberance and violence are near allied, or separated only by the divisions of disposition. In either case restraints fall away, sensibilities and 
their intellectual counterpart, considerations, are dulled; the primitively human, too commonly unrefined and brutally self-assertive, comes forward. Much as the sublime and the ridiculous, ordinarily opposite poles, with an occasional short-circuit flash between them, have a certain proximity, so a similar relation obtains between insight and the occasional drug-released inspiration, the febrile toxemia that in high-strung natures brings to life the difficult potencies of the genius-the superman in the making. In the more commonly resulting disorganizing rather than reorganizing tendency, the release of the normal tension between impulse and conduct, gives rein to cruder, less schooled dispositions, lays bare the underman.

The principle that an abnormal play of the great subjective inciters-sensibilities, emotions and imagination in unrestraint-makes directly for mental and motor extravagance of an expansive, sanguine tone, finds a salient consummation in the symptoms of a well defined pathological complex - that of general paralysis. The diagnosis of general paralysis implies a specific disorder indicative of a degenerative process in the higher nervous centers; the point of interest is that in its course, it exhibits the pathological counterpart of certain phases of a temperament. General paralysis takes its name from the motor impairment. Its onset is as seemingly trivial as its course is ominous. Along with slight impediments of speech appear equally slight emotional and intellectual disorders; there is a general coarseness and exaggeration of the thoughts, feelings and conduct, corresponding to the lack of sensory and motor delicacy in discrimination; and at first there is often great overactivity, associated with, and due to, loss of control. Motor impairment and mental excitement increase as the brain-tissue is invaded. "There are very frequently ideas of grandeur, and Baudelaire's muse, as described by Swinburne, with deep division of prodigious breasts, is the characteristic goddess of the general paralytic." A discern- 
ing witer coneludes his deseription of this typically maseuline disorder thus: "Sueh in the rough are the fundamental characteristies frequently, though by no means invariably, associated in the vietims of general paralysis. Regarded as a whole, the type is charaeteristic as much in what it lacks as in what it possesses. General intelligence and common sense, ambition and energy, sociability and a large capacity for enjoyment, a firm belief in one's self, and a preference for handsome women are all eminently sane eharaeteristies according to our present standards. On the other hand, some admirable qualities are notably wantingqualities which make for a higher control to temper the tendeney to excess, the selfishness, and the restlessness." The resemblanee to the early stage of alcoholic intoxication is conspieuous. The tremor, thickened speech, uneertain movement, coarsened sensibilities, diminution of motor and moral control, exuberanee, extravagant thought and action, as well as the speeial susceptibility to sexual excitement, are common to both states. General paralytics and those disposed thereto, or headed in that direction, present a common range of charaeter. Intelligent, aetive, restless, ambitious, they drift to the eities and high living. "As a rule they are well nourished, and not of a neurotic, phthisieal, or otherwise delieate appearance. On the contrary they are spoken of as men of 'strong constitution,' full-blooded and vigorous, well favored men. In short they are good animals" [6]. The type is "that of men commonly called 'good.' They are deseribed as men who 'would do nobody a bad turn,' 'kind-hearted,' 'generous,' 'hard-working,' sometimes even 'eonscientious' '; but their view of life is essentially a selfish, non-moral view usually devoid of religious interests. "The elraraeteristic general paralytie is a man with a large belief in himself, restless, ambitious, and with a relentless desire for the good things of this life.'

General paralysis represents the tragic onteome of a liability of like order to that inherent in the extreme expres- 
sions of a temperament. Obviously the possession of such a temperament does not make one a candidate for general paralysis-far from it. The relation implies only that the symptoms of such specific impairment offer an impressive enlargement, an exaggerated picture of features recognizable in more normal proportions in temperamental expression. There is a foundation in general human nature, and yet more so, in this predisposed type, for an excessive and distinctive "psychosis." The outcome of a career dominated by such a temperament, far from being tragic, may retain to the end the joyous tone of successful comedy, or stirring drama-a little vainglorious, self-important, tending to overdo, not quite disillusioned, active, hopeful, confident, strenuous, masterful to the drop of the curtain. The type is well established in the vicissitudes of character. Like all temperamental trends it has its due compensations -its fortes. For the moment it illustrates the close kinship of traits inherent in the varied emphases of the components of response, to their pathological expression.

Excesses of sensibility, by way of the complications of response which they entail, offer the largest variety of minor deviations from normal functioning. Melancholia expresses one of its emotional moods, one of its conspicuous issues. The exaggerated sensibility is expressed directly in hyperesthesia-an oversensitiveness not merely to the pain-pleasure susceptibilities of sense-excitation, but even more characteristically to an intensive emotional absorption [7]. To be painfully affected by slight stimuli or by those ordinarily indifferent, to be unable to dismiss from cousciousness minor irritations, is a germinal trait of the abnormal nervous temperament; it is popularly recognized in the tendency for "things" - as variable as life's irritations- "to get on one's nerres." The symptom is characteristic of any lapse from normal adjustment, and is the common response under the discomposure of fatigue. Similarly conditioned is the hesitation of timidity, which in its 
social aspect becomes shyness or more delicately, embar. rassment-a shrinking from social contacts, or a morbid apprehension in meeting them. More imaginatively it appears as dread, a worried emotional anticipation of the unpleasant; reflectively it favors brooding, and through this course reaches the depressed tone of melancholia. Its motor aspect is vitally significant, though in part a negative symptom like taciturnity, unresponsiveness. The overemphasis of the sensibility-emotional stage in relation to action makes for a hesitant irresolution: "the native hue of resolution all sicklied o'er by the pale cast of thought.", For practical issues resolution is the native hue, and sensibilities and emotions serve their normal function in support of action. When they entangle it, impede it, thwart its consummation, and thus "lose the name of action," the condition approaches the abnormal.

The symptoms of "nervousness"-which is the most general term for the irregularities of response thus indicated - shift as the irregularity affects more particularly the heightened sensibility or the impaired responsiveness. The former develops to the hyperesthesias and the phobias of various types; the latter take the form of will impediments-aboulias and dysboulias, as they are termed. They arise in many varieties of conditions from extreme fatigue to pronounced insanities. In one form the defect of will is dominantly an enfeeblement of energy or a sluggishness in overcoming the psychic inertia; languor is the subjective symptom of such inertia. The difficulty in bringing the resolution to get up in the morning to an effective pass is a common if transitory instance; procrastination is of the same kin. More characteristically the irresolution expresses an undue prominence of conflicting tendencies. Pros and cons of motive rather than of reasons toss the mind helplessly and suspend action. Inaction is the easier route; resolution, seemingly eager, quickly fades away. DeQuincy cites some personal instances of this condition 
aggravated by indulgence in opium. Aboulia may become the specific hesitation of the embarrassment of an alternative. In an extreme case a victim of such inactivity stood helpless in a pool of water for lack of decision whether to take the first step with the right or with the left foot. But the indecision, which is a hesitant and an elaborate dwelling upon the preliminaries of action, is most apt to be emotionally induced, may, indeed, have been so in the illustration cited. Emotional depression of direct organic origin may result in an apathy that cuts off interest and motive power; it is then that one does not act because one does not care. Or again, there may be desire, but it may be repressed by dread, largely an emotional conflict-of which the popular verdict reports that one has lost "one's nerve." There may be too prudential an attitude, too reflective of pros and cons, a wavering and indecision of a more intellectual order. All are included under "nervousness," and all impede action. Quite distinctive, even contrasted, is the irregularity of relation, in which the very eagerness of sensibility vitalizes impulse and compels action when excitement runs high, and then subsides to the stage of hesitant restraint-an irregular, spasmodic, impulsive, capricious behavior. The selection of occasion is always strongly emotional in type, and typically also removed from ready control. In brief, the course of action in its relation to motive, impeding or diverting it from the normal flow, is various; and in these varieties appear typical complexities of abnormal trend, related to a similar nervous instability. Such trends though distinctive are not isolated; they combine in their abnormal setting with allied tendencies and form a complex - a type-form of abnormality, to which an inclusive name becomes attached. The result is a certain liability-a liability deviating more or less markedly, in this or in that direction, from the normal one.

For the study of such liabilities the two most instructive abnormal tendencies, which may be brought within the con- 
ception of an exaggerated temperament, are neurasthenia and hysteria. So eommon are these as disqualifications (rather than as disorders) as to justify the term "hysterical temperament" for the tendency to exhibit the traits which when exaggerated develop to hysteria; for those that similarly reflect neurasthenic traits, "neurasthenic temperament." The exaggerated issue points back to the underlying source; the mode of breaking down indicates the inherent liability of the flaw in composition. A temperament becomes a more or less marked liability to a specific type of abnormal complex. This conception furnishes the interpretation for minor details of feeling, thinking, and doing, insignificant in themselves, but by this principle given a meaning. It bridges the series from the normal to abnormal, provides a more sympathetic view of the latter, and suggests [8] a proper educational treatment of like tendeneies when confined to normal limits.

In portraying the neurasthenic temperament, we may begin with its compensations. If it be true, as Bergson affirms, that the future belongs to those who can overwork, then the world will continue to be largely indebted to the neurasthenically disposed, since such disposition is associated with qualities of distinetive worth as well as of peculiar risk. In virtue of the same relations by which a temperament is a biological emphasis, may it favor an occupational specialization. Civilization powerfully magnifies the intellectual function, and requires favored individuals to specialize upon the problem-solving trends of a common nature-thus pushing to their limit a small group of centers of a brain fashioned primarily for more varied, less restricted service. The artificial life brings stresses and strains upon special areas of endowment, and the abnormalities represent the resulting liabilities. The assets of civilization at its higher levels are seience, art, inventions, institutions, organizations, which have been contributed, perfected, and sustained by individuals fitted to spe- 
cialize upon the cognitive and ratiocinative phases of their endowment; and this seems in truth to be part of the white man's burden. The carrying of the burden may entail a deviation from the natural proportion of function, too straining for the endowment to bear. A life of lower tension, of more balanced activities, might well avoid the risk, but equally fall short of the prize. It is the tensed string and the bow bent close to the breaking point, tliat sends the arrow farthest in its flight; the lesser strain and shorter flight are safer. The practical question of how far each may specialize, utilizing the superiorities while avoiding the hazards of his temperament, belongs to the practical wisdom of mental regimen. The present concern is with the vicissitudes of temperamental tendencies in their inclination to abnormal expression.

The neurasthenic complex presents a keen sensibility, which takes its direction from the specific nature of the endowment and of the acquired interests. Artists, poets, musicians, writers, inventors, students, the bearers of responsibility, all lean heavily upon it. It is in part because such persons are peculiarly sensitive that they are artists and creative individualities. It is the strongly toned sensibility that renders them liable to hyperesthesia, irritability, fluctuations of mood-to shudders as well as, and more commonly than, to thrills. The irregular disposition of Bohemianism is a vagrant expression of the liability. Fundamentally the neurasthenic temperament is spurred by sensibility beyond its energizing capacity. From another approach one is neurasthenic when tired; it is more than a pleasantry that some individuals are born tired. This consideration is important in that, in neglect of it, one may be tempted to conclude that the neurasthenic liability is in itself an unmistakable index of unusual powers, with which such sensibility is in truth associated. No such comforting conclusion is available. The energizing capacity may by nature be so limited, so readily disturbed, that an ordinary 
strain is suffieient to disqualify; what remains true is that the scnsitiveness to strain and shock is pronounced. The occasions of such overstrain are present in the common vicissitudes of life, and need not imply any undue absorption in its more difficult adjustments. For all have tasks to meet and difficulties in meeting them, have desires that cannot be fulfilled, disappointments that must be borne, ambitions that must be clipped, crosses that must be carried. The very simplification of life may "cure," that is, lessen the risk of, the neurasthenic liability by lowering the strain and slowing the pace of the emotional and intellectual demands. Yet the common features of the disqualification that ensues, when disaster overtakes the disabled mind, may be turned to a significant psychological lesson.

The symptoms of developed neurasthenia are suggestive. A most common one is a pathological fatigue; hence the popular equivalent, "nervous prostration." Fatigue-producers must be measured in terms of emotion as well as of energy. Worry-an unfavorable condition for work-is far more wearing than work itself. Disposition determines the liability to breakdown, however induced; the nervous system, if overstrained, will react with the typical symptoms. The ability to drive the nervous system beyond its normal limits with disastrous consequences, is part of the temperamental liability; the fact that these limits may be subnolmal is another part. Ready fatiguability is as characteristic as are the symptoms to which fatigue gives rise. Of these a vague nervous apprehension-often accompanied by localized cerebral pain-is most characteristic. The resulting shrinking from effort for fear of its painful consequences, the clouding of consciousness, the feeling of incapacity, make neurasthenia one of the most distressing of disorders, since the very sensibility from which it flows aggravates the intensity of its tortures. The exhausted nerve-centers are aroused only through such painful sense of effort, and the expenditure of energy is accompanied by 
such overpowering, if vague, apprehension, that distressful inactivity is alone possible. Under slighter degrees of its invasion, brief efforts result in the return of menacing subjective symptoms, often relieved in part by set habits of recreation. Mental confusion attaches to any severe strain of attention, and all manner of special irritability occurs; voices, noises, the presence of strangers, or indeed any draught upon the attention, distresses. Insomnia may complicate the trouble, and the digestive reaction readily becomes impaired; for nervous indigestion results from the reflex effect upon the digestive process, of eating under conditions of fatigue and excitement. The exhaustion points to the somatic focus of the neurasthenic impairment; its focus in the psychic mechanism is indicated by the tense sensibilities and troublesome emotions-the hyperesthesia that is reflected in feebleness and hesitant responsiveness, or in peevish, querulous irritability.

It will be true of neurasthenia as of other disabilities viewed as a temperamental bias-the tendency of which is made clear by the symptoms of the pronounced disorderthat there will be far more numerous instances of lighter than of serious forms. This is in obedience to the general law that the proportion of cases of divergence decreases markedly with an increase of the degree of deviation from the normal. Very many individuals of neurasthenic temperament do not develop true neurasthenia. The disqualification may call a halt in time, or the warning may be heeded. Bankruptey is not inevitable, but in the career of this type of mental economy made probable. It may be regarded as a predominantly masculine liability [9]. The lesser liability of women is in part accounted for by their protective exhaustibility; the machine stops before too serious damage is done.

Among the characteristic symptoms is the pronounced introspective tendency - the intellectual phase of sensibility. The mental attitude is excessively subjective. One form of 
such trend is directed to concern for bodily welfare, and results in a minute attention to symptoms bodily or mental. IIypoehondria is the name for the trait, the foster-parent of invalidism-an overattention to regimen, a eonstant prudential attitude toward health and a timid withdrawal from every slightest risk. For this reason the restraint of a preseribed diet at times defeats its end by the added attention and the sense of injury attaehing to deprivation, which it invites. Judieious neglect is often the better rule for the introspectively disposed: hence the grain of truth-a truth so long as it is offered or accepted in grain dosesof the eult of disregard of bodily symptoms which, when stated or practiced in extreme form, approaches the abnormal at another point of its protean eontour. Neurasthenies are apt to suffer from an overconseientiousness of physiology, the freedom from which is a mark of health. The possessor of a perfect digestion is blissfully ignorant that he has any; the hypochondriae never forgets that he has a troublesome one. The chief menace of hypochondria lies in its ingrowing trend, in that it aggravates its own condition; just as worry over one's insomnia deereases the ehances of going to sleep. The aceredited treatment for relief reënforces the diagnosis. A little venture, fair unconeern, wise disregard for symptoms, small tasks successfully aceomplished, give courage and confidence. Action and objective interests help vastly. Outdoor life with a succession of small oceupations that oceupy without straining, freedom from worry-all eultivate motor expression and decrease the subjective symptoms, thus restoring a natural balance. Back to nature means baek to health. In the scheme of nature, action preponderates and dominates above reflection, which is but its support. Too violent a reversal of the natural order exposes to the penalty of disordered funetion. The most eharacteristic violation of the natural relation through which sensibilities stand as the supports of action, is their overstrain, whether in emotional 
or intellectnal service. The neurasthenic symptoms represent nature's protest against or penalty for too extreme a deviation, too exclusive and intense a specialization.

The neurasthenic complex has a rich development on its more distinctly intellectual side. The bodily symptoms may then be slight, the mental ones constituting the focus of the trouble. This variety may properly be termed psychasthenia. It may concentrate upon a few points of least resistance, of special rulnerability, selected partly by the organic cause, partly by accident of situation. The specific phobias arise in that emotion seeks an outlet through an intellectual attachment; vague apprehension settles about more definite fears without losing its peculiar organic alarm and its vascular and motor accompaniment. The physical symptoms, such as the trembling of fear, are less prominent than the mental ones, which may amount to psychic paralysis; such is stage-fright in nervous individuals. Articulation, as the outlet of a fine intellectual expression, reveals the difficulty; the self-terrified actor may be rooted to the spot, tongue-tied, or make the morements of his speech without vocalizing the words. Organic shyness does the same for children-a common issue but a different setting. The voice, always a sensitive index of emotion, betrays the maladjustment keenly. The specialized phobias may take such forms as the ill-at-easeness in the presence of strangers or of crowds; dread of open places or of sitting under a gallery, or more vaguely of impending disaster, if venturing beyond the familiar environment. The details are but slightly significant; the fear attaches itself to situations in which some remote anxiety may be real, or to a situation, such as the social one, that readily induces embarrassment if the individual is not fully prepared to meet it. The fixation-point of the phobia is not a wholly accidental, but yet a merely incidental feature of the psychasthenic failing, which spreads over a large area of conduct and renders the adjustment to the ordinary run of 
situations, particularly to socially complicated situations, difficult and abnormal. By reason of these and allied diffieulties and of their setting in traits of responsiveness-of which they are the unfortunate liabilities-this neurasthenic mode of responsiveness becomes a type-form of differential psychology.

The difficulties, entanglements, perplexities of the neurasthenic disqualifications picture what happens when the psychic "going" becomes subjectively rough and hazardous because of the overconsciousness of movement and the apprehensions which the active imagination and enfeebled resolution set in the path [10]. Obsession and delusion lie farther along in the road to abnormality, but are hardly more seriously disturbing. Neurasthenia presents the desolation and the alarm and the inconsequence of a discouraged, dispirited, even a terror-stricken mind. It shows what order of havoe is imminent when the path of action is eneumbered by morbid crowding and hesitation of impulse, by the impotence of exhaustion, or by the dread of action. It reveals in magnified projection the contingeneies which normal functioning blissfully ignores, which it meets with assurance or unconcern. But a temperamentnot unlike a sport--is directed primarily not by the risks incurred, but by the satisfactions, even by the thrills, offered. The assets of the temperament, however designated, fraught with neurasthenic liabilities, are quality of response and superiority of endeavor. All the components of progressive adjustments of civilization are included-that is, the possibility of leadership in them; for these express a range of qualities which make for a refinement of adjustment, a rank and worth of achievement in one direction or another. Complexity of situation must be met by discrimination of response; leadership demands the nicer, tenser qualities of outlook and responsibility. The life of adjusted routine makes a slight and even draught upon resources, but the venture in the unknown puts the highly 
evolved endowment upon its mettle. Such are the assets of the neurasthenic tendency; not that their pursuit necessarily involves neurasthenic incidents or profits by them, but that these stand as the risk that is run. Many of those launched upon the intellectual career will not meet them at all; most of those who do, only in slight measure. Yet it remains the risk of a temperament, of the original, creative, responsible, specialized mind.

An underlying trait common to the neurasthenic and to the hysterical disposition, is embodied in the protean symptom of "nervousness." This symptom has at least a fourfold reference: as an index of instability; of oversensitiveness; of deficient motor control ; of introspective entanglement. It is of a depressive trend as it approaches the neurasthenic type, and comes forward as fear, apprehension, worry, hesitancy of decision and action. It is of an excitable order as it leans to the hysterical type, inducing impulsiveness, caprice, restlessness, sensational craving for emotion or action. An endowment prone to be thus depressed or thus excited exhibits a native nervousness; while under stress or strain, those with lesser tendency succumb to like manifestations. Nervousness, like many another susceptibility, becomes in its diagnosis a matter of degree as well as of kind; its pressure is measured by the degree of stress and strain that induces the distinctive symptoms, which in turn attain their clearest definition in their abnormal intensities. Recognizing the symptoms of "nervousness" and their significance, we recognize through them the significance of the yet slighter and subtler variations of mood and attitude (as of the restraints exercised or lacking in their expression) characteristic in the ordinary play of temperamental variation under ordinary vicissitudes. It thus comes to be generally true that the instability, the petulance, the captiousness of a bad humor is an index of a slight organic waning in bodily condition. The bad humor would not have resulted without organic inducement; 
and in a less disposed individual, the same amount of orranic "drop" would not have consummated the lapse. For no different reason than that which makes the tired or hungry babe fretful, is its overstrained mother peevish, or its dyspeptic father sullen. It takes a surprising amount of self-study to detect the organic source of such fluctuations and to acquire an adequate control over them. Of such controllability the difference of attitude in a formal relation and in the permitted intimacy of friend or family is convincing. The petulance or sullenness is restrained or overcome when the social restraint is applied, but finds a free vent when it is withdrawn. The overconsciousness of self is an equally common symptom, and equally interferes with normal adjustment and the direction of conduct to useful channels. It is still more characteristic than irritability in that the type of situations that arouse its extreme manifestations-such as the embarrassments of social, particularly of sex relations-stamps the nervousness with the seal of its disqualifying motive source. The nervous fears are of like status, and tell their story most clearly when referable to an original shock. To one who once broke down in a public appearance, every subsequent public occasion became an experience of marked dread, revealed in distressing subjective symptoms. To one of like disposition who suffered psychically by an experience in a cyclone, every windy night became a night of sleepless terror. The common symptoms of neurasthenic and of hysteric liability indicate their related source in functional disorders of the finer adjustment of conduct through the excess functioning of emotional sensibility. Their divergences indicate the difference of setting of such liabilities in the specific factors of the adjustment [11].

The hysterical variety of "nervous" responsiveness falls within the same general formula; but the subjective involution follows a different course, proceeds upon a differently set complex of impulses and motives. The personal tone 
dominates; the keynote of the hysterical tendency is sustained by and in the overpersonalization of experience-an overemphasis of a wholly normal, natural trend. In that the resulting attitude favors contractedness of the mental horizon and an agitated reaction to the moment of interest, the term "hysterical" has been applied to any ardent expressions that escape control, that are sustained by high-tension emotion, with large fluctuations between the extremes of excitement, and a marked or sporadic impulse for expression. The excitable, shouting, partisan crowd at an American football game, spurred by intercollegiate rivalry, grows hysterical; as do Wall Street operators when a panic is imminent. The loss of a sense of proportion is the natural issue of any intense emotion, such as anger, fear, revenge, love, all of which may be madly indulged in; but the analogy inadequately reflects the true inwardness of the hysterical attitude. Again, all emotion tends to overdo; restraint as well as indulgence is prone to excess. The trait appears in children who in shyness will refuse and persist in the refusal of a sweetmeat which they really desire. Similarly a child-and often one of maturer growthmildly reproved or besought to refrain from some extreme indiscretion, will by overaction sulkily refuse to accept the permitted range of privilege. It is as though the prescription of part of one's diet led to a refusal to eat at all. That is near of kin to the hysterical ; it is brought into play by a self-centered, emotional oversensitiveness. Children and their immature elders do things just to spite another; that, too, is hysterical, for spite has not the same emotional genealogy, as revenge. Novelists seem to believe that there is many a woman's "no" which by excess of restraint disguises a real "yes." In olden days the recoil from disappointment in love was the renunciation by way of the cloister. Quick and violent changes from laughter to tears, from rapture to despair, reflect the emotional instability, and a lack of self-control: "Himmelhoch jauchzend, zum 
Tode bctrübt." This oseillation is a fundamental hysterical trait; and associated with it as its prompting souree is the habit of too personal appereeption, too self-eentered responsiveness. To the markedly hysterieal all situations are personal ones. This temperamental habit, nurtured and matured in dominant self-centered interests, may be earried over to other interests, any of whieh may come to be embraced in an exaggerated, passionate, or erratie manner; for the hysterical trend eraves satisfaction and demands expression. A good ery is one of its most innoeent forms of relief. Young women who assert that they are "just erazy" or "wild" about this, or "rave" about that, or "madly dote" on something else, may be free from hysteria; but they are using expressions eongenial to its temperament. The Germans speak of "Schwärmerei" (gush); of a tense, exaggerated manner as "überspannt" (highstrung) ; of a lack of eontrol in behavior as "ausgelassen" (unrestrained, broken loose) - all very apt terms for the miniature trends, whieh enlarged make direetly for the hysterieal complex [12], and which in themselves suggest a similarly eonditioned suseeptibility. An overdone, oseillating, personalized impressionism summarizes the qualities of the hysterical reaction.

Hysteria is so many-sided that it must be viewed from several angles. It embraees a vast range of ill-balaneed responsiveness, from trivial eaprice to the most serious perturbations of personality. The primary emphasis of the formula remains: an exeess of the sensibility-emotion phases; a defeet in the motor control ; an irregular relation between them. In the absenee of an aeeredited term to deseribe the eentral faetor, it may be ealled a psychologieal subjectivism. The hysterieal trend is an emotional subjeetivism ; the introspeetive brooding, and depressed refleetion of the neurasthenic temperament is a more intelleetual and yet related subjectivism. The differenee in sex-traits is eonfirmed, in that the former is more common in women, 
the latter in men. The focus of the hysterical subjectivism is the personal sensitiveness, the hypertrophy of the emotional self; it results in an absorption of experience through the distorted medium of the ever-obtrusive feelings radiating from the self.

Next important in the complex is the dominant fact of conflict. In the social environment self-expression naturally meets with all sorts of checks and oppositions. The self-feelings are dependent upon the reactions of others; if these are not forthcoming according to expectation, tragedy is imminent. Also, high impulses conflict with lower ones; conscience is a check from within, and a source of struggle; the force of convention imposes a check from without, felt even when slightingly or rebelliously regarded. The hysterical temperament [13] is uncertainly played upon by a variety of impulses, yields to each in turn and is likely to be snared in the entanglement of cross-purposes. The primary emotionality becomes an instability of feeling and leads to a vacillating caprice in action. When in the uncertain conflict one impulse is released, it is liable to overintense expression-the loss of control, which is the third important factor. Accepting a personalized emotional subjectivism to denote the peculiar hysterical variety of hyperesthesia, as the major root, and instability of desire and impaired volitional control as the two minor roots, closely bound to it, we may trace the derivation of hysterical traits, many of which naturally find their sources compositely in more than one of these trends and in their interaction [14].

Every person is personally centered, and that not merely in the selfish concern, for "number one" (which, incidentally, as ordinarily displayed may not be a prominent hysterical trait-is indeed too simple to express it), but by virtue at once of the place of self-assertion in the support of development and of the inevitably intimate character, the warmth, of individual, perceptual experience. Life is and must be a personal reaction to experience. The individual 
perspective imposed by his own nature and his own experience is inevitably far more dominant in the mental hor'izon of each individual than reason justifies; but without such foreshortening, confidence and self-esteem-even self-respect-would suffer. A fault may be the disproportion of a forte; a vice may be a virtue carried to the extreme. Overconsciousness may be as truly hysterical as lack of conscience; indulgence and asceticism may both be hysterical in so far as they are circumscribed and restricting, and may even altermate. It is the overpersonalized attitude that is hysterical, judged by such standards as are pertinent.

An interpretation of the hysterical oversensitiveness must consider the situations most likely to evoke it. Self-esteem is derived reflexly from the consideration shown by others; it feeds on the social reaction. If markedly present, it becomes an extreme sensitiveness to the good opinion of others, and an ardent craving for it. The intimate rôle of this dependence in feminine psychology is elsewhere considered; though a trait shared by both sexes, it is centered at a different point in the two, which may be roughly indicated by saying that such social sensitiveness to admiration in a woman is centered rather more narrowly about what she is and appears, in a man about what he does and represents. The craving for attention, sympathy, admiration, may become a marked derivative trait of the hysterical temperament-one of many, and of variable prominence. Combined with the eager sensitiveness that renders the subject open to new sensory or emotional appeals, it favors, when inadequately opposed by moral restraints or disciplined interests, a ready suggestibility. The suggestibility, though a yielding, feels the undertow of opposed tendencies, and may so ardently respond to many suitors as to invite an insincerity, even a duplicity in meeting their several claims. The sense of conflict is rarely absent, and in its very suppression may become irregularly assertive. 
Such is the commonly described hysterical type; its features are a marked dependence upon others, slight intellectual tastes, absorption in dress, society, gayety, frivolity, sensationalism, and personal adventures, in an atmosphere bidding for favor by fair means or foul, with no dominant occupations, few compensating and steadying objective interests. The deception, nrystification, or affectation is entertained primarily to be interesting; the pleasure in deception may be a secondary product; there is overdoing in the part. Though in a measure a social product, the type flourishes in a temperamentally favored soil, and presumably furnishes a considerable share of extreme hysterical cases; its course may show the development of an hysterical diathesis into the pronounced disorders which the physician meets in perplexing variety. From close-to-normal to the markedly abnormal, the type exhibits the annoying duplicity, the lying that is partly believed in, the affectations that are partly real, the spurious symptoms [15] masking true disease, that are not malingering but give way to psychical appeal-the wide range of partly organic and largely psychical expressions, which the word hysteria as a functional disorder has come to signify. For the study of character-traits allied to the normal, the high-grade "cases" are hardly less significant, and in cultivated society equally common, if not more so. Such persons may have well established interests and capacities, moral restraints, and acceptance of standards. Duplicity and falsification may almost completely retire; but characteristically they may withdraw to certain reserved areas where they find a furtive, or even an open outlet. For this reason the hysterical trend is alike protean and contradictory; the symptoms and traits come to expression so variously in the run of cases, so partially, and selectively in the individual case. The high-grade hysterical character may display a normal behavior in almost all the relations of life, a sustained honesty of purpose in conduct and responsibilities, and yet 
harbor, though largely under control, a truly hysterical nucleus of traits, and reveal to the discerning the slight hysterical stamp in ordinary behavior'. The hysterical temperament, by the nature of its psychological conditioning, must be abundantly represented among one's everyday friends and acquaintances; for it is the common liability of the stresses which civilization has placed upon the oversensitive nerve-centers, somewhat disproportionately upon that of the more frail, more delicately poised, more emotionally centered sex. Also is it true that the hysterical tendencies represent in some measure the traits which social ideals undertake to discipline and subdue. The conflict is one between the earlier, primitively dominant centers of control and the imposed rule of the later, more highly developed but less securely evolved regulations. Consequently the strength of the hysterical trend may become as well the mark of imperfect discipline as of hereditary handicap-of a shift of control inadequately established in nature and nurture. The hysterical abnormalities follow in their expression the stages of emotional cultivation; are crude and violent when the emotional life is direct and impulsive; are delicate and evasive when the play of emotions is intricate, conflicting, involved, through social complication. The hysterical trend is broad enough to pervade the cntire individual expression, to color the temperamental reactions in the ensemble of conduct.

The hysterical trend, though thus comprehensive, operates so suppressively, so indirectly, as to cover its tracks, to remain undetected, ignored, it may be, by family and friends, by the subject himself, or more characteristically, herself [16]. It would often come as a surprise, even as a shock, to those intimately acquainted with such a personality, as to the individual concerned, to learn that many of the traits which are rated as virtues or fortes, as likewise the trials and difficulties encountered in meeting ordinary situations, are of hysterical origin. The suggestion is apt 
to be indignantly met and scornfully rejected; the truth would be more hospitably received if the invidious implication of the term could be reduced, and its relations to normal character more sympathetically accepted. It is desirable to recognize that a considerable range of common character-traits-not without their compensations-are hysterical in type, and thus to free the term of too severe an implication. Somewhat crudely stated, there are traits of which many a person is proud, which should be cured; and traits presented for cure which might well be ignored or put to service [17]. Accordingly, hysterical traits must often be looked for in the sporadic expressions, in the incidental activities where vigilance is relaxed and censorship withdrawn, and from the clew thus derived corroborated in the slighter but partly controlled expressions of daily attitude and conduct. They must be looked for also in the realm of indulgences which sporadically break through the reserve or control, or are cherished in private. It makes a critical difference whether the hysterical trend merges with the more stable expressions of the personality and occasionally breaks through it and displaces it, or whether it remains repressed, and finds an area of indulgence in some by-path of interest, as a psychological compensation. Hysteria may seek or make reserved areas of expression where impulses banished from the regulated activities have a chance to disport themselves. These indeed may develop as a vent or a safeguard of the hysterical temperament. The draining of hysterical impulses in constant harmless ways protects against a dangerous overflow; yet the direction of the flow is often uncontrollable. Such by-paths of hysterical invitation are significant. In adolescent cases wholly fictitious personal exploits are indulged in, or related as true, particularly in the field of sex-captivation; there may be an irresistible tendency to appropriate what is not one's own in a limited line of interest-it may be finery, it may be books. Kleptomania is often the acute 
expression of a culminating minor hysterical attack. The very nature of such wayward impulses as kleptomania, the indiscretions of erotic mood, and slighter defections, may demand secrecy and concealment. Suppressed phases of interest and conduct thus develop, and, far more commonly, suppressed phases of thought and desire. Yet the suppression to self-consciousness-whatever it may be to outsiders -is incomplete and by its furtive, unacknowledged presence intrudes and warps the more normal, the still dominant direction of mental affairs.

Such psychic suppression-not unlike a sense of guiltis the point of departure of the view of Freud, who gives to the ignored realm a source in motive. He reminds us that we all share the tendency to banish unpleasant memories from the mind, and equally are harassed by their persistent recurrence; hence ensues the state of conflict so vital in the hysterical complex. It is this seemingly suppressed area of concern that keeps on troubling and bubbling in the undercurrent of mood and emotional tow, disturbing despite the surface calm. The hysterical consciousness is keenly responsive to messages from the shunned area, while yet resisting their invitation. The wall thus erected is translucent, not opaque. The hysterical consciousness is selective in its inclusions and exclusions-so are all our prepossessions-and the peculiar relation results that what is excluded from the one consciousness is incorporated by the growing interests of the subconscious realm; divided consciousness is the pathological result. Alternate assertion of the one or the other set of influences, if developed, leads to the extreme expression of instability in shifting personalities. The refuge from the one self is in the development of another; the restrained personality lets itself go so far as to run loose. In milder cases there is merely a sense of conflict, a liability to loss of control. Freud proposes to relieve this peculiar half-acknowledged kind of suf- fering by explicit confession. Once the source is known 
and acknowledged the emotion finds its outlet, and the road to poise is opened.

Freud's interpretation has an intimate bearing upon character, for it leads to the inclusion of a number of traits, usually regarded as innocent expressions of predilections, within the hysterical complex. He finds that dreams reveal such suppressed desires and longings, which reach expression there because the conscious mentor of the thoughts admitted to the mental hearth is off guard. He finds similar indications in slips of the tongue and in pleasantries or evasions, all concealing embarrassment; it is his opinion that the trivial is peculiarly significant because it is unrevised. Dreams, private romances, and the like speak in parables; the hysterical subconsciousness develops a mythology of its own. The transformation is often dramatic, since this type of thought moves in vivid pictures to rapid consummations. It is refined to cover too direct a meaning -a process which he terms sublimation. The thought, like the impulse, ostracized or deprived of its natural outlet, seeks or creates a substitute. The imaginary life replaces the real life, or itself acquires a spurious touch of reality. The world becomes a stage, and the staged dramatizations may become projected upon the actual scene of response, or confuse its meaning.

The liabilities of pronounced hysteria become more intelligible in consideration of the vital situation about which the hysterical motives naturally circulate. This is no other than the life of sex, the large inclusive interest, saturated with emotional tension, that exerts its sway over all, and reaches its zenith when the hysterical star is in the ascendant. Not alone is the sex-relation the dominant one through which the more conscious and mature personality has become sensitized to the opinion of others, but it is the concentration and culmination of all that is most personally intimate. In its most refined expressions it is hallowed, surrounded by tradition, protected by institutions, 
enshrouded in romance, idealized in poetry, yet never divorced from its primary organic vigor, its original core of sensibility. It implies a refined extension of Freud's interpretation to say that it is sublimated, for it presents two of the vital conditions : it involves the element of the covert, the not openly expressed, but privately eherished; it builds upon a powerful organic stimulus, and builds elaborately. To speak of the greater hysterical trend in women is merely to imply that their natural interests as well as the situations which are more distinctly feminine have a larger and a deeper personal reference. The hysterieal temperament, including its pathologieal forms, lies eloser to the normally feminine than to the maseuline. To reeognize that the life of sex, as it grows, attracts to itself, absorbs, and becomes the medium of expression and expansion of thought and feeling and desire in the realm of the personally cherished, from which matures the fullest, richest fruitage of the emotional nature, in which the intimate life moves and has its being; to admit that for many reasons-organic, physiological, psychologieal, social-this psyehic dominion has a deeper hold upon woman, more comprehensively and intensely engages her nature, is by no means to imply a stronger sexual inclination or occupation. Many who are sympathetie with Freud's views decline to accept his detailed deductions which read into eonseious and subeonscious thought-processes strained and remote sex-symbolisms. It is apt to be forgotten that sex-interest is but a type, even thongh the central type, of intimately personalized tendeneies; and further that its very significance in the upper levels of expression lies in its infusion of the quality, not of the literal rendering, of the sex-attitude to other, though allied, expressions. It is not the sexual passion but the fact of a susceptibility thereto, and all the complex issues eultivated originally and primarily in that relation, that is carried over, refined, transformed, overlaid and redisposed as a quality of response in other spheres of activity. It 
may even be the case that the derived outlets of self-expression usurp the vigor of the primary ones, and are urged to this consummation by an hysterical recoil (again an overdoing) from sex-bondage. Conceding the pertinence and distinct value of Freud's "Leit princip," one may still interpret its applications in accord with the larger principles of emotional psychology, not too specifically as marked expressions of a single trend.

The illustrations cited to show how the hysterical pendulum makes large and violent oscillations-intensity of action followed by intensity of reaction-may itself yield a Freudian parable. The disappointment in love that leads to renunciation and the nunnery implies that religious ministration appeals to a phase of the emotional nature which, losing the one outlet, finds another, congenial to certain denied aspects (but not the original impulses) of the range of emotions evolved as a by-product of sex-susceptibility [18]. A like application may suggest that old maids lavish attention upon pets because deprived of the natural outlets of their mothering emotions; that hysterical old maids leave their fortunes to asylums for stray cats; that hysterical young maids "go in" for the prevention of cruelty to animals and become desperately excited over an ill-treated horse or a friendless dog, while not oversympathetic with children. In like vein, it may be urged that the extreme unreason of the anti-vivisection crusade is similarly supported, and that many an allegiance to fads, "isms," and "ologies" flourishes upon hysterical soil. It is necessary and desirable to recognize in such interests philanthropic and humane considerations which the normalminded share and set in a proper perspective of values, while equally recognizing that as pursued not wisely but too far, they may fall within the expansive net of hysteria. Such causes when thus supported may represent sympathy overdone or sympathy distorted toward the abnormal. The morbid curiosity to see a murderer on trial may lead 
to the morbid sympathy that sends flowers to his cell; yet the curiosity, like the sympathy, may be of other origin. It all depends upon the dominance of motive, the composition of temperament, the setting of action in the personal medium, and the reflection of these in their compromise with disciplined interests.

For the illumination of the liabilities of character in relation to nervous instability, the disqualifications of (mild) hysteria are more pertinent than the extreme issues of hysterical disorder. The hysterical instability in its pathological proportions attains to almost incredible consequences; and among these the assertion of conflicting personalities, contending for the psychical control of an individual, stands forth as the most remarkable. It seems strange that fickleness of mood, changeableness of motive, caprice of conduct should terminate in dual personalityan alternate dominance, in some measure, of a beneficent "Dr. Jekyll" and a malicious "Mr. Hyde." With but one body, one nervous system, one set of tastes, acquisitions, habits, proficiencies, adjustments, purposes, social relations, how can there result anything but a unified personality expressive of these combined traits and tendencies? The question emphasizes the fact that personality is an achievement, an easy one commonly, a successful one normally, an irregular and imperfect one abnormally. The achievement proceeds upon the encounter of an organized system of responsiveness with the molding forces of the world of objects and motives. Character is shaped by the processes by which impulses are fused, desires adjusted, the elements of growth consolidated, experience integrated. That all this is accomplished at the cost of a moderate or considerable stress and strain, risk and uncertainty, is familiar and normal. In the process traits are acquired and shed; trends of impulse and desire assert themselves and are outgrown; character matures. In the resultant individuality there are still harbored vestiges of several selves- 
their rival claims reduced by compromise, renunciation, control, favor and disfavor of circumstance, to a reasonable modus vivendi. How many of us are what we wish to be? How changed these wishes, hopes, expectations, as the years go by! Adjustment exacts its payment; struggle within between rival systems of desire is as real as struggle without between competitive interests and urgencies. That a loosely knit character, an imperfect fusion, a contradictory tolerance should appear as the issue of this process in the hysterically disposed, in the hysterically handicapped personality, is as plausible as that its victims are recognized as difficult, queer, unreliable, impulsive, spasmodic, restless, tense, extreme. Conflicting personality becomes no longer remote but imminent; large emotional oscillations occur, disturbing and profound; the pendulum for a period remains fixed in one or other extreme of position, and the alternations of the two constitute the shifts of personality. The hysterical nature, compelled by the stress of the social forces to appear as one type of person, and compelled by the inner psychic stress of impulse to harbor another, leads a precarious existence. Let there ensue a particularly violent wrench, an upsetting shock, a psychic upheaval, and the suppressed or dispossessed cluster of impulses gains expression; and by repetition of the lapse and the growing organization of the impulses, it mobilizes its forces, establishes a provisional seat of government, that in turn yields under other dominance to the established authorities, though not in an unconditional surrender. Once successful, the rebellious forces succeed again and again, by strategy or by recruiting of allied secessional interests, in invading the territory of personality with militant design and temporary ascendancy. The secretly nourished becomes the openly avowed. The assertion is partial; and the peculiar detachment that divides the house against itself, selects alliances among the psychological growths congenial to its purposes, while it wages a warring feud against the 
rest. Such factional expression finds its favoring conditions in the culture-bed of hysteria; conflicting personalities are its most luxurious blossoms.

The justification of this detailed consideration of hysteria is that it illustrates not alone the dominance of temperament in abnormal issues, but also that it offers a fine field for the exploitation of character-traits. The survey of abnormal tendencies of mind as the overgrowth of hypertrophy of the primary trends (or of secondary ones deriving their vitality from a primary emotional source) proceeds upon the principle that abnormality consists in excess and lack of proportion. Within the normal range the practical virtue is found in balance-the serviceable mean between faults of defect and faults of excess. A well proportioned, all-around development is the ideal, and in fair measure, the normal issue. Self-respect is the mean between domineering conceit and abject humility; courage is the mean between cowardice and bravado; a sense of propriety between shamelessness and prudery; caution between timidity and recklessness; thrift between parsimoniousness and extravagance. The normal self establishes a reasonable regulation of these several traits. But the very temptation to excess, together with the range and nature of the resulting disqualification, constitutes the peculiar liabilities of the abnormal.

Because primary emotional impulses must be strong, ready, and pervasive, are they liable to excess when summoned, and liable to an inopportune summoning. To be adequately and efficiently afraid under a large range of circumstanees renders the fear-susceptibility open to the liabilities of panic and paralyses, of fright and terror, as well as in minor incidents, to needless worries and imaginary dreads. Children and adults continue to struggle with their fears; mental poise is the balance of fear and hope. The primacy of the "fear" motif not alone makes timidity a common factor of human expression, and the 
timid a common type of character; it makes the weakened, strained, or unbalanced nervous system react characteristically in terms of fear; it makes the "fear" symptom and the "fear" response the ready outlet-the index and expression of tension or loss of adjustment. Such descriptions as "fear-mad," "crazed with terror," "panic-stricken," characterize attitudes of response in intense situations, too "terrible" for the human mind to contemplate or endure. The situation may be presentative and directly terrifying, as in war, shipwreck, fire, storm, panic; or the dread may be representative in terms of loss of honor, consequence of impropriety, anxiety for health, anticipation of misfortune. The horse when fear-mad can but blindly run. In the human brain the fears assume the forms of endless imagined terrors: for in that sleep what mighty fears may come; such is the human privilege. The torturers of old knew that dread and uncertainty aggravated the agony. The threat is the primitive instrument, founded in nature and developed by human ingenuity, to expand the realm of fear. Religious creeds have painted the horrors of the damned in terms to inspire fear in the living. The fabled monsters were equipped by an excited imagination with all the panoply of fear-inspiring adjuncts, many of them, like horns and stings and claws and teeth, derived from nature's fertile laboratory; but others, like fire, torture, deprivations and threats, contributed by human ingenuity.

Timidity creates fears and attaches them to objects or situations, and in such "phobias" reaches its abnormal expression. Phobias are characteristic of depressed conditions due to lowered vitality (like fatigue, exposure, neurasthenia) and are frequent accompaniments of melancholic states. They may become systematized and take the forms of delusions of persecution, of suspicion, of dreaded attack. Corroborations are found in warnings, in fact purely subjective, that reach the patient through walls and telephones, in noises and whispered conspiracies, by mystic 
signs and portents. Such is the course of fear in a morbid mind. The normal mind under sufficicnt provocation reacts similarly, and hears ominous sounds when fearful of burglars, smells smoke if apprehensive of fire, and becomes suspicions of mien and attitude and tone, if burdened by morose brooding and worried apprehension. Fear-madness varies largely in type and degree because of its complex alliance with so many other psychological products. It varies from organic ill-at-easeness, like the "fear" of thunder, the alarm of infants aroused by innate aversions, the recoil from insects and reptiles and crawling things, to endless definite fears of uncomfortable experience-fear of fire, fear of drowning, fear of falling, fear of runaway, wrecks or other accidents, to the remoter avoidances purely rational - like fear of infection, to the mental fears of punishment, of financial loss, of dishonor, disgrace, and finally to imaginary dreads, of which superstitions are a sufficient embodiment. As practiced by children upon one another and by foolish nurses, fear invents bogies or makes them by ascribing evil intentions to innocent persons or objects. And it is consistent that disturbed sleep-on so physiological a foundation as indigestion-should result in a nightmare, a panic of fear the more awful because irresistible.

In similar fashion waking adult man frightens himself by conjuring powers to be afraid of ; it is his constitutional response to the unknown, is part of his ancient racial heritage. In human evolution fear has found its only formidable adversary in reason. Though inadequately, reason liberates from superstition-the primitive bondage of fear. In earlier stages the devices used to conquer fear are as "superstitious" as the dangers thus avoided; fears are dismissed by the wearing of amulets as protection, by observing taboos and countercharms. Fear of consequences is the great social motive of conduct; and prudence, the shadow of fear, determines conformity. It would require nothing less than a survey of human institutions to barely 
summarize the history of the maintenance of psychic control through fear. Such institutions are effective because the fear-disposition is not only compatible with, but necessary to normality. Its abnormal liabilities appear in natures predisposed to excess; but its urgency makes it prone to sudden enlargement and alliance with the morbid [19]. Fears readily swell like a spring freshet and loosen the moorings of adjusted conduct; reason is compromised, and in the extreme capitulates. During the actual obsession fear, no less than anger, is a brief madness. The dread of pain, the anxiety of impending disaster, the fear of detection of guilt, may unbalance as well as enforce prudence, restraint, and wisdom. Conscience derives part of its force from a morally directed fear, and "may make cowards of us all" by excess of functioning. A peculiar significance attaches to the mystical element in fear; the unknown, the dark, the silent, the mysterious, incites an uncanny feeling, suggestive of some deep ancestral reverberation. On this side lies its alliance with awe and reverence and the religious emotions, which in turn may lead to an abnormal complex, an exclusive dominance in which the "fear" motive plays a prominent but no longer a simple part. Because the normal psychology of fear is so extensive and significant are its abnormal liabilities equally so.

In terms of temperament fear exhibits the tendency of a primary emotion to excess of action and thereby to abnormal issues, which become the characteristic symptoms of functional disturbances of the nervous system in the insanities. In terms of character, timidity becomes a large influence in the prevention of normal adjustments. The shy, the timid, the shrinking, present temperamental types of sensibility that may readily become the most serious determinant of fortune and career. In this respect the developed social fears, the dread of breakdown, stage-fright, loss of self-confidence, become peculiarly disqualifying. With the disappearance of childish naïveté their sway be 
gins; they are aggravated by the confused impulses and reserves of adolescence, and in the majority of men and women are rarely outgrown. The appeal to reason and will is ealled upon to suppress this interference, which militates against courage and self-assertion, especially in the social relation in which the psychic timidities have predominantly been evolved. To face one's fellow-men in masses, to address them, to entertain them, to be examined by them, to become for the moment the target for their eyes, remains a "fearful" experience, temperamentally so by virtue of the liabilities of nature, modified in its expression by cireumstanee. It forms the most eonstant interferenee with the true appraisal of capacities by others, and with the adequate expression of self. In so many relations of life the courageous rather than the able direet affairs. Self-eonfidence and courage are indispensable to poise and action. Yet too-ready freedom from the sway of timidity may be suspicious; glibness, boldness, ready confidence are the equipments of the astute, the deceiver, the traducer, the shameless as well as the shallow; for this universal psychic restraint has its proper place. Its liability to excess and interference with wholesome functioning is as truly part of its nature as its neeessary place in seeuring psychic control. Its social status complicates its entire psyehology.

This sketch of the pathology of fear is illustrative of the bearing of abnormal to normal traits. So prominent a normal trait inevitably develops an equally prominent abnormal dominanee. Exeess of fear and shrinking lies close to the inability of the sensitive, the nervous disposition. The aggressive counterpart of fear is anger, the goad to courage and attack. Similarly the relation of anger to its pathological expression is indicated in the choleric liability. In a colloquial usage, "mad" means "angry." The violence of mania, of whatever origin-whether expended in distraction, revenge, hatred, eruelty, or passion unrestrainedrepresents its extreme form. It may combine with de- 
nunciation, feed a passion with words or threat and become a raving madness, delirium. As in fear, judgment and control are weakened, and emotion rules conduct to its undoing. Passion becomes supreme, blinding sense and reason and absorbing the avenues of action. Anger, in normal measure, is typically brief, and a brief madness. It is a spasm, a burst, a geyser, long in gathering, quickly over in its rush. Its abnormal status in the serious insanities of maniacal form appears in the long maintained, the incessant explosions, the tirelessness of action through absence of the sense of fatigue; the violence rises and falls but seemingly does not cool below fever heat. In the near-to-normal ranges anger, unlike fear which persists and haunts, is sporadic, fitful, occasional. Hence, as applicable to the normal temperament, it is mainly to the susceptibility to lapses, to ungovernable moments of passion. that the pathology of anger is relevant. Such liability is conspicuous in early childhood; it is common enough at all ages and in all conditions to have attracted to it the term "bad" temper, or, without qualification, temper. In social relations-whether primitive, crude, or immature-where restraint is less imposed, passions easily run high; threats and vituperations abound, and Billingsgate is fluent. The psychology of the curse, and its degenerate variety in vain profanity, harks back to primitive outbreaks of irritation. The lash of the tongue replaces the threat of the fist or the stamp of the foot. Social regulation and breeding have controlled the yielding to and expression of this aggressive trait. It requires a serious situation to justify its public exhibition. Reduced to the proportions of irritability, it enters more comprehensively in the minor and major dramas of life than it is pleasant to acknomledge, so constantly is it deprived of a speaking part.

That so many cultivated persons have to struggle lifelong with a "temper" (as others struggle with fear) and at best achieve an imperfect victory, testifies to the readi- 
ness with which this primary emotion outruns its utility. There scem to be two common ways of losing one's head: to become fearful, nervous, in the vernacular of the street, "to have cold feet," and to be "hot-headed"-to do or say more than calm counsel sanctions. In either case emotion outdoes reason. The two are set in a common reference; the purpose of anger is at once to induce fear in the opponent and to energize the attack. It is through fear of (as well as through respect for) our fellow-men that our expressions are restrained. Constantly frowned upon and subdued as anti-social and unmannerly, our too pronounced selfish trends are restrained, and along with them the restraint of anger when frustrated; in due course a proper ease and self-assertion as well as consideration are established. Politeness, even if formal alone, checks personal aggression, and checks particularly the incipient signs of anger. A sense of humor or of fair play draws the sting of detraction when it is good-natured; a kind word turneth aside wrath. The tendency to anger as to fear remains a natural and a vital asset in that both are instruments for acquiring psychic control. Anger is primarily summoned by a blow or the direct threat of injury; its direct response is the clenched fist. By natural transfer it is summoned by any detraction of self and its belongings; we defend by anger and the issues of anger anything that we hold dear. Its verbal form is familiar, and absorbs much of the energy that might go to the blow; the angry voice and tone are as eloquent as the fist. Even in deliberative assemblies an argumentative encounter may lead to blows. The mental and moral weapons of injury and attack are developed along with the complications of civilized intercourse, and their regulations constitute part of the problem of legal defense. The primacy and comprehensiveness of anger appear in the long and sad history of human conflicts. Persecution, prejudice, torture, race wars, class clashes, all inflame to eruel passion, are all sacrifices to the 
moloch of wrath. Justice, the appeal to reason, is the offset, too readily forsaken under stress of primitive motive. It is not alone in its direct expressions and consequences that anger has a venerable and significant cultural history, but as well by reason of its collateral products and derivative issues in the emotional nature.

Of these jealousy is characteristic and is characteristically prone to excess. Its standard reference is to sexrivalry, presumably as the most intense and intimate form of personal assertion. Jealousy as the emotional attitude toward the rival lies close to revenge, though this may attach mainly to the sense of injury; fear harks back to life itself, and a due timidity avoids risks and dangers; a due anger protects by safeguarding all that is worth fighting for ; out of the same social situations arises the jealousy toward the competitors. Because the sex-relation is an ardent emotional focus, and because the rivalry and the incidental jealousy toward the rival is the natural product, are all these emotions subject to excess of function. The presence of the rival jeopardizes possession. Jealousy is carried along in the pathological liabilities of the intensity of the sex-passion. The lover is the ardent wooer and easily becomes unreasonably, even insanely jealous when favor is shown to a rival. Othello is as intensely wrought in suspicion of falsity in the attained, as Romeo is ardently defensive in behalf of the to-be-attained [20].

That the sympathetic emotions may reach the intensity inclining to pathological excess, is a tribute to their vital place in human psychology. Grief is a typical expression of such order. To be able to grieve imaginatively, reflectively, regretfully; to be prostrated over the loss of the object of tender regard, requires a developed imagination, an appreciative, comprehensive, sentimental life. The grief of children is short-lived; it is more the pain of disappointed expectation, or the irritation of thwarted desire; and this element persists in many phases of mature grief. 
With increasing maturity and experience the power to gricve increases, and as attachment adds its endearing associations, it reaches an emotional climax; the severing of the bond breaks the heart. Presumably those who lose balance of mind from gricf or from disappointed love are fewer in the annals of medicine than of romantic literature; for it is ummistakable that an organic disposition is of itself adequate to produce similar manifestations. The depression of melancholia is often the direct issue of subtle organic change, with no objective inducement. To account for the imposed depression the patient projects a system of fears or losses, broods over baseless troubles, and entertains deluded suspicions. The most hopeless, changeless picture of grief to be met with in the dismal corridors of the asylums for the insane is quite certain to be a case of delusional woe associated with organic or functional trouble of the nervous system. Psychic grief that stuns and for the time drives the storm-tossed emotions from their moorings, reproduces the relentless, introspective, depressed, immovable picture of the despair of melancholia. But in the course of time, and by effort for brief periods, other interests are aroused, other appeals heeded, and normality is asserted by the versatility and balance of the mental movement. The melancholic is swamped in brooding; normal sorrow finds consolation in other memories; resignation in remaining interests.

The psycho-pathology of such an emotion as grief-and its sentimental development-is in several aspects significant. It brings forward the general consideration that the normal emotional state is one of versatile composite interests, and yet dominantly one of adjusted condition; and that any sudden or violent demand for readjustment induces strain. The consequence of strain may be shock; shock is a serious psychic liability in the disposed temperament. Contemplation of loss or disaster provides a more gradual adjustment, prepares the mind for the issue, 
though it may be offset by the protracted anxiety which it induces. The theory of "shock" as a cause of psychic disaster has a large support in experience. The shaking-up in railroad accidents is often far more serious as a mental perturbation than as a physical one. It is the mind rather than the body that bears the scars of the experience. Freud's view of hysteria presents such a shock as the inducing occasion of the hysterical liability and regards the sphere of sex as central in the traumatic vulnerability. Hystericals suffer from their memories. Disposed by constitution to instability of mental state and to excess of reaction, the hysterical candidate requires an inducing occasion-the shock or trauma-to precipitate the crisis. Such an attack so entirely unnerves, induces such a serious interference with normal consciousness, ealls forth such alarming symptoms of one type or another, that any subsequent emotional exposure or strain, or condition of anxiety or depletion, or even a suggestive reminder of the upsetting experience, may induce a repetition of the attack. The attacks, if recurrent, tend to fuse, to reënforce and reinstate the liability to an altered mental state; such liability tends to develop in ignorance of the source, which must be discovered by the psycho-analytic skill of the physician. The shock is unacknowledged by the dominant consciousness, flourishes in an undercurrent of the psychic stream, and in that respect differs from the normal expressions of grief. Yet there is an analogy to the common experience of finding oneself the victim of depression for which one is unable to find a cause, until there is discovered a subconsciously rankling incident, unpleasant to remember, which the undercurrent of thought drags to the surface as frequently as the interests of the moment submerge it. A serious, or intensely dreaded danger or loss, an assault upon the sense of propriety, the witnessing of an accident, exposure to insult, intense disappointment, may act as a shock, and require effort and time to effect a readjustment. 
The wound remains open; and by its eonstant presenee interferes with the establishment of normality. Grief and depression by their relation to so large a range of psyehic values, come almost to equal fear as disturbers of the mental and moral peace-the happiness and eontent of assured joyous adjustment. The abnormal tendency to depression is a common liability of the nervously disposed.

There is an additional reason why the pain of sorrow expresses deep emotional liabilities. The esthetically sensitive shudder more often than they thrill; but they shudder and thrill deeply. Similarly, the intense emotional nature expands joys and sorrows, but particularly exposes to the upsetting dominion of grief, brooding, and sadness. The theme of tragedy is the richest, deepest and most comprehensive one; in a fully matured life it expresses the liabilities of human emotion more adequately than any other. The refined susceptibility to emotional sway provided by the nervous temperament is the necessary disposition to the abnormal liability of the derivatively strong emotions. Such temperament is also apt to entail a slighter power of resistance and recuperation on the motor side; for work alone is the salvation of grief, and oceupation in objective interests its resouree. The innate power of recovery, as well as the seriousness of the wound, determines the injury and the pang.

Grief, typifying the depressive state, suggests the further consideration that the normal stream of experience must present a certain minimum of surplus of pleasure over pain; there must be something to live for as also something to live by. Happiness is a condition of adjustment sustained by the satisfactions of the ordinary run of situations. In the depth of despair the bare eontinuanee of life seems impossible; the ultimate urgeney, the love of life, may so far succumb that the tragic portals of suicide seem the only way out. The tendency to self-destruction in certain forms of melaneholia is its awful menace and stands as the 
culmination of the pathological liabilities. In this view the normal meeting of the vicissitudes of experience without succumbing to the extremes of depression, despair and grief, is seen to be in itself an achievement-the avoidance of an abnormal liability.

The vast group of emotions disposing to excess of function, stimulated by self-assertion, is more variously played upon by the added incentives of the social organization than any other. The sense of elation is the reflex of the struggle for preferment; it serves the will to prevail. Whether a conquest of muscle or of wit, success carries with it an emotional self-aggrandizement; it stimulates self-esteem, pride, triumph, as defeat arouses abasement, despondency, shame. The simpler abnormal liabilities of the "elation" complex may be briefly considered. They develop upon an unusual susceptibility to this stimulating emotional byproduct of combat, unfortified by any corresponding objective support. As such they lie close to frailties or vices of character; in another development they are allied to the delusions of insanity.

The relatively innocent exhibitions of vanity, affectation, conceit, braggadocio, haughty assumption, may imply nothing more than a false sense of values and a narrowing outlook; they are likely to be exercised in the struggle for social preferment which is always largely regulated by convention, and may be trusted to find their offsets in modesty, consideration, sympathy, in the conventionalized safeguards of good manners as well as in the disciplines of failures and losses. Contentiousness (Rechtshaberei) is temperamentally more significant, and develops congenially in certain hysterical and related tendencies. The deeply hysterical nature, however disciplined, cannot easily be sincerely tolerant. When acting under the sway of suggestibility, the hysterical must go far to get the sensational value of opinion or allegiance; hence the hysterical devotion to causes and persons once espoused, and also the violent rejection and 
quick recourse to another when the first has ceased to charm. Physicians are familiar with the type of patient who is an ardent devotee in turn of one and another of the guild, so long as the services rendered imply a flattering attention. In the higher, more intellectual types of hystericals, the personalized appeal, which is the indispensable factor in the hysterical response, is attained through the injection of personality into opinions and conduct, whether trivial or important. The hysterical bias compels an interest not in opinions but in their adherence and adherents. The hysterical interest is not in the fact that the road is the right one, but in the fact that he (or she) has discovered it, recognized it, charted it, espoused it. Any opposition to such a view is resented as a slight to the holder; and the contentious frame of mind results. The point is mentioned as an example of a diagnostic refinement. The pompous vanity of Malvolio invites the irreverence of the practical joker; the waywardness of Katharine is treated diplomatically, considerately, though firmly. For the self-confidence of not yet disillusioned youth, or the buoyancy of exuberant health and spirits, or the foolish extravagance of vanity, may lead to a selfassertiveness superficially similar, but in its affiliations of origin quite distinct from the subtle and insidious selfassertions of the hysterical trend. More generally stated, the similarity of symptoms is but an imperfect evidence of community of source-either of community in the near alliance of temperament, or even of a common temperamental origin. The play of education may establish traits in commanding strength; to distinguish between the natural and the nurtural expression is the problem of psychological wisdom; and to this end their differentiation through their pathologically divergent issues is an instructive means.

From this diagnostic excursion we turn to the varieties of expression of the self-assertive trends in their approaches to the abnormal. The megalomania of general paralysis 
represents the extreme picture of the complex: self-assertion run riot, the world of fact disregarded, the subjective delusion of grandeur enthroned supreme amidst ruins. A slight disarrangement of the balanced forces of self-assertion and self-control and irresponsible favorable excitement may bring about a similar issue; intoxication answers to the formula. That the excited brain reacts by an overstimulated sense of importance, with a royal disdain for the disillusionments of reality, and a tendency to unrestrained indulgence, is shown by the action of certain drugs. In the initial stages of alcoholic intoxication, elation, expansion, release of restraint are common symptoms. The intoxication may result in a confident, foolish or coarse boasting, or in a maudlin appeal for sympathy, or a ludicrous exhibition of self-importance, or the mere suppression of ordinary restraint and propriety. Mescal, affecting the sensory phases of excitation, imparts added values of color, and makes common scenes partake of an illusory glory; hashish glorifies by expanding the self-feelings, but distorts and makes irresponsible as well [21]; while other drugs have been sought by primitive and no less by civilized men as an easy road to an earthly paradise. The temptation of the drug-when not that of a release from dull routine or care or pain-is the invitation to reach the values of expansive exaltation of one order or another; that stages of depletion and abject misery at times follow upon the excitement, is accepted as part of the cost.

To present "megalomania" in action requires the cooperation of circumstances to make the intoxication or the dream come true; it requires a social environment which makes it possible to carry out the expanded ideas. Yet the tendency that leads to their manifestation is of the same order, whether occurring within the walls of the asylum or in the world without. To present it on the extravagant scale of a madman's fancy implies that the organization of society permits the madman to exercise his abnormal will. 
"The insanity of power"' is Dr. Ireland's phrase for the issue: "Unrestrained power always tends toward abuse. Indeed, save to some rare and fine natures, the luxury of power consists in its abuse." He cites the examples of certain of the Claudian-Julian family among the Roman emperors, recounts the career of Mohammed Toglak, Sultan of India, of Ivan the Terrible of Russia, and other lesser instances of the growth of the megalomaniac tendencies when the means to satisfy their cravings are at command. Cruelty, the passionate joy in the pain and torture of others, selfish indulgence of debauchery and notably of sexual lust, the subjection in others that reflects the slavish fear of personal power-the pomp, glitter and all the added sensationalism of extravagance, magnificence, and bigness: these minister to the sense of power which seems prone to revert, if circumstances permit, to the more primitive, barbaric satisfactions. In later days, as instanced in Ludwig of Bavaria, the exuberance takes the more sanctioned form of a passion for elaborate architectural constructions, of financial extravagance, and of reckless pursuit of personal impulse. It is clear that in such instances the manifestation proceeds upon the neurotic or insane tendencies of the royal victim.

The temperamental trait thus expressed is a common failing. Its expressions are naturally less notable, less extreme, less public. That the exercise of authority is fraught with the danger of excess indicates that it appeals to the earlier impulses more readily than to the more recently organized restraints. It seems more apt to bring forth cruelty than philanthropy, the joy of control than the satisfaction of larger opportunity of service. The beneficent despot may not be a myth; but despotism stands psychologically closer to the wanton use of power than to beneficence. The tyrant is a typical figure in the social struggle for freedom. The political boss, the bully, the taskmaster, the holders of authority and the abusers of 
privilege represent the same common temperamental liability, despite the altered expressions which circumstances create. Masterful captains of industry, domineering commercial magnates, ambitious politicians, seek common satisfactions in the exercise of control, in the command of deference and obedience. Wealth, retinues, harems, lackeys, slaves, estates, are but different embodiments of the sense of importance. The satisfactions which they yield may be wholly legitimate; but like public adulation which may turn one's head, in the absence of steadying traits they grow to a proportion and develop expressions allied to the abnormal. It is the purpose of society to direct and control the outward signs of self-esteem-dress, ceremony, honors, orders, titles, or whatever the form assumed-so as to satisfy a legitimate self-elevation without encroachment upon the self-esteem of others, without fostering the extreme pursuit of the self-assertive trend. That such aims and expressions may readily overstep themselves and in their acquired hold combine to produce a "money" madness, "power" madness, "ambition" madness, is as natural as is the place of their underlying emotional trends in the psychology of the ordinary range of the insanities.

The conception thus set forth may be extended to include an undue susceptibility, a disproportionate and unrestrained yielding to a trait or Trieb. The basis of the yielding is temperamental; and this gives the hypertrophied trait a consistent psychic setting-something more than the aspect of a detached vice or accidental fault of training. A further extension reaches the domain in which the varieties of excess are at once of native and of readjusted status; they form composite excesses and disproportions of trends, shading into vices, faults, foibles. The love-passion becomes a love-madness; severance of the attachment to home brings on an attack of nostalgia (homesickness); the pleasures of the imagination lead to extreme romancing and a consequent feeble adjustment to the realities of life; combined 
with the will to prevail it may lead to lying and deception; curiosity, normally useful, may by the accent of the sensational become morbid; belief, the steady guide of conduct, may in superstition or credulity become its enemy; conseience, useful in eurbing impulse, may end in narrow or even crucl fanaticism. Any of the primal passions may become a lust or an obsession; any of the dominant redirected impulses, answering a worthy purpose in life's demands, may grow to abnormal proportion. The loss of the sense of proportion becomes the general practical abnormal liability. By contrast, the normal ideal is a just balance of impulse, a due proportion of opposed qualities. This is an ancient and a favorite view. If carried to its literal issue the conception would seem to lead to an amorphous, featureless, characterless personality. This danger is unreal, though the commonplace abounds. Natures are inevitably specialized; and the temperament, however seemingly nentral, continues to give distinctive values to the common factors of personal equations; the powers by which we live continue to reflect the powers that we bring to life. The inherent variations of men and the variations of their vicissitudes bring forward fortes and weaknesses, stresses and strains. The normal is not a bare plateau, but a rich undulating contour providing for a varied topography. Balance remains a positive virtue, and the unbalanced trend a real liability.

An abnormal liability of a different order is that of degeneracy [22] and perversion; its expressions appear in the faulty adjustment of qualities just reviewed. A perverted impulse attaches an emotion to a false object, orwhich is the same thing-reacts to a situation which would normally arouse one emotion by its opposite. It converts attraction to recoil, and cherishes the normally feared or avoided; more broadly, it substitutes pain for pleasure or pleasure for pain. It is pertinent to recall the principle that the complete esthetic effect combines stimulation and 
satisfaction; lacking the former, experience is dull; lacking the latter, it is undesirable. The factors mingle; the one may overcome the other; the interest of the unpleasant may be preferred to the dullness of the neutral. Fear and fascination combine; curiosity holds, while disgust fails to drive away; sensations remain interesting even when far from pleasurable; it is tempting to touch a sore spot, to feel the tingle of the pain. Even sorrow and distress carry the wave of interest: "Die Wonne des Leides." In the primary realm of sense-satisfaction a similar relation obtains; it takes but a slight prominence of either quality to determine the response. In food-preferences the same flavor attracts one and offends another; tastes may be acquired, as one grows to like by its piquancy the flavor that at first is merely unpleasant. Yet the variation has its limits; it is in the overstepping of these limits that the abnormal tendency consists. In certain forms of insanity the ordinarily repulsive becomes attractive; filth gives a morbid pleasure; and things are eaten that would be utterly repugnant to a normal appetite. It is, however, in the range of emotionalized impulses that the realm of perversion is more characteristic. The sex-relation is liable to perverted expressions of varied type [23]. The attachment of homo-sexuality shows the infusion of one form of attraction with the expression and the range of impulses of another. Mere intensity of reaction or recoil may determine the abnormal trend; the misogynist among men, the temperamental spinster among women, are different representatives of a factor in the sex-complex that is overstated. The cruelty practiced by children with a slight nervous taint is a bondage to sensationalism of a primitive order, which the appeal of sympathetic considerations is powerless to oppose. Perversion and degeneracy are allied to the imperfection of development and retardation of growth, in which, as a fact, they are most commonly symptoms. Viewed more generally, the liability lies in the dominant 
growth of the lower brain-centers and the imperfect development of those of later origin and of controlling function in every complex existence. In feeble-mindedness the lower passions, bound up with biologically ancient nervecenters, assert themselves, while the restraining higher centers are incapable of education. A great mass of criminality is rooted in this condition. The born criminal is temperamentally disposed not to crime, but to strength of primitive impulse, and is temperamentally handicapped by the feebleness of control and of susceptibility to training; thus weakly armed and set in a complex environment he turns to crime as the easiest way. The criminal by accident represents the limit of strain in the same relations. In both cases the environment counts heavily; for the patterns of conduct offered in the conditions and opportunities of social and of anti-social expression, engage a similar range of qualities; their direction may be moral or immoral. The natural attraction of immoral action has its source in the common liabilities of primary impulses to degenerate to their earlier, cruder expression and satisfactions. The taint of criminality remains a liability of heredity; its relation to insanity, its predisposition in alcoholism, its sexual complications, set it in its actual complex; yet the importance of the environment places the problem of the criminal more properly in the realm of social psychology. Criminality as an abnormal tendency is germane to the present argument as an illustration of the composite issue of defect (arrested development) and unbalance (hereditary taint) and unfortunate environment (poverty and vice of the slums). It sets forth from another angle and a practically significant one, the place of a psychological interpretation of the liabilities of character and the consequent direction in such light, of the processes of social control [24].

A further aspect of deviation, pertinent to interpretation of character and temperament, is that of the social bear- 
ings of individual abnormality, concentrated in the sense of being different, and thus falling short of full participation in standards, activities, competition of the normalminded, the normally endowed. The very presence of deviation brings with it-and in large measure in conscious terms-a psychological handicap which is in part determined by the environmental standards. Dwarfs and hunchbacks, even the very short and the very tall, have their psychology altered, not merely by difficulty of adaptation, but by the conspicuousness of their divergence from the physical norm, which so readily becomes the social norm. IIn cases of deformity the concessions and sympathy extended readily make sensitive or depress, and lead to avoidance of society and to the occupations best carried on in solitude. The emotional psychology of Cyrano de Bergerac is profoundly affected by the presence of an abnormally large nose. Clearly issues of this order may in small part follow directly from the deviation or defect-like the limitations of pursuit open to the blind, or the lame, or the stuttering, or the abnormally shy-but are reflected from the social environment back upon the development of the personality. As normality is the possession of the full complement of endowment in fair measure, so abnormality attaches to conspicuous deviations of any order. In the conception is included the normal reactions to the social environment, which are either primarily or derivatively disturbed in the cases just cited. Social conspicuousness, however gained or supported, induces a like effect. Kings and princes, born and bred to privilege, do not lead normal lives; the wielding of unusual power or authority, a constant publicity, notoriety of any order, is a strain on normality. The annals of royal houses, the history of dictatorship, large or small, the deterioration ensuing upon a domineering sway of power, the loss of a sense of proportion due to extreme popularity, the assumptions of the nouveaux riches-all reflect the uncertain poise of character, under too violent, too 
sudden, too extreme change of environment, or too strong departure from its usual support or correetive. Conversely, any marked exclusion from social privilege, a social ostracism, such as race-prejudice, may profoundly alter the eharaeter as well as set up obstacles in the paths of expression. No differently the sense of guilt, of suspicion, of a slur upon the reputation, may tend to abnormality; the released convict, and he who regards every man's hand against him-the social pariah-suffers a distortion of qualities that come within the conception of soeial abnormality. Such sense of social exclusion is eomplicated in some cases with individual taint, yet in others-as in the victims of racial or social prejudice-grows out of institutional forces of similar import.

This survey of the abnormal tendencies of mind, however eclectic and inadequate, cannot fail to suggest the intimacy of relation between the normal and the abnormal issues of temperament and the resulting types of responsiveness which compose the varieties of character. The assets and the liabilities of human quality are bound by a common root in the psychology of humanity. The very possibility of development to the maximum of use exposes to the risk of abuse; hypertrophy and defect, overgrowth and undergrowth, and the varied distortions of maladjustment serve to convey a sense of the complication of processes which must be reasonably consolidated, and consistently as well as coöperatively amalgamated, to establish a normally adjusted individual. Specializations, introduced by the emphases of nature, invite anomaly and deviation, as in turn when developed and applied they are built upon the qualities of temperamental origin. In such variation lies a quality of value, possibly of supreme value. It comes forward in the conception of the genius as at once a rare specialized variant and as a deviation near allied to madnessa common risk but a wholly different issue. The conception is in one sense legitimate and well substantiated by 
the findings. More practically and more generally stated, it reminds a public, inclined to uniformities and to an impatience with departure therefrom, that qualities cost and must be paid for upon whatever terms nature demands. The risk of deviation is a venture; its success or failure may mark the dividing line of genius and insanity.

The qualities associated with the production of genius are conditioned by the same liabilities that come into expression in the insanities-the same tendency to excessive sensibility, the same entanglements of purpose, the same absorption in the realm of the imagination, the same handicaps to the ordinary ranges of practical adjustment, the same individual perspective of outlook and interest, the same protest and disregard of the conventional restraints and satisfactions, the same sporadic and irregular assertion of impulse. In all such deviation lies the potency of high value no less than of futility. The vagaries of paranoia and the flights of genius have a common source as well as a common risk. Indeed without a small measure of this order of mental venture, of this trend toward originality and departure, the normal mind cannot reach its maximum of potency. In this sense no one is hopelessly sane-irrevocably bound to routine responsiveness, immune to all inspiration, fated to a bare, regular, simple treadmill routine of conduct. The spontaneity of childhood is as marked as its suggestibility; it expresses the native initiative, all too promptly absorbed in the conventionalized adjustments demanded by a prescribed and regulated existence. The liability to deviation is itself a possible asset. The bare avoidance of the abnormal does not constitute normality, which consists more truly in the acceptance of the venture and in the balanced capacity to adjust conduct at once to the limitations of capacity and the vicissitudes of career. In such adjustment the part of the abnormal is to be considered as a beacon pointing to the dangers of the route, yet marking the desirable havens of the enterprise. 
The dual aspect has given rise to the conception of genius as a high order of ordinary talent-the common qualities writ large, the infinite capacity for taking pains-and to the conception of it as a rare and irregular exotic growth, prone to wayward expression, transcending the bounds of human limitation in an approach to the superman. A survey of the abnormal tendencies of mind reconciles the two views by relating them to the assets and liabilities of temperament and character. 


\section{CHAPTER VII}

\section{THE PSYCHOLOGY OF GROUP-TRAITS}

THE individual is to be considered as the concrete issue of a cumulative series of influences converging in special variety, measure, and distribution in his heredity and circumstance. In the broader view his individuality is slight; the series of influences determining his "nature" and conduct determine in comparable manner the "nature" and conduct of others of close and remote kinship and of similar social condition. The psychology of human differences is as directly concerned with the larger communities of quality as with their slighter variations. In terms of original nature, the traits shared are more significant than the variations expressing individual differences. The original community persists through the revaluation and specialization of traits introduced by social encouragements and discouragements. Civilization gives added values to selected (small) differences of quality; it does not create the traits thus cherished and fostered. Nature proves to be anterior as well as superior to nurture. The group-traits involved in a common nature, by virtue of a common heredity, remain the directive ones.

The difficulty lies in determining which are presumptively natural, which nurtural group-traits, or in what manner a natural trait has been redirected by nurture, or reënforced, or opposed. Racial and national heritage, immediate ancestry, cultural emphasis, artificial selection, favoring opportunities, stand as momentous but indefinite forces in the concrete issue. They make uncertain the reconstruction or detection of the traits which an American 
"Joln Smith" of the present generation owes to his direct family history, to his eighteenth- or seventeenth-century Puritan ancestry, to his remoter Anglo-Saxon heritage, to the primitive North European hordes that asserted their energies and capacities to prevail above the Romanic civilization which they replaced and in part absorbed, to the generic ethnological group of the genus homo of which, in turn, they formed but one subdivision; and no less so, of the traits which he displays in consequence of his Americanization, his transplanted Westernism in one or more removes from or toward frontierdom, his oceupational bent, his democratic ideals, his political affiliations, his social training, his educational opportunities, his class interests, his absorption and reflection of the "spirit" of the day. And "John Smith" is a type of a composite group to which leaders of men, or we in our special interests appeal when we aim to influence the collective "John Smith's" conduct-his vote, his views, his ventures, his activities, his diversions, his social efforts, his "public" sentiments, his taste in dress, decoration, music, drama, literature. The more closely we approach the individual "John Smith," the larger the play of condition which constitutes the presentative life of the individual as of the group to which he belongs, and absorbs as well as liberates individuality. Traditions are strong, but yield to circumstance; modern life equalizes and promptly brings into selective rivalry the products of distant and foreign cultures. Racial and national trends are mixed by intermarriage, as cultures are mingled by intercourse and contact in the melting-pot of humanity, making of it a cauldron of human qualities. In the nearer perspective the historian and the sociologist undertake the interpretation of the forces that mold the individual and the group. In the background stand the sources and relations of natural group-traits, yielding a psychological basis of interpretation.

There is but one supreme natural differentiation-that 
of sex. If there is any distinctive group-psychology, it must be that of the group of men and the group of women. For men and women are organically different; which means that the physiological differentiation in the reproductive system involves a contrasted psychology, involves differentiated modes of adjustment, of near and remote relation to the original requirements of divergent natural function. The resulting differences are the derivative group-traits of sex. There are also further degrees and manners of differentiation, secondary ranges of contrasted quality in men and women, growing out of the primary mental differences, likewise to be regarded as derivative sex-traits. Such later products are strongly affected by environment, convention, tradition, collectively as effective as original nature. Secondary, tertiary, and yet more remotely derivative sextraits appear and attain large significance for the actual situations. In principle they represent a transformation of by-products of group-traits through the influences of nurture.

We may follow the range of original and derived sexdifferences by the aid of the clews to their expression. First is the bodily clew. Strictly interpreted, the primary sex-traits refer to the reproductive system alone; the term may be extended to include the female mammalian functions from which the order takes its name. All others are secondary, or more remotely derivative bodily traits and extend to anatomical (and physiological) details: size, the skeletal basis of strength, proportion of frame to muscle, contrast of metabolism, specific sex-demarcations-such as the beard in man-variations large and small in structure and associated function. "A man is a man even to his thumbs, and a woman is a woman down to her little toes."

Second is the genetic clew of development. The term "infantilism" summarizes the traits characteristic of immature, constructive stages of growth; "senility" summarizes the traits characteristic of the completing, disin- 
tegrating stages. The feminine traits approach the former, the masculine the latter. Variability is significant, and represents a closer adherence to, or freer departure from the type-traits. This becomes a momentous distinction; it leads to a conforming stereotyped expression (female), or a bent for ereative and divergent expression (male) a conservatism or a liberalism of constitution.

Third is the communal clew. The structures and functions of the two sexes are comprehensively similar; sex does not monopolize function, though it may dominate; even the distinctive sex-features of each sex are found in undeveloped form in the other. Supplementary to the fact that men and women are predominantly human and subject to like, yet not identical conditions of growth, maturity, variation, and disease, every man exhibits feminine traits, and every woman masculine traits. In the derivative sense masculinity and femininity, though primarily divergent, are variable in the degree of divergence-in the extent to which the divergent is assertive above the communal. Combined with the genetic clew, this principle emphasizes the greater community of traits in immaturity, before sex-differentia are fully developed.

Fourth is the elew of physiological expression. Of this the mode of work is typical: the greater strength of man leads to a less constant output of more intense energy in high-tension spurts; woman works by more constant output of energy of lesser strain. The contrast reflects the catabolic (spending) and anabolic (saving) tendencies of the metabolism, and is but one of a group of differences, cumulative and commanding. It occupies a transitional place between the bodily clew, and

Fifth, the clew of psychological expression; this has the largest range, and for present purposes, the largest interest. It embraces the entire compass of human psychology. It relates to fundamental differences of sensibility and action-of the intellectual regulation and its resources in the 
nervous system-and to all that is directive and distinctive of the psychic process and product, first in primitive situations and later in primitive orders of expression. Derivative traits of mind become more significant and practically important as the situations move away from the primary conditions in which natural demands are insistent, and all traits, among them those of sex, come to stand more largely upon their secondary issues and employments.

Sixth, the environmental clew refers to the reënforcement, or suppression, of traits by the environment.) The enviromment is in the first instance the natural habitat, and life is a primitive adjustment to it; secondarily, there develops the transformed environment, largely of artificial order. Yet the earlier demands and forms of adjustment persist in type, though not in detail. The environment comes to be more distinctively psychological than biological or physical. Severe environmental conditions throw the emphasis of traits back upon primary natural trends; freer, richer, transformed situations give play and import to the acquired characteristics.

Seventh is the pathological clew. The liabilities to disorder are to be reckoned among the vicissitudes of growth and life. The issue appears in the different susceptibility - and characteristically for the several periods of lifeto disorders, to organic deviations and functional faults; in different liabilities in succumbing to the stress and strains of living; in different risks of accident and disturbance of economy, including especially the mental economy. Susceptibility to mental defect and exaggeration, to disorder and loss of balance, are significant in the individual and in the pathology of the social life. In these several directions it is evident that men and women differ comprehensively and significantly. The typical differences constitute the primary and the more important secondary, or more remotely derivative and favored group-traits of sex [1].

A marked contrast is that of strength: men are half 
again as strong, even twice as strong, as women. Men are nearly five inches (eight per cent.) taller than women. The larger and differently shaped pelvis_-"long, narrow and strongly built"' in men; "broad, relatively shallow and delicately made" in women-is the most "conspicuous and unchangeable of all the bony, human, secondary characters, and approaches the status of a primary character. Associated therewith is the larger thigh and greater distance between the origins of the thigh-bones in women. The proportion of the members of the body is distinctive: the head and trunk longer in women; the neck, legs and arms longer in men. "Man's bony prominences are usually more conspicuous, and his muscles are everywhere more clearly defined" ; in women the muscles "are softly encased in abundant connective tissue which makes them less obvious.' The fuller, rounder outlines of women appear in the distinctly larger proportion of fat to muscle. The measured differences in size and proportion of hand and foot, even of fingers and toes, extend the structural details. Differences in the skull-apart from size as related to height, and of thickness and muscular prominences as related to strength-are difficult to formulate-though with exceptions, such as the prominence of the glabella in men; yet the fact that skulls reveal sex by a composite judgment of measurements and appearance, with a reasonable margin for error, indicates the reality of the differences. The relative size of the brain in men and women involves the bodily proportion; the brain-mass is a minor and not a major index of the efficiency of that organ. "The superiority in brain mass, so far as it exists, is on the woman's side; this, however, implies no intellectual superiority, but is merely a characteristic of short people and children'; the skull completes its growth earlier in women. The more primary structural contrasts relate to provisions for reproduction, the secondary to derivative modifications associated with them in the resulting adjustment to the mode of life. 
A notable physiological trait is the greater specialization of the male toward action. "While the man's form seems to be instinctively seeking action, the woman's falls naturally into a state of comparative repose." This contrast when extended makes the central physiological trait of the female to store, to save, to be anabolic in constitution; and that of the male to expend, to react with vigor, to be catabolic. The mode of the circulation as well as blood-tests reënforce this conclusion, associating "a high specific gravity, red corpuscles, plentiful hemoglobin" with the catabolic constitution of man. The supporting physiological mechanisms indicate a similar adjustment. "The lung eapacity of women is less, and they consume less oxygen and produce less carbonic acid than men of equal weight, although the number of respirations is slightly higher than in man. On this account women suffer deprivation of air more easily than men." "A comparison of the waste-products of the body and of the quantity of the materials consumed in the metabolic process indicates a relatively larger consumption of energy by man" (Thomas). The more obscure internal economy yields additional data. Pigmentation and the growth of hair are conspicuous; women have more abundant as well as darker hair than men, and darker eyes, but fairer skin. The thyroid gland is absolutely larger in women than in men, and relatively large in childhood; disease thereof-notably goiter-is more common in women. The action of the gland is connected with intense emotional disturbances of the order of terror and fear. The association of voice with sex is a typical issue: it appears in the peculiar transformation of voice at puberty-far more marked in the male -in the greater length of the vocal cords in men, in the better development of larynx and voice in civilized races, in the relation of quality of voice to breeding. "The thoracic organs somewhat predominate in men, and the abdominal in women"; the strength of men depends 
on the coöperation of heart and lungs. The ancient association of (male) courage with the breast and (female) compassion with the bowels is suggestive.

The distinctive pathological liabilities of the sexes are indicated generally in the greater longevity of women. Related thereto is the well established greater disvulnerability of women; which means that they endure surgical operations better, are more tolerant of pain and illness and physiological maladjustment, resist physiological accident and invasion more successfully than men. Such tolerance is shown by surgical records, statistics of recovery from disease, observation of behavior under illness, endurance of prison régime, relative freedom from suicide (three men to one woman) and particularly from suicide due to misery and want (seven to ten times as frequent among men). For specific diseases (apart from a large common susceptibility, and apart from diseases peculiar to the reproductive system and its liabilities), the facts support the statement that there are many (cases of) diseases common in children and women and relatively rare in men, and many (cases of) diseases rare in children and women and common in men; but only few cases in which the converse relation obtains. Woman's liability approaches an "infantile diathesis." The masculine and feminine strengths and wealnesses of function are consistent secondary issues of the divergent anatomy and physiology of sex.

The nervous system participates in a decisive manner in the secondary sex-traits; the abnormal there represents an accentuation of inherent tendencies-a liability of the natural endowment to succumb to stress of condition. The greater liability of men to gross lesions and degenerative changes of the nervous system is established, and equally the greater occurrence among women of lesser functional disorders, particularly of the type involving emotional instability and deficient expressional control. Until within recent years and among the most civilized communities, in- 
sanity as a whole has been more prevalent among men; women continue to show a larger percentage of recovery, as also a slightly greater tendency to relapse. The types of disorder to which each sex particularly succumbs are significant. Chorea, with its strongly emotionalized motor incoördination, in many ways paralleling the symptoms of excessive fright, is a characteristic liability of nervous, adolescent girls, but is far less common in boys. Hysteria, as its etymology implies, was originally recognized as a feminine disorder. It remains the typically feminine form of functional nervous liability; its psychological complexity entitles it to the fuller consideration accorded in the preceding chapter. Speaking broadly, states of melancholic depression are more common in women, as are also explosive states of maniacal outbreak; but the differences in the mode of expressing such mental unbalance is equally distinctive. Dementia precox-a characteristic disorder of early adult life-is consistently more common in women, and presents different types in men and women; so that a differential diagnosis shows one variety dominating in men and another in women.

Among the typically masculine insanities is general paralysis. Its early stages parallel the symptoms of alcoholic intoxication: tremor of speech and movement, coarseness of expression, uncertainty of sensory action, and free indulgence of expansive thought; it develops quickly to the later stages with paralytic symptoms, illusions of grandeur, loss of control, and a generally disordered, excessive functioning-throughout a picture of exaggerated masculine psychology. In its pathology, it is allied to such other serious lesions of the nervous system as tabes, brain-tumors, apoplexy, which are all more common in men. On the functional side, hypochondria and the exhaustion types of neurasthenia, present the more typically masculine frailties of psychic functioning. Relative susceptibility to, or immunity from, specific orders of nervous and mental disease, 
details of onset, course, and prominence of symptoms, reflect characteristic differences in men and women, in boys and girls, and corroborate the mimute adjustment of the nervous system to natural vicissitudes by laying bare the differences in masculine and feminine liabilities and assets, physiological and psychological.

On the basis of such data there may be developed a distinctive psychology of sex-traits. Viewed temperamentally, to be psychologically male implies an organic bias toward a certain composite of qualities which is a consistent expression of masculine function; to be psychologically female implies a yet more pervasive infusion of primary and derivative traits, because of the larger radiation of sex in the feminine organism. Temperamentally, however otherwise conditioned, an overwhelmingly influential factor of one's psychology lies in the primal determination of sex: "Male and female created He them." The derivative issues of sex extend to differentiations of capacities, endowment, interests, emotions, sensibilities, responses to social and environmental conditions. The social organization is an outgrowth of these differences and exerts a reflex influence upon them, in that social institutions embody and reënforce them. One such complex issue in the early social organization is the matriarchal system, which obtains in such conflicting variety among primitive peoples. Woman there represents the center of social stability, the point of return of the provider to his own, the indisputable basis of kinship, and through it, of family unity and tribal consanguinity, the nucleus of the arts and of the conservative tendencies, the cradle of the effective life in the reciprocal relations of mother and child, and equally the primary school of discipline and tradition. However modified by natural and imposed masculine assertion, a core of primitive psychological influences is there expressed. The reproductive function is thus made central in the social structure at a stage at which natural conditions are commanding, and the re- 
adjustment demanded by social-economic relations is but feebly developed.

The directive masculine quality, related to, though extending far beyond, the immediate expression of man's sexual nature, is his superior strength and fitness for strenuous activity. Man's sexual ardor is stronger, and through its stress he develops in courtship and the struggle for mates the assertive qualities of his nature. Conversely, the lesser urgency of the female confers the reserve power of choice, the exercise of selective preference, and leads to the employment of qualities connected with the power of attraction. Masculine forcefulness finds its expression in mastery, physical defense, and social authority. The directive leadership in the guidance of life's activities becomes the individual and collective expression of the masculine mind, a mind of will. Organization through prowess and courage, combat and dominance, promptly assumes the military form as its institutional embodiment. When this becomes strong enough under favorable traditions, it prevails above considerations of descent; and the patriarchy replaces the matriarchy. The terms indicate a difference in the emphasis of relations to which is accorded the recognized as well as the real social control [2].

The existence and the range of sex-differences are thus established. The degree, the origin, the stability, the significance of the differences require interpretation: how far are these differences the issues of temperamental qualities, how far the products of condition, convention, tradition, opportunity? The latter group of factors includes the economic and political disabilities of women, which, though not without a basis in nature, may be in the main an institutional product. In considering this vexed issue a corrective to narrow prejudice may be found in the contrasts of race and nation, time and clime, station and culture, traditions and ideals. It is, however, a principle of large import that the two sets of influences-natural and nurtural 
-are far more likely to reënforce than to oppose one another, strongly as convention and tradition may set the trend in the latter direction. There is also the tendency unreflectively or deliberately to make natural sex-differences stronger by exaggeration or reënforcement; this itself is in accord with nature's ways. Secondary sex-traits serve to stamp men as masculine through and through, women as versatilely feminine; the indices of sex are many and yet of one meaning.

The same conditioning factors that bind structure, function, expression, and application, in determining what humanity makes of its endowment, shape the divergent possibilities and natural emphasis of the masculine and feminine endowments respectively. A series of three factors may be recognized: the organic (biological) structure, the natural (physiological) function, the (psychological) application. The three are correlated: the function associated with the structure, the application with the function. Primarily structure conditions function, and function application. For man, his more powerful structure finds its expression in his masterful part in the struggle for food and for mates, vitalized by his aggressive sexuality; it finds its application in the freer, more constructive, more variable activities and in the resulting interests. For woman, with a larger and more rigid determination-owing to the dominance of her organization-structure makes her reproductive interests larger, gives her functional activities, once adjusted, a steadier, more regular orbit. In the derivative applications it employs a characteristic range of qualities, such as a keen affective zest, a conservative trend, a large impressionistic bias. The yet slighter and more remote issues of this difference in employment of favored aptitudes, and in determining how the finer claims of the environment shall be recognized, radiate to all the nicer complexities of masculine and feminine psychology. They command an urgent detailed interest, in that they continue to affect the 
larger and the finer contours of human relations. They determine masculine and feminine institutions as well as constitute maseuline and feminine modes of adjustment.

Primitive emphasis is certain to reflect natural trends; each sex, like each organism, tends toward the activities which it can most efficiently accomplish by gift of nature; interests respond to and develop eapacities. Tradition enters to fix what is deemed manly and what womanly; contrasted interests and occupations make a different appeal to boys and to girls. Sentiment increases the differentiation by reënforcing the contrast through dress, manner of life, privilege, training, encouragement. Nature sets a similar example; part of the meaning of secondary sex-traits is to render the male and female more unlike, more complementary, more unfamiliar, more mutually attractive. The difference in growth of hair (of beard in man, of the richer tresses in woman), the marked difference in voice (the change of which in the male is a marked adolescent sign), the roundness of form, the greater delicacy of feature, the pose, the step, the gentler touch of the womanall radiate sex to every feature and action, and in due course become romantic enhancements, derivative, idealized attributes of the eternal feminine.

Derivative sex-traits reënforce one another in that they represent a consistent group of associated traits derived from a deeper, more fundamental, nearer-to-nature tone of "sex" conditioning. The "greater youthfulness of physical type in women" is "a very radical characteristic, and its influence vibrates to the most remote psychic recesses." The greater normality of woman, bringing her nearer to the child-type and to the race-norm, are related to her anabolic habit; and that in turn is of a piece with her lesser variability and her greater affectability-affectability being an early form of psychic response. Furthermore, the avoidance of excessive high-pressure energiesby yielding to initial strain-protects woman from many of 
the masculine risks, but removes her from the intense concentration of high effort and daring initiative. Because men are organically eatabolic, they are prone to be masterful by mental habit, and extravagant as well; the larger, bolder venture is masculine; the closer thrift is feminine. In each there is a consistent and reënforeing cluster of tendencies.

Such favoring dispositions, moderately contrasted inclinations, consistent groupings of tendencies, come to the fore in the occupations which men and women seek through the adjustment of powers to performance, and in which they find distinction [3]. The low-pressure energies of women lead to routine employments, requiring patient care, attention to detail, obedience to directions. The affectability appears in the fact that the arts in which women excel are those in which personality dominates, combined with forms of esthetic expression congenial to the emotional medium. The drama, the opera, the song, and the dance are elaborate issues of such inclinations. The minor arts of decoration and embellishment combine types of occupation conforming to the above requirements in expenditure of effort, with the esthetic interest issuing from the keen sensibility. Yet women attain a less notable success than men in original ereation even within the arts making a large appeal to them, in which their opportunities have not been seriously handicapped. Literature confirms the verdict; the novel, reflecting the intimately personal aspects of life, engages the larger number of women writers with a fair proportion of merit; but few women novelists attain the highest rank. Such evidence is suggestive by reason of the fact that the traits thus brought to unusual professional expressions in gifted individuals, represent the generic group-traits that find a congenial and consistent outlet in the ordinary range of adjustments. Considered generically the feminine superiority of adjustment is to situations requiring social tact, keen emotional susceptibility, and a ready responsiveness. 
Contributory to this aptitude is the strength of attachment, the warmth of allegiance, the lesser tendency to leadership and venture; by virtue of this trait women become strong adherents-forces of conservatism-when once their sympathies are enlisted. The fact that they are ready to be aroused by a congenial appeal promotes suggestibility. The religious tendency, however otherwise reënforced, is a high-level derivative of the devotional phase of responsiveness; yet with rare exceptions, religious leaders are men [4], the exceptions themselves capable of interpretation as the products of characteristic feminine mental susceptibility. Women will supply "much of the living spiritual substance, if a man will supply the mold for it to flow into." Appreciations seem to follow the same trends. The slighter objectivity of women keeps them aloof from philosophical pursuits, and from the scientific devotion that reconstructs the interests of life away from the personal, and directs them to theories, systems, principles, rigid conclusions, objective, depersonalized relations. A by-product of the feminine sex-attitude is the "extreme sensitiveness to the judgment of another" and to the persuasive appeal; it enters into "the technique for the conquest of a member of the opposite sex," and is not unlike the processes leading to religious conversion. "In each case the will is to be set aside and strong suggestive means are used, and in both cases the appeal is not of the conflict type, but of an intimate, sympathetic and pleading kind" (Thomas).

These traits are to be considered primarily not for their bearing upon sex-differences as exercised under modern complex conditions, but as derivative consequences of trends more directly significant in their primitive setting. In such setting the typical masculine pursuit is the chase and combat, while the typical feminine occupation is the care of family and courtship; not that either is all-absorbing, or constant, or complete in its range of the qualities which it engages and matures, but that fitness of these survival ac- 
tivities, of which food and race are the foci, is imperative and elemental. Their organic depth is profound; in the formative period of the common racial psychology, the set of the psychic equipment had to be adequate to support these purposes, or fail. Interpreted in its widest aspect, the aggressive "survival" activities of the food-quest emphasizes one set of qualities of the sex, and the "family" situation another; though both sexes experience the claims of each through an underlying common organization, man and woman feel them differently-the masculine getting its major set from the food-quest, the feminine from the "family" interests. 'The sources of the secondary sex-qualities lie in these remote beginnings; in these relations their significance is clearer, the favoring advantages in the type of adjustment which they secure, more direct. In the course of evolution the sex-qualities assume a more derivative aspect; they persist, but are more and more strongly modified by the conditions of life and by the social institutions which they require for their expression and regulation. Furthermore, the resultant qualities of sex are transferred to other applications in a transferred order of employment, and in such high-grade adjustment lead to a further psychological differentiation. There is no absolute contrast of process, but a moderate contrast of favored procedure; there is a difference of emphasis, a shifting of the center of influence. Such is the relative play of reason and of cmotion, of seeking adjustment to situation and of exercising control through cognitive or through affective processes. The emphasis of the one or the other develops fairly contrasted techniques of adjustment. Reason proceeds more by knowing what the situation is and its causes, emotion more by gauging how the situation disposes one to response. The one is the sensitizing of an objective distinction, which is knowledge vitalized by interest, dominantly masculine; the other is the rationalizing of intuition, which is an emotional impressionism, dominantly feminine. The contrast 
may be interpreted as the natural kinship of a supporting process to primary impulse and purpose. The masculine pursuit as naturally enlists and develops the service of the one-the cognitive-as does the feminine that of the other -the emotional nature. Application accentuates functional fitness; and endowment favors the manner of employment of available qualities. The difference is a contrast of degree only, a contrast in the relative strength of a common derivative trend; for a common psychology makes both sexes generically susceptible to common orders of appeal, makes men and women employ both eognition and emotion in common expression of a common nature. The same qualities that serve intelligent adjustment to situation are aroused and drawn upon by varied situations, and with varied emphasis and manner. Situations that naturally evoke the one predominance of qualities will more and more attract and fall to the share of the sex in which such predominance is congenial to endowment; the favored endowment will find or create for itself a field of application in the occupations supplied by the environment. A moderate emphasis of a common trait is enough to determine preferred occupations, later reënforced by tradition and accomplishment. Slight superiorities thus lead to widening differentiations. As the field of expression extends, derivative forms of minor contrasts come to be as momentous as the more real, more direct differences in the primary field of operation [5]. The deviations of sex-interest and proficiency become established and organized in the institutional life.

An original biological emphasis leads to manifold slight but cumulatively important divergences in the psychological and sociological realm. It leads to them through the transfer of traits from primary and direct fields of application to secondary and indirect ones, with a consequent modification of the trait itself through the quality of its transferred exercise. Primary endowment and original 
situation are superseded by secondary acquisition and conventionalized application. In the process by-products of such traits develop, and further complicate the issue. Moreover, educated persons come to live so largely upon the derivative issues of their natures, and shape their endeavors and value them in terms of these, that the parent traits and situations are lost sight of, as they become submerged and overlaid. To restore this earlier perspective is the purpose of the considerations thus reviewed.

However, eclectically, a survey of a masculine and of a feminine psychology may be attempted. The greater variational tendency [6] of the human male, particularly in his physiological expressions, is well established. The trait is rclated or leads to his looser social connection, his detachment from the intimate family concerns, and to his freer movement in the struggle for existence and preferment. Professor Thomas has neatly termed it the man's "tangential disposition." It disposes him to venture, which emotionally is the search for and the welcome of the unfamiliar. The uncertainty of the chase embodies the zest of varying fortune. It presents thrilling moments of intense energy, the "kill" as a stirring climax of keen pursuit and active endurance. Involved in the complex of qualities is the factor of strengtl and the joy of its exercise; it appears in the fondness for athletic games and sports and the hazard thereof, which in turn must make their appeal also to the rivalry situation and the uncertainty of issue. The game is exercise, but also a challenge and a gamble. Even the outsider, who does not play, appreciates its points, bets on the winner, and vicarionsly comes into the game. When the modern business man goes a-fishing, he not only breaks away from routine but seeks the thrill of the eatch, and the uncertainties of fisherman's luck, and the esteem attaching to his record. In his livelihood occupations he is ready to replace industry by risk, labor by shrewdness, to enjoy his game more when a stake is involved, to become a gambler 
in spirit, whether at Monte Carlo or on Wall Street. The breaking away from routine is emphasized at the period of masculine maturity and leads to the Wanderjahre, the frontier, the open road. The "rolling stone," the life of the tramp, becomes a significant expression of men "tortured by their vagrant energies" (Ellis). By contrast, the budding girl, the débutante, at a like period-despite the instability that produces her variable moods and tensesyields more largely to the restraints and shelters of convention, and to the obligations of responsibility. An increased domestication of the one contrasts with the "wild oats" of the other. The sporting type is not absent in women, nor should we expect to find it so in the feminine ensemble. But it there takes a typical feminine form in the adventuress, who gambles on her personal qualities, a craftiness developed in her own more personal technique, quite as man trades upon his skill in getting the better of another in his form of the battle of wits.

The intellectual aspect of the group-quality involved in the combat situation is the shrewdness in meeting a rival or a situation. Its earlier form is a direct securing of advantage by strategy rather than by brute force. Shrewdness becomes an aptitude for the management of men and the functions executive; it leads to coöperation and organization and the pursuit of a policy or a cause lying in part outside of a narrow personal interest, and larger than personal welfare. The pursuit becomes a problem and a challenge of mind; the qualities engaged and matured in solving the problems of defense, and of the chase and the foodsupply, develop a liking and an aptitude for problems of other and of wider scope. Such problems remain more characteristically of the presentative type, dealing practically with things, and the control of their properties and uses. Mechanical construction, devices, shaping materials to use, represent the natural outlets of the trait-as typically a masculine pursuit in the hunter and trapper as in the en- 
gineer. Resources alter the scope and increase the intricacy of the application of what, at bottom, are similar proficiencies of similar origin. As invention extends its domain, the pursuit involves more and more the principles of theory and the insight into laws, becomes abstract and representative, rather than literally strategical and ingenious. Yet its outlook is objective, though it looks to the future and to remote possibilities, constructs ideal situations, and prepares long-range responses thereto. Combine in varied measure the tangential disposition, the zest of the unfamiliar and of its conquest, the shrewdness of wit, the trend toward organization, the objective interest, the mastery of control-all congenial and reënforcing qualities; apply them to different ends, and you proceed measurably in the comprehension of masculine superiority as an executive, as a devotee of science, as a philosopher. All these qualities he carries in fair measure to his pursuits, and insists upon their satisfaction, if he is to find incentive and adjustment therein. A momentous consequence attaches to the yet remoter issues of the objective interest and habit of mind. In its higher reaches it proceeds upon a detachment from the local, momentary, concrete situation, and thereby fosters a faculty for abstraction, for considerations remote but not unrelated to the present-the imaginative construction of what may be, or should be, the enthusiastic devotion to ideals and their promotion. Man is at once a practical schemer, a gambling spirit, admittedly an unprincipled one at times, but also a venturesome theorist, an ardent reformer. Such theoretical proficiencies appear most richly in the scientist and the philosopher, to whose tangential contributions are due the largest advances of culture and of the means and standards of living; in contemplation whereof the vagaries of unsound schemes and extravagant ventures and the eccentricities and absurdities of imagination seem an insignificant price.

A contrasted emphasis of derivative sex-traits appears in 
the mode of sacrifice which such pursuit entails; masculine objectivity promotes devotion to partnerships, movements, corporations, institutions and causes; women's sacrifice is a sympathetic renunciation in behalf of an emotionally cherished "other." Of like "masculine" origin are the cooperation, the team-play, the mass movements, the organization of armies, the practical skill, the commercial organizations, the unions, federations, trusts, that develop and are concentrated upon the varied economic situations, the complexity of which, in the industrial setting of modern commerce and the skill and satisfaction in their management, testify to the strength and educability of this underlying problem-solving, organizing trend. The failings, the risks, the neglects, the vices to which the pursuit may lead, are equally contained in the venture. The selfish ends, the concern for "number one," the disregard of other considerations are inherent in the game; the interest in winning comes to exceed the interest in the play; personal vantage tyrannizes; graft is a ready temptation; the promoter is more common than the philanthropist. By virtue of the qualities which direct their interests, men are shrewd traders and relentless bargainers as well as schemers, are notin their own vernacular-in business for their health. In the direct sex-relations men are tangentially disposed, are prone to lose the ardor of devotion and to seek new alliances. Polygamy, concubinage, represent rival invitations within the domain of sex. Exogamy, it has been suggested, is the sanction by custom, of the tendency to seek alliances outside the clan. The zest in the eager rivalry of other pursuits and of those of sex has a common basis; the rival interests and the qualities which they enlist come to dominate. Because of the absorption in objective projects and of the ardent adoption of such ends within the scheme of life, these ends become truly competitive with those of sex, and compose the manifold interests of the developed masculine mind. They satisfy the masculine desire, irregular and 
vagrant though it be, for expansion, venture, novelty, exploration, control.

To illustrate the feminine complex, one must return to the large affectability, which is an emotional dominance in the technique of adjustment, taking its clew from the absorbing emotional appeal of the courtship and family concerns. The orders of responsiveness fashioned in direct rclation to these interests and occupations extend to the interests of life in general; they set the pattern of endeavor, response, and satisfaction in other pursuits. The affectability is associated with, and reënforced by, the conservative trend; which is in turn coördinated with the lesser variability, more central normality, closer attachment to primary interests, to local, concrete, immediately engaging, personally absorbing, persistent and adjusted activities-all typified in the race-preserving, mothering ministrations. The affectability may be brought into relation with the organic conservatism by going back in the history of the race; for emotionalism is more natural, genetically earlier and deeper, than ideo-motor control. Affectability means that primitive brain-centers are stronger than the more recently developed ones, and are inclined to revolt against the imposed rule. This trait is thoroughly characteristic of child-psychology, and with due modification, of the primitive man and of the simpler, less developed, more child-like members of. society.

As a personal liability, the trait appears in the susceptibility to emotional strain, within normal limits and beyond them [7]. It appears in the greater liability of women to convulsions, and more particularly in the fact that chorea (St. Vitus' dance) is a markedly feminine disorder, and after adolescence an almost exclusively feminine one; the relation of convulsions-as an elaborate "startling" perturbation-to emotional affectability, particularly to the emotion of fear, is suggestive. Of like significance is the part played by young women in religious epidemics and 
hypnotic phenomena. The loss of personality, the assumption of the inspiration of the Delphic oracles, fell to young women. Mesmer's subjects in the hysterical atmosphere of the cures of "animal magnetism" were found generally among women. The somnambules who in the early nineteenth century developed clairvoyant and allied powers were young women; in the modern instances of altered personality, and in the cases of mediumistic phenomena involving trance and trance-like states, women play the larger rôle. Obsessions and mental contagions prevail among women; this factor dominated in the delusions of witchcraft; it is responsible for the violence of outbreak, the destructiveness, noisiness, depravity in prison and in insane asylums (tantrums, Zuchthausknall). Much of this disquietude reaches into the hysterical field; for the feminine liability to hysteria, as well as the typical invasion of the disorder, is but another expression of emotional instability upon the basis of large affectability and motor exuberance. The greater ease and urgency of expression means that the routes to the motor centers, when aroused by emotional states, are more open. Dancing is a characteristic expression, world-wide and world-old, with peculiar relations to the feminine nature. So also is the greater talkativeness or effusiveness of women, which may be socially favored and, like many another such trait, is grafted upon a natural disposition. The infrequency of stuttering in girls is a suggestive fact. Little girls acquire facility in speech more promptly and efficiently, and use vocal expressions, particularly as an emotional outlet (shrieking), more readily than do boys. As is true of other complexes, the congenial traits and their mode of expression form a characteristic ensemble, combining original tendencies with associated derivative forms of expression.

That the feminine "prominence" in the technique of adjustment-typically a mental impressionability in which feeling and knowledge are emotionally welded-makes 
against a cognitive procedure, is in accord with general psychological principles. Intense emotion impedes thought; abstract or objective reasoning is impassive. The angry man cannot think clearly, and no more can the anxious, distressed one; while the lover's perspective of values is not standard. Constructive mental work-itself a derivative product of objective interest-requires freedom from worry and a calm, adjusted frame of mind; yet emotiontrue to its original status-sustains intellectual pursuits, in some directions, conditions it. Varying with the nature of the pursuit, sympathies, in that they condition insight, may interfere with judgment, or be necessary to its fair conclusions. Unduly emotionalized judgments may appear as prejudices, or as superstitions in belief or practice. They affiliate with the conservative trend in custom, in that the familiar acquires an emotional congeniality, in turn reënforced by the intimate hold of concrete personal experience. The contrast may be moderate, yet suggestive in bearing and momentous in issue. Primitive mytl, popular lore, the earlier philosophies, the simpler types of intellectual attitudes-all proceed largely upon an emotionally infused reasoning, and tend toward congenial conclusions. Such products of early excursions into the realm of explanation and interpretation are prominent in the survival of culture. Customs may survive in a superstitious atmosphere; a belief in charms, omens, premonitions, occult relations, often quite subdued and half-acknowledged, has a more natural place in feminine psychology, in just such measure as the emotional bias prevails, which receives such conclusions as congenial, as ministering to an earlier type of satisfaction. The same applies to prejudices and predilections, personal and otherwise, which are often partially reasonable, yet incompletely rationalized. Rationality is so late and limited a human quality, that preponderances of this order will be slight and subject to marked influences of training and tradition. Rationality, as displayed, is as 
typically a cultural trait as a sex trait. A trait stands as a congenial development of a temperamental trend.

It is hardly necessary to survey the familiar field of the preferred interests, occupations, proficiencies, enthusiasms, needs, and expressions of women, in which the temperamental trends, favored in the feminine composite, direct the issue. Their very versatility points to a less specialized, less professionally developed, more generic status, truer to the natural norm. The impress of the ministrations-aptitude and fitness for which stamps the psychological as it is inherent in the physiological endowment-is upon the range of preferred feminine endeavor and proficiency, and still more characteristically upon the mood and manner of the response womanly. The situations that summon it remain closer than in the masculine psychology to the original type of appeal; the appeal is that of the race through sex, and of the endless derivative qualities developed in its defense. A marked divergence of traits is expressed in the relative emphasis of bearing within feminine traits, upon situations of courtship as contrasted with those of care of the young. The craving for flattering attention and social contacts, the personal standards of success, the self-centered reference of the incidents of life seem out of relation to the ready sacrificial devotion, the sympathetic attitude to appeals for pity, the absorption in altruistic ministrations. They find their clews in the fact that charm is the technique of the maiden, and sacrifice the passion of the mother. One set of feminine interests expresses more distinctly the issues of the qualities of courtship and attraction, the other of qualities of motherhood and devotion. The two come to their own at different periods of development. Types of women approximate to divergent composites of character in which the one or the other group of primary traits dominates, as also the same types of traits dominate differently in the several occupations, interests, needs and satisfactions which are generically characteristic of women. Fem- 
inine occupations appeal to qualities congenial to derivative aspects of these distinctive interests, yet combine them with an appeal to the more generic qualities underlying the standard human forms of responsiveness.

For the most part the differential psychology of men and women relates to what both tend to do and learn to do-and with comparable success-but divergently, and with greater or less natural fitness and ability. The more heavily the type or grade of achievement leans upon a strong primitive differentiation, the larger the consequence of even a slight superiority-or more neutrally, deviation-which grows cumulatively in importance as men come to live upon the slighter diverging advantages of their endowment. The slighter contrasts of masculine and feminine tendency continue to be influential while no longer directive, or even important. Delineations of divergent sex-tendencies, though less confident and certain, may still carry the truth of consistency, when supported by a related group of well established inclinations. Such are for the most part the commonly observed differences of men and women. Divergence in manner and valuation in worth should not be confused. Compensation enters and makes the question of superiority "foolish and futile," and the appraisal of value a proper but delicate undertaking. It is not a question of man's way or woman's way being better or worse for this situation or purpose, but of the significance, the source and affiliations of the characteristic differences and preponderant tendencies, as confirmations of a general interpretation. Accepting Mr. Ellis's dictum that in respect to bodily proportion "taken in the average, a man is a man even to his thumbs, and a woman is a woman down to her little toes," we may likewise conclude that a man's mental habit and perspective is masculine and a woman's feminine, down to the details of attitude and tricks of manner, without thereby ascribing either to thumbs or toes or to minute psychological peculiarities any inordinate consequence. 
Each group of traits, as in turn each trait, is significant as articulated in a larger consistent system.

The principle is more important than any group of embodiments. One might descend to minute detail and point out as characteristic the tendency of women to report a conversation subjectively, literally, and dramatically in the first person, and of men to report it objectively, sketchily, and pertinently in indirect phrase. This seems a trivial point indeed; but associate with it the feminine concrete presentative habit that leads to reproducing rather than to summarizing a situation, the readier dramatic instinct that confers upon women a mastery of the personal arts, the more fluid, sympathetic adaptability of women to varying situations, the readier use of language for expression, the keener responsiveness to variations in self-esteem and social appraisal which the literal words and tone conveyand one may assign the contrast a slight niche in the differential psychology of sex. Consider similarly masculine and feminine manner: persuasion and cajolery seem as distinctive for the one sex, as enforcement and defense for the other; while ruse, disguise of motive, duplicity, is not a prerogative of either. Yet there is a line, if an uncertain one, between diplomacy and intrigue, that, traced backward, diverges toward masculine and feminine traits respectively. A finer form of an allied quality, exercised in social intercourse, is tact-distinctly a feminine forte. Its contrast is the blunt, masculine masterfulness, often blundering by too great directness. Tact likewise is sympathetically considerate, a moral quality that in women has a less arduous road to pursue than it meets in reducing the selfishness of men. In so far as the tact invites duplicity, it has a place in feminine nature, there being many things to conceal through weakness, through modesty, in satisfaction of the desire to be interesting and attractive, and probably, in large measure, through imposed restraint and traditions. The white lies of women, the reticence in con- 
fession of age, the attitude toward smuggling, are readily cited as expressions of a common trait, at times offending the more literal commandments of law or morality.

In minor yet typical situations, men and women are differently disposed toward intellectual pursuits, moral principles, and practical activities, yet presumably not so markedly but that tradition and training may equalize them in favored groups. In so far as the tendencies exist, they conform to the lines of differentiation. Furthermore, these nicer distinctions come to expression only in upper-level conditions, in which freedom from primary stress permits subtle levelopment of trends. The same elastic interpretation applies to another phase of the intellectual technique -the ready perceptions, the keen recognition of emotional changes, that make it more difficult in many relations, despite her natural trustfulness, to deceive a woman than a man, and also confer an address and an adaptability not as common in the more deliberate sex. When statements of personal relations of a fair degree of complexity are required-the complexity one of analysis rather than synthesis-women excel. Lawyers and physicians find women of the lower (peasant) classes more helpful and ready in reciting the details of cases. In rises of fortune requiring practical adaptations to ampler social standards, women are more apt at adjustment than men. Indeed, explore as we may into any characteristic field where men and women have found and developed their respective careers in a common yet differentiated social setting, and that despite the imposed restraints of artifice and custom, or again, investigate and tabulate by such methods as are available the resulting preponderant tendencies of the mental machinery, we find a fairly consistent and corroboratory set of differences, requiring, however, a judicious interpretation to gauge their import.

This survey of masculine and feminine psychology indicates the standard procedure desirable, but not unreserv- 
edly applicable, in the consideration of other group-traits. The principles may be thus summarized: (1) Distinctive group-qualities, if traceable to their source, are referable to an organic basis; they also represent a specialized adap. tation to the demands of the enviromment. In the ease of sex, the nature of the organic differentiation is clear and its collateral issues recognizable. In the case of race, the differenees are uncertain in significance and the principle finds a limited application; yet an original specialized adaptation, both organic and environmental, is the presumptive elew. (2) The group-traits, whatever their source, find expression in a considerable range of derivative qualities, in large part of a psychological order. Racial differences imply different modes of reaction of the nervous system. The group-trait becomes an emphasis, a specialization, approaching the status of a temperamental endowment. (3) The psychology of group-traits deals largely with the interrelation, the reenforcement and combination of derivative issues; the traits themselves become favored devices of adjustment to the environment, which is ever more an artificial one, ereated and maintained by the exercise of esteemed or dominant trends. In primary situations the environment directly gives play to and reënforces traits set in a natural fitness; in complex situations the parallel process is more indirect, and by the introduction of ideals may tend to exaggerate or to reduce natural tendencies. Yet the divergent group-traits remain suggestive, even when partly the result of training or equalized by it.

Next to sex, which stands in a class by itself, race indicates nature's most comprehensive intention at human dif. ferentiation; but the scope and purposes of the racial contrasts and emphases thus embodied, are far from elear; nor ean it be determined definitely which are the more original and which the more derivative racial traits. Hence racial psyehology proceeds uncertainly and tentatively. The principles derived from the differential psychology of sex 
serve at the least to indicate the status of the problem, to interpret the imperfect data available, and to avoid superficial conclusions. The demarcation lines of race, however uncertain the principle upon which they are drawn, are clearly of a wholly different order of significance than those of sex; the biological divergences which they incorporate are in such consideration of a slighter, more nearly secondary order. It is their momentous consequence in the nearer view of ethnology and in the history of culture, that gives to racial contrasts their peculiar interest. The several races, like the sexes, present distinctive though moderate organic variations (with corresponding physiological consequences) to which the race breeds true; but what may be the potencies thus conferred or the limitations imposed upon one race or another is uncertain. Structure invites interpretation in terms of function; and function near its source suggests adjustment, the selective pressure of the enviromment. To the nervous system as the central organ of adjustment of function to environment, there attaches a special significance. The adaptive capacity of race with reference to habitat and mode of life primarily determines racial survival and status. The adaptation becomes ever more prominently psychological. It is the mental traits of the human race and of human races that are responsible for their several conditions, notwithstanding the potent influence of circumstance. However racial quality may be shaped by natural condition, it remains true that races under similar conditions, present marked differences in securing control of the resources and forces. of nature and in directing their progress by the products of their minds. In all cultures above the simplest, the environment comes to be inan-made, the organ of adjustment to it largely psychological. The potencies and limitations of race may be considered to be concrete products of biological forces; the forces are in the background, while the foreground is occupied by the play of the qualities thus conditioned in 
the nearer prospect, which is the actual seat of their present operation. Thus closely regarding our own endowment, we are likely to approach it with a favorable prejudice [8] ; hence the need of the larger view for a juster interpretation.

In the differentia of race the racial flag of color is most conspicuous. In the black race and the white, in the yellow race and the red, pigmentation is the outward clew to a range of differences of varied character. When a white man blackens his face, he does not even superficially look like a negro. Physical anthropology undertakes to enumerate and relate the structural and functional differences associated with race. Finding in measurement of the skull and the parts of the skeleton in proportion and ratio a mass of corroborating details, the anthropologist may conclude that a negro is a negro down to his thumbs and little toes. That the negro's head is dolichocephalic (relatively long and narrow); that his face is prognathous (protruding jaw); that his lips are thick and open, his nostrils broad and flat; that his arms are long, reaching well toward the knee; that his heel slopes back from the vertical of the lower leg; that his skin is glossy and has a characteristic odor; that his hair is short and curly and in crosssection oval; that even his blood-crystals show a different appearance from that of the white man: these may all be cited as secondary racial traits to which the race breeds true. But since their origin and meaning are unknown or obscure, they cannot be brought to bear upon the present considerations, however legitimate their interest to the ethnologist. And yet the contrast of black and white is the most marked within the racial group; that of other races is slighter, more elusive and variable. What is true of structural difference holds as well of physiological differentiation in function. Its existence is clear and is disclosed under sufficient refinement of test; it appears markedly in the negro in such immunities as that from 
yellow fever, and in such liabilities as the non-resistance to phthisis or alcoholism.

At what stage of human or anthropoid evolution the differentiations of race were made stable is wholly a matter of conjecture. We may hold to the original unity of the human race, to its descent from a single pair of human or prehuman ancestors; or we may consider the varieties of races as marked as those on which the zoologist bases his classifications-such as those of the black bear, the cinnamon bear, the polar bear-and yet find in such a vicw only the most gencral support of the significance of racial traits, with no precise clew to their meaning. Furthermore, the differentiations to which we attach importance are in the nature of derivative traits molded by circumstance, and are thus still farther removed from a biological interpretation. Generic differences in the physiological capacities of races may be established; the strength, the hardiness, the fecundity, the ratio of infant mortality, the resistance to specific diseases, the tolerance of unwholesome vital conditions, the power to acclimatize in extreme or unaccustomed habitats, and other expressions of the metabolism and mental stamina, show characteristic differences, which may be decisive in the severe conflicts of races and in the economic competition as well. But these variations are complex resultants, the issues of natural qualities, of the pressure of distinctive environments, and of control by training. The "yellow peril" presents itself to the white man's outlook as such a conflict of race-qualities in adjustment to condition. Each race tends to develop the conditions favorable to its own capacities. The physical superiority of race is not readily determined even by conflict, because wit, strategy, organization prominence of military ideals, courage, loyalty, convictions, traditions, affect the issue. The Negro of the Soudan may be a "first-rate fightin' man" by virtue of one group of qualities, as was the Spartan or the Goth, or as is the Japanese for another, 
and the Boer, or the modern Greek, or the Belgian for still others. The underlying qualities may not be radically distinct, but yet differently nurtured and sustained. The fanaticism of the Hindu, the fatalism of the Mohanmedan, and the orderly submission to the "Birkenhead drill," the call of the defense of the home, may lead to like action, yet direct the common issue upon quite different qualities, minutely considered. Such finer differentiation loses its touch with a primary significance, in that it is maintained so largely through the institutional environment which absorbs, energizes, and reflects the racial, tribal, or national genius; it does so, because through such expressions alone group-traits find their outlet. In a similar transference of scope, the physiological assets and liabilities assume an economic aspect. While seemingly competing with policy and resources and statesmanship, men are really competing in terms of race-fertility, capacity to survive to maturity, immunity from epidemics, hygienic precautions, moral regulations, as well as in terms of ideals and the educational provisions that give them efficiency. Yet so fundamental a trait as energy will be decisive, whatever the direction which it may take in expression. Where conflict or rivalry is strong, energetic races are certain to prevail above sluggish ones. The tendency to lapse to a stage of inactive, complacent adjustment is marked; the stress of nature's demands is needed as a stimulus, even as an irritation. Particularly potent as a racial trait is the ability to find zest in mental activity, which leads to original venture, the trial of the unknown, and the advance of technique. The racial endowment that confers it, favors it, emphasizes it, must in the long run lead to a general superiority; its suppression by the institutional organization constitutes a serious menace; its natural succumbing to the slavish tendencies of human gregariousness is an equally real danger. The parts played by the several influences of this order in the preferment of race may be realized in the story of race- 
conflict, but fail to yield any definite gauge of their values. Their consideration leads to a critical view of the potencies of race, and give it about the value of a generic temperamental divergence, a favoring of quality through organic fitness, yet largely modified in its expressions by environmental demands and the molding forces of social and allied encouragement.

Along with racial differences, uncertain but far from negligible, races present a comprehensive community of endowment, physical, physiological, and psychological. Races are predominantly alike, in that the variations of their specific heredities are consistent with a fundamental community of inheritance. Biologically such community is established by the crossing of races of whatever degree of difference; zoologically the human race is one; psychologically the brotherhood of man is still a difficult ideal. The racial fusion resulting from the mixture of races, itself plays a large part in the composite of qualities which peoples now present. Races exhibit large overlapping endowments; with them and despite them emerge the distinctive qualities which remain the specific racial heritage, its temperamental expression. The differences of race are not simply of a quantitative order; races are not similarly endowed in the entire composite of their psychic nature and present merely an inferior or superior order of such parts. Degree and variety enter into the racial equation. Accordingly one race may be no more superior to another than one sex is superior to the other; their differentiated endowments may qualify for different orders of expression in adjustment to different environmental stresses, and thus represent complex embodiments of specialized "grouptrait" aptitudes. Yet the organic needs and the environmental conditions to which races may express an organic adjustment have so large a similarity as to afford some gauge of the value of the instrument of adjustment through its operation. 
The critical problem is that of the significance of achievement. How far is accomplishment an index of ability? Assuming proper standards to compare the cultures which different races have achieved, how far may we look upon such achievements as a measure of the racial mental equipment? Apparently if this test fails, no decisive comparison is available; yet its application is by no means simple. We are prone to apply it at rather short range to the phases of human history that are well along in the story of civilization. We must remember that the essential human qualities were established in pre-historic times; we must think of the older cultural epochs: the early and the late Stone Age, the age of bronze, the age of iron, the nomadic and the primitively agricultural and pastoral types of society. The cultural advances of those stages show the workings of the human mind in the formative period. It is a remote view but a significant one, and a correction of the nearer view of modern days in which momentous achievements have changed the face of the earth, and seemingly the features of the human mind. Yet it is not to be doubted that all races, including the ancestors of the present dominant ones, have had to struggle long and tediously through the earlier, simpler periods of evolution. Does the rate of their emergence, their skill in securing control of natural resources, measure their psychic stature, and thus furnish a reliable measure of their inherent endowment? Some peoples seem still to be fixed in the Stone Age or the Metal Age; in remote portions of the globe, the step from savagery to civilization seems to have been made at various times, under different stress of conditions, and to have assumed fairly variable expressions. Cultures embodying high stages of evolution have come and gone; cruder races have conquered more advanced ones and have absorbed and carried forward the achievements of the vanquished and the displaced. The European discovery of America brought a primitive culture in direct contact with a ma- 
ture civilization; the contrast of the situation seems to our outlook overpowering and essentially a picture of contrasted racial-psychic endowments. The historical consequence seems inevitable-the dominance of the one race, the extermination of the other. In the stupendous transformation of a continent through four centuries, vastly accelerated in the last two generations, the native American Indian has taken no part; his inferiority seems established. In this view race tells; blood is decisive.

There is, however, another side to the argument, for which another American experience furnishes an apt illustration-a great racial experiment in the transplantation of an alien people from primitive African condition, and its enforced enlistment in the service of the white man's pursuits. In a few generations the negro has found adjustment-doubtless of a somewhat simpler and lowlier order-to the habits of life that were the slowly maturing products of centuries of transferred culture, incorporating the most complex achievements of humanity. Speaking broadly, the negro mind has been adequate to follow and adopt the patterns of activity evolved by a culture rated as vastly superior, infinitely more complex than that in which he would now find himself, had he remained in his original habitat. The argument seems to divide at a critical point: Is the fair criterion the ability of a race to evolve independently and from within its own resources the achievements of civilization-in other words, an inherent aptitude for civilization [9], or is it the ability to find adjustment when the machinery is provided, to work under the scheme when circumstances require or invite? Is it the capacity to emerge, or the capacity of the race to maintain itself on this or that level, however attained?

The reasons for adopting the latter criterion are weighty; for these alone are applicable to the vast majority of men, of whatever race or stage of culture. The racial genius rises high in a few selected members, who alone invent, 
modify, improve, contribute constructively to the ensemble which the rest utilize, apply, contrive in large or small measure to adopt and adapt. The few set the patterns; the many follow them. If we gauge the mental status of the average of the white race by the actual accomplishments of this average, we may feel secure in concluding that the average status of the white race is appreciably higher than of the black race; but we could hardly ascribe to the difference any decisive or inordinate degree. It might be true - to venture a statement in quantitative form - that the degree of intellectual capacity attained by eighty or ninety per cent. of the superior race would be attained only by sixty or seventy per cent. of the inferior race; and what is true of mental is presumably true of moral, or esthetic considerations. On this supposition the overlapping community of equipment, parity of endowment, would be far more conspicuous than the favoring excess. In our own rating of the advantage there might accrue to the modest measure of superiority a very momentous consequence, as in turn measured by success and station in the accredited vocations. In consequence thereof one race would assert its domination or social prestige, and the other acquiesce in the relation and accept the subordinate place. But such an issue may mean that the one racial equipment is better suited to prevail in such an environment, and that the environment represents the slow evolution of forces favorable to such racial endowment. It may be true that to the other race might fall the advantage in a different environment. Once established, the dominant eulture absorbs and conditions the expression of endowment, and selects the individuals capable of participating in the favored employments. We are thus brought face to face with the network of assumptions upon which, quite subconsciously - with the prejudices in favor of its own proficiencies, natural to each race and desirable to maintain its self-respect-we infer the superiority of our 
own race from its creditable achievements, from the resulting cultural contrasts of living thus brought about. Natural as it is and in some sense legitimate "to count the gray barbarian lower than the Christian child," and equally defensible to esteem "better fifty years of Europe than a cycle of Cathay," it is well to make clear the basis of such presumptions; whether the "lower pleasures" and the "lower pains" prove the "narrow forehead," or reflect the vacancy "of our glorious gains." Do "I, the heir of all the ages," find my heritage in a superior capacity and endowment, or in the ready-to-use contributions of former generations, to which, from the outset, my capacities are trained to seek adjustment?

Questions such as these illuminate the issue. A psychological consideration of the criteria of capacity narrows the breach between higher and lower races; a historical consideration of achievement and of the contrast of civilization with barbarism widens it [10]. The biological attitude seeks evidences of racial superiority not too markedly affected by the environmental stress, or underlying its expression. Three orders of such differentiation have been appealed to. The first is that of affiliation to a simpler stage in the evolutionary series through which man has reached his present human dignity. It has been argued that the inferior races exhibit the traits characteristic of a simian ancestry in larger variety, in more characteristic degree than do the more developed races. In parallel manner inferior racial cultures exhibit more prominently the traits of the early stages of a human culture. We must avoid the assumption that the Negro or other race is inferior, and then set down the distinctive "negro" traits of the negro skull or heel as evidences of limited development-an argument quite commonly applied to such details as the flat nose of the Negro and of the Mongolian. The evidence is ambiguous. "The specifically human features appear with varying intensity in various races"; "the di- 
vergence from the animal ancestor has developed in varying directions" [11]. Even though the first premise held, the conclusion of inferiority would still require a second premise to show that the bodily traits are correlated with the mental ones; but "a direct relation between physical habitus and mental endowment does not exist." Our presumptions are not disproved, but also not unequivocally supported. There is the danger of transforming a psychological view to a biological issue, while seemingly gathering support from it. Less developed races seem to us more savage, more feral in aspect, more brutal in conduct; and this fact may have a real significance, while not carrying the significance of an ultimate racial inferiority. It may indicate a more limited development, and by that fact, or in virtue of it, a more limited capacity for development.

A second biological test is found in variability. The more variable race is regarded as the higher, since in such variability, if favorable, lies the possibility of the useful, the progressive, the initiative step that elevates achievement, and advances the generations that profit by it. This argument, though complex, has much in its favor. The appearance of a small group of original, creative minds in each generation may be accepted as a special manifestation of the general variability of the group. Races whose average stature is high, or whose intelligence is higl, show a considerable number of very tall men, or very intelligent men, and a decided variation between the extremes of height, as also notable instances of giants and geniuses. Large uniformity tends to a preponderating mediocrity. The presence of a few exceptional men may have an enormous influence upon the racial progress as embodied in achievement; accordingly the ability to produce these, while intrinsically a slight differentiation in biological terms, may prove a momentous one in its issues. This trait is presumably responsible for much of the contrast of races in achievement-a rapidly cumulative contrast-and thus 
becomes an index of racial status-a criterion of the relative (psychological) plasticity or fixity of the racial type. The greater variability of man as compared with woman produces a cumulative contrast of like order, and sets the keynote to the qualities of masculine achievement. The comparison with physical variability is inconclusive. Traits of one order may be rigidly limited, of another fairly plastic, and yet equally carried forward in the racial heritage. Physical racial characteristics are not as stable as was formerly assumed; they, too, show modification under new environments [12]. Moreover, variability of a biological and physiological nature may stand in uncertain relation to the mental variability from which emerges the individual assertion favorable to progress. For the fixity, the non-progressiveness of cultures, is a characteristic of very widely separated orders of society; it may be an expression of the strength of the social organization in repressing such individual assertion as appears, rather than an evidence of its non-existence. Peoples fairly comparable as to race, achieve and utilize very different orders of culture; race alone does not suffice to determine achievement; again, peoples of fairly contrasted and wholly unrelated racial stock develop and remain in substantially the same unprogressive conditions. Races achieving a high order of civilization have degenerated; regeneration is possible. Until it becomes possible to disentangle the order of variability from their variable conditioning factors, their interpretation must be inconclusive.

A third type of evidence relates to precocity. The earlier maturity of primitive races, both physiological and psychological, seems established, though there is some question as to its significance as a sign of racial status. But even with liberal allowance for the effect which domestication produces in the forcing and retardation of powers, and with an appreciation of the fact that early arrest of 
development may not be wholly a disadrantage or sign of inferiority, the argument carries weight. The less developed races reach maturity, physiological and psychological, and in turn approach the decline of senility, more quickly than the higher races. The evolution of race widens the span of the efficient life, despite the fact, or through the fact, that it increases the era of preparation. Forcing and retardation are not eliminated; condition may still be effective. Psychologically, the greater simplicity of the cultural range to which adjustment must be achieved, places that accomplishment within the range of the earlier age; the same applies within the social levels of all eultures. The indiridual maturity is hastened by responsibility, by being thrown upon the individual resources, by mithdrawing the shelter in which immaturity finds its protection. Physiological function is less susceptible to this influence than is psychological expression, but is not withdrawn from it. Duly considered in kind and degree as earlier independence and earlier decay, precocity may be regarded as a significant clew to differentiation. That girls mature earlier than boys is likewise a conclusion consistent with the more infantile status of woman, bringing her at once closer to the status of the race and to the child. Woman is also held to preserve the racial trpe more thoroughly than man, notably so in primitive races. The consistency of the argument in its several phases strengthens its plausibility in its most direct application [13]. Under this composite riew a highly evolred race would present a greater differentiation from the primitive (phrsical) type, a large variability among its members, an extended crele of life, slow maturing of maximum powers and late decline. while vet expressing vigor of endowment in the rapid progress of early years. Such generic criteria, confessedly inadequate. serve but to outline a portion of the background against which the differentiations of race are projected. In retrospect, the potencies conferred by dower of sex, 
assets and liabilities alike, remain paramount. Nature is unwilling to relinquish or subordinate the primary expression of the specialized organism. Sex stands apart, preeminent, unassailable, enduring, and above all comprehensive. Sex does not narrowly condition, but broadly molds, or, in more delicate manner, colors the mode of expression of the individual qualities, all carried along in the common stream of inheritance, at once generically racial, and more specifically and intimately ancestral. In a similar view race appears as an original biological emphasis, uncertain in origin, indefinite in import, and even in its present mixed assertiveness as a momentous conditioning factor in the distribution of quality. Racial traits, function as derivative blendings of more fundamental traits, by-products of earlier demands of adjustment now turned to transferred service; the presumptive parent racial traits are accessible only hypothetically in the qualities of their issues. The racial achievement becomes the historical manifestation-in no sense an historical accident-of the racial genius in operation; it cannot be regarded as a definite measure of endowment, but cannot be disregarded in any appraisal. The racial factor is of all the least susceptible to experiment. The student of race is never able to appraise pure races living under comparable environments, but always mixed races subject to complex and variable condition [14]. The racial factor is overlaid by, and involved with, other types of group-traits, which, along with sex and race, form the generic determiners of the individual temperament and character.

Race forms the outermost circle of the hereditary forces converging upon the individual; remote ancestry and immediate family occupy the intermediate zones. The individual quality owes its largest determination to the immediate ancestry, the specific influence of any one factor of the heritage rapidly waning with remoteness of kinship. The closer community of inheritance, which is read in the 
closer resemblance of traits, demonstrates the tendency of the stock to breed true, true in detail as well as in type. Where qualities are pronounced in degree and recognizable in their bearing, the argument is definite and the evidence convincing. Galton's study of the ancestry and interrelations of men of genius conclusively showed how largely the capacity which such distinction involves is a dower of the family stock [15]. It was shown that the hereditary factor is more decisive in families producing extremely distinguished representatives than in those standing high but not highest in the group. Further studies of eminent men extended the evidence that general ability and specific abilities "run" in families, that the degree of kinship to an eminent man carries almost a quantitative increase of probability of decided capacity in the nearest and next of kin. Although women are themselves far less commonly distinguished than men, the chances of inheriting the capacity for distinction are equally distributed in the maternal and in the paternal lines of relationship. When further extended to types of qualities of more nearly ordinary range, the evidence remains consistent, though often uncertain by reason of its complexity. Mental and moral qualities are in some sense heritable; the accumulation of data tends to strengthen and refine the conclusion. A richer endowment of the intellectual (psychic) nature is the prized quality of race and family. Traits, whatever their bearing upon the endowment in terms of which men compete and contribute to the work of the world, must be primarily selected, and then valued and cultivated. Leaders of men form the choicest product of the choicest strains of mankind. In terms of their common qualities as well as of their distinctive ones, men find their level. Standards of attainment, in lieu of standards of endowment or combining with them, become the means by which society places its recognitions and expresses its approvals. The group-traits thus resulting express the tendencies for the 
variable heredities of men to conform to definite types of endowment.

While specific traits "run" in families, the same orders of traits are widely distributed in different hereditary strains. Different peoples go through comparable stages of culture; different communities are composed of comparable types of men. The common trait is convincing when it presents a definite physical or psychological clew. Physical strength and musical ability may be selected as typical instances; both are conspicuously hereditary, widely distributed, and recognizable. The one, variously serviceable, may lead under Anglo-Saxon auspices to distinction in athletics; the other is a specific distinction, though with temperamental affiliations. Men come by their athleticism or their musicianship no differently than they come by their blue eyes or tall stature. The heredity is unitary; men, like races, are equipped for life and compete not by one but by a composite of qualities. Physical strength carries with it a large determination of other qualities; musical ability is a more specialized excellence. Both serve to develop common interests, expressions, characters.

While the basis for athletic proficiency is laid in natural endowment, the place which the trait finds in this or in another expression depends upon the environmental setting. In the life of ancient Greece a man's physique counted strongly; the winner of the Olympic games became a national hero. Jousts, duels, challenges, sports, contests of all sorts, express a like appreciation of a common physical fitness, and of the part belonging to it in the desirable qualifications of men. Ideals enter to determine how the appeal is met. The doctrine of "mens sana in corpore sano" leads to one perspective; the sentiment that the body is a lure to passion leads to asceticism and the castigation of the flesh. The requirement that Rhodes scholars shall excel alike in intellectual capacity and in 
physique reflects the modern view of their integral relations. Physique is valued for what it brings. Big men and strong ones are "naturally" confident, as small and slight men are as "naturally" shrinking and deferential. Presence and bearing confer a dignity that is psychological as well as physical, and may become an important factor in preferment. The trait of physique affects and conditions careers directly and indirectly. The explorer or the frontiersman finds physical fitness an indispensable equipment. The physician, as the exemplar of physical rectitude, finds in his physique an aid in his ministrations. The less specialized callings of an arduous life (sailor, miner, carrier, hewer, blacksmith) find their work through the fitness of physique. The fundamental physical endowment determines conduct and career, and sets apart those who share a common favoring of physique from those who lack it. In its transferred employment its consequences are equally significant; for the underlying energy that maintains vocational activity determines the quality and measure of response. More derivatively, the common possessors of a group-trait present a sympathetic bond of congenial expressions, like interests, and similar tastes, and "naturally" drift to similar careers. Mental energy and physical energy have an inherent relation, though by no means an identical basis. The group-traits selected for emphasis owe their selection to their prominent parts in shaping the qualities of men.

The musical gift-equally, though far more delicately, a matter of endowment-conditions no other fitness than its own expression. Those who find their careers in this talent require the sustaining qualities of the artistic temperament; and that in turn may be referred to a mode, a quality in the adjustment of the ordinary factors of response. In the conspicuously musical families the gift determines career; the call of the "muse," and of that one alone, is insistent. In the wider and less marked distribu- 
tion of the trait among the ordinary or selected run of persons, the possession becomes a modest contributor to the affective life. Viewed practically its place is slight and hardly touches the generic factors, the larger determiners of action. The musician lives a highly specialized life. The musical endowment in the favored individual supplies a specialized outlet for emotional expression, leavens the mass of practical interests, and shapes the inner qualities of the mind. It is a by-product of luxury and affects not the fundamental but the leisurely qualities of response. As the quality is generalized, it becomes the artistic susceptibility - already adequately considered-and plays its part in the community of human expression. In so far as the artistic and the athletic bent may be opposed-marked vigor of physique tending away from the sensitive endowment of the artist, and responsible for such selective contrasts as the erect pose and sturdy build of the soldier and the stooping shoulders and slight frame of the scholarsuch contrasts indicate the underlying affiliations of the factors of endowment, the compatibilities of temperamental traits, individual and in their recurrence generic.

Group-traits yield a more distinctive psychology when they confer a more or less pronounced deviation from the type. The psychology of genius [16] is significant through its large consequence to racial progress; its interpretation forms a vexed problem. The conception of genius as a marked superiority of the components of the ordinary man makes the genius an intelligible superman, a more highly evolved exemplar of the foremost ranks of men. The conception of genius as a wayward endowment with difficulty held to a profitable orbit, emphasizes the sanity of normality and the price of deviation. However the views be reconciled or combined, the specialized nature of high talents comes forward to reënforce the view that what genius presents in extreme measure is a group-trait of mankind brought by a fortunate play of circumstance to abundant 
fruition. Men of genius, like their more ordinary counterparts among the well endowed, readily fall into the groups of men of thought, men of feeling, and men of action. The relations underlie the specialized proficiencies; they represent the indispensable equipment for maintaining the adjustments of life in well ordered efficiency, which, with the added talent, prepares for the highest service. In this division the men of feeling unmistakably exhibit the largest tendency to irregular and difficult expression, and through this liability exhibit their community with the qualities of the nervous temperament and its possible disastrous issues in the abnormal. The specialized bent of the man of genius or the man of parts, indicates the determining power of a talent to dominate career, to direct effort, to shape the quality of responsiveness in general. Equally pertinent is the formulation that what inherently determines the specialized talent carries a larger and secondary range of determination; and in this similarity-like the similarities of sex or race, but of a different orbit of expression-lies the basis of the group-trait, the recurring type-forms of character with which the biographer as well as the observer of all sorts and conditions of men deal when they record their impressions and estimates of men.

The analysis of a "social" class such as criminals yields a contrasted aspect of group-traits. The view of the criminal as one born to such fate places him as a natural type; the view of the criminal as the product of his circumstances makes him an environmental type. In either view eriminality is, like all careers, an expression, the result of exposure of a certain type of endowment to a certain stress of forces. The defective stock makes the grouptrait [17]. Feebleness of resistance and control, suggestibility to the contagion of the easiest way, susceptibility to the cruder appeals of passion and desire-such are the psychological fundamentals of the endowment for which a career of crime is not inevitable but highly probable under 
the conditions of modern society. The criminal is not born to crime but to the liabilities of his defects. The criminal by accident exemplifies the preponderance of circumstance in the conflict of impulse. The group-traits of the criminal classes form a consistent "complex," supplying an outlet of expression for certain deviating-in this instance psychologically defective and socially undesirable trends. In all such "complexes" nature and nurture combine and coöperate. The group-traits of the criminal classes reflect the common traits of the psychologically defective and the acquired community of traits growing out of anti-social occupations. Neither group of traits is exclusive; all men present the qualities of their defects; the aptitudes that find expression in the criminal career are not different from those entering into the pursuit of more legitimate occupations. The individual follows the bent of his endowment; and others of similar endowment by a like process develop common group-traits in the pursuit of their careers. No differently the temperamentally shy and timid turn to professions-such as the intellectual ones or the artistic ones-which can be pursued largely in solitude, and avoid difficult social contacts and the management of men. The endowments of group-traits qualify and limit; they confer potencies and impose handicaps as they specialize, but specialize only generically in types of character. Group-traits are specialized qualifications and limitations more or less commonly recurring, distributed by natural processes and brought to expression by a common type of responsiveness to a common conditioning environment [18].

The communities established by sex, race, comparable stocks, and related ancestries, when further fused by acquired traditions, ideals, culture, language, intellectual inheritance and standard applications, stand forth as the underlying bases-democratic in their massive assertiveness-of the common and communal enterprises and interests, the common appeals of the social and the organized 
life. Yet no less are the distinctions of such heredities and the contrasts of classes in endowment and station directive for the understanding of the qualities of men individually and collectively. The large practical significance of the group-traits of men as the basis of their social equipment appears in their further issues under the play of the social structure.

It is pertinent to recall that the group-trait is, in a sense, a logical construction; the reality is the individual and his traits. Yet in the natural scale, the distinctiveness of the average individual is slight. "John Smith's" traits are generic as well as specific, and in their conventional expression of an average endowment become the qualities of the generalized "John Smith," standardized by the like action of a like range of circumstances. In the organized, institutionalized world, group-traits of a natural order are overlaid by differentiations of an artificial order; even the reactions of sex are determined by the ideals of manliness and womanliness. Race is absorbed and redirected by national qualities; natural history gives way to institutional history; group-traits become class-traits; endowments are reflected in careers. That the group-traits of common or congenial endowment remain real is shown by the bonds of sympathetic understanding which they further. Men comprehend men, and women women, to a measure debarred to the opposite sex. Race appeals to race, and nation to nation, with a sense of solidarity artificially cultivated as a racial or a national conscionsness, but thus readily cultivated by reason of an underlying nucleus of natural favoring. Similarly once established, the occupational set becomes at once a molding force and a consistent expression of natural bias, which also binds and affiliates groups of men. For the most part the trend is not so strong nor the rocation so specialized as in the case of the artist, for whom the career is determined by his specialized proficiency; the choice of a profession is a practical 
and a critical inquiry as to the nature of one's endowment, tasks, inclinations, opportunities. The decisive leaning may be slight, but, if at all congenial, grows by what it feeds upon. Circumstances control, and changes of occupation may be less common than the desires for them. By and large, professional men and business men, farmers and ranchmen, speculators and politicians, executives and officials, mechanics and artisans, present within each group more or less common traits upon a slight natural fitness readily acted upon by training and tradition. Once developed the career becomes responsible for the secondary community of traits, which form the actual group-traits to which psychological and economical forces make their appeal. In the occupational adjustment lies the practical regulation and adjustment of the traits of men to the work of the world.

Though the vocational bent, which expresses a form of specialization of a group-trait, controls the dominant activity, it may absorb and make articulate but one phase of energies and interest; it may be a little more than a concession, even an uncongenial one, to the necessity of earning a livelihood. Avocations and general interests, reflecting endowment, furnish a wide basis for the sympathies of men, of equal or greater intrinsic import. Social station plays a marked part in fixing community of interest and intercourse, and divides as well as unites. Aristocracy has its distinctive psychology, as bourgeoisie has its group-traits. The urbanity and cosmopolitanism of the city, and the rusticity and simplicity of the country, offer the sharpest contrasts of closely allied stocks of men. The national psychologies of Briton or Teuton, or still more narrowly of English, Scotch, or Irish, no less than of Prussian, Saxon, or Bavarian, are to our specialized view adequately distinctive, and leave their impress upon character. North and South, East and West, Occidental and Oriental, develop group-psychologies as sharply con- 
trasted in traits of mind and habit of response as in appearance and custom. The individual both naturally shares in, and acquires, the traits of his group and class; and the range and composition and mode of expression of his traits are determined by such participation. "John Smith" is each and all of these influences merged and massed, individualized and modified, yet more generically composed in accordance with the type-forms of traits that affiliate him to others of his kind. Endowment does not retire but is overlaid in its expression, conventionalized in its application, standardized in its issue. Through such considerations, the analysis of the sources of human quality leads to an applied psychology of human values, as natural temperament is embodied in environmental character. 


\section{CHAPTER VIII}

\section{CHARACTER AND THE ENVIRONMENT}

THE statement that life is character in action finds its complement in the condition that conduct is ever set in circumstance. Endowment summarizes the subjective, environment, the objective, determinants of conduct. In the temperamental aspects of expression endowment is central in life as in presentation; character as the reflex of the environment is now to be made the focus of consideration. The environment is primarily a biological setting; for animal life it is conclusively so. The instincts of wild animals carry the stamp of environmental adjustment; domestication is man's readjustment of them. In the human kind the natural environment combines with the manmade artificial one of extended scope, which at higher levels becomes commanding. For present-day conditions the environment is substantially what the communitythrough the heritage of previous communities-lhas made it; it includes the reconstructed material and economic bases of life, and more distinctively the intellectual, esthetic, and moral atmosphere-the conventional and institutional intercourse-in which modern men have their being. Yet the physical aspects of circumstances continue to exert a vast influence, to favor or hamper the issues of endowment even under the complex reconstructions.

In primeval conditions the environment acts as a direct pressure. Climate and habitat originally condition adaptation; the physical surroundings apply a stress that encourages the trends best adapted to prevail in the struggle for existence, and compels adjustment through penalty of loss or retirement. The best adapted individuals and groups 
survive; through such favored members the race prevails as a whole, by virtue of a favorable composite of traits. The stream of heredity carries the entire range of qualities; enduring superiority is possible only through the assurance of a progeny to inherit and continue the favoring traits. This eugenic argument illuminates backward as well as forward. With conditions primitive and constant, advantage fell more directly to reproductive superiority. The stronger, the more influential, those who satisfied the tribal standards best, prevailed; and their descendants likewise. At all levels is it true that any type of superiority that is too seriously offset by a lowered reproductive vigor cannot maintain itself [1]. Heredity and environment are the original forces of selection. Adaptation and elimination proceed together. The consciousness of racial integrity and the maintenance of racial tradition pervade the practices of primitive cultures. There is obviously no explicit comprehension-such as is available to our generation-that race improvement must proceed upon such control of heredity as may be practicable. The appreciation of the sanctity of natural forces is directly, if naïvely, expressed in the loyalty to tribal custom and tradition. Practices become established, based in part upon sensibilities or prejudice, supported by the belief that conformity strengthens, and that violation of tribal custom weakens racial vigor and stability. Such beliefs become effective in the assertive racial consciousness that unites generations and preserves their continuity. In the same cultural medium there is developed a regimen of training directed to the mastery of the environment and adjustment to it. The organization of primitive society shows conclusively-in addition to the influence of physical environment-the powerful "psychological" regulation of conduct by customs and beliefs. The dual source of environmental influenee underlies the course of development of civilization, and of the qualities which civilization selects and fosters. 
While distinctive in his power to react upon the environment, man, in common with other organisms, found life determined by physical conditions; in this aspect the foodquest was directive. Man's omnivorous diet facilitated his adaptability to varieties of habitat; he became a dweller anywhere from the arctic zone to the tropics, a migratory exploring animal, predatory by the exercise of wit rather than of natural armament. Just how the process of adaptation was carried on, how far climatic severities eliminated the unfit, how far the habitat brought forward traits to fuller expression and fixed the range of human or racial endowment, is uncertain. The continued play of like forces may be observed in all stages of culture in limited, indirect, refined measure. It may plausibly be argued that the differentiation of race itself, like the conspicuous derivative racial traits, represents an original specialized adjustment to climate, to the physical environment, and to the mode of life thus outwardly conditioned. The vigor, resourcefulness, venture, of Northern races contrast with the less enterprising unconcern, the leisurely softer qualities of the Southern ones. More specifically and despite the equalizations of modern life, the chill gray skies of England continue to affect the stern reserve and orderly industry of the British character, as the blue skies of Italy's balmy atmosphere induces an easy-going direction of life. In such issues physical conditions join with and play upon natural inclination. The abundance of semi-tropical climes makes way for dreamy contemplation and a mystic emotionalism in one aspect, and in another for easy-going leisure and a taste for the amenities of life; courtesy, affability, sympathy, combining with traditional benefits of culture, develop a psychological expansiveness, as they reflect a climatic exuberance. That, in further contrast, the leisure thus developed becomes an accepted privilege and industry retires to a modest place in the scheme of life, while in more mgged environments leisure or idleness is looked upon 
as a shirking of obligation, is a social-moral by-product in ideals. Shiftlessness may be the economic price of the onc, a restless unadjusted energy and sensationalism of the other. Circumstances do not rigidly determine but invite these issues. Once set, the qualities favored by circumstance, are further favored by social ideals, by conformity to tradition, by approved patterns of conduct.

Adjustment to condition plays a constant part in the determination of conduct and character alike. Adaptability is itself a quality of adjustment, in satisfaction of the demand asserted by the environment. The changeable uncertainty and seasonal variation of northern climates impose requirements of vigor in one response, of industry and forethought in another, to meet the stresses of nature's severer moods. A meteorological adaptation persists as a favoring condition in psychological expression. A susceptibility to climate still inheres in the nervous organization, and for many a temperament makes work under unadapted climatic conditions trying and shorn of its best issues. Extreme cold obstructs favorable effort; extreme heat prostrates the nervous resources. Despite the artificial control of this large factor of temperature, men still seek the conditions that agree with their nervous systems-a climate hot or cold, exacting or temperate, of high altitude or low, moist or dry, changeable or equable. It remains a temperamental decision whether the equability that relieves the necessity of the seasonal adjustment and the vicissitudes of weather, leads to a steady output of energy or to a general relaxing disinclination to effort. The daily and seasonal routine must be adapted to the exigencies of climate. Custom and tradition embody the wisdom of experience in such as in other adaptations. The regularity of employment and its monotony, as may be demanded by economic ends, cannot safely ignore psychological and physical condition. The psychical influences of weather may be traced statistically in the progress or the refractoriness of school-children, in 
the fluctuations of insanity and of suicide-greater in the late spring when the unaccustomed heat sets in and greatest in mid-summer-and in many other types of fluctuations. Meteorological sensibility is suggestive of a subconscious, organic type of response-a survival of what originally may have played a more directive part in securing adjustment.

In individual susceptibility directly, and indirectly in collective achievement, the impress of physical condition is felt. In extreme contrasts the influence is marked; life in the aretic regions, and hardly less so in the tropics, is incompatible with a favorable intellectual development; the climate is too exacting, too decisively controlling. Climate in its typical effect loses its controlling direction and combines with other environmental factors of a complex civilization to modify the closer details of adjustment, and through them moderately affects the character of communities and careers. The frequent necessity of finding adjustment under effort may dispose to the making of effort, which habit becomes available as a psychic trait directed to all manners of employment. The seasons change disposition and interests alike; winter and summer by contrast enhance the appeal of each and supply a wider range of incentive. An adjustment through habit and the play of temperament may equalize vantage and disadvantage; in the larger statistical run the influence tells. The great cultural movements standing in closer relation to modern occidental civilizations, as well as the centers of present-day economic initiative and intellectual progress, belong to the peoples dwelling in temperate zones. Historians trace the potent influence of climate and habitat upon the stream of events, as upon the characters of peoples participating in them, but emphasize as well the economic and sociological environment as the efficient medium of their expression [2].

The joint issues of natural and artificial condition supply the more pertinent and convincing illustrations. The 
frontier represents not merely a type of physical enviroument, attracting and developing selected qualities, but equally an economic situation, likewise a sociological and a psychological one. The physical life, and the associated interests, attitude, standards, develop together and consistently. Dwellers in mountain fastnesses or in the open plains find their activities determined, as is their physical horizon, by the prospect that confronts them. The sea molds occupation and character alike. The insularity of Great Britain comes to be a psychological rather than a geographical trait. All local habitations worthy of a name-and not abused Boston alone-come to be states of mind rather than positions on the map. However broadly the term is extended, the original environmental influence must ever be considered, of which climate and topography are typical. Such environment not alone determines the conditions of existence, and thereby develops selected ranges of quality, but in what it supplies and in what it demands, further directs the growth of the slighter artificial readjustments which are distinctive of the civilized, organized life. Man is above all the animal that makes or remakes his environment; he changes the face of nature, but more distinctively the conditions upon which nature yields a livelihood. What is true of his physical environment becomes still truer of his mental one. Cave-dweller or cliffdweller, or pitching his tent as he wanders, he repeatedly shapes his habitat to his needs, and secures control of nature to facilitate the satisfaction of his desires. Nomad, shepherd, or tiller of the soil, he acquires an economic status through the fact that he does not inertly accept but reacts upon the environmental conditions. In the adjustment of endowment to environment lies the clew to his cultural development.

The natural food-supply is a comprehensive condition. When food is abundant without effort, man may vegetate; when the struggle for existence is severe, the food-quest 
may absorb and exhaust all energies. Luxury enfeebles and breeds vices in nations as in individuals. Yet more fundamentally the release from too constant exertion is necessary to secure the leisure for the development of the arts of life. The wealth of nations is indispensable to intellectual triumphs. Civilization develops needs following upon the facilities for their satisfaction. The increased control of natural forces sets new standards of living; the conformity to such standards and the ability to use the acquired resources make the process of adjustment increasingly more complex and more artificial. Education, casual or formal, is the means of acquiring fitness for the environmental demands, always more exacting psychologically than materially. Furthermore, the environment ceases to be wholly or even largely local; contact with other peoples leads to compacts as well as to feuds; if extended, it creates the world of barter and exchange. Industry adds artificial resources to the natural ones; wealth grows in hand-made products as well as in natural property. From the days in which the stone or shell was fashioned to use or ornament, to the age of metals following upon the Stone Age, to the age of machinery and scientific technique, the path of invention and manufacture developed a growing control of material and process. By its encouragement of invention, the economic life placed a tremendous emphasis upon a derivative set of qualities, retiring those vital in a more primitive adjustment, to a secondary but never negligible place. Yet altered conditions of life radically change the direction and the perspective of their exercise. However transformed the environment, adjustment to it must build upon the native vigor of primary traits, reshaping the relative emphasis of qualities and their employment, but not too radically altering their nature. The environment offers to the constant traits of endowment new and more versatile outlets. It does so in part through the stimulus of natural resources; it does so eventually, in far greater measure, through the 
contributions of favored individuals for the benefit of themselves and their associates. These, first devised as special adjustments to circumstance, through the dissemination of the advantages which they confer, become social-environmental forces changing the mode of life. Through their dissemination as communal possessions, progress results. Obvious advantage once experienced creates an attitude favorable to the encouragement of invention, and extends to a general alertness of mind in all the details of adjustment of which the individual life consists. Nature and nurture combine and interact, but in the issue as it touches the higher cultural interests, the artificial redirection becomes commanding, though never exclusive.

The natural conditions the economic environment; and the economic reacts upon the sociological environment, one phase of which becomes dominant as the intellectual environment. These terms are not adequate; each presents a distinctive nucleus of a set of composite influences; yet for convenience of reference they may stand for the whole. The natural environment includes climate, soil, topography, resources-and these in due course with reference to commercial availability and prospects. Countries are rich or poor in one or another contributing factor to property; their wealth shapes their development. Agricultural, industrial, mining, seafaring, manufacturing facilities determine the trends of life; such development assures and further directs the cultural, social and political relations. Social condition and environment react upon one anotler; unless civilization has proceeded far enough to discover, utilize, and require the resources, they are practically nonexistent. A primitive hunting people lives on the same land as the mining or lumber-cutting pioneers who suceed them; and their descendants turn to agriculture when the land is cleared. The resources are such only to those who can discover and use them. All this is elementary, and moreover retires in significance in presence of yet more 
artificial aspects of environment. The physical environment persists, yet may be quite submerged as an influence in the transformed and transforming mode of life, which, as cause and as effect, assumes a commanding position in the determination of the qualities required for adjustment.

Furthermore, as we apply these considerations to our own advanced status, we appreciate that the economic relations which determine their being and value, also more and more equalize their rating. Facilities of intercourse mingle and disseminate the economic and the cultural products, thus making artificial environments less distinctive than in earlier times when geographical barriers and the strong bent of tradition which they furthered, had fuller, completer sway. Similarly the economic environment expands to include the entire range of institutional growths which facilitate, protect, and extend the organized relations of men in society. Though made real in an incorporated embodiment, such products are psychological; they are maintained by an indwelling spirit. There may be ultimate appeals to physical power in peace or war, but right prevails more and more in the spirit of right. Yet more comprehensively, institutions reflect views, attitudes, beliefs, desires, sentiments, sensibilities. Their existence, even in their direct economic relation, is due to the intellectual development which is their source and support. In view of the prominence in such environmental influences of the rational products of science, arts, and the culture of mind, we may call it the intellectual environment. In view of the fact that such relations serve a social purpose and hold together masses of men and their interplay of interests in a social organization with all its manifold radiations of attitude and intercourse, we may call it the social or sociological environment. In view of the fact that this massive influence is primarily effective in redirecting the native qualities of men, we may call it more generically psychological. Moreover, as the standards and ideals thus resulting are 
formulated, recorded, and made authoritative, in custom, in morality, in tradition, in religion, we may call it moral or spiritual. Of the three-natural, economic, and the combined sociological, intellectual, psychological, moral, and spiritual forces-the last dominates in complex cnvironments, does so indeed in one manner or another in all but the most primitive stages of human progress; by virtue of such dominance it becomes the center of theoretical interest and of practical consideration.

Such are the cumulative influences for which the environment stands in present human society; they are maintained in and by institutional provisions, conditioned by economic and sociological circumstances, furthered by educational measures, set in a psychological atmosphere more or less consciously effective. The same cluster of composite and interacting influences shape human careers and thereby determine the interests and expressions of men, through which are interpreted the issues of endowment in traits of character. Two parallel lines of argument must be maintained: that generically the environment plays the same part, exercises the same order and direction of influence upon human traits at whatever level the development, as upon the traits of organisms under natural surroundings; that the process of adjustment is in type similar throughout, and that such primary type of adjustment persists, though restricted in scope, modified in its range; furthermore, that the environment for the human organism is distinctive through the artificial factors introduced by the control of natural resources, and most comprehensively by the reflex influence of the psychological molding forces as expressed in attitude, belief, conduct, desire, and the rationalized, systematized, conventionalized direction of endeavor, individual and collective.

A helpful analogy to the transformation of the human environment by the hand and the mind of man lies in the domestication of animals. Both involve a transformation 
of traits and their application. The traits of animals available for such reëducation find their source-the original nature of the animal paralleled by the original nature of man-in adaptation to natural condition; the reconstructed traits show the same tendency of limitation through ancestral fixation. The social and institutional forces act upon the individual man as an environmental influence of imposed origin, much as the utilities of animal traits for human purposes impose upon the domesticated animal the direction of its native qualities, Animals are chosen for domestication because of their adaptability to new conditions. They have in part laid aside their feral nature; those that have resisted the human overtures reflect the stronger organic loyalty to their natural history. The bars of a cage, not unlike those of a prison-cell, express the rebellious rejection of the rules of conduct enforced by human institutions. It would be unfair to infer from such refractoriness a lesser psychological capacity as tested by pursuits suitable to the natural order of existence. The capacity for domestication, like that for civilization, is an uncertain clew to intelligence. It is but one factor in a composite, which for the human kind comes to be momentous; yet the pacification of the human race is not accomplished, and is not likely to be universal until the lion and the lamb lie down in peace together. Civilization represents man's partial conversion of his own impulses by a gradual control through a social-moral environment, in the ever-widening pursuit of increasing purposes. In his domestication of animals he enlists the animal capacities in a similarly conditioned service; in the reconstructed world, for animal and man alike, acquired purpose determines the standards of value [3].

In turning the traits of animals to his uses, man has followed a composite method of selection and training, which natural forces and his distinctive reaction upon experience have developed in his own "domestication." In this 
process traits developed in one habitat to meet recurrent natural conditions persist and are turned to other uses in related situations of artificial status. The strength of the ox-whose subjection to the yoke formed a momentous step in agriculture-was developed in the mighty contest for supremacy among the leaders of the herd. The flectness and long-windedness of the horse, which met the herdsman's needs, and have survived to satisfy man's sporting nature, were developed to enable the horse to outdistance the wolves on the open plain. The donkey's mountaineering skill was the result of his search on the rough hillsides for shelter from the beasts of prey, with no reference to later service as a pack-animal. The generous udder of the cow, that has become the alma mater of the human race, was developed to meet the needs of the calf while the mother roamed for fodder, which in further adjustment to condition she learned hastily to incorporate and later more leisurely to digest. The sheep acquired its coat of wool (and presumably shed it, though now dependent upon a shearing by human hands) as a protection against the cold of high altitudes. The dog's loyalty to the pack has been transformed into a fidelity to man and his belongings. Dogs may be trained to retrieve and point because allied habits have an instinctive place in the canine nervous system. The pig that is used by French truffle-hunters to "point" their prized delicacy, learned under severe conditions of existence to find roots or die. The animal-traits thus developed in adjustment to environment, man has fostered and selected, in return providing by his own efforts and ingenuity a secure livelihood in the service of which these animal qualities are given a place.

The persistence of other traits which happen to be of no service to man and may indeed be a disservice, he has either tolerated, or, despite his selective breeding, has failed to eradicate or control. The horse shies at a newspaper fluttering by the roadside, because a crouching and quickly 
moving form in the grass might have originally indicated the presence of such an enemy as a snake; and when frightened, he runs, panic-stricken, to regain the protection of the herd; the innocence of the newspaper and the absence of the herd are powerless to check the fright or its expression. They persist sporadically and yield slowly to the new adjustment; blinders that contract vision are not as permanently effective as an altered "character" that is not subject to needless fright. The pony bucks, if this impulse has survived, because such violent contortion would have dislodged a beast of prey that had jumped upon his defenseless back. Original nature continues in service or disservice alike. Horses may be shod with an iron shoe because of the toughness of hoof, developed through ages of adaptation to hard and irregular ground. The horse's gait is elastic, not in order to afford a comfortable seat for his rider, but to ease the shock to his own organism in travel over rough ground; and his versatile pace is an adjustment to different forms of locomotion adapted to different kinds of soil. The donkey is free from the tendency to shy because his original mountainous habitat offered no such dangers as surrounded the horse. Traveling in small herds, his more solitary life made him accustomed to look out for himself; his persistency-in human estimate, obstinacy-was a useful trait in that it kept him going under long marches untired, and conferred a strength of will which his latter-day master may find undesirable. A dog resents interference when feeding, because in the hunt by the pack when once the "kill" was made, his share of the spoils depended upon the defense of his bone from the onslaughts of his mates; it is on such occasions that his fighting instincts-which man breeds for protection or sportwere formed. The dog's submission to the whip is a derivative trait of his submission to the leader of the pack. His pointing habit goes back to an instinctive strategy that restrained his seizure of the bird while hunting with com- 
panions. The wagging of his tail in pleasure is a transformation in expression from the pleasurable excitement in the chase, when the ereet tail in the bush as well as the joyous bark was a sustaining signal of excitement to the rest of the pack. The stolid placidity of the cow has its place in bovine psychology and does not express an inclination to the subjection to the yoke; nor is the East Indian bullock's imperturbability in drawing a gun-carriage into action anything other than the issue of the old habit of the herd to stand firm with horns ready, when even the boldest beast of prey feared to attack. The same animal driven to bay shows the pugnacious quality which man has used by making a sport of the bull-fight.

No differently from the manner in which man has turned the stock of the animal qualities to uses serviceable to human needs, has he also built upon and modified the human qualities fostered in the primitive human habitat and extended them to vastly increased and refined service. In neither case has he, in the relatively short period of civilization or domestication, introduced or devised new qualities, but by selection, natural and artificial, strengthened and eradicated, encouraged, discouraged and redirected one or another of the original composite traits. The transformed emphasis is indeed to present interests far more comprehensive, yet hardly more radical for the human range than for the animal qualities. In the latter ease presumably the stock of ancestral habits and the modifiability are more limited; yet the community of method by which the transformation has been accomplished is instructive, particularly in its simpler types, and at its lower levels.

These considerations propose the problem of the original and the transformed nature of man-the cultural history of the transformation of human instincts. Civilization like domestication places old traits to new service; it ehecks traits that prove undesirable in the altered environment, and reënforces others desirable for more adequate adjustment 
to it. This process is never complete, but finds limitations through the persistence of older tendencies. Such "survival" of traits is variously suggestive; it gives the clew to the conception of value, through which a virtue or functional aid in one condition becomes a vice or functional disservice in another; education is a process of selecting traits for survival or retirement.

Fundamentally the original nature of man, which continues to serve his redirected purposes-however refined or involved-was established in adjustment to far simpler circumstances and in them found its justification. Like the strength of the ox, the fleetness of the horse, the sure-footedness of the donkey, the basic human proficiencies and the fundamental human intellectual habits present traits of adjustment vital or favorable to survival in the primeval habitat [4]. In tracing the relations of racially old to racially new types of service, the persistence of animal traits in use and limitation serve as suggestive clews. The tractability of the horse, the placidity of the cow, the companionability and fidelity of the dog-all as exhibited toward man-may be traced to an original serviceability within the group of their own kind; and no differently the animal qualities which by reason of man's prejudiced view he rates as faults, become intelligible as survivals from older stages to altered conditions in which their utility is reduced, possibly quite eliminated. The horse shies, the donkey is obstinate, the dog is pugnacious, the cat is a nocturnal prowler-all to human discomfort; but discount the "human" bias, and these qualities become virtues in the original status of the animal environment. The changed environment is responsible for the human estimate of animal traits. The braying and general asinine conduct of the donkey on city streets, the silly imitativeness and panicky unrest of sheep in a protected inclosure, the senseless behavior of geese in the barnyard, may reflect the unsuitability of such response to the enforced change of habi- 
tat. On the mountain-sides, on the plains, or in the marshes, these several forms of behavior doubtless were wholly suitable. Nature places no premium on folly, but determines the conditions under which action is folly or wisdom from the point of view of the welfare of the organism. It is obviously unfair to judge ereatures even moderately out of their element; obviously so to test fish out of water. Yet in applying the lesson to human kind, we are mindful that the medium of adjustment is more delicate, more variable, and more psychological. When we comment upon the occasional or frequent futility of human behavior, we may, in charity, consider how far the response is due to the unwonted circumstances rather than to inherent incapacity. As a Spanish proverb observes: the most stupid man is more conversant in his own house than the wise man in a strange dwelling. The primitive man is wholly out of his element in the institutions of civilization. The rustic is at a disadvantage in the city, as is equally the foreigner in a strange land, and the landsman at sea. Tolerance of judgment is compatible with the critical appraisal of quality. Yet the conviction remains that adaptability is itself a quality of supreme value, indispensable to the demands made upon the human adjustment to circumstance. As the test of adaptability is applied within comparable ranges of adjustment, and as these fall more narrowly within the field of artifieial environments of modern civilization, the comparison regains much of its validity. Men in general, like animal species, and groups and individuals in special circumstances, are entitled to judgment in terms of a suitable environment; traits become vices or virtues when judged by the suitability of means to ends; the original environment and natural ends determine the range of native suitability. The survival of traits forms a suggestive elew to the effect of an altered environment, in transforming vantage into disadvantage through a shifting condition [5]. 
It is evident that the simpler cosmic or local environmental conditions act less directly, less cogently, upon the human endowment. The environment does not yield, it is true, but neither does the human mind. Man both selects the environment and adapts it to his uses. In this respect the great step was taken when man not only foraged but planted or cleared the ground for his needs, not only hunted but bred animal life or preserved it. In all environments his adaptability served him. Fearless of fire, he learned to cook his food; his constructive talent made shelters from the elements and protection for his body. He rose superior to the grosser demands of physical environment. His distinctive mode of adjustment appears in contrast to those employed by animal organisms. As against the cold, man neither became an annual migratory creature, summering in the North and wintering in the South (and this from practical considerations of locomotion, which now for the favored few are overcome by having a winter home in Florida and a summer one in Maine); nor did he grow a hairy coat and shed it like the original sheep; nor yet resort to hibernation as do still lower forms of life; but he acquired acclimatizing adjustments and appropriated the furry hide of animals, whose possession of such coat evidences the form of adjustment suitable to their habitat and organization. Still more characteristically he learned to build a fire, and eventually discovered coal; his house became as artificial as his clothes and his mode of life. He anticipated the seasons' alternation in his granary or his woodpile; it is only the primitive Esquimau who lays on a slight accumulation of fat in addition to gathering and salting similar nutriment from the provisions made in response to a like impulse by the walrus. Civilized man made his storehouse, and not his organism, the repository of his goods; still more artificially he deposited his savings in a bank to be drawn upon as needed. He even, bear-like, robbed and then cultivated the hoardings of bees that had 
developed a similar habit, and used these instinctive savings to satisfy his sweet-tooth. But most characteristic is the intellectual response, the prudential habit that provided for a rainy day or a lean year. Such is the human adjustment, directing long-range efforts based upon foresight, upon the comprehension of the sequences of nature, and upon the possession of an adequate imagination. It is the cognitive and rational habits of man that form his dominant equipment, and determine his mode of adjustment to the demands of a variable and complex environment.

The conclusions thus surveyed remain in the background of consideration. The foreground is to be oceupied by the social-psychological agencies: which means that what I as an individual, or we as members of a common social group do, and how we feel and desire, is far more directly determined by considerations of our common and respective immediate and intimate sociological and intellectual environments-and of their developmental history-than of the economic and physical ones, basal as the latter may be or may have been in preparing and supporting the influences which the latter now exert. For our further purpose two excursions into interesting realms of psychology will be helpful. The first traces the mode of action of the primitive group-mind; the second considers the media through which the compositely sociological, psychological, and spiritual forces thus established are manifested and maintained.

The source of the psychology of the mass expressionthe collective psyche-lies in the gregarious habit of the human kind. Men in gromps think otherwise, act otherwise, and are moved otherwise than are the component members in their individual responsiveness and capacity. The aspect of mind that makes it a socially responsive organ of adjustment intimately affects the entire range of responsiveness; the individual psyche is transformed by membership, by absorption, it may be, in a group. The psychic 
habit of the group-the crowd, the mob, the collective consciousuess-affords a clew to the more primitive orders of nentality, to the generic racial mind, through whose operations the fundamental achievements of primitive humanity were wrought. The collective mental responsiveness proceels upon the elemental, communal traits of human nature; it reflects the indispensable, the more nearly original in mental evolution. It fuses individual differences; it merges divergent trends; it neutralizes variant peculiarities. Like tle composite photograph-which in the mechanism of its operation it parallels-it emphasizes the common features and subdues the scattered divergences. The psychology of crowd-reactions touches the fundamental, the elemental, the natural; its expression takes the mind back to the primitive stages of the intellectual life.

The group-mind-like the child-mind-has but a vague awareness of its own motives and trends. The source of its movement is deep, and often incalculable even to a judgment conversant with its nature. For a like reason is it difficult to predict what will prove to be popular. In the individual, though emotion and sentiment are urgent, yet the still small voice of reason and the mentor of personal restraint obtain a hearing; the collective reaction is exposed far more unreservedly to the primal sway of emotion and sentiment. Argument enters to influence conduct, but must be simplified to its lowest terms; it must be persuasive in tone, soothing in mood, oratorical in manner [6]. The appeal must also be made real and tangible-crystallized in precept, sanctioned by custom, worked upon by primary psychic motives. Tradition is so potent a guide because it sets a rigid example, makes reflection unnecessary, and substitutes for it the warm loyalty of tribal custom. Fashion does the same in a more superficial zone of influence. It regulates negatively by restraint-even more powerfully than in its positive form as commandment-in the institution of the taboo (the unfashionable as 
well as the unsanctioned), where fear of violation operates as a more tyrannical force than the obligations of conformity. In both aspects - conformity and taboo-the incliviclual reaction is a reflex of the social one. The communal stock of ideas is small in extent, simple in form, strong in its message; the psychic constitution under which they operate is correspondingly primitive. The collective mentality is uniformly of a lower type than that which its constituent members are capable of attaining.

The intellectual appeal, when effective, is so largely through the imagination, through ideas strongly emotionalized, and dramatically set-a "fairy-tale" stage of interest. In practical prudential matters it is the concrete, the actually presented, and the dramatic that arouses conviction; for primitive man was a close observer of facts, if a fecble and sentimental interpreter of their meaning. Myth is a characteristic issue of the action of the two tendencics; it develops a detailed yet fantastic realism as the medium of its representation. Every people makes its own Heaven and its own Hell imaginatively, and fills them with the vivid details of experience. To the medieval populace, Hell, no differently than the Hellenic Hades, had a familiar reality in pictures of ready meaning; fiery-tongued and cloven-hoofed monsters with human victims tortured in flaming cauldrons, carved in realistic stone, satisfied the sense of reality, however imaginative the motive. The man of the people, like the people collectively, demands an immediate, strong, vital, direct impression. Whether in regal pomp and show, or in the gory contests in the arena, or in the drastic presentation of the judgments of religion, the impression is created by a forcible, trenchant, sensational effect. A like susceptibility obtains even among the juost rationally developed groups of mankind. Statisties are mnimpressive in their slow, drop-by-drop aggregate, and their cold, colorless abstraction. A calamity of heroic proportions compels attention and arouses action. The sweeping 
horror and distress of a plague bring home the lessons of sanitation, and the overpowering catastrophe of the Titanic the peril of a mad pursuit of speed on the high seas.

The collective mind is suggestible, and the momentum of its movement grows by contagion. This conforms to the law of emotionalism; it applies equally to laughter and to tears. The jest that in a small company raises a ripple of a smile, in a crowd creates a gale of merriment. The pathetic tale that momentarily depresses when read alone, in the larger thrill of the public theater compels the free flow of tears. The quick impressionism makes for prompt oblivion as well; out of sight is out of mind. A crowd is at once fickle and obstinate; difficult to move by virtue of ingrained prejudices, yet suggestible through the sway of the simple stock of prepossessions that have gained a foothold. Suggestible by virtue of the readiness to yield to the passing impressions-once the opposition set by momentary prejudice or by deeper feelings is allayed-the crowd may be carried with a rush on the superficial eurrent of a dramatic enthusiasm. The prompt acceptance and equally quick rejection when the first impulse is spent and use dulls, appear in the pursuit of fashions and fads, in the vogue of phrase and habit of dress or action that strikes the popular fancy. The pursuit is eager while it lasts, but transitory in its hold and readily displaced by a newer rival. In the proneness to extremes lies the hysteria of crowds, lacking the steadiness and the restraint which the individual conduct finds in consideration and in the check which social disfavor provides for individual waywardness. From such check the crowd is free, in that it is big enough to create its own sanction. Its mechanism is ever the same-the absence of restraint releasing impulses of a cruder nature. Such impulses may emerge in the privacy of secret indulgence, or appear boldly in the license of bacchanalia, or the unreserve of carnival, or the brutal pillage of war.

The lack of initiative in the mass-consciousness makes 
necessary leadership to give the aggregate mind a set direction. The crowd demands a leader; his eentral place as the focus of loyalty is prone to make a hero of him. 'The chieftain becomes a god, abjectly followed, or in recollection shrouded in myth and glorified; the perseented become martyrs. Prestige is a more general and milder expression of the same tendency. The doings, the sayings, the personality of the leader are invested with exalted significance. Office, station, hereditary rank, momentary exaltation are all adequate to ereate such uncritical aggrandizement. Distance, actual or psychological, magnifies; the leader must not be too familiar, not too much one of the crowd, much as a man is not a hero to his valet, or as prophets are without honor in their own land. Prestige attaches to the unknown, the mystic, as well as to the brilliantly advertised and notorious, to a foreign celebrity, and to show and ceremony. Yet more intimately the leader creates his own following among his kind; the orator, the propagandist must not be too different, too remote from his audience. The sympathetic appeal depends on a fellow community. The alien looses the communal touch, and cannot arouse the genius loci by which the collective consciousness is permeated.

In a measure the primitive psychology of man may be reconstructed from the collective psychology that still comes forward in the appeal to the masses. Simple in ideas simply expressed-whence the power of emblems, slogans. "isms" and eatch-words-emotionally swayed by the momentary impression, more suggestible to manner than to matter, mediocre and fixed in a limited body of prepossessions, suggestible and subject to the spread of contagion, requiring strong direct address when the avenues of expression have been cleared but adroit circumvention to allay prejudices or opposition, prone to glorify or erueify, loud in demand when aroused and eagerly led to exeess, the crowd-mind is at once a prey to the professions of the 
mprincipled and equally the resource of the great enthusiasms of mankind. It is in some such medium of the fixation of beliefs, of the foundation of intellectual loyalty, that folk-psychology has wrought its slow evolution, and shaped the institutions of men. It is with reference to such a complex of mental habit that the group-traits of mind must be interpreted.

Group psychology has its distinctive varieties, its environmental conditions. What may be generally true may be specifically inapplicable. Crowds are crowds the world over; but an American crowd, an English crowd, a German crowd, a French erowd, an Italian crowd, an Oriental crowd, no less than a city crowd and a rural crowd, behave differently under parallel situations. The natural genius and training emerge even in the simpler responses. The foreign spokesman finds himself at a loss to gauge the effect of his words, through ignorance of the psychic reaction of an audience whose traditional temper he imperfectly understands. The foreigner in the crowd is unmoved by the aggregate response, the Stimmung, which he observes but through the different set of his sensibilities fails to absorb. The nature of the bond that unites, as of the prejudice that separates, carries a psychology of its own. The group is more than an aggregate; the components must acquire a unity of spirit, a community of outlook and interest, a mutual sympathy and comprehension. Assemblages, however heterogeneously composed, must be amalgamated on the basis of similarity of psychological traits, before concerted feeling or action is possible. The story of Babel is truer when interpreted as a confusion of minds than of tongues. The collective consciousness assumes more and more the aspect of an artificial solidarity, yet is the more readily established when a temperamental community like that of race underlies it. As an aspect of group-consciousness, the race factor stands as a general psychic disposition favoring certain expressional trends, but is largely modified by circum- 
stance, standardized by tradition; it commonly eomes forward compositely as a national, local, or communal sentiment. Psychic community as observed is typically an institutional amalgamation through the tradition of the environment; it is shaped by accepted but not necessarily rigid or explicit codes of behavior, by prevailing enstom and established usage. Yet a racial factor-like a congenial temperament-if present may strongly coöperate or even dominate [7]. The issue in complex civilizations is complex and variable. This original but variable factor explains why the Americanization of an Italian or a Negro or a Syrian proceeds differently, why each finds distinetive limitations. The varied loyalties, the conflicting mentalities of the group-components condition the mode of response to the group-trait as environmentally fashioned.

The underlying similarity of the collective mind, as of the human individuals of which it is composed, appears in the similarity of the essential modes of operation, in its fundamental constitution, in its natural outlets of expression; it appears compositely in the communal institutional products of peoples and their generic comparability. Transferring the argument from the mode of responsiveness of the communal mind to its achievements, we observe that the general outlines which the earlier stages of human development have followed are strikingly similar. The material development in terms of invention, the mode of satisfying needs, social organization, tribal custom, myth, religion, art, family life, ceremonials, castes, privileges, institutions, military, industrial, economic, and educational provisions-all arise as expressions of common demands and common solutions, appealing to the common neerls, sensibilities, aptitudes, as collectively expressed. Their extent and variety does not conceal their significance as the products of a similar emotional, intellectual, and social nature. The divergences, both in extent and direction, and in their peculiar issues and distinctive details are obvious 
and become momentous as we approach them in the comparative spirit of the anthropologist, the sociologist, the student of culture and the historian of civilization. Viewed as expressions of dominant psychological traits, traditions and institutions are significant as the embodiments and recnforcements of the collective spirit which is favored by affiliation of endowment, but flourishes by the favor of tradition. As organizations and traditions become comprehensive, such a spirit reaches its most typical expression in a national character, the genius of a people. It finds a powerful and stable medium in the arts-notably in the more permanent communal achievements of architecture; in literature; primitively in myth, saga, poetry, drama; in religious beliefs and rites; in ceremonial observances; in family loyalty; in moral sentiment; in the ministrations and observances of daily life; in legal forms and political establishments; in codes and practices. Such achievements are at once historical manifestations and psychological expressions notably determined by the contributions of privileged individuals. Achievement thus becomes an index of the national spirit-a composite result of the dominant forces playing upon, and becoming articulate through, the basal qualities of man. Its direction, emphasis, perspective, its "soul," reflects the character of the psychological environment surrounding the individual as formative influences of development [8].

The formulation thus reached is that the social-psychological setting acts as an environment for the individual. To the embodiment of such collective psychic trends the individual responds; to them he finds adjustment; in their medium he expresses his personality. This psychological environment includes the "family" or clan setting, the local atmosphere, the larger cultural and national ideas incorporated in institutions; it includes particularly the inculcated principles of conduct and the conventional direction of endeavor. Together these form an 
all-comprehensive system of influences, a chuster of forees which mold the individual and set the patterns of his conduct. For the individual, education is the process of learning to employ the institutional system for self-expression. For the environment, the system is a network of positive and negative invitations and restrictions, imposing itself upon the native qualities of the individual and directing their unfoldment by supplying the media of response and the direction of effort and ambition. The institutional forms of these psychological forces merit further consideration.

Institutions-as intellectual products-are developed from the intellectual resources of a people, yet with a subdued measure of explicitness or deliberation. They proceed under a generic preferential guidance by sentiment mingled with insight, under a selective feeling for what is congenial, and a slow achievement of expression, which is repeated in the individual before adjustment to the institutional genius is real and secure. This relation forms the sympathetic bond between social and individual psychology; this amalgamation makes the individual a member of the social structure. When brought about by adoption-an artificial "naturalization"-it becomes a more explicit, but more superficial process, lacking the virgin quality of a birthright. Such is the Americanization of the foreignera huge experiment in psychological colonization in which the qualities of the America of the future are at stake. The natural history of institutions underlies the formulated historical movements. The historian of humanitarian interests finds above the story of material conquest, migration and intercourse, extension of dominion, expansion of commerce, industry, and technique, the real story of humanity in the assertion of the cultural gains of mankind. The psychologist finds in this story the revelation of the qualities of men matured under the stress of the physical and the institutional environment. Both views interpret 
institutions by reference to intent and the situations of earlier cultures which marked intermediate and progressive stages. An institutional conservatism parallels an organic conselvatism; survivals, conventions, traditions-as eonservative forees-are characteristic of both. Through usage and the dominanee of social sanction once established, such iustitutional forees may assume a distorting or usurping place. The streams of envirommental influenee are massive, imbedded in traditional sentiment, moving by a slow, organie growth; in the individual as in the body social the psychological current flows subconseiously, below the surface as well as on it. Conduct is maintained, traits are devcloped by the impressionism and sentimentalism that appear so prominently in the analysis of individual psychology. This prominence indicates the minor part assigned in the order of nature to explicit appreciation of ends in contrast to the driving foree of impulse; it contributes an uncertain faetor to all human undertakings, even to those guided dominantly by reason.

An illuminating example of the mode of operation of the social forces is supplied by the fixation of conduct through the medium of morality. The institutional aspect of morality is developed in the mores, the customs, usages, forms, etiquettes, observances, codes, which surround the individual response and secure approval and adjustment when 'conduct eonforms to the mores, and lead to disapproval and diffieulty when the mores are infringed upon or neglected. Underlying most sueh customs is a plain measure of consideration-it may be a superstition, a prejudice, a token of loyalty, an observance of respect, or a slight altruistic regard-together with the artificial expression which survives by the conserving sanction of usage. As one custom of many, it finds a place in a system fairly artifieial and full of minor inconsistencies. These may be in the nature of irrelevant survivals more pertinent to past conditions; they may be due to the inevitable eonflicts of standards of 
behavior derived from the different phases of a complex system, which though in general mutually supporting, introduce complications and alternatives. Hence the fine art of social intercourse and the perplexities of moial decisions; hence also the need of recognized and stanclardized ready-made solutions in forms and conventions. Conventions represent the institutional aspect of regulation and may be learned and accepted mechanically, yet are practiced more intelligently when guided by an insight-itself a sympathetic quality - into their meaning and value. The psychological habit chiefly responsible for their maintenance is the tendency to conform, which is in turn an issue of the social-gregarious habit and of its development. The tendency to conform supplies the groundwork of response, as convention supplies the pattern of its expression. Yet equally to be considered is the assertion of the individual motive and impulse tending to other and opposed action; therein consists the conflict of the individual and the collective motive, the personal and the larger social will. The subordination of the former to the latter may proceed upon direct compulsion; but normally it involves an acceptance of the imposed standards through the development of a conscience. Conscience proceeds upon the individual reaction of fear, or shame, or psychical discomfort of some sort; it is a restraining force, setting up irritations and perplexities; it is also at once a guide and an assurance in that the resistance of the personal invitation replaces the uneasy fecling by the satisfaction of conformity, and the sense of duty performed. The individual aspect of the process has been adequately considered: the tendency of impulses to find an objective outlet, the emotional development of the satisfaction, its elevation to a sentiment, the influence of suggestion and contagion, the socializing and the intellectualizing of the product, the resulting atmosphere of congenial adjustment and established habits of response. Institutionally the psychology of conformity develops collective forces 
for its operation in a system of beliefs, customs and traditions.

Fashion-fashion in personal appearance conspicuously -projects the products of conformity concretely. It does so the more saliently when the custom (to our remoteness from its psychological basis) violates the trend of nature or the dictates of reason. Conformity then to our eyes becomes deformity. The attempts to modify or improve upon the bodily contour offer a comprehensive example. The flattening, binding, and "beehive" distortion of the head (Chinook, Peruvian, and others) ; the expansion of the earlobes or of the lower lip (Brazil, Eskimo); the binding of the feet among Chinese women; the filing and staining of the teeth (African, Malay); the cultivation of long, curling finger nails (Siam); the piercing of the nose (Australia); the varieties of tattoo marks, from the elaborate decoration of the entire body (Polynesia) to the single brand that forms the "Tracht" of local allegiance (Kabyle people of North Africa) ; the uniform "dress" of the hair, like the pig-tail of the Chinese men; these represent more permanent and conservative fashions. When fashion is transferred from the body to its investiture, its scope is enlarged. The national and local costumes of old-world peoples offer a varied picture of interesting conformities maintained under a social system allied to that of caste, and rapidly disappearing under the cosmopolitan uniformities which displace the older and local loyalties. The inherent conservation of the tribal eult is more persistent in religious and similar observances, which do not come so readily into competition with other institutional establishments of similar import, and are indeed retained to emphasize the peculiar, the favored, the esoteric quality of the tribal ceremonial. Fashion in a developed eulture-like all phases of such culture-reaches into the sphere of conscious sanction and is played upon by the increasing complexities of the social regulative system [9]. Yet the dominant mo- 
tives determining its sway are of much the same order at all stages of expression. The tribal, the ancestral, or other local motive is a large and conservative factor; the decorative motive is another source of direction; the emphasis of natural distinctions is yet another; superstition, historical or commemorative motives, social considerations, and continuously the satisfaction in conformity, carrying the social sanction of tribal duty (later the social sense), cooperate to shape custom and enforce obedience. Under rigid social systems such conformity is inexorably exacted; its violation or neglect takes on the aspect of desecrationthe act of a traitor to a common interest. Under advanced cultures and the freer intercourse of peoples with cosmopolitan standards, and under the growing realization of the foundations of the social sanction, conformity loses its arbitrary rigidity, and finds a more reasonable place among the varied interests which the consolidated social purposes direct.

It is only in mature and liberal cultures that the freedom of individual expression becomes a prized idealthe most difficult apparently to establish, the slowest to come to its own in the national consciousness. The laborious efforts, the slow advances, the painful sacrifices, the burning hatreds, the fierce prejudices, the cruel persecutions, the ingrained intolerances, the disastrous mental stagnation, which the story of social progress records, form a sadly comprehensive evidence of the iron rule of conformity, and the dead hand of the past. Not alone religious wars and trials for heresy and the persecution of the nonconforming, but the imposition of authority to shackle the spirit of inquiry, the crushing rule of absolutism to impose a foreign tyranny, the minor ostracisms and losses of caste, the exclusion from preferment and the subtle intrusions of prejudice, have all combined to obstruct the course of human progress and continue to delay the age of reason and the sway of sympathy. Such is the cost of conformity. 
Returning to a more neutral aspect of the play of conformity, we readily take the objective view of the cultures and the customs of other peoples, much as we look with idle curiosity and a superior wonder at the mementos of their products displayed in a museum of ethnology. These labeled specimens of (to us) lifeless motives make a mute appeal. It is more convincing to survey the living instances of conformity-in which we form the specimens-though they concern trivial and incidental regulations. Yet some of these are of close kin to the cruder customs above cited. The wasp-like waist, the high-heeled, pointed, tight shoe, the changing styles that vary the contour of the human figureall aim to accentuate features of sex, and are followed primarily not by virtue of an esthetic judgment of approval nor yet in ignorance or disregard of hygiene or comfort, but in a conscious, or it may be a complacent or a blind acceptance of style, and the satisfaction of following it. More negatively and more charitably expressed, fashion exacts its toll because of a lack of initiative or moral courage to refuse it. Changes of fashion seem arbitrary and capricious; in highly civilized communities they follow a complicated system of prestige-such as the label of "Paris," adoption by royalty or leaders of fashion-and an equally complex and organized esthetic movement, not to mention the satisfaction of novelty, the pride of wealth, display, and joy in change for its own sake. Conformity with a tinge of rationality is the rule; conformity legitimized by reason, or convenience, or consideration is quite as common. The prejudice against long-haired men and shorthaired women has a natural basis, yet persists by reason of the tendency to accentuate sex-differences. The differentiation of clothing is one of its results, that of manners and codes of behavior another. The decorative instinct of woman is not merely an expression of the desire for beauty as a sexual and social attraction-because such attraction is part of woman's technique-but takes its particular im- 
press from the inculcated emphasis of this factor in feminine psychology, which sentiment and tradition estallish and favor. The hair and the head-dress-more incidentally and more modernly, also the hat-form a distinetive setting for the beauty of face. By its natural conspicuousness as a trait of womanhood, the hair becomes a pride of sex. For most women, the enforced deprivation of the hair would be felt as a degradation; while yet a deliberate renunciation of the adornment might express a rcbellious assertion of liberation from the bonds of social (or sex) conformity.

The essential point is that back of custom lies the psychological or moral or hygienic or esthetic defense which gives it a slight or a conspicuous place in a defensible system of values. Etiquette proceeds upon sensibilities; and the education of the sensibilities-adequately discussed in an earlier chapter-is more and more directed upon the artificial basis, now recognized as the social-environmental molding force. In pursuit of such enforcement the standard psychological process is to establish a feeling of pride in conformity, a feeling of shame in violation-in general, a conscience-which, guided in its finer issues by sensibility, directs conduct and forms traits of character. Such traits are at once the common expressions of the molding influence of the environment and of the common susceptibility to them inherent in the underlying qualities of human nature.

The institutional aspect of the process is shown in the tyrannical force which convention may assume. In the primitive setting its type is the taboo, which may go so far as to regulate to great inconvenience and disadvantage. The use of articles of dress, or of manufacture, may be tabooed; the use of words, particularly of names, may be tabooed; food taboos are extremely common; the uses of certain paths or roads or localities may be tabooed; contact with certain persons may come under the taboo. That the prohibition may be imposed for a variety of reasons (for 
reasons of sacredness, of pollution, of respect, of fearmanly fear of evil spirits), does not conflict with the common filctor that the enforement exereises the same ordel of psychological pressure. In the end, however brought about, an established range of prohibitions or injunctions determines the restrictions of eonduct. and in its massive argresate constitutes the systerm of social organization. Crood form. propriety, etiquette, consists of "Dont's" as well as of "Do thou thus and so." Thus on the one hand a set of avoidanes-partly intelligible or Aefinable, but only partly so and variable-and, on the other hand, an eyually extensive system of conformities of like status contiune to surround the individual and to impose conventional respouses. Of peruliar moment in the maintenance of these enviroumental products is the fact of survival-the persistence through one stage of eulture, or by mere inertia, of a custom long after its basis in reason or other defense, has changed or lapsed. The general consequence is an unthiuking atherence to established usage, an absorption in routine, and a shrinking from imovation-a fear of change. An intellectual conservatism parallels a conservatism of eustom and becomes a momentous foree. An apt, if extreme, instance, is cited by Tylor: the Dyaks of Borneo were not acenstomed to use the $V$-shaped eut when chopping with an ax and showed their scorn of the white man's innovation by levying a fine upon any native who would use it; yet they were so convinced of its advantage that they employed it secretly or when they could rely upon the confidence of companions. Survivals are ordinarily not so bare or so simple: they exert a resistance to innovation more subtly. The set of habit and the foree of tradition emboly a like influence.

The pressure of the institutional enviromment is more rigidly expressed in simpler. earlier cultures than in those of later level, for the very reason that the more developed mores embody complex social intiuenees and a larger rem- 
lation by rationalized systems [10]. Intermediately a con. siderable group of practices, beliefs, and habits of thought survive from earlier to later cultures, with, however, a loss or change of their original aspects and bearing; they come to persist with a sort of tolerance and indulgence which the conservative tendency offers as a token of respect. In this domain practices somerthat remored from the sway of reason and repeating the simpler interests and occupations of the mind, exhibit the conservative environmental impress, as do the simpler orders of mental products. Games, proverbs, riddles, greetings, seasonal customs, forms of address offer examples; though under the desire for novelty subject to innoration, these folklore products of popular culture have a large ritality in the contentional intercourse, attitudes, relations of daily life. Such customs as raising a hat to a lady, or offering an arm, of proposing toasts and drinking healths, of saring "God bless you" when one sneezes, of regarding certain happenings as of ill omen and others as of good omen, of touching wood to escape disastrous consequences; the semi-beliefs in lucky dars; the flirting with palmistry and similar systems, are all tendencies which in their persistence reflect the type of influence that invites a complacent acceptance and ret approaches the intellectual pattern by which more serious types of adherence are propagated and maintained. A superstitious atmosphere makes the indiridual readily superstitious; the sererity of the intellectual as of the moral spirit of the community or the class determines the logical habits of the indiridual. The beharior of mind in class and mass is as characteristic as that of the mores of ceremony and custom. More serious attitudes, inclinations, conduct. follow a similar bent, but fall more consciously under the dominion of reason, or at least of rational defense. They flourish by virtue of the system of thought in which ther are imbedded, by which they are supported [11].

There is a parallel-indeed a close kinship-between the 
contrasted mental procedures which enter into individual conduct and those which direct the collective regulation which the environment supplies. In the individual, the dominant responses proceed upon primary, instinctive, emotionalized, and vaguely conscious impulses; upon these as a derivative, secondary product are developed more explicit, more conscious, more reasoned, more variable, more individual orders of response. Similarly in society there is the earlier, the "folk-way," the collective, the subconscious, the tribal, the traditional, the nearer-to-nature regulation impressed by the psychic environment and sanctioned by the mores in which it finds expression; and in complement as well as in opposition there is the later, more explicit, more analytic, more critical, formulated, acquired regulation, which comes forward in policies, principles, codes, and systems. Intermediately a vast range of social regulation partakes of both aspects, and in its shifting phases reflects each of the two attitudes traceable in the general evolution. Both orders of influence affect particularly the social mind, the collective environmental background in which the individual is enveloped. When the influence inclines more to a feeling tone-a Stimmung-it is called public sentiment; when inclining to a reasoned statement, public opinion. Public sentiment and opinion are commonly concerned with issues near the surface of interest; while settled conviction and deeply organized faiths dispose of the fundamental regulations in an unquestioned directness of habit. In equally typical relations, customs, manners, conventions, as well as minor sentiments and popular verdicts are at once loyal to the earlier, unreflective acceptance, while yet they move toward the later aspects of deliberate regulation. Custom is not altogether unreason [12], though in its slower adjustment to environmental demands it may appear as irrelevant and as futile as the surviving habits of animals out of relation to their radically altered surroundings and needs. Law itself, as codified 
sentiment and opinion, lags behind the actually accomplished stages of progress. Because eonduct reflects the past and progress awaits the break from it, is adjustment a living force.

The movement which matures social ehanges and shifting environmental stresses is spiral in character. The spring forward and upward proceeds from the impetus of variation congenial to the individual, explieit, analytic temper. The curve of reeoil binds it with the past by the seeurity of an accomplished adjustment, and confers the bond of continuity of proved experience, along with the natural veneration of the merely venerable. Law, like custom and all established conformity, is in this view a compromise in the interests of stability. The pivotal issues of the hour, the day, the generation, absorb the conscious energies. They give rise to articulate controversies and explieit inquiries; they form the turning points of the historical movement through which the environment shows its vitality-its eapacity to receive the impress of personality as well as to impose it. Much as present history is past polities, so more truly because more comprehensively, is present sociology past psychology; each outgoing generation is old-fashioned to the next. The rate of eultural movement is most irregular. The fixity of cultural stages seems the largest feature of early periods; the violent changes and reconstruetions are often conspicuous in reeent ones. Periods of retardation and stagnation, as well as periods of illumination, renaissanee, and expansion, emerge above the more ordinary, routine advances. The revolution of the industrial world by the spread of machinery is no more comprehensive than the revolution of the intelleetual world by the discovery and dissemination of the laws of evolution and the insight into the working forces of which the individual and society are alike experimental specimens. Ideas and the systems which they support beeome as readily antiquated as tools or processes. Both are ont- 
grown and are replaced by others more in keeping with the newer demands. The acceptance of the psychological environment is as essential in fixing the standard of living as are the economic considerations which more directly embody it. Every stage of culture is as unitary as a personality, and reflects in manners and industry, in art and science, in morality and in religion, the dominant spirit of the collective environment, as it has been shaped by the responses of the genius of a people to its physical surroundings and its social-historical heritage [13].

The two opposed massive forces of the environmental movement-seemingly static for the moment and the individual, but dynamic in a wider survey of social progresshave not received accredited names. The one is more inherent, like nature; the other more acquired and imposed, like nurture. The one is conservative and secures adjustment by the fixity of habit; the other is variational and secures a finer adjustment by the readier adaptation to a changing order. The one operates dominantly below the surface, is deep, subconscious, pervasive, like an emotional undertow; the other is the surface agitation, the tentative ripples of an intellectual intrusion. No phase of cultural progress is free from the combined influence; conservatism and liberalism are collective as well as individual traits. The contrast between the leaders and the led, between the statesman-philosopher-reformer-inventor type of individual and the man of the people is largely centered about this dividing point of influence. Each tendency is apt to be overstated; each has its qualities of value as well as of danger. Extreme radicalism and an assertive rebellion against things as they are, and a contempt for usage and the established routine, are as common and as dissociated from the insight or the wisdom of the responsible reformer, as are the complacent acceptance of the status quo, the anventional subservience of the ordinary mind, and th the-manger attitude of the privileged classes. In 
chological aspect the distinctive contrast pertains to the phases of conduet and attitude in whieh the one or the other movement characteristieally dominates. Popular movements must always follow the deeper, conservative, temper; the spirit of advanee must get into the blood as well as be in the air before it is effective. Quite commonly in the course of development, there arises a convietion or a sentiment that the two orders of influence should be held apart: the one esoteric for the initiated few, the priestly elass, the illuminati, and the other for the masses-the people fixed in folk-ways and limited in opportunity and outlook. The belief in the gods and the fates and the traditional mythology for the many, but a superior untrammeled philosophical enlightenment for the eleet, is not an exeeptional incident of Greek culture, but is typical in all stages in which the genius of progress-the élan vital of the race -is alive. And the fate of Socrates-the seemingly voluntary but in reality imposed cup of hemlock, no differently than the enforced retraction of Galileo-is typical of the sacrifice of the variational to the conservative trend, of the individual to the social dominance when invested with power, political or spiritual.

It may well be emphasized that the one tendency is characteristic of the collective mind and conservative in trend, that the other is distinctive of the individual assertiveness and variational in trend. The individual is more an individual when he protests than when he conforms, more when he goes his own way than the way of the crowd. It takes courage to vote "No" when the majority votes "Aye"-it may be, the courage of a martyr's fate. Yet equally is there the pride of individuality, the membership in the minority not of the defeated but of the superior and the elect. It is however when the same set of forees are at work not heroically or tragically or even dramatically, but in the commonplace setting of the everyday issues, that they exert their most eharacteristic influence. Certain 
phases of the conduct of life and the conduct of mind fall as naturally to the collective conservative influences, as others proceed upon the individual, variational impulses. In the individual nature there is a basis for the complacent conformity in the gregarious sociability, and an equal basis for the assertive, even rebellious individualism in the egotistical, will-to-prevail, self-interest. In the sophisticated attitude of a modern educated man, there is a more or less conscious acceptance of the established conventions of a polite society in manner, custom, observance; but equally an insistence, born of a slow maturing privilege of liberty of conscience and spirit of tolerance in all really vital matter's of intellectual decision. However mixed may be the two streams of influence in determining his religious or his political affiliations or other adherences of similar complex antecedents, the twentieth-century man is free to decide what he shall believe in the realm of fact or science by the conviction of such evidence as he is able to understand. In reality he frequently depends upon the expert knowledge of others, and is as often swayed by sentiment and prejudice, by what he likes to believe and by the satisfaction of affiliation with congenial minds, as by the logic of events or the objective contemplation of data. He falls back upon the accredited beliefs of his kind, and in so far reverts to the security of the collective sanction. The practical adjustment of the individual in this realistic relation has come to be the measure of his intelligence-the most comprehensive gauge of temperament and character yet evolved. By his intellectual, esthetic, and moral affiliations is the nature of the individual man revealed.

In the general consideration there may be discerned a rather constant set of influences which set the stamp of the social organization in all societies, and coöperatively determine the major outlines and even the minor variations of the psychological environment. Such is the physical environment, a type of the influence from without; and the 
spirit of conformity, which is an inherent influenee from within. Apart from these, there are certain recurrent manifestations of the social-envirommental forees which, despite the varieties of eultural products, confer a fair uniformity of appearance and function. First in the group is the inevitable stratification of society. When pronounced and developed it gives rise to systems of easte. Whether recognized and formulated, or more democratically subdued and discountenanced, it none the less exists everywhere and determines the range and manner of environmental influenee to which the individual responds. Class-distinctions may follow more rigidly hereditary privilege; they may be affected by wealth as well as station; they may attempt to recognize natural talents and the qualities of an intellectual, artistic, or professional order. They are commonly expressed in economic relations, of which that of master and servant, employer and employee, become typical. As an inevitable consequence social traits are formed, which are quite as characteristic in their psychological manners and attitude as in dress, appearance, habit, or prestige. The different manners in which national ideals express eastedistinctions form one of the most characteristic aspects of the psychology of peoples. We think of the rigid and venerable castes of India, or again of the binding distinctions of the feudal system; we are apt to regard democracy as itself a statement of opposition to such social contrasts, and find in the doctrines of socialism a theoretical denunciation of their right to exist. But societies both inherit and fashion class-distinctions, however subdued in expression, or modified by consideration, because human nature invites them. Different forms of behavior, of speech, of mamner, all complicated by results of education, arise and continue by the operation of the same type of psychological forees as are responsible for other institutional expressions in earlier cultures and in later ones.

Over and above the stratification of society which in a 
measure holds men apart or at least in their several places, while yet it gives them a conventional uniformity, there is the supporting spirit of the age, the prevalent collective genius, the Z $Z$ eitgeist. As an initiative it is apt to proceed from or reflect the tone of the leading classes in the social system; it spreads by its congenial appeal to the entire community, and is itself responsible for the class differentiation through which it operates. For a following implies leadership; and in each phase of activity standard forms of behavior become established. The patterns of endeavor, however stereotyped, are inevitably diversified by the variety of interests and the differentiation which the social environment reflects and creates. The Zeitgeist comes forward in the tone of enterprise and attitude, in what men do and think and desire; and however humble their part, something beyond the mere stress of livelihood or routine of employment, permeates to the mental habits of men and makes them men of their day and generation as well as of their class and local conditioning. Men are commercial in a commercial age and nation, and religious in a religious atmosphere. It is when such a spirit finds salient and articulate expression and receives an historical baptism that it becomes recognized as a molding force. In the American environment such an historical attitude is Puritanism. There is no difficulty in recognizing to how large an expression of the imposing environmental attitude there clings the Puritanic flavor. It is a social-environmental force; it is an inheritance from the past, surviving not merely by the inertia of establishment but by the force of vital belief which supports the central attitude which it expresses; it colors the slighter reactions and spreads its influence widely if no longer deeply. In completer control, it imparts a stern severity of conduct, a serious acceptance or moral responsibility, an outlook that discourages indulgence and keenly resents the encroachment of frivolity as akin to $\sin$; that in its overstatement it becomes a dis- 
courager of the arts as well as of the lighter recreations of mind and body is an inevitable by-product. It alfects the temper of a community even when it is obsolescent; it is safe to say that the popular conceptions of propricty in the typical American community bear the marks of such ancestry. It asserts its sway not alone in regard to observances close to its own religious expression, but equally in regard to all expressions of custom and manner which must inevitably be regulated by a larger Kulturanschaunng-a fundamental view of life.

A more "institutional" illustration is supplied by feudalism, which is also a social, collective, conservative attitude, still effective in human relations. Subservieney and deference on the one side, arbitrary and complete expression of power on the other, may become as real in the industrial relations as in the historical ones which the term reeords. In all such regulative systems the inherent principle which they express coöperates with tradition to determine present attitudes and pursuits. Different principles and emphases find distinctive expressions within the social strueture. The military spirit is one such expression and represents the primal resort to force and the organization of enforcement as the criterion of the right to prevail. Militarism is equally an attitude and an organization, an ideal and a fact. The adjustment of the relations of Chureh and State is an expression of the part assigned to each of thesc institutions in the social-spiritual environment. Confliets of ideals are as real and may be as disastrous as confliets of material interests; and the problem of the amalgamation of peoples in a total national strueture is alway's as much in the nature of a psychological achievement as of a politieal one. The inherent dissensions of race and tradition mean that people believe differently, entertain different sentiments, feel different loyalties, are accustomed to different ways, speech, standards of living. All this makes the inposition of a foreign rule and an alien genius an aggressive 
even though a missionary advance. In course of time political absorption effects a psychological amalgamation; but the older local loyalties, inherent qualities, and traditional fealty, may persist and create problems. The German-American, the Italian-American, the Slavic-American, express a dual allegiance which is psychological rather than political, and recedes rapidly in a few generations. Such divided fealty persists more strongly when the original ties are not broken. The problem of the Irish in Great Britain is complex by reason of just such psychological antagonisms; while such historic reconstructions as the unification of Italy and the anulgamation of Austria and Hungary present allied problems of reconciliation of varying traditions. Colonization is a like process; the affiliations of the racial esprit and national temper-representing the older type of collective conservative forces-remain as effective as political treaties, ententes and alliances.

The third factor in the psychological environment is the local genius-that aspect of the environmental influence which achieves an immediate loyalty to the smaller group and the direct tradition. It gives local distinctiveness to communities and represents the social esprit de corps, not detached from the larger influences to which the community responds, but imparting to it a distinctive coloring. As conduct is composed of small decisions, so equally are contacts inevitably local, with the constant, recurrent, detailed surroundings. The influence of the home is due to emphatic assertion and reassertion of the local genius. These experiences of intimate contact with the immediate environment were in older days far more comprehensively formative. The detachment of peoples gave to communities a greater distinctiveness; travel, the dissemination of knowledge, cosmopolitan ambitions, have rapidly equalized conditions and given to these older considerations a slighter value [14]. The local genius is not merely of the people and of one's own people; it equally reflects the special class- 
interest, which is a phase of the local one. It is thus characteristic of the minute, detailed, presentative, intimate bearing which such psychological forees assume before they become directly effective, are bred in the bone, woven in the spirit of the race. It remains consistently true in all relations that the individual reacts to the immediate, local, presentative, recurrent experience. Conversely is it true that the course by whieh principles and ideas and the formulation of doctrines are imposed-however ardent and vital the reforming increment-is more indirect, and becomes even more remote as principles become detached from practice, and by such psychologieal distance are lessened in effect. Hence the need of definite ritual and concrete observance in religion, as well as positive precepts in codes of morality, rules of behavior and sanctioned customs, to give the tangible, visible feeling of conformity, and thereby carry the lesson of the indwelling spirit as far as it may. Hence also the danger of lip-service, from the burnt offering to the subscription list, the prayer machines and the telling of beads and recital of creeds and mummery of sentiment with feeble support in practice. Yet however feeble the comprehension, conformity breeds loyalty. Compositely such practiced and sanctioned observances permeate to every phase of the local environment, and become a psychic climatic influence, an atmospheric pressure, sensitive to the coarser and the slighter fluctuations of the collective spirit. It is with this conservative trend that the variational moods of reformation have constantly to contend.

The fourth consideration, everywhere operative in the social environment, relates to the dominant regulative systems. These become more explicit and elaborate in developed cultures, but may be traced backward to the very beginnings of organized society. Their carliest expressions follow the clew of social stratifications. It is through them that the tribe is organized, that family relations are estab- 
lished, and the proprieties of conduct between classes are fixed. Customs are older than laws, but naturally lead to them. Thus codes arise, principles are stated, traditions become articulate. Of the several systems effective in the intellectual realm, that of religion may in turn be said to dominate in the historical perspective; for its "social" purpose is to afford an all-embracing, spiritual as well as practical guide to life. It provides sanctioned decisions, confers uniformity, unites divergent interests. Its relation to the ethical system is originally intimate, and in that relation typical [14]. Law, justice, and the political regulations form other interpenetrating comprehensive systems, controlling both the social and the personal relations, and develop vested and sanctioned rights conferred by the total social structure. Each system, though asserting a limited sovereignty, becomes in a measure a rival of the others. In due course the scientific system, which justifies itself by proof and practical efficiency, acquires a large place. Men defend conduct by reason, and in such reason make appeal to the orderly interpretation of nature as well as of human experience. Men discover not only what works but why it works. The establishment of such a system of regulation represents the most stupendous achievement of the human mind. Its path is a laborious one; it begins with a supernaturalism, proceeds through ages of superstition and the pursuit of false leads; it is expressed in systems of beliefs inevitably formulated under the auspices of religious tenets and political establishments. The authority of the high priest, the divine right of kings, the supremacy of the orthodox faith, the power of excommunication or ostracism, are all examples of the survival of religious and political power into the domain of intellectual truth. Truth like right has to make terms with might. Knowledge comes to its own slowly, and may excite a suspicion or distrust suggestive of the attitude of the medieval populace toward the practitioner of the black arts. As the central principle 
underlying the growth of control over nature as over society, rationality makes its slow and devious progress. Its partial establishment under a composite allegiance has of ten been the chief obstacle to the further extension of its dominion.

The joint issue of these several forces upon the constitution of the social-psychological environment may be summarized under the comprehensive rubries of standards and ideals. For as a fact both in the larger outlook and in the nearer prospect, the actual regulation of individual conduct by the collective sanction takes the eoncrete form of standards of behavior; when the rules as well as the practices of life are animated and justified in some measure by the more deliberate understanding and approval of supporting principles, there arise ideals of desirable ends and justifiable means. Practically, as the direct impress of the environment, standards prevail; ultimately ideals rulc. Each affects the other, and the two must find a congenial relation. Ideals are supplied by the imagination and the individualized expression of the few; they are conveyed and embodied in standards of attitude and conduct for the many; through these the solidarity of a national consciousness and the special loyalties of class are expressed.

In retrospect the consideration of the psychological environment furnishes the clew to the survival value of the qualities of men as expressed in the prevalent systems of culture. It presents them as modified adaptations of original or ancient impulses to modern requirements. Thus considered the survival of qualities is an issue of nature. Yet values are developed and retained by securing a place for such natural qualities, or by extending their function in the actual arena of social competition. Concretely the direction of quality to expression and the place of any one quality in the total social structure are embodied in standards accepted and maintained, and selected and favored as well. As each individual responds to the environ- 
mental system he develops a personal equation, an individual rendering of the general perspective of values. Supporting the individual and the collective determination of modes, directions and standards of response, there enters the guiding principles under which systems are developed, the ideals under which qualities reach their fullest expression. There emerges a Lebens-philosophie that carries the individual through the more conscious and deliberate situations of life, and constitutes the final phase of the amalgamation of character and temperament, and the equally mature and conclusive expression of the individual, the local, the national, and the generic cultural appraisal of the qualities of men. 


\section{CHAPTER IX \\ THE QUALITIES OF MEN}

THE analysis of the sources of human qualities finds its consummation in the appraisal of their value as determiner's of conduct in the service of purpose. Endowment and environment interact; human qualities mature and receive their finer direction in adaptation to condition; condition becomes the increasing complication and specialization of the artificial environment created by the industrial, social, educational, and institutional provisions of organized communities. The environment becomes a consolidation of influences even more than a set of conditions. Artificial selection is imposed upon natural selection, and both act upon original and derivative qualities to their readjustment. Encouragement and discouragement act as rewards and punishments of limited range but decisive bearing. The selection of qualities proceeds through the favor of adaptation in one direction or another, in major or minor measure, centrally or incidentally. Qualities become rivals as well as mutual supports; their emphasis by and in the environment introduces a changing perspective of value. With increasing complication, advantage is no longer simple; it is of many kinds and degrees, with compensations and offsets-themselves in the nature of nieer adjustments to more specialized conditions. A quality conferring relative advantage in one environment may prove of relative disudvan. tage in another; one of major significance may retire to a minor service; virtues and vices, despite the constancy of their standard relations, may change places under altered circumstances. 
Parallel with the complication of situation is the complication of qualities, characteristically through the transfer of a trait particularly adapted to a primary situation, to other applications and related outlets of expression. There is also the rivalry of traits, making the issue: which trait shall prevail for a given type of situation. Cumulatively the complication attaches to the environmental reconstruction; for through it primary traits are redirected, are supplied with new outlets, and transformed. Briefly they are overlaid by the products of civilized life. The net issue is the establishment of standards and ideals; in terms of adjustment to these, the redirected traits are appraised. This collective institutional encouragement and discouragement operates as a system of values. It confers vantage and disadvantage as did originally the more direct rewards and punishments of nature; in further analogy, it brings into play ever slighter variations and apter adjustments of selected traits to specialized environments.

A principle of large moment issues from this evolutionary process. It sets forth that the central effect of civilization is to make small differences count; in another formulation it indicates that we live upon the most highly differentiated phases, upon the upper ranges of our qualities; such is the law of specialization. The biological emphasis, whether of sex or race or other differentiation, is itself a specialization, a superiority or particular fitness of adaptation to function or condition. In the field of ordinary endowment it is a matter of degree and manner; it summarizes the fact that what many groups of men, races, nations, communities, can do, some can do better than others and all do differently: some predominantly by the support of one set of qualities, others predominantly through other qualities, in part related, in part contrasted. What is done and how it is done reflect the support of achievement in the range of endowment. The economic specialization of service is dependent upon the biological one of quality; unskilled labor 
proceeds upon the common aptitudes of men; skilled labor upon their divergences. The divergenee expresses the fact of emphasis: the fitness of the one is but a higher legree of aptitude common to the many. What one man does well he does for others, receiving in turn the benefit of others' special gifts or applications. Yet individuals and communities compete by a composite of qualities; such dependence upon groupings of traits and the inherent correlation between them fixes the limit of specialization; versatility retains its value. In simpler conditions eaeh individual exercises a larger range of common functions; and eommunities like individuals are more self-sufficient. The complieation of the social institutions develops the specialized craftsman; society provides useful outlets for the specialized endowments by ereating careers for their possessors. Such endowments have a natural basis, a place in the eomposite equipment of the human individual for the normal demands of an adequate life. Endowment is not developed for career, but career is shaped to endowment. The place of what comes to be a directive quality may be central in survival value, or it may be more or less derivative-a byproduct of a trend of the whole. Men are energetic, acquisitive, masterful, as well as combative and lustful for power and control, because that set of qualities has a direct survival value in many a situation. The application of the quality expands and differentiates widely for different orders of environment. Similarly, the fact that there are artists among men is an issue of the inherent esthetic trait in all men. The artist, and no differently the soldier and the captain of industry or the political "boss," thrives upon his specialized qualities.

The principle of specialization sets forth not alone that the soldier or the organizer of industrial competition or the artist has one set of qualities highly developed, and that in one race or nation military ability, organizing ability, or artistic ability may be marked above others, but that slight 
differences in the degree and manner of such specialized quality become more and more momentous; to such slight differences the social differentiation attaches increased value. As a consequence in the exercise as in the appraisal of the artistic gifts, finer distinctions, delicate superiorities count decidedly as standards become more critical. By virtue of the law of distribution the number who can meet an exacting standard rapidly diminishes as the standard is made more rigid; the highly superior are few in any calling; hence the saying that there is always room at the top. It seems fair to assume that the greatest of present-day American painters-to choose a specialized order of ability adequate to a career-has but a slight superiority above his nearest competitors; yet such added quality at the top may almost place him in a class by himself. Lower the qualifications for admission to a national academy of art, and you admit scores and hundreds of decided ability; lower the standards once again and by only a slight step, and thousands may rightfully enter. A slight increase in quality implies rapid elimination of large numbers of competitors; in the surviving group finer and finer distinctions must be made, more careful and balanced judgments be exercised before the prize is awarded; and the best of those who lose may lose by a hair's breadth. Selection proceeds within a selected group; in the upper ranges social selection becomes decisive, and the establishment and maintenance of standards becomes an expert service. Competeney becomes a matter of very fine differences, in which the compensation of one variety of quality must be measured against another [1].

Expressed in biological terms, the shifting of values in the process of adjustment indieates that with the necessities once satisfied, the struggle for preferment is transferred to the spccialized superiorities, all of them derivative products of qualities that owe their existence to phases of service in the original types of situations, for the standard func- 
tions of the human organism. The esthetic satisfaction itself illustrates the prineiple. Under severe conditions esthetic considerations are feebly developed; they cannot assert themselves above urgent and immediate necossitirs. Though a by-product of luxury, the esthetic quality blossoms under the slightest favoring condition, thus proving the inherent tendeney for the perspeetive of endowment to expand and transfer its base. Art is an aneient expression, the art-impulse an early, inherent trait of man. The shifting center of adjustment in human evolution is a movement of several components. Urgency sets the earlier scale of value; and later tendencies, however altered the orbit defining the sphere of their action, cannot too radically depart from the patterns determined by use. But man does not live by bread alone. With the major needs satisfied, the adjustment is transferred to the mode and manner of the minor satisfactions; and art has its chance. 'The primitive expression of an original quality exerts its sway; concomitantly, a cluster of derivative qualities develops and becomes the foeus of the shifted adjustment, the transferred order of satisfaction. An original limited trend gives rise to an ever extending series of derivative trends. The complications of the environment invite a transfer of value to the derived and transformed expansions of the original traits. Under such transformation the expressions of the distinctive qualities of men absorb conscious consideration; in such terms the resemblances and differences of nien are felt and acted upon.

The issue that the finer qualities eount beeause signifieance is attached to them, is as saliently illustrated in the operations of the differences as of the resemblances of men. The statement that birds of a feather flock together expresses the natural influenee of common standards ancl temperamental congeniality. Slight differences of habit or appearance are enough to estrange; the psyehology of prejudice here finds its source. The advocates of the brother- 
hood of mankind rightly contend that in the larger aspects all men are essentially alike; but for actual human relations, these similarities are not adequate, because the congeniality of intercourse depends upon the slighter differentiations, the upper ranges of quality. Such divergences, though artificial, develop upon a natural basis. Through this psychologically altered perspective of significance, broad and even fundamental similarities are obscured and minute and superficial differences emphasized. Not alone in the contacts of sharply contrasted races, but even in the intercourse between foreign peoples of like cultural standards, misunderstandings arise and approaches are difficult. Cultural differences, which in nature's scheme of values are skin-deep, engage attention and direct response by the constant assertiveness of their surface appearance. In an American's intercourse with a Japanese, he is steadily aware of persistent psychological differences, despite the considerable adoption by the latter of the Occidental manners. Even in his relations with a sympathetic German or Frenchman, or a still more closely affiliated Englishman, the difference of manner, speech, training, mode of thought, perspective of importance to be attached to one set of considerations or another-the "foreignness" - occupies a much larger place than it intrinsically merits. Yet these slighter differences have acquired a status as means of adjustment to the specialized environments which American, German, French and English life have established; they enter into the national standards and ideals which these divergent forms of culture maintain. Social stratification produces the same result. One does not readily feel at home among groups of other social training; embarrassments and restraints, suspicions and antagonisms arise. A member of the "intellectual" classes if set in his mental habits, may find almost nothing to say to a man of the people; neighbors at a dinner-table may bore one another, while a discerning redistribution of the guests may provide 
for each a stimulating congeniality of interest. Social tact consists largely in the management and minimizing of the estranging restraints of slighter psychological diverencens, in easing the rapprochements of divergent mental attitudes. The distinctiveness, the intimate appeal of one's own culture and the alien nature of another's, leads to a derogatory view of the other and an implied superiority of one's own. To the Greek other peoples were "barbarians"; to the Jew's those of other faiths were Gentiles; to the Christian, heathens; the delicate "nous autres" renders the distinction more considerately. In latter days tolerance has become the essence of cosmopolitanism, though nations require to be interpreted to other faiths and other standards.

It is not merely nor mainly in the regulation of the intercourses of men that the principle is significant; it has a broader application in the contrast of achievement and endowment. Achievement absorbs and expresses endowment, but it does so in terms of the specialized endoument which in turn proceeds upon the upper ranges, the derivative divergences of qualities. Contrasts of achievement become far more distinctive than the contrasts of endowment which underlie them. Thus compared, the negro in the United States has proved his fair eapacity to use the machinery of adjustment devised by the white man; yet in the established social order the general comparability of capacity in the two races is inevitably overshadowed by the wide divergences which even a modest difference of endowment is certain to develop. To such slighter differences and superiorities civilization accords decisive rewards; it makes their issues in modes and standards of living, in the pursuit of ideals and participation in social regulation, more and more divergent. A complex civilization widens the contrast in that it proceeds upon the slighter, npperrange qualities, and in terms of their marked presence or absence determines the leaders and the led, the controlling and the controlled, the distinguished and the ordinary. 
Similarly between the social classes, it establishes an increasing distinctiveness through the rewards which it bestows, the honors which it distributes in the way of esteem and reputation, and the consequent assumption of divergent standards of living. The professional classes, the moneyed classes, the organizers and the organized, the employer and the employce, the influential and inconsequent become saliently differentiated through the increased importance attaching to specialized gifts and slighter superiorities, in the derivative aspects of human quality and in the several arenas in which they compete. That station, circumstance and opportunity introduce equally real and yet more disturbing difficulties in the appraisal of quality will not be overlooked.

In the practical domain the principle indicates that the more specialized callings imply and impose a nicer fitness of quality to vocation; in such callings a modest failure of endowment, lack of capacity, judgment, sensibility, or of any similar departure from a high-grade standard involves far more disastrous consequences than in less specialized, less exacting vocations. The readjustment of general types of quality to the nicer requirements of a complex social order is precisely the demand which the moderately inferior endowment fails to meet; such limitation dooms the one group to a dependent position or to one of lesser consequence, marks the more primitive races for extinction or absorption in the presence of a dominant race. Yet circumstance is certain to prove momentous, largely by its alternative of supporting or frustrating the issues of endowment. Still more effective is the impress and favoring influence of the social structure in its selective emphasis of one or another of the finer derivative traits; it turns the balance in favor of one or another set of qualities. Qualities are thus made conspicnous and momentous by the social reconstruction; in which formulated ideals assume an increasing control. That in such adjustment society possesses an instru- 
ment and a responsibility for the fostering of the purilities of men, is the theme of later considerations.

The reeiproeal influenee of endowment and the social liavoring environment holds the elew to the interaction of quality and eneouragement in the large range of alctual eonditions. It illustrates that to him who hath shall be given; less nobly it counsels that nothing suceceds like sueeess. Psychologieally it reminds us that we like to do what we can do well, and do it well because we like to do it; we respond to incentives, and the strength and trend of the incentives no less than of the responses illuminate human nature and the institutional forces which the social nature of man develops for the eonsummation and transformation of his endowment. In the eonerete issue the dual aspect readily comes forward. Is the American trait of energy an outeome of the American mode of life, or is it a factor responsible for it? It may be argued that the new world attraeted the energetic and the venturesome from the populations of the older European communities; through this ageney energy was seleeted as a prime quality of adaptation for the new life, and was transmitted to the deseendants whose qualities beeame the standard ones that shaped the social environment and the spirit of American life. In terms of the environment it may be argued that the foundation of new settlements, the clearing of the forests, the exploitation of resources, the expansion of opportunity demanded and encouraged qualities of energy and initiative and gave them a determining importance. The life of the frontier reflects both aspeets: its prospects express the environmental influence; its spirit the favored quality of adaptation. Once established, Ameriean energy, push, and hustling grow and become characteristic as a composite attitude of mind, ineulcated by preeept and example; the prineiple is incorporated in the unwritten constitution of the psychologieal platform of typieal and cherished Americanism. It is eertain to develop extreme and tangential 
expressions; for the form and the appearance, as the carriers of the imitable patterns of conduct and the conscious focus of expression, engage attention and direct the response. Hence a love of movement and hurry, a tendency to violent, persistent, partly inconsiderate outputs of energy; hence also an encouragement of all that is congenial to the resulting patterns of behavior and the discouragement of habits seemingly opposed. Ultimately and consciously strenuosity becomes an ideal, hustling becomes an accepted social injunction; and a man of sober pace is looked upon as a weaker member of society, a straggler or a shirk; while one who too critically questions the pertinence of "rapidity" and aims to transfer attention to such other values as a sense of direction and the appraisal of the goal arouses the suspicion attaching to disioyalty to an established doctrine.

Another instance of American enterprise appears in the vogue of advertising, which has likewise developed a psychology. On the one side there is the appeal, and on the other the quality of response appealed to. If the one is adapted to the other, persuasion is successful and conduct is affected in the desired direction; in this technique, as in all of like pattern, opposing tendencies must be avoided, and the rivalry of qualities directed to the end sought. Yet the qualities appealed to in publicity and persuasion are in but slight measure of an original order, and in very large measurc the result of a special set of customs, fashions, prejudices, predilections. They have a slight foundation in natural psychology, and an elaborate superstructure in acquired psychological architecture. It is to the transformed set of qualities that the appeal is made. Hence for the psychology of the process-the current style of the architecture, as it were-it is the specialized psychology of the persons appealed to, even more than the general psychology of the appeal, that determines the reaction. Advertising proceeds upon the specialized divergences, the surface issues, of elas- 
tic human qualities. A slight shift in the balanee of these complex and derivative traits is sufficient to exert a larre effect upon the result. The very attitude toward the arceptance of advice or the amenability to persuasion may notably alter the issue. Fashion might step in and make it "bad form" to use advertised articles, at least in eritical or pretentious households. Self-assertion might step in and resent the too familiar or presuming advertisement to which American complacency now surrenders. Public sentiment might decide that the disfigurement of modern streets by glaring and insistent display and the destruction of natural and architectural lines of beauty, are social crimes to be avenged by the boycotting of the transgressors. Publicity would then not attract custom but drive it away. Social sentiment is setting up an influence of such tendency by requiring that the personal welfare of employees shall be regarded as well as the cost and merit of the product. More generally the habit of reading advertisements and the tendency to act upon their appeals is itself a social product; it, as well as the conditions of commercial life, enters into the social standards and directly affects the success of the advertising medium [2]. The fluctuation in the relations of stimulus and response results from the fact that the derivative, specialized forms of human qualities are the efficient ones. These indeed owe their presence and their strength to their place in a general perspective of human nature; but this underlying core of common traits is so heavily overlaid and transformed by the manifold transformations of one type of civilization and another that no general appeal will answer for all. Though seemingly effective by the psychology embodied in the appeal, the advertisement actually proceeds upon the similarities of the acquired natures of those appealed to. What attracts in one environment may repel in another, what succeeds in one community may fall flat in another, because of the different set of the responsiveness of the clientèle. 
That in the development of this mutual adjustment of quality and career, of endowment and environment, each reflects the other is indeed the standard issue. Tendencies, attitudes, encouragements grow by what they feed upon; with the fashion set in one direction, it is increasingly difficult to turn it in another. That such changes occur is abundantly demonstrated in every field of human enterprise; that such changes are possible remains the only hope of progress, the only outlook for reform. There is a large difference in the views of men upon how far such changes are determined by the hard realism of the conditions that confront societies; how far by the deliberate, thoughtful and tactful efforts of social and intellectual leaders; how far the entertained and effective ideals arise directly from practice and the experience of established situations; how far they are imposed upon means and measures and determine the further directions of endeavor; how far past experience projects the next stage; how far a constructive imagination anticipates and then realizes the anticipation. Recognizing both influences, we may assert that situations promote the emphasis of certain ranges of qualities, and that likewise the qualities thus emphasized when put into operation develop the situation toward the further expansion of such favored qualities. This gathering force of the set of qualities forming the character of social communities, is of momentous consequence when it affects the deeper appreciations and the serious occupations and directive attitudes of men.

No relation embodies the operation of these forces more significantly than the status of women as shaped by the social control of men. Though ever subject to a similar range of influences, the spirit of social institutions has accorded women the widest divergence of status. A chattel and a slave, an idol and a parasite, a companion and a helpmate, feared and contemned, looked down upon as the weaker vessel and revered as the holier one, woman re- 
flects the views and the eulture of the raees and nations whose heritage she transmits. Yet as an economic fantor woman has influeneed the eommunal life, las played a not: ble part in the religions, as in the eompetitions, ambitions and ideals of soeieties. She has responded to the demands of the harem and the suttee, to the appeal of romance and gallantry, to competitions by display and intrigue as well as by eharm and graeious favor; she has made economic life possible and social life rieh and worthy by her indispensable ministrations. It is argued that the position of woman develops direetly from the inherent nature of the feminine qualities, and that these take their set jointly from the absorbing maternal funetions and from the intense interest of the incidents of courtship. Yet under these common natural conditions the status of women is as shifting as the ideals of communities. From the harem to modern eoedueation and the emaneipation of women in so large measure soeially, eeonomically and politieally, seems an impossible issue of favoring ideals, and yet is substantially nothing else. The qualities of women, though true to their natural status, vary suffieiently in the perspective of accepted encouragement and discouragement to produee these striking contrasts and lesser divergenees. The environment determines which qualities shall come forward and which shall be retired, and how the totality of the possibilities of womanhood shall be developed and esteemed. Subjeet in so many and such vital relations to the play of maseuline eontrol, maseuline desires, or maseuline ideals, the qualities of women have had an additional influence to meet, not quite of the same order as that which has shaped the qualities of men, though the latter are deeidedly affeeted by the actual relations to women and the appreeiations expressed in feminine ideals. What seems most distinetly demonstrated in repent times is that the removal of prejudiee or the ehange of fashion in regard to the womanly ideal has brought forward very different aspeets of the womanly eharacter. The eter- 
nal feminine reflecting the fundamental traits is offset by the plastic responsiveness to a shifting ideal. When the socially accepted pattern of femininity was a type, delicate, susceptible, clinging, women in sheltered positions, in which these upper-range desiderata had free play, were inclined to tears and swoons, were compromised in every frank expression of emotion, and shocked by every contact with the realities of life. When the ideal turned to a sensible, athletic, selfconfident, educated type, women presented these cherished qualities quite as admirably. That the change in ideal brought into prominence different types of women who by endowment were favored in the one direction or the other, is equally true [3]. That the response may have been too sudden and too radical, disturbing the established adjustments, and imperiling the stabler qualities of womanhood is altogether likely; emancipation when overdone leads to a rebellious attitude toward every association and embodiment of the older, abandoned régime. Literary crities may complain of the feminization of literature; the guardians of the educational interests may deplore the loss of virility in the educational programmes; politicians may express alarm at the invasion by women of a domain which they have come to regard as a masculine arena; yet in so far as these protestants appeal to the authority of original nature, they must recognize that such fields of expression represent reconstructions of human aptitudes, that they may be carried on as properly and as efficiently, though differently, upon one set of qualities as upon another.

The real issue in such considerations is twofold: the assertiveness of the inherent (masculine or feminine) perspective in the resulting vocations, and the appraisal of their value in the social system which one or another ideal favors [4]. In the first respect it is significant that with the fairly equal educational opportunities of women and men, engineers are still with few exceptions men, and the law remains a predominantly masculine pursuit. In the 
choice of paths of learning, the same order of selection groes on substantially without external pressure; the election of studies in a coeducational college reflects the divergence of feminine and masculine interests and eapacities. In academic work of this or that type, it remains true that the one or the other group does somewhat better what both do about equally well; but also that the proficiency of the one group is in one direction, and that of the other in another; that the proficiency is based on a contrasted perspective of qualities; that men and women react to studies as to other invitations differently in manner. This is a subtle and complex differenee, and moves toward the upperrange level; as exercised it may have a modest or an important bearing upon what each is able to do with his or her education, which in terms of the currieulum and of standings has about the same face-value. Judged by the rough-and-ready appraisals of the educational standards, women hold their own with men; this is entirely an expected result, primarily because the proficiencies thus tested are in large measure of an artificial status. They represent the by-products of a trend of mind upon which the complex requirements of civilization place a preminm; in such derived products original differences are overlaid and subdued and remain decisive only in so far as their refined issues direct the transformed pursuits. But the qualities concerned are so many, and so specialized, and so interacting that comparisons are diffieult; memory and abstract reasoning, a presentative grasp and an imaginative construction, an esthetic appreciation and an analytical shrewdness, may all be called upon in this or that study and in varying measure. In addition patience and conscientionsness, a willingness to submit to routine, or a chafing under discipline, may have much to do with scholarly suceess or failure. Women suceeed, as they fail, throngh one set of qualities and men through another, partly overlapping, in a fundamental aspect largely so, yet significant in their 
slighter divergences. Only in so far as academic tests reflect older varieties of inherent traits, has the argument a modest weight. For a decisive verdict nothing less than the tests of life and career are adequate. Within the upperlevel range, the divergences of manner and the preferences and proficiencies within a common aptitude acquire significance. Such minor differentiations of interests and tastes form a consistent evidence, though a modest one, of the characteristics of the masculine and of the feminine mind.

With so much admitted, the practical issue that engages the controversial interests of protagonists turns the inquiry to such questions as these: Is not the service of literature such that certain phases of it may be more adequately accomplished by the masculine and others by the feminine endowment? Are not the educational interests broad enough to require the diversified talents of both types of specialized mind? Is it the fixed ideal that polities shall be carried on as a game and a contest, or is it to assume the status of a municipal and a state-wide organized housekeeping? Are there not tasks and situations, concerns of eommon interest to the individual and to the community, which require qualities that owe their strength to the feminine as well as to the masculine roots of human nature? Is it to be maintained that the qualities indispensable to the practical wisdom of political measures are so vitally connected with the forceful quality of the masculine nature or with any other dominantly masculine trait, that only to those possessed of such qualities may the control be safely intrusted, that any weakening of the fitter dominance will react to the disruption of the whole? It is legitimate that such questions shall be raised in the course of the practical dispensations of living issues. It is important that the answer be reached not alone by the judgment of experience, but by a conscious consideration of the purposes to be accomplished by the social machinery-by a far-reaching view not alone of what the institutional life does under its pres- 
ent organization, but of what it may be directed to accom. plish under the encouragement of wise leaders of men. Since the fact of sex is ultimate and comprehensive, the largest social wisdom can be reached only by aljusting upportunities and appreciations intelligently to the endowments of both sexes and to each distinctively.

The play of ideals in determining the perspective of operation of human qualities appears distinctively in the importance and the esteem attaching to the several socially established and esteemed occupations. Of these none is more characteristic historically and aetually than the military spirit and ideal, the military institution. The urgency of self-defense, the safeguard against the aggressive movements of others, as well as the eager ambitions of men, establish the military régime and develop the military classes. Moreover, the inherent combativeness, the devotions of collective enthusiasms, the foundations of fervid loyalties, the thrill of conquest, the pitting of strength and strategy, the eulmination of the racial and national hopes, the appeal of large exploits, have all been sustained through the institution of war. The tremendous selection which centuries of warfare have exercised among men is a biological force of the first magnitude, even though it is offset by the elimination of the fittest, which leaves the survival of the race to those eseaping its ravages. That older methods of warfare under personal encounter may have largely tended in the one direction, while in modern day's, the impersonal mass movements of men and the earlier enlistment and graver risks of the valorous, have tended in quite the opposite direction, is a serious consideration. Questions of fact are supreme in such issues; the possible utility and the particular utility of war is one issue; its inevitableness another. It is in the appraisal of the service for mankind of the military institution and the military attitude as at present organized, that the psychology of human qualities is entitled to a hearing. The military tem- 
per and the emphasis of military qualities may readily dominate the collective ideal of peoples and communities to the exclusion or retirement of other vital intcrests. To point out that such an emphasis furnishes a worthy place for far-reaching energies, sacrifices, endurance, persistence, enthusiasm, loyalty, upon an adequate and heroic scale, is to indicate the value of the institution for the fostering of desirable qualities. To point out that the thrill of warfare makes for the triumph of might and for domination in disregard of the equally cherished qualities of justice, mercy, and self-control; that it encourages cruelty, lust, violence, pillage and overthrows the restraints upon which rest the social sanctity of human institutions, is to indicate the risks and costs of warfare. Nor will an appeal to motive materially alter the judgment of value, however much wars for holy causes and in rebellion against oppression be balanced against wars for greed, glory, power, and conquest. The extension of dominion, the tyrannical imposition of the will to prevail, the triumph of ruthless control of others, appeal strongly as motives to qualities of nature, and support the spirit of warfare; men rally round the flag for mixed and wholly irreconcilable motives. Above this contrast of the qualities appealed to, above the economic and spiritual costs of the military institution, the argument reasserts that war is indispensable to the fullest expression of the potencies of men. There remains the romance of war, the hero-worship, the virility of the military ideal, the facing of the stern realities of life, the bigness of opportunity, the discipline, the consolidation of loyalties. Nothing else can project these qualities upon a scale parallel to that embodied in the achievements of war. Some place for such heroic if only occasional uplifts of enthusiasm, such compelling outbursts of the mass energies of men, should be provided for in modern life; they cannot be omitted from the totality of human quality without serious loss.

Thus considered as a great motive force in human prog- 
ress, war, despite its terrible eosts, receives a powerful defense, an historieal justifieation. But the conclusion that war must continue to exist, either by reason of the inherent constitution of human nature and the inevitable conflicts of organized raeial or national wills, or through the impossibility of finding any aceeptable judicial sulstitute for the ordeal of battle, is a rash statement of an intricate situation; for it disregards the central trend of the impressive argument of human evolution. It might similarly be urged that because the original esthetie tastes of men found satisfaction only in garish colors, erude forms, strong contrasts and grotesque exaggerations, such outlets must still be provided to maintain the esthetic qualities in their native vigor; that because the early stages of intelleetual inquiry ineritably gave rise to superstition and a limited anthropomorphie view of nature, superstitions and myths must be maintained among mature and edueated persons as an exereise of distinctive phases of mentality; that beeause the pathways to morality wandered uncertainly in the jungle of entangled emotions and led to eruelties, hatreds, tortures, inquisitions, and persecutions in the attempt to enforce moralities, we must continue to provide outlets for these indispensable stages or phases of the moral nature. Let it be recalled that every assertion of a quality to a position of direction comes as the result of and at the cost of a rivalry among the several eonflieting native tendencies, is itself a deeision that such quality shall prevail for a given range of situation. That such decisions are determincd by eireumstance as well as by achieved stages of eulture is unquestioned.- But such admissions are wholly compatible with the ultimate faith in the value, and the consiterable social control, of the transforming process that permeates human evolution. The argument for the institution of war either as inevitable or as indispensable is a questioning of the efficieney, the depth, the reality of the evolutionary" process. It implies that in a sincere appraisal eulture is 
but skin-dcep, that in all momentous issues primitive nature must prevail and show its modernity mainly in the refinements of scientific technique available for its persistent ends.

The central position of this essay upholds the intrinsic value of the modification of the qualities of men, the transfer of ancient qualities in a new perspective to newer applications; to which may now be added that in the self-conscious, as less effectively in the vaguely conscious stages of social evolution, the process is aided by the force of sentimentally supported or intellectually formulated ideals. Original nature is paramount, but not in its primitive expressions; circumstances dictate, but not absolutely; in the rivalry of the phases of human nature standards and ideals come to have a decisive voice. The danger of too violent departure from nature's forms of selection is real, and must be met by intelligent measures; the benevolent impulses may be overurged and sympathy overdone. None the less the trend of life is largely its own corrective, in that living gives little promise to be other than a battle and a competition. The vocational pursuits and quite as suggestively the recreational activities continue to engage the old order of competitive qualities in a newer setting, with some losses and some gains. Politics and commerce and professional rivalry represent the transformed arenas of biological struggle. The fitness that qualifies for survival changes with the upward movement of the reconstructed environment to which fitness is adjusted. The game, whether the game of politics, of business, or of sport, is a modification of the contest of war; it proceeds upon a partly similar, partly modified set of qualities, and through such modification ceases to be warfare and becomes a game, a battle royal it may be, but played under rules; the rules the issue of the spirit of humane consideration and fair play derived from other phases of human nature. The competitions of the industrial world continue the ac- 
tivities that appeal to eertain phases of the human endowment and have a place in the system of needs to which man is subject; they serve to satisfy developed forms of needs, desires, and interests, but never quite in the original forms in which these demands shaped the orders of human qualities. They recognize rival elaims, find it necessary to aldjust motives and measures to sueh elaims. Reeent economic movements indicate that the principle of coöperation may come to play a far larger part in the future organization of business, thus supplanting or modifying the principle of eompetition, which is an issue of the eontests of men and is cherished as a means of development of sturdy qualties. As piracy and brigandage and raids have disappeared in favor of regulated, legalized commeree, the qualities requisite for commercial enterprise have changed (though it may be with unmistakable vestiges of the earlier trends) to an altered range. Success still continues the exultation of triumph, but wit, skill, foresight, coördination, and not might, are its weapons; or more truly the mode of combination of original and aequired nature alters the eomplexion of the qualities of eompetition. Economie power may also be brutally exercised, and the cruder traits prevail in all eallings, however high in cultural status. In the larger and more complex social world success, though it yields the thrill of triumph, must receive the sanetion of the socialmoral ideals before it meets with the appreeiations of men. Suceess thus engages fuller and worthier satisfaetions. The energies of men may be exereised and inspired by equally self-sacrificing, equally diseiplinary movements, by equally collective and heroie enterprises necessary to the work of the world, as those that at their best constituted the appeal of the military organization, the military spirit. The argument for war must establish itself against the massive valiclity of the manifold transfers of human quality for which the story of human evolution is a convineing vindieation.

Qualities as observed and appraised eome to expression in 
a system of social forces, which are at once responsible for the composite institutions of civilization and the issue of them. Civilization transforms the upper range of human qualities by reconstructing their perspective; it gives special value to selected ranges of derivative capacities. Such favor, or disfavor, shapes the later, secondary issues of nature under stress of social condition, and thus enters into the ready responsiveness of the social institutions-and still more fluidly of the social attitudes and ideals-to the changing conditions of development. Though in their general contours of like structure and origin, societies differ widely in their established mores by reason of the distinctive perspective in which they present the constituent trends of human nature. Social approval releases and encourages the activities and purposes that shape the lives of men and remake as they reward their qualities. The stream of interests and activities flows in the channels formed by outward circumstance together with the selective course of ideals; both reflect a special conditioning, and give to the psychology of human responsiveness its local character. The working basis of the intercourse and relations of men, in which they develop and display their qualities, is vivid, real, and concrete. In its explicit assertiveness it emphasizes the efficient if superficial communities, and establishes shibboleths of custom, appearance, and attitude as well as of language, belief, and tradition. By attaching peculiar value to the established expressions of human trends, the inevitably local cast of mind may set up prejudices, estrangements, and barriers, even as it fosters a helpful loyalty and supports endeavor. By further expansion different cultural systems come into rivalry, and different phases within a unitary development likewise compete for appreciation. Tolerance and hospitality offset the natural tendency to absorption in one's own system of values and the disparagement of all others; but these are late and uncertain and struggling products of higher levels of eulture, 
and have constantly to reckon with the direct and primitive assertiveness of the "local" cult and its obligations and antagonisms. In the conerete the individual is swayed by an unquestioned system of values whieh is praeticed as it is absorbed subconsciously, and in the same terms, with occasional formulation in codes and prineiples, is active in the genius of the people. The direction of this instrument for the development of the qualities of men shapes the operation of the social appraisals [5].

In the practical contemplation of the facts of achievement, of what men and groups do with the capacities which they command, the dominance of circumstance looms momentously. The fate of the individual, as the destiny of nations, seems imposed; and fatalism as a plilosophical theory or a temperamental conviction finds its support. 'The biological limitations, and the psyehological ones which follow in their train, are less apt to incite rebellion than are the outward symbols which the social institutional life ereets in the contrasts of favor and handicap, of riehes and poverty, of authority and subjection. The injustices, the uncertainties, the capricious distribution of the fortunes of life discourage and irritate. The relations of opportunity and capacity, of reward and desert, seem too seriously disturbed by the inequalities of circumstance [6]. The imagination turns to other states of existence where these imperfections of fate fall away, and the true qualities of men are clearly reflected in purity of motive and singleness of pursuit; or it constructs not a "Paradise" of future reward, but a "Golden Age" of the past, before the complications of existence had encroached upon an innocent age, and the atjustments of simple eontent were still adequate and secure; or it aeeepts the conditions but disposes of them more jistly by fashioning a Utopia where quality is reflected in station and esteem, and the false appraisals of cireumstance rive way to the assured association of true wortl with fitting reward and noble opportunity. 
Every Utopia projects a selective ideal of the desirable; in so doing it enters a protesting criticism of the actual play of circumstance. As a proposal for the remedy of abuses, such an imaginative excursion may earry the profit of a distant view, that permits the forest to stand out above the confusion of trees. Its pertinence to the present consideration is that, however idealistic its architecture, it must build upon the essential qualities and relations of men; these specifications it retains from the confusion of observed conditions as the foundation of its juster and happier state. A Utopia, however patterned, must recognize the special fitness of men to play definite and different rôles, while yet protesting that the rôles which they play on the world's conventional stage are assigned, and the speaking parts arranged by the stagecraft of circumstance. It will do well enough as a dramatic device to have the prince and the pauper exchange robes and each return to his fitter task; but the actual appraisal of the rôle of circumstance in shaping the achievements of men is far from simple. For it is the conditions that make the problems of life; ideal constructions are themselves a selection from among the desirable conditions. Truly careers are at best a compromise between endowment and opportunity; the pressure of circumstance lays a heavy hand upon many a promising talent. To a large measure men of high and of low station might fairly exchange places so far as the fitness of endowment to task is concerned. Yet in the study of condition, justice is one concern, comprehension another. It is in the mode of operation of circumstance that illumination lies. For the most part circumstance is more a track than a barrier; it guides more than it confines. The ordinary bent of nature is not so strong that conventional pursuits hamper; on the contrary a complacent acceptance of condition is the rule, and convention must be relied upon to sustain such limited self-expression as matures. It is only for the keenly assertive mind that the imposed conventions of the collec- 
tive will stand in part as hindranees; for the complacent average mind they serve as supports. In this contrast, moderate or extreme, rests a fundamental issue; in this quality of independence eirenmstance finds its off'set. The endowments as well as the relations of men separrate the leaders and the led; their divergenee is the more significant as conditions become more complex. This distinction continues to mark the great divide in Utopia as in earthly societies. It is the assertive quality that utilizes as it bends the established modes of expression to its purposes. Mr. Wells aptly terms it the "poietie" type of mind; and to the poietics in his Utopia belong the rule and the honor and the influence. The creative impulses of the poietic minds are responsible for the forms of thought and expression that prevail. It is in the inadequate recognition of their part in human progress that the defects of earthly soeieties are most apparent and disastrous.

But no society ean exist upon its poietic classes; they form the leaven, not the mass. Next and far more numerous are the kinetic type of men, the bone and sinew of the nation, who keep things going and skillfully apply and extend and adapt the principles and inventions that owe their existence to the venturesome and imaginative thought of some poietic mind. Naturally these qualities are not sharply divided but variously blended-possibly in no decided tones-in the composite capacities that direct the efforts of men and shape the work of the world. And lastly there is the vast majority, the fair average and the duller stretch below them, to whose capacities the social and eeonomic system must be adjusted, whose routine employment in simple tasks feed and clothe and house and serve the peoples of the world in the supply of their elaborate demands. They may be curtly dismissed by Utopian writers; but they constitute the comprehensive condition under which human quality reaches expression. Every practical outlook must recognize the significant differences among men: that dullness 
takes the form of an unimaginative, formal imitativeness; that it gives to the average a conventional set and a limited responsiveness, which would be the same however altered the outward circumstance; that the more and more ade(uate retain and expand the sterling qualities of the masses, while also responsive to the inspiration and guidance of leadership. Yet the many rule and set the popular standards; the natural conservatism of the majority reflects the impress of condition; their limited imagination, their shortrange outlook, their feebler powers of discrimination, their lesser initiative and uncertain suggestibility, as well as their sturdy, faithful capacities and persistence form the psychological basis upon which communal achievement must be built.

The progress of mankind is due to the single fact that not all men are of the type of the average; it is their differences from the average that form the chief asset of humanity. To the biological trait of variability and the psychological one of originality attaches the peculiar value of the poietic qualities. In their present distribution and recognition, as likewise in their favorable coöperation with other desirable types of quality, lies the hope of further progress. In the manner of recognition of such quality, a society expresses its temper and asserts its true nature.

It thus becomes intelligible that the problem of problems is concerned with the kind of leadership which the majority will accept. Democracy represents a faith in the tendency of widely distributed political equality to make for wise leadership. Its menace is that it develops a suspicious attitude toward the very instruments of its salvation. It insists upon conformity and uniformity; it is suspicious of unjust favor; it encourages the feeling that one order of man if not quality is about as good as another, confusing an absence of privilege with an assurance of the emergence of ability to its rightful place. It throws the emphasis upon a kinetic efficiency and rewards the builders of engines 
rather than the inventors of them. In its disregard of the inherent limitations of capacity it places its hope upon edu. cation to remedy deficiency and remove the drawbacks of incompetency; it relies upon undirected opportunity to reveal and release aptitudes. In spite of this arraignment of the dangers and the shortcomings of democracy, the democratic programme may yet rightfully command the faith and the loyalty of thoughtful men; but it may do so only" upon the condition that as an institution or as an ideal, it must recognize the supreme importance of the poietie qualities of men, must make a place for these in its system of appreciations, and rely upon them for the guidance of its welfare. It is not the qualities of men but the institution of democracy that is on trial in the issue. If democracy is a fitting system for the encouragement of the poietic qualities of men, it is biologically sound; if it tends toward the rule of mediocrity and the waste or the feeble encouragement of the highest evolutionary products that have been wrought in the qualities of mankind, it constitutes a handicap and not an aid to the course of evolution.

Accordingly the consideration of the social forces which make for or against the encouragement of the choicest qualities of men, far from being a remote occupation of the philosophical mind, is as practical as a map, if not as a compass, in steering a course in the turbulent currents of affairs. But the compelling force of condition recurs in the questioning of the validity or the efficiency of ideals, and urges that the seeming leadership is in reality a following; that ideals emerge to support institutions which exert theil. actual hold through their rested interests; that the pressure of events is the motive force, and ideals are only the conscious registry of their trend. This view is congenial to the pragmatic position that ideals have value, as theorics have truth, so far as they work or "pay," and also to the praetical position that actual trends arise directly from experience, and goals as well as policy from achievement; that economic 
couditions develop cultural movements, which in turn are responsible for such facts as the commercialism of the American people, the inevitableness of universal suffrage, or the contrast between the average American taste in clothes and in pictures or music. Condition directs activity, and the satisfactions derived from pursuit and success suggest the further extension of achievement; incidentally some sort of justification of purpose becomes articulate in the form of an ideal, or as a reënforcement of what is largely done for other motives. Undoubtedly the pragmatic shaping of ideals by practice and circumstance is real and vital; and the actual incentives and the formulated motives may differ widely. Undoubtedly also-as experience showsmay ideals be carried out unreasonably and unseasonably. They may be worn as blinders and not as clarifiers of vision. The student of the qualities of men finds indispensable some definite position upon the play of ideals in molding character and action alike. He observes the proved power of ideals to shape, indeed to command completely the decisions of life, as an offset to the skeptical view of their potency, which in turn he accepts as a reminder of the rôle of circumstance. To thoughtful men of however modest parts, some sense of purpose, some unification of divergent activities, some congeniality of belief, must be present as a guiding principle to support the individual in the stream of a larger agency. The choice to the modern mind is not between having ideals or dispensing with them, but between an allegiance to one order of ideal or another; or with what fervor of pursuit and devotion of purpose one or another ideal shall be held. To maintain some singleness of purpose in a competitive and crowded existence, to guide decisions by something more than the direct pressure of circumstance or the push of impulse, requires the sanction of ideals however vaguely absorbed-an acquired sense of direction as well as a practical understanding of the motive force of events. 
If life were lived absorbedly in the moment and oflered no problems of long-range adjustment, pulpose would hardly arise above impulse, and habit and convention would form an adequate guide to eonduet. But such simple alternatives are unreal. There are undereurrents as well as currents of events. An attitude, a belief, a sympathy, is just as practical a motive as an impulse arising from selfinterest or a pressure of condition; it acts more indirectly and at a longer range. Seemingly passive and ineffective at the moment, it eventually holds the balanee of power and decides the nicer issues, even against impulse and interest. Yet in a more refined form the earlier stress of circumstance appears in the high-level direction of human affairs, as a leaning toward expediency in contrast to prineiple. This intellectual predilection represents a tendeney to affiliate conduct to the earlier pattern, the shorter run of experience, the simpler situation. In the management of affairs the tendency comes to expression so characteristically in the politieal arena that it may properly be termed the political temper. Thus arises the conflict between the sanctions of prineiple and the sanctions of practice, between temporary success and ultimate failure, between a satisfaction of lower and of higher standards. Becanse of the importance of wise leadership in the massive social movements of men, is a slight departure in the just disposition of condition and theory a vital matter. The issue in a measure becomes that of finding proper places in the social structure for the poietic and for the kinetic types of men. The national genius is reflected in the spirit of this adjustment; out of it grows the favor for which men compete. For popular favor is itself the large factor of environmental pressure; success, whether as reward or reputation or honor, must come from others, who confer it accorling to the light which is reflected upon their vision from the collective standards of appraisal. Hence the strong desire to interpret popular favor not alone in all ventures in which 
the supply as well as the discovery of a demand is the central purpose, but in those movements in which principles as well as interests contend. The tendency to veer and shift with every wind and wave of public favor, to drift with the momentary popular sentiment, stamps a quality of mind; in its extreme it is the mark of the unprincipled. Yet the wisest and the sturdiest must use the method of compromise, sacrificing the lesser for the greater good and adjusting the claims of principle to the invitations of opportunity. Such conflicts are no more significant as a moral struggle than as a psychological opposition. In both the situation arises by virtue of the attachment of value to the "spiritual" influences, far-reaching attitudes, ideals of purpose, standards of pursuit; the rivalry is among the qualities to which is to be assigned the greater worth, the right to prevail. The verdict that might shall not make right is more direct and potent but intrinsically of no different order than the conviction that a larger good shall not be sacrificed for a momentary advantage. The protest in both cases is directed by the same conviction that to yield in so far tends to place one type of quality above another; against such preferment the loyalty to principle, however supported, arouses the forces of indignation, and all the transferred pugnacity born of self-defense.

It is not alone in the rivalry of men or principles that the social appraisal operates and bestows its rewards; it appears in the rivalry among the several systems of value which the social mind establishes and esteems. This consideration, of similar scope and temper, transfers the decisions to another field. The trend of endeavor expresses something above the economic pressure, in that it reaches into the field of spiritual competition. The social genius decides not only to what "qualities of men," but to which of the human qualities shall be accorded honor and leadership. If one age or one people is commercial and another esthetic and a third religious, this trend is assuredly related to the con- 
dition and the racial and national heritage; but it is also an expression of the esteem which one and another itleal receives in the composite endeavor. An artistic age, an artistic people expresses its conviction that art has a lange platere in life. The convietion that the things of the mind are real and vital gives rise to a society that maintains institutions for their promotion, holds in esteem the men who exrel in intellectual contributions, and regulates its intercourse so that knowledge and acumen shall meet with recognition and opportunity for their excreise. 'The spirit of the age, the genius of the community, affects the selection of men, hy selecting among their various types those that express the traits cherished by the communal trend. Individual genins may make its own appreciations and change, yet not radically, the inherent disposition; for the most part it makes articulate the struggling emergence of the social mind. And far more significantly for the practical issue, the dominant trend of the highways and byways of endeavor determines the course and career of even the most favored individuals. If that trend is commercially minded, it turns the abler minds of the community to commerce and away from rival pursuits. If it be urged that it goes farther in its molding power and deadens the sensibility to interests and values that lie apart from the practical economic conecrns, its limitation becomes far more serious.

In so far as the communal spirit, the local genius, affects the community, it gives it a characteristic enscmble. It determines what manner of men may congenially thrive there, what types of interest are likely to be cultivated, what perspective of importance attaches to this or to that order of occupation. Something of the relative place of art and commerce in the social programme is indicated when it is said that Paris is artistic and Chicago commereial. In so far as the statement pertains, it refers not to artists alone but to all the ways and means, the manners aul measures through which the artistic interests of a complex civilizi- 
tion come to expression. Under modern conditions a further consequence results; for the spirit of the community and its reputation may attract or repel as well as select and mold. In the pursuits dependent upon a nicer adjustment and thriving upon the specialized quality of men, such favor counts heavily. Sensitiveness to the social atmosphere determines the quality of achievement. The ordinary work of the simpler industries may be done almost anywhere, and the economic pressure may rule. The qualities of luxury imply the established satisfaction of the necessities. But the peculiar value remains in the poietic qualities and the specialized capacities of men because the initiative belongs to the few; the esteem in which they are held remains a eritical factor of progress. Those who set the patterns shape the trend of affairs. There is a sense in which nations may exchange their material products and import from without what they need for the supplies of ample living; but the qualities of men they must breed and select from within. No importation of these is possible except by the assimilation of ideals and of the men in whom such ideals are expressed. For science, art, morality, philosophy, are not foodstuffs of the mind, but the tissue of the assimilative system. To omit or weakly encourage the "spiritual" qualities which the intellectual, moral and esthetic disciplines cultivate, is to curtail and impoverish human development, to establish the social institutions upon a crude and imperfect model. No nation can be merely a nation of shopkeepers, however highly and rightly it values cconomic stability as an indispensable asset; nor should it be forgotten that in a practical sense standards of conduct and ideals of principle enter into shopkeeping as into every worthy form of human oceupation.

In the sensitive adjustment of these rival claims of human qualities the social "psyche" asserts its character. Compromise between the desirable and the possible is inevitable but not colorless; a positive character emerges from 
the interplay of forees. It is the fate of the individual, who is thus at the mercy of the institutional forces that concerns the psyehologieal protagonist. For society must find as well as breed its leaders, must reeognize greatness and many' lesser orders of ability, if it is to profit by its assets. 'The most disastrous waste to any community is the waste of its higher qualities; and such danger is real. The "mute, inglorious Miltons" are not myths, though silent in their :1)peal. Monuments testify to reegrnized greatness and achievements brought to issue; but how many unmarlicel graves may bury equal though unrecognized talent, qualities shorn of their potencies in expression! The reflection is vitally practical when transferred to the lesser play of the same appreciations that erect monuments and direct preferment. For it means that the effect of any lowered or false standard of appraisal will be to place second-rate men in first-rate positions, which at once deprives the finer ability of its full expression and gives to the less worthy a larger influence. In such deeisions soeieties as well as men, even more than the men, are judged by the quality of those elected to the high and the highest places. Let it not be supposed that the existence of ability and its recognition are the same problems. The emergence of men is in part a social product, certainly a social phenomenon. The potential artist may fail to emerge in an uneongenial atmosphere, and turn his talents to other directions. Such unfavorable factors, like the favorable ones, do not act in such crude and direct suppression; they turn the talent away from its best and highest expression into a channel still congenial but shorn of its potency. Impossible as it is to separate the existence from the emergence of great men, and uncertain as may be the applieation of negative arguments, it cannot be doubted that the "mute inglorious Mliltons" are a serious loss, and an actual onc, to the worth and the joy and the profit of living. It cannot be doubted that under actual conditions a people may be governed by those 
most likely to be placed in control and not by those most fit for the office. Nor is it merely the limitation and fallibility of human judgment that are at fault, but the trend of institutions and the inadequate consideration of the higher qualities of men.

In terms of the rival systems of appreciation the same situation arises and the same moral may be urged. The danger broadens to the appraisal of the finer types of endeavor by unsuitable standards. When an artist is said to commercialize his art, it means that a set of considerations which should be first is placed second; the products of his art do not completely degenerate, but lose their finer flavor. When the public prefers the commercialized art or is quite indifferent to the esthetic standards, substituting for them the commercial ones, the supreme injury has been done. When the question: Does education pay? is judged by a crude standard of earning-power, regardless of all finer considerations, its discussion is futile. Honesty does not pay unless the social system is so arranged that the play of ultimate and indirect influences makes honesty a superior and effective policy; the social system is quite capable of making honesty little else than folly. To judge the efficiency of the educational process by a spurious application of the standards derived from manufacturing enterprises is to forego the possibility of reaching any proper conception of its value. 'The fact that the attempt is made and finds favor in a commercially minded people shows the practical menace of the encroachment of one standard upon a domain alien to its spirit; it also reflects the insensibility to the appreciations responsible for the attempt. That rival considerations may and must enter into many decisions is obvious. It is commonly a question how far use shall prevail above beauty or beauty compromise to use, style above comfort, or reality above show. It may prove to be a far more delicate issue how far public welfare shall prevail above private interest, or again how far the moral effect or 
flavor of a play shall determine its acceptability, or low far it shall stand purely upon its artistic valıe. Sound but cheap morality may go with dramatic mediocrity; a fine dramatic sense with questionable moral situations. The grounds of decision hark back to the appraisals of quality; the actual decisions reflect the ideals, the standards, and by the same token the prejudices, the assumptions and the limited appreciations of men. The moralists and the artists may eaeh assert their elaim to judgment; but no insistence of the moralist will deprive the artist of his legitimate determination to judge by the standards suitable to his art; for the same reason the box-receipt standard will not save the judgment of a play in the eyes of competent crities. Judgments of this or that order, however sharp the eonfliets, are open and assailable; the misjudgments of edueational values by the intrusion of commercial tests, like the disguised motives of private interest lurking in public proposals, are more subtly insidious in that they conceal the issue in a tangle of assumptions or a maze of intrigne. True effieiency like sound poliey may doubtless be in the nature of a compromise; but the grounds of the compromise and the appreciation of the interests saved and sacrificed form the indispensable basis for the deeision [7].

Quality as well as qualities count and should be paid for. Unless the social approval gives to eherished traits an actual place in the practical preferments of life, unless a true sense of value is ineorporated in the system of appreeiations for which soeial ideals stand, such qualities cannot thrive and must yield to others to which intentionally or by force of eircumstanees a working premium is attached. Here belongs the true import of the pramatie temper, likewise the moral futility of preaehing withont practice. It is readily agreed that courtesy, consideration and good manners are desirable ends; but unless some place for these qualities is found in the aetual relations of life, unless men endowed with these qualities get along better and 
move upward in social esteem more assuredly than men without them, such virtues or graces will not flourish. A courteous people is one that makes courtesy indispensable to social recognition, and envelops all its subtle play of preferment with the quality of courtesy. If the saying that business is business means that no other considerations than profit are in place, and that brusqueness of manner, and brutality of bearing, along with indomitable energy, will bring the rewards of business, we cannot expect any other qualities to come out of such occupations than are given an actual place in their regulation and in the disposal of the rewards. If there is anything sordid in money-making, it is but the reflex of the sordidness of quality that turns men to such pursuit. To admit that a careful education in the clements of a cultured life unfits a man for business, casts a lurid light upon the character of an occupation for which such interests and such a preparation is a handicap. If in political relations or in all the difficult positions of honor and responsibility a society desires to have wise, considerate, responsive and conscientious men, it must see to it that in all the manifold and minor relations of life these qualities shall have a vital value, and the men who have them and cherish them shall find their qualities ready aids to their chosen pursuits. The redemption of a calling, like its attraction, lies in the qualities which the pursuit cultivates and demands. Qualities thrive as they find expression in careers and in their incidents and supports. What is true of careers is true of the enveloping atmosphere in which all careers flourish, which sets the tone for the conduct of affairs. The responsibility for the curatorship of the standards and ideals thus effective falls upon the thoughtful members of the community. What the enlightened social consensus today approves as desirable will in the future direct the energies of men, and decide what orders of men shall be called to the first places and the next places in dignity and influence. The quickening of ap- 
preciation is the only assured method of elevating the qualities of men. It is true that fundamentally human nature remains constant, and we ean do little to supply the qualities that we lack. But it is still truer that hmman nature is all that we have to work upon, all that we have to work with. By supplying outlets for the cherished qualities and so disposing of the social appreciations that the worthier quality shall have the worthier place, the social appraisal serves its highest function.

The operation of social estcem proeeds through the establishment and sensitive adjustment of standards and ideals. The ideals come poietically from the imaginative resources and intellectual formulations of the leaders of men, as well as from the enforcements of experience; the standards that prevail are the practical embodiments of like intluences. Men do largely what they are expected to do; pcrformanee follows the clew of endeavor, as the missile follows the direction of the aim. Careers are definite invitations to the ambitions of men; social esteem spreads its eomprehensive influence over the entire system of endeavors, and exercises the balance of power when endowment or inclination is indecisive. The motive force is rooted inwardly in qualities of nature; the direction of its growth and the manner of its blossoming depend upon the nurturing care and the congeniality of the soil and climate. The same selective forces operate in the finer issues of the social stratification. Educated men are expected to conform to more exacting standards, to consider finer discriminations, to respond to larger appeals and to be affected by broader motives than obtain for those less favored. The standard stamps the man [8], in that it indicates the system with which his qualities and education affiliate him. The ideal of a gentleman imposes high standards and ideals of conduct, and consideration in all respects. The present ideal is the result of ages of social development, and alters its standard in the emphasis of one or another of the component traits. Lapses pardon- 
able in one social setting fall quite beyond the pale of sanction or toleration for another age or people or station.

'The eritical standard, following the clew of civilization which makes small differenees count, attaches significance to slight deviations whether of manners, morals or achievement. It takes but a slight fault to mar the effect, to take the edge off the finish, to lower the quality, when the rating is exacting; for such ranking is in terms of the highest products of development. The rating, social or otherwise, to which one conforms, by which one expects to be measured, is itself rated. The dulling of sensibilities is the beginning of degeneration; the deeline in standards leads to the acceptance of the good enough. The eternal vigilance that is the price of safety is a counterpart of the minute attention to detail that is the cost of quality. For the many the failure to attain a high standard is inevitable by the conditions of endowment; to that condition the adjustments of life and its demands must be made to conform. But the insensibility to the existence or the worth of standards on the part of those responsible in any measure for the conduct of affairs is a menace to the interests of eulture. The still more eommon deliberate adherence to the lower standards, in practice and prineiple alike, like the unsuitable rating of purpose and the imposition of a cruder authority, is the aetual danger in the regulation of social control. For here is the arena of human quality, and these the contests: What knowledge is of most worth? By what standards shall conduct be judged? What energies are most worth while? What shall be the perspective of importance of one set of values and another? What shall prevail, right or might, knowledge or authority? Who shall be invested with power? Which standards and ideals shall be deeisive? Whieh are the eternal values and the ideal qualities of men?

As each thoughtful worker beeomes a eritic of the system under which he works, as each individual judges while yet 
he conforms to the eollective movement, the spirit of the day and the place and the elass to which he belongs, so the student of human quality [9] earns or assumes the privilege of reflecting the temper of his eonelusions in the prouramme of a desirable trend of affairs. Because of the semsitive adjustment of the finer qualities to the congeniality of the milieu, every tendency, every distribution of influence thiat turns social approval and publie sentiment away from the higher goal and toward the lower is inimieal to the public welfare. Condition, it is true, confronts and is insistent in its demands, but it should not confound. Every practical man seeks to utilize the status quo and the established interests and trends, to direct the immediate problems which constitute the condition of his eareer. Compromise with condition is inevitable; the wisdom of its direetion lies not alone in the understanding of motives and the eommand of resourees, but in the interpretation of the spirit of atvance and a firm eonception of values. It is the temper of this adjustment that marks the quality of a man. For the reason that the higher interests are more delicately sensitive to the influences of the "spiritual" elimate, and the further reason that the momentous factor in the direction of human affairs under present-day conditions is the nature of the leadership which a people demand or secure or may be induced to accept, the responsiveness of the leaders of men in whatever callings to the standard of appreciations expressed in approvals-by action, by votes, by sentiment, by influence, by social and institutional affiliations-is the pivotal eoncern of social welfare. In the eonservation of its intellectual resources, a nation exereises its highest wisdom; it is the waste or disregard or inadequate encouragement of the poietic qualities partieularly, and the consequent loss of the uneultivated and unapplied powers of gifted men, that forms the critical weakness of institutional systems. Political policy, edueational poliey, spiritual policy are all subservient and jointly coöperative to the 
common goal of eultivating the worthiest possibilities of men and finding the fittest field for their favor.

Viewed more elosely, the influences actually at work in the body social, favorable and antagonistic to this purpose, present further points of contace with the psychological perspective of liuman endowment and expression. The inherent conservatism of the human mind on the one side, and the stress of condition on the other, operate to set the activities and the loyalties of men in their course and to limit the scope of their expressions. Convention supplies the patterns of endeavor and diminishes the need of initiative, which in its notable and decisive eommand belongs to the few. But the attitude of the many toward innovation governs the trend of opinion as of affairs; they set the rewards and dietate the conditions under which the qualities of the favored shall be exereised. Any failure of sympathy in this relation, any distorted mode of measuring the values of the manifold and sensitive contributions to human progress, is peeuliarly deplorable. The peril in yielding to circumstance or the insistence of a less worthy if more popular or feasible standard, is that the appreciations thus developed and trusted, the rewards permitted or encouraged under stress of immediate advantage, warp the sensibilities and weaken the judging powers, and in so far prevent the restoration of a juster, a more spiritual perspeetive when the stress is removed or a movement forward is possible. It is easy to understand that soeiety eannot permit fortunes to be aceumulated by any sort of means and measures which individuals will resort to, and look for redemption in the philanthropic uses to which such fortunes may be put. The moral welfare of the community requires that the qualities exereised in eommercial competition shall make for the elevation of integrity and the dissemination of consideration of soeial rights and humane principles. It is not so easy to understand that the influences are equally undesirable when the infringements involved are more subtle 
and evasive. Obedience to the letter is asice than rounpliance with the spirit, and is so because the latter frocereds upon a sensitive appreciation of values, and absorplion of the genius of the comformity. Lip-scrvice is ever a templattion; an idol is more real than a god. 'l'he conreption of demoeracy as an equality of the ballot and a lenumeiation of privilege is simpler to establish than as a just system for the securing of the fittest places for the several yllalitiss of men. Life under the form of a monalchy may be thoroughly democratic in spirit and leave the individual as free in initiative as obtains under the most constitutional demoeracy, where the yielding to eireumstance introcluces formidable prejudiees, and the restraints imposed by wealth and other forms of control bind more seriously than traclition. For it is only to a limited extent that society can provide the individual with codes of behavior and formulated restrictions of conduct; for its finer assimilation it depends largely upon collective influences leading to attitudes and views, and to a deposit of standards and ideals. Outward conformity is significant only as an index of an inner assimilation. Such collective sentiments are invaluable; the fact that they may be appealed to for the righting of wrongs as for the elevation of rights makes social progress possible. Unless men shared similar ideals the estem of quality would be dissipated and lost. It is inherent in the life of ideals as formulated and defended, that they should be more effectively operative in the few than in the many; still more significant that their worth should he observed by the sensitive than by the insensitive. By this limitation ideals are in adrance of practice, as the leaders of opinion are in adrance of the led. The problem returns to the regulation of public sentiment toward a favorable regard for all those qualities of insight and muderstanding, of loftiness of aim and purity of motive, which are indispensable to wise leadership.

The difficulties in the way of a reasomalble consunmation 
of this end are not of one order. Self-interest steps in and employs established sentiment for narrow ends; flabbiness of will tires of the struggle and falls back to the easier way; eonflicts of interest arise in principle and praetice; but most commonly, a callousness born of insensitiveness brings forward the less noble qualities and retires the finer wisdom and the worthier end. For we must remember that the wrongs of society have moved upward with the elevation of its secured rights; new conditions breed new vices as well as demand new virtues. In every direction are we living on the upper ranges of our qualities, morally, intellectually, soeially, while yet conserving the fundamental virtues that have made the finer issues possible. The quality and the wisdom of adjustment of the finer "social" appreciations play upon the actual issue of the day and the hour; inevitably the removal, in whatever measure, of leadership from the control of the more worthy and responsible places it in the lands of the less worthy, the less desirable. Lowell's loyalty to democracy and his insight may be trusted when he advises that "the highest privilege to which the majority of mankind can aspire is that of being governed by those wiser than they." It is indeed unfortunate but true that a lapse in appreciation has a doubly disastrous eonsequence. It affeets precisely those callings and interests that have a difficulty in establishing their elaims amid the insistenee of direct and urgent needs; and the interests with which they compete, by their nature less subject to such untoward and delicate invasions, utilize the retirement of the opposition to further assert their rule. A departure in standards of appreciation affects both elasses of interests. Men of high endowment and inclination will under such stress exercise their second-best and neglect their first-best talents, will yield to opportunity and engage in measures questionable to a critical standard, but not disqualifying; best impulses will be sacrificed to nextbest. Nor do the consequences stop here: the more difficult 
orders of achievement will be judged by unsuitable standards and the workers in the poietic fields will be cxposed to an uncongenial environment. The conspicuous dominante of the approved occupations-the callings richly rewarded by the institutions of the day - sets the standards for the appraisal of all. The contrast of station and suceess condemns to neglect the interests that eamot compete on this basis. The disparagement of the one leads to the glorification of the other. More plainly the better man's services are lost, and the less worthy extends his influence. 'T'he still small voice of the higher appreeiation is drowned in the roar of practical success; those placed in positions of influence through their willingness to negleet the finer values-or their insensibility to them-come to pronounce upon and decide the careers of the men and the institutions that alone can minister to the right conduct and progress of societies.

The practical lesson is plain, however difficult its application. It indicates that the need of the moment is a more charitable consideration of the poietic qualities, a willingness to give men of this type a larger control of the interests which their qualities enable them to serve, a readiness to appreciate the conditions favorable to the growth and fruition of such qualities. For nothing is more improvident and impractical than the policy of ostensibly regarding the results and disregarding the conditions under which they flourish, an expression of the wish to have in the community a rich representation of men of science, arts, letters and spiritual guidance, but an unwillingness to provide the conditions for their encouragement. Of a like impractical stupidity is the cultivation of such quilities in the institutions of learning, and their exelusion from any place in the preferments of life, the voting of funds for education and the ridicule of the "highbrow" "sppreciations which is the aim of education to confer; while to insist that these higher interests must see to it that they 
flourish under such conditions as alone are permitted to obtain, is at once dogmatic and stupid. Without subscribing to the doctrine of the superman, one may urge that if only we knew how to find or produce or induce to emerge the men of genius potentially available in the human product, we might well bend all energies to that end, even to the sacrifice of other benefits or comforts. In a yet more practical vein may it be recognized that the actual interference with progress and the actual dangers in the pursuit of false gods or the neglect of true ones are due to simple homely traits. They may be traced back to a lack of finer feeling, or of richer opportunity, that tolerates if it does not invite or defend lower standards, that overrates cheap success, toadies to the gallery and gains glory for the inglorious. In so far as such false appraisals obtain, they doubtless reflect the stress of conditions; and yet no one with a vestige of optimistic faith, born not of the disregard of human shorteomings and perversities but of the reliance upon the compelling power of determination and leadership, can doubt that they may be overcome. The plasticity of human nature in its higher reaches is the psychological guarantee. Such optimistic appreciation is expressed in the conviction of William James: "Though it is no small thing to inoculate seventy millions of people with new standards, yet, if there is to be any relief, that will have to be done. We must change ourselves from a race that admires jerk and suap for their own sakes, and looks down upon low voices and quiet ways as dull, to one that, on the contrary, has calm for its ideal, and for their own sakes loves harmony, dignity, and ease.' Such a conviction summarizes the significance of the esteem of human qualities and the mission which awaits the truer appreciation of the qualities of men. 


\section{NOTES TO CHAL'TER I}

Note 1, page 2. The history of Character and Temperanent is involved in the sucessive contributions that hatre matce modern psychology possible. See particularly Dessuir: "Mistory of Psychology." It goes baek to the intecedents of pisycholory, which, attempted the determination of elaracter-traits. The most signifieant of the attempted solutions is the duetrine of the "temperaments," dating from the early days of Greek philosophy. Its absorption in medieval and in later medical lore galve it it eurreney at once popular and seientifie. It invaded literature an it pervaded practice and diagnosis, and proved most eongenial to the extravagant hypotheses which replaced knowledge in the speeulations of the sixteenth, seventeenth and eighteenth eenturies. Of the rival systems that proelaimed solutions of the secrets of character, astrology, physiognomy, and (as an offshoot of later vogue) palmistry, are most prominent; while a special place mist be reserved for the peculiar product of seience and pseudu-seichee in the early nineteenth eentury that inaugurated the system of phrenology. As we approaeh modern times the logical spirit of these systems of character-reading notably changes; there is a greater loyalty to proof and demonstrable findings, but a common subjection to the tyranny of preconecived assmmption and a common blindness to the subjective tendencies which sustimed the propagandum. Systems of belief of this order are not reluted but outgrown. Their decay followed npon the diseovery of significant elews in medicine, in physiology, in biology, in peychology.

Attention may be directed to the equally ancient literary interest in the delineation of character. The two streams frequently combine; and the control and education of traits offer an incentive to the application of both orders of kinwledpe. The training of character, the determination of rocational titness, the comparison and understanding of national traits, the eontrol of social forees, have all supplied motives for writers and students 
throughout the ages. In the nearer perspective these several interests again unite in a more sober and accredited fashion. A notable contribution introducing the modern approach to the subject is the chapter in Mill's "Logic" (1843) bearing the title "Ethology." The project there outlined was attempted with indifferent success by Bain in the "Study of Character" (1861). A series of French writings represent the most extensive contributions to the modern formulation of the problem; of these the most distinctive are the works of Ribot, Fouillée, Paulhan, Lévy, Malapert and Ribery. I have published an account of the antecedents of this subject in an article in the Popular Science Monthly for June, 1915.

Note 2, page 7. It may be belpful, by way of contrast, to refer more explicitly to the ambitious phrenological solution, which assumed that in its "faculties" it possessed the units of traits, and in the marked or faulty development of the corresponding areas an adequate index of the degree of their relative presence or absence; so much "ideality," so much "tune," so much "love of offspring," so much "pride," so much of this and that -and you had the measure of a man. It was a delightfully simple though futile programme. As a fact the result, quite apart from the defect of the argument, was a caricature by reason of the uneritical and arbitrary assumptions involved. It is well to add that "phrenology" had no means and sought none, of measuring the "tune," the "pride," the "love of offspring" and the like, which it so freely used as evidence of its findings. It relapsed into impressionism and a prejudiced self-deception, finding the evidence where the "bumps" required, and also the "bumps" where the obvious marked presence of the "faculties" demanded them.

Note 3, page 15 . No consideration can avoid an assumption in the very statement of the terms. Height is apparently a single trait; yet it is the resultant of length of leg, of trunk, etc. The separate consideration of these may disclose relations which their merged measurement obscures; two men may be equally tall but differently proportioned. The present argument states that the terms of measurement of traits, physical and mental (but especially of the latter) involve confidence in their significance as well as availability. 
Note 4, page 17. The median or central tendency is often a truer center of distribution. It represents the dopren of $\|_{10}$ trait which is as often exceeded as fallen short of. for must regular distributions, the average, which is more fiamiliar, will serve equally well. Correlation expresses to what extent two traits vary coördinately, independently, or antagonistically; it illuminates the question of compatibility of traits: in how tar orders of traits are likely to be present with the presence of another trait, or present with its absence, or present without regircl thereto, and to what measure. Correlation, like distribution, is a precise instrument, which in skilled hands has proved effective in yielding a graphic picture of the relations of traits. 'To oflset the emphasis which in this essay is placed upon the qualitative method and the problems suited to it, such studies as thuse of Thorndike: "The Original Nature of Man," Part I of "Educational Psychology" (1913), are recommended.

Note 5, page 18. This is a further example of the mutual illumination of quantitative and qualitative eonsiderations. 13y the one the rarity of exceptional individuals is made clcar; by the other the enormous importance of such individuals. The essentially original steps in progress are due to a mere handiul of men of exceptional quality. The rest aceept, adopt, adapt, absorb, apply. The fact that modern sehoolboys are far better equipped to understand, utilize, and control the forces of nature than was Aristotle is not due to the superiority of the schoolboys but to the contributions of the Aristotles of past generations.

Note 6, page 20. The equipment related to specifie instincts exposes the organism to, or provides it with, a far larger range of stimulation than such adaptation alone requires. The calyaleity to make and hear sounds is not limited to sounds concerned in the ery of the infant that leads to relief. The hmman auditury and vocal equipment lead to a vast range of expression, and makes possible language and music. The musical ability is ultimately dependent upon a native refinement of a speeilis nervous structure and gives no hint of the psychological promiso of the developed susceptibility. Similarly the human eye would be the same, were there no such thing as the pleasure of colus and the attraction of esthetic form. For the eye would be necessary to guide conduct, to recognize objects by their forms 
and color-markings. The world of visual art develops upon the basis of the same equipment as serves the primary nced of finding one's way in the world of practical things.

Note 7, page 27. At several points the findings derived from this engaging field are touched upon. The present work logically requires a sequel in which the practical field of occupation and career shall be central.

Note S, page 30. The term "physiological" is equivalent to biological in the larger sense. It is the more precise in that it indicates the presence of a bodily mechanism, of some responsive quality of the nervous system through which the stimulus directs the reaction. The term has become current in this commection since the appearance of Grant Allen's notable book, "Physiologieal Asthetics" (1877).

Note 9 , page 35 . It may be well to repeat that by calling a trait "intellectual," we bring to bear upon it the entire range of considerations thus suggested. Since, however, the functional range of the process is so comprehensive, it carries a less definite meaning than does such a term as "esthetic," with which it is otherwise comparable. The intellectual trait requires a more specific reference to the partial process in the general "intellectual" adjustment which this or that trait serves. This in turn is likely to involve the level of expression of the trait, and the manner in which it affiliates with other traits of like or unlike origin. A special interest attaches to the problem-solving aspect of the intelleetual equipment, in that it matures the control of experience by knowledge. The scientific capacity is in this sense a by-product of the direct, practical recognitional adjustment. Of all the accessory qualities of men it is the most momentous for eivilization; it changes the face of nature to meet. the developed needs of artificial life.

Note 10, page 44. Such terms as "disgust," "shyness," "awe," and their kind have no reality other than that which their functional play gives them; they mean what they effect. Usage is content with a rough and ready assignment of meaning, while the psychologist insists upon tracing the underlying process back to the realities and the system which he aims to establish.

Note 11, page 48. The subject is rather summarily treated; it requires the realistic setting of the several stages of 
transfer to earry the full sense of the importance of the prineiples and the riehness of its applieations in the several levels of evolution. The same comment. may be made in reurard to the sueceeding topic which illustrates the principles governing the higher phases of psyehic regulation, where the sensibilities, onotions, and reasoned actions eombine into a system of sentiments: set and operative in an institntional, social milieu. For the moment the emphasis is upon the mode of reaehing the sentimental stages of psychic regulation.

Note 12, page 56. With a somewhat more limited yot genuine reference Thorndike says: "What might appear to he perverse luxuries in the business of keeping one's self and one's offspring alive, turn ont to be, in comnection with eertain other tendencies, means of exterminating all enemies, seemring food in regular abundanee, and remaking the envromment to suit man's almost indefinite multiplication."

\section{NOTES TO CHAPTER II}

Note 1, page 58. The primary meaning of sensibility refers to the eapacity to respond (through the sense-feeling aroused) to stimulation, and to respond differently to situations presenting variable stimuli. More simply, it refers to the capacity to be differently affected in the presence of eries or laughter, of smiles or tears, of blows or caresses, of bitter or of sweet morsels, of fragrant or of rank odors, of red and of blue, and so on throngh the gamut of natural sense-stimuli and their oeeasions. That the sensibilities in their primitive exereise are part of original nature may be assumed, though how far the response is linked to speeifie types of stimuli is meertain. Presumbly certain ranges of stimuli by their nature are disposed to platse or to irritate, or to contribute slightly in the direetion of satisfaetion or the reverse. Whatever the range of original semsibility, it is prompted direetly by experienee and enlarged in scope as it is applied. Sensibility does not funetion alone but assmmes complications with other phases of psychie responsivents. Henee it would be as futile as undesirable to restriet the term to this original or early applieation. Intellectual, ethical and cmotional forms of response have an aceredited elaim to the term, as responses patterned upon the sensory model. 
Note 2, page 59. Psychologists are not agreed upon the nature of feeling or upon the relation of organic and sensefeelings. The subject is well considered in Ribot: "Psychology of the Emotions," especially Chapters VI to XII. Attention should be directed to the intimate relation of organic "feelings," to the tactile-motor group of special sense-impressions which come from a far larger physiological area than the limited specialized tissues sensitive to light or sound or chemical stimulation. When in animal life an odor arouses an intense and widespread organic disturbance, the sensation sets off a prepared mechanism (which may also be otherwise discharged); the sensory tone of the odor may be pleasant or compositely exciting. Active contact, as tactually reënforced movement, and freedom of movement itself, have a direct and distinctive range of pleasure-value, likewise affiliating with the values of organic stimulation, such as breathing. Heat and cold play a similar part in physiological adjustment. See pages $105 \mathrm{ff}$.

Note 3, page 60 . Note also the tactile ingredient in organic distress: the dry sensation in thirst, the hollow pressurepain of hunger, the burning (temperature) pain of fever, the numbness of an arm "asleep," the tingling of restored circulation.

Note 4, page 61. Or is it fairer to say that their esthetic semsibilities are real but erude? Both may be true. There may be indifference, weak preference, and so far as it is exercised, it may follow a low order of appeal. Yet, as will duly appear, this bespeaks an esthetic incapacity, in that the result is commonly so determined by the intrusion of other factors with an appeal to quite different qualities.

Note 5, page 64. That the olfactory sense may be developed toward recognitions is familiar. The chemist or the cook learns to recognize a variety of substances by odor (as, indeed, we all do); the recognition is explicit, though reënforced by the pleasurable effect or the reverse. Yet in a large view this is a limited service; for in man, smell is a dethroned sense, of which the shrunken size of the olfactory lobes in the human brain gives evidence. To appreciate the nature of a mental world dominated by odor, we must construct with our unsuitable imaginations the absorbing experiences of a dog with the ca- 
nine vividness and richness of olfactory reegunitions and excilements. Dog and master take the same outing; but the lotilile contrasts of their mental, reflecting their sensory vecupations, reveal the vast difference of their psyehologies, and of the preferred ehannels of employment. It has been sugrested that our pre-buman ancestors, arboreal in habit, had a limited use for the sense of smell. As ereet bipeds, their lesser olfactory proficiency led to the keener use of the eyes, and thereby turned the mental bent to a strongly visualized pereeption and to manipulittion by the liberated hand under visual direction.

Note 6, page 65. The usage of these terms varies in common application as well as in philosophical diseussions. It is such directly significant and affective senses as odor that give the set to the term "sensuous." The need of such distinction shows how naturally usage absorbs and then reflects the implieation of moral and esthetic values in qualities of psychic regulation.

Note 7, page 69. Language-a derivative product-is at once the instrument and the embodiment of the sensibilities in their higher development. The range and nature of the auditory appeal is profoundly modified by the fact that through it is carried in intimate fashion the phrased argument and the associative enrichment which words contribute to the movement and expression of thought. By a natural transfer the word, as heard and spoken, absorbs the intellectual and esthetic content and quality of the idea which it conveys. Yet dominantly it is the music of speech, the roll of oratory, as well as the chirm of phrase that eonstitute the vocal appeal, which may serve to beguile or still the voice of reason. The message of language is at once esthetic and intellectual, and the management of specth involves a direct affective influence which the printed word but feebly recalls. Voice, diction, usage, style, develop a selective sensibility that oceupies a unique place in the intellectual as well as in the esthetic psychology of man. Artificial linguage contrasts with natural facial and vocal expression; the original affective factor inheres in vocal speech.

Note 8, page 71. A like relation remains imberlded in sensory experience of a mature and conscious order, where tho primitive organic significance persists. Thus it is sometimes a nice distinction to detect when and whether, in eating, one gets 
first the agreeableness (or the reverse) or the recognition of what one tastes. Genetically the pain-pleasure feeling is older and retains the priority of impression when prompt action-as in rejeeting an intensely bitter or "hot" substance-is demanded. Familiarity merges pleasure and discrimination; and an effort of attention gives prominence to either, to the latter more readily. The most favorable observation is the unexpeeted one. If one has an aversion to parsnips and with lax attention conveys a morsel to the lips, casually supposing it to be potato, there is a momentary feeling of distaste, instantly followed by the recognition, "That's the detestable parsnips!"

Note 9, page 74 . As indieated, the term "hygienic" carries too strongly a eivilized flavor. We are prone to limit it to personal condition, separating it from the food-aceptances regulated by appetite. More generally considered, the latter is but a more intimate variety of contaet, carrying the specific and original reaction of disgust attaching to this order of offense. For purposes of exposition the "hygienic" sensibilities may carry with them the "food" situation as a whole, as well as the direct and indirect contaets of person and belongings. Pure food is part of the pure living to which Hygeia ministers.

Note 10, page 75 . Even when in the boliday mood of camping we abandon our customary standards with a certain zest, we carry our sensibilities with us and insist that however bare the table or surroundings, they shall be clean. That very insistence is born of the upper level of sensibility and is serving a missionary part in its reactions upon the lower. It is not so easy as is often contended, to separate the one order of sensibility from its kin and its favoring conditions and to maintain it above or isolated from its kind. Cleanliness costs in labor and expense and in the general emphasis and standards of life which it facilitates or requires: hence its true place in the psychology of the civilizing process.

Note 11, page 77. The naturalness with which terms of primary hygienic pertinence yield "moral" metaphors testifies to the affiliation of sensibilities for their kind. We speak of a clean record, of an unsullied reputation, of a character without spot or blemish, of a tarnished name, of mud-slinging, of a dirty low rascal, of washing one's hands of a transaction, of a 
foul deed, of contaminating assoeiates, and of tainted moncy. Note 12, page 79. Training and social status are nll-inportant. It is the issue of such training that falls away in that profound ehange of eharaeter which we eall insanity, and which when thus lapsing in a high-bred nature, produces the most conspienous and distressing impression of estrangement and alienation-a passing-out of one's self and out of the social standards of one's kind.

Note 13, page 79. Social expression and soeial reёnforeement of sensibilities are many-sided. Mere eonformity is often strong enongh to enforee, as is the taboo to forbid. Hence the vast differences in hygienie standards of different countries and in different directions; henee also the slow advance of measures of publie hygiene-perhaps the most characteristic of all the self-assumed white man's burden. The unhygienic act may come to be avoided for different and for mixed reasons, as the sources of the regulation of conduct and the motives of appeal are differently effective. Even superstition and the vagaries of folklore thus serve a large use. The Biblieal regulation of what is clean and unelean, both for food and person, and the ritual of purifieation and the symbolism of bodily and spiritual eleansing may be cited as an instance of the reënforeement of measures -in some part, doubtless, justified by experience-by a sense of religious and moral obligation.

Note 14, page 80 . The fact that abnormal aenteness of sensibilities (hyperesthesia) as well as of their absence (anesthesia) may oceur, is true also of the hygienic sensibilities. 'The excess is shown in the morbid phobia of contanination and in an abnormal absence of aversion, or in a perverted order of sensibility in which the thoroughly disgusting attracts.

Note 15, page 81 . The soeial implications of such a term as "gentleman" serve to illustrate its large subjection to convention and economie ideals. The phrase "gentleman of leisure" calls attention to the exemption from toil of the privileged classes -at least from directly profitable or menial labor-which may readily become the central connotation of the word. 'The gentleman having leisure is said to use this leisure for the cultivation of manners and sensibilities and thereby proves and tisplays the possession of the eoveted quality. See Veblen: 
"Theory of the Leisure Classes." The sensibilities, themselves the issue of leisure and luxury in the primitive scale of service, retain that relation in the invidious artificial scale of a stratified society. Practically the interests of one order compete with those of another, and retire or prevail according to nearness to fundamental needs.

Note 16, page 83 . The presentation does not consider the direct effect of the social sanction upon the act of eating. The very subjection to the need of nourishment has in certain civilizations carried a suppressed sense of shame. The seclusion attending the ceremonial in Oriental countries suggests this. We feel it in the embargo against eating on the street. When young ladies were subject to ideals of fragile delicacy, their spiritual life just barely compatible with a bodily one, they nibbled at food and disdained appetite. A more natural, even athletic ideal readily dissipated the attitude. Yet the hungry male remains more robust and frank in his desire for nourishment, wore indifferent to cireumstances, than his more sensitive mate.

There is further no consideration of the reflex attitude of the social incorporation of the function of eating upon its individual expression. This brings it about that the social occasion is the excuse for eating, the circumstance that raises it above the selfish indulgence; its absence makes the solitary meal approach too closely to the level of unqualified use. The sociability that is promoted by the companionship of the table is not alone that of the community of need, but that of the relief of undue attention to the utilitarian aspect of the process. The communion of sharing salt or breaking bread together acquires a more refined, even a spiritualized significance. Contrariwise, the leaning toward solitary indulgence accentuates the "gourmand" aspect of character, the yielding to the tyranny of the flesh, the absence of the restraints supplied by other considerations socially valued. Still more pointedly does the comment apply to the luxurious indulgence of private drinking, which seems grossly unjustifiable without the social motive; hence the habit of promiscuous "treating" and the abuse thereof.

There is likewise omitted a reference to the preliminary preparations, the getting the house in order when guests are expected, whereby the cleanliness, tidiness, orderliness and good 
taste of one's "household" sensibilities are exposed to jud loment; and nothing is said of the pertinent test of table-minners, to which a social rating is attached. $\Lambda$ s usual the defections alfford the most convincing test. $\Lambda$ whward handling of linifo and fork, or leaving one's spoon in the cup while drinking, secus to expose a man's antecedents at a glance; yet obriously not tor their intrinsic offensiveness, but for the social rating attichurel to them-a force quite sufficient to convert innocence into suilt. Thronghout the series, the sanction of propriety disparages too direet sensory eagemess, and approves the outer expressions of finer appreciations of quality and fitness of manner thereto.

Note 17, page 83. By such motor regulation is meant the direction of sensibility more in the determination of what we do or refrain from, rather than of what we accept or reject. 'Tlie distinction is ever one of degree, but is important. 'The hysienie reactions are primarily to what is acceptable to the senses, a passive responsiveness, which, in turn, true to its natural serviee, directs conduct. But speech is conspicuously an active function, and places the emphasis on the active factor.

Note 18 , page 85 . The contrast may be indicated in the distinction between usage directed more by logical distinction or more by esthetic feeling. The use of "let" for "leave" or" "lay" for "lie," or the reverse, is a stumbling-block in which insight is a safer guide than inclination. Apt examples of the social-esthetic feelings are found in the numerous class of things that should be omitted-the avoidance of the superfluous-always an excellent test. The current tendeney of adding a superfluous "all right" to every assertion is correct "all right," but hopelessly offensive in style. Then those unnecessary prepositions! These offend the "tidiness" which inheres in the spirit of the English language. The superfluous offends; so likewise does the meager by its suggestion of poverty of resourec.

Note 19, page 86 . The same applies to attractions as well, in which case the desire to complete the stimulation mity be strong. A good example is the attractiveness of polislied ur otherwise interesting surfaces to the touch. Few persons resist the temptation, in passing along a marble corridor, to feel the smoothness of the stone, the sign of which the eye reeognizes by its bright reflections. The common sign, "Do not touch," indi- 
cates how much more satisfying is the message eonveyed by the tangible and feelable than by the merely visible.

Note 20, page 86. "Contact" is our conventional "tactile" word for the intimate association, in which, however, odor often plays a notable part.

Note 21, page 89. In further illustration the literary critic or littérateur differs from the philologist in his larger employment of esthetic judgments; the bent of the latter is scientific. Even in so minor an issue as the establishment or defense of usage, varied importance will be assigned to principles of reason, precepts of good taste, and the sanction of custom. The question is more often not as to what the verdicts of either may be, but as to which shall be accorded the precedence.

Note 22, page 91 . As cited in note 8 , a certain unpleasant flavor comes to mean parsnips, the "taste" of parsnips. Instances diverging from the usual are often instructive. The tactile sensibility as exereised upon the appreciation of form is ordinarily so subordinated to the visual, that one ean hardly realize the possibilities of its independent development. The blind necessarily are depenelent upon it; and blind sculptors and carvers occasionally appear whose work, conveying the truthful impression of the hand, is accepted by our visual standards. The biography of so remarkable an individual as Miss Helen Keller is replete with instances of the richness of sensibilities which the hand may develop when its resources (neglecting the clews of odor) are alone available. Once more we realize that we develop the sensibilities by support of the senses most fit or eonvenient for the purpose.

A slight example of the interference with an established association between the senses may be observed in some of the artificial "Burbank" fruits. A plum presents the downy skin of a peach and is sampled with a sense of surprise, but is accepted by its flavor as a plum. Such hybrid sense-experiences are rare. Doubtless, however, our eyes mislead our sensibilities. Things may look dirty or nasty and actually be quite clean. Fortunately the same susceptibility to education may correct as well as establish associations.

Note 23, page 93. In this connection Thorndike's conclusion from the point of vicw of origiual nature is pertinent. "As 
to the aim seen $a b$ extra, the end as gained rather than as foreseen, no instinets have surer utility than the apparently objectless voice, eye and finger-play. For the end of voice-play is language; the end of eye- and finger-play is knowledge. In the long run the apparently random voiee-play is more usefinl to tho species than the speeifie calls of hunger, pain, fright, protection and wooing; the puttering with eyes and fingers is more useful than the movements of flight, pursuit, attack, capture and eating."

Note 24, page 94. A somewhat grotesque instance of the disregard of the prineiple is found in the philanthropie provisions of bath-tubs in tenements the ocenpants of which find no place for this prized symbol of hygienie reetitnde in their range of desiderata; the convenience of the tub as a bin for coal or potatoes determines its use.

Note 25, page 95 . Usage is often suggestive as embodying the insight fixed by a psychological "sense." We speak literally of a sense of color or of a musieal sense; yet also by analogy of a sense of propriety; a sense of honor, shame, duty; of a dramatic sense, and a soeial sense. The eommon implieation is that discernment in these varied fields is guided by a selection similar in function to the sensibility of the ear or eye; these are natural, and the others acquired, orders of sensibilities, yet subject to like eultivation. Once established, they select and proteet after the pattern set by the innate sensibilities.

Note 26, page 100. What from the point of view of sensibility becomes a corollary is in its own setting the leading thesis. The position of the behaviorists in psyehologieal theory, and no less the interpretation of the division of funetion of brain-areas, derive their psychological basis from the central place of action in response. Sensibilities become supporting, introduetory inciters and modifiers of responsiveness and in sueh service find their true value; we have our being in doing, eonstantly and at all stages. The philosophical implieations of the position are significant; they may be followed in sueh volumes as l'arnialce: "The Seience of Human Behariour"; Max Meyer: "Fundamental Laws of Human Behaviour"; Watson: "Behavior." Ou the physiological side the conception favors the view that all brain functions are fundamentally motor; that kinesthetie fictors play 
the central part in guidance, and that even the most sensory aspects of nervous response have a motor trend or tone. This is in the field of sense; a like application makes the essential part of the emotion its favoring of impulse and the direction of its expression. Such is the view of MacDongall: "Soeial Psychology." The bearings of this position will be encountered in later discussions.

Note 27, page 101 . In intellectual adjustment there is wide room for diversity of process according as the method of reasoning conforms more closely to the model built upon the discriminations which grow ont of sensibility and the powers of observation congenial to it, or follows the explicit principles of a formulated logic and a systematized orderly knowledge. The former process approaches the wood-lore of the hunter, the weather wisdom of the farmer, the practical versatility of the frontiersman, all of whom have to deal with the types of situations not too remote from those of natural origin. Such native shrewdness is readily transferred to commercial dealings which replace the more primitive encounters, and then becomes eharacteristic of the trader, the promoter, of the horse-dealer proverbially. The opposite type is the scholarly habit, the habit of the thinker, who ponders over relations and the principles of things, traces events to their causes and eventually acquires the disinterested curiosity of the man of science. These divergences of intellectual traits near their beginnings may prove to be momentous in their consequences in the later intellectual history of mankind. Their bearing is at once upon the problem of temperamental differences and upon practical issues.

\section{NOTES TO CHAPTER III}

Note 1, page 109. The psychology of the emotions is rich in problems; most of these must be slighted in the present exposition or some plausible conclusion assumed. For their disenssion see Ribot: "The Psychology of the Emotions," particnlarly the earlier chapters. The James-Lange view, regarding the somatic reactions as indispensable to the emotion-and antecedently so, holding that I am afraid because I tremble, or grow pale, and joyons because I smile or chnckle-is (with reservations) compatible with the applications here to be made of 
analysis; the more conmon reverse order of emplissis secms to be better sustained. The three phases of inlet, cmolional diflusion, and outlet, merge and fuse; and the motor alspeet of expression replaces any more explicit outlet, when emotions are milder, vaguer, broader, remoter in service. The emotim is drained in the expression; the outlet becomes the expressim, als the natural heir of the motor values of emotion. If sulficiently alarmed, I run or withdraw, or do something to avoil danger and escape its consequences; if moderately alarmed or repressedly alarmed, my only ontward indication is ny expresision; when amused there is nothing to do but to smile. Snch enrtailed emotional states, shom of their completing phases or realling them partially, circuitously, are altogether the most common ones in human intereourse. The ordinary emotional play is in terms of tendencies, attitudes, influences, incipient trends and threits and approaches of intention, all carrying a motor flavor but with no more real participation of an executive quality than is embodied in the expression; yet that element of expression saves the psychological formula.

The record of the physiological spread of the emotional wave requires delicate devices. The circulation is a sensitive index of emotional tone. The traditional designation of the heart as the seat of the emotions testifies to the popular reegnition of the relation, while such expressions as a "blood-curdling" sight, reflect the consciousness of cireulatory changes in extreme autation. The change of breathing in sleep when the sleeper withunt awaking responds to a disturbance and, as it ceases, resimes the deeper, slower respiration, shows the parallel fluctuations of states of consciousness and organic condition. The offect of emotion on the secretion of glands appears in the aetion of the salivary glands, and is felt as the parehed throat of emotional distress, or in the fact that the sight or flavor of food makes the mouth water. We sicken not only at repulsive and at appialling sights, but are digestively upset by emotional strain. 'I'laat conversely indigestion induces depression is familiar.

Dr. W. B. Cannon's "Bodily Changes in Pain. IIunger, Far and Rage" (1915) gives the experimental evidence that the adrenal glands are stimulated at times of excitement, that the secretion enters into the blood, and augments or induces the 
changes which accompany pain and the major emotions. The whole is an emergency mechanism particularly related to the intense moments when a life struggle or a major excitement is urgent, and calls forth energies not ordinarily available. That similar excitements of a transferred order continue to induce the same variety of effects is shown in the physiological changes of a like type in students (notably the sccretion of sugar) in connection with the excitement of an approaching football game or of a University examination. The digestive secretions seem chiefly an emotional product through the zest of appetite.

The most pervasive effect of the emotion is upon the neuromuscular tone. Positive or life-enlarging emotions like joy are dynamogenic, which means that under their sway, the release of energy is readier and fuller; while negative emotions, like grief, are literally depressing, diminishing the flow of energy. In so plastic a nervous system as that of the infant, the waving of arms and legs, and crowing and chuckling, in the joy of approaching food, of an attractive toy, of the welcome nurse or parent, makes a picture of dynamogenic reaction, convincing without other record. An interesting record is afforded by the "knee-jerk" (patellar tendon reflex). It may be interpreted as a result of shifting tension between the higher impulses in their play upon the lower nervous centers. When the higher centers are engaged in intellectual work or in an emotional excitement, the restraining tension is released; the tendon when struck a constant blow reacts more vigorously. The sound of music, the slamming of a door, the crying of a child, show decided effect upon the succeeding records of the "swing" of the knee-jerk. Equally pertinent are the records of fatigue-fluctuations in physiological as well as psychological work, emotionally induced, as by rivalry.

The fact that in some measure we can affect disposition by physiological as well as by psychological stimuli indicates the dual approach. We may cheer the disposition and release artificial restraint by alcohol or by sympathy, by good humor or good news, just as we may keep awake when drowsy by means of a cup of coffee, or by the help of an interesting novel or an entertaining visit. The restoration of reactive tone by suitable diet, exercise, elimination of clogging waste-products, is as much 
a part of the regimen in treatment of emotional depression or brain exhaustion as a cheerful environment, pleasant oceupation, restful diversion. It is further substantially true that by assuming the suitable expression of an emotion, we nlay, in part, induce or facilitate the inner feeling or at least dispel its opposite. A smile will induee good feeling, a seowl dispel it when no stronger or deeper psyeho-physiologieal conditions deternine the issue.

Note 2, page 110. It is obvious that some measmre of affective excitation accompanies the constant stream of the psychic life. The affective moment fluetnates about a nentral equilibrium which is however not a zero, but is itself the issue of the same range of forees that sends the eurrent up and down. When a voice rises above the murmur of the affective life and speaks in distinct tones, it is recognized as the voice of an emotion. It speaks with a purpose; and the message varies with the oeeasion. It rises to explicitness when the occasion is elear; quite as commonly it fails to become artieulate and merely imbues the response with a vague trend of conflicting and interaeting ineentives. Emotions dip down below the level of conseious report and derive their "genius" from the deepest strata of the psychie structure. Yet for the most part their discussion proceeds upon a recognition of their speeific eharaeter. It is in this sense that they are defined as the high-points of the affective wave. The analysis of the component forces of the wave is acknowledged as the fundamental task of psychology; and its equation, if it could be written, would contain about the same terms for the submerged as for the emerged points of the movement.

Note 3, page 112. The experiences of lion-tamers show that the uncertainty of response of "tamed" animals is similarly conditioned. An apparently subdned and ordinarily submissive lion will, with slight warning, suddenly turn upon its trainer with all the feral instinets of its nature aroused. The far more frequent cases of incipient rebellion quelled by threat or eowed by punishment shows the continuous conflict of original and imposed nature. The violent outbreak is doubtless indueed by an organic condition, for which the play of the finer rivalries of emotional impulses of human kind offer a remote but pertinent parallel. 
Note 4, page 115. It is suggestive that for human kind there are more sights and experiences that emotionally disturb the physiological equilibrium than do so directly through offense to sensibility alone. The effect is also more enduring by reason of the intellectual alliance. With the offensive stimulus removed, readjustment quickly ensues; or if it continues to disturb, it does so by its emotional associations. The impression of a bad odor fades; but the remembrance of a sickening aceident is constantly reinstated. It is the emotionalized sensibility that develops a moral and social sense. Remorse depresses and organically upsets; eriticism rankles and saps the flavor of enjoyment. Yet these effects involve a mature high-grade susceptibility.

There are various ways of bringing into relief the convergences and the divergencies of the sensibilities and the emotions. The community of response is clear; either may dominate in the recoil, avoidance, or aversion. The appearance may excite prudential retreat indirectly, or disgust directly; it may be a shyness, a withdrawal from strange contacts and thus fairly emotionalized, or a loathing and distrust close to the shunning by the affected sensibilities. As already explained, the rôle of the senses in the psychic endowment may decide. For human kind odor is largely exercised in food-rejections and similar situations (disregarding sex sensibility); its emotional play is limited. For organisms for which a large range of situations are olfactorily perceived and pursued, odor may form the common inlet to emotional excitement. The visual dominance of the human endowment favors the seen appearance as the emotional inlet; the close alliance of appearance with meaning favors the indirect intellectual route of emotionalism. When complicated by imagination-again dominantly a visual procedure-the response yet more completely sheds its "sensibility" aspect and stands forth as emotionally matured and independent. The variability and intricacy of the response remove it still further from the limited regulation that alone can be provided for by and in the mechanism of sensibility. The manner, motive, direction, and "meaning" reference as well as the esthetic flavor of an avoidance become more significant than the bare reaction.

Note 5, page 120. Flight is here used as a type-form of the fear-reaction. The emotion may be organically set to engage 
one or another phase of protective expression, or it may presint several trends and leave a choiee of response. There nerd not be a simple or a single response, since the nervous system is a meehanism that embodies composite and condlieting trends. 'Th" neglect of this consideration is the fault of such andyses as MaeDougall's, which makes fear the "flight" emotion, or sets it too definitely as an instinetive response to one specilie emotion. The natural strueture deeides. Animals that ean run fias and far will run when frightened, as the horse and deer and halle; slower ones, or those that run for short spmrts, will hide, or run to cover and then hide, as the mouse, gopher, partrilge; still more sluggish ones will withdraw within the shell, als the tortuise, or curl up as if dead, as the opossum or the eaterpillar; others will dive, like ducks or frogs; some will shout, like the crow. and others suddenly keep silent, like the eroaking frog; the young will run to the mother, as do chieks; the grearious will run to the protection of the herd, like horses or butfaloes; thourl frightened, the animal may still prepare for attack; like the monse, if bronght to bay, it may tum and bite, or like some orders of snake it may ehange color, eurl, and prepare to spring. Among human kind there are many instinctive responses, and they may all be observed under the same fear-inducing exeitement. A frightened man may run, may hide, may beeome silent, may turn pale, may eling to some person or thing, may start, may shriek, may call for help, may be rooted to the spot, may fight if restrained; all these expressions together make the bedlam of a panic. Such eomposite tendeneies may give eolor to the recapitulation theory-making it appear as thongh all the expressions of the animal ancestry of man had left a physiologieal vestige in his reative systen. I't it is more eonsistent to conjecture that the instinet is elaborately set in lis seneral reactive system, and gradnally leans to the expression most suitable to the occasion. In the end man "sizes up" the situation, and the more or less appropriate fear-response is summoned. He starts, or shrinks, or shouts, or elings, as oceasion warrants: yet he is prone to irrational expressions. The involuntary start remains beyond his control; the shriek comes quite withm it : men learn not to shriek, regarding it as a feminine privilegr. Plasticity of instinet and expression is the human privilengenot the 
absence of impulse but the choice among many. The choice is aequired, but upon a natural basis.

Note 6, page 121. Many varieties of attraction or shrinking are composite. Consider an humble instance: A "tenderfoot" fisherman removing the hook from the mouth of a fish, shrinks from the contact, the clammy sliminess offending his tactile sensibility; he has a sympathetic recoil from the possible pain of the operation and the forbidding appearance of it; he may be prudentially cautious not to cut his fingers on tooth or fin; and he may entertain the belief that if touched, the fish will sting. The shrinking is of several sources; the timidity involves mixed motives. But in most such cases, the timidity is aroused acutely by presentative moments. Let the fish flop violently, and the mild but controlled recoil changes to instant retreat and alarm-like the timid sleeper in a lonely house starting in terror at a suspicious sound.

Note 7, page 122. Accepting the fact of the ready access which sound has acquired to the provocation of fear, one may be inquisitive as to its souree. The most obvious suggestion is that the auditory susceptibility is an index of a gregarious fear. The tendency to shriek or make a noise when frightened would be a call or a warning to mates, and the sound more readily reaches the flock or herd as a signal for a collective stampede. It is not necessary that each of the flock should individually see the enemy; all profit by the alarm of any one.

Note 8, page 122. The so-called "fear" of thunder illustrates the composite source; it is partly organic; it may be reënforced by a knowledge of danger, but is essentially a direct reaction to the sensory effects upon a sensitive nervous system. To the sensory effect the atmospheric condition may contribute as well as the flash and the rumble. The difficulty of controlling such fears indicates how slightly the refleetive element and how largely the organic emotional element enters. The same consideration affects the morbid development of fears against which reason is of slight avail. We must also be taught to fear (or at least to shun) natural objects, such as poison-ivy, as well as artificial ones, "live" electric wires, for instance.

Note 9, page 127. It is clear that with reservation the view presented favors the "conduct" emphasis of emotion en- 

From Portrait in the National Gallery.

Square Iace, Outspread Nose, Short Neck.

See scheme, Chap. iv.

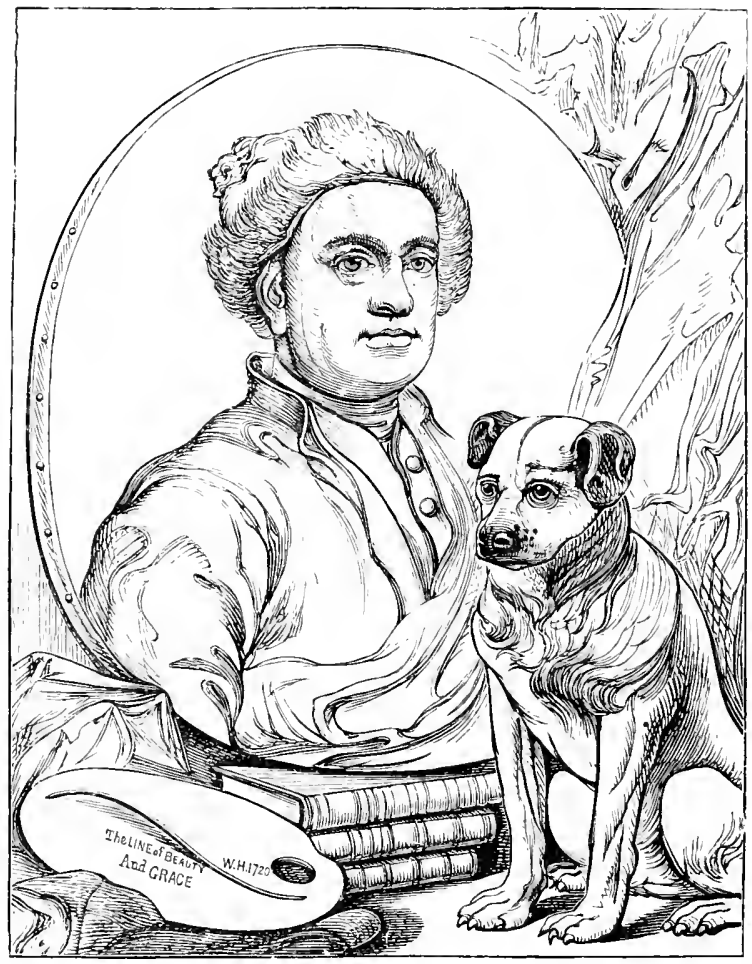

Other SANGUine Characteristics.

“ Wm. Hogarth ont of his apprenticeship is, I take it, a stuıdy, rucldy"complexioned, clear-eyed (blue eyed-Austin Dobson) rather round"shouldered young fellow.

"A healthful, sanguine constitution.

"He was an outspoken man, and his pencil and graver were as " unlridled as his tongue."-G. A. SALA. 
dorsed by James, Ribot, and MacDougall. The title of this chapter indieates that what hmman nature las joined tongetleel, the psychologist shall not put asunder.

Note 10, page 128. Even with this precaution ond maly fail to eonceive the primitive quite primitively (momels. 1): might propose the test that no emotion is primary muless it appears in the higher animal world, is manifest in carly lumbu infancy, has a characteristic (nervons and) physiological cxpression, and satisfies a natural need. If adopted, the test will nut lead far astray, but requires correction at $t w_{j}$ points at least; for it considers too shightly the "situation" faetor. First, it tails to consider that delayed situations give rise to delayed instiurts and emotions. The sexual instinct and its emotional life is a notable but not unique example; for walking, flying and other locomotive instincts are in prineiple of like deferred status. Second, varieties of instinct may be peculiar to the human situation, or essentially modified by it. Hence one might propose an early appearance in the race rather than in the indivituul as a proper amendment for certain emotions.

Note 11, page 131. Classification serves a useful purpose in suggesting the range and relations of the emotions. $\Lambda$ dillerence of emphasis of detail and of allowance for variation modilies the result. Mr. MacDougall's enumeration will serve as an example. He regards all primary emotions as embodiments of primary instincts. He distinguishes the instinct of flight and the emotion of fear as its indueing stage; similarly the instinct of repulsion and the emotion of disgust; next curiosity ats all instimt and wonder as its emotion; pugnacity as an instinct and an!er as its emotion; self-abascment as an instinct and negative selffeeling or subjection as the emotion; self-assertion as an instinct and positive self-feeling or elation as the emotion; parental care as an instinct and the tender emotions as corresponding ther.to. In addition he must find a place in the scheme for the instincts with more diffuse emotional tendencies; such as the instiun of reproduction-including sexual jealousy and female criness; the gregarious instinct; the instincts of acquisition and construclion. All that this enumeration implies is that these lmman instincts and the corresponding emotions represent the ehief primary varieties of conduct and modes of fecling. 
The classification resulting from the analysis in the text yields the following table:

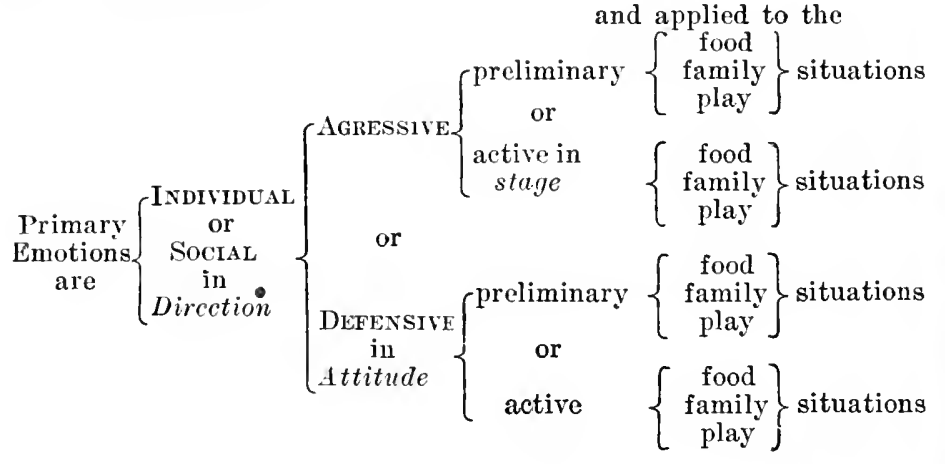

The above classification may be repeated for the social emotions, although the situations apply so imperfectly that they may be considered as merged. There will accordingly be fewer distinctive or nameable social emotions of primary type. They abound in derivative varieties, as the text illustrates.

Such a table does not imply that there are just the twelve primary individual emotions for which spaces are provided, or that each situation engages but a single emotion. Its purpose is to place and relate the chief emotions. Thus anger is individual, aggressive, preliminary, and may be aroused by play, combat, sex-rivalry, or any derivative situation; it implies self-assertion, which may be aroused in combat or in the chase. The food-situations are most specific; the play-situations most variable. "Family" covers such diverse attitudes as those concerned in courtship and in the care of the young; yet the coyness of the female in the one relation makes for tendemess in the other relation. Curiosity is exercised in nearly all situations. In brief the fusion of emotions sets a prompt limit to the rigidity and profit of classification.

Note 12, page 133. The original tendencies of man act piece-meal and in combinations. The potency of a situation is a compound of forces. Its bouds are real but there are so many of them that the best of inventories, if brief, would have to be a caricature. Original nature is not a set of perfectly independent mechanisms any more than it is a hodge-podge for chance. It is a cluster or hierarchy of mechanisms with very many compo- 
nents, of which many coöperate in response to any one situation. "An approaching man may, by the peculiar combination of size, rate of approach, gesture, facial expression and cries which he offers, and by the peculiar combination of darkness, familiar surroundings, hmman companionship and plysical contact, full stomach, wakefulness and so on eharacteristic of the coneomitant situation, draw on a score of different response."-Thomdike.

Note 13, page 142. A characteristic contrast may be observed in the rigid, smooth. intent. featureless set of the face in certain forms of insanity, in which all outward and social play of the attention and interest is obliterated, and the convirumm exists not at all or only as the object of maniacal detemination. With the alienation of the social impulses the fare becomes a waxen mask: the flexible museles are deserted by the indwelling mind. In other types of insanity the muscles obey the physinlogical impulses and assume the set of features presumably withont the accompanying emotion; the vacant expression of idiocy is of this order.

Note 14, page 142. The emotions expressed by facial and by other gestures or attitudes are of one nature: and attention may be limited to the leading rôle of the face. The senses as foremarning and forearming heralds become concentrated in the head-the ranguard of the body in adrancing morement. The eyes, as the leaders in reconnoitering, absorb the chief interest and become the center of attention in guidance of one's ow approach and attack, and in noting and meeting the morements of the enemr. Teeth (and clams) form an able support or bodrguard: and the primitive foray is so dominantly conducted as a food expedition that the mimiery of mastieation persists. With these two foei established, the face becomes the center of expression. The expressive nostrils gude the fool-reactions and regulate the breath. the organic barometer of effort and excitement: the roice serres for social appeal. intimidation, etc. Primitive expressions mar be more directly traced in the infant than in the modified and restrained expressions of adults, where, however, the finer differentiations are to be found. The child. like the expressive animals. shows the diffuse emotion radiating orer the mobile body. particularly finding an outlet in hands and feet, even in fingers and toes. The adult becomes by restraint 
largely a facial specialist in expression. Within the face the month is more markedly the center of facial expression in the child than in the adult.

Note 15, page 144. To continue the problem of expression: (1) The physiological vents or expressions of emotion posit other and perplexing queries: Why shonld the contraction of the tear-glands serve pain, and by this route grief and the selfabasing as well as the tender emotions? Why do we blush, and seemingly only in connection with a mental stimulus? Why does tickling produce laughter, and why the shrinking of fear or of sensory aversion, why cold shivers or goose-flesh? (2) The problems of specialization are many. The release of impulse may require effort; effort shows itself outwardly, and thus develops an expressional mien. Redness, restrained breath, muscular strain are its signs; the brow wrinkles, and certain special furrows form at the root of the nose. This last, as the slightest and most mobile contraction, becomes the sign of mental effort, in its most delicate nuance of thonghtfulness, contemplation. Effort may stand close to pain or in the mental counterpart, to worry. A worried thoughtfulness is a familiar expression, read largely in the furrows of the upper face. The specialization may be nearer to the source; as the sneer of disdain points back directly to the snarl, which is the raising of the special musele to expose the canine tooth. It is likewise associated with the half-closed eye of aversion, and may be most delicately shaded to so faint a suggestion of a slighting disregard as to belie its remote descent from so coarse a mien as a snarl and a baring of a tooth. The supplementing of expression by the vocal gesture is peculiarly significant. The smile becomes a langh, and the index of joy is more strongly attached to the vocal than to the visual sign; though the facial mien remains the more specialized. The tone of voice merges with the set of features in stern command, in pleading, in pitying, in anger and reproof. Through the medium of communication in speech, the voice contributes the emotional value to the word. It plays this part because of its original qualification in the sob, the sigh, the moan, the groan, the cry, the laugh. (4) The persistence of expression is shown convincingly in its dissociation from serviceable habit. Natrre cannot be prophetic, for nature is reminiscent. The dog's bark as now exer- 
eised may serve only for the escape of his prey; the expessimn seems linked to the wrong oecasion through ehange of situation. Just why the hen should become so vociferons on laying an egre is not easy to explain; nor why Chanticleer shonlel so noisily greet the break of day. That such response is the organized course of agitation induced by specialized states is clear, and must be accepted as an index of minor serviceability under other cuntitions. (5) As persistence expresses original and uncontrollable nature, the control or assumption of expression indicates the acpuired factor. The supremacy of the former appears in the inilility to summon the full expressional quality artificially. 'The "stage" laugh and the "society" smile are transparent imitations; the real emotion alone has access to the museles of expression in minute detail, and alone ean summon the genuine expression. Affectation has its limits, and therein has true emotion its protection. Yet training may be carried indefinitely far, partienlarly in the direction of repression. Decorum and convention may discourage facial play almost to its extinetion, and thereby impede rearly understanding. To what extent suppression of the expression suppresses the emotion is doubtful. The search for an anthentie elew when the individual interests require suppression as in case of guilt, has led to a psychological "third degree" in the methorl of psycho-analysis, as well as a reliance upon the physiologiteal record. (6) The reduction of the sources of expression to a few explanatory principles is bound to shift its emphasis as the problem is differently approached. Darwin's original three prineiples, despite the legitimacy of the criticism expressed in regard to their inadequacy, retain a general validity. The "associated serviceable" habit" applies to the more specific expressions. In man these are early overlaid with the products of imitation. The seeonel prineiple of "antithesis" has been most questioned. It is more defensible if interpreted as an opposing tendeney within the nervous system. Thus, assertive emotions contract the dor'sal museles, and depressive emotions let the ventral ones prevail. This principle supplements the third prineiple of "nervous discharge" by" organized route, not specifieally of associated serviceability. Much of human facial mimiery is a composite of all the somrese; yet the standard reference of an expression is to the sitmation which it suggestively if remotely pietures. 
Note 16, page 144. It is possible to connect the instinctive responses with the later reactions; in this sense nature in its incipient trends may be prophetic of mature ones. The struggling, fist-clenching, striking movements of the infant when held, and the similar kicking, stiffening of the back, and skirmishing with the arms when crying, seem aimless as well as helpless. They may foreshadow the destructive tendeney which induces the smashing of things in rage, and the ready irritability when jostled. The infant can express only what its motor development commands. In a sense the infant is antieipating the destruetive resisting eomplex, while yet inadequately matured to exhibit it.

Note 17, page 146. A few further instances from animal life: In the experiments in compatibility made in zoological gardens, it is often an uncertain issue and a matter of critical coneern whether a mate or companion offered to the more feral beasts will arouse the sympathetic play-instincts or the combative ones; and this applies as well to those of their own kind as to the strange tolerances and friendships among diverse species. As an instance of aequired conflict of emotions, note the attitude of a dog abont to receive corporal punishment; he responds to the call in abject humility, dragging his shrunken body slowly to the whip, yet controls any tendency to shrink or run away. He forms a complete picture of physical submission triumphing, though with evidences of the conflict, over rebellious flight. The situation finds its higher analogy in moral courage or resignation. A like uncertainty of emotional response makes neeessary the largest psychologieal slitl in the handing of men.

Note 18, page 154. Clearly objects cannot arouse emotion and become incitements to response unless they first arouse attention; the start of fright is the first signal to the mind that anything has occurred. The tendeney to be startled is itself a nervous disposition. For all complex emotional states, the range of experience is decisive. I may be startled by a sudden noise; but if it is often repeated $I$ am no longer disturbed.

Note 19, page 159. The emotional point of departure of such experience appears in the hysterically matured relation in which the recurrence of a situation or of a referenee to it or of a situation of analogons type precipitates a moment or a period of distressing psychical agitation; the upset revives the emo- 
tional shock associated directly with an original disaster. Of such process of revival the dominant eonscionsuess is unal are; yot the similarity of the indueing oecasion is of sneh lipht-granle interlectual order, though disguised and indireet, that it reyuires for its recognition an intellectual operation, or coöperation.

The abnormal expression reveals a tendeney to overdo, to develop an extreme or a distorted proportion. The vitality for such overgrowth is derived from the transfer of the primitive vigar to a related or remote issue of the original cmotional impulse. With this tendeney there combines the natural trend of emotion, onse? attaining mastery, to grow by its own momentum-much as when once the center of gravity is lost, the further crash is inevitable.

Note 20, page 170 . Of the more specific individual application little need be added at this juncture. To say that one is irritable, combative, proud, shy, timid, sensitive, sympathetic, harsh, critical, complacent, gullible, is a easual judgment that unc set of qualities is more readily summoned by the ordinary run of situations than another.

\section{NOTES TO CHAPTER IV}

Note 1, page 176. This type of argument appearcd in the discussion of facial and related expression. Primitive emotions took possession of all the available museles; later emotions had to utilize the same outlets and modify and refine their use to later purposes. The psychological analogy is close. The socialized and intellectualized "expressions" continue the carlier, self-centered trends, and are conditioned by them.

Note 2, page 177. The comparison of animal emotions with those of children is beset with the difficulty that the situations under which the emotional impulse develops are so widely divergent in the two. The capacity for development of infant emotion makes it a different emotion at the outset. In the animal the emotion can (largely) at once take the trend of its mature nature. The difference appears in the use of the terms-all of them dorived from human psychology-which we are willine to aptly to the animal mind. Thus we are more ready to admit that durs show jealonsy than that they show shyness. If we interpret shyness as an impulsive shrinking from certain contacts, particularly unfamiliar ones, there is no diffienlty in eomparing the instinctive 
shrinkings of ehildren, and those of dogs, and recognizing how much they have in eommon. But if we have in mind the form that shyness soon assumes in ehildren, with its element of selfconseionsness added to the organic factor, we prefer to restrict the term to the humanized variety of shrinking. The two begin on much the same level; but shyness moves so rapidly away from this bare organie shrinking that we find it desirable to make the distinction. Jealousy seems to maintain a more intimate relation to the situation which is its common emotional stimulus. It develops to a very much richer status in the human kind, but retains enough of its primitive character to warrant the statement that dogs as well as children may be jealous. Adoleseent shyness and the jealousy of sex rivalry may require no new terms, but they imply new areas of emotional enlargement.

A similar comment applies to imitation. If it occurs at all in animals, it is limited to high-grade organisms. In infant psychology, imitation is limited to the more deliberate actions established upon the basis of habit and training. Cases of apparent imitation abound, but find their explanation in the like appeal of like situations to like endowments. Once within the field in which training enters, the scope of imitation rapidly enlarges.

Note 3, page 183. Such emotional attitudes as jealousy, envy, shame, pity, surprise may be so defined as to limit the quality to man, possibly to man of higher mental development; the latter would imply an introspective reflection, a deliberate intent-the whole set in a system of emotional and intellectual tendencies. It is also possible so to define jealousy (and more or less the other emotional states) that the behavior of the higher animals and of infants meets the qualifications. Confined to its full-blown issue, jealousy is undoubtedly a "sentiment" in the strict sense presently to be defined. Considered as a social complication of a close-to-nature competitive impulse, the trait becomes an example of the course of a primary impulse which germinates early, flourishes in the middle psychologieal zone, and grows to a considerable sentimental elaboration in its highest products.

The term "social" cannot be confined to a single sense. The dominant nsage has been set by sociological considerations; its connotations hamper, yet without seriously disturbing psychological purposes. "Sociability" has come to mean an exercise, in 
the favorable and friendly sense, of a social trait; "inti-suriall"

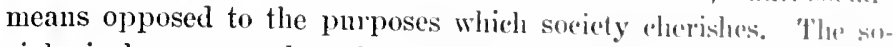
ciological usage makes the value prominent; the purduluminal sense is more neutral, and thus broaler. 'the contrist with "in. dividual" is inevitably nneertain. When the selt"-senking tromls are systematized and explicitly realized they becone "indivinhalistic"; yet "individualism" refers to a philosinhtical pusitim, making a elaim for an intellectual and social liberty relliasul from the imperious sway of the imposed conventions of socicty; while "socialism," which should designate the opposite emitention, has drifted to imply a special and peculiarly liniterl mogramme or policy. Under such circumstanees the psyeholourist has no course available but to place large reliance upun the enutext and bearing of his analyses to convey the simnifieant fealures of his usage. "Individual," as here used, describes the bearin! of a trait with reference to self-interest; it is the self-centered aspect; and where there is no social play, it is the primary and exclusive functional import of the trait. The "social" is the group-aspect of the trait; it includes the reflex effect upon the individual aspect induced by the social reference, and it includes particularly the aspects of traits which would not energe at all without the presence of the social factor and setting.

Note 4, page 184 . The rivalry inherent in the competitive struggle for existence develops both jealousy and emulation. As these two trends diverge, jealousy becomes the attitude of injurcol self-esteem due to the absence of expected preferment and the painful enhancement of desire by the thwarting of impulse. Emulation is the positive spur of effort by the adderl zest of excelling above another, above all competitors; it is the transter of the joy of possessing to the joy of defeating, ant is thus allied to triumph. MacDougall suggests that the impulse of rivaliy may be the impulse "to playful fighting, the impulse of an instinet differentiated from the combative instinet in the first instann an the animal world to secure practice in the movenents of comblit." $\mathrm{He}$ points out that the impulse to emulation is strong where the combative impulses are strong, and weak where the latter are weak. He cites the traits of the mild Ilimbo and linman, in contrast to those of the strenuous Anglo-Saxon; the one is pronceable and finds no interest in games of rivalry, the other boasts 
that its heroes are trained on the ericket-field. To the unwarlike people such games as football seem irrational, while the warlike Maoris take them up with zest and suceess.

Note 5, page 192. Mere contagion is limited also in the gregarionsness of animals. It becomes much more than a slavish following of another's responses; for the actual "following" becomes selection upon a (limited) intellectual basis. When a pack of hounds has lost the scent, there ensues a scattered and random search among the more energetic or knowing members of the pack; the more confident alarm of the hound that regains the trail brings the pack after him, each follower possibly proving the scent as he runs. Leadership is provided for in the gregarious response when it is set in an elaborate system of instincts. The social endowment thus includes a double impulse: the tendency to follow and submit, and the tendency to lead and impose. The former matures the submissive, the latter the assertive qualities of the self in the social relation. The gregarious habit must not be thought of as a simple contagion of disposed impulse; it is capable of complex psychological expression according to the psychic capacities of the constituent individuals. Gregariousness takes its set from the status of the natural unit of grouping. If this is the family-strictly or liberally defined -the helpful relations developed by the care-of-young situation will play a large part in the collective impulses of the larger groups or flocks bred in different nests. The social capacities of man are so much more versatile and so much more highly intellectualized than those of animal societies that their adequate consideration requires the resources of a sociological system for their interpretation.

The topic is more involved than is indicated in this treatment, which is intended only to outline the place of gregarious responsiveness in the evolution of sympathetic emotion. Sympathy must assert itself against the stress of other impulses. It has a precarious hold in man and is readily silenced by the primitive stress of stronger, earlier impulses; the impulses of mastery readily include subjugation, and the signs of subjugation are suffering as well as cringing-both incompatible with the emergence of sympathy. It is the less urgent and more playful situation that favors the emergence of sympathy; the "fair play" 
spirit-one of the sources of the sense of justipe-may ussert itself, feebly suggestive of the golden rule, while its elimination from love and war in which all is fair, places those contests upon the non-sympathetic basis of urgeney.

Note 6, page 195. The use of the term "ideo-motor" to express the motive force of an intellectual or an intellectualizoul process, though challenged, is legitimate if it means only that the idea is an acquired inlet to the sensory discharge. Initation is ideo-motor; suggestion is still largely sensori-notor; contagions sympathetic response wholly so. The distinction between strongly intellectualized channels of impression, with a weak sensury tone, and strongly sensualized impressions, with a weak intellectual flavor, points to a signifieant evohtionary contrast. The finet maly be otherwise stated: it means that the mind comes to respond to a mental situation as it would to a physieal one, to one of representative status as to one of presentative status. The latter is the original experience and remains imbedded in and supports the other; the latter is a weaker, derivative appeal. It is the weak hold of representative experience that limits its influcnce; it requires as a rule a strong dramatic incident to enforce action, where argument fails. The older type of response dominates; nothing can replace the warmth and cogrency of experience. The emotional reënforcement is one of the ways of griving to an "intellectual" situation, an imagined situation, a like vitality as attaches to the actual experience. Description is vivid as it summons the presentative values of the scene and its emotional impressions.

Note 7 , page 197 . The fixation of this bounlary line forms one of the perplexing problems of psychology. Exprerinental studies have proven that imitation is a higl-level prodnct. Allowing for possible and limited exceptions, animals do mot learn by imitating' one another; children do. The apparent "aping" of apes is due to their strong curiosity, the similarity of their responses to similar stimuli. The training of animals must be imposed from first to last upon each animal. Their greminious responsiveness does not specifically help the trainer's tisk.

Note 8, page 202. Maternal devotion means the arousing of tender feelings by the sight, touch, call of the young; it implies a strength of such feclings sufficient to assert themselves 
instantly and above the appeals of other emotional responses which the trials and eares of the young may present. This favorably prejudiced attitude toward the child matures the sentiment of love, makes the child the object of love. Upon the child are concentrated the full richness of tender feelings, longings, hopes, solicitudes, endearments, which in psychologically qualified persons release the sympathies, and create a sense of satisfaction in the joys, a sense of grief in the pains and sorrows of the clild, and a striving to further the one and prevent the other by any measures, in disregard of the sacrifices of self which they may entail. Altruism in the actual range of its exereise is a rast expansion by artificial protection, of a slender root, thriving uncertainly in the rigors of the natural habitat. It is essentially a garden product, a cultivated variety of human response. The altruistic quality enters vitally into many relations: patriotism, religious zeal, moral reform, social service. All are supported by a disciplined and elevated human sympatliy.

Note 9, page 209. The development of plays and games parallels in its appeal the development of real experience. Solitaire is but a pastime, lacking the true quality of an opponent or participant or the expression of sociability. The social quality becomes the core of the play. Good luck or skill brings approval that enlances self-esteem; losing and winning may carry the burden of the interest, yet are socially reënforced. As diverse as the fortunes which plays and games are devised to provide-commonly simulating the fortunes of life itself-are the social motives from which they spring, to which they appeal. The enjoyment of play is saturated in the medium of sociability and proceeds upon the lead of sympathy. That play also illustrates the battle of wits will not be overlooked; yet it is sustained by the competitive rivalry and the pleasure of gain; playing may be gambling as well; the financial stake is at best but an added zest, and to many, because of its economical-moral intrusions, a marring of the play interest.

Note 10, page 228. The theory of modesty is not clear, especially in relation to modesty of person and demeanor. The physiological "record" of blushing complicates rather than aids explanation. Even if capable of the expression, animals could 
not blush for shame, or feel shame in expesure of the burly, though in man blushing is most readily ealled forth by bulily axposure or its suggestions. Yet it has been drawn into the feyche

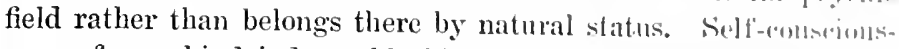
ness of any kind induces blushing in those disposerl thereto. It is aggravated at the period of late adolescence and is wealiemon in later years. It is most readily aroused by social cmbirritsiment; there is presumably more blushing by reason of shytuess than by reason of shame, despite the readier association with the latter. Yet embarrassment is in one sense a deliente, refincel and innocent form of shame. The subjection of shame to the social influenee is more than an indieation of the direet pressure of that sentiment alone. It is markedly affected by the generil somso of conformity which is the common exaction imposed by society for a share in its benefits. It is a violation of conformity, however innocent or even morally commendable the course taken, that brings the sense of shame. This is true of modesty in clothing (such as the prejudice against the ride-astride saddle for women) or of non-conformity to a social custom, such as the giving of fees, which continues as Thorndike observes, beeause "no man is brave enough to withstand the scorn of a line of lackeys whom lie heartily despises, or a few onlookers whom he will never see again." Similarly a man in formal dress without his necktie would be as intensely ashamed as though the rest of his alprarel were quite insignificant.

Social standards affect the readiness with which we yich to and display sentiments or the emotions which inspire them. liy this influence they affect the occasions of expression of the more primary emotions, such as fear. Girls and women are permitter to feel and exhibit fears which would be repressed so far ats they are felt by boys and men. The more intimate relation of shime and modesty to the feminine psychology equally modities the antventionally permissible for the two sexes. In the man it is as much a difference in the outlets of the emotions as of their prisence. Courage is held up as an ideal for boys more consphinoms!y than for girls; but feminine courage is still more signifirantly ditferently expressed than is masculine comrage. The two sexes atre in a measure proud and ashamed of different thims more than they vary in their participation in the sentiments of priele and 
shame. Racial and national ideals are sinilarly operative. The effusive emotionalism of the Latin races may indicate a readier play of sympathy or a more sanctioned approval of its expression.

Note 11, page 229. The fact that we also regret what we fear does not impair the pertinence of the analysis. Sorrow also goes out to losses, failures, frustrations, actual or imminent; the unpleasant affect spreads over both. Fear and dread are painful, at the least, unpleasant experiences. By the similar analysis hope and joy share in a common tone and go out to like welcome and pleasant experiences in realization and anticipation.

Note 12, page 231. A practicable scheme for the classification of the sentiments is the following: Sentiments are (1) general emotional; (2) intellectual; (3) esthetic; (4) moral; (5) institutional; (6) special complexes. Many of the sentiments result from the interaction of the tendencies which these group-headings specify, and accordingly belong to or spread across several groups; sub-types are readily distinguished.

(1) The general emotional elaborations are represented by those reviewed. Their central reference is to the welfare of the self; their most constant application is in the standard contacts of men in "social" intercourse; they grow more directly out of primitive relations and present significant stages of development. Jealousy, pride, sympathy, solicitude, humility, love, hate, revenge, joy, sorrow, despair, repugnance, etc., are its forms.

(2) The intellectual sentiments represent an emphasis, the directive play of a function present in sentiments in general; there are similarly no purely intellectual sentiments but many dominantly intellectual ones. The type-form is curiosity, an attitude of motive interest in the pursuit of knowledge. The satisfaetions of consistency, logicality, and the several allegiances and enthusiasms characteristic of the scientific temper are examples of its play. The presence of the intellectual flavor in sentiments elsewhere centered is notable.

(3) The esthetic sentiment bears the general name of the sense of beauty. It dominates in all the arts, and subdivides finely as these arts develop special techniques. The picturesque, the dramatic, the comic, the tragic, the sublime, the romantic, are dominantly (or even exclusively) esthetic. They merge readily with 
intellectual, and, in a different issne, with the moral sentiments. The esthetie quality frequently plays the part of contributing the form, tone, color, or manner of the sentimental regulation, when the content is contributed by another (typically, the intellectual) phase of human interest.

(4) Morality is rieh in sentimental produets. It is itself in sueh close relation to emotions and their social expression that the sentiment is its characteristie issue, though its formulation in prineiples requires intelleetual support. Conscience summarizes its attitude. It may elaim truthfulness, chastity, altruism, reverence, loyalty, justiee and other virtues; sin, guilt, indulgence, brutality, covetousness, insolenee, eruelty and other vices. The virtues of morality and the graces of beauty are frequently allied.

(5) Institutions as naturally develop sentimental speeializations as they grow upon them. Justice as fair dealing is a moral sentiment, but is coneeived and practiced under institutional provisions. Such sentiments as conservatism, patriotism, demoeracy, soeialism, are strongly institutionalized. The same may be said of eourtesy and similar formal regulations.

(6) This division is strietly umnecessary, as all sentiments not referable to one or another of the groups enumerated may be referred to variations, combinations and derivative forms of the others. Yet it may be useful to indicate the comprehensiveness of such sentiments as gentlemanliness; the "gentleman" is both an ideal, an emphasis of sentiments, and an institution. Chivalry, piety, religiosity, individualism, Christianity, Puritanism, Hellenism, Amerieanism have similar bearings. Selecting a typical quality from each group, we may reach an ideal of humanity as a sympathetic, diseriminating, conscientions, just, refined gentleman.

Sentimental fusions abound. Fastidiousness is esthetic and moral; mysticism, pessimism, liberalism, tolerance, epieureanism, aseeticism, stoicism are intellectual, moral, and, it may be, esthetic. Wonder, awe, surprise, admiration, are intellectual and soeial in the first instanec. The aneestral sentiment is general (pride), institutional, and social. Democracy is a eomposite sentiment, as are also charity, opportmuism, the esprit de corps of professions. Language develops sentinental associations with 
words and usages; in the attempt to analyze the basis of offense in non-conformity to usage in speech, manners, fashions, we come upon the compositeness of sentimental regulation. To explain the status of nobility, vulgarity, Philistinism, ceremonialism, Chauvinism, slavery to fashion, sensationalism, requires a reference to the several type-forms of sentiment. The spirit of different ages, communities, movements, proceeds upon distinctive perspectives of sentimental components.

Note 13, page 234. The social sentiment determines the attitude toward offenses as toward criminals, and it is thus itself gauged by the general cultural status in which it finds a place. Medieval tortures seem to us inconceivable and to disclose the imperfect moral advance of the days in which they flourished. They seem at once eruel and unenlightened. Social sentiment in its composite reflects the place of the several sentiments in the social structure; the ordering of life indicates which types of sentiment are supported and which slighted, and how each group comes to expression. It is also pertinent to add that such social sentiment is not of one order or stratum, but promptly subdivides along the distinctive lines of the social organization. The sentiment of one class diverges in part from that of another; each group imposes upon its members the code and the power of its traditions. There is honor amongst thieves; and the attitude of the offender toward the machinery of justice as well as toward the social establishments which he slights or attacks, must also be taken account of in the psychology of criminality. It is in these aspects that the social sentiment develops and may be considered as the traits of organized groups of individuals. See Chapter VII.

Note 14, page 239. It is neither possible nor desirable to supply a survey of the psychology of the rational processes. Of the accounts available in psychological treatises, that of Lloyd Morgan: "Introduction to Comparative Psychology" may be recommended in connection with the present exposition. The type-forms of thinking and the place of thought in the securing of control are on the whole but few. It is the delicacy and intricacy of their application and the enormous consequence of the thought-processes in securing a rational control of nature's ways and resources and of an understanding of human behavior, 
that makes the world of reason so dominant in the shiping of the world as we see it and respond in it and to it. Sece chinptor VII.

Note 15, page 241. The similar bearing of intelligetse? sensibility (Chapter II) should be recalled. It leals to the distinction between dulmess of pereeption and stmpility in adjustment-the imperviousness to relations. 'The primary sivile of the intellect is in differentiating situations; and this process tontinues to ever-increasing accuraey and refinement, in elassificntion, association, systematization, and in the association of their products with proper responses or preparatory attitmies. In such primary service the intellect is greatly aided by sensibility. The intellectual specialization thus initiated leads to far-reaching consequences in the reconstruction of the human estate.

Note 16, page 243. It will not escape attention that the development of concepts and the introduetion of standards and ideals, of attitude and belief, and of the systems of thought and institutions in which all these are embodied, play the largest part in the actual measures of establishing social control.

- Note 17, page 247. The omission of the moral sentiments in the lineage of the higher phases of psychic control may appear to be as fatal as the omission of Hamlet from the play. Perhaps the simplest of the sentiments clearly moral in stature is justice; to find a place for it in original nature or in its early derivative issues is far from simple. Its growth is substantially a social product. Why soeiety should aim at justice is clear: why the individual should be so inclined is not. For these amel related reasons it is better to review this problem in eonuection with the mature produets of the moral sentiments in the social fabric of the environment.

\section{NOTES TO CHAPTER $\mathrm{T}$}

Note 1, page 248. An application of the reent reconstruetions of the theories of heredity would be premature. A eritical point is the determination of the unit-character. Are there such claaracters, and what are they? In low far are such pualities as musical ability, or a refined color-sense, or a general intellentual aptitude, or a special mathematieal gift, or a moral sense, or man- 
ual skill, comparable to tallness, eye-color, early aging, muscular strength, longevity, a tendency to gout, to adipose tissue, baldness or other failing? What is the clew to the alphabet of heredity? These questions are imperfectly answered. An important aid to their comprehension is afforded by the heredity of defects and extreme variations. Idiocy and genius, color-blindness and musical incapacity, neurasthenic and hysterical as well as phthisical and diabetic dispositions, mental and physical signs of degeneracy, illustrate the scope of hereditary factors, and through their presence in families and stocks reveal a similarity of mechanism. A somatic unit-character is a tendency toward a definite mode of response. Temperament as a special disposition is hereditary; and psychic abnormality is the cxaggeration of a marked temperamental trend. See Chapter VI.

Note 2, page 252. Gross defect is rarely enlightening. One does not speak of the temperament of the idiotic or fecbleminded, because the term is reserved for the middle scale of psychological variation. Idiocy may be viewed as the extreme stage of the inert, apathetic, phlegmatic temperament, with sensibilities, impulses, emotions, coördinations, severely reduced, or even distorted. For the feeble-minded and the high-grade idiot, the formula is not so simple; and it may require expert tests to reveal the departure from normality. Disproportion and limitation of development both enter. In a comparable sense genius represents the extreme variation of a temperamental trend. It follows as a rule a strong, specialized disposition, based upon native endowment. Excess offers more complicated departures from normality than does defect, yet in its extreme departure approaches the abnormal. The alliances of genius, in its major and minor exemplars, to the liabilities and assets of the nervous temperament, have ever attracted attention. The problem is considered more fully in Chapter VI.

Note 3, page 256. Products of deductive psychology such as this scheme embodies must be accepted with caution. Their general validity may be granted; their application is a matter of judgment. They tell a partial story only, and often distort relations. Promptness and vigor and scope and nice adjustment of reaction are not indicated in the bare emphasis upon the vigor of the process, which, however, remains significant. Sensibility and 
action are neither coördinate nor so strictly separable as are the terms of an equation. Classifications serve as elews or memo. randa; they must not be imposed upon the exposition or replace it, but direct attention to its truer, finer conclusions.

Note 4, page 25S. It is a proper deduction that the sk: sitive-active and the sensitive-ACTIVE types are more strietly representative temperaments and contrasted ones, than those assuming a comparable or like presence of the two qualities. The conclusion is sound. The emphasis upon sensibility detracts from action, and upon action detracts from sensibility. Even in the older delineations "melancholic" and "sanguine" figured more distinctively than the other groups. There is a certain strain in interpretation in bringing the other temperaments within the necessary formula, something of a shift in the values of the component factors of the equation. One who really combined the strong points of both temperaments would have a superior advantage. The "cholerie" is not the equivalent of this relation; the added implication is that the emphasis is possible only by limitation of the field of application. Similarly the "phlegmatic" may be said to combine the weak points of both temperaments, but by that fact to be saved from the risks of the more pronounced developments. It is in view of this relation that a "balanced" temperament, not answering strictly to any of the four usually scheduled, is recognized and may well represent the standard relation. It combines the middle-range presence of the components common to all the temperamental formulæ. The average is always the most common.

Note 5, page 261. A corollary may be added, suggested by the adage that the child is father to the man; yet prediction is far less secure than retrospection. In anticipation judgment must decide how far conspicuous traits are developmental and transitory-like milk teeth-in due course to give way to the more permanent qualities, as yet obscured by immature expression. How far they are temperamental and developmental cumulatively, the more permanent stamp, persisting in altered relation through the transformations of childhood and adolesecnec, alone decides. It is easier, as parents and intimate friends testify, to go back and find the reflections or suggrestions of mature character in ehildhood traits than to predict mature frum im- 
mature responsiveness. The problem is germane to the practical one of adjusting training to disposition. It also involves the problem of the play of reënforcing and of antagonistic factors, all temperamental, but shifting in assertiveness: those of sex, age, constitution, heredity, specific bent, emotional trend. Such complex forces make the determination of leading factors or consistent composites of character a matter of insight-the insight that makes mankind the proper study of man.

Note 6, page 265. Even biography, the most individual of studies, accepts the "type" view. It does not attempt to give an exhaustively complete description of the subject's personal traits, but to characterize them; to give them a setting and relation in a generic view of life and lives. Comparative biography, apart from attempting a mutual illumination by comparison and contrast of related interests, products and careers, would in a sense form the complement of differential psychology by inductively reaching the type-traits through a study of notable exemplars.

Note 7, page 266. Temperament may be viewed as an imposed psycho-physiological budget. The body-machine takes its type of efficiency from its metabolism, its adaptability of output to income; and this is reflected in the emotional tone as well as in the order and quality of achievement. Under this view temperaments whose incomes exceed the drafts upon them, which expend their resourees cautiously, are saving (anabolic) in their physiological and psychological economy; the converse, generous or extravagant temperaments, expend freely, are catabolic. The sanguine, like children, are impulsive; they assimilate and express predominantly through excess of nutrition, have quick reactions but not deep or durable ones. In them slight incentives release responses and prompt a brief sporadic strenuousness; they crave new excitements-ever up and doing-because old ones, having spent their force, are dismissed and forgotten. They have a short-lived budget of quick returns, but large ones. The budget of the phlegmatic is perforce arranged on the opposite plan; they are living simply, even meagerly, with fewer needs, upon a fixed capital; income and ontgo are both reduced. The choleric budget makes a fitful splurge, goes bankrupt, again expands on slight capital, alternates between periods of normal and of ab- 
normal activity-is irregular in its accomnts. 'l'he nervous bul get is diffieult mainly because of the adjustment in mann' $1^{*}$ :mul direction of expenditure; the mechanism of exchange is involvent: obligations are complex, and discharged nuecrtalnly-some with conscientious avidity, others with painful eflort. "The "buldera" view' suggests a phase of temperamental regrulation, lunt insulequately reflects the involved relations. The buldet here concerned deals in quality. Face-values are not decisive; the inlluences that maintain values above and below par are complex. The budget is real; mental output is conditioned by physiolurical supplies. But the condition is only one of many, and in many cases a subordinate consideration. The quality of the product is an inherent complication.

Note 8, page 267. The advantage of the term Anlage is that it implies, as no English word in common use allequatcly suggests, the aptitude in terms of sensory or intellectual power along with the emotional disposition, inclination, susceptibility; it might be rendered as "aptitude of disposition."

Note 9, page 275. In simple hoarding the actual grlitter and weight and size of the piles of gold offer a tangible satisfattion for which the contemplation of a bank-book is but a teeble substitute. Yet gold and bank-account alike are socially and representatively effective. Credit, and the repute of wealth, the solace of thrift, the contrast with less fortunate fellow-men, become the avenues through which self-assertion comes forwarl. Furthermore, it is the inability of other appeals to gain a hearin and thus reduce the indulged satisfactions to a proper place in the perspective of values, that makes possible the trait of nigrandliness. The sources of the tendencies that make for thrift and the tendencies that make for extravagance have each a place in orisinal nature, and may be directed to a valuable motive in the social life. Most of us are saved from miserliness by the merely partial hold which any one trend exereises in the eomposite psychic regulation. We are all susceptible to the satisfactions of thrift, and practice petty economies that are more servicealble in giving a sense of satisfaction and in correcting the natural $\mathrm{ex}$ travagance of reckless unconecrn, than in their true thriftiness. In cultured and disciplined persons ideals direet the alljustment. and establish a rational perspective of motives to replace impulses. 
We may indulge the hoarding trait by collecting anything from postage-stamps up or down, and give such interests a deeper hold on our energies and attention than their intrinsic worth merits; but in so doing we present the redeeming quality of a disinterested motive, an "amateur" love of the pursuit and its object, that makes the bare expression of acquisitiveness in the two cases a merely incidental resemblance. The diagnosis must reach psychological realities and appraise symptoms by their place in such a systematic interpretation. Symptoms derive their significance from the complex in which they are set. It is such setting and proportion that makes them innocent or dangerous, significant or trivial. Note 10, page 278. Studies of this nature have extended applied psychology toward the "vocational" analysis of endowment. For the groundwork of musical capacity see Seashore on the "Measure of a Musician" in "The Psychology of Daily Life" (Conduct of Mind Series). Compatibilities are quite as likely to be generic as specific. The psychology of painters and that of musicians overlaps in so far as both are expressions of the artistic endowment; they diverge in the media of their expression and accordingly in the proficiencies of endowment. It is the contrast of endowment between musician or painter and that of captain of industry or military leader that is fundamental in the direction of specialization. See Dauriac: "Psychologie du Musicien" (1891); Feiss: "Genealogie und Psychologie der Musiker"; Arreat: "Psychologie du Peintre" (1892).

Note 11, page 287. The senses of smell and taste contribute but modestly to the intellectual callings. Their chief rôle is in the appreciation of the composite zests of life; their direction of appetite is typical. They help to shape the satisfactions of existence, the euphoria of being. Good appetite and good digestion make for sanity of mind as well as of body; the control that enjoys their wholesome activity yet releases from too tyrannical a dependence, is the established normal relation, the product of a trained will. Esthetic sensibility is distinctly enriched by its olfactory flavor. Individual differenees in these respects are most difficult to formulate; they shade over into idiosyncrasies and caprice. Variability is proverbially recognized in the statement that tastes differ. Psychology does not give up the hope of accounting for them. 
Note 12, page 297. The stamdardized tests of mature attainment are largely of an aeademice status, the things llat wh cated persons of certain stations are expected to know of (1) he? able to do; that is, they test familiarity and a cortain mow on' acquisition under eneouragement and instruction. The experimental method aims so far as possible to eliminate or allow tol this element by testing the power to form new acquisitions-reactions to the unfamiliar-also to find collateral evidence in the ralle and manner of aequisition. A significant elew lies in the prompt and efficient transfer from the solution of problems by the nethod of trial to the method of rational insight into principles.

Tests for normal development and the determination of the degree to which backward or defective ehildren are retarded (BinctSimon tests) reflect both eapacity and familiarity. These tests are empirical and must be presented in terms that are realily undèrstood. The fact that they yield useful differentiations shows that even data of this order may be valuable under proper interpretation.

A more specific difficulty should be noted. When an answer to a question is ready because the data are familiar, the solution, which is the test, is of one psychological status; when ready, despite the unfamiliarity, it is evidence of a different psychological proficiency. If I have once been taught the solution or told the answer, I merely recall it when put to the test; by direet or indirect elew I remember; memory is, then, the quality chictly tested. If I work it ont freshly without aids, my logical carracity is tested. Once more the inference of capacity from achicvement becomes uncertain. We do not doubt that college scuiors have larger intellectual profieieneies than freshmen; yet must seniors would have diffienlty in passing their entrance cximinations. And the specific difficulty still applies; that the yualities constituting the progress may be put down as intellectnal withont indieating their type. In brief, eapacity and attainment move in overlapping and yet dissimilar orbits ; furthermore, while we may devise tests to show what individuals ean do or what they linow. the tests are adequate only when they indicate as well how the! do it and by what steps the knowledge is sustaincel, the process carried on.

Note 13, page 303. The limitations of the programme of in- 
dividual psychology on the emotional side are quite as marked and of a similar nature. The laboratory tests cannot supply the proper situations to engage or test the strength and quality of emotion as it is effective in eonduct; for this nothing less real and less adequate than the situations of life itself suffices. Psychoanalysis is an experimental method that aims at once to determine the intellectual play of psychic elements in general and of their emotional hold specifically. For the most part emotional trends are included in the survey of individual nature by the method of the questionaire asking for self-analysis, or by the method of observation and impression or judgment of the competent observer. No measure of a man is at all complete or fundamental which does not fully recognize the standard importance of this aspect.

\section{NOTES TO CHAPTER VI}

Note 1, page 304 . The field of mental abnormality has been studied mainly in the interests of mental disease; abnormal psyehology attempts an interpretation of the abnormal phenomenain part common to psychiatry and in part distinct-for the interests of psychology. It emphasizes the minor deviations in disposition and in psychological manifestation, and looks upon the grosser disorders as the terminal issues of trends related to the liabilities of the normal. The human mind is subject to distinctive forms of loss and impairment by reason of the natural demands made upon the psychic endowment, and of the complex systems of impulses which it harbors to meet them. Its failures and aberrations are significant to the psychologist; hence the interest in the abnormal tendencies of mind, which forms the subject of this chapter. Such tendencies are set within the normal range of variation; and the interpretation embraces both the ineipient tendencies and the extreme issues.

Note 2, page 305. A peculiarly instructive illustration is that of the periodical fluctuation in the mental life of women in direct response to a rhythmical physiological liability. The emotional tone, the mental impressionability, the self-control, the energies, vary characteristically at such periods; even erimes and suicides and offenses against the social order show a striking inerease 
in relation to this aggravating organie faetor of instability. " $\mathrm{A}$ woman always lives on the upward or downward slepe of a eurve; men, though likewise not miformly at their best or at their worst, live more on a level of effiejency. The susecptihility to abnormal mental disturbanees in women is oreanically related to the periodic factor and to the reproductive function of which it is the primary expression." See Haveloek Ellis: "Mlan and Woman," ehapter XI.

It is becanse the sexnal factor is more pervasive and more imperions (as well as organically more distinctive) in the feminine cycle that its liabilities at eritical periods are framght with greater risks. Here belong the wayward lapses of adoleseent lyysteria; here belong also the abnormal liabilities of the later perios of sexual wane, the significance of which is so eommonly overlookerl. In every large community there oceur baffling instances to which this factor supplies the clew. It may be the case of the mother of an only child who develops delusions regarding her son's peceadillos, falls for some months into a true melanelolia, and in due course recovers. It may be the case of a highly esteemed, eapable mother of a family who develops the delusion that a bachelor of mature years is paying undne attention to her. Or it may be the ease of an unmarried woman who magnifies the congenial interest of a male associate in intellectual or other enterprise into an inplied, more serious attention. In yet other cases there oceurs a period of reckless extravagance for finery or other forms of display, or of restless dissatisfaction with interests hitherto absorbing and adequate, without marked irregularity, yet distinctly verering upon the abnormal. What is signifieant throughout is the subtle invasion of the psyehological realm, wherein the aecredited traits of character are displayed, by a deep-seated plyysiological unrest, whose surface tendencies are apt to attach themselves with some measure of accident to one or another phase of the emotional life, and through such attachment to disguise their true origin. Of similar import are the sporadic hysterieal ineidents in late adolescence-a single kleptomaniac outbreak, a single venture in the field of improprieties-in an otherwise normal life.

Note 3 , page 311 . A distinetion must be drawn between deprivation of the eonvenient avenues of sense-discrimination rosulting in blindness or deafness, which involve substantially no in- 
herent defect of sensibilities so far as their reports reach the brain, and the subnormal reception of such messages for which the instruments of transmission may be fairly normal. The blind and deaf, despite their handicap, attain a development in all essentials parallel to that of the seeing and hearing, though they reliect in their derivative qualities the issues of their deprivations. The feeble-minded are cut off from all but a small measure of development. It is thus evident that the mental impressionability and responsiveness form the basal qualities of the nervous endowment that make or mar the possibilities of development; they use the sense-equipment in this process, in turn adjusting employment to endowment. It is accordingly an extreme subnormality of. nervous sensibility - not of sensory function-that is to be considered as vital. It is this fundamental defect, or its distorted relation, that constitutes idiocy, doubtless conditioned by a speeific organic abnormality of the nervous system. See Goddard: "The Kallikak Family" (1912), and Goddard: "Feeble-mindedness" (1914).

Note 4, page 312. The psychology of minor mental defect is beginning to receive a more careful attention. Backwardness, arrest of development, premature decline as well as simple stupidity are phases of its appearance. Surveys of children of sehool-age indicate that at least two in a hundred are feebleminded; and presumably three, four, five, or six in every hundred are subnormal to such a degree as to remove them from full participation in the training provided for the average mind. By the law of distribution of mental qualities, it follows that for every distinetive case of defect, there must be several times as many cases of less pronounced defieiency of the same order. It is thus established that a considerable number of the persons employed in the simpler occupations are mentally below par; the arrangements of life must be simplified, or even made "fool-proof," to permit of their adjustment to them, much as the sheltered environment of an institution is alone possible for the truly feebleminded. It is not so much the democratic distribution of stupidity or its relation to the strain of the environment that is here pertinent as the insight into its nature. Mere insensibility is involved; likewise lack of observation, feeble impressionability, shortness of memory, inability to hold much at a time in the mind, 
limited interests, a meehanieal responsiveness, elisreural of alifferences, lowered energies, are all fuctors in the pricholury of stupidity, in the complex that makes the mental movemont stals, flat, and unprofitable. The liabilities of defect mingle with thuse of distortion; they thus complicate the types of montal impritrment and disability and make the analogy between the promominow forms of disease and the deviating trends of temperament uncrtain and limited. The fact that development may fromed nurmally to a given point and then diselose its inherent limitatiuns or abnormal taint, is shown in eases of ehildisl preconeity and peeuliarity, promising marked if uneertain intellectual calpacitics, which at adoleseenee reveal their true basis in a deviation that then turns to what is substantially a higli-grade feeble-mincledness.

Note 5, page 314. In the typical cholerie action, it is not the bare exeess of action but as well the limitation of the type of action and attitude which it favors, that makes it choleric. The excess and the limitation go together. Moreover the same type of issues-violent explosions of anger, and of other primary personal emotions like grief, passion, hatred-are such eatholic forms of psyehic excitement that they may appear in any temperamental setting. Hysterical persons give way to outbursts that are eholerie. Yet when the energetic and expansive dispusition direets the enterprise, the eholerie outburst is more typical; this in the extreme is in line with the maniacal symptoms. like symptoms oeeur in different temperamental liabilities.

The dominance of action on the sanguine basis is agrain to be differentiated from the action of eholerie type. $\Lambda$ differently disposed range of sensibility underlies it. Excitement, folly. wild oats, extravaganee, and the open temptations of sport, venture, eontagion, together with a limited sway of the restraining moral, intelleetual, esthetie considerations, give the setting under which the liability to exeess operates. It may be alin to mere wealkuess of eharaeter; it may be low taste and vulgarity. It is the formula of intoxieation acting upon favoring dispositim, in which the exuberance of ready action invites, and excitcment further leads on, and restraints are by nature weak. Vigur is itself a temptation as well as a resource, as weakness may be at protection against exeess. The manner of expression uf the 
exeited (erethic) temperament is likewise eharacteristic, and emphasizes the optimistie trend of the energetically endowed.

Note 6, page 316. Dr. G. R. Wilson in Journal of Mental Science, Jan., 1892.

Note 7, page 317. Such terms as sensitiveness, pereeption, imagmation, are readily transferred from the sensory to the emotional field. "Sensitiveness" applies ordinarily to the susceptibility to the slight encouragement and disparagement of self-esteem. The fine "touch" of the pianist eombines both the sensory and the emotional order of affect. Similarly, morbid sensitiveness may be of the sensory order, as hyperesthesia of touch, sensitiveness to sounds; but even in these cases the sensitiveness is associated with the emotionally disturbing (or soothing) character. For the most part the quality that is involved in the abnormal tendencies is an emotional hyperesthesia in the realm of the self-centered emotions.

Note 8, page 320. The types of normal temperaments and abnormal disorders are but partly parallel. The term "diathesis" expresses the fact of an hereditary trend toward a certain disorder. "Hysterical" is a term readily carried over from the abnormal, where it originates, to the normal, where it expresses a diathesis.

Note 9, page 323 . The contrary statement is often made; there is no real contradiction. With neurasthenia as a general nervous disorder, hysteria becomes one of its varieties, and the group as a whole, including lysteria, becomes more common in women. Neurasthenia as a specific disorder is distinctly more common in men. This is but one way of saying that when the masculine nervous system breaks down, it tends to break down in one way, the neurasthenic way; and when the woman's nervous system breaks down, it breaks down in its typical way, the hysterical way. It seems far better to specialize the terms since they represent divergent tendencies and sources. There are characteristic phases in each as well as common liabilities: neurasthenia prostrates, hysteria tends to action. The phobias that paralyze, like the fear of social contact, of open places, of contamination, are neurasthenic; the manias, like kleptomania, or other inordinate tendencies, are hysterical. The confusion is also due to the fact that in concrete cases the two groups of symptoms overlap. 
Neurasthenies quite commonly exhibit some hysterieal sympums, but may be free from them; the converse is true of hysteriats. Also hysteria in men assumes a neurathenic color, neurastlunia in women an hysterical color.

The prostration of the nemasthenie is the persistent obstando in

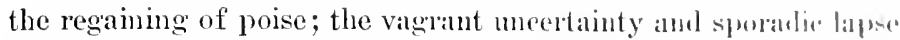
of the hysterical marks the course of compuest. The nembithunie learns to become less alarmed and disturbed by the renturnee of symptoms; the hysterical, fairly oblivious of symutoms, lan to summon the greater resisting power of reacentured habits t" ward off periods of terse temptation. Both elispusitimns rejure sent bad mental habits nurtured upon a nature ofteriug fusitive invitation to the formation of such vieious trends. Hysterial is ats much ontgrown as eured. It leaves a scar, but a very elifferent kind of a sear from that of neurasthenia.

Note 10 , page 326 . The impedinent may be more characteristically a motor or a seusory one. The phobia, worry, salfconscionsness may dominate, or the diffienlty becone aroute only when action is demanded. A deeided interference with intellectual work may oceur becanse of a subjective dwelling on the articulatory images. In one such instance a lawyer eould not plead his cause because of the dominance in his conceimsuss of the sound and "feel" of his own articulation. The manner" of psychic impediment varies widely; but it remains true to the type,-namely, an overabsorption in the realm of sensibility and emotion, a consequent hesitation and entangled action.

Note 11, page 328. Stammering and stuttering furnish pointed examples of the indueing oecasions of nervousmess. There are many persons disposed to this type of motor instability (and the most seenre of speech hesitate moler nervolls tentsion) who have outgrown or conquered the impediment fiur ordinary occasions; but in whom fatigne, stain, excitenlent. worry, even the departure from established routine, will bring bisk the trouble in slight or marked measure. In some eases the lkerrere of excitement that will induce it-and the degree of its fresenta -becomes a reliable index of nervous condition, almust a dian-

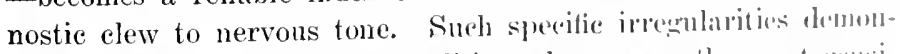
strate how a physiological comlition plays num the mus sousitive and highly developed portions of the nervons mexhanism. 
Note 12, page 330. It is undesirable to carry a point too far; yet the fact that hysteria permeates to the minutest details of expression, forms part of the conception. Thus the readiness to uso a londer, higher-pitched voice than is necessary, to laugh more boisteronsly than convention approves and to be unable to stop, to follow a statement with a slight guttural sound of approval, may readily reveal the hysterical tendency, because these are all miniature instances of slight motor impulses overflowing their confines; they show the absence of clear-cut, well poised reactions. Of themselves they are trivial, but combined with other symptoms they are corroborative. It is this type of diagnosis that leads to the early detection of abnormal tendencies, and thus practically to treatment and prevention of more serious developments. It also differentiates one type of defect from others allied to it.

Note 13, page 331 . The naming of a temperament by the risk which it entails has no other justification than the suggestiveness of the term and its convenience; yet the procedure has the special warrant that in the contemplation of the natural liabilities, the distinctive qualities of the venture come to the fore. The temperament is the positive reality, the condition of achievement, and the neurasthenia is one of its risks made real. The neurasthenic risk may be, yet need not be bound up with an unusual degree of the valued qualities of the "nervous" temperament. It will take but a slight oversensibility to precipitate the disasters of neurasthenia or of hysteria when the powers of resistance are slight, the heredity enfeebled. Many quite ordinary minds succumb to neurasthenia; still more of the same caliber to hysteria. The mode of their suceumbing commonly reflects the strain of their psychological nature. What remains true and characteristic is that the neurasthenic risk obtains in cases of sensitive adjustment to complex intellectual situations, and that out of such sensitiveness may issue, and have issued, the rarer and finer products of the human mind. Disqualifications may come to many and in much the same terms; for each has something to lose, and in such loss suffers similarly. It is just this similarity of symptom under loss that is significant, though not necessarily indicative of a like possession, beyond the fundamental similarities of endowment. 
Note 14, page 331. The analogy in natural chilul-traits muy be summarized. Its foremost condition lies in the malevingped eontrol. The irritability, the passionate anger, the yuick ehamges of mood, the ready forgetfulness, the caprice of tiste allul prodilection, the guidance of action by feeling, the subjection to the interests of the moment, the prompt fitinge, tlue ned of new stimuli, the eager absorption when ocenpied, the realy imitgmition, find a place in the earlier stages of mental growth, but m their disproportionate development furnish the basis ol hystcria.

Note 15, page 333. Hysterical tendeneies, wen if linily pronounced, are commonly remote from the disorders of hysteria as standardized in the medieal literature. The bodily sympums are important in diagnosis. Hysterical patients ma present areas of anesthesia often strictly defined, or curious limititions of vision. Paralyses may be present that show their psychic: origin by their disappearance under distraction, and their limitation to actions requiring voluntary control. Symptoms indicating disturbances of nutrition and cireulation are common. With these may be associated the tendeneies in milder hysteria that result in blushing, ticklishness, giggling, spasmodie action (hiccough, globus, choreic movement, uncontrollable tears and laughter). The interpretation of these symptoms varies; the point at issue is whether they are primarily psychic in origin, forming points of fixation in the physiology of disowned or marouned phases of consciousness; or whether they are primarily physiological and the actual instigators of the hysterical dissociation in the mental realm. What is unmistakable is that organic lluetuations and mental ones go together. The patient is in ome mental condition, is in one mood, is indeed one persontlity, when the anesthesias or paralyses are present, and is anuther personality when they disappear; there may be several cyoles of such sensory and motor (psychic) defect, and concomitantly. with them shifts of personality, with different tastes, resources. expressions. Characteristic are the rifts and bridges of memury separating and yet bridging the several personalitics. such manifestations, physiologieal and psychologieal, are the "xtrme issues of hysterical disintegration. They seem remote trom the lesser liabilities, yet are conneeted by manitold resemblancess arguing a common source. 
The dissociation which is responsible for a large range of the symptoms may be imposed, accepted, encouraged, and even, it has been suggested, assumed. Yet one must proceed cantiously. As belief and make-belief, self-deception and intentional deception are often uncertainly divided, so may hysterical incidents suggest one or the other interpretation. Yet the practical reality of the conflicting state finds its evidence in the amnesias and anesthesias, in the struggles and fusions that mark the course of the disorder and its treatment. The hysterical nature of the functional malady gives it a distinctive status in the abnormal realm where truth and falsity, subjective and objective, lose the ordinary sharpness of their boundaries.

It would lead too far afield to dwell more explieitly upon the genesis of conflicting personality. In the extreme ease it is the depth of dissociation and its complete organization that is striking. The disruption is then disastrous in that it affects memories, tastes, attitudes, habits, social relations, conduct in all its phases; divorce is impossible since both organized trends occupy the same tenement of elay, are bound to the same nervous and muscular system for their expressions. "Personality One" indulges in tastes abhorrent to "Personality Two," plays pranks by which the "Other" suffers, loses her property, plots her undoing, forgets her commissions, taunts her for remissness, ousts her from the ascendancy momentarily gained, is bold where the "Other" is shy, is strong where the "Other" is weak, is gay where the "Other" is morose, is frivolous where the "Other" is sedate, is conscientious where the "Other" is irresponsible, is kind where the "Other" is spiteful. The evidence, though complex, is convineing that the detached psychic cluster of trends and qualities is organized about some central assertion of motive; that it is partial in its invasion, handicapped in its composition, rebellious in its attitude; and particularly that it is related to the dominant or more stable consciousness in the manner of a subconscious secession, and carries on a peculiar intercourse with it. It is this intercourse that forms at once the elew to treatment and fusion by a sort of psychical surgery, and establishes the entire complex as a form of deep "suggestive" product similar to the altered personalities that may be obtained in hypnosis, sleepwalking, and allied trance-states. Altered, detached, warring, 
handicapped personalities are brought into relation with the many manifestations of hysteria, of cultural and historimal significance (oracles, witches, sommambules; victins of contagin, tantrums, obsessions, delusions, ete.), and thus complete the interpretation of extreme hysterical liability. 'T'le pliysiolomienal symptoms-anesthesia, pseudo-paralysis, loss of seisory or motor profieiencies, peculiar susceptibilities-deserve speeial ensideration and often afford a clew to the disorder. $A$ bricf review of the subject together with the citation in alstrant of typical cases will be found in my volume on "The Subeonseious" (1906), especially Part Two, Chapter V.

Note 16, page 334. The suggestion that hysterical natures are such as incompletely mature, proposes the pertinent query: What is implied in being psychologically adult? It is not so simple a question as it appears. On the intellectual side it implies a ripening of powers of insight and application, and a commaml of resources. One grows intellectually so long as his powers do not begin to fail; the adult stage is launched when mature and consistent purpose directs the enterprise. A writer may so outgrow his earlier outlook (and he, or any of us, ontgrows tastes and inclinations) as to look upon his youthful writings as alien to his present personality; yet they formed a stage in his development. Experience promotes the ripening medium; desire and purpose support the mind's fruition. Fundamentally, to be adult is mainly an emotional matter, a balance and poise of the self-centering impulses. Allowances are made for childlioot and, in different terms, for youth, before the onset of years of discretion. The undue persistence of the youthful fluctuations. the belated coming to one's own, forms a significant factor in tlo genetic life-history. Varying widely in its normal expression through temperament, eireumstance, opportunity, enenuragement, it assumes characteristic deviations in its abnormal course. 'The hysterical temperament (tlough not it alone) is the persistently youthful one, the dominantly adolescent character, the personality that never grows up. Even the youthful appearance of the more fortunately hysterieal types impresses the observer; they du not show their years. Such generalization is, however, hazardous. There are fortunately normal ways of keeping young by retaining wide interests, by richly sustained energies, by living 
cagerly upon genuine sympathies; yet the gift is primarily a temperamental asset and forms a compensation of the hysterical, or more generally, of the nervous type. The view, accepted for its suggestive value, yields as a conception of psychological maturity, the attainment of that in which those hysterically handicapped conspicuously fail: the acquisition of a depersonalized attitude, the pursuit of objective interests in life. To be "grown up" means to achieve an adjusted poise of the self-centered emotional economy, to have an objective system of interests and activities, a reflective and independent outlook upon the world, a sane and sobered view of self: to see life steadily and to see it whole. Doubtless this is too exacting a criterion to be indiscriminately applied; but with a charitable leniency in gauging its fulfilment, it may serve to indicate the true nature of the maturing process in complex individuals. In such manner does the view of the abnormal reflect upon the understanding of the normal mental life, and present the abnormal as a deviation from its standard course or issue.

Note 17 , page 335 . In accord with such a view of the hysterical liability is the conclusion that a large number of "candidates" for its snares successfully avoid them. Brilliant examples of suppressed and controlled hysterical tendencies are available for those who have the insight to discern them, or the necessary confidence of their victims to entice the confession of the private battle and the unrecorded victory. Possibly the most fortunate of such temperamental victims are those who occasionally yield to a rush of impulse, a passionate tantrum, a geyser-like outburst of pent-up tension, an emotional "jag," and then return to periods of composure. But by its very temperamental setting lysteria, even in its mildest form, is not apt to be simple, not barely violent, but subtle, disguised, circuitous, evasive, elaborate. In trend it is abnormal, though a commonplace temptation. In the average nature, either because the emotional tide does not run as strongly, or because the controlling dams are built more solidly, adjustment ensues even to difficult erises, though at the cost of severe effort. Hysterical tendencies are as often overcome as expressed. Cireumstance plays its part. Vacancy of employment, the mischief that the devil of undisciplined impulse finds for idle hands or neurotic minds to do, may 
tempt a repressed emotionalism to wayward expressine, when wholesome interests would drain the flow innorently. lindue stress may overthrow the natural defonses, which are stromen enough to weather the ordinary storm. Overrestraint ats well als indulgence may precipitate disaster. Morality and the varionl checks that social organization ereets in the interests of sinity. have to reckon with the hysterical temperament. Charinter, Hir. embodiment of personality, is an achievement; eunsisteney is at jewel, yet a jewel, though not flawless, possessed by must and unconcernedly worn. The hazard of hysteria is often fresent, but successfully avoided. Many a personality owes its emergence to the overcoming of the hysteria that threatened its muluing. It may then continue to profit by the assets of its endownent, and feel confident that the further eareer will be undisturbed lyy the uncertainties of urgent impulse. Part of the compromise is due to the waning of impulse consequent lipon the settling process of years.

Note 18, page 339. The argument and the eridence are involved. The religions of lower culture abound in symbulie and ceremonial expressions of the sex-relations from direct enlt of the passion to all manners of indirect usages reflecting its pervasive influence. As religion develops the institutional means of exercising control over impulse, it becomes more refined and spiritualized, but even in its highest stages revenls the strength of the hold of the earlier ones. What is more signilienut to the present argument is that a considerable portion of the expressions upon which hysteria builds may also eome forwald in religious interests and their expression. The prycholony of "onversion and extreme religions devotion has been interureted in this light. Revivals, eamp-meeting phenonena, spiritualistic séances, the experiences of mysties, the selection of alulusint maidens as oracles, certain aspects of the witcheraft delusimn, the growth of peculiar seats, the contagion of motor manifistaltions in ecstatic rapture or religious absorption, as well as miner devotions and "possessions" have been reviewed as purtial, wyward or complex outlets of hysterical tendencies. se't starbuck: "The Psychology of Religion"; Hall: "Adolesermee." Though readily overstated, the thesis unmistakably includes a real relation, which cannot be ignored in determining the nature, 
the assets and liabilities, of the religious temperament and the religious sentiment. The tendeney to fanaticism and excess in connection with so powerful and absorbing an emotional experience as religious feeling is the natural liability. The entire series of experiences thus referred to forms an important contribution to the data of abnormal psychology.

Note 19, page 345. One of the most remarkable examples in recent times-remarkable because of its actual influence in shaping the beliefs of a large constituency-is the rôle of fear in the personal history of Mrs. Eddy and in the doctrines of Christian Science, in which the "fear-thought" plays the part of bogey. Mrs. Eddy's delusions were focused upon "malicious animal magnetism," the product of her own abnormal brain. of this practice she aceused others; the precautions which she exercised to aroid its menace are typical of morbid fear, though her mental vagaries have a more specific and complex basis. See my article in Hampton's Magazine, 1911.

Note 20, page 349. The pathological aspects of the "love" passion seem to come forward more characteristically in the aggressive "jealousy" complex than in the subdued setting of tenderness and longing and devotion, though the latter also develops a "complex" allied to the plaintive mood of sorrow and pity, yearning and affection. It is suggestive that the one group of emotions is congenial to the ancient setting of courtship as conquest, while the other places it in the modern atmosphere of persuasion, romance, and appeal. The challenge and the duel reflect the hostility of anger; the rivalry motive appears in the saying that all is fair in love and war. In the by-products that enter into its abnormal expression, the two phases may merge or alternate. Jealousy reflects the tender as well as the aggressive source. Yet it seems to act more directly in feeding anger, and in arousing the attacking impulse to action. Jealonsy goes out to the offending rival and to every aspect of his offending presence. It turns to hatred; it affiliates with vindictiveness and rerenge. The added pang that one's own loss should be another's gain is the counterpart in the jealous setting of rivalry, of the added zest of triumph that one's own victory should debase the rival. Jealousy thus becomes a passion of violence and follows the clew of anger. Merging with revenge, it feeds the fires of 
fends through generations of Hontagnes and Capulets. livantually it is lost in hatred and prejudice that crowd ont all other considerations, and give rise to the emotional excesies of untugonism and persecution. The point of interest is the common tendency of sueh passions to carry away the defonses of the mind and lapse back to primitive violence of expression. The result may also be expressed by saying that the "lore" complex and the "rivalry" complex, the "anger" complex and the "revenge and hatred" complex, have overlapping fields of application. The fact that such developments may spread to a croup, and give rise to racial and social enmities gives them a momentous place in the history of man's emotionalism in its pathological phases.

Note 21, page 355: To cite a single instance: $\Lambda$ medical student experimenting with a dose of bashish wis overome by a compelling sense of expansion of personal worth. His route homeward from the scene of the experiment was by way of the street-car; he felt impelled to remark to the conductor upon the strength and the beauty of his own person, and advised the official to eject the other passengers as unworthy to ride with so august a personage as himself. He was able to reach his home safely; the portal of the modest dwelling seemed grand, the setting palatial, his wife a great lady. Then followed a series of delusions of distorted rather than of exalted value; for the drus, like most such "psyehie" poisons, releases now one and now another of the constitutent "centers" that jointly regulate feeling and thought. Such abnormal liabilities are the issues of the selective stimulation of the brain-centers, as the drug plays mpon the stops of the mind. The "psychic poison" weakens the cherks which the control of experience has gradually extablished, and in so far leaves the higher centers, which are the custodians of sanity, at the merey of the direet stimulation of the lower ones. It allays the critical powers to see things as they are, to nise memory, judgment, knowledge, for the control of impulsis and imagination. The loss of the muscular sense of effort and the further loss of mental impediment and of noral hesitation are allied, in that they represent different phases of control. In the tirelessness of pursuit effort vanishes; the controls of elcsire are dismissed, and the natural frietion of fatigue is rednecl. Manin 
implies intensity of impulse, excitement, inconsiderate action or illusory, contemplative satisfactions; monomania cmphasizes the narrowness of the mental movement. The critical adjustment fades away. The pretense and the delusional state attract attention in the maniacal exaltation of insanity. The patient is to himself a king, a man of might, controlling destinies, holding dominion over hordes; the owner of fabulous wealth, extravagant, indulgent, arrogant, honored, feared, splendid in mien and manner; yet his surroundings are of the plainest, and he defers to an attendant. The "alcoholie" behavior presents similar incongruities in miniature.

Note 22, page 358. The significant aspect of degeneracy of the atavistic trend biologically considered, is the strong assertion of traits characteristic of lower stages of development. The bad heredity of a defective stock appears in the inability to meet the established standards of normality, in the succumbing to primitive tendencies and unrestrained passion. The unremitting effort that is the price of social safety demands a certain standard brain-development to balance and restrain the older tendencies of primitive man; the reassertion of these in primitive strength, with an inability to use the established cultural machinery for their adjustment to modern nceds, constitutes the defect. Insanity as well as criminality is conspicuous for the degenerative trends which it exhibits; refinements disappear, sensibilities are lost; there is a marked dropping to a lower plane of existence. Degeneracy thus lays bare the underman, yet exposes the undeveloped psychic powers to the stresses and strains and temptations of a complex social system. It exposes the old vices to new sins. It plays a large part in social pathology.

Note 23, page 359. The pathological liabilities of the seximpulse in the warping of the mind are many-sided. The subjection to the love-passion engenders an emotional erethism favorable to the abnormal. The imperiousness of its sway subordinates all interests, judgment, restraint; in that way lies madness as well as strength and inspiration. The relation to mental instability, from aggravation of chronic liabilities to outbreaks of pronounced insanity, sufficiently demonstrates the vital part of sex in psychic determination. When sex monopolizes thought 
and motive, the vietim of the monomania beromes the pirtume of the enslavement that makes insanity, the denratation of the psychic nature when reduced to one inessant round. The forther relations of sexmal depravity and the morbid expressions of the impulse to degenerative tendencies is likewise a motahle fandor in its psychopathology. See Havelock Ellis: "Stullies in the P'sy'chology of Sex."

Note 24, page 360 . It is also characteristic that thr axpressions of abnormal emotionalism and of the semsibilities underlying them may incorporate the aecinired plases of the sensitive life. On the one hand the loss of sensibility and the lapse back to primitive, eruder, coarser tolerances and expressions appears in the abnormality of defeet; and on the ofler hand the extremes of sensibilities and the harassing subjoction to the finer maladjustments appear in the exeesses of neurasthenia and hysteria. Of the acquired sensibilities, the attitude towarl pollution or taint, as the excess of the hygienic response, is characteristic. The transfer of disgust, and the refinements of its cxereise in the avoidance of unpleasant contacts, brings about a morbid reaction-a constant fear of contamination, an incessant washing of the hands, a suspicion of pollution. The sensory basis combines with a sensitive emotional shrinking from the unpleasant: an hyperesthesia that resents even the eontacts of tenderness, and may also develop in an atmosphere of self-acensiltion, or self-pity, and move toward the complex of a depressed mood or of religious exacting orerconscientiousuess and sense of unworthiness.

\section{NOTES TO CHAPTER TII}

Note 1, page 369. Traits and their objects merre; if we say that men are conceited and women vain, we mily remard the two as different expressions of the same trait-the desire for esteem, and the satisfaction in its evidence, being the eommon quality; or we may find it desirable to enumerate these traits as distinct, because of the difference in expression. Trats must he considered primarily as to their souree, secondarily in relation to their natural outlets in expression and the situations alrousing them. 
Primitive stress emphasizes both the primarily human and primarily "sex" traits, affording lesser play to the as yet feebly developed, derivative traits. Civilization tends to reverse the perspective by giving men and women larger ranges of (derivative) conduct within which to express their distinctive trends. Otherwise expressed, this means that primitive societies emphasize primary traits and through these the contrast of men and women; but primitive men and women are strongly alike in the expression of common primary traits. Civilized men and women are strongly contrasted in the derivative fields.

Note 2, page 375. Anthropologists are not agreed upon the positions of the patriarchal and the matriarchal dominance in the evolution of societies. That such institutions, along witl the many other embodiments of social contrasts in the customs and obligations of sex, express the inherent issues of the psychology of masculinity and femininity, remains the common conviction. The position of Thomas in "Sex and Society," is followed in the interpretation here given.

Note 3, page 378. From the economic to the literary discussions of "woman's sphere," opinions vary widely; facts are challenged by counterfacts, experiences and judgments favorable opposed by contrary ones. Similar emotional judgments abound in history and lead to adoration and idolatry of the feminine, and to suspicion and denunciation as well as renunciation, to gallantry and contempt, to prejudices erystallized in customs, that surround and bind the expression of femininity, and lead to varied efforts to secure emancipation from the (largely masculine) views and standards. For a more systematic survey, see Gross: "Criminal Psychology," pages 300. to 364; Havelock Ellis: "Man and Woman."

Note 4, page 379. Two modern American contributions to religious movements present the contrast conspicuously: those of Mrs. Eddy and of John Alexander Dowie. What is characteristic is the personal form of expression: the constant leaning of Mrs. Eddy upon the support of men, the passive acceptance of a "mother-worship," the peculiar personal timidities, the absorption in a mystical-emotional phrasing of doctrine and a "sex" complement of ritual; the bombastic vehemence of assertive denunciation of Dowie, his bold ventures and large projects, his master- 
ful dominance of men, and insistence npon frersmal inllume through threat, abnse, intimidation.

Note 5, page 381. The degree of conlimation of sox-lifterences to be expeeted of an experimental test amomg nuen and women of the ordinary range ot' sensory, intellectual, ('motinmal, and volitional capaeities may be said to be well mot by the ditis accumulated. Miss Thompson presents eomprehensive dala in "The Mental Traits of Sex." The marked superiority "it" men is in physical strength and the qualities of motor respmis associated with a greater musenlar development and rontrol; women show a greater readiness in aequiring novel motor responses. The marked mental superiority of women is in menory. Minor differenees in other fields oceur, but leave undetermined how far they result from the different edneational traditions and stresses of men and of, women. It is entircly to be expected that in tests of facilities largely derivative in status, the two sexes should show comparable proficiency. In a review of reeent literature (Psychological Bulletin, October, 1914) the same author (Mrs. Woolley) finds corroboration of the more significant differences in a fair proportion of the results. Siuggested generalizations are that girls develop more rapidly tham boys; that boys excel girls in rapidity of movements under tixcel attention, with the reverse the case when the attention is shifting: that tactile and color sensibility are better in women, pressuresense (lifting) and sense of space-areas in men; that women excel in rote memory, men are better in free associations, women better in practiced systems; men somewhat excel in tests of judgment and reasoning; in schools there are more acederated girls than boys, more retarded boys than girls; boys exerel in furspective drawing and girls in decorative drawing. In a large number of general and miscellaneous mental tests no signifinant differences appear. See Havelock Ellis: "Man and Moman" (rovised edition).

Note 6, page 382 . The greater variational tendency of man is a fact of the widest significance. Despite exceptions in details, the fact grows in certainty and scope since linrwin indicated its import. The greater tendency to abnormality-uf defect and excess alike-is a comprehensive expressim of the ynality. Its derivative consequences in the pryehe matme are like- 
wise momentous; in this respect also exceptions will oceur in regard to expressions of derivative status not closely connected with primary significance. Psychologically the greater variational tendency of men, as likewise the greater conservative tendency of women, radiates to every distinctive aspect of their contrasted natures and expressions. "The center of gravity is lower in women and less easily disturbed." This is fundamentally a biological, not a sociological or more narrowly political distinction; the transference of the conception from the one field to the other is hazardous, yet not impertinent, since the divergent tendency is a major clew to the psychology of masculinity. See the chapter in Havelock Ellis's "Man and Woman" on "The Variational Tendency of Men."

Note 7, page 386. Any such characterization of feminine psychology is so obviously eclectic that its only purpose is to direct attention to the salient and typical distinctions, and thus to suggest a correct perspective of interpretation. See Havelock Ellis: "Man and Woman," especially the chapter on "The Affectability of Woman."

Note 8, page 395. The origin of human races is bound up with the origin of the human race in its divergence from a prehuman ancestry. It has been suggested that along with the inerease in size of the simian ancestor and the tendency to descend from his arboreal habitat, came an increased adjustment to the vertical position; hence a larger skull and brain-mass could be carried; the foot, losing its equal prehensibility with the hand, could be shaped for adequate support, and the released hand further specialized. Thus was man started on the career of homo sapiens. In this view the differentiation of races is a matter of subordinate magnitude.

The dominance of a psychic order of adjustment in the human kind appears saliently in contrast with that of the animal world. If by some "sport" an individual of the intelligence of "Br'er Rabbit" should really appear in a rabbit colony, he might profit individually by his shrewdness, and extend his benefits slightly to the group. The next generation of rabbits would be unaffected by his exploits. Animals live more strongly upon their group-qualities; their individualized expression remains merely a fact of variation. 
Note 9, page 400. Civilization, ancient or molern, is not the product of the genius of a single people. The historieal stages show the widest borrowing and mutual influence of enltural products. The talent for rapid assimilation seens in this view the determining trait, and in sueh adaptability may lie a true souree of racial emergence. The modern experience of a highly evolved race meeting and dispossessing a primitive one clearly presents a superlative eontrast, whereas in primitive times the degrees of superiority were decidedly more moderatte, and assimilation of the less developed race a far more likely issue than extermination. If the negro stocks, which the North Amurican and the South American nations have attempted to assimilate by such divergent methods, and those which the white $\mathbf{M}_{1}$ hammedans of North Afriea have incorporated, are comparable, the vast importance of mode of treatment, of esteem or prejudice. of intermarriage or exclusion from equality of opportunity, is demonstrated. However strongly by personal inelination the prepoteney of the racial endowment-the élan vital of raceis favored, the difficulties which that view encounters must be faced. If it be argued that the half-century eareer of the enfranchised negro in the United States could be no other than it is by reason of his racial quality, other expericnces must be considered to offset this verdict. There are no direct means of converting this contrast, however inevitable it may be, into terms of differences of inherent racial ability. Galton is inclined to judge races by their ability to produce great men. In this view he places the Greeks of the fifth century before Christ as murlt above the dominant races of to-day as the latter rank above the Negro. The validity of the criterion is disputable.

Note 10, page 402. Thomas says: "It is probable that brain efficieney [speaking from the biological standpoint] las been, on the average, approximately the same in all races and in both sexes since nature first made up a good working model, and that differences in intellectual expression are mainly social rather than biological, dependent upon the fact that different stanges of culture present different experiences to the mind, and nulventitious circumstances direct the attention to different ficlds of interest." We shall thus be led to "rednce very much our usual estimate of the difference in mental eapacity between ourselves 
and the lower races, if we do not eliminate it altogether; and we shall perhaps have to abandon altogether the view that there has been an increase in the mental capacity of the white race since prehistoric times."

Note 11, page 403. "The European and Mongol have the largest brains; the European has a small face and a high noseall features farther removed from the probable animal ancestor of man than the corresponding features of other races. On the other hand the European shares lower characteristics with the Australian, both retaining in the strongest degree the hairiness of the animal ancestor, while the specifically human development of the red lip is developed most markedly in the negro. The proportions of the limbs of the negro are also more markedly distinct from the corresponding proportions in the higher apes than those of Europeans." (This citation, as well as the others in the text, is from Boas: "The Mind of Primitive Man.") While other writers make out a stronger case for the correlation of cultural achievements with structural development, the case remains uncertain at best. In such a view all traits are not of equal value; the argument follows the more significant traits, but finds difficulty in determining significance. The consideration of the order of descent from the presumptive animal ancestor, might yield a clew in the most generalized, least specialized human type; this may be the less markedly colored (Mongolian) type, from which the darker races (Negro) on the one hand, and the lighter races (White) on the other, may have been differentiated in adaptation to environment.

Note 12, page 404. Professor Boas presents a considerable range of evidence for changes in bodily form of European-born and American-born emigrants of like racial affiliation-and that for such different races as those of Southern Italy and the Jews of Russia. The change suggests an approach to the American type. In brief, the circumstances that affect variations also affect variability, so that the fixity of structure loses much of its unequivocal prestige. Mixture of races complicates the issue. Pure races of whatever grade of capacity or eulture may be more uniform than mixed ones; we cannot observe like races under radically different conditions, or unlike races under comparable ones, nor in so doing correlate the contrast more with the factor 
of race or more with that of condition. We must alsu lenmenturer that physieal qualities, no less than mental ones, refuire the differentiation between factors determined prinarily by inhoritance, and factors largely anenable to envirommentil stress. Even so apparently structural a character as height, ur propurtion of skull, may receive its more definite impress (which hlieate measurements reveal) at a relatively late stane of develnpment. This would mean that the heredity brings the structure in a more or less plastie determination to the stage at which it is subject to the play of eondition. The laws of plyysieal heredity and the variations due to them serve as surgestive clews for the interpretation of the parallel relations in the mental world; but the special conditions affeeting the latter alone remain deeisive in the argument here followed.

Note 13, page 405. This is one of the eases in which we ean, in a measure, offset the argument of race by that of environment as represented by elimate. There is a fair range of evidenee that the inhabitants of tropical and semi-tropical elimates mature earlier than those of temperate and frigid ones. But race seems to outweigh climate; for the primitive inhabitants of the aretic regions show a comparable preeocity of function with those of the South and a contrast with the eultured peoples of the North. The fact seems to throw the deeisive influence back upon the stress of the habit of life. Furthermore, the data for gauging precoeity vary considerably in their availability and may have a variable signifieanee; those most commonly employed are the appearance of sex maturity in girls, the age of walking in children, the onset of the infirmities of years.

Note 14, page 406. The one type is furnished, as nearly as conditions approximate, by the Chinese. With a high ravial unity and a distinctive cultural expression, the Chinese for many generations developed an independent national life. In that consummation the great masses of the people appear to show a fairly stagnant, limited, mediocre endowment. That much of this expression was due to an imposed conservative systen eannot be donbted; that the race was able to produce leacless who eould maintain the system and organize it as well as direct the large intellectual and technieal progress under it, is also estal,lished. Yet in reent years the evidence that the Chinese mind 
could adopt a westem point of view and go forward rapidly in its application, came with a sense of surprise. The ready conclusion that the Chinese were an inferior race had to be revised. Accustomed to our own standards of expression, we appreciate the mental endowments of other peoples only when they turn to similar ends by similar means. Professor Thomas's statement may be added in corroboration.

"The Chinese afford a fine example of a people of great natural ability letting their intelligence run to waste from lack of a scientific standpoint. As indicated above, they are not defective in brain weight, and their application to study is long continued and very severe; but their attention is directed to matters which cannot possibly make them wise from the occidental standpoint." He adds prophetically: "But when this people is in possession of the technique of the western world-a logic, general ideas and experimentation-we cannot reasonably doubt that they will be able to work the western system as their cousins, the Japanese, are doing, and perhaps they, too, may better the instruction."

The opposite type of instance is furnished by the Jews. An unorganized, scattered people, living among scores of different nations under wholly different institutional conditions, yet maintaining a high degree of racial purity through restrictive marriage traditions, they present a rare approximation to the scientifically desired status. What distinctive qualities they have must be largely racial. Individually and in groups, the expression of such racial traits comes under the influence of the several environmental conditions and ideals, to which, however, they bring the superimposed capacities and distinctive ideals, which they have maintained in a spiritual medium of culture without outward embodiment. There can be no doubt that the racial eapacity of the modern Jew is of a high order-in the broad terms of the present comparison, of an unmistakably higher order than obtains among most, if not all, of the peoples among which this race has found a dwelling place. Their history is long; their conditions have, with few exceptions, been unfavorable, frequently overwhelmingly so. To have maintained themselves against such severe hostility, such heavy cultural odds, is itself an evidence of superiority. Taken in its ensemble the his- 
tory of the Jew forms the nust convineing evidence of the porteney of race-an evidenee the more comvinuing by ratsm wh tha varied types of excellenee which the members of this rame hat displayed when opportmities were favoralle.

Note 15, page 407. In lis study of notewortlyy finnilies derived from about four hundred menbers ol the lioyal sioeiety, Galton finds that to have a father thus distinguisluel makes one's own chance of being "notewortly" 24 times as great ats that of the average individual without such notable kin; with a brother thus noteworthy, the ehances rise to 31 times as grout as those of the undistinguished average; for a gramdlatler tluy fall to 12 , for an uncle to 14 , for a male consin to $7 .(3)$. viously no special significance attaches to these precise numbers; they express approximately a relation of hereditary intiniley. The degree of noteworthiness of this group, though not extraordinarily high, is high enough to be recognizable; it earries an even great directness of application because the qualities concerned are so elosely related to the eommon bases of the grouptraits of men.

The intimate as well as the specialized nature of the hereditary factor appears in the comprehensive resemblances of those most elosely sharing a common inheritance-brothers, sisters, and most of all, twins-and the dominance of a common trend in the family heredity, however variable the traits of the individual members in other respects.

Note 16, page 410. The psychology of the "genius" group has developed a notable literature. Facts are acressible in regard to illustrious and eminent men which are not ordinarily available for average persons, unless speeifically collected fur comparative study. The view that the man of genins is an "abnormal" variation does not indorse the notion that "genius" is a disease, nor does it regard insanity as the mental condition which holds the elew to its eomprehension. Insanity is sirnitiont $11 \mathrm{~s}$ the risk that is run; it is the "Nemesis" of genins, but nuthing more. Feeble-mindedness and genius, statistieally considered, present eommon traits, the elew to which is again in eswerne that they represent abnormal variations. Both are more common in the male; both are more common in the eldest and in the youngest ebild (son); both are more common in children born to parents 
with considerable discrepancy of age; both show an uncommon perecntage of weakly infancy; both show a diffieulty in achieving ordinary adjustment to the average situation. Like every temperament, its fortes must be paid for in risks and defects. The general position of $\mathrm{Mr}$. Havelock Ellis ("A Study of British Genius"), from whose work are cited several of the above conelusions, is particularly to be commended.

Note 17, page 411. In regard to the bereditary factor in the genesis of crime, Lombroso is so convinced of the abnormality of the criminal class as to regard every physical variation which the class presents as a sign of degeneracy; lie forgets how common are the same types of stigma and variations in the normal, or at least, the non-criminal classes. The truer view places in the first order of consequence the fact of defect-which is unmistakably hereditary-and looks upon the crime as a significant incident in the ensemble, a direct issue of the defective character. The hereditary affiliations of such defect are particularly well established. The experiment of contrast is shown in the ease of the "Kallikak" family; for the progenitor of this stock presenting such a heavy criminal and defective record, has also a legitimate posterity, which is normal and includes many examples of creditable achievement. Statistically expressed, in the illegitimate line of descent there were 143 of 480 persons known to be feeble-minded, and only 46 known to be normal (the rest unknown); in the legitimate line, of 490 persons all were normal so far as records are available. of 41 matings in which both parents were feeble-minded, there were 222 feeble-minded children and only two ranked as normal.

Recent investigations indicate that under favorable circumstances it is possible to obtain a statistical demonstration of the hereditary character of such a quality as a "bad temper." It comes forward in the mass of contributory factors to social waywardness and irregularity of conduct. Similarly, good and bad qualities alike show the strong tendency to "run" in families when adequate data are available. Sir Francis Galton showed the "run" of like qualities in prominent English families. Mr. Woods has carefully shown the parallel conclusion among royal families, indicating further the correlation of mental and moral qualities of good and bad type. Sommers has traced through several generations the reappearance of special strains of ability. 
Such conelusions suggest how very different womld be the naturil history of "John Smith," if he had happened to be "Hapshurn or a Bacl, a Soldan or an Edwards. 'The family strain, in its determination of the dominance of qualities, determines the fromp to which the individual beloners by virtue of similar traits, whether of bad temper or criminality, of musical alhility ur mental or moral superiority. See F. A. Woods: "Mental and Moral Heredity in Royalty" (1906); Robert Sommers: "Fumilienforschung und Vererbungslehre" (1907).

Note 18, page 412. Within the field in which native trends and applied proficiencies combine, gromp-traits of any desires degree of refinement may be distinguished. It would be possible to develop a "group-psychology" of any of the prof'essional or industrial classes: of doctors or lawyers, of professors or ministers, of bankers and officials, of artisans and eraftsmen, of clerks and subordinates, of day-laborers and odd-job men; or, adding the environmental conditions, of farmers and villagers, of cosmopolitan and provincial, of seamen and landsmen, of mountain tolk and dwellers on plain or seaside, of North and Sonth, of equable and changeable climates, in deserts or in fertile lands, of woodsmen and ranchmen, of the frontier and the old-settled regions; or considering the further complications of the intellectnal heritane. of aristocracy and bourgeoisie, of extreme conservative ceonomic regulation and the free opportunity of newer demoeracy or colonial development, of pious orthodoxy or liberal tolerance of belief, of the educated and the uneducated, of the poor and the rich or the favored middle classes, of the ambitious struggling climbers and the arrived settled possessors of station. All these groups have among themselves something in common; and althongh the classifications cross one another's tracks and yield raricd eomposites of allegiance, they are subject to a moderately definite delineation.

\section{NOTES TO CHAPTER VIII}

Note 1, page 417. Statements so summary are inevitably partial. Selection is exercised by the enviromment, by sex, by social forces. Survival stands eloser to sex-selection. The fact that this is not freely exercised but itself comes under the swing of custom and tenet and the stratification of soriety, grives its operation an uncertain trend. In the extreme ease-als amengit 
diffieult; the single fact of tribal allegiance determined the entire life, regulated its every significant act and issue.

Note 5, page 431. This is clearly not the whole of the story. The persistence of "undesirable" traits in the human kindpartly also in the higher animals-results from the uncertain release of impulse in complex situations, and the resultant conflict among the contending impulses for the mastery. If it be urged that the one set of impulses represents tendencies more closely related to primitive condition, and the other tendencies artificially nurtured by education, the argument returns to the influence of environment in retiring or reënforeing traits.

Note 6, page 434 . The classic example in the field of oratory is the address of Mare Antony: at first allaying distrust, then covertly inviting sympathy, later appealing for support, and at the last arousing to rebellion. Political shrewdness has been developed largely upon a practical mastery of crowd-psychology, favored by mass meetings and the collective method of conducting a campaign. The catering to the prepossessions of the people is the generally acknowledged instrument of persuasion, whether in seeking political favor, in selling goods, in enlisting interest, in overcoming opposition of any type. It is as much at the service of the promoter and the "confidence man" as of the reformer" and worthy advocate. Yet the psychology of persuasion like the psychology of advertising (which is one of its aspects) develops specialized techniques according to the type of response aimed at, and yet more distinctively according to the phases of response represented by the particular character-which comes to mean the reaction to the social environment-of those to whom the appeal is addressed.

Note 7, page 439. "It is because persons belonging to the same race have certain definite characters in common that they are capable of thriving in the same conditions of climate, in the same mental and moral atmosphere, of undertaking the same class of labor, of resisting the same diseases." (Whetham: "Heredity and Society.") The application of the argument, as of the fact which it expresses, is twofold: it indicates the basis upon which the differentiation of class has proceeded, each doing best that which it is called upon to do in the increasing differentiation of social needs; and it indicates that the environmental 


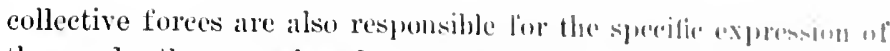
the needs, the mental and moral atmosphere, cven the orders of labor which win distinction and rewarl. That the responsilility is referable to such influences rather than to the andjusturent in climate and resistance to disease, is obvious, and fmothre ruphlnsizes the distinctive relations of cause and effect that apply to the psychological enviromment.

Note 8, page 440. The individual response sets a condition to the action of the psychic enviromment. Primary in develop. ment is the direct gregarious susceptibility, the tendeney to take on sympathetically the mood of others; cmmulatively there arises the emotional contagion that is characteristic of ehildren and so readily takes hold of a crowd to its enthusiastic uplift or it. temporary undoing. A popular charitable subscription or a public indignation meeting, even a mob on lynching bent, in so far as feeling runs high, proceeds upon a common psychological nature. Such social responsiveness is as primary for the collective mind as for the individnal component. $\mathrm{U}_{\mathrm{p}}$ on a like basis there appears the imitativeness which is the expression of the like trend in the intellectual field. In mature and calm situations a truer and more conscious sympathy arises which is more in the way of an acquisition and is fostered by precept and influenced by example. It combines with suggestibility, docility, edneability. all of which are thus the instruments of adaptation, yet by no means to the extinction of desire, rather as a gricie to its expression, and a medium for its application.

The individual is sensitized to the psyehic environment by his sensitiveness to the esteem and good opinion of others. This personal reaction directs the spirit of conformity, yet does st with the cumulative force of other allied motives and tembencies which are equally an integral part of the (social) luman nature. The transfer of traits is involved, the earlier helplessurss, annplacency, suggestibility are carried orer to more mature imbl cial situations; similarly the esteen nurtured in the sex-molitim is earried over to relations in general, and gives the fominimo a $x$ pressions of conformity to the eollective sanction a preuliar flavor. The environment supplies the unfoluling inpulses with appropriate objects, substituting the foar of infringement tur the fear of pain, the satisfaction of approbation and compliment 
for the satisfaction of direct sensory pleasure. The environment determines what it is that one is proud of, though ever along the line of the natural incentives of pride. The sense of conformity may thus be presented as very complex development of the social conscionsness of the individual, reflecting each and all of its varied stages. The individual is not a savage and society is not a mob, largely because society can surround the individnal with a traditional system of restraints and guidance.

Note 9, page 444. The expression of ideals and sentiment through dress is interesting. The garb of religious orders is characteristic; in the garb of monk or nun it becomes a sign of a life of renunciation. It may be refined to the cut or the blackness of the cloth, or find its last vestige in the whiteness of a necktie. It may express a protest against the vanity of dress in the gray garb of the Society of Friends (Quakers). The use of dress for class distinctions as well as an evidence of official position is still current, and in a democratic society open to protest as well as approbation. The same conventional eveningdress is worn by the guests and by the waiters; the dress is a livery or a symbol of social adequacy, according to the manners of the wearer. In many parts of the United States housemaids refuse to wear a cap, while trained nurses accept it as an honorable badge. Policemen, conductors, and other officials must carry the sign of their authority conspicuously when on duty; at other times they may prefer to retire to a civilian obscurity. Interesting is the reënforcement of custom by intentional differentiation, making boy and girl and man and woman as unlike as possible. Every slight detail of costume acquires a feminine or a masculine touch. Even so purely conventional a matter as buttoning a left button-hole over a right button, which is the way of male attire, is reversed for women's garments. Obviously a series of customs so elaborately considered and so conspicuously exposed to the social influences, are certain to assume complicated conventional forms; which means that they respond to a variety of psychological motives. But through the network of motives, esthetic, economical, hygienic, distinctive, runs the thread of conformity; the simpler complacency that accepts the feeling of satisfaction in the "stylishness," the consolation of "correct" adjustment that directs behavior. To express social value through dress, individual- 
ity amidst conformity, a general conformity to style along with the partieular conformity to the fashion of onc's awn dass, makes the art of dressing a fine art indeed. Yet the more philosophie eonformer cares only to axoid eomspicuonsucss either ly marked neglect or by extreme pursuit of the latest leparture.

Note 10, page 449. The Biblical reeord of at people living under a system of established tribal rule offers the unst familial" example. The rite of eircumeision became the act of cosenant of" a chosen people with their God. To the dietary laws was attached the solemnity of a religious prescription amd moseription. The cleanliness thus inculcated was as much spiritual as hygienic. To a believer the partaking of forbidden food aroused the emotional sense of guilt or sin, which remains the standart medium of enforcement of moral regulations. The ceremonialism of Oriental life develops an elaboration of ritual in and out of the religious domain. It presents also the tendency to extreme enforeement and literal application. It develops a symbolism of custom and representation, itself satisfying the sense of literal conformity. The prohibition presents the most definite and the most intense appeal, acquiring the sanetity of a taboo, while its violation became a desecration. The verbal taboo appears in the prohibition of the utterance of the sacred name of Jehoval. In the Biblical code, agricultural, hygienie, economic, social, and religious regulations were consolidated in a communal syst(m, fusing the sanction of law, usage, morality, and religion. 'I'" minute conformity to the rich ritualistie, symbolie tradition was attached the unitary tribal approval, and to transeression a like disapproval, eonverting the sense of violation to one of persomal guilt. The individual conscience, even in the more elastir surial systems of the present day, takes its dircetion almost entirely from the reflex of the social system of obligation.

Note 11, page 449. The variable play of the sneial entvironment in shaping conventions appears in the use of eresture. The Italian, and the Latin races of Europe frencrally, use it freely; the Anglo-Saxon uses it sparingly and is offended by any intrusion of it, even to the useful habit of pointing to insure attention. Yet all this is a natural issue of the illeal underlying the proscription. Restraint, repression, even to the extinction of any emotional play that intrudes upon another's attention, follows 
from the idea of consideration to others; it counsels a low voice and a modest address, and makes any assumption a rudeness. Whether and when it goes too far is not for the moment relevant. The Anglo-Saxon ideal is consistent with a desire for privacy and a regulation of social contacts, just as obvious in the manners of the street or the arrangements of house and garden, in the development of a public café-life in one country and its total uneongeniality to the ideals of another. If one considers such customs as the giving of fees, the prominence of the dowry and the arrangement of marriages by parents, the respect for old age and the attitude of young to old, the dread amongst women of becoming old maids, the (American) habit of "treating," one has ample opportunity to note the varieties and the vagaries of fashion, yet ever with a consistent reference to a system of appreciations established or highly regarded in the one milieu and less so or differently in another. Inconsistencies are not absent: it seems strange to the Ameriean, sharing so many ideals with the Englishman, that the latter shonld permit and even expect his guests to pay his private servants. That economio conditions are responsible for some of the differences in attitude and observance just eited is obvious; that they move with as well as reflect the spirit of the community in which they are observed, is equally so. No more suggestive index to such standards and the principles underlying them is available than in the minor infringements of propriety. The freedom of speech permits the German to say, "Ach, Gott!" or the Frenehman, "Mon Dieu" to express mild consternation. A similar appeal in English would be warranted only by tragie despair.

Note 12, page 450 . The utility of convention will readily be understood. Mere uniformity is useful, as in determining the rule of the road, or the adjustment of the fittings of the table to right-handed usage. It dispenses with the need of initiative, and settles once for all in modern society how a man may dress for formal appearance. So usage determines good form in speech and manners. The tendeney for such obvious ntility-in sueh instances perfectly consistent with a dictatorial finality-to encroach upon weightier and more disputable matters is one of the serious dangers of convention. When thus extended, far from being a utility, convention may become a millstone and 


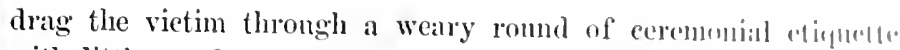
with little profit and much trial. 'The elasticity of soreial lorms in thus providing for freedom and intiative is a rather sirniticant mark of the measure to which the spirit of conformity is understood, and the letter assigned to its proprer and sulwolinite place. Not umrelated to the same appreciation $01^{\circ}$ lark of it is the vulgarian notion that etiquette eonsists in such runtime (1)servance-as it does in small part-and may be aldefluttely learned ont of a book. The very faet that manners elepenl upen appreeiation gives them a value in the social regulation. It is illways a mixed produet, partly of tradition, partly of an mululying consideration defensible in its bearing ats an exfnessim ol a valued quality. Manners are no more arbitrary than sperect, though both contain an arbitrary factor; they involve an aprreciation of the genius of the people that set the standards; and their inculeation must ever remain an important part of a liberil education. The differentiation of social classes is eertain to proeeed upon the manners, speech and eonsiderations to he experetiol or tolerated or exeused beeause of lack of opportunity and social connections. Thus eonformity eomes to express the response $u t^{\circ}$ the individual to the selective pressure of the enviromment; it. expresses his conformity along with his individuality; for he selects the specifie type and order of manners of his own elass.

Note 13, page 452. The attitudes and observanees expected of women reveal the cultural tone unmistakably. Supporting surels custom is the idea of modesty and retirement. It may prococel to the Oriental extreme of the inviolate harem, to the ultimate salcrifice of the suttee, the absolute dietation of marriage, the disirnas of even the slightest exposure of the person. Outwarlly the veil comes to be its symbol, a concealment of the face. It survives in the use of the bridal veil and again in the ceremonies of the chureh, in "taking the veil" as a renmeiation of the worlly lif". as also in the veil of widowhood. That like a tan or a littire it may beeome both a sereen and a shelter, and direet attention in esthetic mood to the facial charm, shows how diverumbly "untul. may refleet prineiples. Quite the same is true of the ronvontinnal aets of devotion. The eontact of the lips is the and of lowe. and is introduced in the administration of the oath in kising tho Bible, or in the sign of devotion or subjection or veneration to a 
superior power, spiritual or political. The lover beseeches upon beuded knee, which is also the attitude of the devout in church.

Dress and manner as the outward index of attitude carry a special significance. Modesty, vulgarity, station, age are all indicated by dress, but ever under the shifting ideals of one view of life or another. Jewelry and ornamentation are as carefully scrutinized in expression of individual quality as speech or action; cosmeties and the aids to beauty carry a like implication from a mere conventional habit to the motives of "the painted lady." The index of coveted leisure and station may be as obvious in the manicured hand as in the inch-long finger nails of Siamese ladies or in the tortured foot of Chinese ladies. The age of powdered wigs and lace for men inevitably expressed a different perspective of the social system. But to return to the feminine embodiment: such a custom as the ride-astride habit could prevail only because of its support in the greater freedom of feminine behavior already established. The significance of details is derived from their place in the larger system of which they form a slight part; that significance in turn is derived from the ideals and principles which direct approval. The system is always but partially logical and in its adjustment meets with shifting standards; none the less it is by such adherence saved from caprice, and saved for a useful function in the effective solidarity of the communal spirit.

Note 14, page 460 . The cosmopolitanism of modern occidental life and the directive leadership of the centers of eulture, the free interchange of ideas, the formulated political relationships and interchanges of institutions, have all conspired to impart a universality to modern life in notable contrast to the distinctive, isolated, and self-sufficient insularity of older conditions. The tendency to lose the local distinctiveness has led to the reaction in favor of various national movements in language, literature, customs. The assimilation of divergent stocks seems the inevitable issue of the massive trends of modern civilization. All this makes it difficult for the humanitarian sociologist to reconstruct the local quality of allegiance to standards and traditions. Yet the assertiveness of race or nation persists, and persists quite too commonly in the assumption of superiority and a prejudiced indifference to the divergent qualities of other 
races. That eulture consists in a certain magnanimity of outlowk is not an unfair deduction for present-rlay considerations. Yet the adjustment of one's loyalties to the several phasus of the anvironmental influences responsible for the oppurtunity lo live the life of one's consummation, is a practical problem; its solution lies in nothing less comprehensive ant irrevocable than the experiences of life itself.

Note 15, page 460 . The regulative value of the religious system is of the highest significance in the historieal considgration. Supreme by the nature of its authority, it may determine d.rectly the total range of life and interests, and hecome biologrieally signifieant in that it direets the eustoms of marriage and divittes which order of qualities shall prevail and continue in the rase or people. The perspective of older enltures is that of a unitary regulative system in which the religious features form the central moments; all other regulative systems must make terms with this supreme direction and either receive its sanction or extenl its dominion. With Church, State, and Society as one, the religious sanetion dominates as the expression of the superior source of influence, a tutelary protection by divine powers. In this aspect the central function of religion is to provide a supernatural sanction for the restraint of individual impulse and for its subjection to the collective will. Loyalty, sacrifiee, devotion become duties prescribed by custom, at times dominantly political, yet more commonly religious in type of obligation imposed.

Incidentally in this relation may be traced the environmental aspect in the dominance of the natural phenomena or of social organization in the color and $\operatorname{mood}$ of the religions cults. The relation of the original religious mood to the dominance of 1 montain and sea, forest and desert, thunder and windstorm, and the mighty forces of nature, is direct; it has brought it about thut religions have been conceived and wrought to expression in solitary and impressive places, and that they change their chararter and wane in importance under the dommance of the crowiled artificial habitations of men. In changing the emphasis of the relation to be regulated from that of man to nature and to nature's God, to that between man and man, and man and soriety, the regulative system inevitably comes into rivalry-it may he, into conflict-with other systems; and the gods acunire a nar- 
rower tutelary, tribal character. The regulation of man's relation with nature through science represents the limitation of the older views in the first aspect. The reconciliation of the several systems as of their practical interests, is a constant and significant problem.

\section{NOTES TO CHAPTER IX}

Note 1, page 466. It is clear that artists cannot be graded in any, such mechanical manner, because each expression of the artistic gift is or may be specialized, and present yet finer distinctions; merits and excellences are variously combined and have shifting values in a critical appraisal. One painter excels in the handling of color, another in truth of drawing, another in originality of conception, another in skill of composition. The specialization within a specialty-dominance of the qualities that make the portrait painter, the landscape painter, the decorative painter, the animal painter-is itself an expression of the nicer adjustment of talents to chosen tasks, under the influence of tastes, opportunities or circumstance.

Exacting careers require a favorable social environment as well as specialized endowments. The psychology of skill illustrates the relation. In coarse movements, like scrubbing a floor or digging a ditch, it matters little whether the movements vary a few inches one way or the other; in the bandling of the artist's brush or pencil, in the jeweler's or the surgeon's craft, the slightest deviation is disastrous. Artists, jewelers, and surgeons must be more carefully selected than scrubbers of floors and diggers of ditehes. Their finer fitness involves a nicer adjustment of conditions; it takes less to throw them out of condition. The sensitiveness of the finer eallings to delicate fluctuations is but another aspect of the effect of civilization to make finer differences count.

Note 2, page 473. The citation of the advertising process is for the single purpose of indicating the specialized nature of the appeal, which in other phases incorporates general laws of attention, interest, motive, persuasion, etc. It is a highly specialized psychological art; hence inference and generalization are hazardous. Advertising may pay for economic reasons; business may be good enough to make the purchaser able to pay both for the article and for the advertisement; the independence 
of a local market, the need of a willely distributed one, ma!y support or require publicity. Yet in the end, the plane of pure suasibility, though exereised as an individual response, is redlunted from the soeially aequired phase of responsiveness, which is always of a speeialized order.

Note 3, page 476 . In the socializing of the emotional renpulations of the individual response (see ('hatpter IV) nature supplies inherent tendeneies to fear, to be ashamed, to loxe, to desire, to expand the self, to be stimulated or depressed, but the social environment steps in to determine what shill bo feared and what shall induee shame, what shall be desimol and thus develop self-esteem, and cause joy or urict. So struly is the aequired babit that the bare opimion of one's neighlors, however unjust, is enough to induce a semse of gruilt or shante. Pride is similarly soeially acquired, and esteem beeonses a phtont foree in the redirection of quality. The enviromment as the medium of operation determines the objects that stimmlite seleeted qualities: hence the shifting ideals of the desirable and the undesirable; and hence also the responsibility of the leamlers of men in attaching the rewards of soeial esteem to the qualities of men.

Note 4, page 476. The tests of life differ from the inevitably artifieial tests of the school, for the very reason that prefierment in the open is exposed to the sum total of the social intluenees that exert a stroing hold upon the sentiments and julgments that award sueeess. It would be foolish to suppose that a member of the black race competes upon equal terms with a whito man in the desirable eareers for which he may have a sperinl fitness or training. Discrimination is inevitable. though its degree and manner vary with the attitude assumed by the dominint race toward those of other lineage. Prejudice is subtle and permeates to all the finer appraisals that practically form ails or hindranees to suceess. Every faetor comits: and no plat form of equal opportmity will remove the clisqualifieations attaching to a soeial-sentimental exelusion from the spontaneous almision to "one's own kind." Similarly, women do not and cammot connuete on like tems with men in the professions to whils they have gained aceess. Allowanees and considerations for sex intrule, farorably or unfavorably; the avenues of frelorment, though 
ostensibly open, are really barred by invisible barriers of social prejudice. The suppressed play of such influences appears in the slighter and often resisted prejudices of a dominant caste against the foreigner or the descendant of an alien stock. There are castes within castes, loyalties within loyalties, all of which play upon the composite of qualities that lead to sucess. Snch is the rôle of circumstance in the intricacy of the social organization; such is the difficulty of adjusting reward to endowment. The favored swim with the current and rise to positions above their merits; the less favored struggle against the current and reach stations below their attainments. It takes but a slight difference in circumstance to divide the issue. Each social milieu establishes its peculiar perspective of importance of one set of qualities or another. Failure in one respect may disqualify; for men compete and prevail with the composite of their qualities, while the environment may determine that they sliall be called by one dominantly.

Note 5, page 485. The congeniality of the intellectual climate is a factor of prime importance in the issues of endeavor. Happiness lies in the adjustment of task to inclination as well as to eapacity. An uncongenial climate is the most irritating, as it is the most constant disturber of endeavor. Content is indispensable; like interest in one's work, it is a psychological factor that disappears in the records of hours or product, and yields only to the finer appraisals of quality. It is indeed predominantly a temperamental matter, but is none the less keenly sensitive to the approvals of social esteem. One of the most practical methods of making men efficient is to make them happy. But content, like all else, becomes a more delicate adjustment with the complication of nature and task and condition. The provision of an environment stimulating to the choicest forms of endeavor thus becomes the true social mission. To neglect or disregard this vital factor in encouragement is most impractical. Social esteem in its operation may at least attain the negative virtue of remoring distinct hindrances in false standards of appraisal. The more positive creation of a congenial milieu requires the placing of control in the hands of those fitted to the poietic callings, together with a sensitive elevation of the social appreciation. 
presumptive evidences and no more, of the attainment of a certain standard of suceess. But the standards themselves must be critically examined, are indeed most eritically considered in the nicer judgments of men, before verdicts inspire confidence. Snecess may properly please but should not dazzle; it may encomrage but should not confuse. Hence the constant pertinence of the gospel of appreciation.

Note 8, page 499. As a popular choice or social appreciation ean be exercised only among available or presented candidates, suceess-in terms of sales, box-receipts, or circulation-shows what people will accept, rather than what they want. Such acceptance, however, tends to fix the standards of taste and to make further substitution difficult. Yet taste improves precisely by rejecting what it formerly aceepted; in this sense, inertia and complacency, thougl efficient, are negative forces. Through response to new enterprises, to more critical appeals, is the elevation of opinion made possible.

A statement of the same relation in individual terms indicates that mental, moral, social or esthetic growth means the constant outgrowing of older standards. What once gave satisfaction is now neutral or decidedly objectionable. The "ages of man" represent not alone a change of interests but of standards. Experience, if combined with the capacity to grow, means the development of a more critical sense, and the elevation of sentiment. Such change forms the actual support of all movements for betterment.

Note 9, page 501. The theme of the closing portions of this cbapter, together with a proper introductory survey of the source and play of human endowment, is developed in a volume issued under the title, "The Qualities of Men" (Houghton, Mifflin \& Co., 1910). That "Essay in Appreciation" is intended to make a more general appeal and a more practical one. For the reason that the "Qualities of Men" (to which the reader's attention is indulgently invited) provides an expansion of the present theme, is its statement reduced in the present connection to a brief indication of its message. 


\section{INDEX}

Ability; mathematical, 17 musical, 16, 409

See also Traits, esthetic; Traits, intellectual

Abnormal tendencies of mind, $238,277,30+\mathrm{tr}$.

and age, $307-3] 0,559-560$

and criminality, 574

and defect, $311,544,552-553$, 574

and deviation, $361 \mathrm{ff}$., 565

and disproportion, $314 \mathrm{fl}$., 358 if.

and excess, $312 \mathrm{ff} ., 317 \mathrm{fl} ., 345$ ff., 533, 556, 564-565

and excitation, $315 \mathrm{fl}$., $353 \mathrm{fr}$., 563-564

and genius, $363,410,573$

and organic condition, $304 \mathrm{ff}$., 550-551

and perversion, $359 \mathrm{fl} ., 41 \mathrm{l}$

and the normal, $310 \mathrm{ff}$., 342

Affective. See Emotions; Traits, esthetic

Allen, Grant, 510

Altruism, 208 ff., 213, 237, 537538

Anger, 106, 107, $124 \mathrm{ff} ., 132,140$, $143,144,191,262$

pathology of, $347 \mathrm{ff}$.

Animal traits. Sce Traits, transformation of, in animals

Arreat, 548

Bain, 508

Binet-Simon, 549

Boas, 570

Burbank, 518, 576

Cannon, W. B., 521

Character and 'Temperament, ix and psychology, l

as a general inquiry, 7
Cliaracter and Temperamint historieal usprect of, 2,507 $50 \mathrm{~s}$

practical asprect of, $5 \pi, 5] 0$

Character rending, ix, $x, 7$

Character training, ix, x, 578

Chinese, 572

Choleric. See Temperununt.

Civilization, $x-x i$, 211, fitt if, 569

Community of traits. See Traits, conmmunty of

Complex, 53, 311, 319

Conduct, the emotions and. Sien Emotions

Conformity, 443, 44 $i, 502,50 \% 3$, $515,579-582$

Sce also Group-mind

Conscience. See Morality.

Convention. See Conformity

Coüperation. See Sorinlization

Correlation. See lindowment

Criminality. See Alnornal tond. encies of mind and perver. sion

Crowd. Sce Group-mind

Curiosity, 49, 152, 155, 186, $240 \mathrm{tr}$.

Cyrano de Bergerae, 361

Darwin, 139, 140, 141, 144, 531, 567

Dauriac, 548

Degeneracy. See Abnormal tende encies of mind tunt per. virsion

10. Quiney, 318

Dessoir, 507

Dexter, 576

Dillerences, homun, $1019 ., 23$

s'er also l'enperunent

Disg11, 108, 115, 141, 510

Distinetion. Se' Truits, intel. lertunl; Finotions, and intellect. 
Domestication, 152, 211, 426-431

Dowie, 566

Eddy, 562, 566

Ellis, Havelock, 383, 390, 551, $565,566,567,568,574$

Emotionalization, 97, 116

Emotions, $104 \mathrm{ff}$.

aggressive, 109, 128, 130, 132 ff., 188, $222 \mathrm{ff} ., 354$

and conduct, 113

and instinct, $118 \mathrm{ff} ., 124 \mathrm{ff} ., 151$ ff., 532

and intellect, $155 \mathrm{ff} ., 195 \mathrm{ff} ., 216$ ff., 239 ff., 532

and object, 156, 159, 199

and sensibilities, $112 \mathrm{ff}$., 523, 524

and situation, $122 \mathrm{ff} ., 126,128$ ff., 131,134 ff., 527

and will, $244 \mathrm{ff}$.

as motive, 111, 113, 225

as personal quality, $169 \mathrm{ff}$., 205

as zest, $109 \mathrm{ff}$.

classification of, 527-528

complexity of, $114 \mathrm{ff} ., 117,146$ ff., 222, 526

derivative, $117 \mathrm{ff} ., 138,150 \mathrm{ff}$., $171,208 \mathrm{ff} ., 229 \mathrm{ff} ., 535$

development of, 533-534

expression of, 106, $121 \mathrm{ff}$., 123 ff., $126,138,139 \mathrm{ff} ., 164$ ff., 515, 521 ff., 529-531, 533

function of, $106 \mathrm{ff}$., 127, 131, 522-523

luxurious, $110 \mathrm{ff}$.

organic aspect of, $106 \mathrm{ff} ., 126$, $172,185,520 \mathrm{ff}$.

pathology of, $356 \mathrm{ff}$.

preliminary and active stages of, $131 \mathrm{ff}$., 148

primary, 104, 118, $119 \mathrm{ff} ., 134$ ff., $170,525,536$

retreating, $109,120,128,130$, $132 \mathrm{ff} ., 184 \mathrm{ff} ., 227 \mathrm{ff}$.

sensory inlet of, $121 \mathrm{ff}$., 141, $520-521,526,527$

social, $52,109,130,133,146$ ff., $163,177 \mathrm{ff} ., 181 \mathrm{ff} ., 191$ ff., 534

See also Socialization
Emotions,

specialization of, 153

transformation of, $117 \mathrm{ff}$.

urgency of, $106 \mathrm{ff}$.

Endowment, 408

and achievement, $296 \mathrm{ff}$., 399 ff., 469 ff., 577,589

and the psychic environment, 471 ff., 474 fl., 486 ff., 501

and will, $297 \mathrm{ff}$.

constancy of, 12, 175

correlation of, $287 \mathrm{ff}$.

intellectual, $285 \mathrm{fr} ., 290 \mathrm{ff}$.

motor, $286 \mathrm{ff}$.

original, $175,576-577$

sensory, $282 \mathrm{ff} ., 511$

Energy. See Will

Environment,

adjustment to, $420 \mathrm{ff}$., $432 \mathrm{ff}$. and heredity, 46 . See also Heredity ; Gronp-traits, and the environment

and institutions, $425,440 \mathrm{ff}$., $447 \mathrm{ff} ., 457 \mathrm{ff} ., 459 \mathrm{ff} ., 578-$ $579,584-585,588$

and race, 418

artificial, 419, 451, 463

as biological emphasis, 416

as conserving, 452

economic, 423

effect of, 44

physical, 417, $420 \mathrm{ff} ., 576$

psychological, $423 \mathrm{ff}$.

transformation effected by, 425, $576-577$

in arimal life, 426

Esthetic. See Traits, esthetic

Excitation. See Abnormal tendencies of mind and excitation

Expression, 45, 54

of emotion. See Emotions, expression of

of traits. See Traits, expression of

"Family" situation, $128 \mathrm{ff} ., 200$

Fashion, 434, $444 \mathrm{ff} ., 446,580$ 581. See also Groupmind 
Fear, 108, $115, \quad 119 \mathrm{fr} ., 124 \mathrm{fr}$., 132, 190, 209) 11., 2(62, $3+3$ iT., $524-525,539), 510$ pathology of, $34: 311 ., 555,56 t^{2}$

Feeling. See Selusibilities; Emo tions; Atreetive

tender. see Sympathy

Feeling-value, $64,73,89$

Feiss, 548

Food-sensibilities. Sce Sensibilities

Food-situation, 78, $128 \mathrm{ff}$.

Gourillée, 508

Frend, 336, 337, 338, 339, 351

Galton, 407, 573, 574

Genius. Sice Abnormal tendencies of mind and genius

Goddard, 552

Gregariousuess. Sce Socialization; Sympathy

Grief, 135 tr., $1+3$

pathology of, $350 \mathrm{ff}$.

See also Pain

Gross, 566

Group-mind, 433 ff., 579

and public sentiment, $450 \mathrm{fr}$., $47 \mathrm{lfi}$.

as local genius, 458,493

as Zeitgeist, 456

constancy of, 439

varieties of, $438 \mathrm{ff}$.

Group-traits,

and family, $408 \mathrm{ff} ., 573,574-$ 575

and heredity, 407

and the eluvironment, $412 \mathrm{ff}$.

and the individual, 365,366

and vocation, 414, 482, 575

derivative, $377-382,390-393$

feminine, $386-390,566,567$

masculine, 382-356, 567-568

pathologieal, 372-374

psychological, 374-376

interrelation of, $406 \mathrm{ll}$.

of race, $393 \mathrm{fl}$., 5 tis

and achievement, $399 \mathrm{ff} ., 569$, 572

and preeocity, 404

and primitive type, 402,570

and variability, 403

derivative, 397
Group-truils,

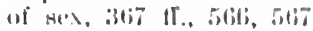

bendily, :370, 37 I

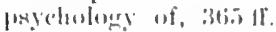

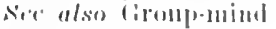

Hall, G. S., $56 \mathrm{il}$

Herodity, s, 15, 543-511, 57l, 574575

and anvironment, 116,117

sere also knvirommont

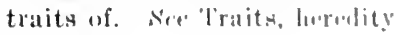
of

IJonor, 5i2

Hypoelundria, :3e!

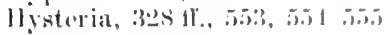

and shock, 3.51

minor traits of, 3330 II., 5isti, $557,554,560,561$

Ideals and standiards, ni. Itil, 476 11., 4!91, 4! $46,5: 5 ! 1,54: 1-$ $586 . .8 s !$

See alse Standards

Ideo-motor, $5: 37$

Idol, of interest, 4 , is $\mathrm{tl}$.

of the practical mind, $3,5 \pi$.

Imitation, 19.5 11., 5837

Impressionisul, 87

Impulse. See Emotions and instinet

Individual differences. Sire Tim. perament

and group-traits. Ser ciroup. traits and the individual

Individuality, 445, 15:3, 49:3

Instinct. See lemotions and in. stinct

Institutions. Ser linviromm.ut and institut ions

Intellect. Site Emotions and in tellecet

Intellectualization, ltio ir., tititr., lsti, $20151 \%$.

Intelligences, fornerut. Sire lin. dowment, intellertual

Intoxication. sie lluormal tendencies of mind and ex. citation

Irelumd, :356;

Irresolut ion, 318 IT.

Irritulitity. Sie .lugur

Ivan the ficroble, 3iti 
James, 205, 520, 527

Jealousy, $124 \mathrm{ff} ., 181 \mathrm{ff} ., 203$ pathology of, $349 \mathbb{f f}$., 562 See also Anger

Jews, 572

Joy, 135 ff.

sce also Pleasure

Kaffir, 46

Kallikak, 552, 574

Keller, Miss, 518

Kinctic, 487

Knowledge-value, 64, 73, 89

Lange, 520

Language. See Sensibilities, lan-

Lévy, 508 guage-

Lombroso, 574

Love, 202, 208 ff., 214. See also Sympathy

Ludwig of Bavaria, 356

MacDougall, xii, 520, 525, 527, 535

Malapert, 508

Manners. See Fashion

Mayer, A. G., 576

Megalomania. See Abnormal tendencies of mind and excitation

Melancholic. See Temperament

Mesmer, 387

Meyer, Max, 519

Militarism, $457 \mathrm{ff}$., $479 \mathrm{ff}$.

Mill, J. S., 50 S

Mind, primitive. See Groupmind

Miser, traits of, $274 \mathrm{ff} ., 547$

Modesty, 227, 538-539

Mood, 113, 262, 268, 301, 305

Morality, 442 ff., 449, 543

Mores, 442, 444, 449, 581-582

See also Morality; Nashion; Conformity

Morgan, Lloyd, 542

Needs and their satisfaction, 25

Nervousness, 62, $317 \mathrm{ff}$., $327 \mathrm{ff}$., $343 \mathrm{ff} ., 555$

Neurasthenia, $320 \mathrm{ff} ., 554-555$ minor traits of, $323 \mathrm{ff}$.
Pains, 59 ff., 105, 144

Palmistry, 2

Paralysis, general, $315 \mathrm{ff}$.

Parmalee, 519

Paulhan, 508

Persecution, 52

Personality, 188, 222, 558. See also Hysteria

Perversion. See Abnormal tendencies of mind and perversion

Phlegmatic. See Temperament

Phobia. See Fear

Phrenology, 2

Physiognomy, 2

Play-situation, $128 \mathrm{ff}, 146,177 \mathrm{fl}$., 538

Pleasures, 59 ff., 105

Poietic, 487, 491, 505

Presentative, $68 \mathrm{ff} ., \quad 158,161$, $526-527$

Pride, 45, $223 \mathrm{ff}$.

Problem-solving, 50, $240 \mathrm{fl} ., 292$, 295

See also Curiosity

Psychic control, 17+ff.

Psycho-analysis, 550

Psychology, 35

see also Character and Temperament

Pugnacity. See Anger

Punishment, psychology of, 4s, 233 fi.

Qualitative method, 14, 509

Qualities of men, 463 ff., 590

encouragement of, 489, 495, $498 \mathrm{ff}$

Sec also 'Traits

Quantitative method, 9 ff., 12, 14, $17,508,509$

Race, traits of, 13

Represcntative, $68 \mathrm{fr} ., 158,161$

Resemblances, human, 23

Rilbery, 508

Ribot, 508, 512, 520, 527

Sanguine. See Temperament

Seashore, 548

Self-estecm, 48 
Sensibilities, 58 ก

and conduct, 66

and discrimination, 40

and emotions. See Emotions, and sensibilities

and feeling, 512

and intellect, $73,78,99,520$, 543

composite rature of, 13, 9.5, $511,518,519$

delicacy of, $62,76 \mathrm{fr}, 87 \mathrm{ff}$., 100 , 586

derivative, $102,51 !$

development of, 91

food-, $81 \mathrm{fr}$.

function of, 64, 70, 91, 94, 97 fr. hygienic, 74 1f., 514

language, $83 \mathrm{ff} ., 517$

order's of, 63

organic root of, 59, 105, 513514,518

overlay of, 67,516

regulation by, $79,96,517,519-$ 520

special-sense, root of, 59, 512, $513,514,518,548$

standards of, $80,516-517$

supporting sense of, $91 \mathrm{fi} ., 514$

Sentiments, 4!, 199, $208 \mathrm{ff} ., 215$, $220 \mathrm{ff} ., 228,534$

system of, $51 \mathrm{fr} ., 231 \mathrm{ff} ., 540$ 542

Sex, traits of, 13, 49, 115, 200$202,213,337 \mathrm{ff} ., 367 \mathrm{fr}$.

Shame, $234 \mathrm{ff} ., 538 \mathrm{ff}$.

See also Modesty

Shand, xii

Shyness, $184 \mathrm{ff} ., 187,18 \mathrm{~s}, 203$, 510

Situation. Sce Food; Family; Play

Skill. Sce Endowment, motor

Socialization, 131, 149, 163, $176 \mathrm{ff} ., 196,203 \mathrm{fl} ., 206,587$ stages of, 17711., 536-537

Socicty, stratification of, 455

See also Enviromment, and institutions

Sommer, 575

Specialization. Sce Traits, specialization of; Limotions, specialization of
Niamdards, tiil

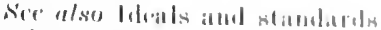

Niturhal, jol

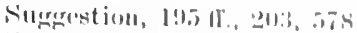

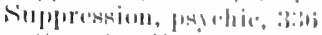

ser alse llistoria

sympathy, fos, 145, I I!!, I4!) II", $20711 ., 53$.3i

System. Ner Sintiments, Mystrm of: limviromment, anid institutions

Tabou, $413,41711.0$, 15,5 , is

T'astr. Sere Trails, esthetice

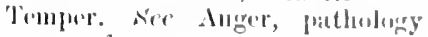
of

Temperaturent,

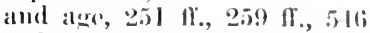

and "motion, 27 11 11.

and esthetic suscentibility, $267 \pi$

and lixed bent, 20.5il., 270, 27211 .

and herodity, 250

and individual difforoucos, $2 S 111 ., 548$

See also Endowmint

and primary traits, 253

and $\mathrm{se}^{2}, 250,252$

aml temperamental traits, 25:3, $260 \mathrm{1f} ., 27201 \mathrm{~T} ., 278 \mathrm{fr}$.

budget view of, $541 ;-5.17$

emotional mupliasis of, 2 int

intellertual (mphlasis of, "2)ib

melancliolic, "litj

organic conditioning of, 리, $26 ; 4$

satmenime, 2665 $11 ., 553$

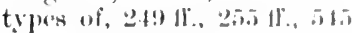

sec also Charamotor and 'lim priantemt

Thoman, 33:2, 566, 56!1-5711, 57. 577

Thompson, Miss, 5ו7

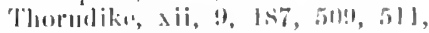
$518,52 ! 1,53 ! !$

Torlak, Molatmmund, aisti

'Truits,

alld the mervous mytom, 20, $40-12$

biologicul uspect of, :24, 46ti 
Traits,

community of, $10 \mathrm{fr}$.

compatibility of, $279 \mathrm{ff}$.

derivative, 22, 24, 25, $37 \mathrm{fr}$.

directive trend of, 42,44

distribution of, 17-19

encouragement of, $55,56,58 \mathrm{~s}$

esthetic, 30 ff., 43, 60, 65, 67, 70, 82 ff., 85 ff., 267 ff., 512,518

evolution of, 43, 45, 51, 71

expression of, $40,42,44$

function of, 22,83

group-. See Group-traits, psyehology of

heredity of, $15 \mathrm{ff}$.

intellectual, $34 \mathrm{ff} ., \quad 51, \quad 99$, $195 \mathrm{ffi} ., \quad 218 \mathrm{ff} ., \quad 240 \mathrm{ff}$., $288 \mathrm{ff} ., 510,542,549$

maturing of, 38,43

national, $467 \mathrm{fr}$.

nature of, $19 \mathrm{ff} ., 27$

orders of, $21 \mathrm{ff}$.

persistence of, 42

primary, 20, 523

racial. See Race, traits of

sex. See Sex, traits of

sourees of, $8 \mathrm{ff}$.

specialization of, $36 \mathrm{ff} ., 45,465$, $470,586-587$
Traits,

temperamental. See Temperament

transfer of. Sce Transfer, principle of

transformation of, $426 \mathrm{ff} ., 429$, 482 ff., 506,578

in animals, 427 ff., $430-433$

value of, $24,55,484 \mathrm{fr} ., 492$

Trausfer, 43, 48, 583-584

prineiple of, 162 ff., 211,481 , 510-511

Utopia, $485 \mathrm{ff}$.

Value, 231

of traits. See Traits, value of

Vanity, 45

Veblen, 515

Vocation. See Group-traits and vocation

Wallas, xii

Watson, 519

Whetham, 577, 578

Will, $244 \mathrm{ff}$.

See also Endowment and will; Emotions and will

Wilson, G. R., 554

Woman, status of, $474 \mathrm{ff}$.

Woods, F. A., 575

Woolley, Mrs., 567 
ULT IVIULVIR USE

FROM WHICH BORROWED

EDUCATION-PSYCHOLOGY

EDUC.

LIBRARY

This book is due on the last date stamped below, or or the date to which renewed.

- month loans may be renewed by calling 642-4209

Renewals and recharges may be made $\div$ days prior

to due dare.

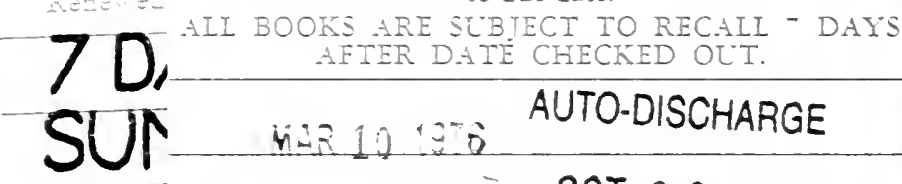

OCT 091993

alluplife ED-P

$$
\begin{aligned}
& \text { JUN } \\
& \text { JUN } 5 \text { 19:5 } \\
& \text { Jud } 24 \% \text { सेतिए }
\end{aligned}
$$

JUL:

JAN $3 \quad 1979$

FEE 3 

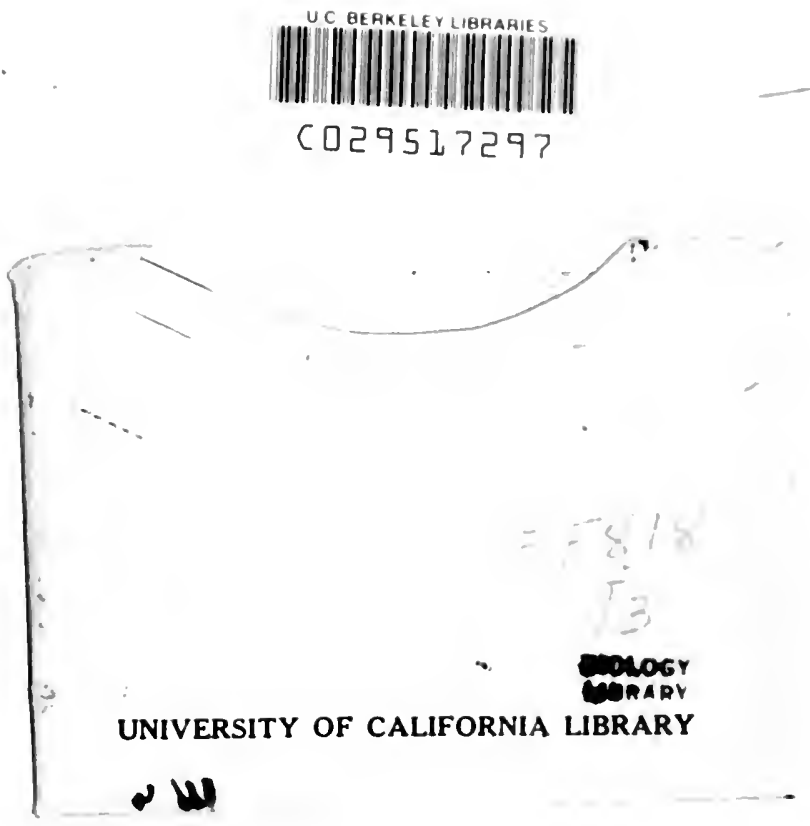
